Cochrane Database of Systematic Reviews

\title{
Anaesthetic interventions for prevention of awareness during surgery (Review)
}

Messina AG, Wang M, Ward MJ, Wilker CC, Smith BB, Vezina DP, Pace NL

Messina AG, Wang M, Ward MJ, Wilker CC, Smith BB, Vezina DP, Pace NL. Anaesthetic interventions for prevention of awareness during surgery.

Cochrane Database of Systematic Reviews 2016, Issue 10. Art. No.: CD007272.

DOI: 10.1002/14651858.CD007272.pub2.

www.cochranelibrary.com 
TABLE OF CONTENTS

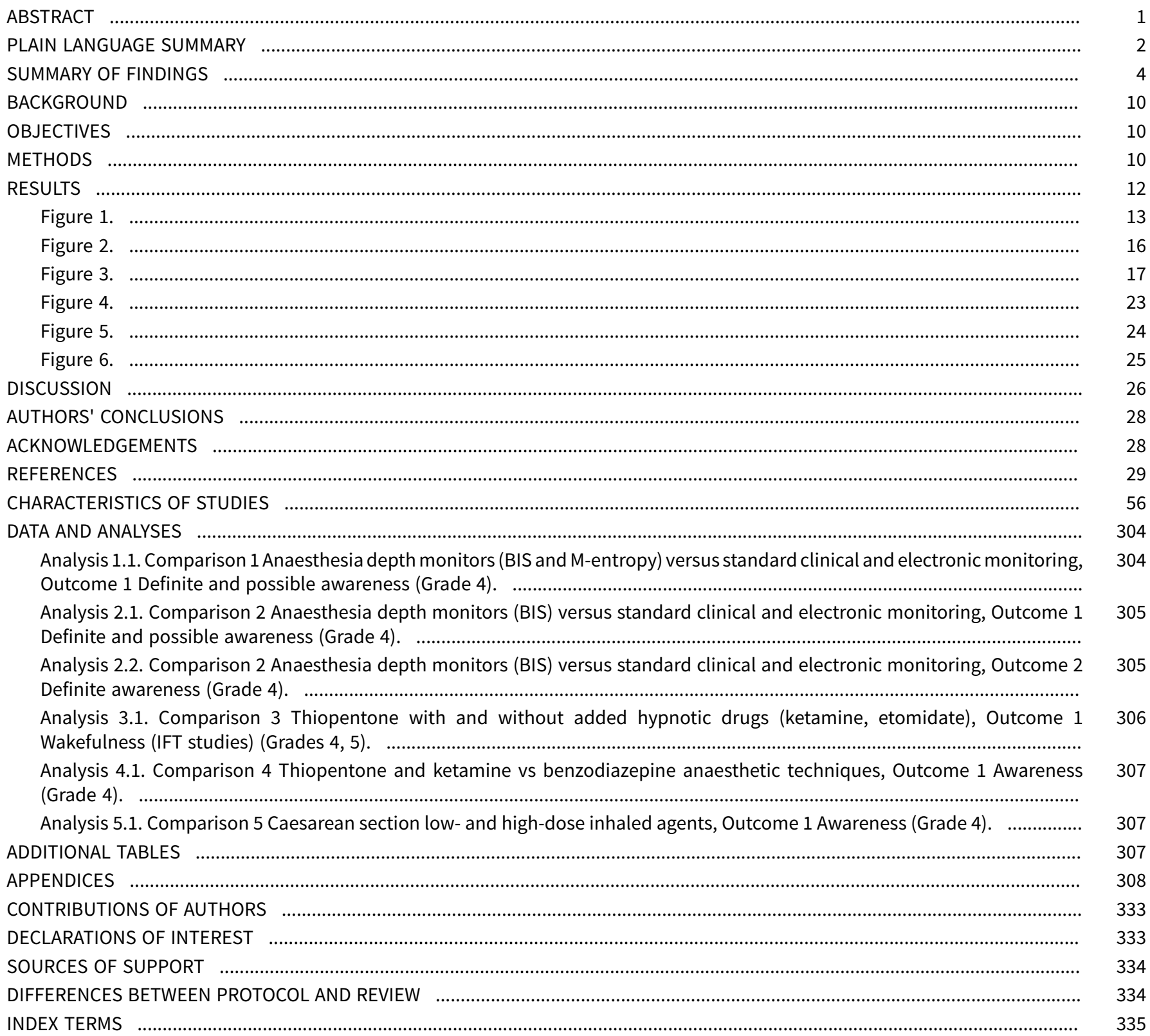


[Intervention Review]

\section{Anaesthetic interventions for prevention of awareness during surgery}

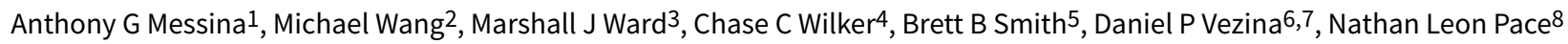

1The Alliance for Medical Management Education, School of Management, University of Texas at Dallas, Richardson, TX, USA. ${ }^{2}$ Clinical Psychology Unit, University of Leicester, Leicester, UK. ${ }^{3}$ Dartmouth-Hitchcock Medical Center, Lebanon, NH, USA. ${ }^{4}$ Clinical Toxicology III, ARUP Laboratories, Salt Lake City, UT, USA. 5 University of Utah School of Medicine, University of Utah, Salt Lake City, UT, USA. 6Department of Anesthesiology, Department of Internal Medicine, Division of Cardiology, University of Utah, Salt Lake City, UT, USA. ${ }^{7}$ Echocardiography Laboratory, Veteran's Administration, Salt Lake City, UT, USA. ${ }^{8}$ Department of Anesthesiology, University of Utah, Salt Lake City, UT, USA

Contact: Anthony G Messina, The Alliance for Medical Management Education, School of Management, University of Texas at Dallas, Box 233, 1920 N. Coit Road, Richardson, TX, 75080, USA. awareness.research@gmail.com.

Editorial group: Cochrane Anaesthesia Group.

Publication status and date: New, published in Issue 10, 2016.

Citation: Messina AG, Wang M, Ward MJ, Wilker CC, Smith BB, Vezina DP, Pace NL. Anaesthetic interventions for prevention of awareness during surgery. Cochrane Database of Systematic Reviews 2016, Issue 10. Art. No.: CD007272. DOI: 10.1002/14651858.CD007272.pub2.

Copyright () 2016 The Cochrane Collaboration. Published by John Wiley \& Sons, Ltd.

\section{A B S T R A C T}

\section{Background}

General anaesthesia is usually associated with unconsciousness. 'Awareness' is when patients have postoperative recall of events or experiences during surgery. 'Wakefulness' is when patients become conscious during surgery, but have no postoperative recollection of the period of consciousness.

\section{Objectives}

To evaluate the efficacy of two types of anaesthetic interventions in reducing clinically significant awareness:

- anaesthetic drug regimens; and

- intraoperative anaesthetic depth monitors.

\section{Search methods}

We searched the Cochrane Central Register of Controlled Trials (CENTRAL, ISSUE 4 2016); PubMed from 1950 to April 2016; MEDLINE from 1950 to April 2016; and Embase from 1980 to April 2016. We contacted experts to identify additional studies. We performed a handsearch of the citations in the review. We did not search trial registries.

\section{Selection criteria}

We included randomized controlled trials (RCTs) of either anaesthetic regimens or anaesthetic depth monitors. We excluded volunteer studies, studies of patients prior to skin incision, intensive care unit studies, and studies that only randomized different word presentations for memory tests (not anaesthetic interventions).

Anaesthetic drug regimens included studies of induction or maintenance, or both. Anaesthetic depth monitors included the Bispectral Index monitor, M-Entropy, Narcotrend monitor, cerebral function monitor, cerebral state monitor, patient state index, and lower oesophageal contractility monitor. The use of anaesthetic depth monitors allows the titration of anaesthetic drugs to maintain unconsciousness. 


\section{Data collection and analysis}

At least two authors independently scanned abstracts, extracted data from the studies, and evaluated studies for risk of bias. We made attempts to contact all authors for additional clarification. We performed meta-analysis statistics in packages of the $\mathrm{R}$ language.

\section{Main results}

We included 160 studies with 54,109 enrolled participants; 53,713 participants started the studies and 50,034 completed the studies or data analysis (or both). We could not use 115 RCTs in meta-analytic comparisons because they had zero awareness events. We did not merge 27 of the remaining 45 studies because they had excessive clinical and methodological heterogeneity. We pooled the remaining 18 eligible RCTs in meta-analysis. There are 10 studies awaiting classification which we will process when we update the review.

The meta-analyses included 18 trials with 36,034 participants. In the analysis of anaesthetic depth monitoring (either Bispectral Index or M-entropy) versus standard clinical and electronic monitoring, there were nine trials with 34,744 participants. The overall event rate was $0.5 \%$. The effect favoured neither anaesthetic depth monitoring nor standard clinical and electronic monitoring, with little precision in the odds ratio (OR) estimate (OR $0.98,95 \%$ confidence interval $(\mathrm{Cl}) 0.59$ to 1.62 ).

In a five-study subset of Bispectral Index monitoring versus standard clinical and electronic monitoring, with 34,181 participants, 503 participants gave awareness reports to a blinded, expert panel who adjudicated or judged the outcome for each patient after reviewing the questionnaires: no awareness, possible awareness, or definite awareness. Experts judged 351 patient awareness reports to have no awareness, 87 to have possible awareness, and 65 to have definite awareness. The effect size favoured neither Bispectral Index monitoring nor standard clinical and electronic monitoring, with little precision in the OR estimate for the combination of definite and possible awareness (OR 0.96, $95 \% \mathrm{Cl} 0.35$ to 2.65). The effect size favoured Bispectral Index monitoring for definite awareness, but with little precision in the OR estimate (OR $0.60,95 \% \mathrm{Cl} 0.13$ to 2.75 ).

We performed three smaller meta-analyses of anaesthetic drugs. There were nine studies with 1290 participants. Wakefulness was reduced by ketamine and etomidate compared to thiopental. Wakefulness was more frequent than awareness. Benzodiazepines reduces awareness compared to thiopental, ketamine, and placebo., Also, higher doses of inhaled anaesthetics versus lower doses reduced the risk of awareness.

We graded the quality of the evidence as low or very low in the 'Summary of findings' tables for the five comparisons.

Most of the secondary outcomes in this review were not reported in the included RCTs.

\section{Authors' conclusions}

Anaesthetic depth monitors may have similar effects to standard clinical and electrical monitoring on the risk of awareness during surgery. In older studies comparing anaesthetics in a smaller portion of the patient sample, wakefulness occurred more frequently than awareness. Use of etomidate and ketamine lowered the risk of wakefulness compared to thiopental. Benzodiazepines compared to thiopental and ketamine, or higher doses of inhaled anaesthetics versus lower doses, reduced the risk of awareness.

\section{PLAIN LANGUAGE SUMMARY}

\section{Methods to prevent people waking during surgery and remembering surgical events}

\section{Key question}

We reviewed the evidence about the use of devices to adjust the amount of drugs given during anaesthesia to prevent premature waking up. We also reviewed the evidence about the choice of drugs used during anaesthesia to prevent premature waking up.

\section{Background}

Anaesthesia is the use of drugs to render a patient unconscious for painful procedures and surgery. Being anaesthetized is not the same as being asleep. Someone sleeping may be easily awakened. Someone anaesthetized should only be allowed to awake when the surgery or procedure is completed. A very small percentage of patients may wake up during anaesthesia and surgery; this is called wakefulness. Patients usually do not remember being awake after emerging from anaesthesia. However, an even smaller percentage of patients do remember or recall events from surgery afterwards. This memory is called an awareness event. If that memory is distressing, it can impair the individual's quality of life.

New devices known as anaesthetic depth monitors are being used to monitor the patient's brainwave response to anaesthetic drugs. Anaesthetic depth monitors have been compared to the usual clinical observations (e.g. fast heart rate, tearing, movement, etc.) during surgery to adjust the amount of drugs given and reduce the risk of wakefulness and awareness.

Anaesthetic drugs have many different effects on brain function. Some drugs are used alone as the sole anaesthetic. Other drugs have insufficient effect to be used as a sole anaesthetic, but are used in combination with more powerful drugs. Drugs may have different risks of the patient waking up prematurely. 


\section{Search date}

The evidence is current to April 2016.

\section{Study characteristics}

We found 160 randomized controlled trials with 54,109 participants. Eighteen studies with 36,034 participants contributed evidence about devices and drugs to prevent premature waking up during surgery. Nine studies compared anaesthetic depth monitoring versus other methods to adjust drugs. Nine studies compared different drugs. There are 10 studies awaiting classification, which we will process when we update the review.

\section{Key results}

In the largest studies of anaesthetic depth monitors (five studies with 31,181 participants) there were 152 participants with possible or definite awareness (recall of surgery events after surgery). The use of anaesthetic depth monitors to adjust drugs during anaesthesia may have similar effects on the risk of awareness when compared with standard clinical and electrical monitoring. Wakefulness is reduced by ketamine and etomidate compared to thiopental. Benzodiazepines reduces awareness compared to thiopental, ketamine, and placebo. Also higher doses of inhaled anaesthetics versus lower doses reduced the risk of awareness.

\section{Quality of evidence}

The quality of the evidence was low or very low because the studies the results were not similar across studies, and there were not enough data. 
SUMMARY OF FINDINGS

\section{Summary of findings for the main comparison. Anaesthesia depth monitors (BIS and M-entropy) versus standard clinical and electronic monitoring}

Anaesthesia depth monitors (BIS and M-entropy) compared with standard clinical and electronic monitoring

Patient or population: patients with prevention of recall of events during surgery

Settings: All patients undergoing various surgical procedures in hospitals in Europe/Australia/Asia/Middle East/North America

Intervention: anaesthesia depth monitors (BIS, M-Entropy)

Comparison: standard clinical and electronic monitoring

\begin{tabular}{|c|c|c|c|c|c|c|}
\hline \multirow[t]{3}{*}{ Outcomes } & \multicolumn{2}{|c|}{ Illustrative comparative risks* $(95 \% \mathrm{Cl})$} & \multirow{3}{*}{$\begin{array}{l}\text { Relative effect } \\
(95 \% \mathrm{CI})\end{array}$} & \multirow{3}{*}{$\begin{array}{l}\text { No of partici- } \\
\text { pants } \\
\text { (studies) }\end{array}$} & \multirow{3}{*}{$\begin{array}{l}\text { Quality of the } \\
\text { evidence } \\
\text { (GRADE) }\end{array}$} & \multirow[t]{3}{*}{ Comments } \\
\hline & Assumed risk & $\begin{array}{l}\text { Corresponding } \\
\text { risk }\end{array}$ & & & & \\
\hline & $\begin{array}{l}\text { Standard clini- } \\
\text { cal and electronic } \\
\text { monitoring }\end{array}$ & $\begin{array}{l}\text { Anaesthesia depth } \\
\text { monitors }\end{array}$ & & & & \\
\hline $\begin{array}{l}\text { Adverse effects of intraoperative wakefulness } \\
\text { and/or postoperative awareness } \\
\text { (i.e. post-traumatic stress syndrome, myocardial } \\
\text { infarction, cardiac arrest, etc.) }\end{array}$ & - & - & - & - & - & $\begin{array}{l}\text { Not defined or } \\
\text { not identified }\end{array}$ \\
\hline
\end{tabular}

*The basis for the assumed risk (e.g. the median control group risk across studies) is provided in footnotes. The corresponding risk (and its $95 \%$ confidence interval) is based on the assumed risk in the comparison group and the relative effect of the intervention (and its $95 \% \mathrm{Cl}$ ).

BIS: Bispectral Index; CI: confidence interval; OR: odds ratio

GRADE Working Group grades of evidence

High quality: Further research is very unlikely to change our confidence in the estimate of effect.

Moderate quality: Further research is likely to have an important impact on our confidence in the estimate of effect and may change the estimate.

Low quality: Further research is very likely to have an important impact on our confidence in the estimate of effect and is likely to change the estimate.

Very low quality: We are very uncertain about the estimate.

${ }^{1}$ Inconsistency: downgraded one level for inconsistency of effect. Heterogeneity (12) was moderate (49\%). There were non-overlapping $95 \%$ Cls. 
2Imprecision: downgraded one level for imprecision. Although the number of participants was large (34,744), the number of events was small (173) and the upper and lower bounds of the OR $95 \% \mathrm{Cl}$ did not exclude important effects.

\section{Summary of findings 2. Anaesthesia depth monitors (BIS) versus standard clinical and electronic monitoring}

Anaesthesia depth monitors (BIS) versus standard clinical and electronic monitoring with expert panel adjudication (Grade 4 and 5 ) during surgery

Patient or population: patients with prevention of recall of events during surgery

Settings: All patients undergoing various surgical procedures in hospitals in Europe/Australia/Asia/Middle East/North America

Intervention: anaesthesia depth monitors (BIS)

Comparison: standard clinical and electronic monitoring

\begin{tabular}{|c|c|c|c|c|c|c|}
\hline \multirow[t]{3}{*}{ Outcomes } & \multicolumn{2}{|c|}{$\begin{array}{l}\text { Illustrative comparative risks* }(95 \% \\
\mathrm{CI})\end{array}$} & \multirow[t]{3}{*}{$\begin{array}{l}\text { Relative effect } \\
(95 \% \mathrm{CI})\end{array}$} & \multirow{3}{*}{$\begin{array}{l}\text { No of partici- } \\
\text { pants } \\
\text { (studies) }\end{array}$} & \multirow{3}{*}{$\begin{array}{l}\text { Quality of the } \\
\text { evidence } \\
\text { (GRADE) }\end{array}$} & \multirow[t]{3}{*}{ Comments } \\
\hline & Assumed risk & $\begin{array}{l}\text { Corresponding } \\
\text { risk }\end{array}$ & & & & \\
\hline & $\begin{array}{l}\text { Standard clini- } \\
\text { cal and electron- } \\
\text { ic monitoring }\end{array}$ & $\begin{array}{l}\text { Anaesthesia depth } \\
\text { monitors (BIS) }\end{array}$ & & & & \\
\hline $\begin{array}{l}\text { Awareness: definite and possible } \\
\text { Postoperative interview }\end{array}$ & 5 per 1000 & $\begin{array}{l}5 \text { per } 1000 \\
(3 \text { to } 8)\end{array}$ & $\begin{array}{l}\text { OR } 0.96 \\
(0.35 \text { to } 2.65)\end{array}$ & $\begin{array}{l}34,181 \\
\text { (5 studies) }\end{array}$ & $\begin{array}{l}\oplus \oplus \oplus \ominus \\
\text { low } 1,2\end{array}$ & - \\
\hline \multicolumn{7}{|l|}{ Follow-up: 1 to 72 days 5} \\
\hline $\begin{array}{l}\text { Awareness: definite } \\
\text { Postoperative interview }\end{array}$ & 2 per 1000 & $\begin{array}{l}1 \text { per } 1000 \\
\text { (0 to } 4)\end{array}$ & $\begin{array}{l}\text { OR } 0.60 \\
\text { (0.13 to } 2.75)\end{array}$ & $\begin{array}{l}34,181 \\
\text { (5 studies) }\end{array}$ & $\begin{array}{l}\oplus \oplus \oplus \ominus \\
\text { low } 3,4\end{array}$ & - \\
\hline \multicolumn{7}{|l|}{ Follow-up: 1 to 72 days 6} \\
\hline $\begin{array}{l}\text { Adverse effects of intraoperative wakefulness } \\
\text { and/or postoperative awareness }\end{array}$ & - & - & - & - & - & $\begin{array}{l}\text { Not defined or } \\
\text { not identified }\end{array}$ \\
\hline $\begin{array}{l}\text { (i.e. post-traumatic stress syndrome, myocardial } \\
\text { infarction, cardiac arrest, etc.) }\end{array}$ & & & & & & \\
\hline
\end{tabular}

*The basis for the assumed risk (e.g. the average control group risk across studies) is provided in footnotes. The corresponding risk (and its $95 \%$ confidence interval) is based on the assumed risk in the comparison group and the relative effect of the intervention (and its $95 \% \mathrm{Cl}$ ).

BIS: Bispectral Index; Cl: confidence interval; OR: odds ratio

GRADE Working Group grades of evidence

High quality: Further research is very unlikely to change our confidence in the estimate of effect.

Moderate quality: Further research is likely to have an important impact on our confidence in the estimate of effect and may change the estimate.

Low quality: Further research is very likely to have an important impact on our confidence in the estimate of effect and is likely to change the estimate. 
1Inconsistency: BIS definite and possible downgraded one level for inconsistency of effect. Heterogeneity (12) was substantial (68\%). There were non-overlapping 95\% Cls.

2Imprecision: BIS definite and possible downgraded one level for imprecision. Although the number of participants was large (34,181), the number of events was small (152) and the upper and lower bounds of the OR $95 \% \mathrm{Cl}$ did not exclude important effects.

3 Inconsistency: BIS definite downgraded one level for inconsistency of effect. Heterogeneity ( 12 ) was substantial (60\%). There were non-overlapping $95 \% \mathrm{Cl}$.

4Imprecision: BIS definite downgraded one level for imprecision. Although the number of participants was large $(34,181)$, the number of events was small $(64)$ and the upper and lower bounds of the OR $95 \% \mathrm{Cl}$ did not exclude important effects.

5The assumed risk is the average control group event rate in the five studies: 0.0047 (78/16,749).

6 The assumed risk is the average control group event rate in the five studies: $0.0024(41 / 16,749)$.

\section{Summary of findings 3. Thiopentone with and without added hypnotic drugs (ketamine, etomidate)}

Thiopentone with and without added hypnotic drugs (ketamine, etomidate)

Patient or population: patients with prevention of recall of events during surgery

Settings: All patients undergoing various surgical procedures in hospitals in Europe/Australia/Asia/Middle East/North America

Intervention: anaesthetic drugs introduced after thiopentone for prevention of recall of events during surgery

Comparison: Thiopentone with and without added hypnotic drugs (ketamine, etomidate)

\begin{tabular}{|c|c|c|c|c|c|c|}
\hline \multirow[t]{3}{*}{ Outcomes } & \multicolumn{2}{|c|}{ Illustrative comparative risks ${ }^{\star}(95 \% \mathrm{Cl})$} & \multirow{3}{*}{$\begin{array}{l}\text { Relative effect } \\
(95 \% \mathrm{Cl})\end{array}$} & \multirow{3}{*}{$\begin{array}{l}\text { No of partici- } \\
\text { pants } \\
\text { (studies) }\end{array}$} & \multirow{3}{*}{$\begin{array}{l}\text { Quality of the } \\
\text { evidence } \\
\text { (GRADE) }\end{array}$} & \multirow[t]{3}{*}{ Comments } \\
\hline & Assumed risk & Corresponding risk & & & & \\
\hline & Thiopentone & $\begin{array}{l}\text { Anaesthetic drugs introduced } \\
\text { after thiopentone for preven- } \\
\text { tion of recall of events during } \\
\text { surgery: Ketamine, etomidate }\end{array}$ & & & & \\
\hline $\begin{array}{l}\text { Adverse effects of intraoperative } \\
\text { wakefulness and/or postoperative } \\
\text { awareness } \\
\text { (i.e. post-traumatic stress syndrome, } \\
\text { myocardial infarction, cardiac arrest, } \\
\text { etc.) }\end{array}$ & - & - & - & - & - & $\begin{array}{l}\text { Not defined or } \\
\text { not identified }\end{array}$ \\
\hline
\end{tabular}

${ }^{\star}$ The basis for the assumed risk (e.g. the median control group risk across studies) is provided in footnotes. The corresponding risk (and its $95 \%$ confidence interval) is

based on the assumed risk in the comparison group and the relative effect of the intervention (and its 95\% $\mathrm{Cl}$ ). 
GRADE Working Group grades of evidence

High quality: Further research is very unlikely to change our confidence in the estimate of effect.

Moderate quality: Further research is likely to have an important impact on our confidence in the estimate of effect and may change the estimate.

Low quality: Further research is very likely to have an important impact on our confidence in the estimate of effect and is likely to change the estimate.

Very low quality: We are very uncertain about the estimate.

1Within-study risk of bias: downgraded one level.

2Imprecision of results: downgraded one level for imprecision of effect. The high proportion of wakefulness events to sample size in these small studies was the reason for the one level downgrade compared to two levels for Comparison 4 and 5. The optimal information size threshold cannot be reached.

\section{Summary of findings 4. Thiopentone and ketamine versus benzodiazepines (diazepam, midazolam, lorazepam)}

Thiopentone and ketamine versus benzodiazepines (diazepam, midazolam, lorazepam)

Patient or population: patients with prevention of recall of events during surgery

Settings: All patients undergoing various surgical procedures in hospitals in Europe/Australia/Asia/Middle East/North America

Intervention: benzodiazepine use versus other intravenous anaesthetic techniques

\begin{tabular}{|c|c|c|c|c|c|c|}
\hline \multirow[t]{3}{*}{ Outcomes } & \multicolumn{2}{|c|}{ Illustrative comparative risks* $(95 \% \mathrm{CI})$} & \multirow{3}{*}{$\begin{array}{l}\text { Relative effect } \\
(95 \% \mathrm{CI})\end{array}$} & \multirow{3}{*}{$\begin{array}{l}\text { No of partici- } \\
\text { pants } \\
\text { (studies) }\end{array}$} & \multirow{3}{*}{$\begin{array}{l}\text { Quality of the } \\
\text { evidence } \\
\text { (GRADE) }\end{array}$} & \multirow[t]{3}{*}{ Comments } \\
\hline & Assumed risk & Corresponding risk & & & & \\
\hline & $\begin{array}{l}\text { Control: Keta- } \\
\text { mine, } \\
\text { thiopentone }\end{array}$ & $\begin{array}{l}\text { Benzodiazepine use ver- } \\
\text { sus other (control) intra- } \\
\text { venous anaesthetic tech- } \\
\text { niques }\end{array}$ & & & & \\
\hline $\begin{array}{l}\text { Adverse effects of intraoperative wakeful- } \\
\text { ness and/or postoperative awareness } \\
\text { (i.e. post-traumatic stress syndrome, myocar- } \\
\text { dial infarction, cardiac arrest, etc.) }\end{array}$ & - & - & - & - & - & $\begin{array}{l}\text { Not defined or } \\
\text { not identified }\end{array}$ \\
\hline
\end{tabular}

*The basis for the assumed risk (e.g. the median control group risk across studies) is provided in footnotes. The corresponding risk (and its $95 \%$ confidence interval) is based on the assumed risk in the comparison group and the relative effect of the intervention (and its $95 \% \mathrm{Cl}$ ).

Cl: confidence interval; RR: risk ratio 
GRADE Working Group grades of evidence

High quality: Further research is very unlikely to change our confidence in the estimate of effect.

Moderate quality: Further research is likely to have an important impact on our confidence in the estimate of effect and may change the estimate.

Low quality: Further research is very likely to have an important impact on our confidence in the estimate of effect and is likely to change the estimate.

Very low quality: We are very uncertain about the estimate.

1Within-study risk of bias: downgraded one level.

2 Imprecision of results: downgraded two levels for imprecision of effect. The optimal information size threshold cannot be reached.

3The assumed risk is the average control group event rate in the four studies: 0.162 (16/99).

\section{Summary of findings 5. Caesarean section with low- and high-dose inhaled agent}

Caesarean section with low- and high-dose inhaled agent

Patient or population: patients with decreasing recall of events during surgery

Settings: All patients undergoing various surgical procedures in hospitals in Europe/Australia/Asia/Middle East/North America

Intervention: deeper anaesthetic techniques

Comparison: lighter anaesthetic techniques

\begin{tabular}{|c|c|c|c|c|c|c|}
\hline \multirow[t]{3}{*}{ Outcomes } & \multicolumn{2}{|c|}{ Illustrative comparative risks* $(95 \% \mathrm{Cl})$} & \multirow{3}{*}{$\begin{array}{l}\text { Relative effect } \\
(95 \% \mathrm{Cl})\end{array}$} & \multirow{3}{*}{$\begin{array}{l}\text { No of partici- } \\
\text { pants } \\
\text { (studies) }\end{array}$} & \multirow{3}{*}{$\begin{array}{l}\text { Quality of the } \\
\text { evidence } \\
\text { (GRADE) }\end{array}$} & \multirow[t]{3}{*}{ Comments } \\
\hline & Assumed risk & Corresponding risk & & & & \\
\hline & $\begin{array}{l}\text { Lighter anaes- } \\
\text { thetic tech- } \\
\text { niques }\end{array}$ & $\begin{array}{l}\text { Deeper anaesthetic } \\
\text { techniques }\end{array}$ & & & & \\
\hline $\begin{array}{l}\text { Awareness } \\
\text { Postoperative interview } 1 \\
\text { Follow-up: } 1 \text { day }\end{array}$ & 51 per 1000 & $\begin{array}{l}7 \text { per } 1000 \\
(2 \text { to } 22)\end{array}$ & $\begin{array}{l}\text { RR } 0.13 \\
(0.04 \text { to } 0.43)\end{array}$ & $\begin{array}{l}858 \\
\text { (2 studies) }\end{array}$ & $\begin{array}{l}\oplus \Theta \Theta \Theta \\
\text { very low } 1,2\end{array}$ & - \\
\hline $\begin{array}{l}\text { Adverse effects of intraoperative wakefulness } \\
\text { and/or postoperative awareness } \\
\text { (i.e. post-traumatic stress syndrome, myocardial } \\
\text { infarction, cardiac arrest, etc.) }\end{array}$ & - & - & - & - & - & $\begin{array}{l}\text { Not defined or } \\
\text { not identified }\end{array}$ \\
\hline
\end{tabular}

*The basis for the assumed risk (e.g. the median control group risk across studies) is provided in footnotes. The corresponding risk (and its $95 \%$ confidence interval) is based on the assumed risk in the comparison group and the relative effect of the intervention (and its $95 \% \mathrm{Cl}$ ).

Cl: confidence interval; RR: risk ratio

GRADE Working Group grades of evidence

High quality: Further research is very unlikely to change our confidence in the estimate of effect 
Moderate quality: Further research is likely to have an important impact on our confidence in the estimate of effect and may change the estimate.

Low quality: Further research is very likely to have an important impact on our confidence in the estimate of effect and is likely to change the estimate.

Very low quality: We are very uncertain about the estimate.

1Within-study risk of bias: downgraded one level.

2Imprecision of results: downgraded two levels for imprecision of effect. The optimal information size threshold cannot be reached.

3The assumed risk is the average control group event rate in the two studies: 0.051 (21/409). 


\section{B A C K G R O U N D}

\section{Description of the condition}

The American Society of Anesthesiology (ASA) task force has defined awareness as "when a patient becomes conscious during a procedure performed under general anaesthesia and subsequently has recall of these events" (ASA 2006). Recent estimates of the number of patients having awareness under general anaesthesia in the United States have been as high as approximately 1 to 2 per 1000 anaesthetics (Sebel 2004).

People may wake up far more often during surgery than they remember after surgery (wakefulness) (Artusio 1955; Russell 1985; Russell 1993; Tunstall 1977; Appendix 1). Wakefulness and awareness cases that are not associated with pain or distress are considered, by some, to be clinically insignificant. There are no published data that define the frequency of wakefulness or awareness cases that are associated with pain and or panic. It has been reported that $10 \%$ of awareness cases are associated with pain (Jones 1994).

Awareness with pain or panic, or both, almost exclusively occurs with the use of neuromuscular blocking drugs (Cundy 1995; Lennmarken 2002; Mainzer 1979; Sandin 2000; White 1987). Neuromuscular blocking drugs in current use are also associated with significant complications other than awareness (Brull 2008; Murphy 2008; Wahl 2011).

The psychological sequelae of cases of anaesthetic awareness have been described (Appendix 1).

\section{Description of the intervention}

Two types of interventions have been proposed for preventing wakefulness and awareness: medication and specialized monitoring.

\section{Medication}

Different medications may be administered before and during general anaesthesia; these may have oral, intramuscular, intravenous, or volatile routes of administration. They include anaesthetic gases and vapours, sedatives or hypnotics, and analgesics. The choice may consist solely of the different medications that can be administered prior to the induction of anaesthesia. However, management options may also include two different protocols for general anaesthesia:

- techniques consisting of intravenous drugs only;

- traditional general anaesthesia combining both volatile anaesthetics and intravenous drugs.

\section{Specialized monitoring}

Modern anaesthesia depth monitors provide a real time electroencephalogram (EEG) for the patient in the operating theatre. Various algorithms are applied, i.e. the EEG is processed. The processed EEG is usually displayed as a unit less number scaled from 0 to 100 . The value displayed is updated frequently (within seconds) with newly acquired EEG epochs. Calibration has been established by anaesthesia depth monitor manufacturers, with a value of 100 reflecting an awake state and a value of 0 reflecting cerebral electrical silence and unconsciousness (Rampil 1998). The use of anaesthesia depth monitors involves two stages.
Firstly, the monitor is placed on the patient in order to generate monitoring data. Secondly, the anaesthetist uses these data to make adjustments to the anaesthetic management of the patient.

\section{How the intervention might work}

Both types of intervention, choice of medication and use of anaesthesia depth monitors, have a common expected pathway for reducing the risk of awareness. Both are expected to produce a more intense (deeper) anaesthetic state through the selection of the type or amount of medication.

\section{Why it is important to do this review}

Patients who wake up during surgery may experience pain and distress. Besides the immediate suffering during the surgery itself, there maybe longer-term consequences. Awareness and possibly wakefulness can lead to post-traumatic stress disorder, which is a serious condition that can greatly impair quality of life. It may also cause patients to delay follow-up medical care. In some patients it may be sufficiently severe to lead to suicide (Breen 2007).

\section{O B JECTIVES}

To evaluate the efficacy of two types of anaesthetic interventions in reducing clinically significant awareness.

- anaesthetic drug regimens; and

- intraoperative anaesthetic depth monitors.

\section{METHODS}

\section{Criteria for considering studies for this review}

\section{Types of studies}

We included randomized controlled trials (RCTs).

\section{Types of participants}

We included paediatric and adult patients having all types of surgery. We excluded volunteer studies, studies of patients prior to skin incision, intensive care unit studies, and studies that only randomized different word presentations for memory tests (not anaesthetic interventions).

\section{Types of interventions}

Anaesthetic drug regimens included studies of induction or maintenance, or both. We included two types of interventions:

- anaesthetic drug regimens;

- intraoperative anaesthetic depth monitors.

Anaesthetic drug interventions included those during premedication, during induction and/or during maintenance phases of anaesthesia. Intraoperative anaesthetic depth monitors are those instruments that putatively allow anaesthesiologists to monitor the level of unconsciousness.

\section{Types of outcome measures}

Sebel et al introduced a classification system to improve the categorization of awareness complications (Sebel 2004). It was argued that more objective criteria were needed to identify a valid patient awareness report (Eger 2005), Therefore Wang and colleagues proposed a further refinement of this classification 
of awareness (Wang 2012). This classification includes a six-level hierarchy from unconsciousness to consciousness that includes wakefulness, awareness, explicit and implicit memory, posttraumatic stress disorder (PTSD), and perioperative dreams and nightmares (Table 1; Appendix 1).

\section{Primary outcomes}

- Awareness or wakefulness as defined using the awareness classification system in Table 1.

The classification used in this review had not been conceived or published prior to 2012 (Wang 2012), therefore studies may not have adhered to these criteria for the determination of intraoperative state. We therefore had to infer this from study descriptions and our author survey.

We tallied details of the adjudication process from the published study or sought the details by communication with the authors. In some trials a formal two-stage process using structured interviews of patients was conducted. Potential awareness episodes were recorded in a narrative report. An independent committee of three anaesthetists, blinded to treatment group, coded the report as no awareness, possible awareness, and awareness.

\section{Secondary outcomes}

- Signs or adverse effects of intraoperative wakefulness or postoperative awareness, or both, are intraoperative patient movement, haemodynamic changes, portions of intraoperative dreams and postoperative dreams or nightmares, or both, delayed memory, full (PTSD) or partial (PTS) forms of posttraumatic stress syndrome, myocardial infarction, cardiac arrest, death, and suicide.

\section{Search methods for identification of studies}

\section{Electronic searches}

We searched the Cochrane Central Register of Controlled Trials (CENTRAL, Issue 4, 2016), PUBMED (1950 to April 2016) and MEDLINE (1950 to April 2016), and Embase (1980 to April 2016). We searched CENTRAL using the search terms found in Appendix 2. We searched MEDLINE using the search terms described in Appendix 3 and Embase using the terms found in Appendix 4, via SilverPlatter.

\section{Searching other resources}

We contacted experts in the field to identify any additional studies. We performed a handsearch from the citations found in included and excluded studies and other footnoted papers. We did not impose any language restriction. We did not search trial registries (ClinicalTrials.gov; World Health Organization (WHO) International Clinical Trials Registry Platform (ICTRP)).

\section{Data collection and analysis}

A group of the authors (AGM, NLP, MaW, CCW, and BS) independently scanned the titles and abstracts of reports identified by electronic and manual searching and by contact with experts. We evaluated full-text versions of potentially relevant studies. We used the web app Rayyan to assist in citation review (Elmagarmid 2014).

\section{Selection of studies}

A group of the authors (AGM, NLP, MaW, CCW, and BS) independently selected trials that met the inclusion criteria by using a checklist designed for that purpose. Where there was disagreement we discussed the differences and reached a consensus. The criteria used to merge included studies in metaanalysis are described in Appendix 5.

\section{Data extraction and management}

A group of the authors (AGM, NLP, MaW, CCW, and BS) independently extracted parts of the data using a standardized study record form (see Appendix 5).

\section{Assessment of risk of bias in included studies}

A group of the authors (AGM, NLP, MaW, CCW, and BS) used Cochrane's domain-based evaluation method for assessing the risk of bias (Guyatt 2011; Higgins 2011). The assessment of risk of bias was based on the seven domains in the 'Risk of bias' table: random sequence generation (selection bias), allocation concealment (selection bias), blinding of participants, blinding of personnel (performance bias), blinding of outcome assessment (detection bias), incomplete outcome data (attrition bias), selective reporting (reporting bias), and other bias. We sent a survey to study authors to inquire about study methodology (Appendix 6). We sent this survey to authors who had email addresses in the included paper or that were readily available in a literature search of other published papers.

\section{Measures of treatment effect}

The definitions of rare and uncommon adverse events and diseases overlap (EUC 2009; HR4013; WHO 2002). Therefore, we use the terms 'rare' and 'uncommon' interchangeably in this review. Awareness is a dichotomous outcome and an uncommon or rare event. We used relative event rates, odds ratio (OR) or risk ratio (RR), as the effect size measure.

\section{GRADE and 'Summary of findings' table methods}

We used the GRADE methods to assess the quality of the body of evidence associated with specific outcomes: awareness - definite and definite and possible awareness, intraoperative wakefulness, and adverse effects of intraoperative wakefulness and/or postoperative awareness (i.e. post-traumatic stress syndrome, myocardial infarction, cardiac arrest, etc.), and to assess the quality of the evidence for the five comparisons of merged studies (Guyatt 2008). We used five domains to downgrade the quality of evidence: risk of bias, inconsistency, indirectness, imprecision, and publication bias. We used three domains to upgrade the quality of evidence: large effect, plausible confounding that could change the effect, and dose response gradient.

\section{Unit of analysis issues}

For studies of both anaesthetic drug interventions and anaesthetic depth monitors, we analysed participants in the groups to which they were randomized regardless of the actual intervention delivered, i.e. by intention-to-treat.

The unit of analysis for all outcomes was the individual participant. We defined the experimental group in a comparison as the newer treatment in each study and the control group as the older treatment.

All studies were parallel-group trials. There were no unit of analysis issues such as those arising from cross-over or cluster-randomized trials. 


\section{Dealing with missing data}

To investigate the consequence of missing data, we considered using best-case or worst-case imputation. We considered including and excluding any study that appeared to have a large effect size (often the largest or earliest study) in order to assess its impact on the meta-analysis.

We described the missing data that resulted from such factors as attrition or exclusions, or both (see Characteristics of included studies). We calculated the number and percentage of missing data from each outcome group of the included studies and based our grade on the authors' account of those missing data.

\section{Assessment of heterogeneity}

We expected to find a great deal of clinical heterogeneity in the included studies, for example anaesthetic types, patient ages, etc. We considered this clinical heterogeneity when deciding whether to pool results in a meta-analysis.

To assess statistical heterogeneity, we used the 12 statistic, which describes the percentage of the variability in effect estimates that is due to heterogeneity rather than sampling error (chance). The importance of the observed value of $1^{2}$ depends on the magnitude and direction of effects and the strength of evidence for heterogeneity. The thresholds for interpreting $\mathrm{I}^{2}$ heterogeneity were: moderate (30\% to $60 \%)$, substantial (50\% to $90 \%)$, and considerable (75\% to $100 \%$ ) (Higgins 2002).

\section{Assessment of reporting biases}

There were insufficient studies of the same interventions (fewer than 10) to allow the creation of funnel plots.

\section{Data synthesis}

As Review Manager has no statistical methods for very rare and uncommon events with between-study heterogeneity, we used the statistical packages in R (R 2016). For ORs, we estimated random- or mixed-effects generalized linear models in the R package metafor (Viechtbauer 2010). In some comparisons, the sparseness of data prevented logistic model estimation. In those cases, we estimated an exact fixed-effect RR (Tian 2008), in the R package exactmeta (Yu 2013). We also estimated a random-effects multivariable meta-analysis comparing the logit transformed proportions of awareness versus wakefulness in the $\mathrm{R}$ package metafor. We declared statistical significance for $\mathrm{P}<0.05$ and if the $95 \% \mathrm{Cl}$ for effect sizes failed to include the line of unity. Results from the random- or mixed-effects model included an approximate $95 \%$ prediction interval $(\mathrm{PI})$; this interval estimated where $95 \%$ of true outcomes fall in the hypothetical population of all possible studies (Dean 2007; Tian 2008).

Results from individual studies are displayed in forest plots. Summary statistics from non-Review Manager packages are displayed in the forest plots. Statistical analyses including data sets, codes, and outputs are shown in an appendix (Appendix 7).

\section{Subgroup analysis and investigation of heterogeneity}

We considered the following subgroup analyses:

- anaesthesia depth monitoring method;

- patients at high risk of awareness;

- specific anaesthetic techniques with and without neuromuscular blocking drugs;

- implicit or explicit memory.

In a subgroup analysis, the magnitude and direction of treatment effect may be inconsistent among subgroups.

There were only sufficient data for a comparison of subgroups based on studies with high risk of awareness and alarms/alerts and total intravenous anaesthesia (TIVA).

\section{Sensitivity analysis}

We considered performing a sensitivity analysis to assess the impact of studies with a higher risk of bias. The patients lost to follow-up in these studies may be associated with higher rates of awareness, since one important sequela of awareness is a phobic avoidance of hospitals and physicians. In the context of trials, this is likely to lead to dropout during follow-up.

We did not perform a sensitivity analysis for risk of bias for the following reasons:

- Analysis 1.1, Analysis 2.1, and Analysis 2.2 had predominantly low risk of bias for all seven domains and therefore were not suitable for risk of bias sensitivity analysis;

- Analysis 3.1, Analysis 4.1, and Analysis 5.1 were candidates for a sensitivity analysis because of the predominantly unclear risk of bias for Analysis 3.1 and the low to unclear risk of bias for Analysis 4.1 and Analysis 5.1. Nonetheless, we did not conduct sensitivity analyses because there were a small number of included studies in these comparisons.

\section{RE S U L T S}

\section{Description of studies}

See Characteristics of included studies; Characteristics of excluded studies.

\section{Results of the search}

Five search periods characterized this review: 2008, 2011, 2012, 2013, 2014, and 2016. We employed three databases: CENTRAL, MEDLINE, and Embase (Appendix 2; Appendix 3; Appendix 4). The total yield for 2008 to 2016 was 11,328 records: 1997 from CENTRAL, 3662 from MEDLINE, and 5669 from Embase plus two records from other sources. We did not search ClinicalTrials.gov or the World Health Organization (WHO) International Clinical Trials Registry Platform (ICTRP). The details of the search results can be found in Figure 1. 
Figure 1. Study flow diagram.

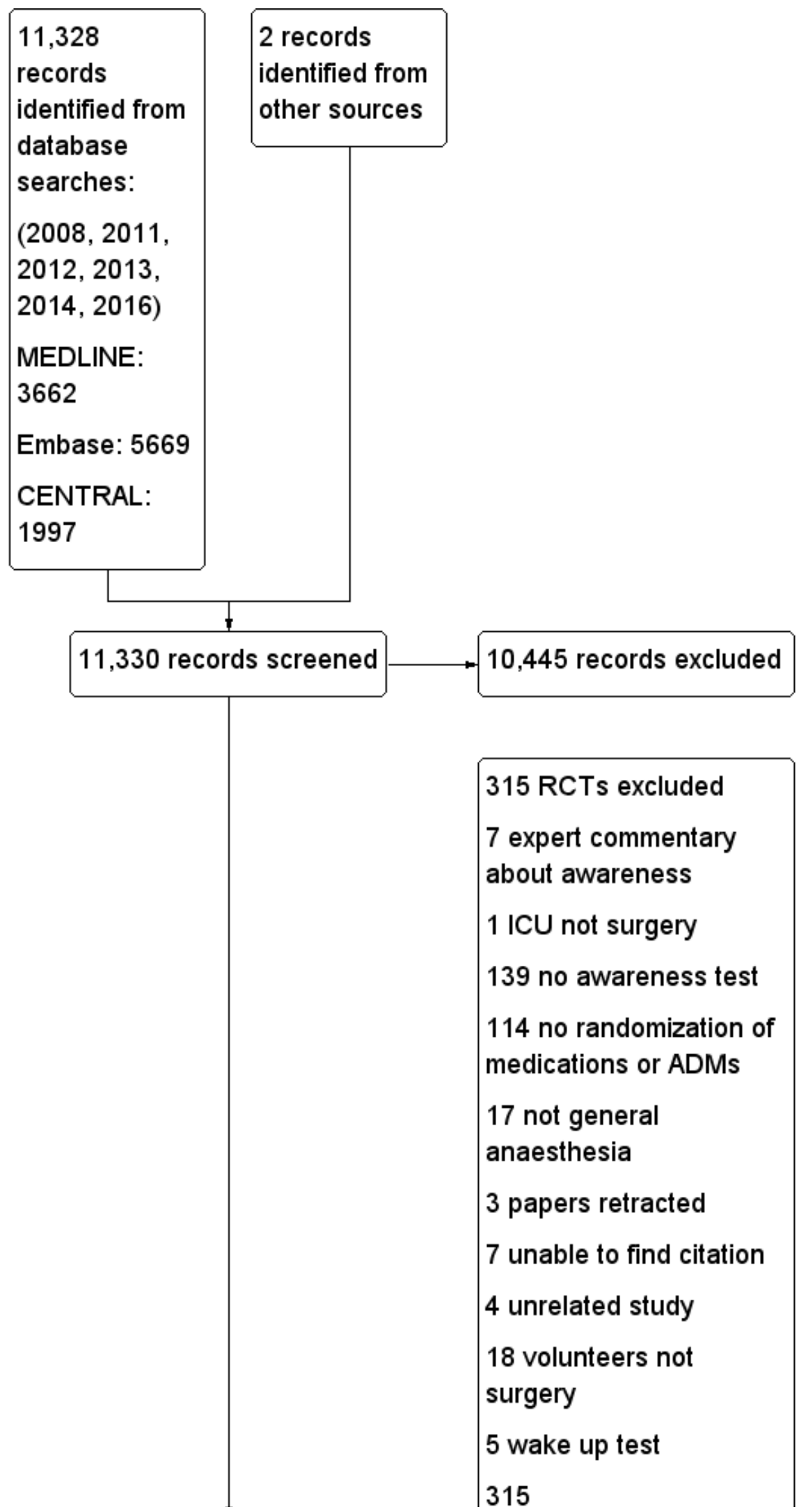


Figure 1. (Continued)

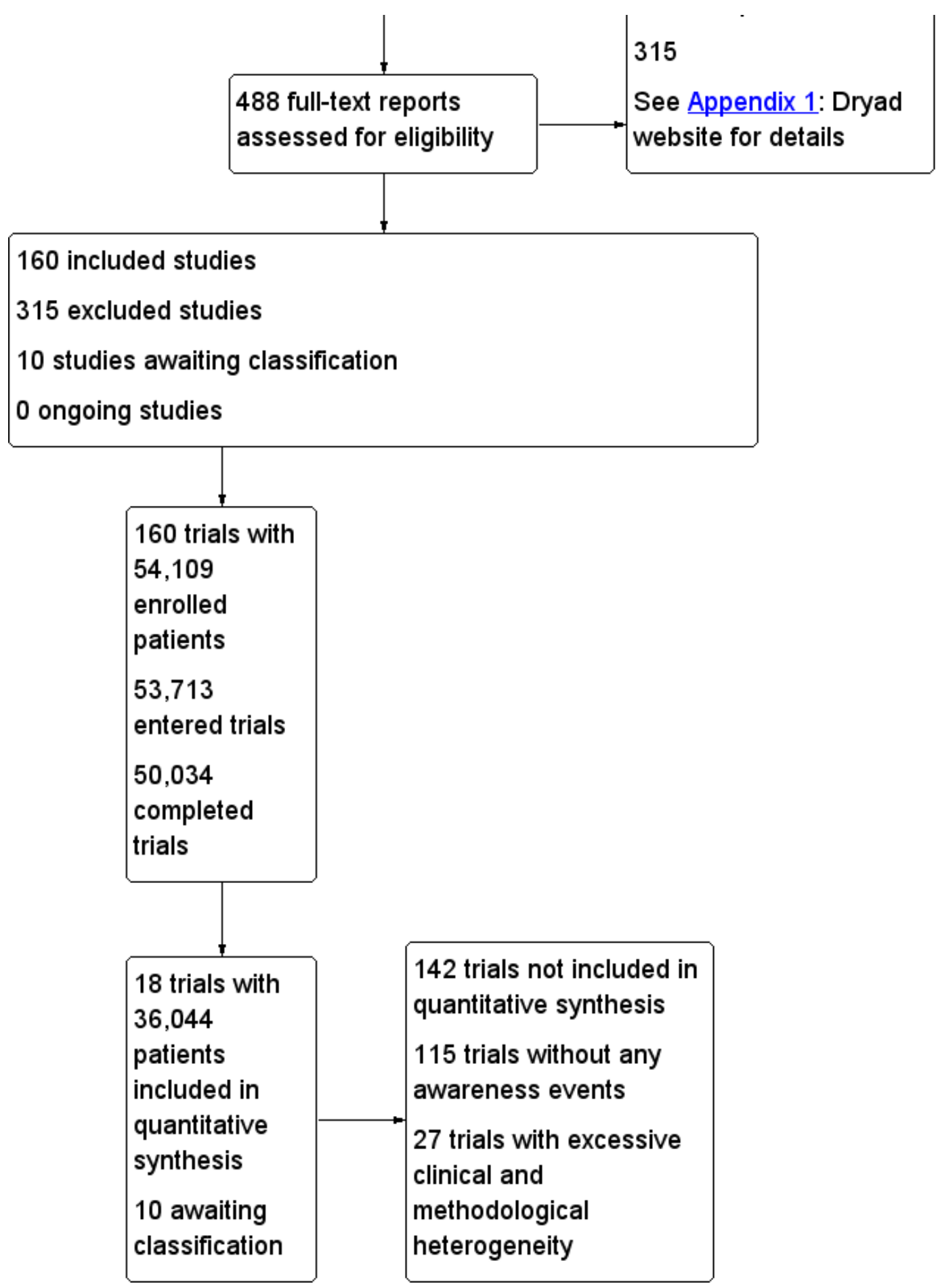

\section{Included studies}

We found 160 randomized controlled trials (RCTs) with 54,109 enrolled participants, of whom 53,713 started the studies and 50,034 completed the studies or data analysis (or both) (Appendix $1)$.

Sixteen of the included studies had to be translated into English: one Chinese (Zhou 2008), four Italian (Aceto 2002; Aceto 2003;
Bonato 2001; Girardi 1994), one French (Haimeur 1997), six German (Adams 1994; Blendinger 1976; Kasmacher 1996; Lehmann 1985; Lehmann 1992; Navarro 2000), two Japanese (Masuda 2002; Morimoto 2002), four Spanish (Anez 2001; Echevarria 1998; Hachero 2001; Monedero 1994), and one Turkish (Yildiz 2002). The remaining 141 were in English (Appendix 1).

Surgical risk was classified as minor in $16(10 \%)$, moderate in $74(46 \%)$, major in $25(16 \%)$, and mixed in $45(28 \%)$. There were 
142 studies that could not be used in meta-analytic comparisons because 115 had zero awareness events and 27 had excessive clinical and methodological heterogeneity. Most of the 115 studies assessed awareness as a secondary outcome and, therefore, were not powered to identify awareness events. We classified 27 studies that did have awareness events as too dissimilar to merge mainly because of the lack of consensus regarding the definition of intravenous techniques (Appendix 1).

We merged 18 out of the 45 studies with awareness events in meta-analysis. These 18 studies involved 36,044 participants. In the analysis of anaesthesia depth monitoring (either Bispectral Index or M-entropy) versus standard clinical and electronic monitoring, there were nine studies of the most commonly used anaesthetics with a merged sample of 34,754 participants, which was $96 \%$ of the entire patient sample. There were nine studies, with $1290(4 \%)$ participants, of older anaesthetics that are more commonly used in low-income countries (WHO 2015).

\section{Trial location}

One hundred and forty-two (89\%) of the studies were from three continents: Europe 72 (45\%), Asia 42 (26\%), and North America 28 $(18 \%)$. Five countries were the locations for $75(47 \%)$ of the included studies: Germany $23(14 \%)$, the USA 21 (13\%), the UK $13(8 \%)$, Italy $10(6 \%)$, and India $8(5 \%)$. The remaining countries varied between $1 \%$ and $4 \%$ (Appendix 1).

\section{Anaesthetic interventions}

\section{Frequency of anaesthetic techniques}

Different intravenous techniques were compared in 66 studies (41\%). Intravenous techniques were compared to volatile agent techniques in 23 studies (14\%). Volatile agent techniques were compared in 68 studies (43\%). Other techniques were randomized in three studies (2\%). Nitrous oxide was randomized in 13 studies (8\%): it was used, but not randomized, in 69 studies (43\%), and not used in 78 studies (49\%). No neuromuscular blocking drugs were used in $13(8 \%)$ of the included studies. In no study was the use of neuromuscular blocking drugs the experimental intervention (Appendix 1).

\section{Anaesthetic depth monitoring interventions}

Ninety-four (59\%) of the included studies had one or more processed electroencephalogram (EEG) or auditory evoked potentials (AEP) anaesthetic depth monitors that were part of the randomized or non-randomized protocols. The Bispectral Index monitor was used in $66(70 \%)$ of the 94 studies that included anaesthetic depth monitoring. Forty-three (65\%) of the 66 studies that used a Bispectral Index monitor defined a target range against which to titrate anaesthetics. Forty-three (16.3\%) used a target range of less than 50 ; five (11.6\%) used a target range of less than $55 ; 28(65.1 \%)$ used a target range of less than 60 ; two (4.7\%) used a target range of less than 65 ; and one (2.3\%) used a target range of less than 75 (Appendix 1).

In the five largest studies of anaesthetic depth monitors, three recruited participants expected to be at high risk of awareness (Avidan 2008; Avidan 2011; Myles 2004); in the other two studies a high expected risk of awareness was not described as an inclusion criterion (Mashour 2012; Zhang 2011). Additionally, in the smaller trials of anaesthetic depth monitors three were not high-risk patient studies (Gruenewald 2007; Kerssens 2009; Mozafari 2014), and one study was in high-risk patients (Puri 2003). In the high-risk studies, there were 86 definite and possible awareness events (a rate of $0.85 \%$ in 10,147 participants); in the other five studies there were 86 definite and possible awareness events (a rate of $0.35 \%$ in 24,597 participants) (Appendix 1).

\section{Classification of outcomes}

Grade 0 is a descriptor for adequate anaesthesia (Russell 1997). Adequate anaesthesia is defined as no signs of light anaesthesia such as tachycardia, hypertension, or non-purposeful to purposeful movement. For the purpose of this review, we included participants from studies that did not display such signs but we had limited data to make this judgement; we classified six studies (4\%) as such.

Grade 1 is a descriptor for intraoperative wakefulness with obliterated explicit and implicit memory (Andrade 2008). One hundred included studies (63\%) reported Grade 1 outcomes. This classification was assigned by the presence of signs of light anaesthesia such as tachycardia and/or hypertension identified in haemodynamic data, BIS data and/or patient movement etc, within a study's reported results (Appendix 1).

Grade 2 is a descriptor for intraoperative wakefulness with subsequent implicit memory (Merikle 1996). Ten of the included studies (6\%) reported Grade 2 outcomes.

Grade 3 is a descriptor for intraoperative wakefulness with implicit emotional memory (Wang 2000). No included study reported Grade 3 outcomes.

Grade 4 is a descriptor for patients with awareness yet resilience (Sandin 2000). Forty-three of the included studies (27\%) reported Grade 4 outcomes.

Grade 5 is a descriptor for patients with awareness with emotional sequelae (Osterman 2001). Two of the included studies (1\%) reported Grade 5 outcomes.

In the five comparisons of included studies reporting Grade 4 cognitive states we merged $17(94 \%)$ of the 18 studies (Abboud 1985; Avidan 2008; Avidan 2011; Baraka 1989; Crawford 1985; Ellingson 1977; Gruenewald 2007; Haram 1981; Kerssens 2009; Mashour 2012; McNulty 1995; Miller 1996; Mozafari 2014; Myles 2004; Puri 2003; Schultetus 1986; Zhang 2009), and one (6\%) included study reporting Grade 5 cognitive states (Russell 1986), which were suitable for meta-analysis (Appendix 1; Table 1).

\section{Excluded studies}

We excluded 315 randomized controlled trials for the reasons described in Characteristics of excluded studies and Figure 1.

\section{Studies awaiting classification}

There are 10 studies awaiting classification for the reasons detailed in the Characteristics of studies awaiting classification table (Aceto 2015; Asouhidou 2015; Elbadawy 2015; Hoymork 2007; Jiang 2016; Khanjani 2014; Lequeux 2014; Mehmandoost 2013; Rajan 2015; Xie 2015).

\section{Ongoing studies}

There are no ongoing studies. 


\section{Risk of bias in included studies}

We were able to find 113 (70.6\%) of the included study authors' email addresses and we sent them 'Risk of bias' surveys. Fifty-four $(47.8 \%)$ of the authors who were sent surveys responded (survey responders), which is $33.8 \%$ (54) of the included studies (Appendix $1)$.

We assessed the impact of the 'Risk of bias' survey results on the change in risk of bias classification groups of high, low, or unclear risk of bias from the total included group of 160 studies in two subgroups: survey responders and non-responders.
In the 160 included studies group there were $1120\left(7^{\star} 160\right)$ domains and in the 18 studies included in meta-analyses there were 126 domains (Figure 2; Figure 3; Appendix 6). There was a large shift from unclear to either high or low risk of bias as a result of the response from authors (survey responders) (Appendix 6). In comparisons three to five, the lack of survey response resulted in a high percentage of unclear risk of bias domains and, therefore, downgrading of the quality of the evidence for risk of bias. More importantly, this downgrading of the quality of the evidence for risk of bias compared to the lack of downgrading for comparisons one and two was the difference between a very low quality grade compared to a low quality grade in those comparisons (Appendix 6).

Figure 2. 'Risk of bias' graph: review authors' judgements about each risk of bias item presented as percentages across all included studies.

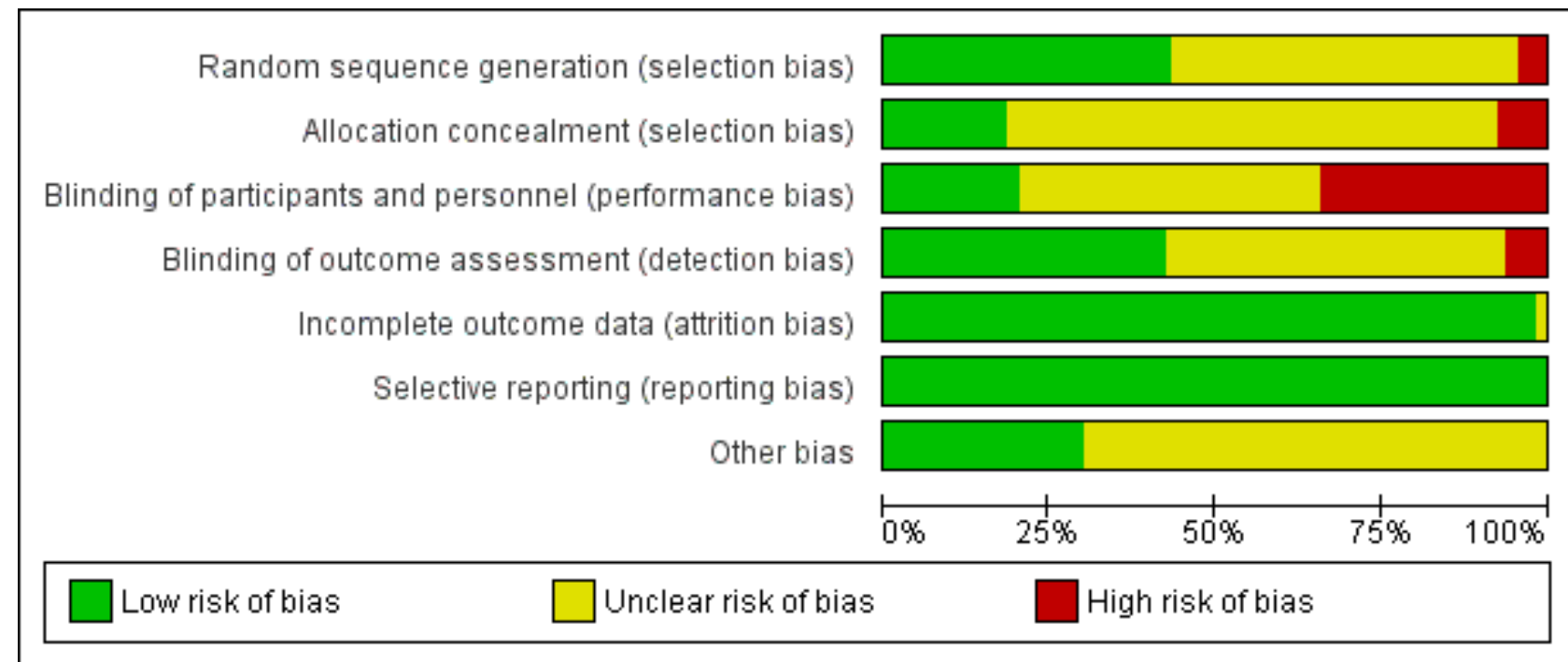


Figure 3. 'Risk of bias' summary: review authors' judgments about each risk of bias item for each included study.

\begin{tabular}{|c|c|c|c|c|c|c|c|}
\hline & 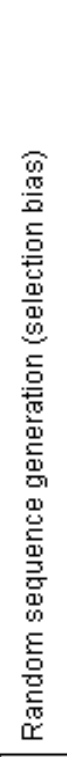 & 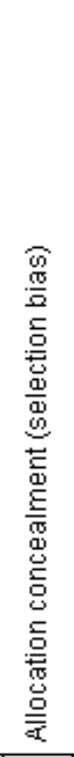 & 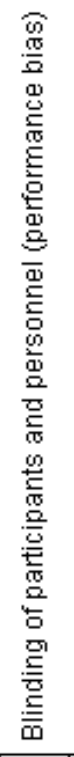 & 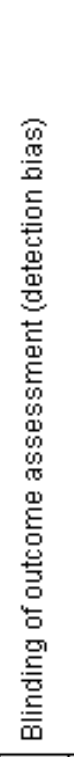 & 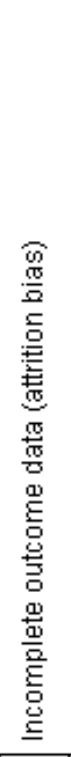 & 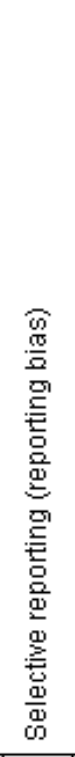 & 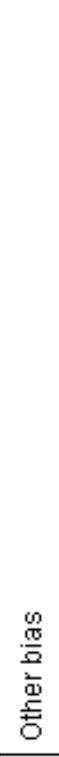 \\
\hline Abboud 1985 & $?$ & $?$ & $?$ & + & 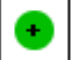 & + & $?$ \\
\hline Abboud 1989 & $?$ & $?$ & $?$ & $?$ & $\odot$ & $\odot$ & $?$ \\
\hline Abboud 1995a & $?$ & $?$ & $?$ & $?$ & 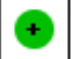 & + & $?$ \\
\hline Abboud 1995b & $?$ & $?$ & $?$ & + & $\oplus$ & + & $?$ \\
\hline Aceto 2002 & $?$ & $?$ & $?$ & $?$ & + & + & $?$ \\
\hline Aceto 2003 & + & $?$ & $?$ & $?$ & $\oplus$ & + & $?$ \\
\hline Adams 1994 & + & + & + & + & + & + & + \\
\hline Agarwal 1977 & $?$ & $?$ & $?$ & $?$ & + & + & $?$ \\
\hline Aime 2006 & + & $?$ & - & + & + & + & $?$ \\
\hline Akcali 2008 & $?$ & $?$ & - & 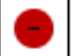 & + & 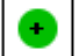 & + \\
\hline Anez 2001 & $\Theta$ & $?$ & 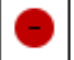 & $?$ & 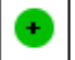 & + & $?$ \\
\hline Arellano 2000 & + & + & 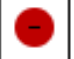 & + & + & + & $?$ \\
\hline Ashworth 1998 & $?$ & $\theta$ & $\odot$ & $?$ & $\odot$ & + & $?$ \\
\hline Avidan 2008 & + & 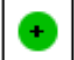 & 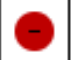 & + & $\odot$ & + & + \\
\hline Avidan 2011 & + & + & $O$ & + & + & + & $\odot$ \\
\hline Baraka 1989 & $?$ & $?$ & $?$ & $?$ & + & + & $?$ \\
\hline Baraka 1998 & + & 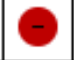 & 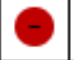 & + & + & + & + \\
\hline Barr 1977 & + & $?$ & + & $\odot$ & + & + & $?$ \\
\hline Bauer 2004 & + & $?$ & 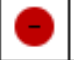 & $?$ & + & + & + \\
\hline Bergmann 2013 & + & $?$ & $\odot$ & $?$ & + & + & $?$ \\
\hline
\end{tabular}


Figure 3. (Continued)

\begin{tabular}{|c|c|c|c|c|c|c|c|}
\hline Bergmann 2013 & $\odot$ & $?$ & $\odot$ & $?$ & + & + & $?$ \\
\hline Bestas 2004 & $\oplus$ & $\odot$ & $\odot$ & + & $\odot$ & $\odot$ & $\odot$ \\
\hline Bethune 1992 & $?$ & $?$ & $?$ & $?$ & $\odot$ & $\odot$ & $?$ \\
\hline Bhawna 2012 & $?$ & $\oplus$ & $\oplus$ & + & $\oplus$ & $\oplus$ & 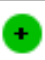 \\
\hline Blendinger 1976 & $?$ & $?$ & $?$ & $?$ & $\odot$ & $\odot$ & $?$ \\
\hline Block 1991 & $?$ & $?$ & $?$ & $?$ & $\odot$ & $\odot$ & $?$ \\
\hline Bonato 2001 & $?$ & $?$ & $\odot$ & $?$ & $\odot$ & $\odot$ & $?$ \\
\hline Browne 1973 & $?$ & $?$ & $?$ & $?$ & $\odot$ & $\odot$ & $?$ \\
\hline Bruhn 2005 & $\odot$ & $\odot$ & $\odot$ & $?$ & $\odot$ & $\odot$ & $?$ \\
\hline Casati 1999 & $?$ & $?$ & ? & ? & $\odot$ & $\odot$ & ? \\
\hline Celebioglu 2002 & $\ominus$ & $\Theta$ & $?$ & $?$ & + & $\odot$ & $?$ \\
\hline Celleno 1993 & 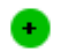 & $\odot$ & $\oplus$ & $\Theta$ & $\odot$ & $\odot$ & $\odot$ \\
\hline Chen 2009 & $?$ & $?$ & $?$ & + & + & $\odot$ & $?$ \\
\hline Cheun 1987 & $?$ & $?$ & ? & $?$ & $\odot$ & + & $?$ \\
\hline Chin 2004 & $\oplus$ & $\oplus$ & $?$ & $?$ & $\odot$ & $\odot$ & $?$ \\
\hline Choi 2012 & $\odot$ & $?$ & $\odot$ & $?$ & $\odot$ & $\odot$ & $?$ \\
\hline Clyburn 1986 & + & 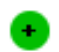 & $\odot$ & $\Theta$ & $\odot$ & $\odot$ & + \\
\hline Coates 1987 & $?$ & $?$ & $?$ & $?$ & $\odot$ & $\odot$ & $?$ \\
\hline Collins 1996 & $?$ & $?$ & ? & $\odot$ & $\odot$ & $\odot$ & $?$ \\
\hline Crawford 1985 & $\oplus$ & $?$ & $\odot$ & $?$ & $\odot$ & $\odot$ & $?$ \\
\hline Crawford ME 1984 & $?$ & $?$ & $?$ & $?$ & + & + & $?$ \\
\hline Czarko 2013 & $?$ & $?$ & $\odot$ & $\odot$ & $\odot$ & $\odot$ & $?$ \\
\hline Deeprose 2005 & $\oplus$ & $\odot$ & $\odot$ & + & $\odot$ & $\odot$ & $\odot$ \\
\hline De Kock 1995 & $\oplus$ & 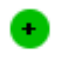 & $\oplus$ & + & $\odot$ & $\odot$ & + \\
\hline Deshpande 2009 & $?$ & $?$ & ? & $?$ & + & + & $?$ \\
\hline Dhadphale 1979 & $?$ & $?$ & $?$ & $?$ & + & + & $?$ \\
\hline Drover 2002 & $\odot$ & $?$ & $\odot$ & $\Theta$ & $\odot$ & $\odot$ & $\odot$ \\
\hline Dunnett 1977 & ? & $?$ & $?$ & + & $\odot$ & $\odot$ & $?$ \\
\hline Echevarria 1998 & $\odot$ & $\odot$ & $?$ & + & $\odot$ & $\odot$ & + \\
\hline Elhakim 2010 & + & + & $\odot$ & $\odot$ & $\odot$ & $\odot$ & + \\
\hline Ellingson 1977 & $?$ & $?$ & $?$ & $?$ & $\odot$ & $\odot$ & $?$ \\
\hline
\end{tabular}


Figure 3. (Continued)

\begin{tabular}{|c|c|c|c|c|c|c|c|}
\hline Ellingson 1977 & $?$ & $?$ & $?$ & ? & + & + & $?$ \\
\hline Fehr 2001 & $?$ & $?$ & $\odot$ & $?$ & $\odot$ & $\odot$ & $?$ \\
\hline Forestier 2003 & $\oplus$ & $?$ & $?$ & $?$ & $\oplus$ & $\oplus$ & $?$ \\
\hline Fragen 1981 & $\oplus$ & $?$ & $\odot$ & $?$ & $\odot$ & $\odot$ & $?$ \\
\hline Gaitini 1995 & $\oplus$ & $?$ & $?$ & $?$ & + & + & $?$ \\
\hline Gale 2001 & $\oplus$ & $\odot$ & $\odot$ & + & $\odot$ & $\odot$ & $\odot$ \\
\hline Ghaly 1988 & $?$ & $?$ & $?$ & $?$ & $\odot$ & $\odot$ & $?$ \\
\hline Ghoneim 2000 & $\oplus$ & $?$ & $?$ & + & $\oplus$ & $\oplus$ & $?$ \\
\hline Ghosh 2008 & $\oplus$ & $\odot$ & $\oplus$ & $\odot$ & $\odot$ & $\odot$ & $\odot$ \\
\hline Girardi 1994 & $?$ & $?$ & $?$ & $?$ & $\odot$ & 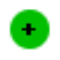 & $?$ \\
\hline Gokce 2009 & $\oplus$ & $?$ & $?$ & $\odot$ & $\odot$ & $\odot$ & $?$ \\
\hline Goto 2000 & 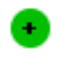 & $\odot$ & $\odot$ & + & $\odot$ & + & + \\
\hline Gruenewald 2007 & $?$ & $?$ & $\odot$ & + & $\odot$ & $\odot$ & $?$ \\
\hline Grundmann 2001 & $?$ & $?$ & $?$ & $\oplus$ & $\odot$ & $\odot$ & $?$ \\
\hline Gupta 1992 & $?$ & $?$ & $?$ & $?$ & $\odot$ & $\odot$ & $?$ \\
\hline Gurman 1994 & $\odot$ & $\odot$ & $\odot$ & + & $?$ & + & + \\
\hline Hachero 2001 & $\odot$ & $?$ & $?$ & $\odot$ & $\odot$ & $\odot$ & $?$ \\
\hline Hackner 2003 & $?$ & $?$ & $\odot$ & $\odot$ & $\odot$ & $\odot$ & $?$ \\
\hline Haimeur 1997 & $?$ & $?$ & $?$ & $?$ & $\odot$ & $\odot$ & $?$ \\
\hline Haram 1981 & $?$ & $?$ & $\oplus$ & + & $?$ & 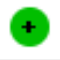 & $?$ \\
\hline Hug 1988 & $?$ & $?$ & $?$ & $?$ & $\odot$ & $\odot$ & $?$ \\
\hline Hung 1992 & $?$ & $?$ & $?$ & $?$ & $\odot$ & $\oplus$ & $?$ \\
\hline Ibraheim 2008 & $?$ & $?$ & $\odot$ & + & $\odot$ & $\odot$ & $?$ \\
\hline Inoue 2005 & $?$ & $?$ & $?$ & + & $\odot$ & $\odot$ & $?$ \\
\hline Jensen 1995 & 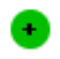 & 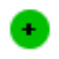 & 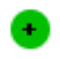 & + & $\odot$ & $\odot$ & + \\
\hline Jiahai 2012 & $?$ & $?$ & $?$ & $?$ & $\odot$ & $\odot$ & $?$ \\
\hline Kamal 1990 & $?$ & $?$ & $\odot$ & $?$ & $\odot$ & $\odot$ & $?$ \\
\hline Kasmacher 1996 & $?$ & $?$ & $?$ & $?$ & $\odot$ & $\odot$ & $?$ \\
\hline Kerssens $2005 b$ & $\odot$ & $?$ & $\odot$ & + & $\odot$ & $\odot$ & $?$ \\
\hline Kerssens 2009 & $\odot$ & $?$ & $?$ & $\odot$ & $\odot$ & + & + \\
\hline Kim 2007 & $?$ & $?$ & $?$ & $?$ & $\odot$ & + & $?$ \\
\hline
\end{tabular}


Figure 3. (Continued)

\begin{tabular}{|c|c|c|c|c|c|c|c|}
\hline Kim 2007 & $?$ & $?$ & $?$ & $?$ & $\odot$ & + & $?$ \\
\hline Kiyama 1997 & $?$ & $?$ & + & $\theta$ & $\odot$ & + & $?$ \\
\hline Kreuer 2003 & $?$ & $?$ & $?$ & $?$ & + & + & $?$ \\
\hline Kreuer 2005 & + & $?$ & 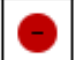 & $\odot$ & $\odot$ & + & + \\
\hline Krissel 1994 & $?$ & $?$ & $?$ & $?$ & $\odot$ & + & $?$ \\
\hline Kudoh 1999 & $?$ & $?$ & $?$ & $?$ & $\odot$ & + & $?$ \\
\hline Kwon 2013 & $?$ & $?$ & 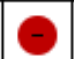 & + & + & + & $?$ \\
\hline Lallemand 2003 & $\odot$ & $\odot$ & $\odot$ & $\odot$ & $\odot$ & $\odot$ & + \\
\hline Lam 2013 & $?$ & $?$ & 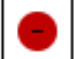 & $?$ & $\odot$ & $\odot$ & $?$ \\
\hline Lehmann 1985 & $\odot$ & $\odot$ & $\odot$ & $\odot$ & $\odot$ & $\odot$ & + \\
\hline Lehmann 1992 & + & + & + & + & + & + & + \\
\hline Lehmann 2007 & $\odot$ & $\odot$ & 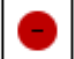 & $\Theta$ & $\odot$ & $\odot$ & + \\
\hline Lim 1992 & $?$ & $?$ & $?$ & $?$ & $\odot$ & 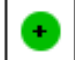 & $?$ \\
\hline Lin 2011 & $?$ & $?$ & $?$ & $?$ & + & + & ? \\
\hline Lindholm 2008 & $\odot$ & $\odot$ & - & $?$ & $\odot$ & $\odot$ & + \\
\hline Liu 2013 & + & $?$ & $?$ & $?$ & $\odot$ & $\odot$ & $?$ \\
\hline Lu 2005 & 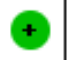 & $\odot$ & + & + & $\odot$ & + & + \\
\hline Maattanen 2002 & $?$ & $?$ & - & + & + & + & $?$ \\
\hline Mashour 2012 & 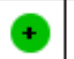 & $\odot$ & - & $\odot$ & $\odot$ & + & + \\
\hline Masuda 2002 & $?$ & $\odot$ & $\odot$ & $\odot$ & $?$ & + & + \\
\hline McNulty 1995 & $?$ & $?$ & $\odot$ & $?$ & $\odot$ & + & $?$ \\
\hline Menigaux 2002 & 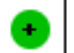 & $\oplus$ & $\odot$ & $\odot$ & $\odot$ & + & $?$ \\
\hline Mertens 2003 & $?$ & $?$ & $?$ & $?$ & $\odot$ & + & $?$ \\
\hline Miller 1996 & 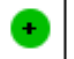 & $?$ & + & $?$ & + & $\odot$ & $?$ \\
\hline Miranda 1992 & $?$ & $?$ & $?$ & $\odot$ & $\odot$ & $\odot$ & $?$ \\
\hline Monedero 1994 & $?$ & $?$ & $?$ & $?$ & $\odot$ & $\odot$ & $?$ \\
\hline Morimoto 2002 & $?$ & $?$ & 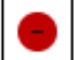 & $\Theta$ & $\odot$ & $\odot$ & + \\
\hline Mozafari 2014 & $\odot$ & $?$ & 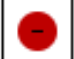 & $?$ & $\odot$ & $\odot$ & $?$ \\
\hline Muralidhar 2008 & $?$ & $?$ & $?$ & $?$ & $\odot$ & $\odot$ & $?$ \\
\hline Myles 1997 & $?$ & $\odot$ & 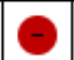 & $?$ & $\odot$ & + & $?$ \\
\hline Myles 2004 & $\oplus$ & $\odot$ & $?$ & $\odot$ & $\odot$ & $\odot$ & $?$ \\
\hline
\end{tabular}


Figure 3. (Continued)

\begin{tabular}{|c|c|c|c|c|c|c|c|}
\hline Myles 2004 & $\odot$ & $\odot$ & $?$ & $\odot$ & $\odot$ & $\odot$ & $?$ \\
\hline Myles 2007 & $\odot$ & $?$ & $\odot$ & $\odot$ & $\odot$ & 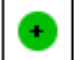 & $?$ \\
\hline Navarro 2000 & $?$ & $?$ & $?$ & $?$ & $\odot$ & + & $?$ \\
\hline Nayar 2009 & $?$ & $?$ & $?$ & $\odot$ & $\odot$ & $\odot$ & $?$ \\
\hline Ngan 1997 & 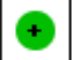 & $?$ & $\odot$ & $?$ & $\odot$ & $\oplus$ & $?$ \\
\hline Ngan Kee 2002 & 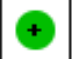 & $\odot$ & + & + & $\odot$ & 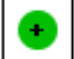 & + \\
\hline Oddby-Muhrbeck 1993 & $?$ & $\odot$ & $\odot$ & + & $\odot$ & + & + \\
\hline Panousis 2009 & 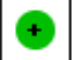 & $\odot$ & + & $?$ & 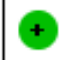 & 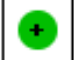 & $?$ \\
\hline Pauls 2009 & + & $?$ & 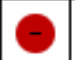 & $\odot$ & $\odot$ & + & + \\
\hline Paventi 2001 & $?$ & $?$ & $?$ & $?$ & $\odot$ & + & $?$ \\
\hline Pedersen 1992 & $?$ & $?$ & + & $?$ & 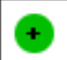 & + & $?$ \\
\hline Persec 2012 & $?$ & $?$ & $\odot$ & $?$ & + & + & $?$ \\
\hline Piggott 1990 & 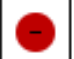 & $\Theta$ & $\odot$ & + & $\odot$ & $\odot$ & + \\
\hline Plourde 1996 & + & $?$ & $\theta$ & + & + & + & + \\
\hline Puri 2003 & $\odot$ & $?$ & $?$ & $?$ & $\odot$ & + & $?$ \\
\hline Puri 2007 & $\odot$ & $\odot$ & 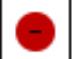 & + & $\odot$ & $\odot$ & $\odot$ \\
\hline Rehberg 2007 & $\odot$ & $?$ & $O$ & $\odot$ & $\odot$ & 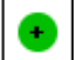 & $\odot$ \\
\hline Renna 2000 & + & $?$ & $\theta$ & $?$ & + & + & $?$ \\
\hline Rinaldi 2005 & $?$ & $?$ & $\odot$ & $\odot$ & $\odot$ & $\odot$ & $?$ \\
\hline Russell 1986 & $\odot$ & $\odot$ & $\odot$ & $\odot$ & $\odot$ & + & $\odot$ \\
\hline Samarkandi 2004 & 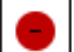 & ? & $?$ & + & + & + & $?$ \\
\hline Sareen 1997 & $?$ & $?$ & + & $?$ & + & + & $?$ \\
\hline Schultetus 1986 & $\odot$ & $?$ & $?$ & $?$ & + & + & $?$ \\
\hline Schwender 1994 & $?$ & $?$ & $\odot$ & $\odot$ & $\odot$ & $\oplus$ & $?$ \\
\hline Schwender 1996 & $?$ & $?$ & $?$ & $?$ & $\odot$ & + & $?$ \\
\hline Shin 2012 & + & $?$ & $?$ & $?$ & $\odot$ & + & $?$ \\
\hline Sidi 1990 & $?$ & $?$ & $?$ & $?$ & $\odot$ & + & $?$ \\
\hline Smith 1999 & $?$ & $?$ & $?$ & $?$ & $\odot$ & + & $?$ \\
\hline Song 1997 & + & $?$ & $\theta$ & $?$ & $\odot$ & + & $?$ \\
\hline Sorbara 1995 & $?$ & $?$ & $?$ & $?$ & $\odot$ & + & $?$ \\
\hline Soyannwo 1988 & $?$ & $?$ & $?$ & $?$ & $\odot$ & $\odot$ & $?$ \\
\hline
\end{tabular}


Figure 3. (Continued)

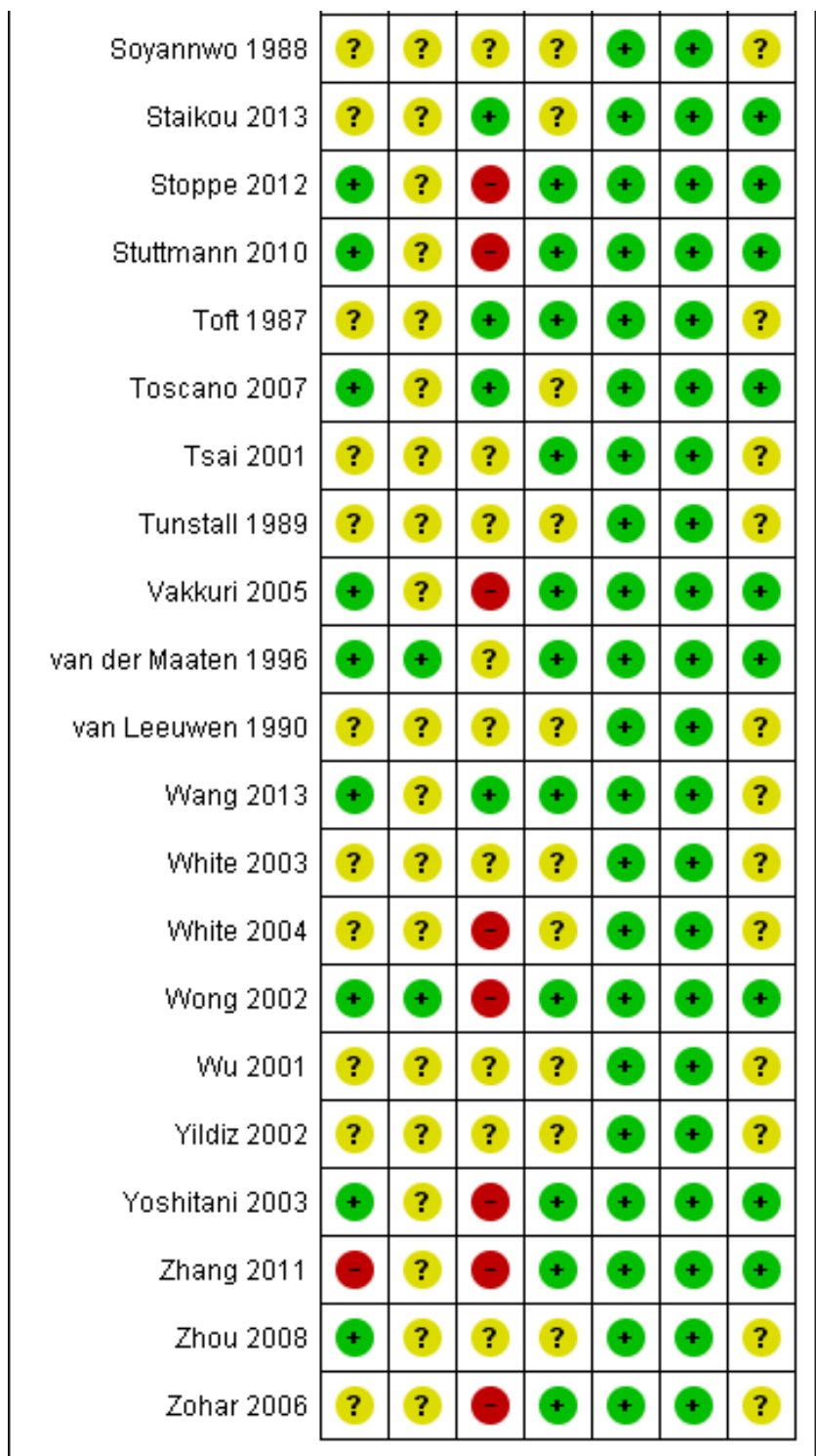

\section{Allocation}

\section{Random sequence generation}

For the 18 studies included in meta-analysis, the risk of bias was high in $11 \%(2 / 18)$, low in $56 \%(10 / 18)$, and unclear in $33 \%(6 / 18)$.

\section{Random allocation concealment}

For the 18 studies included in meta-analysis, the risk of bias was high in $0.0 \%(0 / 18)$, low in $27.8 \%(5 / 18)$, and unclear in $72.2 \%$ $(13 / 18)$.

\section{Blinding}

\section{Blinding of participants}

For the 18 studies included in meta-analysis, the risk of bias was high in $44.4 \%(8 / 18)$, low in $22.2 \%(4 / 18)$, and unclear in $33.3 \%$ $(6 / 18)$.

\section{Blinding of outcome assessment}

For the 18 studies included in meta-analysis, the risk of bias was high in 5.6\% (1/18), low in 50.0\% (9/18), and unclear in $44.0 \%(8 / 18)$.

\section{Incomplete outcome data}

For the 18 studies included in meta-analysis, the risk of bias was high in $0 \%(0 / 18)$, low in 94\% (17/18), and unclear in 6\% (1/18).

\section{Selective reporting}

For the 18 studies included in meta-analysis, the risk of bias was high in $0 \%(0 / 18)$, low in $100 \%(18 / 18)$, and unclear in $0 \%(0 / 18)$.

\section{Other potential sources of bias}

For the 18 studies included in meta-analysis, the risk of bias was high in $0 \%(0 / 18)$, low in $33 \%(6 / 18)$, and unclear in $67 \%(12 / 18)$. 


\section{Effects of interventions}

See: Summary of findings for the main comparison Anaesthesia depth monitors (BIS and M-entropy) versus standard clinical and electronic monitoring; Summary of findings 2 Anaesthesia depth monitors (BIS) versus standard clinical and electronic monitoring; Summary of findings 3 Thiopentone with and without added hypnotic drugs (ketamine, etomidate); Summary of findings 4 Thiopentone and ketamine versus benzodiazepines (diazepam, midazolam, lorazepam); Summary of findings $\mathbf{5}$ Caesarean section with low- and high-dose inhaled agent

\section{Primary outcomes}

\section{Awareness}

1.1 Anaesthesia depth monitors (either Bispectral Index (BIS) or Mentropy) versus standard clinical parameter (Grade 4)

Awareness was an uncommon event in nine studies (Avidan 2008; Avidan 2011; Gruenewald 2007; Kerssens 2009; Mashour 2012;
Mozafari 2014; Myles 2004; Puri 2003; Zhang 2011). There were 173 occurrences among 34,744 patients (anaesthesia depth monitors $85 / 17,713$ versus standard clinical and electronic monitoring $88 / 17,031$ ), an overall event rate of about $0.5 \%$ (Analysis 1.1 ). These nine studies had considerable clinical and methodological heterogeneity. There was moderate statistical heterogeneity $(12$ $=49 \% ; P=0.04$ ) (Figure 4). The effect size favoured neither anaesthesia depth monitoring nor standard clinical and electronic monitoring, with little precision in the odds ratio (OR) estimate (OR $0.98,95 \%$ confidence interval $(\mathrm{Cl}) 0.59$ to $1.62 ; 95 \%$ prediction interval (PI) 0.33 to 2.90) (Analysis 1.1). There was no difference in the odds of awareness between high-risk and non-high-risk patients $\left(F_{1,7}=1.70 ; P=0.23\right)$. With an assumed risk for awareness using standard clinical and electronic monitoring being 5 per 1000 , the corresponding risk using anaesthesia depth monitoring was 5 per $1000(95 \% \mathrm{Cl} 3$ to 7$)$. The quality of the evidence was low (Summary of findings for the main comparison).

Figure 4. Meta-analysis patient awareness reports not adjudicated or adjudicated as possible and definite awareness: ADM versus standard clinical and electronic monitoring

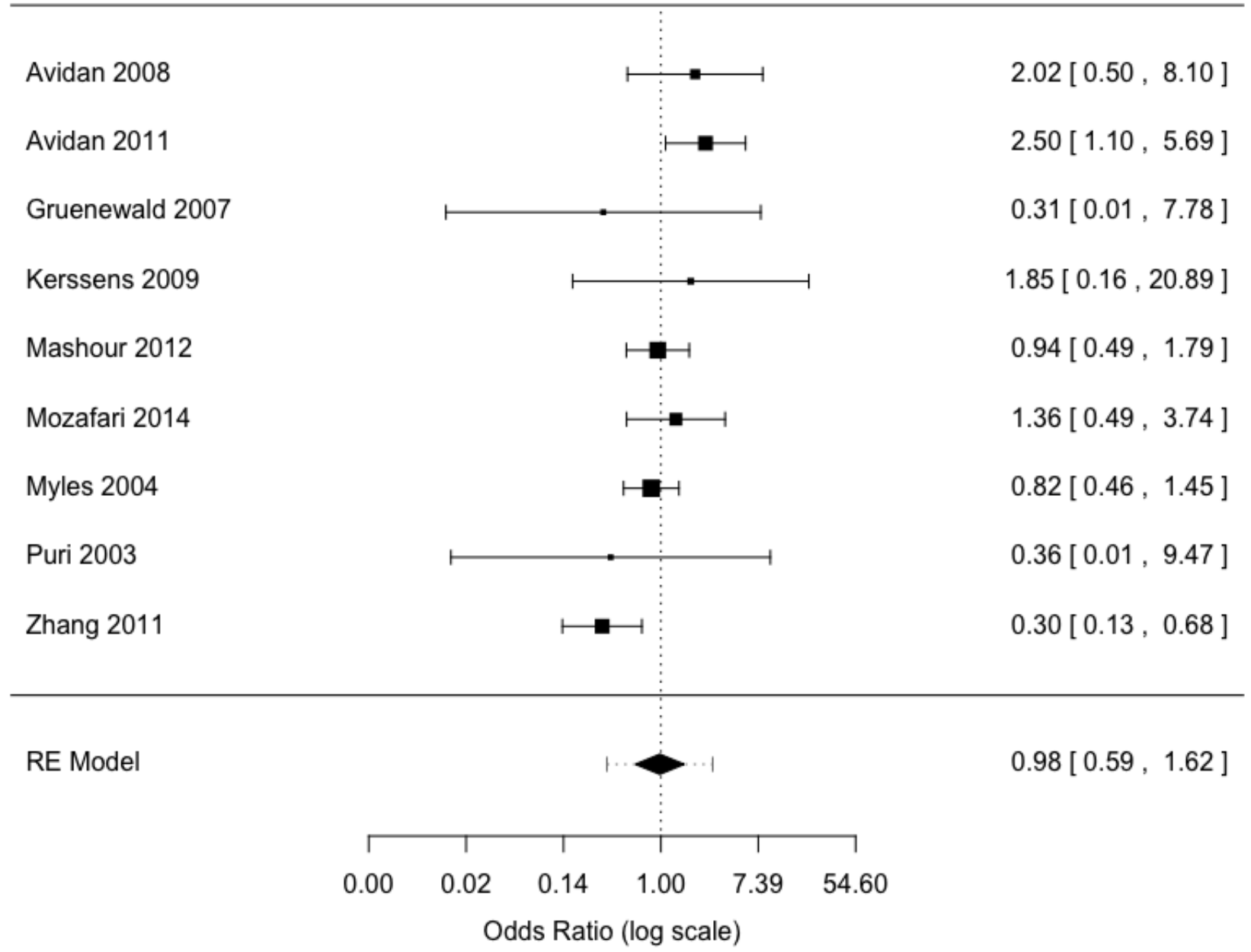


2.1 Anaesthesia depth monitors (Bispectral Index) versus standard clinical and electronic monitoring (Grade 4)

In five of the anaesthesia depth monitoring studies a narrative report of potential awareness events identified in one or more interviews was submitted to a blinded, expert panel (Avidan 2008; Avidan 2011; Mashour 2012; Myles 2004; Zhang 2011). This pane adjudicated the outcome for each patient: no awareness, possible awareness, or definite awareness. Episodes of dreaming were also declared in two studies (Myles 2004; Zhang 2011). Expert panel adjudication was not used in the other studies in Analysis 1.1 (Gruenewald 2007; Kerssens 2009; Mozafari 2014; Puri 2003). Unpublished data were provided by the authors (Avidan 2008; Avidan 2011; Mashour 2012; Myles 2004; Zhang 2011), with details of the adjudication results (Appendix 8). There was wide variation in the results of the adjudication process.
2.1 Anaesthesia depth monitors (Bispectral Index) versus standard clinical and electronic monitoring: risk of definite and possible awareness (Grade 4)

Definite and possible awareness was an uncommon event with 152 occurrences among 34,181 participants (Bispectral Index 74/17,432 versus standard clinical and electronic monitoring 78/16,749), an overall event rate of about $0.4 \%$ (Analysis 2.1 ). The five studies had considerable clinical and methodological heterogeneity. There was a substantial degree of statistical heterogeneity $(12=68 \%$; $P=$ 0.01) (Figure 5). The effect size favoured neither Bispectral Index nor standard clinical and electronic monitoring, with little precision in the OR estimate (OR 0.96, 95\% Cl 0.35 to $2.65 ; 95 \% \mathrm{Pl} 0.15$ to 6.41) (Analysis 2.1). The assumed risk for awareness (definite and possible awareness) using standard clinical and electronic monitoring was 5 per 1000; the corresponding risk using Bispectral Index monitoring was 5 per 1000 (95\% Cl 2 to 8$)$. The quality of the evidence was low (Summary of findings 2).

\section{Figure 5. Meta-analysis possible and definite awareness: ADM versus standard clinical and electronic monitoring} (adjudication)

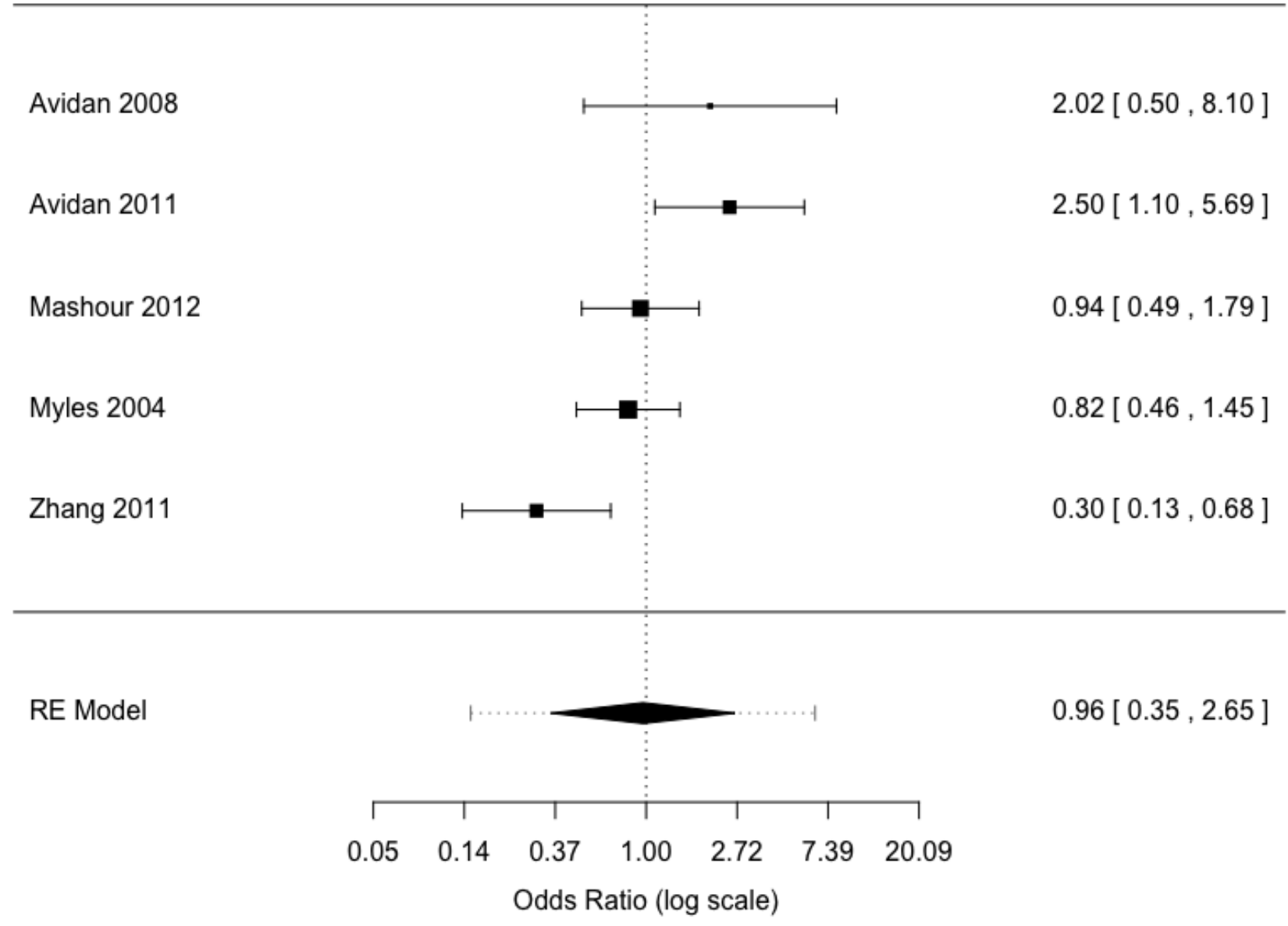

We subgrouped the studies by the use of alarms or alerts (or both) in the protocol and by the type of anaesthesia used (inhalation versus total intravenous anaesthesia (TIVA)). The protocols in three studies included alarms/alerts and the use of inhalation anaesthesia (Avidan 2008; Avidan 2011; Mashour 2012); the protocols in two studies did not include alarms or alerts and used predominantly or exclusively TIVA (Myles 2004; Zhang 2011)). We repeated the meta-analysis with the studies separated into these two subgroups. There was no difference in the OR between the two subgroups $\left(F_{1,3}\right.$ $=37 ; \mathrm{P}=0.16)$. 
We subgrouped the studies by the risk of awareness in patient recruitment. We repeated the meta-analysis with the studies separated into these two subgroups. There was no difference in the OR between the two subgroups $\left(F_{1,3}=2.11 ; P=0.24\right)$.

2.2 Anaesthesia depth monitors (Bispectral Index) versus standard clinical and electronic monitoring: risk of definite awareness (Grade 4)

Definite awareness was a rare event with 65 occurrences among 34,181 patients (Bispectral Index 24/17,432 versus standard clinical and electronic monitoring 41/16,749), an overall event rate of about
$0.2 \%$ (Analysis 2.2). The five studies had considerable clinical and methodological heterogeneity. There was a substantial degree of statistical heterogeneity $\left(I^{2}=60 \% ; P=0.02\right)$ (Figure 6$)$. The effect size favoured Bispectral Index monitoring but with little precision in the OR estimate (OR $0.60,95 \% \mathrm{Cl} 0.13$ to $2.75 ; 95 \% \mathrm{PI} 0.04$ to 9.20$)$ (Analysis 2.2). The assumed risk for awareness (definite awareness) using standard clinical and electronic monitoring was 2 per 1000; the corresponding risk using Bispectral Index monitoring was 1 per 1000 ( $95 \% \mathrm{Cl} 1$ to 4 ). The quality of the evidence was low (Summary of findings 2).

Figure 6. Meta-analysis definite awareness: ADM versus standard clinical and electronic monitoring (adjudication)

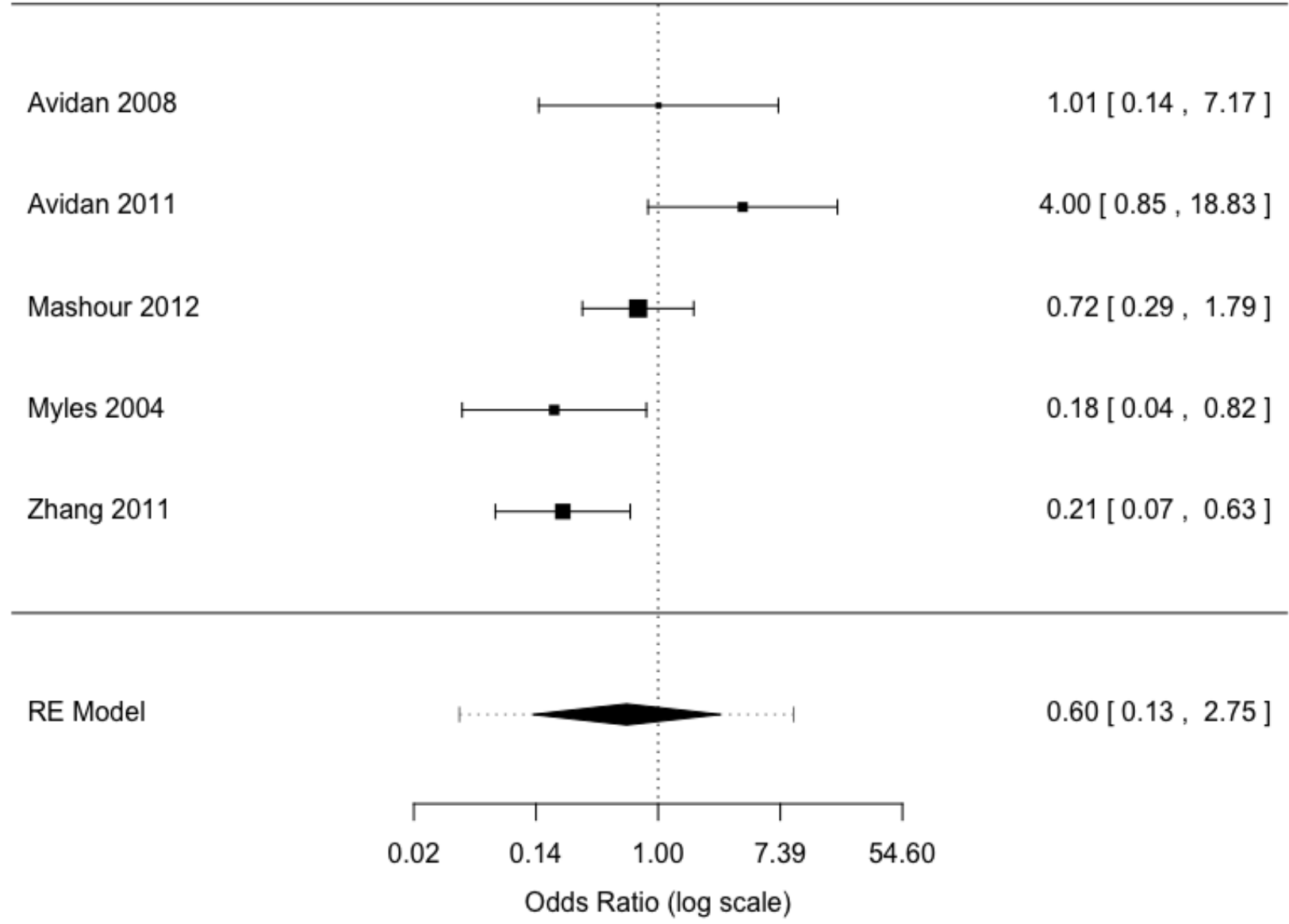

We subgrouped the studies by the use of alarms or alerts (or both) in the protocol and by the type of anaesthesia (inhalation versus TIVA). The protocols in three studies included alarms or alerts and the use of inhalation anaesthesia (Avidan 2008; Avidan 2011; Mashour 2012); the protocols in two studies did not include alarms/alerts and used predominantly or exclusively TIVA (Myles 2004; Zhang 2011). We repeated the meta-analysis with the studies separated into these two subgroups. There was no difference in the OR between the two subgroups $\left(F_{1,3}=7.21 ; P=0.08\right)$.

We subgrouped the studies by the risk of awareness in patient recruitment. We repeated the meta-analysis with the studies separated into these two subgroups. There was no difference in the OR between the two subgroups $\left(F_{1,3}=0.43 ; P=0.56\right)$.
With regard to the analysis of expert adjudication of awareness in Analysis 2.1 and Analysis 2.2, as a percentage of study size the events flagged for adjudication ranged from $0.40 \%$ to $5.73 \%$. As a percentage of study size, 'no awareness' ranged from $0.21 \%$ to $5.18 \%$, 'possible awareness' ranged from $0.10 \%$ to $1.46 \%$, and 'definite awareness' ranged from $0.10 \%$ to $0.53 \%$. There was a large degree of between-study heterogeneity $(12=99 \%)$ in the analysis of the expert panels' adjudication of patient awareness reports (Appendix 1; Appendix 8).

\section{Wakefulness}

3.1 Thiopentone with and without added hypnotic drugs (ketamine, etomidate) (Grades 4, 5)

In four studies the isolated forearm technique was used to assess intraoperative wakefulness (Grade $0,1,2$, or 3) by response 
to complex commands (Baraka 1989; Russell 1986; Schultetus 1986; Tunstall 1989). The surgery was caesarean delivery or a gynaecological procedure. In three studies wakefulness was compared between thiopentone with and without added hypnotic drugs (ketamine, etomidate) after induction (Baraka 1989; Russell 1986; Schultetus 1986) (Analysis 3.1). There was a lower risk of wakefulness with the addition of hypnotic drugs (risk ratio (RR) $0.18,95 \% \mathrm{Cl} 0.09$ to 0.41 ). For an assumed risk of wakefulness for thiopentone of 562 per 1000, the corresponding risk will be 101 per 1000 (51 to 230) with the administration of hypnotic drugs. The quality of the evidence was low (Summary of findings 3 ).

Patients were questioned postoperatively concerning recall (Grade 4 or 5) (Baraka 1989; Russell 1986; Schultetus 1986; Tunstall 1989). We compared the proportion of patients with wakefulness (Grade $0,1,2$, or 3 ) versus awareness (Grade 4 or 5 ) in a random-effects meta-analysis. Of the 254 participants studied, there were six with awareness and 90 demonstrated wakefulness. The proportion with awareness was 0.04 (95\% $\mathrm{Cl} 0.01$ to 0.11 ) while the proportion with wakefulness was $0.34(95 \% \mathrm{Cl} 0.25$ to 0.45$)$; these proportions were different $\left(F_{1,6}=26.4, P=0.0021\right)$, with non-significant statistical heterogeneity $(P=0.12)$ (Appendix 1; Appendix 7).

\section{Awareness}

4.1 Thiopentone and ketamine versus benzodiazepines (diazepam, midazolam, lorazepam) (Grade 4)

In four studies there were 18 occurrences among 291 participants (benzodiazepines 2/192 versus thiopentone and ketamine 16/99), an overall event rate of about 6\% (Ellingson 1977; Haram 1981; McNulty 1995; Miller 1996), (Analysis 4.1). There was a lower risk of awareness with the addition of benzodiazepines (RR $0.17,95 \%$ $\mathrm{Cl} 0.02$ to 0.25 ). The assumed risk for awareness for thiopentone and ketamine was 131 per 1000; the corresponding risk using benzodiazepines was 28 per $1000(95 \% \mathrm{Cl} 3$ to 42$)$. The quality of the evidence was very low (Summary of findings 4).

\subsection{Caesarean section with low-dose and high-dose inhaled anaesthetic agents}

There were two studies with 848 participants that compared low-dose to high-dose volatile agents (halothane, enflurane, trichloroethylene) with and without nitrous oxide during caesarean section (Abboud 1985; Crawford 1985). There were 24 occurrences among 848 participants (high-dose $3 / 449$ versus low-dose $21 / 435$ ), an overall event rate of about 3\% (Analysis 5.1). There was a lower risk of awareness in the group receiving high-dose inhaled anaesthetics (RR $0.13,95 \% \mathrm{Cl} 0.04$ to 0.42 ). The assumed risk for awareness for low-dose inhaled anaesthetics was 57 per 1000; the corresponding risk using a high dose was 7 per 1000 ( $95 \% \mathrm{Cl} 2$ to 23). The quality of the evidence was very low (Summary of findings 5).

We graded the quality of the evidence as low in Summary of findings for the main comparison, Summary of findings 2, and Summary of findings 3 , and as very low in Summary of findings 4 and Summary of findings 5 .

\section{Secondary outcomes}

We were unable to assess the secondary outcomes because they were not defined or not identified as outcomes in the included studies. Most studies would miss the diagnosis of post-traumatic stress disorder because the postoperative interview period was usually within one month.

\section{DISCUSSION}

\section{Summary of main results}

The main finding of this review is based on 34,744 (96\%) of the entire patient sample. The use of processed electroencephalogram anaesthetic depth monitoring does not reduce the risk of awareness during surgery compared to standard clinical and electronic monitoring. Bispectral Index monitors, the most commonly used anaesthetic depth monitors, did not reduce the frequency of awareness compared to standard clinical and electronic monitoring (Summary of findings for the main comparison; Summary of findings 2). Five studies comparing anaesthetic depth monitoring versus standard clinical and electronic monitoring used an expert panel to adjudicate possible events. There was significant heterogeneity in the range of patient awareness reports adjudicated as 'no awareness' by expert panels (Appendix 8).

The mapping of data within the individual randomized controlled trials (RCTs) included in this review into the broader classification system of Wang et al (Table 1) was difficult. The classification system was designed for use following surgery using the patient interview and anaesthesia record as the data source. In contrast, there are limitations to its retrospective application to patients grouped in a trial report. We assigned the highest grade(s) that were consistent with the clinical signs of anaesthetic depth contained in each study or comparison (Appendix 1). Nonetheless, the algorithm that we created allowed us to classify all of the included studies, except for six (4\%) (Appendix 1). Those six studies could not be classified because the authors did not include data from ADMs (BIS) or standard clinical parameters such as hemodynamic and/or somatic data in their results sections.

In three smaller meta-analyses based on nine older studies of 1290 participants from among the entire review's patient sample, the evidence indicates that ketamine, a dissociative agent, and etomidate, an intravenous imidazole general anaesthetic, are associated with less wakefulness than the ultra-short-acting barbiturate thiopentone. The World Health Organization's list of essential medicines is based on the "...most efficacious, safe and cost-effective medicines for priority conditions..." (WHO 2015). The anaesthetics studied in this review are on this list; many of the older drugs are still in common use in developing countries. Therefore, the merged findings from the smaller, older studies are relevant to current practice: benzodiazepines reduced episodes of awareness compared to thiopentone and ketamine and a higher dose of inhaled anaesthetic agents reduced episodes of awareness compared to a lower dose (Summary of findings 3; Summary of findings 4; Summary of findings 5). Five of eight (63\%) of the medications studied (ketamine, thiopentone, halothane, nitrous oxide, benzodiazepines) in these older studies are essential medications commonly used by low-income countries (WHO 2015).

As mentioned, benzodiazepines are associated with less awareness than ketamine and thiopental. However, there are no means of determining whether this is simply an amnesic effect rather than an actual increase in anaesthetic depth. This finding highlights the problematic confusion between awareness (with explicit recall) and intraoperative wakefulness without explicit recall and the 
inadequacy of the criterion of postoperative recall as the definition of adequate anaesthesia. Hence, this suggests a need for a more sophisticated classification of intraoperative cognitive states (Wang 2012). In three small studies using the isolated forearm technique, wakefulness was far more frequent than awareness (Analysis 3.1; Effects of interventions; Appendix 1).

\section{Overall completeness and applicability of evidence}

Our literature search identified RCTs published over a 56-year period (1960 through 2016). We classified the entire set of 160 included studies as either included in meta-analyses (18) or not used (142) (Appendix 1; Included studies). Although the majority of studies were not merged in meta-analysis, these 142 studies contributed to the evidence contained in this review by allowing the creation of descriptive statistics (Appendix 1; Table 1). This may be helpful to future researchers studying interventions to decrease the frequency of wakefulness and awareness. There are 10 studies awaiting classification, which we will process when we update the review. In any update of this review, trial registries should also be searched.

\section{Quality of the evidence}

The patient awareness report classification system adjudicated by an expert panel used in the studies in Analysis 2.1 and Analysis 2.2 was introduced in 2004. One of the goals of this classification system was to capture more patient awareness events compared to a system that requires confirmation from intraoperative staff that patient memories of intraoperative events actually happened (Sebel 2004). We found evidence of heterogeneity between centres in the expert panels' classification of awareness from our author survey (Appendix 8).

We successfully applied the classification system of Wang et al to $96 \%$ of included studies (Wang 2012; Table 1). The classification criteria are clinical signs of light anaesthesia such as haemodynamic variables, lacrimation, and response to command, and symptoms such as the report of pain, postoperative recall and/ or distress during surgery, as well as nightmares and post-traumatic stress disorder-like criteria in the postoperative period. In the 18 studies submitted for meta-analysis, all awareness events were graded 4 (awareness but resilient patient) or 5 (awareness with emotional sequelae).

We improved the quality of the evidence by identifying unpublished data for the 'Risk of bias' tables derived from our author survey (Appendix 6). The author responses to the survey provided more information about the seven risk of bias domains. This significantly changed the number of 'unclear' risk ratings to more appropriate ratings of high or low risk of bias in this review (Characteristics of included studies).

The survey allowed us to update domains for studies included in Analysis 1.1, Analysis 2.1, and Analysis 2.2. However, we received no responses from authors of studies contributing to Analysis 3.1, Analysis 4.1, or Analysis 5.1.

The risk of bias due to study funding source (anaesthesia depth monitor manufacturers and pharmaceutical companies) was unclear due to a lack of detailed disclosure information in many of the included studies. There were two types of interventions in this review: drugs and devices.
Investigator blinding was used in $31(19 \%)$ of the 160 included studies (Appendix 6). In the drug studies that did not use blinding, performance bias may have occurred. The experimental design of anaesthesia depth monitor device trials precludes the possibility of blinding the provider.

We downgraded all comparisons in the 'Summary of findings' tables by two or three levels to a low or very low quality of evidence. The downgrades were for within-study risk of bias, inconsistency, and imprecision.

We analysed the strengths and weaknesses of the criteria that we used to merge the studies in the five comparisons in this review (Appendix 1).

\section{Potential biases in the review process}

A strength of this review was the avoidance of potential bias in the electronic literature search: we used no language restrictions. The included studies came from Europe, North America, Asia, the Middle East, Australia and New Zealand, and Africa Appendix 1. Therefore, there was no evidence of reporting bias due to location. Included studies were written in seven languages other than English Appendix 1, therefore there was no evidence of language bias. However, we did not search ClinicalTrials.gov or the World Health Organization (WHO) International Clinical Trials Registry Platform (ICTRP).

In addition, there were insufficient studies in each comparison to allow statistical testing for reporting bias. We did survey study authors to obtain additional information to rate the risk of bias domains, which enabled a shift from unclear to low and from unclear to high risk of bias for various domains, as reported above (Appendix 6).

\section{Agreements and disagreements with other studies or reviews}

A Cochrane review has compared the incorporation of the Bispectral Index anaesthetic depth monitor into standard practice for the management of anaesthesia (Punjasawadwong 2014). This review used search language that focused on identifying anaesthesia depth monitor (Bispectral Index) trials. The authors assessed the effects of Bispectral Index monitoring versus clinical signs and Bispectral Index monitoring versus end-tidal anaesthetic gas (ETAG) monitoring on the risk of definite awareness events; other outcomes of awakening times and anaesthetic usage were also compared. For definite awareness, they reported that the summary Peto odds ratio (OR) was significantly lower for Bispectral Index monitoring compared to clinical signs (OR 0.24 , 95\% confidence interval $(\mathrm{Cl}) 0.12$ to 0.48 ) (Analysis 1.1 in Punjasawadwong 2014), but not lower for Bispectral Index monitoring compared to ETAG (OR $1.13,95 \% \mathrm{Cl} 0.56$ to 2.26) (Analysis 1.2 in Punjasawadwong 2014). Their two analyses included five studies that used the adjudication process (Avidan 2008; Avidan 2011; Mashour 2012; Myles 2004; Zhang 2011), two studies without awareness events (Muralidhar 2008; Samarkandi 2004), and one additional study included in our Analysis 1.1 (Puri 2003). Our current review used search language focused on identifying awareness studies. Analysis 1.1 includes two additional studies not found in Punjasawadwong 2014 (Gruenewald 2007; Kerssens 2009). As a result, the reviews have unique included studies. 
We did not find a difference in definite awareness rates (OR 0.60 $95 \% \mathrm{Cl} 0.13$ to 2.75 ) (Analysis 2.2). Our review employed different statistical models from Punjasawadwong 2014. Generally the point estimates of the individual Peto ORs in Punjasawadwong 2014 (Avidan 2008; Avidan 2011; Mashour 2012; Myles 2004; Zhang 2011), were similar to the OR point estimates found here. However, the $95 \% \mathrm{Cls}$ were wider.

Following the publication of Punjasawadwong 2014, a Cochrane editorial recommended continued use of processed electroencephalogram monitors and standard clinical and electronic monitoring in research protocols to assess the ability of anaesthetic interventions to reduce the frequency of awareness (Kettner 2014).

A Cochrane review has also compared the use of the anaesthetic depth monitor spectral entropy monitoring to standard practice; one of the secondary outcomes was awareness during anaesthesia (Chhabra 2016). Eight trials with 797 participants reporting awareness were found. Of these, only one study reported awareness, with one participant in the control group having an episode (Gruenewald 2007). This study is included our review. The authors of Chhabra 2016 concluded that there was insufficient evidence to support spectral entropy monitoring to detect awareness.

\section{AUTHORS' CONCLUSIONS}

\section{Implications for practice}

Based on the largest portion of evidence in this review, the use of processed electroencephalogram (EEG) anaesthesia depth monitoring may have similar effects on awareness during surgery to standard clinical and electrical monitoring; the risk of awareness is not reduced (Summary of findings for the main comparison; Summary of findings 2).

Based on a smaller amount of evidence, drawn from older studies, ketamine and etomidate reduces wakefulness compared with thiopental, if this is the goal of anaesthesia. If the goal of anaesthesia is to reduce awareness, then benzodiazepines reduces awareness compared to thiopental, ketamine, and placebo.. The safety, clinical efficacy, and low cost of these older anaesthetics are the reasons why they are still used in both high-income and low-income countries (WHO 2015). Clinicians who use the older anaesthetics assessed in our review can refer to the evidence displayed in Summary of findings 3, Summary of findings 4, and Summary of findings 5.

Our confidence in the conclusions of this review is not strong. There are a large number of unclear risk of bias domains in the included studies. There is also a large degree of heterogeneity in the expert panels' adjudication of patient awareness reports (Appendix 8). In addition, the event rate is so small in the anaesthetic depth monitoring studies that, despite the large total sample size, we downgraded the effect estimates for imprecision.

\section{Implications for research}

We agree with other investigators (Mashour 2012), that continuing to study the effects of current processed EEGs on awareness seems futile considering the rarity of the event and the heterogeneity of the effect estimates in five large trials (Avidan 2008; Avidan 2011; Mashour 2012; Myles 2004; Zhang 2011). Future studies should randomize patients between current total intravenous anaesthesia (TIVA) and potent volatile techniques, with and without muscle relaxants. Tracking wakefulness as well as awareness in future trials will allow the use of smaller sample sizes, given the increased frequency of wakefulness compared to awareness. In addition, the relationship between wakefulness and the risk of developing posttraumatic stress disorder needs further study.

Despite the controversy regarding the definition of a 'conscious' patient under anaesthesia, when surveyed anaesthetists state that if they were a patient, it would be 'unacceptable' to be paralysed, awake, and in pain even with postoperative amnesia of the event (Girgirah 2006). Hence, there is an increasing consensus amongst many anaesthetists that persistent unconsciousness (lack of wakefulness) rather than simply lack of postoperative awareness (amnesia) should be the goal of anaesthesia (Sanders 2011). The proposal of Wang et al can be used to classify both wakefulness and awareness (Wang 2012; Table 1).

The proper methods to adjudicate events as being or not being awareness should also be explored.

\section{ACKNOWLEDGEMENTS}

We would like to thank Mathew Zacharias and Andrew Smith (content editors), Marialena Trivella and Cathal Walsh (statistical editors), Paul Myles, Yodying Punjasawadwong, lan Russell, and Jackie Andrade (peer reviewers), and Tracey Lloyd (consumer representative) for their help and editorial advice during the preparation of this review.

We would also like to thank Mary McFarland from the Eccles Library at the University of Utah and Karen Hovhannisyan, MD, former Trials Search Co-ordinator, Cochrane Anaesthesia, Critical and Emergency Care Group (ACE), for their help with the literature search.

We would like to also thank the following translators: Finnish: Elena Yorgason, Spanish: Isabel Dulfano and Brett Smith, Chinese: Fen Feng, Turkish: Murat Cakia, Japanese: Jiro Kurata, German: Lore Schultheiss, Korean: Hae An Jung, Italian and French: Anthony Messina.

Finally, we would like to thank Maria Eggers (ME) and Devin B Miller (DM) for their extensive assistance in the review. 


\section{R E F E R E N C E S}

\section{References to studies included in this review}

Abboud 1985 \{published data only\}

* Abboud TK, Kim SH, Henriksen EH, Chen T, Eisenman R, Levinson $\mathrm{G}$, et al. Comparative maternal and neonatal effects of halothane and enflurane for cesarean section. Acta Anaesthesiologica Scandinavica 1985;29(7):663-8. [PUBMED: 4072589]

\section{Abboud 1989 \{published data only\}}

* Abboud TK, D'Onofrio L, Reyes A, Mosaad P, Zhu J, Mantilla M, et al. Isoflurane or halothane for cesarean section: comparative maternal and neonatal effects. Acta Anaesthesiologica Scandinavica 1989;33(7):578-81. [PUBMED: 2816239]

\section{Abboud 1995a \{published data only\}}

Abboud TK, Zhu J, Richardson M, Peres da Silva E, Donovan M. Desflurane: a new volatile anesthetic for cesarean section. Maternal and neonatal effects. Acta Anaesthesiologica Scandinavica 1995;39(6):723-6. [PUBMED: 7484023]

\footnotetext{
Abboud 1995b \{published data only\}

* Abboud TK, Zhu J, Richardson M, Peres Da Silva E, Donovan M. Intravenous propofol vs thiamylal-isoflurane for caesarean section, comparative maternal and neonatal effects. Acta Anaesthesiologica Scandinavica 1995;39(2):205-9. [PUBMED: 7793188]
}

\section{Aceto 2002 \{published data only\}}

Aceto P, Valente A, Adducci E, Gorgoglione M, De Cosmo G. Implicit memory, dream and auditory evoked responses during anaesthesia. Acta Medica Romana 2002;40(1):21-9.

\section{Aceto 2003 \{published data only\}}

Aceto P, Valente A, Gorgoglione M, Adducci E, De Cosmo G. Relationship between awareness and middle latency auditory evoked responses during surgical anaesthesia. British Journal of Anaesthesia 2003;90(5):630-5. [PUBMED: 12697591]

\section{Adams 1994 \{published data only\}}

Adams HA, Bauer R, Gebhardt B, Menke W, Baltes-Götz B. Total i.v. anesthesia with $\mathrm{S}-(+)$-ketamine in orthopedic geriatric surgery. Endocrine stress reaction, haemodynamics and recovery. Anaesthetist 1994;43(2):92-100. [PUBMED: 8141443]

\section{Agarwal 1977 \{published data only\}}

Agarwal G, Sikh SS. Awareness during anaesthesia. A prospective study. British Journal of Anaesthesia 1977;49(8):835-8. [PUBMED: 889672]

\section{Aime 2006 \{published data only\}}

Aime I, Verroust N, Masson-Lefoll C, Taylor G, Laloe PA, Liu N, et al. Does monitoring bispectral index or spectral entropy reduce sevoflurane use?. Anesthesia and Analgesia 2006;103(6):1469-77. [PUBMED: 17122226]

\section{Akcali 2008 \{published data only\}}

Akcali DT, Ozkose Z, Yardim S. Do we need bispectral index monitoring during total intravenous anaesthesia for lumbar discectomies?. Turkish Neurosurgery 2008;18(2):125-33. [PUBMED: 18597226]

\section{Anez 2001 \{published data only\}}

Anez C, Papaceit J, Sala JM, Fuentes A, Rull M. The effect of encephalogram bispectral index monitoring during total intravenous anaesthesia with propofol in outpatient surgery. Revista Espanola de Anestesiologia y Reanimacion 2001;48(6):264-9. [PUBMED: 11446941]

\section{Arellano 2000 \{published data only\}}

* Arellano RJ, Pole ML, Rafuse SE, Fletcher M, Saad YG, Friedlander M, et al. Omission of nitrous oxide from a propofolbased anaesthetic does not effect the recovery of women undergoing outpatient gynaecologic surgery. Anesthesiology 2000;93(2):332-9. [PUBMED: 10910478]

\section{Ashworth 1998 \{published data only\}}

Ashworth J, Smith I. Comparison of desflurane with isoflurane or propofol in spontaneously breathing ambulatory patients. Anesthesia and Analgesia 1998;87(2):312-8. [PUBMED: 9706922]

\section{Avidan 2008 \{published and unpublished data\}}

* Avidan MS, Zhang L, Burnside BA, Finkel KJ, Searleman AC, Selvidge JA, et al. Anesthesia awareness and the bispectral index. New England Journal of Medicine 2008;358(11):1097-108. [PUBMED: 18337600]

\section{Avidan 2011 \{published and unpublished data\}}

* Avidan MS, Jacobsohn E, Glick D, Burnside BA, Zhang L, Villafranca $A$, et al. Prevention of intraoperative awareness in a high-risk surgical population. New England Journal of Medicine 2011;365(7):591-600. [PUBMED: 21848460]

Villafranca AJ, Arenson BG, Avidan MS, Glick D, Mashour GA, Jacobsohn E. Volitional delay of self-reported outcomes: insights from a case of intraoperative awareness with explicit recall. Anesthesia and Analgesia 2013;116(2):365-7. [PUBMED: 23302976]

\section{Baraka 1989 \{published data only\}}

Baraka A, Louis F, Noueihid R, Diab M, Dabbous A, Sibai A. Awareness following different techniques of general anaesthesia for caesarean section. British Journal of Anaesthesia 1989;62(6):645-8. [PUBMED: 2502168]

\section{Baraka 1998 \{published data only\}}

Baraka A, Siddik S, Assaf B. Supplementation of general anaesthesia with tramadol or fentanyl in parturients undergoing elective caesarean section. Canadian Journal of Anaesthesia 1998; Vol. 45, issue 7:631-4. [PUBMED: 9717593]

\section{Barr 1977 \{published data only\}}

Barr AM, Moxon A, Woollam CH, Fryer ME. The effect of diazepam and lorazepam on awareness during anaesthesia for caesarian section. Anaesthesia 1977;32(9):873-8. [PUBMED: 23704] 


\section{Bauer 2004 \{published data only\}}

Bauer M, Wilhelm W, Kraemer T, Kreuer S, Brandt A, Adams HA, et al. Impact of bispectral index monitoring on stress response and propofol consumption in patients undergoing coronary artery bypass surgery. Anesthesiology 2004;101(5):1096-104. [PUBMED: 15505444]

\section{Bergmann 2013 \{published data only\}}

Bergmann I, Gohner A, Crozier TA, Hesjedal B, Wiese CH, Popov AF, et al. Surgical pleth index-guided remifentanil administration reduces remifentanil and propofol consumption and shortens recovery times in outpatient anaesthesia. British Journal of Anaesthesia 2013;110(4):622-8. [PUBMED: 23220856]

\section{Bestas 2004 \{published data only\}}

Bestas A, Yasar MA, Bayar MK, Inalkac S. The effects of two different anaesthesia techniques on bispectral index values and awareness during off-pump coronary artery bypass grafting. Journal of Clinical Monitoring and Computing 2004;18:347-51. [PUBMED: 15957626]

\section{Bethune 1992 \{published data only\}}

Bethune DW, Ghosh S, Gray B, Kerr L, Walker IA, Doolan LA, et al. Learning during general anaesthesia: implicit recall after methohexitone or propofol infusion. British Journal of Anaesthesia 1992;69(2):197-9. [PUBMED: 1389826]

\section{Bhawna 2012 \{published data only\}}

Bhawna, Bajwa SJS, Lalitha K, Dhar P, Kumar V. Influence of esmolol on requirement of inhalational agent using entropy and assessment of its effect on immediate postoperative pain score. Indian Journal of Anaesthesia 2012;56(6):535-41. [PUBMED: 23325937]

\section{Blendinger 1976 \{published data only\}}

Blendinger I, Patschke D. Experiences with continuous infusions of etomidate in cardiac surgery. Der Anaesthesist 1976; Vol. 25, issue 8:391-2. [PUBMED: 949108]

\section{Block 1991 \{published data only\}}

Block RI, Ghoneim MM, Sum Ping ST, Ali MA. Human learning during general anaesthesia and surgery. British Journal of Anaesthesia 1991;66(2):170-8. [PUBMED: 1817616]

\section{Bonato 2001 \{published data only\}}

Bonato R, Sorbara C, Mapelli D, lannizz P, Volpe B, Pittarello D, et al. Bispectral EEG analysis: a target of hypnosis during general anesthesia in cardiac surgery. Acta Anaesthesiologica Italica/Anaesthesia and Intensive Care in Italy 2001;52:83-102.

\section{Browne 1973 \{published data only\}}

Browne RA, Catton DV. Awareness during anaesthesia: a comparison of anaesthesia with nitrous oxide-oxygen and nitrous oxide-oxygen with innovar. Canadian Anaesthetists' Society Journal 1973;20(6):763-8. [PUBMED: 4769611]

\section{Bruhn 2005 \{published data only\}}

Bruhn J, Kreuer S, Bischoff P, Kessler P, Schmidt GN, Grzesiak A, et al. Bispectral index and A-line AAl index as guidance for desflurane-remifentanil anaesthesia compared with a standard practice group: a multi centre study. British Journal of Anaesthesia 2005;94(1):63-9. [PUBMED: 15516347]

\section{Casati 1999 \{published data only\}}

Casati A, Valentini G, Zangrillo A, Senatore R, Mello A, Airaghi B, et al. Anaesthesia for ultrasound guided oocyte retrieval: midazolam/remifentanil versus propofol/fentanyl regimens. European Journal of Anaesthesiology 1999;16(11):773-8. [PUBMED: 10713871]

Celebioglu 2002 \{published data only\}

Celebioglu B, Pamuk AG, Aypar U, Pasaoglu I. Use of sevoflurane during cardiopulmonary bypass decreases incidence of awareness. European Journal of Anaesthesiology 2002;19(4):283-7. [PUBMED: 12074418]

\section{Celleno 1993 \{published data only\}}

Celleno D, Capogna G, Emanuelli M, Varrassi G, Muratori F, Costantino $\mathrm{P}$, et al. Which induction drug for cesarean section? A comparison of thiopental sodium, propofol, and midazolam. Journal of Clinical Anesthesia 1993;5:284-8. [PUBMED: 8373604]

\section{Chen 2009 \{published data only\}}

Chen G, Buell O, Gruenewald M, Fudickar A, Scholz J, Bein B. A comparison between target-controlled and manually controlled propofol infusions in patients undergoing routine surgical procedures. European Journal of Anaesthesiology 2009;26(11):928-35. [PUBMED: 19842242 ]

\section{Cheun 1987 \{published data only\}}

Cheun JK. Intraspinal narcotic anesthesia in open heart surgery. Journal of Korean Medical Science 1987;2(4):225-9. [PUBMED: 3268179]

\section{Chin 2004 \{published data only\}}

Chin KJ, Yeo SW. Bispectral index values at sevoflurane concentrations of $1 \%$ and $1.5 \%$ in lower segment cesarean delivery. Anesthesia and Analgesia 2004;98(4):1140-4, table of contents. [PUBMED: 15041614]

\section{Choi 2012 \{published data only\}}

Choi WJ, Kim SH, Koh WU, Hwang DI, Cho SK, Park PH, et al. Effect of pre-exposure to sevoflurane on the bispectral index in women undergoing Caesarean delivery under general anaesthesia. British Journal of Anaesthesia 2012;108(6):990-7. [PUBMED: 22434266]

\section{Clyburn 1986 \{published data only\}}

Clyburn P, Kay NH, McKenzie PJ. Effects of diazepam and midazolam on recovery from anaesthesia in outpatients. British Journal of Anaesthesia 1986;58(8):872-5. [PUBMED: 2942163]

\section{Coates 1987 \{published data only\}}

Coates DP, Monk CR, Prys-Roberts C, Turtle M. Hemodynamic effects of infusions of the emulsion formulation of propofol during nitrous oxide anesthesia in humans. Anesthesia and Analgesia 1987;66(1):64-70. [PUBMED: 3492156]

Collins 1996 \{published data only\}

Collins SJ, Robinson AL, Holland HF. A comparison between total intravenous anaesthesia using a propofol/ 
alfentanil mixture and an inhalational technique for laparoscopic gynaecological sterilization. European Journal of Anaesthesiology 1996;13(1):33-7. [PUBMED: 8829934]

\section{Crawford 1985 \{published data only\}}

Crawford JS, Lewis M, Davies P. Maternal and neonatal responses related to the volatile agent used to maintain anaesthesia at caesarean section. British Journal of Anaesthesia 1985;57(5):482-7. [PUBMED: 3994881]

\section{Crawford ME 1984 \{published data only\}}

Crawford ME, Carl P, Andersen RS, Mikkelsen BO. Comparison between midazolam and thiopentone-based balanced anaesthesia for day-case surgery. British Journal of Anaesthesia 1984;56:165-9. [PUBMED: 6691877]

\section{Czarko 2013 \{published data only\}}

Czarko K, Kwiatosz-Muc M, Fijalkowska A, Kowalczyk M, Rutyna R. Intraoperative awareness--comparison of its incidence in women undergoing general anaesthesia for Caesarean section and for gynaecological procedures. Anaesthesiology Intensive Therapy 2013;45(4):200-4. [PUBMED: 24407896]

\section{Deeprose 2005 \{published data only\}}

Deeprose C, Andrade J, Harrison D, Edwards N. Unconscious auditory priming during surgery with propofol and nitrous oxide anaesthesia: a replication. British Journal of Anaesthesia 2005;94(1):57-62. [PUBMED: 15486010]

\section{De Kock 1995 \{published data only\}}

De Kock M, Famenne F, Deckers G, Scholtes JL. Epidural clonidine or sufentanil for intraoperative and postoperative analgesia. Anesthesia and Analgesia 1995;81(6):1154-62. [PUBMED: 7486097]

\section{Deshpande 2009 \{published data only\}}

Deshpande CM, Mohite SN, Kamdi P. Sufentanil vs fentanyl for fast-track cardiac anaesthesia. Indian Journal of Anaesthesia 2009;53(4):455-62. [PUBMED: 20640208]

\section{Dhadphale 1979 \{published data only\}}

Dhadphale PR, Jackson AP, Alseri S. Comparison of anesthesia with diazepam and ketamine vs. morphine in patients undergoing heart-valve replacement. Anesthesiology 1979;51:200-3.

\section{Drover 2002 \{published data only\}}

Drover DR, Lemmens HJ, Pierce ET, Plourde G, Loyd G, Ornstein $\mathrm{E}$, et al. Patient State Index: titration of delivery and recovery from propofol, alfentanil, and nitrous oxide anesthesia. Anesthesiology 2002;87:82-9. [PUBMED: 12131107]

\section{Dunnett 1977 \{published data only\}}

Dunnett IA. Awareness during endotracheal intubation: a comparison of ketamine and thiopentone. British Journal of Anaesthesia 1977;49(5):491. [PUBMED: 861118 ]

\section{Echevarria 1998 \{published data only\}}

Echevarría M, Caba F, Rodríguez J, Olmedo L, Avila C, Vázquez T, et al. Explicit and implicit memory during inhalation and intravenous anesthesia. Revista Espanola de Anestesiologia y Reanimacion 1998;45(6):220-5. [PUBMED: 9719718 ]

Elhakim 2010 \{published data only\}

Elhakim M, Abdelhamid D, Abdelfattach H, Magdy H, Elsayed A, Elshafei M. Effect of epidural dexmedetomidine on intraoperative awareness and post-operative pain after one-lung ventilation. Acta Anaesthesiologica Scandinavica 2010;54(6):703-9. [PUBMED: 20085547]

\section{Ellingson 1977 \{published data only\}}

Ellingson A, Haram K, Sagen N. Ketamine and diazepam as anaesthesia for forceps delivery. A comparative study. Acta Anaesthesiologica Scandinavica 1977;21:37-40. [PUBMED: 320809]

\section{Fehr 2001 \{published data only\}}

Fehr SB, Zalunardo MP, Seifert B, Rentsch KM, Rohling RG, Pasch T, et al. Clonidine decreases propofol requirements during anaesthesia: effect on bispectral index. British Journal of Anaesthesia 2001; Vol. 86, issue 5:627-32. [PUBMED: 11575336]

\section{Forestier 2003 \{published data only\}}

Forestier F, Hirschi M, Rouget P, Rigal JC, Videcoq M, Girardet P, et al. Propofol and sufentanil titration with the bispectral index to provide anesthesia for coronary artery surgery. Anesthesiology 2003;99(2):334-46. [PUBMED: 12883406]

\section{Fragen 1981 \{published data only\}}

Fragen RJ, Caldwell NJ. Awakening characteristics following anesthesia induction with midazolam for short surgical procedures. Arzneimittel-Forschung 1981; Vol. 31, issue 12a:2261-3. [PUBMED: 7199331]

\section{Gaitini 1995 \{published data only\}}

Gaitini L, Vaida S, Collins G, Somri M, Sabo E. Awareness detection during caesarean section under general anaesthesia using EEG spectrum analysis. Canadian Journal of Anaesthesia 1995;42(5):377-81. [PUBMED: 7614642]

\section{Gale 2001 \{published data only\}}

Gale T, Leslie K, Kluger M. Propofol anaesthesia via target controlled infusion or manually controlled infusion: effects on the bispectral index as a measure of anaesthetic depth. Journal Anaesthesia Intensive Care 2001; Vol. 29, issue 6:579-84. [PUBMED: 11771598]

\section{Ghaly 1988 \{published data only\}}

Ghaly RG, Flynn RJ, Moore J. Isoflurane as an alternative to halothane for caesarean section. Anaesthesia 1988;43(1):5-7. [PUBMED: 3344947]

\section{Ghoneim 2000 \{published data only\}}

Ghoneim MM, Block RI, Dhanaraj VJ, Todd MM, Choi WW, Brown CK. Auditory evoked responses and learning and awareness during general anesthesia. Acta Anaesthesiologica Scandinavica 2000; Vol. 44, issue 2:133-43. [PUBMED: 10695905]

Ghosh 2008 \{published data only\}

Ghosh I, Bithal PK, Dash HH, Chaturvedi A, Prabhakar H. Both clonidine and metoprolol modify anesthetic depth indicators 
and reduce intraoperative propofol requirement. Journal of Anesthesia 2008;22(2):131-4. [PUBMED: 18500609]

\section{Girardi 1994 \{published data only\}}

Girardi G, Rossi R, Cellai MP, Pieraccioli E, Novelli GP. Anesthesia with isoflurane in air and with isoflurane and nitrous oxide. Minerva Anestesiologica 1994;60(6):321-8.

\section{Gokce 2009 \{published data only\}}

Gokce BM, Karabiyik L, Karadenizli Y. Hypotensive anesthesia with esmolol. Assessment of hemodynamics, consumption of anesthetic drugs, and recovery. Saudi Medical Journal 2009;30(6):771-7. [PUBMED: 19526158]

\section{Goto 2000 \{published data only\}}

Goto T, Nakata Y, Saito H, Ishiguro Y, Niimi Y, Suwa K, et al. Bispectral analysis of the electroencephalogram does not predict responsiveness to verbal command in patients emerging from xenon anaesthesia. British Journal of Anaesthesia 2000;85(3):359-63. [PUBMED: 11103174]

\section{Gruenewald 2007 \{published data only\}}

Gruenewald M, Zhou J, Schloemerkemper N, Meybohm P, Weiler N, Tonner PH, et al. M-Entropy guidance vs standard practice during propofol-remifentanil anaesthesia: a randomised controlled trial. Anaesthesia 2007;62:1124-9. [PUBMED: 17991257]

\section{Grundmann 2001 \{published data only\}}

Grundmann U, Silomon M, Bach F, Becker S, Bauer M, Larsen B, et al. Recovery profile and side effects of remifentanil-based anaesthesia with desflurane or propofol for laparoscopic cholecystectomy. Acta Anaesthesiologica Scandinavica 2001;45:320-6. [PUBMED: 11207468]

\section{Gupta 1992 \{published data only\}}

Gupta A, Larsen LE, Sjöberg F, Lindh ML, Lennmarken C. Thiopentone or propofol for induction of isoflurane-based anaesthesia for ambulatory surgery?. Acta Anaesthesiologica Scandinavica 1992;36:670-4. [PUBMED: 1441867]

\section{Gurman 1994 \{published data only\}}

Gurman GM, Fajer S, Porat A, Schily M, Pearlman A. Use of EEG spectral edge as index of equipotency in a comparison of propofol and isoflurane for maintenance of general anaesthesia. European Journal of Anaesthesiology 1994; Vol. 11, issue 6:443-8. [PUBMED: 7851350]

\section{Hachero 2001 \{published data only\}}

Hachero A, Alamo F, Caba F, Echevarria M, Merino S, Gomez P, et al. Influence of bispectral index monitoring on fentanyl requirements during total intravenous anesthesia for major gynecological surgery. Revista Espanola de Anestesiologia y Reanimacion 2001;48(8):364-9. [PUBMED: 11674982]

\section{Hackner 2003 \{published data only\}}

Hackner C, Detsch O, Schneider G, Jelen-Esselborn S, Kochs E. Early recovery after remifentanil-pronounced compared with propofol-pronounced total intravenous anaesthesia for short painful procedures. British Journal of Anaesthesia 2003; Vol. 91, issue 4:580-2. [PUBMED: 14504162]

\section{Haimeur 1997 \{published data only\}}

Haimeur CT, Alaoui I. General anaesthesia for caesarean section. A comparison of thiopental and ketamine. Cahiers d'Anesthesiologie 1997;45:9-13.

\section{Haram 1981 \{published data only\}}

Haram K, Lund T, Sagen N, Bøe OE. Comparison of thiopentone and diazepam as induction agents of anaesthesia for Caesarean section. Acta Anaesthesiologica Scandinavica 1981;25(6):470-6. [PUBMED: 7347074]

\section{Hug 1988 \{published data only\}}

Hug CC Jr, Hall RI, Angert KC, Reeder DA, Moldenhauer CC. Alfentanil plasma concentration v. effect relationships in cardiac surgical patients. British Journal of Anaesthesia 1988; Vol. 61, issue 4:435-40. [PUBMED: 3142509]

Hung 1992 \{published data only\} Hung OR, Varvel JR, Shafer SL, Stanski DR. Thiopental pharmacodynamics. II. Quantitation of clinical and electroencephalographic depth of anesthesia. Anesthesiology 1992; Vol. 77, issue 2:237-44. [PUBMED: 1642341]

Ibraheim 2008 \{published data only\} Ibraheim O, Alshaer A, Mazen K, El-Dawlaty A, Turkistani A, Alkathery $\mathrm{K}$, et al. Effect of bispectral index (BIS) monitoring on postoperative recovery and sevoflurane consumption among morbidly obese patients undergoing laparoscopic gastric banding. Middle East Journal Anesthesiology 2008;19(4):819-30. [PUBMED: 18630768]

\section{Inoue 2005 \{published data only\}}

Inoue $\mathrm{Y}$, Koga K, Sata T, Shigematsu A. Effects of fentanyl on emergence characteristics from anesthesia in adult cervical spine surgery: a comparison of fentanyl-based and sevofluranebased anesthesia. Journal of Anesthesia 2005; Vol. 19, issue 1:12-6. [PUBMED: 15674509]

\section{Jensen 1995 \{published data only\}}

Jensen AG, Møller JT, Lybecker H, Hansen PA. A random trial comparing recovery after midazolam-alfentanil anesthesia with and without reversal with flumazenil, and standardized neurolept anesthesia for major gynecologic surgery. Journal of Clinical Anesthesia 1995;7:63-70. [PUBMED: 7772362]

\section{Jiahai 2012 \{published data only\}}

Jiahai M, Xueyan W, Yonggang X, Jianhong Y, Qunhui H, Zhi L, et al. Spectral entropy monitoring reduces anesthetic dosage for patients undergoing off-pump coronary artery bypass graft surgery. Journal of Cardiothoracic and Vascular Anesthesia 2012;26(5):818-21. [PUBMED: 22502772]

Kamal 1990 \{published data only\}

Kamal RS, Khan FA, Khan FH. Total intravenous anaesthesia with propofol and buprenorphine. Anaesthesia 1990;45(10):865-70. [PUBMED: 2240504]

\section{Kasmacher 1996 \{published data only\}}

Käsmacher $\mathrm{H}$, Petermeyer $\mathrm{M}$, Decker $\mathrm{C}$. Incidence and quality of dreaming during anesthesia with propofol in comparison with enflurane. Der Anaesthesist 1996;45:146-53. [PUBMED: 8720887] 


\section{Kerssens 2005b \{published data only\}}

Kerssens C, Ouchi T, Sebel PS. No evidence of memory function during anesthesia with propofol or isoflurane with close control of hypnotic state. Anesthesiology 2005;103:11-9. [PUBMED: 15618787]

\section{Kerssens 2009 \{published data only\}}

Kerssens C, Gaither JR, Sebel PS. Preserved memory function during bispectral index-guided anesthesia with sevoflurane for major orthopedic surgery. Anesthesiology 2009;111(3):518-24. [PUBMED: 19672180]

\section{Kim 2007 \{published data only\}}

Kim JH, Lee YS, Kim WY, Kim HJ, Chang MS, Park JY, et al. Effect of nicardipine on haemodynamic and bispectral index changes following endotracheal intubation. Journal of International Medical Research 2007;35:52-8. [PUBMED: 17408055]

\section{Kiyama 1997 \{published data only\}}

Kiyama S, Takeda J. Effect of extradural analgesia on the paradoxical arousal response of the electroencephalogram. British Journal of Anaesthesia 1997;79(6):750-3.

\section{Kreuer 2003 \{published data only\}}

Kreuer S, Biedler A, Larsen R, Altmann S, Wilhelm W. Narcotrend monitoring allows faster emergence and a reduction of drug consumption in propofol-remifentanil anesthesia. Anesthesiology 2003;99(1):34-41. [PUBMED: 12826839]

\section{Kreuer 2005 \{published data only\}}

Kreuer S, Bruhn J, Stracke C, Aniset L, Silomon M, Larsen R, et al. Narcotrend or bispectral index monitoring during desfluraneremifentanil anesthesia: a comparison with a standard practice protocol. Anesthesia and Analgesia 2005;101(2):427-34, table of contents. [PUBMED: 16037157]

\section{Krissel 1994 \{published data only\}}

Krissel J, Dick WF, Leyser KH, Gervais H, Brockerhoff P, Schranz D. Thiopentone, thiopentone/ketamine, and ketamine for induction of anaesthesia in caesarean section. European Journal of Anaesthesiology 1994;11:115-22. [PUBMED: 8174531]

Kudoh 1999 \{published data only\}

Kudoh A, Matsuki A. Middle latency auditory evoked potentials during total intravenous anesthesia with droperidol, ketamine and fentanyl. Clinical Electroencephalography 1999;30(2):79-83. [PUBMED: 10358788]

\section{Kwon 2013 \{published data only\}}

Kwon MA, Song J, Kim J R. Tracheal intubation with rocuronium using a "modified timing principle". Korean Journal of Anesthesiology 2013; Vol. 64, issue 3:218-22. [PUBMED: 23560186]

\section{Lallemand 2003 \{published data only\}}

Lallemand MA, Lentschener C, Mazoit JX, Bonnichon P, Manceau I, Ozier Y. Bispectral index changes following etomidate induction of general anaesthesia and orotracheal intubation. British Journal of Anaesthesia 2003;91(3):341-6. [PUBMED: 12925471]

\section{Lam 2013 \{published data only\}}

Lam F, Liao CC, Lee YJ, Wang W, Kuo CJ, Lin CS. Different dosing regimens for propofol induction in obese patients. Anaesthesia 2013; Vol. 51, issue 2:53-7.

\section{Lehmann 1985 \{published data only\}}

Lehmann KA, Horrichs G, Hoeckle W. The significance of tramadol as an intraoperative analgesic. A randomized doubleblind study in comparison with placebo. Der Anaesthesist 1985;34(1):11-9. [PUBMED: 3883843]

\section{Lehmann 1992 \{published data only\}}

Lehmann KA, Krauskopf KH. Intraoperative awareness in balanced anesthesia. A literature review based on a randomized double blind study using fentanyl, pentazocine and ketamine. Der Anaesthesist 1992;41:373-85. [PUBMED: 1497125]

\section{Lehmann 2007 \{published data only\}}

Lehmann A, Schmidt M, Zeitler C, Kiessling AH, Isgro F, Boldt J. Bispectral index and electroencephalographic entropy in patients undergoing aortocoronary bypass grafting. European Journal of Anaesthesiology 2007;27:751-60. [PUBMED: 17241504]

\section{Lim 1992 \{published data only\}}

Lim BL, Low TC. Total intravenous anaesthesia versus inhalational anaesthesia for dental day surgery. Anaesthesia and Intensive Care 1992;20:475-78. [PUBMED: 1463176]

\section{Lin 2011 \{published data only\}}

Lin CF, Yang CY, Chao E, Lee MS, See LC. Short-term inhalation of sevoflurane during induction of general anesthesia can inhibit the A-line ARX index response to intubation: a randomized trial. Chang Gung Medical Journal 2011;34(6):599-606. [PUBMED: 2219606]

\section{Lindholm 2008 \{published data only\}}

Lindholm ML, Brudin L, Sandin RH. Bispectral index monitoring: appreciated but does not effect drug dosing and hypnotic levels. Acta Anaesthesiologica Scandinavica 2008;52:88-94. [PUBMED: 17976226]

\section{Liu 2013 \{published data only\}}

Liu N, Pruszkowski O, Leroy J E, Chazot T, Trillat B, Colchen A, et al. Automatic administration of propofol and remifentanil guided by the bispectral index during rigid bronchoscopic procedures: a randomized trial. Canadian Journal of Anesthesia 2013;60(9):881-7. [PUBMED: 23857041]

\section{Lu 2005 \{published data only\}}

Lu CH, Borel CO, Wu CT, Yeh CC, Jao SW, Chao PC, et al. Combined general-epidural anesthesia decreases the desflurane requirement for equivalent A-line ARX index in colorectal surgery. Acta Anaesthesiologica Scandinavica 2005;49:1063-7. [PUBMED: 16095444]

\section{Maattanen 2002 \{published data only\}}

Maattanen $\mathrm{H}$, Anderson R, Uusijarvi J, Jakobsson J. Auditory evoked potential monitoring with the AAITM-index during spinal surgery: decreased desflurane consumption. Acta 
Anaesthesiologica Scandinavica 2002;46(7):882-6. [PUBMED: 12139546]

Mashour 2012 \{published and unpublished data\}

* Mashour GA, Shanks A, Tremper KK, Kheterpal S, Turner CR, Ramachandran SK, et al. Prevention of intraoperative awareness with explicit recall in an unselected surgical population: a randomized comparative effectiveness trial. Anesthesiology 2012;117(4):717-25. [Pubmed: 22990178]

\section{Masuda 2002 \{published data only\}}

Masuda T, Yamada H, Takada K, Sagata Y, Yamaguchi M, Tomiyama $Y$, et al. Bispectral index monitoring is useful to reduce total amount of propofol and to obtain immediate recovery after propofol anesthesia. Masui 2002;51(4):394-9. [PUBMED: 11995347]

\section{McNulty 1995 \{published data only\}}

McNulty SE, Gratch D, Costello D, Heropoulos M, Kim JY. The effect of midazolam and lorazepam on postoperative recovery after cardiac surgery. Anesthesia and Analgesia 1995;81(2):404-7. [PUBMED: 7618736]

\section{Menigaux 2002 \{published data only\}}

Menigaux C, Guignard B, Adam F, Sessler DI, Joly V, Chauvin M. Esmolol prevents movement and attenuates the BIS response to orotracheal intubation. British Journal of Anaesthesia 2002;89(6):857-62. [PUBMED: 12453930]

\section{Mertens 2003 \{published data only\}}

Mertens MJ, Olofsen E, Engbers FH, Burm AG, Bovill JG, Vuyk J. Propofol reduces perioperative remifentanil requirements in a synergistic manner: response surface modeling of perioperative remifentanil-propofol interactions. Anesthesiology 2003;99(2):347-59. [PUBMED: 12883407]

\section{Miller 1996 \{published data only\}}

Miller DR, Blew PG, Martineau RJ, Hull KA. Midazolam and awareness with recall during total intravenous anaesthesia. Canadian Journal of Anaesthesia 1996;43(9):946-53. [PUBMED: 8874913]

\section{Miranda 1992 \{published data only\}}

Miranda AF, Kyi W, Sivalingam N. Propofol and methohexitone for elective caesarean--a comparative study. Medical Journal of Malaysia 1992;47(4):280-6. [PUBMED: 1303480 ]

\section{Monedero 1994 \{published data only\}}

Monedero P, Carrascosa F, Garcia-Pedrajas F, Panadero A, Hidalgo F, Arroyo JL. Does propofol have advantages over midazolam and isoflurane? Comparative study of 2 total intravenous anesthesia techniques using midazolam and propofol, versus balanced anesthesia with isoflurane. Revista Espanola de Anestesiologia y Reanimacion 1994;41(3):156-64. [PUBMED: 8059043 ]

\section{Morimoto 2002 \{published data only\}}

Morimoto Y, Oka S, Mii M, Shinjo Y, Yamashita A, Gohara T, et al. Efficacy of bispectral index monitoring in improving anesthetic management, economics, and use of the operating theater. Masui 2002;51(8):862-8. [PUBMED: 12229134]

\section{Mozafari 2014 \{published data only\}}

Mozafari H, Fakhr AA, Salehi I, Moghimbigi A. The ability of bispectral-guided management compared to routine monitoring for reflecting awareness rate in patients undergoing abdominal surgery. Iranian Red Crescent Medical Journal 2014;16(9):e13584.

\section{Muralidhar 2008 \{published data only\}}

Muralidhar K, Banakal S, Murthy K, Garg R, Rani GR, Dinesh R. Bispectral index-guided anaesthesia for off-pump coronary artery bypass grafting. Annals of Cardiac Anesthesia 2008;11(2):105-10. [PUBMED: 18603750 ]

Myles 1997 \{published data only\}

Myles PS, Buckland MR, Weeks AM, Bujor MA, McRae R, Langley $M$, et al. Hemodynamic effects, myocardial ischemia, and timing of tracheal extubation with propofol-based anesthesia for cardiac surgery. Anesthesia and Analgesia 1997;84(1):12-9. [PUBMED: 8988992]

Myles 2004 \{published and unpublished data\}

* Myles PS, Leslie K, McNeil J, Forbes A, Chan MT. Bispectral index monitoring to prevent awareness during anaesthesia: the B-Aware randomised controlled trial. Lancet 2004;363:1757-63. [PUBMED: 15172773 ]

\section{Myles 2007 \{published data only\}}

Myles PS, Leslie K, Chan MT, Forbes A, Paech MJ, Peyton P, et al. Avoidance of nitrous oxide for patients undergoing major surgery: a randomized controlled trial. Anesthesiology 2007;107(2):221-31. [PUBMED: 17667565]

\section{Navarro 2000 \{published data only\}}

Navarro EM. Desflurane--general anesthesia for cesarean section compared with isoflurane and epidural anesthesia. Anasthesiologie, Intensivmedizin, Notfallmedizin, Schmerztherapie 2000;35(4):232-6. [PUBMED: 10830075]

\section{Nayar 2009 \{published data only\}}

Nayar R, Sahajanand H. Does anesthetic induction for Cesarean section with a combination of ketamine and thiopentone confer any benefits over thiopentone or ketamine alone? A prospective randomized study. Minerva Anestesiologica 2009;75(4):185-90. [PUBMED: 18946429]

\section{Ngan 1997 \{published data only\}}

Ngan Kee WD, Khaw KS, Ma ML, Mainland PA, Gin T. Postoperative analgesic requirement after cesarean section: a comparison of anesthetic induction with ketamine or thiopental. Anesthesia and Analgesia 1997;85(6):1294-8.

\section{Ngan Kee 2002 \{published data only\}}

Ngan Kee WD, Khaw KS, Ma KC, Wong AS, Lee BB. Randomized, double-blind comparison of different inspired oxygen fractions during general anaesthesia for Caesarean section. British Journal of Anaesthesia 2002;89(4):556-61. [PUBMED: 12393355]

Oddby-Muhrbeck 1993 \{published data only\}

Oddby-Muhrbeck E, Jakobsson J. Recall of music: a comparison between anaesthesia with propofol and isoflurane. Acta 
Anaesthesiologica Scandinavica 1993;37:33-7. [PUBMED: 8424291]

\section{Panousis 2009 \{published data only\}}

Panousis P, Heller AR, Koch T, Litz RJ. Epidural ropivacaine concentrations for intraoperative analgesia during major upper abdominal surgery: a prospective, randomized, doubleblinded, placebo-controlled study. Anesthesia and Analgesia 2009;108(6):1971-6. [PUBMED: 19448234]

Pauls 2009 \{published data only\}

Pauls RJ, Dickson TJ, Kaufmann AM, Cappellani RB, Ringaert KR, West M, et al. A comparison of the ability of the EEGo and BIS monitors to assess emergence following neurosurgery. Canadian Journal of Anaesthesia 2009;56(5):366-73. [PUBMED: 19340492]

\section{Paventi 2001 \{published data only\}}

Paventi S, Santevecchi A, Metta E, Annetta MG, Perilli V, Sollazzi $L$, et al. Bispectral index monitoring in sevoflurane and remifentanil anesthesia. Analysis of drugs management and immediate recovery. Minerva Anestesiologica 2001;67(6):435-9. [PUBMED: 11533541]

\section{Pedersen 1992 \{published data only\}}

Pedersen JE, Fernandes A, Christensen M. Halothane 2\% for caesarean section. European Journal of Anaesthesiology 1992;9:319-24. [PUBMED: 1628635]

\section{Persec 2012 \{published data only\}}

Persec J, Persec Z, Kopljar M, Sojcic N, Husedzinovic I. Effect of bispectral index monitoring on extubation time and analgesic consumption in abdominal surgery: a randomised clinical trial. Swiss Medical Weekly 2012; Vol. 142:w13689. [PUBMED: 23135976]

\section{Piggott 1990 \{published data only\}}

Piggott SE, Bogod DG, Rosen M, Rees GA, Harmer M. Isoflurane with either $100 \%$ oxygen or $50 \%$ nitrous oxide in oxygen for caesarean section. British Journal of Anaesthesia 1990;65:325-9. [PUBMED: 2121203]

\section{Plourde 1996 \{published data only\}}

Plourde G, Villemure C. Comparison of the effects of enflurane/ $\mathrm{N} 2 \mathrm{O}$ on the $40-\mathrm{Hz}$ auditory steady-state response versus the auditory middle-latency response. Anesthesia and Analgesia 1996;82:75-83. [PUBMED: 8712429]

\section{Puri 2003 \{published data only\}}

Puri GD, Murthy SS. Bispectral index monitoring in patients undergoing cardiac surgery under cardiopulmonary bypass. European Journal of Anaesthesiology 2003;20:451-6. [PUBMED: 12803261]

\section{Puri 2007 \{published data only\}}

Puri GD, Kumar B, Aveek J. Closed-loop anaesthesia delivery system (CLADS) using bispectral index: a performance assessment study. Anaesthesia and Intensive Care 2007;35(3):357-62. [PUBMED: 17591128]
Rehberg 2007 \{published data only\}

Rehberg B, Ryll C, Hadzidiakos D, Baars J. Use of a targetcontrolled infusion system for propofol does not improve subjective assessment of anaesthetic depth by inexperienced anaesthesiologists. European Journal of Anaesthesiology 2007;24:920-6. [PUBMED: 17588273 ]

Renna 2000 \{published data only\}

Renna M, Lang EM, Lockwood GG. The effect of sevoflurane on implicit memory: a double-blind, randomised study. Anaesthesia 2000;55(7):634-40. [PUBMED: 10919417]

\section{Rinaldi 2005 \{published data only\}}

Rinaldi S, Consales G, Gallerani E, Ortolani O, De Gaudio AR. A-line autoregression index monitoring to titrate inhalational anaesthesia: effects on sevoflurane consumption, emergence time and memory. Acta Anaesthesiologica Scandinavica 2007;49:692-7. [PUBMED: 15836686]

Russell 1986 \{published data only\}

Russell IF. Comparison of wakefulness with two anaesthetic regimens. Total i.v. v. balanced anaesthesia. British Journal of Anaesthesia 1986;58(9):965-8. [PUBMED: 3756056]

\section{Samarkandi 2004 \{published data only\}}

Samarkandi AH, Abdel Meguid ME, Abdullah KM, Riad W. Bispectral index monitoring and titration of anaesthetics during off-pump coronary artery bypass surgery. Egyptian Journal of Anaesthesia 2004;20:357-61.

\section{Sareen 1997 \{published data only\}}

Sareen J, Hudson RJ, Rosenbloom M, Thomson IR. Dose-response to anaesthetic induction with sufentanil: haemodynamic and electroencephalographic effects. Canadian Journal of Anaesthesia 1997;44(1):19-25. [PUBMED: 8988819]

\section{Schultetus 1986 \{published data only\}}

Schultetus RR, Hill CR, Dharamraj CM, Banner TE, Berman LS. Wakefulness during cesarean section after anesthetic induction with ketamine, thiopental, or ketamine and thiopental combined. Anesthesia and Analgesia 1986;65:723-8. [PUBMED: 3717612]

\section{Schwender 1994 \{published data only\}}

Schwender D, Kaiser A, Klasing S, Peter K, Pöppel E. Midlatency auditory evoked potentials and explicit and implicit memory in patients undergoing cardiac surgery. Anesthesiology 1994;80:493-501. [PUBMED: 8141445]

\section{Schwender 1996 \{published data only\}}

Schwender D, Daunderer M, Mulzer S, Klasing S, Finsterer U, Peter K. Spectral edge frequency of the electroencephalogram to monitor "depth" of anaesthesia with isoflurane or propofol. British Journal of Anaesthesia 1996;77:179-84. [PUBMED: 8881621]

\section{Shin 2012 \{published data only\}}

Shin MK, Shim HS, Yang GY, Sung WS. Effect of a targetcontrolled infusion of remifentanil in combination with desflurane during the "maintenance" phase of general 
anesthesia. Korean Journal of Anesthesiology 2012;63(1):25-9. [PUBMED: 22870361]

\section{Sidi 1990 \{published data only\}}

Sidi A, Halimi P, Cotev S. Estimating anesthetic depth by electroencephalography during anesthetic induction and intubation in patients undergoing cardiac surgery. Journal of Clinical Anesthesia 1990;2(2):101-7.

\section{Smith 1999 \{published data only\}}

Smith TL, Zapala D, Thompson CL, Hoye W, Kelly T. Relationship of auditory middle latency response and stem-word completion test as indicators of implicit memory formation during general anesthesia. Journal of the American Association of Nurse Anesthetists 1999;67(3):247-53. [PUBMED: 10488296]

\section{Song 1997 \{published data only\}}

Song D, Joshi GP, White PF. Titration of volatile anesthetics using bispectral index facilitates recovery after ambulatory anesthesia. Anaesthesiology 1997;87(4):842-8. [PUBMED: 9357886]

\section{Sorbara 1995 \{published data only\}}

Sorbara C, Pittarello D, Rizzoli G, Pasini L, Armellin G, Bonato R, et al. Propofol-fentanyl versus isoflurane-fentanyl anesthesia for coronary artery bypass grafting: effect on myocardial contractility and peripheral hemodynamics. Journal of Cardiothoracic and Vascular Anesthesia 1995;9(1):18-23. [PUBMED: 7718750]

\section{Soyannwo 1988 \{published data only\}}

Soyannwo OA, Elegbe EO, Odugbesan CO. Effect of flunitrazepam (Rohypnol) on awareness during anaesthesia for caesarean section. African Journal of Medicine and Medical Sciences 1988;17(1):23-6. [PUBMED: 2834929]

\section{Staikou 2013 \{published data only\}}

Staikou C, Paraskeva A, Karmaniolou I, Vezakis A, Tsaroucha A. Intravenous lidocaine does not affect the anesthetic depth during rapid sequence induction and intubation as assessed by Bispectral Index monitoring: a randomized double blind study. Archives of Medical Science 2013; Vol. 9, issue 4:713-8. [PUBMED: 24049534]

\section{Stoppe 2012 \{published data only\}}

Stoppe C, Peters D, Fahlenkamp AV, Cremer J, Rex S, Schalte G, et al. aepEX monitor for the measurement of hypnotic depth in patients undergoing balanced xenon anaesthesia. British Journal of Anaesthesia 2012;108(1):80-8. [PUBMED: 22139005]

\section{Stuttmann 2010 \{published data only\}}

Stuttmann R, Jakubetz J, Schultz K, Schäfer C, Langer S, Ullmann $U$, et al. Recovery index, attentiveness and state of memory after xenon or isoflurane anaesthesia: a randomized controlled trial. Anesthesiology 2010;10:5. [PUBMED: 20459661]

\section{Toft 1987 \{published data only\}}

Toft P, Romer U. Comparison of midazolam and diazepam to supplement total intravenous anaesthesia with ketamine for endoscopy. Canadian Journal of Anaesthesia 1987;34(5):466-9. [PUBMED: 3311432]
Toscano 2007 \{published data only\}

Toscano A, Pancaro C, Peduto VA. Scopolamine prevents dreams during general anesthesia. Anaesthesiology 2007;106(5):952-5. [PUBMED: 17457126]

Tsai 2001 \{published data only\}

Tsai PS, Huang CJ, Hung YC, Cheng CR. Effects on the bispectral index during elective caesarean section: a comparison of propofol and isoflurane. Acta Anaesthesiologica Sinica 2001;39:17-22. [PUBMED: 11407290]

\section{Tunstall 1989 \{published data only\}}

Tunstall ME, Sheikh A. Comparison of 1.5\% enflurane with $1.25 \%$ isoflurane in oxygen for caesarean section: avoidance of awareness without nitrous oxide. British Journal of Anaesthesia 1989;62(2):138-43. [PUBMED: 2923765]

Vakkuri 2005 \{published data only\}

Vakkuri A, Yli-Hankala A, Sandin R, Mustola S, Hoymork S, Nyblom $S$, et al. Spectral entropy monitoring is associated with reduced propofol use and faster emergence in propofol-nitrous oxide-alfentanil anesthesia. Anesthesiology 2005;103(2):274-9. [PUBMED: 16052109]

\section{van der Maaten 1996 \{published data only\}}

van der Maaten JM, Epema AH, Huet RC, Hennis PJ. The effect of midazolam at two plasma concentrations of hemodynamics and sufentanil requirement in coronary artery surgery. Journal of Cardiothoracic and Vascular Anesthesia 1996;10(3):356-63. [PUBMED: 8725417]

\section{van Leeuwen 1990 \{published data only\}}

van Leeuwen L, Zuurmond WW, Deen L, Helmers HJ. Total intravenous anaesthesia with propofol, alfentanil, and oxygenair: three different dosage schemes. Canadian Journal of Anaesthesiology 1990;37(3):282-6. [PUBMED: 2182204]

\section{Wang 2013 \{published data only\}}

Wang J, Ren Y, Zhu Y, Chen JW, Zhu MM, Xu YJ, et al. Effect of penehyclidine hydrochloride on the incidence of intraoperative awareness in Chinese patients undergoing breast cancer surgery during general anaesthesia. Anaesthesia 2013;68(2):136-41. [PUBMED: 23237605]

\section{White 2003 \{published data only\}}

White PF, Wang B, Tang J, Wender RH, Naruse R, Sloninsky A. The effect of intraoperative use of esmolol and nicardipine on recovery after ambulatory surgery. Anesthesia and Analgesia 2003;97(6):1633-8. [PUBMED: 14633533]

White 2004 \{published data only\}

White PF, Ma H, Tang J, Wender RH, Sloninsky A, Kariger R. Does the use of electroencephalographic bispectral index or auditory evoked potential index monitoring facilitate recovery after desflurane anesthesia in the ambulatory setting?. Anesthesiology 2004;100(4):811-7. [PUBMED: 15087615]

\section{Wong 2002 \{published data only\}}

Wong J, Song D, Blanshard H, Grady D, Chung F. Titration of isoflurane using BIS index improves early recovery of elderly 
patients undergoing orthopedic surgeries. Canadian Journal of Anaesthesia 2002;49(1):13-8. [PUBMED: 11782323]

Wu 2001 \{published data only\}

Wu CC, Mok MS, Lin CS, Han SR. EEG-bispectral index changes with ketamine versus thiamylal induction of anesthesia. Acta Anaesthesiologica Sinica 2001;39(1):11-5. [PUBMED: 11407289]

Yildiz 2002 \{published data only\}

Yildiz K, Esmaoglu A, Dogru K, Tercan E, Boyaci A. A comparison of alfentanil and remifentanil accompanying with BIS monitorization for total intravenous anaesthesia. Türk Anesteziyoloji ve Reanimasyon Derneği Dergisi [Journal of the Turkish Anaesthesiology and Intensive Care Society] 2002;30:309-14.

\section{Yoshitani 2003 \{published data only\}}

Yoshitani K, Kawaguchi M, Takahashi M, Kitaguchi K, Furuya H. Plasma propofol concentration and EEG burst suppression ratio during normothermic cardiopulmonary bypass. British Journal of Anaesthesia 2003;90(2):122-6. [PUBMED: 12538365]

Zhang 2011 \{published and unpublished data\}

* Zhang C, Xu L, Ma YQ, Sun YX, Li YH, Zhang L, et al. Bispectral index monitoring prevent awareness during total intravenous anesthesia: a prospective, randomized, double-blinded, multi-center controlled trial. Chinese Medical Journal 2011;124(22):3664-9. [PUBMED: 22340221]

\section{Zhou 2008 \{published data only\}}

Zhou S-L, Zhang R, Shen N, Wei J-Q, Hei Z-Q. Comparison of induction anesthesia with sevoflurane inhalation and intravenous propofol in gynaecologic laparoscopy operation. Zhongguo Xin Yao Za Zhi [Chinese Journal of New Drugs] 2008;17(21):1880-3.

\section{Zohar 2006 \{published data only\}}

Zohar E, Luban I, White PF, Ramati E, Shabat S, Fredman B. Bispectral index monitoring does not improve early recovery of geriatric outpatients undergoing brief surgical procedures. Canadian Journal of Anaesthesiology 2006;53(1):20-5. [PUBMED: 16371605]

\section{References to studies excluded from this review}

\section{Abboud 1990 \{published data only\}}

Abboud TK, Afrasiabi A, Davidson J, Zhu J, Reyes A, Khoo N, et al. Prophylactic oral naltrexone with epidural morphine: effect on adverse reactions and ventilatory responses to carbon dioxide. Anesthesiology 1990;72(2):233-7. [PUBMED: 2105673]

\section{Abdel-Meguid 2005 \{published data only\}}

Abdel-Meguid ME. Bispectral index guided evaluation of the optimal midazolam induction dosing for coronary revascularization. Egyptian Journal of Anaesthesia 2003;21(2):101-4.

\section{Abott 1980 \{published data only\}}

Abott TR, Bentley G. Intra-operative awakening during scoliosis surgery. Anaesthesia 1980;35(3):298-302. [MEDLINE: 7396143]

\section{Abouleish 1976 \{published data only\}}

Abouleish E, Taylor FH. Effect of morphine-diazepam on signs of anesthesia, awareness, and dreams of patients under $\mathrm{N} 2 \mathrm{O}$ for cesarean section. Anesthesia and Analgesia 1976;55(5):702-5. [PUBMED: 987727]

\section{Absalom 2002 \{published data only\}}

Absalom AR, Sutcliffe N, Kenny GN. Closed-loop control of anesthesia using bispectral index: performance assessment in patients undergoing major orthopedic surgery under combined general and regional anesthesia. Anesthesiology 2002;96(1):67-73. [PUBMED: 11753004]

Acil 2004 \{published data only\}

Acil M, Basgul E, Celiker V, Karagoz AH, Demir B. Perioperative effects of melatonin and midazolam premedication on sedation, orientation, anxiety scores and psychomotor performance. European Journal of Anesthesiology 2004;21(7):553-7. [PUBMED: 15318468]

Adams 1998 \{published data only\}

Adams DC, Hilton HJ, Madigan JD, Szerlip NJ, Cooper LA, Emerson RG. Evidence for unconscious memory processing during elective cardiac surgery. Circulation 1998;98(19 Suppl):II289-92; discussion II292-3. [PUBMED: 9852916]

Adams 2003 \{published data only\}

Adams HA, Meyer P, Stoppa A, Muller-Goch A, Bayer P, Hecker H. Anaesthesia for caesarean section. Comparison of two general anaesthetic regimens and spinal anaesthesia. Der Anaesthesist 2003;52(1):23-32. [PUBMED: 12577162]

Ahmad 2003 \{published data only\}

Ahmad S, Yilmaz M, Marcus RJ, Glisson S, Kinsella A. Impact of bispectral index monitoring on fast tracking of gynecologic patients undergoing laparoscopic surgery. Anesthesiology 2003;98(4):849-52. [PUBMED: 12657845]

\section{Ahonen 2007 \{published data only\}}

Ahonen J, Jokela R, Uutela K, Huiku M. Surgical stress index reflects surgical stress in gynaecological laparoscopic daycase surgery. British Journal of Anaesthesia 2007;98(4):456-61. [PUBMED: 17350969]

\section{Alexander 1999a \{published data only\}}

Alexander R, Booth J, Olufolabi AJ, El-Moalem HE, Glass PS. Comparison of remifentanil with alfentanil or suxamethonium following propofol anaesthesia for tracheal intubation. Journal of Anesthesia 1999;54(11):1032-6. [PUBMED: 10540090]

Alexander 1999b \{published data only\}

Alexander R, Olufolabi AJ, Booth J, El-Moalem HE, Glass PS. Dosing study of remifentanil and propofol for tracheal intubation without the use of muscle relaxants. Anaesthesia 1999;54(11):1037-40. [PUBMED: 10540091]

\section{Al-Ruzzeh 2006 \{published data only\}}

Al-Ruzzeh S, George S, Bustami M, Wray J, Ilsley C, Athanasiou T, et al. Effect of off-pump coronary artery bypass surgery on clinical, angiographic, neurocognitive, and quality of life 
outcomes: randomised controlled trial. BMJ (Clinical research ed.) 2006;332(7554):1365. [PUBMED: 16740529]

\section{Alvarez 2000 \{published data only\}}

Alvarez AO, Cascardo A, Albarracin Menendez S, Capria JJ, Cordero RA. Total intravenous anesthesia with midazolam, remifentanil, propofol and cisatracurium in morbid obesity. Obesity Surgery 2000;10(4):353-60. [PUBMED: 11007629]

\section{Andelman 2004 \{published data only\}}

Andelman F, Zuckerman-Feldhay E, Hoffien D, Fried I, Neufeld MY. Lateralization of deficit in self-awareness of memory in patients with intractable epilepsy. Epilepsia 2004;45(7):826-33. [PUBMED: 15230708]

\section{Anderson 2003 \{published data only\}}

Anderson RE, Barr G, Assareh H, Jakobsson J. The AAl index, the BIS index and end-tidal concentration during wash in and wash out of sevoflurane. Journal of Anesthesia 2003;58(6):531-5. [PUBMED: 12846616]

\section{Anderson 2004 \{published data only\}}

Anderson RE, Barr G, Owall A, Jakobsson J. Entropy during propofol hypnosis, including an episode of wakefulness. Journal of Anesthesia 2004; Vol. 59, issue 1:52-6. [PUBMED: 14687099]

\section{Andrade 2001 \{published data only\}}

Andrade J, Englert L, Harper C, Edwards ND. Comparing the effects of stimulation and propofol infusion rate on implicit and explicit memory formation. British Journal of Anaesthesia 2001; Vol. 86, issue 2:189-95. [PUBMED: 11573658]

\section{Aono 1999 \{published data only\}}

Aono J, Mamiya K, Manabe M. Preoperative anxiety is associated with a high incidence of problematic behavior on emergence after halothane anesthesia in boys. Acta Anaesthesiologica Scandinavica 1999;43(5):542-4. [PUBMED: 10342002]

\section{Apfelbaum 1996 \{published data only\}}

Apfelbaum JL, Lichtor JL, Lane BS, Coalson DW, Korttila KT. Awakening, clinical recovery, and psychomotor effects after desflurane and propofol anesthesia. Anesthesia and Analgesia 1996;83(4):721-5. [PUBMED: 8831309]

\section{Aqil 2009 \{published data only\}}

Aqil M, Aziz-ul-Haq, Rasheed A, Altaf R. Effect of two different doses of fentanyl on intubating conditions with sevoflurane inhalation without neuromuscular blocking agents in adults. Anaesthesia, Pain \& Intensive Care 2009;13(2):55-6.

\section{Arndt 1995a \{published data only\}}

Arndt VM, Hofmockel R, Benad G. EEG changes during propofolalfentanil-nitrous oxide anesthesia. Anaesthesiologie und Reanimation 1995; Vol. 20, issue 5:126-33. [PUBMED: 8526965]

\section{Aubrun 2008 \{published data only\}}

Aubrun F, Gaillat C, Rosenthal D, Dupuis M, Mottet P, Marchetti F, et al. Effect of a low-dose ketamine regimen on pain, mood, cognitive function and memory after major gynaecological surgery: a randomized, double-blind, placebo-controlled trial. European Journal of Anaesthesiology 2008;25(2):97-105. [PUBMED: 17894912]

\section{Ausems 1983 \{published data only\}}

Ausems ME, Hug CCJ, de Lange $\mathrm{S}$. Variable rate infusion of alfentanil as a supplement to nitrous oxide anesthesia for general surgery. Anesthesia and Analgesia 1983;62(11):982-6. [PUBMED: 6414340]

\section{Ausems 1986 \{published data only\}}

Ausems ME, Hug CC Jr, Stanski DR, Burm AG. Plasma concentrations of alfentanil required to supplement nitrous oxide anesthesia for general surgery. Anesthesiology 1986; Vol. 65, issue 4:362-73. [PUBMED: 3094407]

\section{Bailey 1985 \{published data only\}}

Bailey PL, Wilbrink J, Zwanikken P, Pace NL, Stanley TH. Anesthetic induction with fentanyl. Anesthesia and Analgesia 1985;64(1):48-53. [PUBMED: 2981489]

\section{Balci 2006 \{published data only\}}

Balci C, Akbulutt G, Ibis AH, Arikan Y. Comparison of desflurane and sevoflurane recovery duration with BIS values. Anestezi Dergisi [Journal of Anesthesia] 2006;14(1):32-6.

\section{Bannister 2001 \{published data only\}}

Bannister CF, Brosius KK, Sigl JC, Meyer BJ, Sebel PS. The effect of bispectral index monitoring on anesthetic use and recovery in children anesthetized with sevoflurane in nitrous oxide. Anesthesia and Analgesia 2001;92(4):877-81. [PUBMED: 11273918]

\section{Baraka 1990 \{published data only\}}

Baraka A, Louis F, Dalleh R. Maternal awareness and neonatal outcome after ketamine induction of anaesthesia for Caesarean section. Canadian Journal of Anaesthesia 1990; Vol. 37, issue 6:641-4. [PUBMED: 2208534]

\section{Barclay 1980 \{published data only\}}

Barclay A, Houlton PC, Downing JW. Total intravenous anaesthesia: a technique using flunitrazepam, ketamine, muscle relaxants and controlled ventilation of the lung. Anaesthesia 1980;35(3):287-90. [PUBMED: 6104936]

\section{Barr 1973 \{published data only\}}

Barr AM, Wong RM. Awareness during general anaesthesia for bronchoscopy and laryngoscopy using the apnoeic oxygenation technique. British Journal of Anaesthesia 1973;45(8):894-900. [PUBMED: 4753687]

\section{Barr 1999 \{published data only\}}

Barr G, Jakobsson JG, Owall A, Anderson RE. Nitrous oxide does not alter bispectral index: study with nitrous oxide as sole agent and as an adjunct to i.v. anaesthesia. British Journal of Anaesthesia 1999;82(6):827-30. [PUBMED: 10562773]

\section{Barr 2001 \{published data only\}}

Barr G, Anderson RE, Owall A, Jakobsson JG. Being awake intermittently during propofol-induced hypnosis: a study of BIS, explicit and implicit memory. Acta Anaesthesiologica Scandinavica 2001;45(7):834-8. [PUBMED: 11472283] 


\section{Barvais 2003 \{published data only\}}

Barvais L, Engelman E, Eba JM, Coussaert E, Cantraine F, Kenny GN. Effect site concentrations of remifentanil and pupil response to noxious stimulation. British Journal of Anaesthesia 2003; Vol. 91, issue 3:347-52. [PUBMED: 12925472]

\section{Basar 2003 \{published data only\}}

Basar H, Ozcan S, Buyukkocak U, Akpinar S, Apan A. Effect of bispectral index monitoring on sevoflurane consumption. European Journal of Anaesthesiology 2003; Vol. 20, issue 5:396-400. [PUBMED: 12790212]

\section{Becker-Blease 2006 \{published data only\}}

Becker-Blease KA, Freyd JJ. Research participants telling the truth about their lives: the ethics of asking and not asking about abuse. American Journal of Psychology 2006; Vol. 61, issue 3:218-26. [PUBMED: 16594838]

\section{Bejjani 2009 \{published data only\}}

Bejjani G, Lequeux PY, Schmartz D, Engelman E, Barvais L. No evidence of memory processing during propofol-remifentanil target-controlled infusion anesthesia with bispectral index monitoring in cardiac surgery. Journal of Cardiothoracic and Vascular Anesthesia 2009;23(2):175-81. [PUBMED: 19026570]

\section{Bennett 1985 \{published data only\}}

Bennett HL, Davis HS, Giannini JA. Non-verbal response to intraoperative conversation. British Journal of Anaesthesia 1985;57(2):174-9. [PUBMED: 3970796]

\section{Bilotta 2007 \{published data only\}}

Bilotta F, Caramia R, Paoloni FP, Favaro R, Araimo F, Pinto G, et al. Early postoperative cognitive recovery after remifentanilpropofol or sufentanil-propofol anaesthesia for supratentorial craniotomy: a randomized trial. European Journal of Anaesthesiology 2007; Vol. 24, issue 2:122-7. [PUBMED: 16938153]

\section{Bischoff 1997 \{published data only\}}

Bischoff P. Intracranial pressure and anesthesia--EEG and p-EEG monitoring. Anasthesiologie, Intensivmedizin, Notfallmedizin, Schmerztherapie 1997;32(2 Suppl):122-7. [PUBMED: 9417237]

\section{Block1991b \{published data only\}}

Block RI, Ghoneim MM, Sum Ping ST, Ali MA. Efficacy of therapeutic suggestions for improved postoperative recovery presented during general anesthesia. Anesthesiology 1991; Vol. 75, issue 5:746-55. [PUBMED: 1952199]

\section{Bogetz 1984 \{published data only\}}

Bogetz MS, Katz JA. Recall of surgery for major trauma. Anesthesiology 1984; Vol. 61, issue 1:6-9. [PUBMED: 6742485]

\section{Bogod 1990 \{published data only\}}

Bogod DG, Orton JK, Yau HM, Oh TE. Detecting awareness during general anaesthetic caesarean section. An evaluation of two methods. Journal of Anesthesia 1990; Vol. 45, issue 4:279-84. [PUBMED: 2337210]

\section{Bonhomme 2006 \{published data only\}}

Bonhomme V, Llabres V, Dewandre PY, Brichant JF, Hans P. Combined use of Bispectral Index and A-Line Autoregressive Index to assess anti-nociceptive component of balanced anaesthesia during lumbar arthrodesis. British Journal of Anaesthesia 2006; Vol. 96, issue 3:353-60. [PUBMED: 16415310]

Bonke 1986 \{published data only\}

Bonke B, Schmitz PI, Verhage F, Zwaveling A. Clinical study of so-called unconscious perception during general anaesthesia. British Journal of Anaesthesia 1986;58(9):957-64. [PUBMED: 3756055]

\section{Bonke 1992 \{published data only\}}

Bonke B, Van Dam ME, Van Kleff JW, Slijper FM. Implicit memory tested in children during inhalation anaesthesia. Journal of Anesthesia 1992; Vol. 47, issue 9:747-9. [PUBMED: 1415970]

\section{Bould 2007 \{published data only\}}

Bould MD, Mahtani DG, Davies R, Roughton M, Hunter DN, Kelleher A. Bispectral index values during elective rigid bronchoscopy: a prospective observational pilot study. Anaesthesia 2007;62:438-45. [PUBMED: 17448053]

\section{Brice 1970 \{published data only\}}

Brice D, Hetherington R, Utting J. A simple study of awareness and dreaming during anaesthesia. British Journal of Anaesthesia 1970;42:535-42. [PUBMED: 5423844]

Brosius 2002 \{published data only\}

Brosius KK, Bannister CF. Oral midazolam premedication in preadolescents and adolescents. Anesthesia and Analgesia 2002;94(1):31-6, table of contents. [PUBMED: 11772796]

Bruhn 2000 \{published data only\}

Bruhn J, Bouillon TW, Shafer SL. Electromyographic activity falsely elevates the bispectral index. Anesthesiology 2000; Vol. 92, issue 5:1485-7. [10781298]

\section{Buffett-Jerrott 2003 \{published data only\}}

Buffett-Jerrott SE, Stewart SH, Finley GA, Loughlan HL. Effects of benzodiazepines on explicit memory in a paediatric surgery setting. Psychopharmacology 2003;168(4):377-86. [PUBMED: 12845417]

\section{Bulach 2005 \{published data only\}}

Bulach R, Myles PS, Russnak M. Double-blind randomized controlled trial to determine extent of amnesia with midazolam given immediately before general anaesthesia. British Journal of Anaesthesia 2005;94(3):300-5. [PUBMED: 15567810]

\section{Burn 1963 \{published data only\}}

Burn JM. Relaxant anesthesia for abdominal operations using hyperventilation with air. Preliminary report. Anaesthesia 1963;18:84-7. [PUBMED: 14017121]

\section{Burrow 2001 \{published data only\}}

Burrow B, McKenzie B, Case C. Do anaesthetized patients recover better after bispectral index monitoring?. Journal Anaesthesia Intensive Care 2001; Vol. 29, issue 3:239-45. [PUBMED: 11439793] 
Byers 1997 \{published data only\}

Byers GF, Muir JG. Detecting wakefulness in anaesthetised children. Canadian Journal of Anaesthesia 1997;44(5 Pt 1):486-8. [PUBMED: 9161741]

\section{Capitanio 1997 \{published data only\}}

Capitanio L, Jensen EW, Filligoi GC, Makovec B, Gagliardi M, Henneberg SW, et al. On-line analysis of AEP and EEG for monitoring depth of anaesthesia. Methods of Information in Medicine 1997;36:311-4.

\section{Chiu 2007 \{published data only\}}

Chiu CL, Ong G, Majid AA. Impact of bispectral index monitoring on propofol administration in patients undergoing cardiopulmonary bypass. Anaesthesia and Intensive Care 2007;35(3):342-7. [PUBMED: 17591126]

\section{Chortkoff 1995 \{published data only\}}

Chortkoff BS, Gonsowski CT, Bennett HL, Levinson B, Crankshaw DP, Dutton RC, et al. Subanesthetic concentrations of desflurane and propofol suppress recall of emotionally charged information. Anesthesia and Analgesia 1995; Vol. 81, issue 4:728-36. [PUBMED: 7574002]

\section{Cirillo 2012 \{published data only\}}

Cirillo V, Volpe ML, Iacono C, Crisconio P, De Robertis E, Tufano R. Is Navigator a useful tool in guiding anesthesia practice in nephropatic patients? Preliminary study. European Journal of Anaesthesiology 2012; Vol. 29:52.

\section{Clark 2009 \{published data only\}}

Clark G, Licker M, Younossian AB, Soccal PM. Titrated sedation with propofol or midazolam for flexible bronchoscopy: a randomised trial. European Respiratory Journal 2009;34(6):1277-83. [PUBMED: 19443532]

\section{Coetzee 1998 \{published data only\}}

Coetzee JF, van LH. Tramadol or morphine administered during operation: a study of immediate postoperative effects after abdominal hysterectomy. British Journal of Anaesthesia 1998;81(5):737-41. [PUBMED: 10193286]

\section{Coppens 2010 \{published data only\}}

Coppens M, Van Limmen JG, Schnider T, Wyler B, Bonte S. Study of the time course of the clinical effect of propofol compared with the time course of the predicted effect-site concentration: performance of three pharmacokinetic-dynamic models. British Journal of Anaesthesia 2010;104(4):452-8. [PUBMED: 20190259]

\section{Cormack 1979 \{published data only\}}

Cormack RS. Awareness during surgery--a new approach. British Journal of Anaesthesia 1979;51(11):1051-4. [PUBMED: 42425]

\section{Crawford 1976 \{published data only\}}

Crawford JS, James FM, 3rd, Davies P, Crawley M. A further study of general anaesthesia for Caesarean section. British Journal of Anaesthesia 1976;48(7):661-7. [PUBMED: 1016643]

\section{Dahaba 2009 \{published data only\}}

Dahaba AA, Bornemann H, Rehak PH, Wang G, Wu XM, Metzler $\mathrm{H}$. Effect of flumazenil on bispectral index monitoring in unpremedicated patients. Anesthesiology 2009;110(5):1036-40. [PUBMED: 19352163]

Dahaba 2010 \{published data only\}

Dahaba AA, Xue JX, Zhao GG, Liu QH, Xu GX, Bornemann H, et al. BIS-vista occipital montage in patients undergoing neurosurgical procedures during propofol-remifentanil anesthesia. Anesthesiology 2010;112(3):645-51. [PUBMED: 20179501]

Davidson 2005 \{published data only\}

Davidson AJ, Huang GH, Czarnecki C, Gibson MA, Stewart SA, Jamsen $\mathrm{K}$, et al. Awareness during anesthesia in children: a prospective cohort study. Anesthesia and Analgesia 2005;100(3):653-61, table of contents. [PUBMED: 15728046]

Davies 1996 \{published data only\}

Davies FW, Mantzaridis H, Kenny GNC, Fisher AC. Middle latency auditory evoked potentials during repeated transitions from consciousness to unconsciousness. Anaesthesia 1996;51(25):107-13. [PUBMED: 8779362]

\section{De Cosmo 2008 \{published data only\}}

De Cosmo G, Congedo E, Lai C, Sgreccia M, Amato A, Beccia G, et al. Ropivacaine vs. levobupivacaine combined with sufentanil for epidural analgesia after lung surgery. European Journal of Anaesthesiology 2008;25(12):1020-5. [PUBMED: 18538053]

\section{De Kock 2005 \{published data only\}}

De Kock M, Lavand'homme P, Waterloos H. The short-lasting analgesia and long-term antihyperalgesic effect of intrathecal clonidine in patients undergoing colonic surgery. Anesthesia and Analgesia 2005;101(2):566-72. [PUBMED: 16037177]

\section{Ding 1993 \{published data only\}}

Ding Y, Fredman B, White PF. Recovery following outpatient anesthesia: use of enflurane versus propofol. Journal of Clinical Anesthesia 1993;5(6):447-50. [PUBMED: 8123267]

\section{Ding 2007 \{published data only\}}

Ding LA, Sun LQ, Chen SX, Qu LL, Xie DF. Modified physiological and operative score for the enumeration of mortality and morbidity risk assessment model in general surgery. World Journal of Gastroenterology 2007;13(38):5090-5. [PUBMED: 17876874]

Diz 2010 \{published data only\}

Diz JC, Del Rio R, Lamas A, Mendoza M, Duran M, Ferreira LM. Analysis of pharmacodynamic interaction of sevoflurane and propofol on Bispectral Index during general anaesthesia using a response surface model. British Journal of Anaesthesia 2010;104(6):733-9. [PUBMED: 20385571]

\section{Doufas 2009 \{published data only\}}

Doufas AG, Komatsu R, Orhan-Sungur M, Sengupta P, Wadhwa A, Mascha E, et al. Neuromuscular block differentially affects immobility and cortical activation at near-minimum alveolar concentration anesthesia. Anesthesia and Analgesia 2009;109(4):1097-104. [PUBMED: 19762737] 
Downing 1976 \{published data only\}

Downing JW, Mahomedy MC, Jeal DE, Allen PJ. Anaesthesia for caesarean section with ketamine. Anaesthesia 1976;31(7):883-92. [PUBMED: 9839]

\section{Dressler 2007 \{published data only\}}

Dressler I, Fritzsche T, Cortina K, Pragst F, Spies C, Rundshagen I. Psychomotor dysfunction after remifentanil/propofol anaesthesia. European Journal of Anaesthesiology 2007;24(4):347-54. [PUBMED: 17087850]

\section{Driscoll 2007 \{published data only\}}

Driscoll WD, Columbia MA, Peterfreund RA. Awareness during general anesthesia: analysis of contributing causes aided by automatic data capture. Journal of Neurosurgical Anesthesiology 2007;19(4):268-72. [PUBMED: 17893580]

\section{Eisele 1976 \{published data only\}}

Eisele V, Weinreich A, Bartle S. Perioperative awareness and recall. Anesthesia and Analgesia 1976; Vol. 55, issue 4:513-8. [PUBMED: 945955]

\section{Ekman 2004a \{published data only\}}

Ekman A, Lindholm ML, Lennmarken C, Sandin R. Reduction in the incidence of awareness using BIS monitoring. Acta Anaesthesiologica Scandinavica 2004; Vol. 48, issue 1:20-6. [PUBMED: 14674969]

\section{Ekman 2004b \{published data only\}}

Ekman A, Brudin L, Sandin R. A comparison of bispectral index and rapidly extracted auditory evoked potentials index responses to noxious stimulation during sevoflurane anesthesia. Anesthesia and Analgesia 2004; Vol. 99, issue 4:1141-6, table of contents. [PUBMED: 15385365]

\section{Eldar 1992 \{published data only\}}

Eldar I, Lieberman N, Shiber R, Nerubay J, Perel A. Use of flumazenil for intraoperative arousal during spine fusion. Anesthesia and Analgesia 1992;75(4):580-3. [PUBMED: 1530171]

\section{El-Kerdawy 2000 \{published data only\}}

El-Kerdawy HM, Zalingen EE, Bovill JG. The influence of the alpha2-adrenoceptor agonist, clonidine, on the EEG and on the MAC of isoflurane. European Journal of Anaesthesiology 2000; Vol. 17, issue 2:105-10. [PUBMED: 10758454]

\section{Erhan 2003 \{published data only\}}

Erhan E, Ugur G, Gunusen I, Alper I, Ozyar B. Propofol - not thiopental or etomidate - with remifentanil provides adequate intubating conditions in the absence of neuromuscular blockade. Canadian Journal of Anaesthesia 2003; Vol. 50, issue 2:108-15. [PUBMED: 12560298]

\section{Erk 2007 \{published data only\}}

Erk G, Ornek D, Donmez NF, Taspinar V. The use of ketamine or ketamine-midazolam for adenotonsillectomy. International Journal of Pediatric Otorhinolaryngology 2007; Vol. 71, issue 6:937-41. [PUBMED: 17418428)]

\section{Eroglu 2003 \{published data only\}}

Eroglu A, Solak M, Ozen I, Aynaci O. Stress hormones during the wake-up test in scoliosis surgery. Journal of Clinical Anesthesia 2003; Vol. 15, issue 1:15-8. [PUBMED: 12657405]

Evans 1988 \{published data only\}

Evans C, Richardson PH. Improved recovery and reduced postoperative stay after therapeutic suggestions during general anaesthesia. Lancet 1988; Vol. 2, issue 8609:491-3. [PUBMED: 2900410)]

Fahlenkamp 2010 \{published data only\}

Fahlenkamp AV, Krebber F, Rex S. Bispectral index monitoring during balanced xenon or sevoflurane anaesthesia in elderly patients. European Journal of Anesthesiology 2010;27(10):906-11. [PUBMED: [20671557]]

Fairley 1956 \{published data only\}

Fairley HB. An evaluation of local and general anaesthesia for diagnostic bronchoscopy. Canadian Anaesthetists' Society Journal 1956;3(4):366-77.

\section{Famewo 1976 \{published data only\}}

Famewo CE. Awareness and dreams during general anaesthesia for caesarian section a study of incidence. Canadian Anaesthetists' Society Journal 1976; Vol. 23, issue 6:636-9. [PUBMED: 990980]

\section{Farag 2006 \{published data only\}}

Farag E, Chelune GJ, Schubert A, Mascha EJ. Is depth of anesthesia, as assessed by the Bispectral Index, related to postoperative cognitive dysfunction and recovery?. Anesthesia and Analgesia 2006; Vol. 103, issue 3:633-40. [PUBMED: 16931673]

\section{Filipov 2007 \{published data only\}}

Filipov TZ, Smilov IV. Comparison of the quality of anesthesia between two techniques ascertained with bispectral index. Anaesthesiology and Intensive Care 2007;34:3-13.

\section{Fisher 2006 \{published data only\}}

Fisher J, Hirshman E, Henthorn T, Arndt J, Passannante A. Midazolam amnesia and short-term/working memory processes. Consciousness and Cognition 2006; Vol. 15, issue 1:54-63. [PUBMED: 16546038]

\section{Fitzgerald 2001 \{published data only\}}

Fitzgerald RD, Lamm C, Oczenski W, Stimpfl T, Vycudilik W, Bauer $\mathrm{H}$. Direct current auditory evoked potentials during wakefulness, anesthesia, and emergence from anesthesia. Anesthesia and Analgesia 2001; Vol. 92, issue 1:154-60. [PUBMED: [11133619]]

\section{Flaishon 1997 \{published data only\}}

Flaishon R, Windsor A, Sigl J, Sebel PS. Recovery of consciousness after thiopental or propofol. Bispectral index and isolated forearm technique. Anesthesiology 1997; Vol. 86, issue 3:613-9. [PUBMED: [9066327]] 
Flaitz 1986 \{published data only\}

Flaitz CM, Nowak AJ, Hicks MJ. Evaluation of the anterograde amnesic effect of rectally administered diazepam in the sedated pedodontic patient. ASDC Journal of Dentistry for Children 1986; Vol. 53, issue 1:17-20. [PUBMED: [3455953]]

Flier 1986 \{published data only\}

Flier FJ, Smorenburg JM, van der Ent CK, Bonke B, Rupreht J. Postanesthetic recall ability, anxiety and dreams in surgical patients. A clinical study. Der Anaesthesist 1986; Vol. 35, issue 10:609-12. [PUBMED: [3789390]]

Forrest 1990 \{published data only\}

Forrest JB, Lam L, Woo J, Rifkind A. Recovery after neuroleptanalgesia for cataract surgery. Canadian Journal of Anaesthesia 1990; Vol. 37, issue 4 Pt 2:S82. [PUBMED: 2193762]

\section{Frank 2000 \{published data only\}}

Frank T, Thieme V, Olthoff D. Clonidine within the scope of balanced inhalation anesthesia with sevoflurane--effects on pEEG parameters [Clonidin im Rahmen einer balancierten Inhalationsanasthesie mit Sevofluran--Effekte auf Parameter des pEEG.]. Anaesthesiologie und Reanimation 2000;25(2):32-6. [PUBMED: 10816895]

\section{Fung 2008 \{published data only\}}

Fung NY, Hu Y, Irwin MG, Chow BE, Yuen MY. Comparison between sevoflurane/remifentanil and propofol/remifentanil anaesthesia in providing conditions for somatosensory evoked potential monitoring during scoliosis corrective surgery. Anaesthesia and Intensive Care 2008;36(6):779-85. [PUBMED: 19115644]

\section{Gajraj 1998 \{published data only\}}

Gajraj RJ, Doi M, Mantzaridis H, Kenny GN. Analysis of the EEG bispectrum, auditory evoked potentials and the EEG power spectrum during repeated transitions from consciousness to unconsciousness. British Journal of Anaesthesia 1998; Vol. 80, issue 1:46-52. [PUBMED: [9505777]]

\section{Gajraj 1999 \{published data only\}}

Gajraj RJ, Doi M, Mantzaridis H, Kenny GN. Comparison of bispectral EEG analysis and auditory evoked potentials for monitoring depth of anaesthesia during propofol anaesthesia. British Journal of Anaesthesia 1999; Vol. 82, issue 5:672-8. [PUBMED: [10536541]]

\section{Gan 1997 \{published data only\}}

Gan TJ, Glass PS, Windsor A, Payne F, Rosow C, Sebel P, et al. Bispectral index monitoring allows faster emergence and improved recovery from propofol, alfentanil, and nitrous oxide anesthesia. BIS Utility Study Group. Anesthesiology 1997; Vol. 87, issue 4:808-15. [PUBMED: [9357882]]

\section{Gan 1999 \{published data only\}}

Gan TJ, Glass PS, Sigl J, Sebel P, Payne F, Rosow C, et al. Women emerge from general anesthesia with propofol/alfentanil/ nitrous oxide faster than men. Anesthesiology May;90(5):1283-7. [PUBMED: 10319774]

\section{Gazzanelli 2005 \{published data only\}}

Gazzanelli S, Vari A, Tarquini S, Fermariello A, Caputo M, Almansour $\mathrm{M}$, et al. Monitoring of consciousness with BIS during induction of anesthesia. Which muscle relaxant?. /l Giornale di Chirurgia 2005;26(4):163-9. [PUBMED: 16035253]

\section{Ge 2003 \{published data only\}}

Ge SJ, Zhuang XL, Wang YT, Wang ZD, Chen SL, Li HT. Performance of the rapidly extracted auditory evoked potentials index to detect the recovery and loss of wakefulness in anesthetized and paralyzed patients. Acta Anaesthesiologica Scandinavica 2003; Vol. 47, issue 4:466-71. [PUBMED: 12694147]

\section{Gelman 1984 \{published data only\}}

Gelman S, Rivas JE, Erdemir H, Oparil S, Proctor J, Mackrell T, et al. Hormonal and haemodynamic responses to upper abdominal surgery during isoflurane and balanced anaesthesia. Canadian Anaesthetists' Society Journal 1984;31(5):509-16. [MEDLINE: 6498567]

\section{Ghabash 1996 \{published data only\}}

Ghabash M, Matta M, Kehhaleh J. Depression of excitatory effects of propofol induction by fentanyl. Middle East Journal of Anesthesiology 1996;13(4):419-25. [PUBMED: 8713637]

\section{Ghoneim 1988 \{published data only\}}

Ghoneim MM, Hinrichs JV, O'Hara MW, Mehta MP, Pathak D, Kumar V, et al. Comparison of psychologic and cognitive functions after general or regional anesthesia. Anesthesiology 1988; Vol. 69, issue 4:507-15. [PUBMED: 3177911]

\section{Ghoneim 1998 \{published data only\}}

Ghoneim MM, Block RI, Dhanaraj VJ. Interaction of a subanaesthetic concentration of isoflurane with midazolam: effects on responsiveness, learning and memory. British Journal of Anaesthesia 1998; Vol. 80, issue 5:581-7. [PUBMED: 9691858]

\section{Ghoneim 2007 \{published data only\}}

Ghoneim MM, Block RI. Immediate peri-operative memory. Acta Anaesthesiologica Scandinavica 2007;51(8):1054-61. [PUBMED: 17697300

\section{Glass 1997 \{published data only\}}

Glass PS, Bloom M, Kearse L, Rosow C, Sebel P, Manberg P. Bispectral analysis measures sedation and memory effects of propofol, midazolam, isoflurane, and alfentanil in healthy volunteers. Anesthesiology 1997; Vol. 86, issue 4:836-47. [PUBMED: 9105228]

\section{Gordon 1994 \{published data only\}}

Gordon PC, Morrell DF, Pamm JD. Total intravenous anesthesia using propofol and alfentanil for coronary artery bypass surgery. Journal of Cardiothoracic and Vascular Anesthesia 1994;8(3):284-8. [PUBMED: 8061261]

\section{Gregory 1969 \{published data only\}}

Gregory GA, Eger El, 2nd, Munson ES. The relationship between age and halothane requirement in man. Anesthesiology 1969; Vol. 30, issue 5:488-91. [PUBMED: 5778106] 


\section{Greif 2002 \{published data only\}}

Greif R, Greenwald S, Schweitzer E, Laciny S, Rajek A, Caldwell JE, et al. Muscle relaxation does not alter hypnotic level during propofol anesthesia. Anesthesia and Analgesia 2002; Vol. 94, issue 3:604-8; table of contents. [PUBMED: 11867383]

\section{Gross 1988 \{published data only\}}

Gross JB, Alexander CM. Awakening concentrations of isoflurane are not affected by analgesic doses of morphine. Anesthesia and Analgesia 1988; Vol. 67, issue 1:27-30. [PUBMED: 3276238]

\section{Gu 2010 \{published data only\}}

Gu X J, Zhong T D. The effect of flurbiprofen axetil on laparoscopic cholecystectomy. Zhonghua Yi Xue Za Zhi 2010;90(11):760-2. [PUBMED: 20627022]

\section{Guignard 2001 \{published data only\}}

Guignard B, Coste C, Menigaux C, Chauvin M. Reduced isoflurane consumption with bispectral index monitoring. Acta Anaesthesiologica Scandinavica 2001; Vol. 45, issue 3:308-14. [PUBMED: 11207466]

\section{Gunawardane 2002 \{published data only\}}

Gunawardane PO, Murphy PA, Sleigh JW. Bispectral index monitoring during electroconvulsive therapy under propofol anaesthesia. British Journal of Anaesthesia 2002; Vol. 88, issue 2:184-7. [PUBMED: [1187865]]

\section{Guo 2012 \{published data only\}}

Guo Zheng-gang, Wang Xiao-yan, Lu Xu-lei, Su Xiao-jun, Hao Jian-hua. Application of Narcotrend-assisted anesthesia indepth monitor during escharectomy and skin transplantation in burn patients with target-controlled infusion of remifentanil hydrochloride and propofol. Chinese Journal of Burns. Department of Anesthesiology, the First Hospital Affiliated to the General Hospital of PLA, Beijing 100048, China., 2012:178-82.

\section{Gupta 2006 \{published data only\}}

Gupta A, Kaur R, Malhotra R, Kale S. Comparative evaluation of different doses of propofol preceded by fentanyl on intubating conditions and pressor response during tracheal intubation without muscle relaxants. Paediatric Anaesthesia 2006; Vol. 16, issue 4:399-405. [PUBMED: 16618293]

\section{Hadzidiakos 2006 \{published data only\}}

Hadzidiakos D, Petersen S, Baars J, Herold K, Rehberg B. Comparison of a new composite index based on midlatency auditory evoked potentials and electroencephalographic parameters with bispectral index (BIS) during moderate propofol sedation. European Journal of Anaesthesiology 2006; Vol. 23, issue 11:931-6. [PUBMED: 16824245]

\section{Haessler 1993 \{published data only\}}

Haessler R, Schwender D, Leppmeier U, Klasing S, Rindfleisch F, Peter K. Anaesthesia for coronary artery bypass grafting: opioid-analgesia combined with either flunitrazepam, propofol or isoflurane. Acta Anaesthiologica Scandinavica 1993;37(6):532-40. [PUBMED: 8213015]
Hall 1986 \{published data only\}

Hall KD, Talton IH, Fox E, Klein FF, Christian C, Jobsis FF. Brain function and level of consciousness in fentanyl anesthesia in heart surgery [Gehirnfunktion und Bewusstseinslage wahrend der Fentanylnarkose in der Herzchirurgie]. Der Anaesthesist 1986;35(4):226-30. [PUBMED: 3487258]

\section{Hans 1998 \{published data only\}}

Hans P, Lamy MM, Brichant JF, Cantraine F, Coussaert E, Byttebier $\mathrm{G}$, et al. Emergence from target-controlled anesthesia with propofol and sufentanil in patients undergoing intracranial surgery. Acta Anaesthesiologica Belgica 1998; Vol. 49, issue 1:13-9. [PUBMED: 9627733]

\section{Harris 1971 \{published data only\}}

Harris TJ, Brice DD, Hetherington RR, Utting JE. Dreaming associated with anaesthesia: the influence of morphine premedication and two volatile adjuvants. British Journal of Anaesthesia 1971; Vol. 43, issue 2:172-8. [PUBMED: 5550848]

\section{Hartridge 1963 \{published data only\}}

Hartridge VB, Wilson RB. Balanced anesthesia for cesarean section. American Journal of Obstetrics and Gynecology 1963; Vol. 85:619-25. [PUBMED: 13953166]

\section{Hartung 1986 \{published data only\}}

Hartung, HJ, Osswald PM, Puhl R, Jacoby R. Modification of postoperative somnolence following halothane anesthesia by physostigmine. Anasthesie, Intensivtherapie, Notfallmedzin 1986;21(2):82-4. [PUBMED: 3728891]

\section{Hashimoto 2012 \{published data only\}}

Hashimoto A, Fujiwara Y. Relationship between bispectral index and auditory evoked potential index for propofol and midazolam during induction of general anesthesia. British Journal of Anaesthesia. Oxford University Press, 2012:ii116.

\section{Hayashi 2007 \{published data only\}}

Hayashi K, Tsuda N, Sawa T, Hagihira S. Ketamine increases the frequency of electroencephalographic bicoherence peak on the alpha spindle area induced with propofol. British Journal of Anaesthesia 2007;99(3):389-95. [PUBMED: 17621599]

\section{Head-Rapson 1995 \{published data only\}}

Head-Rapson AG, Devlin JC, Parker CJ, Hunter JM. Pharmacokinetics and pharmacodynamics of the three isomers of mivacurium in health, in end-stage renal failure and in patients with impaired renal function. British Journal of Anaesthesia 1995; Vol. 75, issue 1:31-6. [PUBMED: 7669465]

\section{Heipertz 1986 \{published data only\}}

Heipertz W, Vontin H, Hempel V, Eichinger V. Plasma concentration and amnesia following lormetazepam and flunitrazepam in i.v. premedication. Anasthesie, Intensivtherapie, Notfallmedizin 1986; Vol. 21, issue 3:113-6. [PUBMED: 3752422]

\section{Heisterkamp 1975 \{published data only\}}

Heisterkamp DV, Cohen PJ. The effect of intravenous premedication with lorazepam (ativan), pentobarbitone 
or diazepam on recall. British Journal of Anaesthesia 1975;47(1):79-81. [PUBMED: 238548]

\section{Heller 2005 \{published data only\}}

Heller H, Hatami R, Mullin P, Sciacca RR, Khandji AG, Hamberger $M$, et al. Bilateral bispectral index monitoring during suppression of unilateral hemispheric function. Anesthesia and Analgesia 2005; Vol. 101, issue 1:235-41, table of contents. [PUBMED: 1597623]

\section{Hellwagner 2003 \{published data only\}}

Hellwagner K, Holzer A, Gustorff B, Schroegendorfer K, Greher M, Weindlmayr-Goettel M, et al. Recollection of dreams after short general anaesthesia: influence on patient anxiety and satisfaction. European Journal of Anaesthesiology 2003;20(4):282-8. [PUBMED: 12703832]

\section{Hetem 2000 \{published data only\}}

Hetem LA, Danion JM, Diemunsch P, Brandt C. Effect of a subanesthetic dose of ketamine on memory and conscious awareness in healthy volunteers. Psychopharmacology 2000; Vol. 152, issue 3:283-8. [PUBMED: 11105938]

\section{Hirschi 2000 \{published data only\}}

Hirschi M, Meistelman C, Longrois D. Effects of normothermic cardiopulmonary bypass on bispectral index. European Journal of Anaesthesiology 2000; Vol. 17, issue 8:499-505. [PUBMED: 10998033]

\section{Honarmand 2008 \{published data only\}}

Honarmand A, Safavi M. Prevention of propofol-induced injection pain by sufentanil: a placebo-controlled comparison with remifentanil. Clinical Drug Investigation 2008;28(1):27-35. [PUBMED: 18081358]

\section{Hong 2008 \{published data only\}}

Hong JY, Kang YS, Kil HK. Anaesthesia for day case excisional breast biopsy: propofol-remifentanil compared with sevoflurane-nitrous oxide. European Journal of Anaesthesiology 2008;25(6):460-7. [PUBMED: 18298873]

\section{Horn 2009 \{published data only\}}

Horn B, Pilge S, Kochs EF, Stockmanns G, Hock A, Schneider G. A combination of electroencephalogram and auditory evoked potentials separates different levels of anesthesia in volunteers. Anesthesia and Analgesia 2009;108(5):1512-21. [PUBMED: 19372330]

\section{Hoymork 2003 \{published data only\}}

Hoymork SC, Raeder J, Grimsmo B, Steen PA. Bispectral index, serum drug concentrations and emergence associated with individually adjusted target-controlled infusions of remifentanil and propofol for laparoscopic surgery. British Journal of Anaesthesia 2003; Vol. 91, issue 6:773-80. [PUBMED: 14633743]

\section{Hoymork 2005 \{published data only\}}

Hoymork SC, Raeder J. Why do women wake up faster than men from propofol anaesthesia?. British Journal of Anaesthesia 2005; Vol. 95, issue 5:627-33. [PUBMED: 16169889]
Huang 1988 \{published data only\}

Huang ST, Sum CW, Hui YL, Tan PP. Awareness of intubation with thiopental as induction agent. Acta Anaesthesiologica Sinica 1988; Vol. 26, issue 2:169-72. [PUBMED: 3185166]

\section{Huang 2005 \{published data only\}}

Huang GH, Davidson AJ, Stargatt R. Dreaming during anaesthesia in children: incidence, nature and associations. Anaesthesia 2005;60(9):854-61. [PUBMED: 16115245]

Hudetz 2007 \{published data only\}

Hudetz JA, Iqbal Z, Gandhi SD, Patterson KM, Hyde TF, Reddy DM, et al. Postoperative cognitive dysfunction in older patients with a history of alcohol abuse. Anesthesiology 2007;106(3):423-30. [PUBMED: 17325499]

\section{Hughes 1994 \{published data only\}}

Hughes JA, Sanders LD, Dunne JA, Tarpey J, Vickers MD. Reducing smoking. The effect of suggestion during general anaesthesia on postoperative smoking habits. Anaesthesia 1994;49(2):126-8. [PUBMED: 7864913]

Hughes 2009 \{published data only\}

Hughes TF. Modifiable midlife risk factors for late-life cognitive impairment and dementia. Current Psychiatry Review 2009;5(2):73-92. [PUBMED: 19946443]

\section{Hutchinson 1960 \{published data only\}}

Hutchinson R. Awareness during surgery. A study of its incidence. British Journal of Anaesthesia 1960;33:463-9. [PUBMED: 14450247]

\section{Iannuzzi 2005 \{published data only\}}

lannuzzi M, lannuzzi E, Rossi F, Berrino L, Chiefari M. Relationship between bispectral index, electroencephalographic state entropy and effect-site EC50 for propofol at different clinical endpoints. British Journal of Anaesthesia 2005; Vol. 94, issue 5:613-6. [PUBMED: 15734785]

\section{Ibrahim 2001a \{published data only\}}

Ibrahim AE, Ghoneim MM, Kharasch ED, Epstein RH, Groudine SB, Ebert TJ, et al. Speed of recovery and side-effect profile of sevoflurane sedation compared with midazolam. Anesthesiology 2001; Vol. 94, issue 1:87-94. [PUBMED: 11135727]

\section{Ibrahim 2001b \{published data only\}}

Ibrahim AE, Taraday JK, Kharasch ED. Bispectral index monitoring during sedation with sevoflurane, midazolam, and propofol. Anesthesiology 2001; Vol. 95, issue 5:1151-9. [PUBMED: 11684984]

\section{Inagaki 1997 \{published data only\}}

Inagaki Y, Shindo H, Mashimo T, Yoshiya I. The effects of epidural fentanyl on hemodynamic responses during emergence from isoflurane anesthesia and tracheal extubation: a comparison with intravenous fentanyl. Anesthesia and Analgesia 1997;85(2):328-35. [PUBMED: 9249109] 
Ingelmo 2007 \{published data only\}

Ingelmo PM, Bendall EJ, Frawley G, Locatelli BG, Milan B, Lodetti D, et al. Bupivacaine caudal epidural anesthesia: Assessing the effect of general anesthetic technique on block onset. Paediatric Anaesthesia 2007;17(3):255-62. [PUBMED: 17263741]

Inglis 1993 \{published data only\}

Inglis S, Farnill D. The effects of providing preoperative statistical anaesthetic-risk information. Journal Anaesthesia Intensive Care 1993; Vol. 21, issue 6:799-805. [PUBMED: 8122737]

\section{Iqbal 1985 \{published data only\}}

Iqbal KM, Hussain P, Afzalunnessa B. Study of awareness during noninhalational anaesthesia. Bangladesh Medical Research Council Bulletin 1985; Vol. 11, issue 1:8-14. [PUBMED: 4026761]

\section{Iselin-Chaves 1998 \{published data only\}}

Iselin-Chaves IA, Flaishon R, Sebel PS, Howell S, Gan TJ, Sigl J, et al. The effect of the interaction of propofol and alfentanil on recall, loss of consciousness, and the Bispectral Index. Anesthesia and Analgesia 1998; Vol. 87, issue 4:949-55. [PUBMED: 9768800]

\section{Iselin-Chaves 2000 \{published data only\}}

Iselin-Chaves IA, El Moalem HE, Gan TJ, Ginsberg B, Glass PS. Changes in the auditory evoked potentials and the bispectral index following propofol or propofol and alfentanil. Anesthesiology 2000; Vol. 92, issue 5:1300-10. [PUBMED: 10781275]

\section{Iselin-Chaves 2005 \{published data only\}}

Iselin-Chaves IA, Willems SJ, Jermann FC, Forster A, Adam SR, Van der Linden M. Investigation of implicit memory during isoflurane anesthesia for elective surgery using the process dissociation procedure. Anesthesiology 2005; Vol. 103, issue 5:925-33. [PUBMED: 16249665]

\section{Ishiyama 2005 \{published data only\}}

Ishiyama T, Kashimoto S, Oguchi T, Yamaguchi T, Okuyama K, Kumazawa T. Epidural ropivacaine anesthesia decreases the bispectral index during the awake phase and sevoflurane general anesthesia. Anesthesiology 2005;100(3):728-32. [PUBMED: 15728060]

\section{Isomura 2008 \{published data only\}}

Isomura $\mathrm{H}$, Hashiguchi K. Combination of dexmedetomidine and midazolam is useful for postoperative sedation in healthyyoung patients. Nippon Shika Masui Gakkai Zasshi [The Journal of the Japanese Dental Society of Anesthesiology] 2008;36(1):28-32.

\section{Ittichaikulthol 2007 \{published data only\}}

Ittichaikulthol W, Sriswasdi S, Prachanpanich N, Watcharotayangul J, Seangrung R, Sithamwilai W. Bispectral index in assessment of 3\% and 4.5\% desflurane in 50\% N2O for caesarean section. Journal of the Medical Association of Thailand 2007;90(8):1546-50.

\section{Ivanov 1969 \{published data only\}}

Ivanov SD, Nunn JF. Methods of evaluation of PCO2 for restoration of spontaneous breathing after artificial ventilation of anaesthetized patients. British Journal of Anaesthesia 1969; Vol. 41, issue 1:28-37. [PUBMED: 5774302]

\section{Jacoby 1981 \{published data only\}}

Jacoby LL, Dallas M. On the relationship between autobiographical memory and perceptual learning. Journal of Experimental Psychology. General 1981; Vol. 110, issue 3:306-40. [PUBMED: 6457080]

\section{Jaffrelot 2007 \{published data only\}}

Jaffrelot M, Jendrin J, Floch Y, Lockey D, Jabre P, Vergne M, et al. Prevention of awakening signs after rapid-sequence intubation: a randomized study. American Journal of Emergency Medicine 2007;25(5):529-34. [PUBMED: 17543656]

\section{Jeleazcov 2007 \{published data only\}}

Jeleazcov C, Schmidt J, Schmitz B, Becke K, Albrecht S. EEG variables as measures of arousal during propofol anaesthesia for general surgery in children: rational selection and age dependence. British Journal of Anaesthesia 2007;99(6):845-54. [PUBMED: 17965418]

\section{Jelicic 1993a \{published data only\}}

Jelicic M, Bonke B, Millar K. Effect of different therapeutic suggestions presented during anaesthesia on post-operative course. European Journal of Anaesthesia 1993;10(10):343-7. [PUBMED: 11767423]

\section{Jelicic 1993b \{published data only\}} Jelicic M, Asbury AJ, Millar K, Bonke B. Implicit learning during enflurane anaesthesia in spontaneously breathing patients? Anaesthesia 1993;48(9):766-8. [PUBMED: 8214493]

\section{Jellish 2000 \{published data only\}}

Jellish WS, Leonetti JP, Avramov A, Fluder E, Murdoch J. Remifentanil-based anesthesia versus a propofol technique for otologic surgical procedures. Otolaryngology and Head and Neck Surgery 2000; Vol. 122, issue 2:222-7. [PUBMED: 10652394]

Jellish 2009 \{published data only\}

Jellish WS, Leonetti JP, Buoy CM, Sincacore JM, Sawicki KJ, Macken MP. Facial nerve electromyographic monitoring to predict movement in patients titrated to a standard anesthetic depth. Anesthesia and Analgesia 2009;109(2):551-8. [PUBMED: 19608831]

\section{Jensen 1996 \{published data only\}}

Jensen EW, Lindholm P, Henneberg SW. Autoregressive modeling with exogenous input of middle-latency auditory-evoked potentials to measure rapid changes in depth of anesthesia. Methods of Information in Medicine 1996;35(3):256-60. [PUBMED: 8952311]

\section{Jeon 2000 \{published data only\}}

Jeon SY, Lim HJ. Awareness detection during a cesarean section under general anesthesia using bispectral index monitoring. Daehan Machwigwa Haghoeji [Society of Anesthesiologists] 2000:39:632-7. 


\section{Jessop 1991 \{published data only\}}

Jessop J, Griffiths DE, Furness P, Jones JG, Sapsford DJ, Breckon DA. Changes in amplitude and latency of the P300 component of the auditory evoked potential with sedative and anaesthetic concentrations of nitrous oxide. British Journal of Anaesthesia 1991; Vol. 67, issue 5:524-31. [PUBMED: 1751264]

\section{Jones 1990 \{published data only\}}

Jones MJ, Piggott SE, Vaughan RS, Bayer AJ, Newcombe RG, Twining TC, et al. Cognitive and functional competence after anaesthesia in patients aged over 60: controlled trial of general and regional anaesthesia for elective hip or knee replacement. BMJ 1990; Vol. 300, issue 6741:1683-7. [PUBMED: 2390547]

\section{Jordan 2012 \{published data only\}}

Jordan D, Schneider G, Omerovic A, Kreuzer M, Berger S, Kochs E. Reliability to detect wakefulness and burst suppression: a new anesthesia multimodal indicator and bis. Journal of Neurosurgical Anesthesiology 2012:480-1.

\section{Jospin 2007 \{published data only\}}

Jospin M, Caminal P, Jensen EW, Litvan H, Vallverdu M, Struys MMRF, et al. Detrended fluctuation analysis of EEG as a measure of depth of anesthesia. IEEE Transactions on Biomedical Engineering 2007;54(5):840-6. [PUBMED: 17518280]

\section{Juckenhofel 1999 \{published data only\}}

Juckenhofel S, Feisel C, Schmitt HJ, Biedler A. TIVA with propofol-remifentanil or balanced anesthesia with sevoflurane-fentanyl in laparoscopic operations. Hemodynamics, awakening and adverse effects. Anaesthesist 1999;48(11):807-12. [PUBMED: 10631440]

\section{Katoh 1993 \{published data only\}}

Katoh T, Suguro Y, Kimura T, Ikeda K. Morphine does not affect the awakening concentration of sevoflurane. Canadian Journal Anaesthesia 1993;40(9):825-8. [PUBMED: 8403176]

\section{Katoh 1994 \{published data only\}}

Katoh T, Uchiyama T, Ikeda K. Effect of fentanyl on awakening concentration of sevoflurane. British Journal of Anaesthesia 1994;73(3):322-5. [PUBMED: 7946857]

\section{Kavey 1979 \{published data only\}}

Kavey NB, Ahshuler KZ. Sleep in herniorrhaphy patients. American Journal of Surgery 1979; Vol. 138, issue 5:683-7. [PUBMED: 227283]

\section{Kennedy 1985 \{published data only\}}

Kennedy DJ, Ogg TW. Alfentanil and memory function. A comparison with fentanyl for day case termination of pregnancy. Anaesthesia 1985;40(6):537-40. [PUBMED: 3927763]

\section{Kenny 1999 \{published data only\}}

Kenny GN, Mantzaridis H. Closed-loop control of propofol anaesthesia. British Journal of Anaesthesia 1999; Vol. 83, issue 2:223-8. [PUBMED: 10618933]

\section{Kerssens 2002 \{published data only\}}

Kerssens C, Lubke GH, Klein J, van der Woerd A, Bonke B. Memory function during propofol and alfentanil anesthesia: predictive value of individual differences. Anesthesiology 2002; Vol. 97, issue 2:382-9. [PUBMED: 12151928]

Kerssens 2003 \{published data only\}

Kerssens C, Klein J, Bonke B. Awareness: monitoring versus remembering what happened. Anesthesiology 2003; Vol. 99, issue 3:570-5. [PUBMED: 12960540]

\section{Kerssens 2005a \{published data only\}}

Kerssens C, Hamann S, Peltier S, Hu XP, Byas-Smith MG, Sebel PS. Attenuated brain response to auditory word stimulation with sevoflurane: a functional magnetic resonance imaging study in humans. Anesthesiology 2005; Vol. 103, issue 1:11-9. [PUBMED: 15983451]

\section{Kertai 2011 \{published data only\}}

Kertai MD, Palanca BJ, Pal N, Burnside BA, Zhang L, Sadiq F, et al. Bispectral index monitoring, duration of bispectral index below 45, patient risk factors, and intermediate-term mortality after noncardiac surgery in the B-Unaware Trial. Anesthesiology 2011;114(3):545-56. [PUBMED: 21293252]

\section{Kestin 1990 \{published data only\}}

Kestin IG, Harvey PB, Nixon C. Psychomotor recovery after three methods of sedation during spinal anaesthesia. British Journal of Anaesthesia 1990; Vol. 64, issue 6:675-81. [PUBMED: 2116156]

\section{Kevin 2002 \{published data only\}}

Kevin LG, Cunningham AJ, Bolger C. Comparison of ocular microtremor and bispectral index during sevoflurane anaesthesia. British Journal of Anaesthesia 2002; Vol. 89, issue 4:551-5. [PUBMED: (Print)12393354]

\section{Khandwala 2008 \{published data only\}}

Khandwala M, Ahmed S, Goel S, Simmons IG, McLure HA. The effect of hyaluronidase on ultrasound-measured dispersal of local anaesthetic following sub-Tenon injection. Eye (London, England) 2008;22(8):1065-8. [PUBMED: 17525774]

\section{Kiernan 1995 \{published data only\}}

Kiernan BD, Dane JR, Phillips LH, Price DD. Hypnotic analgesia reduces $\mathrm{R}$-III nociceptive reflex: further evidence concerning the multifactorial nature of hypnotic analgesia. Pain 1995; Vol. 60, issue 1:39-47. [PUBMED: 7715940]

\section{Kim 1978 \{published data only\}}

Kim CL. Awareness during cardiopulmonary bypass. American Association of Nurse Anesthetists Journal 1978; Vol. 46, issue 4:373-83. [PUBMED: 362790]

Kim 2010 \{published data only\}

Kim HT, Heo HE, Kwon YE, Lee MJ. Effect of remifentanil on consumption of sevoflurane in entropy monitored general anesthesia. Korean Journal of Anesthesiology 2010;59(4):238-43. [PUBMED: 21057612]

\section{Kliempt 1999 \{published data only\}}

Kliempt P, Ruta D, Ogston S, Landeck A, Martay K. Hemisphericsynchronisation during anaesthesia: a double-blind randomised trial using audiotapes for intra-operative 
nociception control. Anaesthesia 1999; Vol. 54, issue 8:769-73. [PUBMED: 10460529]

\section{Kocaman 2007 \{published data only\}}

Kocaman Akbay B, Demiraran Y, Sezen GY, Akcali G, Somunkiran A. Use of the bispectral index to predict a positive awareness reaction to laryngeal mask airway-Fastrach insertion and intubation. Acta Anaesthesiologica Scandinavica 2007;51(10):1368-72. [PUBMED: 17944640]

Kokki 2007 \{published data only\}

Kokki, H, Wennervirta J, Laisalmi M, Vakkuri A. Regular tramadol use does not effect the propofol dose requirement for induction of anaesthesia. European Journal of Anaesthesiology 2007;24(9):776-81. [PUBMED: 17462119]

Kotiniemi 1996 \{published data only\}

Kotiniemi LH, Ryhanen PT, Moilanen IK. Behavioural changes and children's memories after intravenous, inhalation and rectal induction of anaesthesia. Paediatric Anaesthesia 1996;6(3):201-7. [PUBMED: 8732611]

\section{Kreuer 2001 \{published data only\}}

Kreuer, S, Biedler A, Larsen R, Schoth S, Altmann S, Wilhelm W. The Narcotrend--a new EEG monitor designed to measure the depth of anaesthesia. A comparison with bispectral index monitoring during propofol-remifentanil-anaesthesia. Der Anaesthesist 2001;50(12):921-5. [PUBMED: 11824075]

\section{Lapidus 2007 \{published data only\}}

Lapidus LJ, Rosfors S, Ponzer S, Levander C, Elvin A, Larfars G, et al. Prolonged thromboprophylaxis with dalteparin after surgical treatment of achilles tendon rupture: a randomized, placebo-controlled study. Journal of Orthopaedic Trauma 2007;21(1):52-7. [PUBMED: 17211270]

\section{Latto 1977 \{published data only\}}

Latto IP, Waldron BA. Anaesthesia for Caesarean section. Analysis of blood concentrations of halothane using $0.2 \%$ or $0.65 \%$ halothane with $50 \%$ nitrous oxide in oxygen. British Journal of Anaesthesia 1977;49(4):371-8. [PUBMED: 889651]

\section{Lefoll-Masson 2007 \{published data only\}}

Lefoll-Masson C, Fermanian C, Aime I, Verroust N, Taylor G, Laloe PA, et al. The comparability of bispectral index and state entropy index during maintenance of sufentanilsevoflurane-nitrous oxide anesthesia. Anesthesia and Analgesia 2007;105(5):1319-25, table of contents. [PUBMED: 17959961]

\section{Lehmann 2000 \{published data only\}}

Lehmann A, Zeitler C, Thaler E, Isgro F, Boldt J. Comparison of two different anesthesia regimens in patients undergoing aortocoronary bypass grafting surgery: sufentanil-midazolam versus remifentanil-propofol. Retractions. [J Cardiothorac Vasc Anesth. 2011]. Journal of Cardiothoracic and Vascular Anesthesia 2000;14(4):416-20. [PUBMED: 10972607]

\section{Lehmann 2002 \{published data only\}}

Lehmann A, Boldt J, Thaler E, Piper S, Weisse U. Bispectral index in patients with target-controlled or manually-controlled infusion of propofol. Retraction in Bispectral index in patients with target-controlled or manually-controlled infusion of propofol: Retraction. [Anesth Analg. 2011]. Anesthesia and Analgesia 2002;95(3):638-44. [PUBMED: 12198052]

Lehmann 2003 \{published data only\}

Lehmann A, Karzau J, Boldt J, Thaler E, Lang J, Isgro F. Bispectral index-guided anesthesia in patients undergoing aortocoronary bypass grafting. Retraction inBispectral indexguided anesthesia in patients undergoing aortocoronary bypass grafting: Retraction. [Anesth Analg. 2011]. Anaesthesia and Analgesia 2003;96:336-43. [PUBMED: 12538174]

Lequeux 2003 \{published data only\}

Lequeux PY, Cantraine F, Levarlet M, Barvais L. Absence of explicit and implicit memory in unconscious patients using a TCl of propofol. Acta Anaesthesiologica Scandinavica 2003;47(7):833-7. [PUBMED: 12859304]

Leslie 2007 \{published data only\}

Leslie K, Skrzypek H, Paech MJ, Kurowski I, Whybrow T. Dreaming during anesthesia and anesthetic depth in elective surgery patients: a prospective cohort study. Anesthesiology 2007;106(1):33-42. [PUBMED: 17197843]

\section{Levine 1993 \{published data only\}}

Levine MF, Hartley EJ, Macpherson BA, Burrows FA, Lerman J. Oral midazolam premedication for children with congenital cyanotic heart disease undergoing cardiac surgery: a comparative study. Canadian Journal of Anaesthesia 1993;40(10):934-8. [PUBMED: 8222032]

\section{Liao 2010 \{published data only\}}

Liao R, Li JY, Liu GY. Comparison of sevoflurane volatile induction/maintenance anaesthesia and propofol-remifentanil total intravenous anaesthesia for rigid bronchoscopy under spontaneous breathing for tracheal/bronchial foreign body removal in children. European Journal of Anaesthesiology 2010;27(11):930-4. [PUBMED: 20683333]

\section{Liou 1994 \{published data only\}}

Liou CM, Kang HM, Lai HC, Liu YC, Hung CJ, Wang SJ, et al. Will epidural with light general anesthesia increase the incidence of awareness with recall or dream postoperatively. Acta Anaesthesiologica Sinica 1994;32(4):229-36. [PUBMED: 7894918]

\section{Liu 2005 \{published data only\}}

Liu N, Chazot T, Huybrechts I, Law-Koune JD, Barvais L, Fischler M. The influence of a muscle relaxant bolus on bispectral and datex-ohmeda entropy values during propofolremifentanil induced loss of consciousness. Anesthesia and Analgesia 2005;101(6):1713-8. [PUBMED: 16301247]

\section{Liu 2006 \{published data only\}}

Liu N, Chazot T, Genty A, Landais A, Restoux A, McGee K, et al. Titration of propofol for anesthetic induction and maintenance guided by the bispectral index: closed-loop versus manual control: a prospective, randomized, multicenter study. Anesthesiology 2006;104:686-95. [PUBMED: 16571963] 
Liu 2009 \{published data only\}

Liu SH, Wei W, Ding GN, Ke JD, Hong FX, Tian M. Relationship between depth of anesthesia and effect-site concentration of propofol during induction with the target-controlled infusion technique in elderly patients. Chinese Medical Journal 2009;122(8):935-40. [PUBMED: 19493418]

\section{Lopez 2007 \{published data only\}}

Lopez U, Habre W, Laurencon M, Haller G, Van der Linden M, Iselin-Chaves IA. Intra-operative awareness in children: the value of an interview adapted to their cognitive abilities. Anaesthesia 2007;62(8):778-89. [PUBMED: 17635425]

\section{Low 2007 \{published data only\}}

Low D, Ng I, Ng WH. Awake craniotomy under local anaesthesia and monitored conscious sedation for resection of brain tumours in eloquent cortex--outcomes in 20 patients. Annals of the Academy of Medicine, Singapore 2007;36(5):326-31. [PUBMED: 17549278]

\section{Luginbuhl 2007 \{published data only\}}

Luginbuhl M, Ypparila Wolters H, Rufenacht M, Petersen Felix S, Korhonen I. Heart rate variability does not discriminate between different levels of haemodynamic responsiveness during surgical anaesthesia. British Journal of Anaesthesia 2007;98(6):728-36. [PUBMED: 17468493]

\section{Luginbuhl 2010 \{published data only\}}

Luginbühl M, Schumacher PM, Vuilleumier P, Vereecke H, Heyse B, Bouillon TW, et al. Noxious stimulation response index: a novel anesthetic state index based on hypnotic-opioid interaction. Anesthesiology 2010;112(3):872-80. [PUBMED: 20216387]

\section{Lyons 1991 \{published data only\}}

Lyons G, Macdonald R. Awareness during caesarean section. Anaesthesia 1991;46(1):62-4. [PUBMED: 1996761]

\section{Magni 2009 \{published data only\}}

Magni G, Rosa IL, Melillo G, Savio A, Rosa G. A comparison between sevoflurane and desflurane anesthesia in patients undergoing craniotomy for supratentorial intracranial surgery. Anesthesia and Analgesia 2009;109(2):567-71. [PUBMED: 19608833]

\section{Mahomedy 1976 \{published data only\}}

Mahomedy MC, Downing JW, Jeal DE, Allen PJ. Ketamine for anaesthetic induction at Caesarean section. South African Medical Journal 1976;50(22):846-8. [PUBMED: 935971]

\section{Malek 2009 \{published data only\}}

Malek J, Hess L, Votava M, Marecek F, Kurzova A. The combination of dexmedetomidine, fentanyl, midazolam and atropine may result in dangerous respiratory depression and hypoxemia. European Journal of Anaesthesiology 2009;26(Suppl 45):136.

\section{Malek 2010 \{published data only\}}

Malek B, Seghlis R, Dabbagh A. Awareness during anesthesia in elective abdominal surgery in opium abusers. Tehran University Medical Journal 2010;67(10):731-5.

\section{Malviya 2009 \{published data only\}}

Malviya S, Galinkin JL, Bannister CF, Burke C, Zuk J, Popenhagen $\mathrm{M}$, et al. The incidence of intraoperative awareness in children: childhood awareness and recall evaluation. Anesthesia and Analgesia 2009;109(5):1421-7. [PUBMED: 19713260]

\section{Martorano 2008 \{published data only\}}

Martorano PP, Aloj F, Baietta S, Fiorelli A, Munari M, Paccagnella F, et al. Sufentanil-propofol vs remifentanilpropofol during total intravenous anesthesia for neurosurgery. A multicentre study. Minerva Anestesiologica 2008;74(6):233-43.

\section{Mathews 2008 \{published data only\}}

Mathews DM, Gaba V, Zaku B, Neuman GG. Can remifentanil replace nitrous oxide during anesthesia for ambulatory orthopedic surgery with desflurane and fentanyl?. Anesthesia and Analgesia 2008;106(1):101-8, table of contents. [PUBMED: 18165562]

\section{Maybauer 2007 \{published data only\}}

Maybauer DM, Geldner G, Blobner M, Puhringer F, Hofmockel R, Rex $C$, et al. Incidence and duration of residual paralysis at the end of surgery after multiple administrations of cisatracurium and rocuronium. Anaesthesia 2007;62(1):12-7. [PUBMED: $17156221]$

\section{Mayer 2007 \{published data only\}}

Mayer J, Boldt J, Schellhaass A, Hiller B, Suttner SW. Bispectral index-guided general anesthesia in combination with thoracic epidural analgesia reduces recovery time in fasttrack colon surgery. Retraction in Bispectral index-guided general anesthesia in combination with thoracic epidural analgesia reduces recovery time in fast-track colon surgery: Retraction. [Anesth Analg. 2011]. Anesthesia and Analgesia 2007;104(5):1145-9, tables of contents. [PUBMED: 17456665]

\section{Mellema 2010 \{published data only\}}

Mellema A, Borner M, Joppich R, Burmester S, Schutte JK, Wappler F. Comparison of inhalational versus intravenous anaesthetic techniques for elective spinal surgery under comparable anaesthetic depth using BIS monitoring. A randomized, prospective, clinical trial. Perioperative Medizin 2010;2(2):86-93.

\section{Messahel 2003 \{published data only\}}

Messahel FM, Al-Qahtani AS. Awareness during surgery. Saudi Medical Journal 2003;24(9):967-70. [PUBMED: 12973479]

\section{Messahel 2007 \{published data only\}}

Messahel FM, Gregorio MJ. Intraoperative awareness--a three year prospective study using bispectral index monitor (BIS). Middle East Journal of Anesthesiology 2007;19(3):587-94. [PUBMED: 18044286]

\section{Mi 1998 \{published data only\}}

Mi WD, Sakai T, Takahashi S, Matsuki A. Haemodynamic and electroencephalograph responses to intubation during induction with propofol or propofol/fentanyl. Canadian Journal of Anaesthesia 1998; Vol. 45:19-22. [PUBMED: 9466021] 
Mi 1999 \{published data only\}

Mi WD, Sakai T, Singh H, Kudo T, Kudo M, Matsuki A. Hypnotic endpoints vs. the bispectral index, 95\% spectral edge frequency and median frequency during propofol infusion with or without fentanyl. European Journal of Anaesthesiology 1999;16(1):47-52. [PUBMED: 10084101]

\section{Mirakhur 1986 \{published data only\}}

Mirakhur RK, Lavery GG, Gibson FM, Clarke RS. Intubating conditions after vecuronium and atracurium given in divided doses (the priming technique). Acta Anaesthesiologica Scandinavica 1986;30(5):347-50. [PUBMED: 2876574]

\section{Moerman 1995 \{published data only\}}

Moerman A, Herregods L, Foubert L, Poelaert J, Jordaens L, D'Hont $L$, et al. Awareness during anaesthesia for implantable cardioverter defibrillator implantation. Recall of defibrillation shocks. Anaesthesia 1995; Vol. 50, issue 8:733-5. [PUBMED: 7645710]

\section{Motsch 1996 \{published data only\}}

Motsch J, Wandel C, Neff S, Martin E. A comparative study of the use of sevoflurane and propofol in ambulatory surgery. Der Anaesthesist 1996;45(Suppl 1):57-62. [PUBMED: 8775105]

\section{Mourisse 2007 \{published data only\}}

Mourisse J, Lerou J, Struys M, Zwarts M, Booij L. Multi-level approach to anaesthetic effects produced by sevoflurane or propofol in humans: 1. BIS and blink reflex. British Journal of Anaesthesia 2007;98(6):737-45. [PUBMED: 17519261]

\section{Moustafa 2008 \{published data only\}}

Moustafa AM, Negmi HH, Rabie ME. The combined effect of ketamine and remifentanil infusions as total intravenous anesthesia for scoliosis surgery in children. Middle East Journal of Anesthesiology 2008;19(5):1151-68. [PUBMED: 18637615]

\section{Nakagawa 2001 \{published data only\}}

Nakagawa M, Mammoto T, Sakai T, Kishi Y, Mashimo T. Premedication modifies the quality of sedation with propofol during regional anesthesia. Canadian Journal of Anaesthesia 2001;48(3):284-7. [PUBMED: 11305831]

\section{Nelskyla 2001 \{published data only\}}

Nelskyla KA, Yli-Hankala AM, Puro PH, Korttila KT. Sevoflurane titration using bispectral index decreases postoperative vomiting in phase II recovery after ambulatory surgery. Anesthesia and Analgesia 2001;93(5):1165-9. [PUBMED: 11682388]

\section{Ng 1974 \{published data only\}}

$\mathrm{Ng} \mathrm{KH}$, Gurubatham Al. Awareness during caesarean section under general anaesthesia. Medical Journal of Australia 1974;2 (21):774-6. [PUBMED: 4453236]

\section{Nishijima 1999 \{published data only\}}

Nishijima S, Konno M, Sakurada H. The effects of propofol anesthesia with or without the use of nitrous oxide on the intraoperative involuntary movement, the postoperative awareness and vomiting. Masui 1999;48(11):1216-9. [PUBMED: 10586554]

\section{O'Sullivan 1988 \{published data only\}}

O'Sullivan EP, Childs D, Bush GH. Peri-operative dreaming in paediatric patients who receive suxamethonium. Anaesthesia 1988;43(2):104-6. [PUBMED: 3190825]

\section{Oikkonen 1994 \{published data only\}}

Oikkonen M. Propofol vs isoflurane for gynaecological laparoscopy. Acta Anaesthesiologica Scandinavica 1994;38(2):110-4. [PUBMED: 8171944]

Onaka 1998 \{published data only\}

Onaka M, Yamamoto H, Akatsuka M, Mori H. Anesthetic management by continuous total intravenous anesthesia. Masui 1998;47(10):1200-6. [PUBMED: 9834591]

Oudenaarden 1979 \{published data only\}

Oudenaarden JJ. Etomidate as an induction agent in minor operative procedures. Current Medical Research and Opinion 1979;6(1):30-4. [PUBMED: 378555]

\section{Padmanabhan 2009 \{published data only\}}

Padmanabhan U, Leslie K, Eer AS, Maruff P, Silbert BS. Early cognitive impairment after sedation for colonoscopy: the effect of adding midazolam and/or fentanyl to propofol. Anesthesia and Analgesia 2009;109(5):1448-55. [PUBMED: 19617584]

\section{Panousis 2007 \{published data only\}}

Panousis P, Heller AR, Burghardt M, Bleyl JU, Koch T. The effects of electromyographic activity on the accuracy of the Narcotrend monitor compared with the Bispectral Index during combined anaesthesia. Anaesthesia 2007;62(9):868-74. [PUBMED: 17697211]

\section{Philbin 1990 \{published data only\}}

Philbin DM, Rosow CE, Schneider RC, Koski G, D'Ambra MN. Fentanyl and sufentanil anesthesia revisited: how much is enough?. Anesthesiology 1990;73(1):5-11. [PUBMED: 2141773]

\section{Philipp 2002 \{published data only\}}

Philipp A, Wiesenack C, Behr R, Schmid FX, Birnbaum DE. High risk of intraoperative awareness during cardiopulmonary bypass with isoflurane administration via diffusion membrane oxygenators. Perfusion 2002;17(3):175-8.

\section{Piano 2007 \{published data only\}}

Piano G, Ketteler ER, Prachand V, DeValk E, Van Ha TG, Gewertz BL, et al. Safety, feasibility, and outcome of retrievable vena cava filters in high-risk surgical patients. Journal of Vascular Surgery 2007;45(4):784-8. [PUBMED: 17398387]

\section{Pomfrett 2009 \{published data only\}}

Pomfrett CJ, Dolling S, Anders NR. Delta sleep-inducing peptide alters bispectral index, the electroencephalogram and heart rate variability when used as an adjunct to isoflurane anaesthesia. European Journal of Anaesthesiology 2009;26(2):128-34. [PUBMED: 19142086]

Pompeo 2007 \{published data only\}

Pompeo E, Tacconi F, Mineo D, Mineo TC. The role of awake video-assisted thoracoscopic surgery in spontaneous 
pneumothorax. Journal of Thoracic and Cardiovascular Surgery 2007;133(3):786-90. [PUBMED: 17320585]

\section{Porter 2008 \{published data only\}}

Porter R, Booth D, Gray H, Frampton C. Effects of the addition of remifentanil to propofol anesthesia on seizure length and postictal suppression index in electroconvulsive therapy. Journal of ECT 2008;24(3):203-7. [PUBMED: 18772705]

\section{Pryor 2010 \{published data only\}}

Pryor KO, Reinsel RA, Mehta M, Li Y, Wixted JT, Veselis RA. Visual P2-N2 complex and arousal at the time of encoding predict the time domain characteristics of amnesia for multiple intravenous anesthetic drugs in humans. Anesthesiology 2010;113(2):313-26. [PUBMED: 20613477]

\section{Qi 2014 \{published data only\}}

Qi S, Wu X Q, Lu X B. Application of transcutaneous electrical acupoint stimulation combined with infusion of propofol in anodynia bronchoscopy. Zhongguo Zhen Jiu [Chinese Acupuncture \& Moxibustion] 2014;NA:483-6.

Rabiee 2012 \{published data only\}

Rabiee SM, Alijanpour E, Naziri F, Alreza H, Esmaeili V. A comparison of depth of anesthesia and hemodynamic variables with sodium thiopental and propofol as induction agents for cesarean section. Journal of Babol University of Medical Sciences 2012:7-12.

\section{Reinhart 1985 \{published data only\}}

Reinhart K, Dallinger-Stiller G, Dennhardt R, Heinemeyer G, Eyrich K. Comparison of midazolam, diazepam and placebo i.m. as premedication for regional anaesthesia. A randomized double-blind study. British Journal of Anaesthesia 1985;57(3):294-9. [PUBMED: 3156614]

\section{Russell 1997 \{published data only\}}

Russell IF, Wang M. Absence of memory for intraoperative information during surgery under adequate general anaesthesia. British Journal of Anaesthesia 1997;78(1):3-9. [PUBMED: 9059196 ]

\section{Russell 2001 \{published data only\}}

Russell IF, Wang M. Absence of memory for intra-operative information during surgery with total intravenous anaesthesia. British Journal of Anaesthesia 2001;86(2):196-202. [PUBMED: 11573659]

\section{Samuelsson 2007 \{published data only\}}

Samuelsson P, BruDin L, Sandin RH. Late psychological symptoms after awareness among consecutively included surgical patients. Anesthesiology 2007;106(1):26-32. [17197842]

\section{Schneider 2005 \{published data only\}}

Schneider G, Hollweck R, Ningler M, Stockmanns G, Kochs EF. Detection of consciousness by electroencephalogram and auditory evoked potentials. Anesthesiology 2005;103(5):934-43. [PUBMED: 16249666]

\section{Schraag 1998 \{published data only\}}

Schraag S, Mohl U, Bothner U, Georgieff M. Clinical utility of EEG parameters to predict loss of consciousness and response to skin incision during total intravenous anaesthesia. Anaesthesia 1998;53(4):320-5. [PUBMED: 9613295]

Schroeck 2010 \{published data only\}

Schroeck H, Fecho K, Abode K, Bailey A. Vocal cord function and bispectral index in pediatric bronchoscopy patients emerging from propofol anesthesia. Pediatric Pulmonology 2010;45(5):494-9. [PUBMED: 20425858]

Schulz 2007 \{published data only\}

Schulz U, Keh D, Barner C, Kaisers U, Boemke W. Bispectral index monitoring does not improve anesthesia performance in patients with movement disorders undergoing deep brain stimulating electrode implantation. Anesthesia and Analgesia 2007;104(6):1481-7, table of contents. [PUBMED: 17513646]

Schwender 1991a \{published data only\}

Schwender D, Keller I, Schlund M, Klasing S, Madler C. Acoustic evoked potentials of medium latency and intraoperative wakefulness during anesthesia maintenance using propofol, isoflurane and flunitrazepam/fentanyl. Anaesthesist 1991;40(4):214-21. [PUBMED: 2058823]

\section{Schwender 1991b \{published data only\}}

Schwender D, Keller I, Daschner B, Madler C. Sensory information processing during general anesthesia-- acousticevoked $30-40 \mathrm{~Hz}$ oscillations and intraoperative wakefulness during cesarean section [Sensorische Informationsverarbeitung wahrend Allgemeinanasthesie--Akustisch evozierte $30-40 \mathrm{~Hz}-$ Oszillation und intraoperative Aufwachreaktion wahrend Sectio caesarea]. Anasthesiologie, Intensivmedizin, Notfallmedizin, Schmerztherapie: AINS 1991;26(1):17-24. [PUBMED: 1863679]

\section{Schwender 1993 \{published data only\}}

Schwender D, Muller A, Madler M, Faber-Zullig E, Ilmberger J. Recovery of psychomotor and cognitive functions following anesthesia. Propofol/alfentanil and thiopental/isoflurane/ alfentanil. Anaesthesist 1993;42(9):583-91. [PUBMED: 8214530]

\section{Schwender 1994 \{published data only\}}

Schwender D, Faber-Zullig E, Klasing S, Poppel E, Peter K. Motor signs of wakefulness during general anaesthesia with propofol, isoflurane and flunitrazepam/fentanyl and midlatency auditory evoked potentials. Anaesthesia 1994;49(6):476-84. [PUBMED: 8017589]

\section{Schwender 1997 \{published data only\}}

Schwender D, Daunderer M, Mulzer S, Klasing S, Finsterer U, Peter K. Midlatency auditory evoked potentials predict movements during anesthesia with isoflurane or propofol. Anesthesia and Analgesia 1997;85(1):164-73. [PUBMED: 9212142]

\section{Schwieger 1989 \{published data only\}}

Schwender D, Faber-Zullig E, Klasing S, Poppel E, Peter K. Motor signs of wakefulness during general anaesthesia with propofol, isoflurane and flunitrazepam/fentanyl and midlatency auditory 
evoked potentials. Anaesthesia 1994;49(6):476-84. [PUBMED: 8017589]

Schwieger IM, Hug CCJ, Hall RI, Szlam F. Is lower esophageal contractility a reliable indicator of the adequacy of opioid anesthesia?. Journal of Clinical Monitoring 1989;5(3):164-9. [PUBMED: 2769314]

\section{Schwieger 1991 \{published data only\}}

Schwieger IM, Hall RI, Hug CCJ. Assessing the adequacy of fentanyl anesthesia: plasma concentrations and lower esophageal contractility. Acta Anaesthesiologica Scandinavica 1991;35(3):227-34. [PUBMED: 2038929]

\section{See 2007 \{published data only\}}

See JJ, Lew TWK, Kwek TK, Chin KJ, Wong MFM, Liew QY, et al. Anaesthetic management of awake craniotomy for tumour resection. Annals of the Academy Medicine, Singapore 2007;36(5):319-25. [PUBMED: 17549277]

\section{Shariffuddin 2007 \{published data only\}}

Shariffuddin II, Wang CY. Randomised crossover comparison of the Ambu AuraOnce Laryngeal Mask with the LMA Classic laryngeal mask airway in paralysed anaesthetised patients. Anaesthesia 2008;63(1):82-5. [PUBMED: 18086075]

\section{Shiau 2007 \{published data only\}}

Shiau JM, Chen WH, Yang YL, Su HP, Wu YH, Tseng CC. Earlier cessation of desflurane supply in closed-circuit anesthesia reduces emergence time in patients undergoing breast surgery. Acta Anaesthesiologica Taiwanica 2007;45:21-6. [PUBMED: 17424755]

\section{Shimohata 2007 \{published data only\}}

Shimohata T, Shinoda H, Nakayama H, Ozawa T, Terajima K, Yoshizawa $\mathrm{H}$, et al. Daytime hypoxemia, sleep-disordered breathing, and laryngopharyngeal findings in multiple system atrophy. Archives of Neurology 2007;64(6):856-61. [PUBMED: 17562934]

\section{Short 1991 \{published data only\}}

Short TG, Chui PT. Propofol and midazolam act synergistically in combination. British Journal of Anaesthesia 1991;67(5):539-45. [PUBMED: 1751266]

\section{Sidiropoulou 2008 \{published data only\}}

Sidiropoulou T, Buonomo O, Fabbi E, Silvi MB, Kostopanagiotou G, Sabato AF, et al. A prospective comparison of continuous wound infiltration with ropivacaine versus single-injection paravertebral block after modified radical mastectomy. Anesthesia and Analgesia 2008;106(3):997-1001, table of contents. [PUBMED: 18292452]

\section{Sintavanuruk 2010 \{published data only\}}

Sintavanuruk K, Pongruekdee S, Thaharavanich R, Laosuwan S, Charuluxananan S. Comparative study of effective-site target controlled infusion with standard bolus induction of propofol for laryngeal mask airway insertion. Asian Biomedicine 2010;4(1):177-82.

\section{Skaja 2006 \{published data only\}}

Skaja D, Fgraff M. Bispectral index monitoring during volatile anaesthesia for optimal selection of inhalation anaesthetics in lumbar laminotomy. Anaesthesiology Intensive Therapy 2006;38:72-5.

\section{Sosner 2010 \{published data only\}}

Sosner P, Rigouzzo A, Sabourdin N, Laude D, Constant I. Non-invasive investigation of cardiovascular autonomic nervous system activity under anesthesia controlled by EEG: a comparative study between sevoflurane and propofol, in children. European Society of Cardiology, ESC Congress 2010. 2010; Vol. 31:1014.

\section{Spaulding 1984 \{published data only\}}

Spaulding BC, Choi SD, Gross JB, Apfelbaum JL, Broderson H. The effect of physostigmine on diazepam-induced ventilatory depression: a double-blind study. Anesthesiology 1984;61(5):551-4. [PUBMED: 6437287]

Stonell 2006 \{published data only\}

Stonell CA, Leslie K, He C, Lee L. No sex differences in memory formation during general anesthesia. Anesthesiology 2006;105(5):920-6. [PUBMED: 17065885]

\section{Struys 2001 \{published data only\}}

Struys MM, De Smet T, Versichelen LF, Van De Velde S, Van den Broecke R, Mortier EP. Comparison of closed-loop controlled administration of propofol using Bispectral Index as the controlled variable versus "standard practice" controlled administration. Anesthesiology 2001;95(1):6-17. [PUBMED: 11465585]

\section{Suarez 1994 \{published data only\}}

Suarez M, Mendoza CU, Castaneda R, Lux E, Rufino C, Sanchez R. Incidence of memory of transoperative events during total intravenous general anesthesia with propofol. Archives of Medical Research 1994;25(4):413-7.

\section{Suliman 2007 \{published data only\}}

Suliman S, Ericksen T, Labuschgne P, de Wit R, Stein DJ, Seedat S. Comparison of pain, cortisol levels, and psychological distress in women undergoing surgical termination of pregnancy under local anaesthesia versus intravenous sedation. BMC Psychiatry 2007;7:24. [PUBMED: 17565666]

\section{Terblanche 2008 \{published data only\}}

Terblanche N, Coetzee JF. A comparison of induction of anaesthesia using two different propofol preparations. Southern African Journal of Anaesthesia and Analgesia 2008;14(6):25-9.

Ting 2004 \{published data only\}

Ting CK, Hu JS, Teng YH, Chang YY, Tsou MY, Tsai SK. Desflurane accelerates patient response during the wake-up test for scoliosis surgery. Canadian Journal of Anaesthesia 2004;51(4):393-7. [PUBMED: 15064271]

Toraman 2013 \{published data only\}

Toraman F, Ustalar Ozgen S, Sayin Kart J, Ariturk C, Erkek E, Guclu P, et al. Target Controlled Infusion (TCI) of fentanyl and midazolam in coronary artery bypass surgery: effects 
on anaesthesia depth and drug consumption. [Turkish]. Gogus-Kalp-Damar Anestezi ve Yogun Bakim Dernegi Dergisi 2013;19:113-7.

\section{Treggiari 2009 \{published data only\}}

Treggiari MM, Romand JA, Yanez ND, Deem SA, Goldberg J, Hudson L, et al. Randomized trial of light versus deep sedation on mental health after critical illness. Critical Care Medicine 2009;37(9):2527-34. [PUBMED: 19602975]

Trillo 2009 \{published data only\}

Trillo L, Garca C, Ramn J, Sadurni M, Molt L. Conference: European Anaesthesiology Congress, EUROANAESTHESIA 2009 Milan Italy. Euroanaesthesia 2009;26:138.

\section{Tufano 2000 \{published data only\}}

Tufano R, Palomba R, Lambiase G, Giurleo LG. The utility of bispectral index monitoring in general anesthesia. Minerva Anestesiologica 2000;66(5):389-93. [PUBMED: 10965722]

\section{Tunstall 1981 \{published data only\}}

Tunstall ME, Hawksworth GM. Halothane uptake and nitrous oxide concentration. Arterial halothane levels during Caesarean section. Anaesthesia 1981;36(2):177-82. [PUBMED: 7212227]

\section{Turan 2010 \{published data only\}}

Turan A, Kasuya Y, Govinda R, Obal D, Rauch S, Dalton JE, et al. The effect of aminophylline on loss of consciousness, bispectral index, propofol requirement, and minimum alveolar concentration of desflurane in volunteers. Anesthesia and Analgesia 2010;110(2):449-54. [PUBMED: 19955506]

\section{Turner 1969 \{published data only\}}

Turner DJ, Wilson J. Effect of diazepam on awareness during caesarean section under general anaesthesia. British Medical Journal 1969;2(5659):736-7. [PUBMED: 4891882]

\section{Ueyama 1986 \{published data only\}}

Ueyama H, Tashiro C, Mori T, Yoshiya I. Risk factors for awareness and dreams during general anesthesia. Masui 1986;35(4):593-8. [PUBMED: 3747105]

\section{Valtonen 1988 \{published data only\}}

Valtonen M, Kanto J, Klossner J. Anaesthesia for cardioversion: a comparison of propofol and thiopentone. Canadian Journal of Anaesthesia 1988;35(5):497-83. [PUBMED: 3048754]

\section{Vanacker 2002 \{published data only\}}

Vanacker B, Van Geldre L. A randomized study of the efficacy and recovery of remifentanil-based and alfentanil anaesthesia with desflurane or sevoflurane for gynecological surgery. Acta Anaesthesiologica Scandinavica 2002;53(1):21-6. [PUBMED: 11975425]

\section{Vanacker 2007 \{published data only\}}

Vanacker BF, Vermeyen KM, Struys MMRF, Rietbergen $\mathrm{H}$, Vandermeersch E, Saldien V, et al. Reversal of rocuroniuminduced neuromuscular block with the novel drug sugammadex is equally effective under maintenance anesthesia with propofol or sevoflurane. Anesthesia and Analgesia 2007;104(3):563-8. [PUBMED: 17312209]

\section{Vann 2007 \{published data only\}}

Vann MA, Ogunnaike BO, Joshi GP. Sedation and anesthesia care for ophthalmologic surgery during local/regional anesthesia. Anesthesiology 2007;107(3):502-8. [PUBMED: 17721254]

\section{Velly 2007 \{published data only\}}

Velly LJ, Rey MF, Bruder NJ, Gouvitsos FA, Witjas T, Regis JM, et al. Differential dynamic of action on cortical and subcortical structures of anesthetic agents during induction of anesthesia. Anesthesiology 2007;107(2):202-12. [PUBMED: 17667563]

\section{Wanatabe 1984 \{published data only\}}

Watanabe A, Namiki A, Omote T, Takahashi T, Ichinose H. Evaluation of isolated forearm technique for detection of wakefulness during endotracheal intubation procedures. Masui 1984;33(8):870-4. [PUBMED: 6512958]

\section{Wang 2005 \{published data only\}}

Wang Y, Yue Y, Sun YH, Wu AS, Wu QW, Zhang YQ, et al. Investigation and analysis of incidence of awareness in patients undergoing cardiac surgery in Beijing, China. Chinese Medical Journal 2005;118(14):1190-4. [PUBMED: 16117864]

\section{Wang 2007 \{published data only\}}

Wang SM, Constable RT, Tokoglu FS, Weiss DA, Freyle D, Kain ZN. Acupuncture-induced blood oxygenation level-dependent signals in awake and anesthetized volunteers: a pilot study. Anesthesia and Analgesia 2007;105(2):499-506. [PUBMED: 17646512]

\section{Watanabe 1998 \{published data only\}}

Watanabe A, Namiki A, Ujike Y, Watanabe H, Aoki M. Wakefulness during the induction with high-dose fentanyl and oxygen anesthesia. Journal of Anesthesia 1998;2(2):165-9. [PUBMED: 15236075]

\section{Weber 2005 \{published data only\}}

Weber F, Pohl F, Hollnberger H, Taeger K. Impact of the Narcotrend Index on propofol consumption and emergence times during total intravenous anaesthesia with propofol and remifentanil in children: a clinical utility study. European Journal of Anaesthesiology 2005;22(10):741-7. [PUBMED: 16211731]

\section{Weber 2009 \{published data only\}}

Weber F, Kriek N, Blusse H. Conference: European Anaesthesiology Congress, EUROANAESTHESIA 2009 Milan Italy; Influence of a muscle relaxant bolus on BIS, Cerebral State Index (CSI) and Spectral Edge Frequency (SEF) in children under propofol anaesthesia.. Euroanaesthesia 2009;26:144.

\section{Wellisch 2012 \{published data only\}}

Wellisch OM, Kronenfeld M, Saberito D, Pagala M, Choueka J, Gupta P. A prospective randomized controlled trial comparing the efficacy and safety of dexmedetomidine versus propofol TIVA in conjunction with regional block for shoulder surgery in beach chair sitting position. Regional Anesthesia and Pain Medicine 2012;0(6):1. 
Wihelm 2000 \{published data only\}

Wilhelm W, Grundmann U, Aken HV, Haus EM, Larsen R. A multicenter comparison of isoflurane and propofol as adjuncts to remifentanil-based anesthesia. Journal of Clinical Anesthesia 2000;12(2):129-35. [PUBMED: 10818327]

Wilson 1970 \{published data only\}

Wilson J, Lewis SA, Jenkinson JL. Electroencephalographic investigation of awareness during anaesthesia. British Journal of Anaesthesia 1970;42(9):804-5. [PUBMED: 5470077]

\section{Wu 2005 \{published data only\}}

Wang Y, Yue Y, Sun YH, Wu AS, Wu QW, Zhang YQ, et al. Investigation and analysis of incidence of awareness in patients undergoing cardiac surgery in Beijing, China. Chinese Medical Journal 2005;118(14):1190-4. [PUBMED: 16117864]

\section{Xu 2009 \{published data only\}}

Xu L, Wu AS, Yue Y. The incidence of intra-operative awareness during general anesthesia in China: a multi-center observational study. Acta Anaesthesiologica Scandinavica 2009;53(7):873-82. [PUBMED: 19496761]

Yan 2005 \{published data only\}

Yan M, Wang Y, Hu XS, Cheng W, Liu ZM. Target-controlled infusion of remifentanil and propofol during operation with suspension laryngoscopy. Zhejiang Da Xue Xue Bao Yi Xue Ban [Journal of Zhejian University Medical Sciences] 2005;34(6):557-61, 565. [PUBMED: 16331821]

\section{Yan 2014 \{published data only\}}

Yan J, Lin CQ, Zhang CZ, Ou JY, Luo FR, Zhang SL, et al. Effects of assisted-electroacupuncture on recovery of fast tracking anesthesia in MPCNL. Zhongguo Zhen Jiu [Chinese Acupuncture \& Moxibustion] 2014;34(4):385-8.

Yang 1994 \{published data only\}

Yang LH, Lin S M, Lee WY, Liu CC. Intraoperative transcranial electrical motor evoked potential monitoring during spinal surgery under intravenous ketamine or etomidate anaesthesia. Acta Neurochirurgica 1994;127(3-4):191-8. [PUBMED: 7942202]

\section{Yeh 2009 \{published data only\}}

Yeh YC, Lin TF, Chang HC, Chan WS, Wang YP, Lin CJ, et al. Combination of low-dose nalbuphine and morphine in patientcontrolled analgesia decreases incidence of opioid-related side effects. Journal of the Formosan Medical Association 2009;108(7):548-53. [PUBMED: 19586828]

\section{Yi 2008 \{published data only\}}

Yi C, Jee D. Influence of the anaesthetic depth on the inhibition of the oculocardiac reflex during sevoflurane anaesthesia for paediatric strabismus surgery. British Journal of Anaesthesia 2008;101(2):234-8. [PUBMED: 18524784]

\section{Yildiz 2007 \{published data only\}}

Yildiz TS, Solak M, Toker K. Comparison of laryngeal tube with laryngeal mask airway in anaesthetized and paralysed patients. European Journal of Anaesthesiology 2007;24(7):620-5. [PUBMED: 17376250]

\section{Zhang 2009 \{published data only\}}

Zhang GH, Sun L. Peri-intubation hemodynamic changes during low dose fentanyl, remifentanil and sufentanil combined with etomidate for anesthetic induction. Chinese Medical Journal 2009;122(19):2330-4. [PUBMED: 20079135]

\section{Zohar 2007 \{published data only\}}

Zohar E, Noga Y, Davidson E, Kantor M, Fredman B.

Perioperative patient safety: correct patient, correct surgery, correct side--a multifaceted, cross-organizational, interventional study. Anesthesia and Analgesia 2007;105(2):443-7. [PUBMED: 17646503]

\section{References to studies awaiting assessment}

\section{Aceto 2015 \{published data only\}}

Aceto P, Perilli V, Lai C, Sacco T, Modesti C, Luca E, et al. Minimum alveolar concentration threshold of sevoflurane for postoperative dream recall. Minerva Anestesiologica 2015; Vol. 81 , issue $11: 1201-9$.

\section{Asouhidou 2015 \{published data only\}}

Asouhidou I, Trikoupi A. Esmolol reduces anesthetic requirements thereby facilitating early extubation; a prospective controlled study in patients undergoing intracranial surgery. BMC Anesthesiology 2015;15(11):172.

Elbadawy 2015 \{published data only\}

Elbadawy AM, Khidr AM, Saleh AA. Comparative study of implicit memory during bispectral index guided total intravenous anesthesia versus sevoflurane inhalation anesthesia. Egyptian Journal of Anaesthesia 2015;31(1):9-13.

Hoymork 2007 \{published data only\}

Hoymork SC, Hval K, Jensen EW, Raeder J. Can the cerebral state monitor replace the bispectral index in monitoring hypnotic effect during propofol/remifentanil anaesthesia?. Acta Anaesthesiologica Scandinavia 2007;51(2):210-6. [PUBMED: 17330331]

\section{Jiang 2016 \{published data only\}}

Jiang A, Chen LJ, Wang YX, Li MC, Ding YB. The effects of different methods of anaesthesia for laparoscopic radical gastrectomy with monitoring of entropy. Anticancer Research 2016;36(3):1305-8

\section{Khanjani 2014 \{published data only\}}

Khanjani S, Naghibi K, Azarnoush H. Awareness and Apgar score in elective Cesarean section under general anesthesia with propofol or Isoflurane: a prospective, randomized, doubleblinded clinical trial study. Advances in Biomedical Engineering Research 2014;3:234.

\section{Lequeux 2014 \{published data only\}}

Lequeux PY, Hecquet F, Bredas P. Does anesthetic regimen influence implicit memory during general anesthesia?. Anesthesia and Analgesia 2014;119(5):1174-9. 
Mehmandoost 2013 \{published data only\}

Mehmandoost MK, Naghibi K. Comparative study of the effects of two anesthetic methods with propofol and isoflurane on mother's awareness during the operation and Apgar score in the newborns delivered by elective cesarean section. Journal of Isfahan Medical School; http://english.mui.ac.ir/content/iumsjournals 2013;31(228):265-73.

\section{Rajan 2015 \{published data only\}}

Rajan S, Hassain A, Puthenveettil N, Kumar L. Efficacy and safety of low-dose ketamine as an adjunct analgesic and amnesic during caesarean section under general anaesthesia. Indian Journal of Anaesthesia 2015;59(10):653-7.

\section{Xie 2015 \{published data only\}}

Xie M, Lan ZX, Liu YF. Effects of sevoflurane and propofol on preoperative implicit and explicit memories in general anaesthesia patients of elective surgery: a randomized controlled trial. Chinese Journal of Evidence-Based Medicine 2015;15(9):1000-4

\section{Additional references}

\section{Andrade 2008}

Andrade J, Deeprose C, Barker I. Awareness and memory function during paediatric anaesthesia. British Journal of Anaesthesia 2008; Vol. 100, issue 3:389-96. [PUBMED: 18222981]

\section{Artusio 1955}

Artusio JF Jr. Ether analgesia during major surgery. JAMA 1955;157(1):33-6.

\section{ASA 2006}

ASA Task Force. Practice advisory for intraoperative awareness and brain function monitoring: a report by the American Society of Anesthesiologists Task Force on intraoperative awareness. Anesthesiology 2006;104(4):847-64.

\section{Benhamou 2003}

Benhamou D, Ghosh C, Mercier FJ. A randomized sequential allocation study to determine the minimum effective analgesic concentration of levobupivacaine and ropivacaine in patients receiving epidural analgesia for labor. Anesthesiology 2003;99(6):1383-6. [PUBMED: 14639153]

\section{Breen 2007}

Breen T. Lawsuit: Wide-Awake Surgery Led to Death. Retrieved September 19, 2016. Fox News Channel April 10, 2007.

\section{Brull 2008}

Brull SJ, Naguib M, Miller RD. Residual neuromuscular block: rediscovering the obvious. Anesthesia and Analgesia 2008; Vol. 107 , issue 1:11-4.

\section{Chhabra 2016}

Chhabra A, Subramaniam R, Srivastava A, Probhakar H, Kalaivani M, Paranjape S. Spectral entropy monitoring for adults and children undergoing general anaesthesia. Cochrane Database of Systematic Reviews 2016, Issue 3. [DOI: 10.1002/14651858.CD010135.pub2]

\section{Cundy 1995}

Cundy JM. Post traumatic stress disorders (Letter). British Journal of Anaesthesia 1995; Vol. 75:501-2. [PUBMED: 7488502]

\section{Dean 2007}

Dean CB, Nielsen JD. Generalized linear mixed models: a review and some extensions. Lifetime Data Analysis 2007;13(4):497-512.

\section{Eger 2005}

Eger EI, Sonner JM. How likely is awareness during anesthesia?. Anesthesia and Analgesia 2005;100(5):1544-5. [PUBMED: 15845735]

\section{Elmagarmid 2014}

Elmagarmid A, Fedorowicz A, Hammady H, Ilyas I, Khabsa M, Ouzzani M. Rayyan: a systematic reviews web app for exploring and filtering searches for eligible studies for Cochrane Reviews. Evidence-Informed Public Health: Opportunities and Challenges. Abstracts of the 22nd Cochrane Colloquium; 2014 21-26 Sep; Hyderabad, India. John Wiley \& Sons, 2014.

\section{EUC 2009}

EUC. Useful Information on Rare Diseases from an EU Perspective. Retrieved 19 May 2009. European Commission: Health \& Consumer Protection Directorate-General. Luxembourg: Commission Européenne, 2009.

\section{Girgirah 2006}

Girgirah K, Kinsella SM. Propofol and memory. British Journal of Anaesthesia 2006; Vol. 97, issue 5:746-7; author reply 747-8. [PUBMED: 17032664]

\section{Guyatt 2011}

Guyatt GH, Oxman AD, Vist G, Kunz R, Brozek J, Alonso-Coello P, et al. GRADE guidelines: 4. Rating the quality of evidence-study limitations (risk of bias). Journal of Clinical Epidemiology 2011;64(4):407-15

\section{Higgins 2002}

Higgins JP, Thompson SG. Quantifying heterogeneity in a metaanalysis. Statistics in Medicine 2002;21(11):1539-58. [PUBMED: 12111919]

\section{Higgins 2011}

Higgins JPT, Green S (editors). Cochrane Handbook for Systematic Reviews of Interventions Version 5.1.0 [updated March 2011]. The Cochrane Collaboration, 2011. Available from www.cochrane-handbook.org.

\section{HR4013}

HR4013. Public Law 107-280. An act to amend the Public Health Service Act to establish an Office of Rare Diseases at the National Institutes of Health, and for other purposes. United States Government Printing Office. Washington, D.C., 2002; Vol. H.R. 4013, issue H. Rept. 107-543:AE 2.110:107-280.

\section{Jones 1994}

Jones JG. Perception and memory during general anaesthesia. British Journal of Anaesthesia 1994;73(1):31-7. [PUBMED: 8038054] 


\section{Kettner 2014}

Kettner S. Not too little, not too much: delivering the right amount of anaesthesia during surgery. Cochrane Database of Systematic Reviews 2014;6:ED000084.

\section{Lacassie 2004}

Lacassie HJ, Lacassie HP, Muir HA. Is the minimum local analgesic concentration method robust enough?. Anesthesiology 2004;101(2):550; author reply 550-1. [PUBMED: 15277943]

\section{Lennmarken 2002}

Lennmarken C, Bildfors K, Enlung G, Samuelsson P, Sandin R. Victims of awareness. Acta Anaesthesiologica Scandinavica 2002; Vol. 46, issue 3:229-31. [PUBMED: 11939910]

\section{Mainzer 1979}

Mainzer J Jr. Awareness, muscle relaxants and balanced anaesthesia. Canadian Anaesthetists' Society Journal 1979;26(5):386-93. [PUBMED: 385118]

\section{Malek 2010a}

Malek J, Marecek F, Hess L. A combination of dexmedetomidine with ketamine and opioids results in significant inhibition of hemodynamic changes associated with laparoscopic cholecystectomy and in prolongation of postoperative analgesia. Rozhledy V Chirurgii 2010;89:275-81.

\section{Mashour 2009}

Mashour G, Tremper KK, Avidan MS. Protocol for the "Michigan Awareness Control Study": a prospective, randomized, controlled trial comparing electronic alerts based on bispectral index monitoring or minimum alveolar concentration for the prevention of intraoperative awareness. BMC Anesthesiology 2009;9(7):1.

\section{Merikle 1996}

Merikle PM, Daneman M. Memory for unconsciously perceived events: evidence from anesthetized patients. Consciousness \& Cognition 1996; Vol. 5, issue 4:525-41. [PUBMED: 9063614]

\section{Murphy 2008}

Murphy GS, Szokol JW, Marymont JH, Greenberg SB, Avram MJ, Vender JS. Residual neuromuscular blockade and critical respiratory events in the postanesthesia care unit. Anesthesia and Analgesia 2008; Vol. 107, issue 1:130-7. [1526-7598: (Electronic)]

\section{Myles 2015 (personal communication)}

Myles PS. Professor/Director of Anaesthesia and Perioperative Medicine, Alfred Hospital and Monash University, Melbourne, Australia. Letter to: Anthony Messina 5 April 2015.

\section{Osterman 2001}

Osterman JE, Hopper J, Heran WJ, Keane TM, van der Kolk BA. Awareness under anesthesia and the development of posttraumatic stress disorder. General Hospital Psychiatry 2001; Vol. 23, issue 4:198-204. [PUBMED: 11543846]

\section{Punjasawadwong 2014}

Punjasawadwong Y, Phongchiewboon A, Bunchungmongkol N. Bispectral index for improving anaesthetic delivery and postoperative recovery. Cochrane Database of Systematic Reviews 2014, Issue 6. [DOI: 10.1002/14651858.CD003843.pub3]

\section{R 2016 [Computer program]}

R Core Team. R: A language and environment for statistical computing. R Foundation for Statistical Computing, Vienna, Austria, 2016.

\section{Rampil 1998}

Rampil IJ. A primer for EEG signal processing in anesthesia. Anesthesiology 1998;89(4):980-1002. [PUBMED: 9778016]

\section{Review Manager [Computer program]}

The Nordic Cochrane Centre, The Cochrane Collaboration. Review Manager (RevMan). Version 5.3. Copenhagen: The Nordic Cochrane Centre, The Cochrane Collaboration, 2014.

\section{Russell 1985}

Russell IF. Balanced anaesthesia: does it anaesthetize?. Anesthesia and Analgesia 1985; Vol. 64, issue 9:941-2. [PUBMED: 4025858]

\section{Russell 1993}

Russell IF. Midazolam-alfentanil: an anaesthetic? An investigation using the isolated forearm technique. British Journal of Anaesthesiology 1993;70(1):42-6. [PUBMED: 8431332]

\section{Sanders 2011}

Sanders RD, Sleigh JW. Prevention of intraoperative awareness. New England Journal of Medicine 2011;365(21):2033; author reply $2034-5$.

\section{Sandin 2000}

Sandin RH, Enlund G, Samuelsson P, Lennmarken C. Awareness during anaesthesia: a prospective case study. Lancet 2000; Vol. 355, issue 9205:707-11. [PUBMED: 10703802]

\section{Schulz 2010}

Schulz KF, Altman DG, Moher D, CONSORT Group. CONSORT 2010 statement: Updated guidelines for reporting parallel group randomised trials. BMJ 2010;340(c):332.

\section{Sebel 2004}

Sebel PS, Bowdle TA, Ghoneim MM, Rampil IJ, Padilla RE, Gan TJ, et al. The incidence of awareness during anesthesia: a multicenter United States study. Anesthesia and Analgesia 2004; Vol. 99, issue 3:833-9, table of contents. [PUBMED: 15333419]

\section{Tian 2008}

Tian L, Cai T, Pfeffer M, Piankov N, Cremieux P, Wei LJ. Exact and efficient inference procedure for meta-analysis and its application to the analysis of independent two by two tables with all available data but without artificial continuity correction. Biostatistics 2008;10(2):275-81. [PUBMED: 18922759] 


\section{Tunstall 1977}

Tunstall ME. Detecting wakefulness during general anaesthesia for caesarean section. British Medical Journal 1977;1(6072):1321. [PUBMED: 861598]

\section{Vakkuri 2000}

Vakkuri A, Yli-Hankala A, Llindgren L. BIS-monitored depth of anaesthesia in laparoscopic tubal ligation. Memory and Awareness in Anaesthesia IV. Proceedings of the 4th International Symposium on Memory and Awareness in Anaesthesia. London: Imperial College Press, 2000:304-11.

\section{Viechtbauer 2010}

Viechtbauer W. Conducting meta-analyses in $\{R\}$ with the \{metafor\} package. Journal of Statistical Software 2010;36(3):1-48. [1548-7660]

\section{Villafranca 2013}

Villafranca AJ, Arenson BG, Avidan MS, Glick D, Mashour GA, Jacobsohn E. Volitional delay of self-reported outcomes: insights from a case of intraoperative awareness with explicit recall. Anesthesia and Analgesia 2013;116(2):365-7. [PUBMED: 23302976]

\section{Wahl 2011}

Wahl RU, Wurpts G, Merk HF. Perioperative anaphylaxis caused by rocuronium allergy in a child. Hautarzt 2011;62(11):812-4.

\section{Wang 2000}

Wang M. The psychological consequences of awareness during surgery. In: Jordan C, Vaughan DJA, Newton DEF editor(s). Memory and Awareness in Anaesthesia IV. London: Imperial College Press, 2000:315-24.

\section{Wang 2012}

Wang M, Messina AG, Russell IF. The topography of awareness: a classification of intra-operative states. Anaesthesia 2012;67(11):1197-201. [PUBMED: 23033820]

\section{CHARACTERISTICS OF STUDIES}

Characteristics of included studies [ordered by study ID]

\section{White 1987}

White DC. Consciousness Awareness and Pain in General Anaesthesia. 7. London: Oxford: Butterworths, 1987.

\section{WHO 2002}

WHO. Pharmacovigilance: Frequency of adverse drug reactions. World Health Organization (http://www.who.int/medicines/ areas/quality_safety/safety_efficacy/trainingcourses/ definitions.pdf). Council of International Organizations of Medical Science (CIOMS), 2002.

\section{WHO 2015}

WHO. Annex 1, 19th WHO Model List of Essential Medicines (April 2015). Explanatory notes. World Health Organization (WHO) (http://www.who.int/medicines/publications/ essentialmedicines/EML2015_8-May-15.pdf) 2015.

\section{Wilson 1980}

Wilson ME. Awareness in general anaesthesia. British Medical Journal 1980;280:1270.

\section{Yu 2013 [Computer program]}

Yu Y, Tian L. Exactmeta: Exact fixed effect meta analysis. $\mathrm{R}$ package version 1.0-1 [http://CRAN.R-project.org/ package=exactmeta]. Stanford University, 2013.

\section{References to other published versions of this review Messina 2008}

Messina AG, Ward MJ, Pace NL. Anaesthetic interventions for prevention of awareness during surgery. Cochrane Database of Systematic Reviews 2008, Issue 3. [DOI: 10.1002/14651858.CD007272]

* Indicates the major publication for the study

Abboud 1985

\begin{tabular}{ll} 
Methods & Study design: randomized parallel groups \\
& Study dates: not stated \\
\hline Participants & Country: USA \\
& Sex: female \\
& Age: mean $27,24,24,26,25$ \\
& ASA: not stated ("healthy") \\
& Procedure: caesarean delivery ("elective") \\
& Study size: 81
\end{tabular}


Abboud 1985 (Continued)

Intervention 1: maintenance: general anaesthesia $50 \% \mathrm{~N}_{2} \mathrm{O}(\mathrm{N}=16)$ : control

Intervention 2: maintenance: general anaesthesia $0.25 \%$ halothane $+50 \% \mathrm{~N}_{2} \mathrm{O}(\mathrm{N}=16)$

Intervention 3: maintenance: general anaesthesia $0.5 \%$ halothane $+50 \% \mathrm{~N}_{2} \mathrm{O}(\mathrm{N}=18)$

Intervention 4: maintenance: general anaesthesia $0.5 \%$ enflurane $+50 \% \mathrm{~N}_{2} \mathrm{O}(\mathrm{N}=18)$

Intervention 5: maintenance: general anaesthesia 1.0\% enflurane $+50 \% \mathrm{~N}_{2} \mathrm{O}(\mathrm{N}=13)$

Primary outcomes: Quote: "adverse neonatal effects of sub anesthetic doses of halothane or enflu-
rane."
Secondary outcome: awareness/wakefulness as defined using an awareness classification system (see
Table 1): class 4
Quote: "Of the patients who had $\mathrm{N}_{2} \mathrm{O}$ alone [Intervention 1$], 12.5 \%(2 / 16)$ had awareness versus none in
the other groups"

Notes

Non-randomized portion of anaesthetic: parts of potent inhalational technique (volatile agent)/ $\mathrm{N}_{2} \mathrm{O}$ yes/hypnotic/supplemental narcotics/muscle relaxants induction yes/maintenance unclear

Anaesthesia induction: $4 \mathrm{mg} / \mathrm{kg}$ thiopental + succinylcholine $1.5 \mathrm{mg} / \mathrm{kg}+$ curare $3 \mathrm{mg}$; anaesthesia maintenance after delivery: $\mathrm{N}_{2} \mathrm{O}+$ narcotics

No titration anaesthetic strategy for light anaesthesia defined in the paper

Comment: no sample size calculation (power analysis) provided in paper

Time of outcome determination: $24 \mathrm{~h}$ post partum

Method of outcome determination: interview

Email sent jsl3nov42@webtv.net 3 November 2010; as with most RCTs that were published years ago, it was difficult to find current contact information for most authors

\section{Risk of bias}

\section{Bias} Authors' judgement Support for judgement

Random sequence genera- Unclear risk Quote: "patients were randomly assigned" tion (selection bias)

\begin{tabular}{lll}
\hline $\begin{array}{l}\text { Allocation concealment } \\
\text { (selection bias) }\end{array}$ & Unclear risk & Comment: no information provided \\
\hline $\begin{array}{l}\text { Blinding of participants } \\
\text { and personnel (perfor- }\end{array}$ & Unclear risk & Comment: no information provided \\
mance bias) & & \\
All outcomes & &
\end{tabular}

\begin{tabular}{|c|c|c|}
\hline $\begin{array}{l}\text { Blinding of outcome as- } \\
\text { sessment (detection bias) } \\
\text { All outcomes }\end{array}$ & Low risk & $\begin{array}{l}\text { Quote: "All patients were interviewed } 24 \mathrm{~h} \text { post-partum to determine the inci- } \\
\text { dence of awareness by a person who was unaware of the anesthetic manage- } \\
\text { ment of the mother" }\end{array}$ \\
\hline
\end{tabular}

Incomplete outcome data Low risk Comment: no missing outcome data
(attrition bias)

All outcomes 
Abboud 1985 (Continued)

Selective reporting (re- Low risk Comment: awareness outcome part of inclusion criteria
porting bias)

Other bias Unclear risk Comment: no information provided

\section{Abboud 1989}

\begin{tabular}{ll}
\hline Methods & $\begin{array}{l}\text { Study design: randomized parallel groups } \\
\text { Study dates: not stated }\end{array}$ \\
\hline Participants & Country: USA \\
Sex: female & Age: mean 28 \\
ASA: not stated ("healthy") & Procedure: caesarean delivery ("elective primary or repeat, or arrest of dilatation") \\
Study size: 60
\end{tabular}

\section{Interventions Randomized portion of anaesthetic: volatile agent doses}

Intervention 1: maintenance: $0.5 \%$ isoflurane $(\mathrm{N}=20)$

Intervention 2: maintenance: $1 \%$ isoflurane $(\mathrm{N}=20)$

Intervention 3: maintenance: $0.5 \%$ halothane $(\mathrm{N}=20)$

$50 \% \mathrm{~N}_{2} \mathrm{O}$ and $\mathrm{O}_{2}$ was added in each case

Primary outcomes: cbc chemistry urine analysis etc.; the maternal and neonatal effects of isoflurane or
halothane for caesarean section
Secondary outcome: awareness/wakefulness as defined using an awareness classification system (see
Table 1): class 1
Quote: "...none of the patients developed intraoperative awareness"
$\mathrm{N}_{2} \mathrm{O}$ yes/hypnotic/supplemental narcotics/muscle relaxants induction yes/unclear maintenance

Dryad topic from this RCT:light and deep anaesthesia and operating room turnover 1940s to current time

Time of outcome determination: not stated

Method of outcome determination: not stated

ROB surveyemailed jsl3nov42@webtv.net

\section{Risk of bias}

\begin{tabular}{lll}
\hline Bias & Authors' judgement & Support for judgement \\
\hline $\begin{array}{l}\text { Random sequence genera- } \\
\text { tion (selection bias) }\end{array}$ & Unclear risk & Quote: "patients were randomly assigned" \\
\hline
\end{tabular}


Abboud 1989 (Continued)

\begin{tabular}{lll}
$\begin{array}{l}\text { Allocation concealment } \\
\text { (selection bias) }\end{array}$ & Unclear risk & Comment: no information provided \\
\hline $\begin{array}{l}\text { Blinding of participants } \\
\begin{array}{l}\text { and personnel (perfor- } \\
\text { mance bias) }\end{array}\end{array}$ & Unclear risk & $\begin{array}{l}\text { Comment: anaesthesiologist and postoperative interviewer: no information } \\
\text { provided }\end{array}$ \\
\hline $\begin{array}{l}\text { All } \\
\text { putcomes }\end{array}$ & &
\end{tabular}
mance bias)

All outcomes

\begin{tabular}{lll}
\hline Blinding of outcome as- & Unclear risk & Comment: no information provided. Although Cochrane guidelines allow re- \\
sessment (detection bias) & view authors to make judgements about domain grades based on previous \\
All outcomes & studies by the author (Abboud 1985), our editorial team prefers that we only \\
& assess what is written in the current study
\end{tabular}

Incomplete outcome data Low risk $\quad$ Comment: no missing outcome data
(attrition bias)

All outcomes

Selective reporting (re- Low risk Comment: awareness outcome part of inclusion criteria
porting bias)

\begin{tabular}{ll}
\hline Other bias $\quad$ Unclear risk $\quad$ Comment: no information provided \\
\hline
\end{tabular}

\begin{tabular}{ll} 
Abboud 1995a & Study design: randomized parallel groups \\
\hline Methods & Study dates: not stated \\
\hline Participants & Country: USA \\
& Sex: female \\
& Age: mean 28 to 29 \\
& ASA: not stated \\
Procedure: caesarean delivery & Study size: 75
\end{tabular}

\section{Interventions Randomized portion of anaesthetic: volatile agent doses}

Pre-delivery: induction/maintenance

Intervention 1: desflurane end-tidal 3\% (N=25)

Intervention 2: desflurane end-tidal $6 \%(\mathrm{~N}=25)$

Intervention 3: enflurane end-tidal 0.6\% ( $\mathrm{N}=25)$

\begin{tabular}{ll}
\hline Outcomes & Primary outcomes: cbc chemistry urine analysis etc. \\
& Secondary outcome: awareness/wakefulness as defined using an awareness classification system (see \\
& Table 1): class 1 \\
& Quote: "none of the patients developed intraoperative awareness." \\
\hline Notes & $\begin{array}{l}\text { Non-randomized portion of anaesthetic: parts of potent inhalational technique (volatile agent)/ } \\
\mathbf{N}_{\mathbf{2}} \mathbf{O} \text { yes/hypnotic/supplemental narcotics/muscle relaxants induction yes/unclear maintenance }\end{array}$
\end{tabular}


Anaesthesia maintenance: before delivery $\mathrm{N}_{2} \mathrm{O} 50 \%$ and $\mathrm{O}_{2}$; after delivery $\mathrm{N}_{2} \mathrm{O} 67 \%+$ butorphanol $1 \mathrm{mg}$

to $2 \mathrm{mg}$ and reduced doses of desflurane and enflurane

ROB survey emailed js13nov42@webtv.net

\section{Risk of bias}

\begin{tabular}{lll}
\hline Bias & Authors' judgement & Support for judgement \\
\hline $\begin{array}{l}\text { Random sequence genera- } \\
\text { tion (selection bias) }\end{array}$ & Unclear risk & Quote: "patients were randomly assigned" \\
\hline $\begin{array}{l}\text { Allocation concealment } \\
\text { (selection bias) }\end{array}$ & Unclear risk & Comment: no information provided \\
\hline $\begin{array}{l}\text { Blinding of participants } \\
\text { and personnel (perfor- } \\
\text { mance bias) }\end{array}$ & Unclear risk & $\begin{array}{l}\text { Comment: anaesthesiologist and postoperative interviewer: no information } \\
\text { pll outcomes }\end{array}$ \\
\hline
\end{tabular}

\begin{tabular}{lll}
\hline Blinding of outcome as- & Unclear risk & $\begin{array}{l}\text { Comment: anaesthesiologist and postoperative interviewer: no information } \\
\text { provided }\end{array}$ \\
sessment (detection bias) & & \\
All outcomes &
\end{tabular}

\begin{tabular}{lll}
\hline $\begin{array}{l}\text { Incomplete outcome data } \\
\text { (attrition bias) } \\
\text { All outcomes }\end{array}$ & Low risk & Comment: no missing outcome data \\
\hline $\begin{array}{l}\text { Selective reporting (re- } \\
\text { porting bias) }\end{array}$ & Low risk & Comment: awareness outcome part of inclusion criteria \\
\hline Other bias & Unclear risk & Comment: no information provided \\
\hline
\end{tabular}

\begin{tabular}{ll} 
Abboud 1995b & \\
\hline Methods & Study design: randomized parallel groups \\
& Study dates: not stated \\
\hline Participants & Country: USA \\
& Sex: female \\
& Age: mean 30 \\
& ASA: not stated \\
& Procedure: caesarean delivery ("repeat, failure to progress, malpresentation, placenta praevia (non- \\
bleeding)") & Study size: 74 \\
Randomized portion of anaesthetic: parts of IV $\mathbf{M C l}$ \\
Intervention $1:$ induction: propofol $1.5 \mathrm{mg}$ to $2.5 \mathrm{mg} / \mathrm{kg}$; maintenance: propofol $0.2 \mathrm{mg} / \mathbf{k g} / \mathbf{m i n}$ and re- \\
duced to $0.05 \mathrm{mg} / \mathrm{kg} / \mathrm{min}$ ( $\mathrm{N}=37$ )
\end{tabular}


Abboud 1995b (Continued)

intervention 2: induction: thiamylal $3 \mathrm{mg}$ to $4 \mathrm{mg} / \mathrm{kg}$; maintenance: $0.25 \%$ to $0.75 \%$ isoflurane $(\mathrm{N}=37)$

Notes

Primary outcomes: cbc chemistry urine analysis etc.

Secondary outcome: awareness/wakefulness as defined using an awareness classification system (see Table 1): class 4

Quote: "One patient in the isoflurane group reported awareness of the surgical procedure when interviewed $24 \mathrm{~h}$ later (Table 1 )"

\section{Non-randomized portion of anaesthetic: parts of IV $\mathrm{N}_{2} \mathrm{O}$ yes/narcotics/hypnotics bolus/muscle re- laxants induction yes/maintenance unclear}

Anaesthesia induction: group specific induction regimen + succinylcholine $1.5 \mathrm{mg} / \mathrm{kg}$; anaesthesia maintenance: before delivery $\mathbf{N}_{\mathbf{2}} \mathrm{O} 50 \%$; after delivery $\mathrm{N}_{2} \mathrm{O} 67 \%$ + butorphanol $1 \mathrm{mg}$ to $2 \mathrm{mg}$

No titration anaesthetic strategy for light anaesthesia defined in the paper

Time of outcome determination: $24 \mathrm{~h}$ post partum

Method of outcome determination: interview

ROB survey emailed js13nov42@webtv.net

\section{Risk of bias}

\begin{tabular}{lll}
\hline Bias & Authors' judgement & Support for judgement \\
\hline $\begin{array}{l}\text { Random sequence genera- } \\
\text { tion (selection bias) }\end{array}$ & Unclear risk & Quote: "patients were randomly assigned" \\
\hline $\begin{array}{l}\text { Allocation concealment } \\
\text { (selection bias) }\end{array}$ & Unclear risk & Comment: no information provided \\
\hline $\begin{array}{l}\text { Blinding of participants } \\
\text { and personnel (perfor- } \\
\text { mance bias) }\end{array}$ & Unclear risk & $\begin{array}{l}\text { Comment: anaesthesiologist and postoperative interviewer: no information } \\
\text { provided }\end{array}$ \\
\hline $\begin{array}{l}\text { Coutcomes } \\
\text { study when very light anaesthesia used (all groups) compared to today's stan- } \\
\text { dards. That low-dose inhalational agents had a significant effect on awareness } \\
\text { rates is consistent with other studies. Therefore, the lack of blinding unlikely to } \\
\text { impact the outcomes (Cochrane Handbook table 8.5.c). }\end{array}$
\end{tabular}

$\begin{array}{ll}\begin{array}{l}\text { Blinding of outcome as- } \\ \text { sessment (detection bias) }\end{array} & \text { Low risk }\end{array} \begin{aligned} & \text { Quote: "All patients were interviewed 24-h post-partum to determine the inci- } \\ & \text { dence of awareness by a person who was unaware of the anesthetic manage- } \\ & \text { ment of the mother" }\end{aligned}$

All outcomes dence of awareness by a person who was unaware of the anesthetic manage-

Incomplete outcome data Low risk Comment: no missing outcome data

(attrition bias)

All outcomes

\begin{tabular}{lll}
\hline $\begin{array}{l}\text { Selective reporting (re- } \\
\text { porting bias) }\end{array}$ & Low risk & Comment: awareness outcome part of inclusion criteria \\
\hline Other bias & Unclear risk & Comment: no information provided \\
\hline
\end{tabular}

Methods Study design: randomized parallel groups


Aceto 2002 (Continued)

Study dates: not stated

Country: Italy
Sex: both
Age: NA "no statistically significant differences among the group regarding age"
ASA: I-II
Procedure: elective laparoscopic cholecystectomy
Study size: 32
Randomized portion of anaesthetic: volatile agent types $\pm \mathrm{N}_{2} \mathrm{O}$
Intervention 1: maintenance: (Group A) sevoflurane + air $\left(\mathrm{FIO}_{2} 40 \%\right)(\mathrm{N}=8)$
Intervention 2: maintenance: (Group B) sevoflurane $+\mathrm{N}_{2} \mathrm{O}(60 \%)$ in oxygen $40 \%(\mathrm{~N}=8)$
Intervention 3: maintenance: (Group C) isoflurane + air $(\mathrm{FIO} 240 \%)(\mathrm{N}=8)$
Intervention 4: maintenance: (Group D) isoflurane $+\mathrm{N}_{2} \mathrm{O}(60 \%)$ in oxygen $40 \%(\mathrm{~N}=8)$
Inhalation dose not specified except for 1 MAC prior to $\mathrm{MLAER}_{2}$ recordings

Outcomes

Primary outcomes: Quote: "latency of the Pa waves in patients with or without subconscious awareness before and during anaesthesia"

Secondary outcome: awareness/wakefulness as defined using an awareness classification system (see Table 1): class 2

Quote: "In the postoperative interview none of the patients was able to recollect explicit memories of intra-operative events"

Quote: "One of the patients from isoflurane group (Group C) showed implicit memory of the intra-operative tape story"

Notes Non-randomized portion of anaesthetic: parts of volatile agent: $\mathrm{N}_{\mathbf{2}} \mathrm{O}$ no/narcotics/hypnotics bolus/muscle relaxants induction yes/maintenance PRN/ADM: MLAERs

Anaesthesia induction: thiopental sodium $5 \mathrm{mg} / \mathrm{kg}$, fentanyl $3 \mathrm{mg} / \mathrm{kg}$ and vecuronium $0.08 \mathrm{mg} / \mathrm{kg}$. Anaesthesia maintenance: see above and boluses of fentanyl $2 \mu \mathrm{g} / \mathrm{kg}$ and vecuronium PRN clinical necessity

Comment: the authors: 4 interventions MAC equivalents

"MLAERs were recorded before anaesthesia, at 1 MAC mechanisms of dreams"

"We think that, during anaesthesia, dreams imply a mental state in the transition zone between explicit and implicit memory (subconscious awareness)"

Time of outcome determination: "An interview was conducted in the hospital about $24 \mathrm{~h}$ after awakening for assessing explicit and implicit memory"

Method of outcome determination: explicit recall test and implicit free association test; author's survey sent 26 November 2013 gdecosmo@rm.unicatt.it

\section{Risk of bias}

\begin{tabular}{lll}
\hline Bias & Authors' judgement & Support for judgement \\
\hline $\begin{array}{l}\text { Random sequence genera- } \\
\text { tion (selection bias) }\end{array}$ & Unclear risk & Quote: "For the maintenance of anaesthesia patients were randomly..." \\
\hline
\end{tabular}


Aceto 2002 (Continued)

Comment: although Cochrane policy allows review authors to use study authors' methods from other RCT papers that they have published, this approach was discouraged by the editors of this Cochrane review. The same authors in Aceto 2003 were more specific in their description of randomization and it had a low risk rating

\begin{tabular}{|c|c|c|}
\hline $\begin{array}{l}\text { Allocation concealment } \\
\text { (selection bias) }\end{array}$ & Unclear risk & Comment: no information provided \\
\hline $\begin{array}{l}\text { Blinding of participants } \\
\text { and personnel (perfor- } \\
\text { mance bias) } \\
\text { All outcomes }\end{array}$ & Unclear risk & Comment: information provided is inadequate \\
\hline $\begin{array}{l}\text { Blinding of outcome as- } \\
\text { sessment (detection bias) } \\
\text { All outcomes }\end{array}$ & Unclear risk & $\begin{array}{l}\text { Quote: "In the postoperative interview none of the patients was able to recol- } \\
\text { lect explicit memories of intra-operative events" }\end{array}$ \\
\hline $\begin{array}{l}\text { Incomplete outcome data } \\
\text { (attrition bias) } \\
\text { All outcomes }\end{array}$ & Low risk & Comment: no missing outcome data \\
\hline $\begin{array}{l}\text { Selective reporting (re- } \\
\text { porting bias) }\end{array}$ & Low risk & Comment: awareness outcome part of inclusion criteria \\
\hline Other bias & Unclear risk & Comment: no information provided \\
\hline
\end{tabular}

\section{Aceto 2003}

\begin{tabular}{ll}
\hline Methods & Study design: randomized parallel groups \\
& Study dates: not stated \\
\hline Participants & Country: Italy \\
Sex: both & Age: 18 to 70 \\
ASA: I and II & Procedure: elective laparoscopic cholecystectomy \\
Study size: 40
\end{tabular}

\section{Interventions}

\section{Randomized portion of anaesthetic: volatile agent types $\pm \mathrm{N}_{\mathbf{2}} \mathrm{O}$}

Intervention 1: maintenance: (Group A) sevoflurane $+\operatorname{air}\left(\mathrm{FlO}_{2} 40 \%\right)(\mathrm{N}=10)$

Intervention 2: maintenance: (Group B) sevoflurane $+\mathrm{N}_{2} \mathrm{O}(60 \%)$ in oxygen $40 \%(\mathrm{~N}=10)$

Intervention 3: maintenance: (Group C) isoflurane $+\operatorname{air}\left(\mathrm{FIO}_{2} 40 \%\right)(\mathrm{N}=10)$

Intervention 4: maintenance: (Group D) isoflurane $+\mathrm{N}_{2} \mathrm{O}(60 \%)$ in oxygen $40 \%(\mathrm{~N}=10)$

\section{Outcomes}

Primary outcomes: Quote: "latency of the Pa waves in patients with or without subconscious awareness before and during anaesthesia." 
Secondary outcome: awareness/wakefulness as defined using an awareness classification system (see Table 1): class 2

Quote: "In the postoperative interview, none of the patients were able to recollect explicit memories of intraoperative events"

Quote: "One of the male patients from the isoflurane+air group (Group C) showed implicit memory of the intraoperative tape story"

Quote: "A dream-like process, related to the story played during anaesthesia, occurred in one of the female patients in the sevoflurane+nitrous oxide group"

\section{Non-randomized portion of anaesthetic: parts of volatile agent: $\mathrm{N}_{2} \mathrm{O}$ no/narcotics/hypnotics bo- lus/muscle relaxants induction yes/maintenance PRN/ADM MLAERs}

Anaesthesia induction: thiopental sodium $5 \mathrm{mg} / \mathrm{kg}$, fentanyl $3 \mathrm{mg} / \mathrm{kg}$, and vecuronium bromide 0.08 $\mathrm{mg} / \mathrm{kg}$. Anaesthesia maintenance: see above + boluses of fentanyl $2 \mu \mathrm{g} / \mathrm{kg}$ were given according to clinical necessity.

\section{MLAERs were recorded}

\section{Subconscious awareness:}

Quote: "The two patients with subconscious awareness were in the group with a Pa latency increase less than the 10th percentile. This cut-off showed a sensitivity of $100 \%$ and a specificity of $95 \%$, with a positive predictive value of $75 \%$ and a negative predictive value of $100 \%$ in distinguishing patients with subconscious awareness...increase in Pa latency was related to subconscious awareness"

Time of outcome determination: an interview was conducted in the hospital about $24 \mathrm{~h}$ after awakening for assessing explicit and implicit memory

Method of outcome determination: explicit recall test and implicit free association test

Author's survey sent 26 November 2013 gdecosmo@rm.unicatt.it

\section{Risk of bias}

\begin{tabular}{|c|c|c|}
\hline Bias & Authors' judgement & Support for judgement \\
\hline $\begin{array}{l}\text { Random sequence genera- } \\
\text { tion (selection bias) }\end{array}$ & Low risk & $\begin{array}{l}\text { Quote: "For the maintenance of anaesthesia, patients were assigned, using } \\
\text { randomisation tables, to one of four anaesthetic regimen groups..." }\end{array}$ \\
\hline $\begin{array}{l}\text { Allocation concealment } \\
\text { (selection bias) }\end{array}$ & Unclear risk & Comment: no information provided \\
\hline $\begin{array}{l}\text { Blinding of participants } \\
\text { and personnel (perfor- } \\
\text { mance bias) } \\
\text { All outcomes }\end{array}$ & Unclear risk & Comment: information provided is inadequate \\
\hline $\begin{array}{l}\text { Blinding of outcome as- } \\
\text { sessment (detection bias) } \\
\text { All outcomes }\end{array}$ & Unclear risk & Comment: Aceto 2002 \\
\hline $\begin{array}{l}\text { Incomplete outcome data } \\
\text { (attrition bias) } \\
\text { All outcomes }\end{array}$ & Low risk & Comment: no missing outcome data \\
\hline $\begin{array}{l}\text { Selective reporting (re- } \\
\text { porting bias) }\end{array}$ & Low risk & Comment: awareness outcome part of inclusion criteria \\
\hline
\end{tabular}


Aceto 2003 (Continued)
Other bias
Unclear risk
Comment: no information provided

Adams 1994

\begin{tabular}{|c|c|}
\hline Methods & $\begin{array}{l}\text { Study design: double-blind, randomized parallel groups } \\
\text { Study dates: Quote: "ca. } 1991 \text { - 1993" (ROB survey) }\end{array}$ \\
\hline Participants & $\begin{array}{l}\text { Country: Germany } \\
\text { Sex: both } \\
\text { Age: greater than } 60 \text {; mean } 68 \\
\text { ASA: I-II } \\
\text { Procedure: elective hip or knee replacement } \\
\text { Study size: } 37 \text { ( } 40 \text { enrolled) }\end{array}$ \\
\hline Interventions & $\begin{array}{l}\text { Randomized portion of anaesthetic: parts of intravenous (IV) anaesthesia/induction/dissociative } \\
\text { agent } \mathbf{M C I} \\
\text { Intervention 1: induction: } 1 \mathrm{mg} / \mathrm{kg} \mathrm{S-(+)-ketamine;} \mathrm{maintenance:} 2 \mathrm{mg} / \mathrm{kg} / \mathrm{h} \mathrm{S}-(+)-k e t a m i n e ~(\mathrm{~N}=20) \\
\text { Intervention 2: induction: } 2 \mathrm{mg} / \mathrm{kg} \text { racaemic ketamine; maintenance: } 4 \mathrm{mg} / \mathrm{kg} / \mathrm{h} \text { racaemic ketamine (N } \\
=20)\end{array}$ \\
\hline Outcomes & $\begin{array}{l}\text { Primary outcomes: endocrine stress response - recovery - haemodynamic reaction } \\
\text { Secondary outcome: awareness/wakefulness as defined using an awareness classification system (see } \\
\text { Table 1): class } 1 \\
\text { Quote: "no intraoperative awareness was reported." } \\
\text { Quote: "After racaemic ketamine, } 1 \text { patient remembered a negative dream and } 1 \text { patient a positive } \\
\text { dream. In the S (+)-group, } 1 \text { positive dream was reported" }\end{array}$ \\
\hline Notes & $\begin{array}{l}\text { Non-randomized portion of anaesthetic: parts of intravenous (IV) anaesthesia/ } \mathbf{N}_{\mathbf{2}} \mathbf{O} \text { no: } \text { narcotics } \\
\text { and/or hypnotics bolus/muscle relaxants induction yes/maintenance unclear } \\
\text { Anaesthetic induction: } 0.1 \mathrm{mg} / \mathrm{kg} \text { midazolam }+0.5 \mathrm{mg} \text { atropine }+2 \mathrm{mg} \text { vecuronium }+1.5 \mathrm{mg} / \mathrm{kg} \text { suxam- } \\
\text { ethonium + } 0.1 \mathrm{mg} / \mathrm{kg} \text { vecuronium; anaesthetic maintenance: see above interventions } \\
\text { Time of outcome determination: before discharge } \\
\text { Method of determination: interview } \\
\text { Translator: Lore Schultheiss } \\
\text { adams.ha@mh-hannover.de ROB survey response } 24 \text { January } 2011\end{array}$ \\
\hline
\end{tabular}

\section{Risk of bias}

\begin{tabular}{lll}
\hline Bias & Authors' judgement & Support for judgement \\
\hline $\begin{array}{l}\text { Random sequence genera- } \\
\text { tion (selection bias) }\end{array}$ & Low risk & Quote: "were investigated in a double-blind, randomised design...."
\end{tabular}


Adams 1994 (Continued)

ROB survey response by Dr Adams: "Random by computer program with random numbers. Random numbers were opened not earlier then the study was finished"

\begin{tabular}{ll}
\hline $\begin{array}{l}\text { Allocation concealment } \\
\text { (selection bias) }\end{array}$ & Low risk \\
& $\begin{array}{l}\text { ROB survey response: "Double blinded study to patient and anaesthesist as } \\
\text { well. Random numbers were opened not earlier then the study was finished" }\end{array}$
\end{tabular}

\begin{tabular}{|c|c|c|}
\hline $\begin{array}{l}\text { Blinding of participants } \\
\text { and personnel (perfor- }\end{array}$ & Low risk & $\begin{array}{l}\text { ROB survey response: "Patient, Anesthesiologist, Awareness outcome assessor } \\
\text { (interviewer)" }\end{array}$ \\
\hline
\end{tabular}
(interviewer)"

mance bias)

All outcomes

\begin{tabular}{|c|c|c|}
\hline $\begin{array}{l}\text { Blinding of outcome as- } \\
\text { sessment (detection bias) }\end{array}$ & Low risk & $\begin{array}{l}\text { ROB survey response: "Patient, Anesthesiologist, Awareness outcome assessor } \\
\text { (interviewer)" }\end{array}$ \\
\hline
\end{tabular}

All outcomes

Incomplete outcome data Low risk
(attrition bias)

(attritic

Quote: "Three patients in the ketamine-racemate group showed severe arteri-

All outcomes al hypertension and were withdrawn from the study"

Comment: imbalanced exclusion of $3 / 40$ patients at high risk of awareness, but no significant difference between groups ( $3 / 20$ vs $0 / 20)$ : Peto OR $8.23(0.81$ to 84.07 )

$\begin{array}{ll}\begin{array}{l}\text { Selective reporting (re- } \\ \text { porting bias) }\end{array} & \text { ROB survey response: "Study protocol is not more available (study before } \\ & \text { 2000). The published record included all expected data and outcomes, no se- } \\ & \text { lective reporting. Non significant results were reported to show missing differ- } \\ \text { ences between the groups" }\end{array}$

Other bias Low risk ROB survey response: "Limited number of patients"

Agarwal 1977

\begin{tabular}{ll}
\hline Methods & Study design: randomized parallel groups \\
& Study dates: not stated \\
\hline Participants & Country: India \\
& Sex: both \\
& Age: 15 to 50 \\
& ASA: not stated \\
& Procedure: Quote: "elective surgical operations": appendectomy, exploratory laparotomy, gastro-je- \\
& junostomy and vagotomy, partial gastrectomy, pyelo-nephrolithotomy, nephrectomy, herniorrhaphy, \\
& suprapubic cystolithotomy, fallopian tube ligation \\
& Study size: 138
\end{tabular}

Interventions

\section{Randomized portion of anaesthetic: IV: premedication}

Intervention 1: premedication: atropine $0.6 \mathrm{mg}$

Intervention 2: premedication: atropine $0.6 \mathrm{mg}+$ diazepam $0.15 \mathrm{mg} / \mathrm{kg}$

Intervention 3: premedication: atropine $0.6 \mathrm{mg}$ + pethidine $1.5 \mathrm{mg} / \mathrm{kg}$

$\begin{array}{ll}\text { Outcomes } & \text { Primary outcomes: postoperative recall of intraoperative awareness: Quote "ability premedication } \\ \text { to lessen frequency unpleasant recall when patients premedicated with narcotics before nitrous ox- } \\ \text { ide-oxygen-relaxant anaesthesia": class } 1\end{array}$


Quote: "No patient in any of the three groups reported pain during surgery or awareness of the surroundings"

\section{Notes}

\section{Non-randomized portion of anaesthetic: parts of intravenous (IV) anaesthesia: $\mathrm{N}_{2} \mathrm{O}$ yes/narcot-} ic/hypnotic/muscle relaxants induction yes/maintenance yes

Anaesthesia induction: thiopental $7 \mathrm{mg} / \mathrm{kg}$ + suxamethonium $1 \mathrm{mg} / \mathrm{kg}$ + lignocaine 4\%; anaesthesia maintenance: $\mathrm{O}_{2}: \mathrm{N}_{2} \mathrm{O} 2: 1+$ curare $0.6 \mathrm{mg} / \mathrm{kg}$ then bolus to maintain apnoea; reversed neostigmine + atropine $1.2 \mathrm{mg}$

Time of outcome determination: in operating room, 30 to $45 \mathrm{~min}$ after surgery, on ward 4 to $8 \mathrm{~h}$ after surgery

Method of outcome determination: interview

Comment: no awareness reports is interesting in setting of only $\mathrm{O}_{2} / \mathrm{N}_{2} \mathrm{O} /$ curare major surgery and randomization was premed; these results are contrary to the merged studies of comparison 4 (benzodiazepines vs other drugs)

No email could be found for author survey

\section{Risk of bias}

\begin{tabular}{|c|c|c|}
\hline Bias & Authors' judgement & Support for judgement \\
\hline $\begin{array}{l}\text { Random sequence genera- } \\
\text { tion (selection bias) }\end{array}$ & Unclear risk & Quote: "patients were allocated randomly to one of three groups..." \\
\hline $\begin{array}{l}\text { Allocation concealment } \\
\text { (selection bias) }\end{array}$ & Unclear risk & Comment: as above \\
\hline $\begin{array}{l}\text { Blinding of participants } \\
\text { and personnel (perfor- } \\
\text { mance bias) } \\
\text { All outcomes }\end{array}$ & Unclear risk & $\begin{array}{l}\text { Comment: anaesthesiologist and postoperative interviewer: no information } \\
\text { provided }\end{array}$ \\
\hline \multirow{2}{*}{$\begin{array}{l}\text { Blinding of outcome as- } \\
\text { sessment (detection bias) } \\
\text { All outcomes }\end{array}$} & Unclear risk & $\begin{array}{l}\text { Comment: anaesthesiologist and postoperative interviewer: no information } \\
\text { provided }\end{array}$ \\
\hline & & $\begin{array}{l}\text { Quote: "No patient in any of the three groups reported pain during surgery or } \\
\text { awareness of the surroundings" }\end{array}$ \\
\hline $\begin{array}{l}\text { Incomplete outcome data } \\
\text { (attrition bias) } \\
\text { All outcomes }\end{array}$ & Low risk & Comment: no missing outcome data \\
\hline $\begin{array}{l}\text { Selective reporting (re- } \\
\text { porting bias) }\end{array}$ & Low risk & Comment: awareness outcome part of inclusion criteria \\
\hline Other bias & Unclear risk & Comment: no information provided \\
\hline
\end{tabular}

Aime 2006

\begin{tabular}{ll}
\hline Methods & $\begin{array}{l}\text { Study design: randomized parallel groups } \\
\text { Study dates: not stated }\end{array}$ \\
\hline Participants & Country: France \\
\hline
\end{tabular}


Aime 2006 (Continued)

Sex: both

Age: 18 to 80

ASA: I-III

Procedure: Quote: "elective abdominal, gynaecologic, urologic, or orthopaedic surgery expected to last at least $1 \mathrm{h"}$

Study size: 140 enrolled 125 results = 15 dropouts; $15 / 140$ ( $\left.{ }^{\sim} 10 \%\right)$

\author{
Interventions Randomized portion of anaesthetic: volatile agent types: ADM: BIS vs SCPs \\ Intervention 1: sufentanil and sevoflurane - standard clinical practices (SCPs) N = $60-54=6$ exclu- \\ sions \\ Intervention 2: sufentanil and sevoflurane - BIS 40 to $60 \mathrm{~N}=40-34$ \\ Intervention 3: sufentanil and sevoflurane - spectral entropy 40 to $60 \mathrm{~N}=40-37=3$ exclusions
}

Primary outcomes: sevoflurane consumption
Secondary outcome: awareness/wakefulness as defined using an awareness classification system (see
Table 1): class 1
Quote: "No patient reported intraoperative recall"

Notes
lus $\mathrm{MCl} /$ muscle relaxants induction yes/maintenance yes

Premedication: $100 \mathrm{mg}$ hydroxyzine

Induction: propofol $2 \mathrm{mg}$ to $3 \mathrm{mg} / \mathrm{kg}$ + sufentanil $0.2 \mu \mathrm{g}$ to $0.3 \mu \mathrm{g} / \mathrm{kg}$ + atracurium $0.5 \mathrm{mg} / \mathrm{kg}$

Maintenance: sevoflurane in $60 \% \mathrm{~N}_{2} \mathrm{O}$ with oxygen $1 \mathrm{~L} / \mathrm{min}+$ sufentanil 0.15 to $0.20 \mu \mathrm{g} / \mathrm{kg} / \mathrm{h}$ and $5 \mu \mathrm{g}$ bolus + atracurium $0.3 \mathrm{mg} / \mathrm{kg} / \mathrm{h}+$ propofol $50 \mathrm{mg}$ to $100 \mathrm{mg}$ bolus if needed

Time of outcome determination: 1 and 3 days postoperatively

Method of determination: standardized interview

Quote: "The primary end point of this study was defined as the reduction in sevoflurane consumption"

Comment: this RCT was not powered for awareness - inadequate sample size

Author's survey sent on 26 November 2013 to: m.fischler@hopital-foch.org; second request sent 18 September 2014; author response on 19 September 2014: "Our methodology was that postop interviewer was blinded to intraop data and to randomization"

\title{
Risk of bias
}

\begin{tabular}{lll}
\hline Bias & Authors' judgement & Support for judgement \\
\hline $\begin{array}{l}\text { Random sequence genera- } \\
\text { tion (selection bias) }\end{array}$ & Low risk & $\begin{array}{l}\text { Quote: "...were randomly allocated to one of three groups, the standard prac- } \\
\text { tice group, the BIS-guided group, or the spectral entropy-guided group, using } \\
\text { a randomization list performed with computer generated random numbers." }\end{array}$ \\
\hline $\begin{array}{l}\text { Allocation concealment } \\
\text { (selection bias) }\end{array}$ & Unclear risk & Comment: insufficient information provided \\
\hline $\begin{array}{l}\text { Blinding of participants } \\
\text { and personnel (perfor- } \\
\text { mance bias) }\end{array}$ & High risk & $\begin{array}{l}\text { Quote: "In the standard practice group, the screen monitor was customized to } \\
\text { make BIS and Entropy values invisible to the attending anesthesiologist. In the } \\
\text { Bls and in the spectral entropy guided groups, only the guiding parameter was } \\
\text { displayed to the users" }\end{array}$
\end{tabular}


Aime 2006 (Continued)

Comment: anaesthesiologist not blinded to the randomized anaesthetics and both groups not blinded to SCPs even though both control groups blinded to ADM

\begin{tabular}{|c|c|c|}
\hline $\begin{array}{l}\text { Blinding of outcome as- } \\
\text { sessment (detection bias) } \\
\text { All outcomes }\end{array}$ & Low risk & $\begin{array}{l}\text { Quote: "...all patients were visited in the postanaesthesia care unit and on the } \\
\text { first and third postoperative days and interviewed about intraoperative recall } \\
\text { using a standardized interview..." }\end{array}$ \\
\hline & & $\begin{array}{l}\text { Comment: author response on } 19 \text { September 2014: "Our methodology was } \\
\text { that postop interviewer was blinded to intraoperative data and to randomiza- } \\
\text { tion" }\end{array}$ \\
\hline
\end{tabular}

Incomplete outcome data Low risk (attrition bias)

All outcomes
Comment: patients who had clinical signs of intraoperative arousal were excluded. Awareness was a secondary outcome and the imbalance of excluded patients as they relate to the risk of awareness was inadvertently high risk in order to remove the confounding effect of propofol administration on sevoflurane consumption

Comment: SCP: $3 / 60$ high-risk awareness exclusions; ADM (BIS and Entropy): 2/80 high-risk awareness exclusions; imbalanced between groups but not significantly different Peto OR 0.49 (0.08 to 2.93 ); similar results with all types exclusions: $9 / 80$ vs $6 / 60,1.14$ (0.39 to 3.35 )

Quote: "For dichotomous outcome data, the proportion of missing outcomes compared with observed event risk enough to induce clinically relevant bias in intervention effect estimate" (Higgins 2011)

\begin{tabular}{l}
$\begin{array}{l}\text { Selective reporting (re- Low risk } \\
\text { porting bias) }\end{array} \quad$ Comment: awareness outcome part of inclusion criteria \\
\hline
\end{tabular}

Other bias Unclear risk Comment: no information provided

\section{Akcali 2008}

\begin{tabular}{ll}
\hline Methods & Study design: randomized parallel groups \\
& Study dates: Quote: "2001-2002" (ROB bias survey) \\
\hline Participants & Country: Turkey \\
& Sex: both \\
Age: 42 \\
ASA: I-II \\
Procedure: lumbar discectomy \\
Study size: 56
\end{tabular}

Interventions

\section{Randomized portion of anaesthetic: TIVA bolus ADM (BIS) vs SCP}

Intervention 1: remifentanil bolus $(1 \mu \mathrm{g} / \mathrm{kg})+$ propofol $(2 \mathrm{mg} / \mathrm{kg}) \mathrm{SCP}), \mathrm{N}=28$

Intervention 2: remifentanil bolus + propofol titrated BIS 45 to $65, \mathrm{~N}=28$

Outcomes Primary outcomes: effect of Bispectral Index (BIS) monitoring on haemodynamic parameters, drug
consumption

Secondary outcome: awareness/wakefulness as defined using an awareness classification system (see Table 1): class 1 
Akcali 2008 (Continued)

Quote: "None of the patients remembered intubation, positioning and incision moments but haemodynamic reactions were recorded in some cases"

\section{Notes}

\section{Non-randomized portion of anaesthetic: parts of TIVA/ $\mathrm{N}_{2} \mathrm{O}$ no/narcotics/hypnotics bolus $\mathrm{MCl} /$ muscle relaxants induction yes/maintenance yes}

Anaesthesia induction: remifentanil bolus $(1 \mu \mathrm{g} / \mathrm{kg})+\operatorname{propofol}(2 \mathrm{mg} / \mathrm{kg})$ or $(1 \mathrm{mg} / \mathrm{kg}+10 \mathrm{mg}$ boluses to achieve BIS of 45 to 65$)+$ pancuronium $(0.1 \mathrm{mg} / \mathrm{kg})+$ intubation, additional muscle relaxants given 1 to 2 twitch response to TOF

Anaesthesia maintenance: $33 \% \mathrm{O}_{2}$ and $67 \%$ air propofol infusion $(4 \mathbf{~ m g} / \mathbf{k g} / \mathrm{h})+$ remifentanil $(0.1 \mu \mathrm{g} /$ $\mathrm{kg} / \mathrm{min}$ )

Quote: "In order to avoid observer bias, the control group was studied first while a BIS monitor was attached to the patient but the screen was blinded to the anesthesiologist by covering by a card"

Time of outcome determination: first postoperative day

Method of outcome determination: interview

Survey response: 27 March 2011 from Didem Akcali didemakcali@yahoo.com

Email sent on 26 November 2013 to clarify randomization process

\section{Risk of bias}

\begin{tabular}{|c|c|c|}
\hline Bias & Authors' judgement & Support for judgement \\
\hline $\begin{array}{l}\text { Random sequence genera- } \\
\text { tion (selection bias) }\end{array}$ & Unclear risk & $\begin{array}{l}\text { Quote: "The first } 28 \text { patients scheduled for surgery were randomised to control } \\
\text { group. The last } 28 \text { patients were used as BIS group as first control group was } \\
\text { studied in order to avoid observer bias." (Email bias survey, see notes) } \\
\text { Quote: "These patients were randomly assigned to one of two study group- } \\
\text { s." (author's survey) }\end{array}$ \\
\hline $\begin{array}{l}\text { Allocation concealment } \\
\text { (selection bias) }\end{array}$ & Unclear risk & Comment: no information \\
\hline $\begin{array}{l}\text { Blinding of participants } \\
\text { and personnel (perfor- } \\
\text { mance bias) } \\
\text { All outcomes }\end{array}$ & High risk & $\begin{array}{l}\text { Quote: "Patient" (author's survey) } \\
\text { Quote: "first the control group was studied in order to avoid observer bias. } \\
\text { The BIS monitor screen was blinded by a card and important instances were } \\
\text { marked without seeing the monitor screen. Afterwards BIS group was stud- } \\
\text { ied." (author's survey) }\end{array}$ \\
\hline $\begin{array}{l}\text { Blinding of outcome as- } \\
\text { sessment (detection bias) } \\
\text { All outcomes }\end{array}$ & High risk & Quote: "Patient" (author's survey) \\
\hline $\begin{array}{l}\text { Incomplete outcome data } \\
\text { (attrition bias) } \\
\text { All outcomes }\end{array}$ & Low risk & Comment: no missing outcome data \\
\hline $\begin{array}{l}\text { Selective reporting (re- } \\
\text { porting bias) }\end{array}$ & Low risk & $\begin{array}{l}\text { Quote: "The study protocol is available and all of the study's pre-specified (pri- } \\
\text { mary and secondary) outcomes that are of interest in the review have been re- } \\
\text { ported in the pre-specified way." (Author's survey) }\end{array}$ \\
\hline Other bias & Low risk & $\begin{array}{l}\text { Quote: "there was no bias. The study was performed as planned without any } \\
\text { source of bias." (Author's survey) }\end{array}$ \\
\hline
\end{tabular}


Anez 2001

\begin{tabular}{ll}
\hline Methods & $\begin{array}{l}\text { Study design: randomized parallel groups } \\
\text { Study dates: not stated }\end{array}$ \\
\hline Participants & Country: Spain \\
& Sex: unclear \\
& Age: group A 43.05 \pm 15.2 , group B $38.1 \pm 14.7$ \\
& ASA: I and II \\
& Procedure: vascular, venous, ortho outpatient \\
& Study size: 40 , completed 39
\end{tabular}

Interventions

\section{Randomized portion of anaesthetic: TIVA ADM (BIS) vs SCP}

Intervention 1: BIS blinded, $\mathrm{N}=20$

Intervention 2: BIS open (40 to 60 ), $\mathrm{N}=20$

Outcomes Primary outcomes: effect of Bispectral Index (BIS) monitoring on propofol consumption, awakening, time to discharge, haemodynamic parameters, drug consumption

Secondary outcome: awareness/wakefulness as defined using an awareness classification system (see Table 1): class 1

No awareness reports

Notes Non-randomized portion of anaesthetic: parts of intravenous (IV) TIVA anaesthesia/ $\mathrm{N}_{2} \mathrm{O}$ no/nar-
cotics and/or hypnotics bolus $\mathrm{TCl} /$ muscle relaxants induction yes/maintenance unclear

Premedication: midazolam $0.03 \mu \mathrm{g} / \mathrm{kg}$ + atropine $0.01 \mu \mathrm{g} / \mathrm{kg}$; anaesthesia induction: alfentanil $10 \mu \mathrm{g} /$ $\mathrm{kg}$, boluses 5-10 $\mathrm{\mu g}$, rocuronium $0.2 \mathrm{mg} / \mathrm{kg}$ (smaller than usual intubating dose) TCI propofol initial dose $3.5 \mu \mathrm{g}$ to $4 \mu \mathrm{g} / \mathrm{mL} / \mathrm{min}$, LMA; anaesthesia maintenance: propofol $2 \mu \mathrm{g} / \mathrm{mL}$ ambulatory surgery/ propofol administered intravenously through a computerized system (Diprifuso ${ }^{\circledR}$ ) and laryngeal mask

Translated by Brett Smith; survey sent: canez@galenics.com

\section{Risk of bias}

\begin{tabular}{lll}
\hline Bias & Authors' judgement & Support for judgement \\
\hline $\begin{array}{l}\text { Random sequence genera- } \\
\text { tion (selection bias) }\end{array}$ & High risk & $\begin{array}{l}\text { Quote: translation: "sequential randomisation: picked first 20 into one group } \\
\text { and 2nd 20 into the second group" }\end{array}$ \\
\hline $\begin{array}{l}\text { Allocation concealment } \\
\text { (selection bias) }\end{array}$ & Unclear risk & Comment: rule: no information \\
\hline $\begin{array}{l}\text { Blinding of participants } \\
\text { and personnel (perfor- } \\
\text { mance bias) } \\
\text { All outcomes }\end{array}$ & High risk & Comment: randomization was performed for BIS open or closed \\
\hline $\begin{array}{l}\text { Blinding of outcome as- } \\
\text { sessment (detection bias) } \\
\text { All outcomes }\end{array}$ & Unclear risk & BIS blinded to SCP group but SCP open to both groups \\
\hline $\begin{array}{l}\text { Incomplete outcome data } \\
\text { (attrition bias) } \\
\text { All outcomes }\end{array}$ & Low risk & $\begin{array}{l}\text { Comment: anaesthesiologist and postoperative interviewer: no information } \\
\text { provided }\end{array}$ \\
\hline
\end{tabular}


Anez 2001 (Continued)

Selective reporting (re- Low risk Comment: awareness outcome part of inclusion criteria porting bias)

Other bias Unclear risk Comment: no information provided

Arellano 2000

Methods Study design: randomized parallel groups

Study dates: not stated

\begin{tabular}{l} 
Country: Canada \\
Sex: female \\
Age: 18 to 55 \\
ASA: I and II \\
Procedure: elective ambulatory termination of pregnancy or gynaecologic laparoscopy \\
Study size: 1490 , completed 1207, dropouts 283 (dropout 19\%) \\
\hline
\end{tabular}

Interventions

\section{Randomized portion of anaesthetic: parts of TIVA no $\mathrm{N}_{2} \mathrm{O}$}

Intervention 1: maintenance: propofol $\mathrm{N}_{2} \mathrm{O} \mathrm{O}_{2} 65 \%$ to $35 \%$

Intervention 2: maintenance: propofol alone $\mathrm{TIVA} \mathrm{O}_{2} 100 \%$

Outcomes Primary outcomes: time to home readiness, postoperative recovery

Secondary outcome: awareness/wakefulness as defined using an awareness classification system (see Table 1): class 4

Quote: "We did not observe any cases of awareness in the TIVA...the incidence of intraoperative awareness is not greater than $0.4 \%$ inpatients undergoing outpatient gynaecologic surgery with our TIVA protocol... The aggregated incidence of awareness in the $\mathrm{N}_{2} \mathrm{O}$ group was $0.13 \%$...we did not encounter this unacceptably high incidence of recall as our protocol specified a starting propofol infusion rate of $>160$ $\mathrm{pg} \mathrm{kg} \mathrm{-} \mathrm{min} \mathrm{with} \mathrm{subsequent} \mathrm{reductions} \mathrm{if} \mathrm{indicated} \mathrm{clinically"}$

Quote: "...one patient in this study reported intraoperative awareness (laparoscopy, $\mathrm{N}_{2} \mathrm{O}$ group). The attending anaesthesiologist noted that this was likely caused by a kinked intravenous line that interrupted the flow of propofol for a short period"

Comment: not powered for awareness

TP anaesthesia induction: fentanyl $0.7 \mathrm{mg} / \mathrm{kg}+20 \mathrm{mg}$ lidocaine and $2.0 \mathrm{mg} / \mathrm{kg}$ propofol

TP maintenance: propofol $20 \mathrm{mg}$ boluses at signs of light anaesthesia

Laparoscopy induction: fentanyl $1.5 \mathrm{mg} / \mathrm{kg}+\mathrm{d}$-tubocurare $3 \mathrm{mg}+20 \mathrm{mg}$ lidocaine $+2.0 \mathrm{mg} / \mathrm{kg}$ propofol with propofol titrated to loss of lid reflex + succinylcholine $1.5 \mathrm{mg} / \mathrm{kg}$ vecuronium $0.075 \mathrm{mg}$ to $0.1 \mathrm{mg}$ / $\mathrm{kg}$

Laparoscopy maintenance: propofol $100 \mu \mathrm{g}$ to $200 \mu \mathrm{g} / \mathrm{kg} / \mathrm{min}+$ propofol $20 \mathrm{mg}$ boluses if needed

Time of outcome determination: $24 \mathrm{~h}$

Method of outcome determination: interview "...these two surgical procedures represented the vast majority of ambulatory gynaecologic surgery performed at the institutions studied, patients undergo- 
Arellano 2000 (Continued)

ing other ambulatory gynaecologic procedures were not studied to reduce heterogeneity in study population"

Email sent to arellano@is.dal.ca and arel111@yahoo.com on 26 November 2013

\section{Risk of bias}

Bias Authors' judgement Support for judgement

Random sequence genera- Low risk tion (selection bias)

Allocation concealment Low risk
(selection bias)
Quote: "Patients were randomly allocated by computer-generated random numbers in blocks of four..."

\begin{tabular}{ll}
\hline $\begin{array}{l}\text { Blinding of participants } \\
\text { and personnel (perfor- }\end{array}$ & High risk \\
$\begin{array}{l}\text { mance bias) } \\
\text { All outcomes }\end{array}$ & $\begin{array}{l}\text { Quote: "... The anaesthesiologists were not blinded to treatment allocation to } \\
\text { ensure safe anaesthetic care. Biased administration of the anaesthetics and } \\
\text { un-blinding of the research assistants were prevented by the following...." }\end{array}$ \\
& $\begin{array}{l}\text { Comment: based on the criteria for this domain we graded it high risk but } \\
\text { would use discretion if RCT merged into meta-analysis }\end{array}$
\end{tabular}

\begin{tabular}{|c|c|c|}
\hline $\begin{array}{l}\text { Blinding of outcome as- } \\
\text { sessment (detection bias) } \\
\text { All outcomes }\end{array}$ & Low risk & $\begin{array}{l}\text { Quote: "Subjects were assessed by a blinded research assistant every } 20 \text { min } \\
\text { until they reached it score } 9 . \text { In addition, the same research assistant inter- } \\
\text { viewed patients by telephone } 24 \text { hours after discharge ..." }\end{array}$ \\
\hline $\begin{array}{l}\text { Incomplete outcome data } \\
\text { (attrition bias) } \\
\text { All outcomes }\end{array}$ & Low risk & $\begin{array}{l}\text { Comment: imbalanced but not significantly different between groups: } \mathrm{N}_{2} \mathrm{O} \\
\left.(40 / 740) \text { vs TIVA } \mathrm{O}_{2}(32 / 750) \text {, Peto OR } 1.28 \text { (0.80 to } 2.06\right)\end{array}$ \\
\hline $\begin{array}{l}\text { Selective reporting (re- } \\
\text { porting bias) }\end{array}$ & Low risk & Comment: awareness outcome part of inclusion criteria \\
\hline Other bias & Unclear risk & Comment: insufficient information provided \\
\hline
\end{tabular}

\section{Ashworth 1998}

\begin{tabular}{ll}
\hline Methods & Study design: randomized parallel groups \\
& Study dates: not stated \\
\hline Participants & Country: UK \\
& Sex: female and male \\
Age: 18 to 70 \\
ASA: I-II \\
Procedure: ambulatory surgery \\
Study size: 90
\end{tabular}

\footnotetext{
Interventions
}

\section{Randomized portion of anaesthetic: parts of IV vs parts of volatile agent}

Intervention 1: maintenance: isoflurane ET $0.6 \%$, then $0.25 \%$ to $1 \%$; $=30$

Infusion of propofol, $160 \mu \mathrm{g} / \mathrm{kg} / \mathrm{min}$ then $50 \mu \mathrm{g}$ to $200 \mu \mathrm{g} / \mathrm{kg} / \mathrm{min} ; \mathrm{N}=30$ 
Ashworth 1998 (Continued)

Intervention 3: desflurane ET 3.6\% then $1.4 \%$ to $6 \%$ PRN; N = 30

Outcomes Primary outcomes: postoperative recovery; respiratory complications; heart rate (h) $(A)$ and mean arterial blood pressure; episodes of purposeful movement

Secondary outcome: awareness/wakefulness as defined using an awareness classification system (see

Table 1): class 4

Quote: "The IV anaesthetic propofol was associated with more patient movement (without awareness)

during surgery"

Comment: no awareness events

Notes

\section{Non-randomized portion of anaesthetic: parts of IV vs parts of volatile agent $\mathrm{N}_{2} \mathrm{O}$ yes/nar- cotics/hypnotics bolus/muscle relaxants induction no/maintenance no}

Induction: a single anaesthesiologist, fentanyl $1 \mu \mathrm{g} / \mathrm{kg} /$ lidocaine $20 \mathrm{mg}$ and propofol $20 \mathrm{mg}$ to $40 \mathrm{mg}$ every $10 \mathrm{~S}$, LMA was inserted after adequate jaw relaxation. No muscle relaxant used, $\mathrm{N}_{2} \mathrm{O} 67 \% / \mathrm{O}_{2} 6 \mathrm{~L} /$ $\min$ for 10 min then $2 \mathrm{~L} / \mathrm{min}$

Quote: "In spontaneously breathing patients, inadequate anaesthesia is manifested by purposeful movements, which allows corrective action to be taken promptly. As a result, awareness is unlikely, and none of our patients recalled intraoperative events. When muscle relaxants and controlled ventilation are used, however, awareness is a greater risk because inadequate anesthesia can occur without obvious changes in clinical signs"

No email found

\section{Risk of bias}

\begin{tabular}{lll}
\hline Bias & Authors' judgement & Support for judgement \\
\hline $\begin{array}{l}\text { Random sequence genera- } \\
\text { tion (selection bias) }\end{array}$ & Unclear risk & $\begin{array}{l}\text { Quote: "An open-label, prospective study design was used involving random } \\
\text { allocation to one of three parallel groups for the maintenance of anesthesia } \\
\text { (isoflurane, propofol, or desflurane) with blind assessment of postoperative } \\
\text { recovery" }\end{array}$ \\
\hline
\end{tabular}

\begin{tabular}{|c|c|c|}
\hline $\begin{array}{l}\text { Allocation concealment } \\
\text { (selection bias) }\end{array}$ & High risk & $\begin{array}{l}\text { Quote: "Participants or investigators enrolling participants could possibly } \\
\text { foresee assignments and thus introduce selection bias, such as allocation } \\
\text { based on: Using an open random allocation schedule (e.g. a list of random } \\
\text { numbers)" (Higgins 2011) }\end{array}$ \\
\hline
\end{tabular}

Blinding of participants High risk Comment: see above
and personnel (performance bias)

All outcomes

\begin{tabular}{|c|c|c|}
\hline $\begin{array}{l}\text { Blinding of outcome as- } \\
\text { sessment (detection bias) }\end{array}$ & Unclear risk & $\begin{array}{l}\text { Quote: "No patient subsequently had recall of any intraoperative event on di- } \\
\text { rect postoperative questioning" }\end{array}$ \\
\hline
\end{tabular}

\begin{tabular}{lll}
\hline $\begin{array}{l}\text { Incomplete outcome data } \\
\text { (attrition bias) } \\
\text { All outcomes }\end{array}$ & Low risk & Comment: no missing data \\
\hline $\begin{array}{l}\text { Selective reporting (re- } \\
\text { porting bias) }\end{array}$ & Low risk & Comment: awareness outcome part of inclusion criteria \\
\hline Other bias & Unclear risk & Comment: inadequate information \\
\hline
\end{tabular}


Avidan 2008

\begin{tabular}{|c|c|}
\hline Methods & $\begin{array}{l}\text { Study design: randomized parallel groups } \\
\text { Study dates: September } 2005 \text { to October } 2006\end{array}$ \\
\hline \multirow[t]{6}{*}{ Participants } & Country: USA \\
\hline & Sex: both \\
\hline & Age: mean age 59.5 to 59.2 at high risk of awareness \\
\hline & ASA: I-IV \\
\hline & Procedure: not identified \\
\hline & Study size: 2000 entered study and 1941 completed possible interviews \\
\hline \multirow[t]{3}{*}{ Interventions } & Randomized portion of anaesthetic: volatile agent types ADM BIS vs ETAG \\
\hline & Intervention 1: BIS guided anaesthesia (target BIS range, 40 to 60 ), $N=1000$ \\
\hline & $\begin{array}{l}\text { Intervention 2: ETAG guided anaesthesia (target ETAG } 0.7 \text { to } 1.3 \mathrm{MAC} \text { ), enrolled 2000, completed study } \\
1941\end{array}$ \\
\hline \multirow[t]{4}{*}{ Outcomes } & $\begin{array}{l}\text { Primary outcomes: awareness/wakefulness as defined using our "Classification of intra-operative cog- } \\
\text { nitive states" Table 1: class } 4\end{array}$ \\
\hline & $\begin{array}{l}\text { Comment: } 16 \text { awareness reports by patients }=4 \text { definite }+5 \text { possible }+7 \text { no awareness: expert pan- } \\
\text { el classification. } 12 / 16 \text { patient awareness reports NOT used in calculation of awareness rate (definite } \\
\text { awareness) }\end{array}$ \\
\hline & Definite and possible BIS 10/967 vs SCP 6/974 \\
\hline & Definite: BIS 2/967 vs SCP 2/974 \\
\hline
\end{tabular}

Notes

\section{Non-randomized portion of anaesthetic: parts of volatile agent: $\mathrm{N}_{\mathbf{2}} \mathrm{O}$ unclear/narcotics/hyp- notics/muscle relaxants induction unclear/maintenance unclear}

Anaesthesia induction: left to discretion of anaesthetist

Anaesthesia maintenance: left to discretion of anaesthetist

Comment: high risk of anaesthesia awareness/isoflurane, sevoflurane or desflurane/supplemental $\mathrm{N}_{2} \mathrm{O}$ permitted

Time of outcome determination: within $24 \mathrm{~h}, 1$ to 3 days, and 72 days postoperative period

Survey response: 27 September 2011 Michael Avidan, avidanm@anest.wustl.edu

Email sent to author to clarify missing data issues: 7 December 2013: Michael Avidan, avidanm@anest.wustl.edu. Dr Avidan responded. Senior authors developed consensus on ROB domain emailed to authors and response acknowledging our assessment sent/received 28 December 2013. Email sent 21 October 2014 adjudicated awareness reports and response 21 October 2014; 14 November 2014 adjudicated awareness reports for review copies of reports not published in RCT. Dr Avidan responded 14 November 2014

\section{Risk of bias}

\begin{tabular}{lll}
\hline Bias & Authors' judgement & Support for judgement \\
\hline $\begin{array}{l}\text { Random sequence genera- } \\
\text { tion (selection bias) }\end{array}$ & Low risk & $\begin{array}{l}\text { Quote: "The design was a single-center, prospective study, in which 2000 pa- } \\
\text { tients underwent pre-randomization electronically in blocks of } 100, \text { with 50 }\end{array}$ \\
\hline
\end{tabular}


Avidan 2008 (Continued)

patients assigned to a BIS-guided protocol and 50 to an ETAG-guided protocol"

Quote from survey: "Computer generated randomization. Block randomized in blocks of 100 (50 in each group per block). Unique case identifier and information on group allocation (BIS or ETAG) was sealed in opaque envelopes"

\begin{tabular}{ll}
\hline $\begin{array}{l}\text { Allocation concealment } \\
\text { (selection bias) }\end{array}$ & Low risk \\
& $\begin{array}{l}\text { Quote from survey: "The opaque envelope was opened by a research coordi- } \\
\text { nator only after the patient (who had already signed consent) was transferred } \\
\text { to the operating room" }\end{array}$
\end{tabular}

\begin{tabular}{|c|c|c|}
\hline $\begin{array}{l}\text { Blinding of participants } \\
\text { and personnel (perfor- }\end{array}$ & High risk & $\begin{array}{l}\text { Quote: "The anesthesiologists were not blinded to treatment allocation to en- } \\
\text { sure safe anaesthetic care" }\end{array}$ \\
\hline
\end{tabular}

mance bias) sure safe anaesthetic care"

All outcomes

Quote from paper: "formed consent. The anesthesia practitioners were aware of the assignments of the patients, but the patients, the postoperative interviewers, the expert reviewers, and the statistician were not"

\begin{tabular}{|c|c|c|}
\hline $\begin{array}{l}\text { Blinding of outcome as- } \\
\text { sessment (detection bias) } \\
\text { All outcomes }\end{array}$ & Low risk & $\begin{array}{l}\text { Quote: "Patient, Awareness outcome assessor (interviewer), Statistician, ex- } \\
\text { pert reviewers who determined whether awareness was definite, possible or } \\
\text { not awareness" }\end{array}$ \\
\hline
\end{tabular}
All outcomes

Comment: 2000 patients enrolled, in table 1, trial enrolment, there were $33 \mathrm{BIS}$

Incomplete outcome data Low risk (attrition bias) and 26 ETAG patients excluded after randomization. 1905/1941 (98\%) complet-

All outcomes ed 1 to 3 awareness interviews and 36/1941 (2\%) completed no awareness interviews

Senior authors' consensus: ... because of the balanced event rates and sample sizes, even though the reasons for a portion of the dropouts are not known, there would be little impact on the reported outcome from the study if these patients had been interviewed for awareness

$33 / 2000$ vs $26 / 2000$, Peto OR 1.27 (0.76 to 2.13 )

Email sent to author to clarify these issues: 7 December 2013: Michael Avidan, avidanm@anest.wustl.edu

\begin{tabular}{lll}
\hline $\begin{array}{l}\text { Selective reporting (re- } \\
\text { porting bias) }\end{array}$ & Low risk & $\begin{array}{l}\text { Quote: "The study protocol was not published in the public domain. The trial } \\
\text { was registered on clinical trials.com (NCT00281489)" }\end{array}$ \\
\hline Other bias & Low risk & Quote: "We know of no bias related to the study design" \\
\hline
\end{tabular}

Avidan 2011

\begin{tabular}{ll}
\hline Methods & Study design: randomized parallel groups \\
Study dates: May 2008 through May 2010
\end{tabular}

Participants

Country: USA

Sex: both

Age: mean $60 \pm 14.2,61 \pm 14.4$; high risk of awareness

ASA: I-IV (> 80\% patients ASA III-IV)

Procedure: elective surgery 
Avidan 2011 (Continued)

Study size: 6041 enrolled, 49,000 screened, 5801 included in trial, 5713 completed >= 1 interview (primary outcome analysis) (98.3\%)

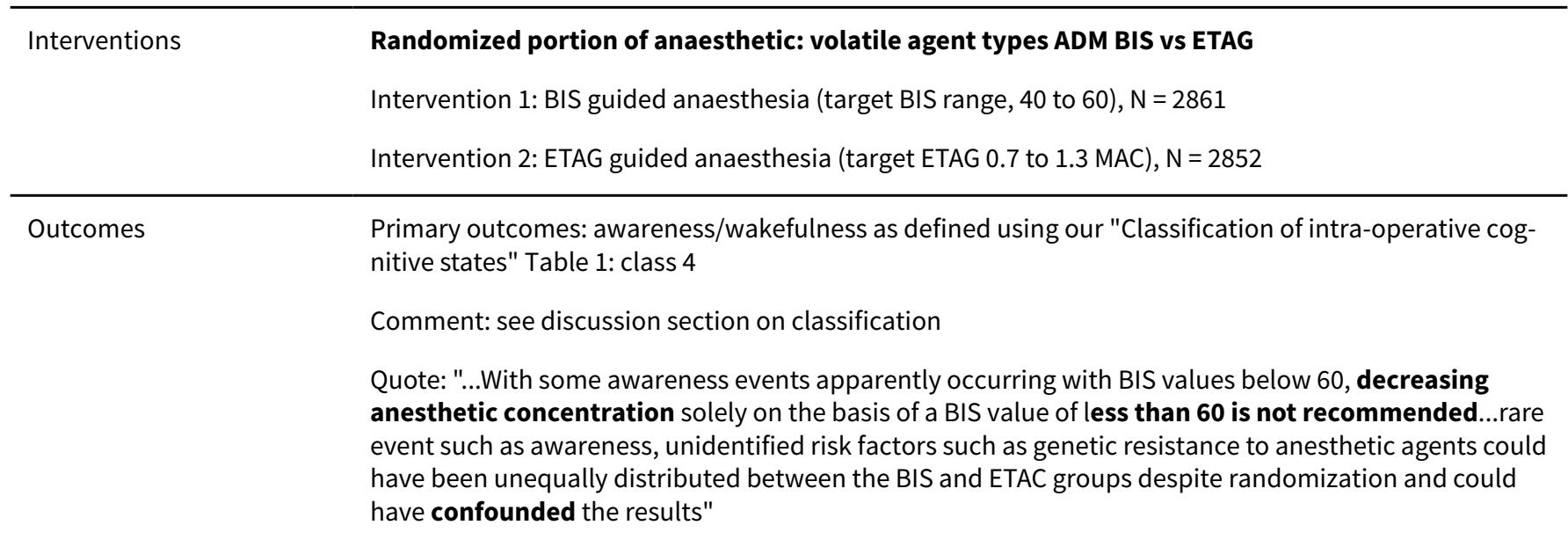

Notes

\section{Non-randomized portion of anaesthetic: parts of volatile agent: $\mathrm{N}_{\mathbf{2}} \mathrm{O}$ unclear/narcotics/hyp- notics/muscle relaxants induction unclear/maintenance unclear}

BIS or Anaesthetic Gas to Reduce Explicit Recall (BAG-RECALL)

General anaesthesia with isoflurane, sevoflurane or desflurane

Patients at high risk were defined as those with at least one risk factor (Table 1)

Anaesthesia induction: left to discretion of anaesthetist

Anaesthesia maintenance: left to discretion of anaesthetist

Time of outcome determination: modified Brice questionnaire, within $72 \mathrm{~h}$ after surgery and at 30 days after extubation

Method of outcome determination: interview

Survey response: 27 September 2011Michael Avidan, avidanm@anest.wustl.edu; see Avidan 2008 for subsequent email communications; email sent 21 October 2014 adjudicated awareness reports and response21 October 2014; 14 November 2014 adjudicated awareness reports for review copies of reports not published in RCT. Responded 14 November 2014; emails January to February 2015: adjudicated awareness reports

A delayed report of an awareness event was published in 2013 (Villafranca 2013)

\section{Risk of bias}

Bias Authors' judgement Support for judgement

Random sequence genera- Low risk tion (selection bias)

Quote: "6100 pre-randomization designations were generated electronically in blocks of 100 , divided equally between the groups"

Quote from survey: "Computer generated randomization. Block randomized in blocks of 100 (50 in each group per block), randomization was generated at the coordinating site. Unique case identifier and information on group allocation (BIS or ETAG) was sealed in opaque envelopes"

Allocation concealment Low risk (selection bias)
Quote: "Labels indicating BIS group or ETAC group were sealed in opaque, numbered envelopes" 
Avidan 2011 (Continued)

Quote from survey: "The opaque envelope was opened by a research coordinator only after the patient (who had already signed consent) was transferred to the operating room"

$\begin{array}{ll}\begin{array}{l}\text { Blinding of participants } \\ \text { and personnel (perfor- }\end{array} & \text { High risk } \\ \begin{array}{l}\text { mance bias) } \\ \text { All outcomes }\end{array} & \begin{array}{l}\text { Quote: "Patients in the ETAC group had monitors configured to conceal the BIS } \\ \text { number, so the anesthesia practitioners were unaware of the BIS values. The } \\ \text { practitioners in both groups could view the ETAC. Summaries of the BIS and } \\ \text { ETAC protocols" } \\ \text { Comment: see this domain's comments in Avidan } 2008 \\ \text { Comment: anaesthesia practitioners ETAG group using monitor configuration } \\ \text { omits BIS number, so unaware of BIS values; both groups view ETAG concen- } \\ \text { trations }\end{array}\end{array}$

\begin{tabular}{ll}
\hline $\begin{array}{l}\text { Blinding of outcome as- } \\
\text { sessment (detection bias) }\end{array}$ & Low risk
\end{tabular}$\quad \begin{aligned} & \text { "Patient, Awareness outcome assessor (interviewer), Statistician, expert re- } \\
& \text { viewers who determined whether awareness was definite, possible" }\end{aligned}$

All outcomes

\begin{tabular}{ll}
\hline $\begin{array}{l}\text { Incomplete outcome data } \\
\text { (attrition bias) }\end{array}$ & Low risk \\
All outcomes & $\begin{array}{l}\text { Comment: see Avidan } 2008 \\
\text { (46/2907) vs (50/2902), Peto OR 0.92 (0.61 to 1.37) }\end{array}$ \\
& $\begin{array}{l}\text { Email sent to author to clarify this issue: 25 November 2013: Michael Avidan, } \\
\text { avidanm@anest.wustl.edu }\end{array}$
\end{tabular}

\begin{tabular}{ll}
\hline $\begin{array}{l}\text { Selective reporting (re- } \\
\text { porting bias) }\end{array}$ & $\begin{array}{l}\text { Quote from survey: "The study protocol is available and was pub- } \\
\text { lished in the journal BMC Anesthesiology (http://www.ncbi.nlm.ni- } \\
\text { h.gov/pubmed/19948045), and the study's pre-specified (primary and sec- } \\
\text { ondary) outcomes that are of interest in the review have been reported in the } \\
\text { pre-specified way. The distressing experience of awareness was reported as a } \\
\text { post hoc analysis" }\end{array}$ \\
\hline Other bias & Low risk \\
& $\begin{array}{l}\text { Quote from survey: "We know of no important source of bias related to study } \\
\text { design" }\end{array}$ \\
\hline
\end{tabular}

\section{Baraka 1989}

\begin{tabular}{ll}
\hline Methods & Study design: randomized parallel groups \\
& Study dates: not stated \\
\hline Participants & Country: Lebanon \\
& Sex: female \\
& Age: mean age 31 \\
& ASA: not available, "healthy" \\
& Procedure: caesarean section \\
Study size: 50
\end{tabular}


Intervention 5: induction: ketamine $1.5 \mathrm{mg} / \mathrm{kg}$; maintenance: $100 \% \mathrm{O}_{2}, \mathrm{~N}=10$

Primary outcomes: APGAR, blood loss maternal artery $\mathrm{PO}_{2}(\mathrm{kPa}), \mathrm{PCO}_{2}(\mathrm{kPa})$, umbilical vein $\mathrm{PO}_{2}(\mathrm{kPa})$,
$\mathrm{PCO}_{2}(\mathrm{kPa})$
Secondary outcome: awareness/wakefulness as defined using an awareness classification system (see
Table 1$)$ : class 4
Quote: "Awareness following induction of anaesthesia was detected using isolated forearm technique"
Comment: in this review this is referred to as "wakefulness"; "recall" is used by the authors as patient
memory of postoperative events (awareness)
Table 1 p646: "awareness" (wakefulness) 18 (14 in thiopentone and 4 in ketamine groups) patients,
"recall" (awareness) 2 patients, intraoperative dreams 1 , intraoperative hallucination 1 (classified as
dream; both dreams in ketamine group)
"Two of the 20 thiopentone patients had recall, confined to the time of delivery"

Notes Non-randomized portion of anaesthetic: parts of intravenous (IV) vs parts of volatile agent/nar-
cotics/hypnotics bolus/muscle relaxants induction yes/maintenance yes

Anaesthetic induction: suxamethonium $1.5 \mathrm{mg} / \mathrm{kg}$

After delivery - anaesthetic maintenance: $66 \mathbf{N}_{\mathbf{2}} \mathbf{O}$ in $\mathrm{O}_{2}+$ fentanyl $3 \mu \mathrm{gg} / \mathrm{kg} /$ alcuronium $0.25 \mathrm{mg} / \mathrm{kg}$

Time of outcome determination: following recovery and the next day

Method of outcome determination: interview

"Awareness following induction of anaesthesia was detected using the isolated forearm technique...Following tracheal intubation, the patient's right hand was clasped by the anaesthetist and the patient was asked to squeeze and relax her hand three times successively... Because hand movement may occur spontaneously or as a response to surgical stimulation, the test was considered positive only if the patient squeezed and relaxed her hand according to instructions"

ROB survey see Baraka 1998: the Cochrane Anaesthesia, Critical and Emergency Care Group's editorial team prefers not to extrapolate to previously published RCTs in assigning ROB risk

\section{Risk of bias}

\begin{tabular}{lll}
\hline Bias & Authors' judgement & Support for judgement \\
\hline $\begin{array}{l}\text { Random sequence genera- } \\
\text { tion (selection bias) }\end{array}$ & Unclear risk & Quote: "The 50 patients were allocated randomly to five equal groups" \\
\hline $\begin{array}{l}\text { Allocation concealment } \\
\text { (selection bias) }\end{array}$ & Unclear risk & Comment: no information provided \\
\hline $\begin{array}{l}\text { Blinding of participants } \\
\text { and personnel (perfor- } \\
\text { mance bias) }\end{array}$ & Unclear risk & Comment: no information provided \\
$\begin{array}{l}\text { All outcomes } \\
\text { Blinding of outcome as- } \\
\text { sessment (detection bias) } \\
\text { All outcomes }\end{array}$ & Unclear risk & Comment: insufficient information provided \\
\hline
\end{tabular}


Baraka 1989 (Continued)

Incomplete outcome data Low risk Comment: no dropout
(attrition bias)

All outcomes

\begin{tabular}{lll}
\hline $\begin{array}{l}\text { Selective reporting (re- } \\
\text { porting bias) }\end{array}$ & Low risk & Comment: awareness outcome part of inclusion criteria \\
\hline Other bias & Unclear risk & Comment: insufficient information provided \\
\hline
\end{tabular}

Baraka 1998

\begin{tabular}{ll}
\hline Methods & Study design: randomized parallel groups \\
& Study dates: "January 1997 till October 1997" (email bias survey, see notes) \\
\hline Participants & Country: Lebanon \\
Sex: female & Age: mean 30 \\
ASA: I-II & Procedure: elective caesarean section \\
Study size: 40
\end{tabular}

\section{Interventions Randomized portion of anaesthetic: parts of TIVA: narcotic vs narcotic}

Intervention 1: induction with $100 \mathrm{mg}$ tramadol + tramadol $50 \mathrm{mg}$ as needed, $\mathrm{N}=20$

Intervention 2: induction with $100 \mathrm{mg}$ fentanyl + fentanyl $50 \mu \mathrm{g}, \mathrm{N}=20$

Primary outcomes: similar to Baraka 1989
Secondary outcomes: awareness/wakefulness as defined using an awareness classification system (see
Table 1): class 4
$\begin{aligned} & \text { Quote: "No patient in the fentanyl group had any intraoperative recall, while two patients in the tra- } \\ & \text { madol group recalled crying of their newborns at the delivery time; no pain was experienced at that } \\ & \text { time" }\end{aligned}$

Notes
Non-randomized portion of anaesthetic: parts of TIVA: $\mathrm{N}_{2} \mathrm{O}$ yes/narcotics/hypnotics bolus/muscle relaxants induction yes/maintenance yes

Anaesthesia induction: $100 \mathrm{mg}$ tramadol or $100 \mathrm{mg}$ fentanyl + thiopental $3 \mathrm{mg} / \mathrm{kg}+$ succinylcholine 1.5 $\mathrm{mg} / \mathrm{kg}$

Anaesthesia maintenance: $\mathrm{N}_{2} \mathrm{O} 50 \%$ + vecuronium $0.1 \mathrm{mg} / \mathrm{kg}$; post partum: $\mathrm{N}_{2} \mathrm{O} 50 \%$

TIme of outcome determination: following recovery and day after operation

Method of outcome determination: interview

Survey response: 10 March 2011 Boutros Assaf, nbassaf@cyberia.net.lb

\section{Risk of bias}

\section{Bias}

\section{Authors' judgement Support for judgement}


Baraka 1998 (Continued)
Random sequence genera- Low risk
Quote: "paper draw" (email bias survey)
tion (selection bias)
Quote: "Patients were randomly allocated into two groups"

\begin{tabular}{lll}
\hline $\begin{array}{l}\text { Allocation concealment } \\
\text { (selection bias) }\end{array}$ & High risk
\end{tabular}

Blinding of participants High risk Comment: see below
and personnel (perfor-
mance bias)
All outcomes

\begin{tabular}{lll}
\hline $\begin{array}{l}\text { Blinding of outcome as- } \\
\text { sessment (detection bias) } \\
\text { All outcomes }\end{array}$ & Low risk & $\begin{array}{l}\text { Quote: "the anaesthesiologist was not blinded...Patient, Awareness outcome } \\
\text { assessor (interviewer)" (email bias survey, see notes) }\end{array}$ \\
\hline $\begin{array}{l}\text { Incomplete outcome data } \\
\begin{array}{l}\text { (attrition bias) } \\
\text { All outcomes }\end{array}\end{array}$ & Low risk & Comment: no missing outcome data \\
\hline $\begin{array}{l}\text { Selective reporting (re- } \\
\text { porting bias) }\end{array}$ & Low risk & "study protocol not available" (email bias survey) \\
\hline Other bias & Low risk & Comment: awareness outcome part of inclusion criteria \\
\hline
\end{tabular}

Barr 1977

\begin{tabular}{ll}
\hline Methods & Study design: randomized parallel groups \\
& Study dates: not stated \\
\hline Participants & Country: UK \\
Sex: female & Age: 28 \\
ASA: not available \\
Procedure: caesarean section \\
Study size: 220 enrolled, 37 dropouts, 183 completed study
\end{tabular}

Interventions

Randomized portion of anaesthetic: parts of intravenous (IV) anaesthesia: maintenance: post-delivery: hypnotics

Intervention 1: post-delivery: lorazepam $2 \mathrm{mg}, \mathrm{N}=110$ enrolled; 93 results

Intervention 2: post-delivery: diazepam $10 \mathrm{mg}, \mathrm{N}=110$; 90 results

\begin{tabular}{ll}
\hline Outcomes & Primary outcomes: awareness/wakefulness as defined using an awareness classification system (see \\
& Table 1): class 4 \\
& $\begin{array}{l}\text { Quote: "A total of seven patients had pleasant dreams, seven had unpleasant dreams and three had ac- } \\
\text { tual recall" }\end{array}$ \\
\hline Notes & $\begin{array}{l}\text { Non-randomized portion of anaesthetic: parts of intravenous (IV) anaesthesia (Liverpool tech- } \\
\text { nique): } \mathbf{N}_{\mathbf{2}} \mathbf{O} \text { yes/narcotics/hypnotics bolus/NMBs induction yes/maintenance yes }\end{array}$ \\
\hline
\end{tabular}


Barr 1977 (Continued)

Anaesthesia induction: sodium thiopentone to max of $300 \mathrm{mg}$ or $4 \mathrm{mg} / \mathrm{kg}$ + suxamethonium or pancuronium; anaesthesia maintenance: $\mathrm{N}_{2} \mathrm{O}$ in oxygen 2:1. If signs of lightness PRN: incremental doses pethidine $25 \mathrm{mg}$ max dose (Liverpool technique). Post-delivery medication: ergometrine $0.5 \mathrm{mg}+$ pethidine $0.5 \mathrm{mg}+$ study drug

Comment: see discussion of $r$ etrograde amnesia

Quote: "unpleasant dreams indicate inadequate depth of anaesthesia"

Time of outcome determination: second or third postoperative day

Method of outcome determination: interview

No email address available for ROB survey

\section{Risk of bias}

\begin{tabular}{|c|c|c|}
\hline Bias & Authors' judgement & Support for judgement \\
\hline $\begin{array}{l}\text { Random sequence genera- } \\
\text { tion (selection bias) }\end{array}$ & Low risk & $\begin{array}{l}\text { Quote: "The trial ampoules...were distributed from a table of random num- } \\
\text { bers" }\end{array}$ \\
\hline $\begin{array}{l}\text { Allocation concealment } \\
\text { (selection bias) }\end{array}$ & Unclear risk & Comment: as above \\
\hline $\begin{array}{l}\text { Blinding of participants } \\
\text { and personnel (perfor- } \\
\text { mance bias) } \\
\text { All outcomes }\end{array}$ & Low risk & $\begin{array}{l}\text { Quote: "Immediately following delivery the anaesthetist injected ergometrine } \\
0.5 \mathrm{mg} \text {, pethidine } 25 \mathrm{mg} \text {, and the contents of a trial ampoule into the intra- } \\
\text { venous infusion. The trial ampoules contained lorazepam } 2 \mathrm{mg} \text { in } 2 \mathrm{ml} \text {, or di- } \\
\text { azepam } 10 \mathrm{mg} \text { in } 2 \mathrm{ml} \text {; these were distributed from a table of random num- } \\
\text { bers" }\end{array}$ \\
\hline $\begin{array}{l}\text { Blinding of outcome as- } \\
\text { sessment (detection bias) } \\
\text { All outcomes }\end{array}$ & High risk & $\begin{array}{l}\text { "Postoperative interview. The patient was interviewed on the second or third } \\
\text { postoperative day by one of the authors. The questions asked are listed in Ta- } \\
\text { ble 1" }\end{array}$ \\
\hline \multirow{2}{*}{$\begin{array}{l}\text { Incomplete outcome data } \\
\text { (attrition bias) } \\
\text { All outcomes }\end{array}$} & Low risk & $\begin{array}{l}\text { Comment: } 17 \% \text { dropouts; lorazepam } 93(110-93=17 \text { exclusions, } 110-90=20 \\
\text { exclusions) and diazepam } 90 \text { completed study; Peto OR } 0.82(0.41 \text { to } 1.67)\end{array}$ \\
\hline & & $\begin{array}{l}\text { Quote: "Thirty-seven of the } 220 \text { patients originally admitted to the trial were } \\
\text { later excluded because of deviation from the protocol, incomplete records, } \\
\text { broken ampoules, or lost forms; as far as the authors are able to ascertain } \\
\text { none of these patients was aware during the procedure" }\end{array}$ \\
\hline $\begin{array}{l}\text { Selective reporting (re- } \\
\text { porting bias) }\end{array}$ & Low risk & Comment: awareness outcome part of inclusion criteria \\
\hline Other bias & Unclear risk & Comment: insufficient information provided \\
\hline
\end{tabular}

\section{Bauer 2004}

\begin{tabular}{ll}
\hline Methods & Study design: randomized parallel groups \\
& Study dates: "December 2000 - February 2002" (email bias survey, see notes) \\
\hline Participants & Country: Germany \\
& Sex: both \\
Age: 60 \\
ASA: not available \\
Procedure: elective coronary artery bypass grafting
\end{tabular}


Bauer 2004 (Continued)

\section{Study size: 40}

\section{Interventions $\quad$ Randomized portion of anaesthetic: parts of TIVA TCI vs MCI and ADM BIS 40 to 50}

Intervention 1 (TCl group): background infusion of remifentanil $(0.3 \mu \mathrm{g} / \mathrm{kg} / \mathrm{min})$ and propofol at a target concentration of $3 \mu \mathrm{g} / \mathrm{mL}$ using target-controlled infusion (TCl, Diprifusor), $\mathrm{N}=20$

Intervention 2 (BIS group): general anaesthesia background infusion of remifentanil $(0.3 \mu \mathrm{g} / \mathrm{kg} / \mathrm{min})$ and propofol titrated to maintain a BIS value of 40 to $50, \mathrm{~N}=20$

\section{Outcomes}

Primary outcomes: awareness/wakefulness as defined using an awareness classification system (see Table 1): class 1

Quote: "None of the patients reported awareness during a standardized interview"

\section{Notes}

\section{Non-randomized portion of anaesthetic: parts of TIVA: $\mathrm{N}_{2} \mathrm{O}$ no/narcotics/hypnotics bolus $\mathrm{MCI}$ TCI/ muscle relaxants induction yes/maintenance yes/ADM no}

Anaesthesia induction: remifentanil infusion $(0.1 \mu \mathrm{g} / \mathrm{kg} / \mathrm{min})+$ propofol at target concentration of ( 3 $\mu \mathrm{g} / \mathrm{mL})+$ atracurium plus additional boluses: ensure relaxation throughout surgery

Anaesthesia maintenance: remifentanil infusion $(0.3 \mu \mathrm{g} / \mathrm{kg} / \mathrm{min})+$ propofol titrated in group specific manner (see above) + atracurium boluses as needed; controlled ventilation; BIS group was titrated to BIS $<60$

Time of outcome determination: first and third postoperative day

Quote: "Total intravenous anesthesia using propofol- remifentanil effectively attenuates the neurohumoral stress"

Method of outcome determination: standardized interview

Survey response: 2 February 2011, Michael Bauer michael.bauer@med.uni-jena.de

Re-emailed 26 December 2013 re allocation

\section{Risk of bias}

\begin{tabular}{lll}
\hline Bias & Authors' judgement & Support for judgement \\
\hline $\begin{array}{l}\text { Random sequence genera- } \\
\text { tion (selection bias) }\end{array}$ & Low risk & Quote: "computer-generated randomisation list" (email survey) \\
\hline $\begin{array}{l}\text { Allocation concealment } \\
\text { (selection bias) }\end{array}$ & Unclear risk & $\begin{array}{l}\text { Quote: "sealed envelopes; opened immediately prior to induction of anaesthe- } \\
\text { sia" (email bias survey) }\end{array}$ \\
& $\begin{array}{l}\text { Comment: unclear if envelope opaque as per Cochrane guidelines (Higgins } \\
\text { 2011) }\end{array}$ \\
\hline $\begin{array}{l}\text { Blinding of participants } \\
\begin{array}{l}\text { and personnel (perfor- } \\
\text { mance bias) }\end{array}\end{array}$ & High risk & Quote: "patient" (email survey) \\
\begin{tabular}{l} 
All outcomes \\
\hline
\end{tabular} &
\end{tabular}

Blinding of outcome assessment (detection bias) All outcomes
Unclear risk

Quote: "None of the patients reported intraoperative recall during the standardised interview on postoperative days 1 and $3 "$

Incomplete outcome data Low risk Quote: "data complete" (email survey)
(attrition bias)

All outcomes 
Bauer 2004 (Continued)

Selective reporting (re- Low risk Quote: "Study protocols are not available but report includes all expected outporting bias) comes" (email survey)

Comment: awareness outcome part of inclusion criteria

Other bias Low risk Quote: "none" (email survey)

Bergmann 2013

Methods Study design: randomized parallel groups

Study dates: not stated

$\begin{array}{ll}\text { Participants } & \text { Country: Germany } \\ & \text { Sex: male/female } \\ & \text { Age: } 18 \text { to } 75: \text { mean } 44 \text { to } 48 \\ \text { ASA: ASA I and II (90\%) to III (10\%) } \\ \text { Procedure: orthopaedic: shoulder/knee/ankle } \\ \text { Study size: } 170 \text { entered; } 151 \text { completed study }\end{array}$

Interventions Randomized portion of anaesthetic: parts of TIVA ADM (SPI (plethysmograph)) vs SCP

"The propofol dose was adjusted according to entropy in both groups"

Intervention 1 (SPI group): remifentanil adjusted surgical pleth index (SPI), SPI: 20 - 50, (N=76)

Intervention 2 (control group): remifentanil adjusted clinical parameters (SCPs), $(\mathrm{N}=75)$

Propofol dose was adjusted SE entropy in an identical manner in both groups

Outcomes

The primary endpoints of the study were differences between the groups in the recovery times and the consumption of anaesthetic drugs

Secondary outcome: awareness/wakefulness as defined using an awareness classification system (see Table 1): class 1

Secondary endpoints were the occurrence of complications such as intraoperative awareness, nausea and vomiting, postoperative pain, patient satisfaction with the anaesthesia, shivering, and haemodynamic stability

"No patient reported intraoperative awareness" NMBs induction PRN/maintenance PRN SR and CV ADM (Entropy)

Quote: "surgical pleth index (SPI) is an index based on changes in plethysmographic characteristics that correlate with the balance between the sympathetic and parasympathetic nervous system"

All patients: IV midazolam (1 mg to $3 \mathrm{mg}$ ), total IV technique remifentanil/propofol: bolus remifentanil ( $1 \mathrm{mg} / \mathrm{kg}$ ), infusion $0.2 \mathrm{mg} / \mathrm{kg} / \mathrm{min}$, propofol $2 \mathrm{mg} / \mathrm{kg} / \mathrm{min}$ until entropy $\mathrm{SE}<60$; propofol $4 \mathrm{mg} / \mathrm{kg} / \mathrm{h}$, than adjusted entropy target range between $\mathbf{4 0}$ to $\mathbf{6 0}$; infusion reduced $10 \mathrm{~min}$ before end of the operation SE value allowed increase 60 and 65 . The airway was securedwhenever possible with a laryngeal mask airway for lower limb surgery, and with a tracheal tube for shoulder operations; mivacurium $(0.2 \mathrm{mg} / \mathrm{kg})$ for intubation; AP was lowered with titrated $5 \mathrm{mg}$ IV doses urapidil

Quote: "SPI is a dimensionless number between 0 (low stress) and 100 (high stress) that is calculated from the heart rate $(\mathrm{HR})$ and the pulse wave amplitude obtained with a finger clip...SPI $=100-(0.33 \times$ HBInorm $+0.67 \times$ PPGnorm)...The precise description and calculation of the algorithm is provided elsewhere.22" 


\section{Risk of bias}

\begin{tabular}{|c|c|c|}
\hline Bias & Authors' judgement & Support for judgement \\
\hline $\begin{array}{l}\text { Random sequence genera- } \\
\text { tion (selection bias) }\end{array}$ & Low risk & $\begin{array}{l}\text { Quote: "After randomization using a computer-generated list, the patients } \\
\text { were assigned to one of the two study groups" }\end{array}$ \\
\hline $\begin{array}{l}\text { Allocation concealment } \\
\text { (selection bias) }\end{array}$ & Unclear risk & Comment: no information \\
\hline $\begin{array}{l}\text { Blinding of participants } \\
\text { and personnel (perfor- } \\
\text { mance bias) } \\
\text { All outcomes }\end{array}$ & High risk & $\begin{array}{l}\text { Quote: "In the SPI group, the remifentanil dose was adjusted according to the } \\
\text { SPI, while in the control group, it was administered according to standard clin- } \\
\text { ical criteria. The propofol dose was adjusted according to SE entropy in an } \\
\text { identical manner in both groups" }\end{array}$ \\
\hline $\begin{array}{l}\text { Blinding of outcome as- } \\
\text { sessment (detection bias) } \\
\text { All outcomes }\end{array}$ & Unclear risk & $\begin{array}{l}\text { Quote: "Telephone interviews were conducted on the evening after the opera- } \\
\text { tion, and on the first and second postoperative days" }\end{array}$ \\
\hline \multirow[t]{2}{*}{$\begin{array}{l}\text { Incomplete outcome data } \\
\text { (attrition bias) } \\
\text { All outcomes }\end{array}$} & Low risk & $\begin{array}{l}\text { Quote: "One hundred and fifty-one of the } 170 \text { recruited patients were included } \\
\text { in the final analysis. Nineteen patients were excluded due to incomplete data } \\
\text { sets or retraction of } \\
\text { consent. The anthropometric data are shown in Table } 1 \text {. Seventy-six patients } \\
\text { were in the group with SPI-guided remifentanil administration and } 75 \text { patients } \\
\text { in the control group" }\end{array}$ \\
\hline & & $\begin{array}{l}\text { Comment: no high-risk dropouts; } 170 \text { recruited, all exclusions no significant } \\
\text { difference between groups: SCP (10/85) vs SPI (9/85), } 1.13 \text { ( } 0.43 \text { to } 2.91 \text { ) }\end{array}$ \\
\hline $\begin{array}{l}\text { Selective reporting (re- } \\
\text { porting bias) }\end{array}$ & Low risk & Comment: awareness outcome part of inclusion criteria \\
\hline Other bias & Unclear risk & Comment: no information \\
\hline
\end{tabular}

\section{Bestas 2004}

\begin{tabular}{ll}
\hline Methods & Study design: randomized parallel groups \\
& Study dates: "2003" (email survey) \\
\hline Participants & Country: Turkey \\
& Sex: both \\
Age: 59.6 \\
ASA: not available \\
Procedure: off-pump CABG surgery \\
Study size: 50
\end{tabular}

\section{Randomized portion of anaesthetic: IV bolus MCI ADM (BIS) vs SCP}

Intervention 1: induction: fentanyl ( $7 \mu \mathrm{g}$ to $15 \mu \mathrm{g} / \mathrm{kg}$ ) + propofol ( $2 \mathrm{mg}$ to $2.5 \mathrm{mg} / \mathrm{kg}$ ); maintenance: fentanyl $(15 \mu \mathrm{g} / \mathrm{kg} / \mathrm{h})+\operatorname{propofol}(6 \mathrm{mg} / \mathrm{kg} / \mathrm{h}), \mathrm{N}=25$

Intervention 2: induction: fentanyl ( $7 \mu \mathrm{g}$ to $15 \mu \mathrm{g} / \mathrm{kg})+$ midazolam ( $0.1 \mathrm{mg}$ to $0.3 \mathrm{mg} / \mathrm{kg})$; maintenance: fentanyl $(15 \mu \mathrm{g} / \mathrm{kg} / \mathrm{h})+$ midazolam $0.1 \mathrm{mg} / \mathrm{kg} / \mathrm{h}, \mathrm{N}=25$ 
Bestas 2004 (Continued)

Comment: depth of anaesthesia was based on clinical signs. BIS values were not shown

Outcomes Primary outcomes: awareness/wakefulness as defined using an awareness classification system (see Table 1): class 1

"No patients were noted to recall the sounds presented during the operation and the preoperative events...no patients reported to have heard anything or had any dreams intraoperatively"

\section{Notes}

\section{Non-randomized portion of anaesthetic: parts of IV:/ $\mathrm{N}_{2} \mathrm{O}$ no/narcotics/hypnotics bolus $\mathrm{MCl} / \mathrm{mus}$ - cle relaxants induction yes/maintenance yes}

Anaesthesia induction: fentanyl ( $7 \mu \mathrm{g}$ to $15 \mu \mathrm{g} / \mathrm{kg}$ ) + group-specific study drug (see above) + vecuronium $(0.1 \mathrm{mg} / \mathrm{kg})$. Anaesthesia maintenance: fentanyl $(15 \mu \mathrm{g} / \mathrm{kg} / \mathrm{h})+$ group-specific study drug (see above) + vecuronium $0.02 \mathrm{mg} / \mathrm{kg}$ as needed

Time of outcome determination: $24 \mathrm{~h}$ after surgery

Method of outcome determination: standardized questionnaire

Author responded to email survey

Survey response: 24 January 2011 Azize Bestas, abestas@firat.edu.tr

Email sent to clarify allocation on 26 November 2013 to Azize Bestas, abestas@firat.edu.tr

\section{Risk of bias}

\begin{tabular}{|c|c|c|}
\hline Bias & Authors' judgement & Support for judgement \\
\hline $\begin{array}{l}\text { Random sequence genera- } \\
\text { tion (selection bias) }\end{array}$ & Low risk & $\begin{array}{l}\text { Quote: "randomly divided into two groups" } \\
\text { Quote (email bias survey): "A random numbers table was used" }\end{array}$ \\
\hline $\begin{array}{l}\text { Allocation concealment } \\
\text { (selection bias) }\end{array}$ & High risk & $\begin{array}{l}\text { Quote (email bias survey): "Anesthesia was administered to patients by an } \\
\text { anaesthesiologist not blinded to the study allocation (blinded for BIS values)" }\end{array}$ \\
\hline $\begin{array}{l}\text { Blinding of participants } \\
\text { and personnel (perfor- } \\
\text { mance bias) } \\
\text { All outcomes }\end{array}$ & High risk & $\begin{array}{l}\text { Quote: "Patient, Anesthesiologist, Awareness outcome assessor (interviewer)" } \\
\text { Comment: although many authors define ADM vs SCP as a blinded method, } \\
\text { SCP is exposed to both groups }\end{array}$ \\
\hline $\begin{array}{l}\text { Blinding of outcome as- } \\
\text { sessment (detection bias) } \\
\text { All outcomes }\end{array}$ & Low risk & Quote: "Patient, Anesthesiologist, Awareness outcome assessor (interviewer)" \\
\hline $\begin{array}{l}\text { Incomplete outcome data } \\
\text { (attrition bias) } \\
\text { All outcomes }\end{array}$ & Low risk & Comment: no dropouts \\
\hline $\begin{array}{l}\text { Selective reporting (re- } \\
\text { porting bias) }\end{array}$ & Low risk & $\begin{array}{l}\text { Quote: "There is no any important risk of bias." (Email bias survey, see notes) } \\
\text { Comment: awareness outcome part of inclusion criteria }\end{array}$ \\
\hline Other bias & Low risk & Quote: "There is no any important risk of bias." (Email bias survey, see notes) \\
\hline
\end{tabular}

Bethune 1992

Methods Study design: randomized parallel groups


Bethune 1992 (Continued)

Study dates: not stated

\begin{tabular}{ll}
\hline Participants & Country: England \\
& Sex: both \\
& Age: 60.6 \\
& ASA: not available \\
& Procedure: coronary artery surgery \\
& Study size: 44 enrolled 43 completed study \\
\hline
\end{tabular}

\section{Interventions Randomized portion of anaesthetic: parts of IV}

Intervention 1: maintenance: propofol $2 \mathrm{mg} / \mathrm{kg} / \mathrm{h}, \mathrm{N}=22$

Intervention 2: maintenance: methohexitone $1.5 \mathrm{mg} / \mathrm{kg} / \mathrm{h}, \mathrm{N}=22$

Primary outcomes: awareness/wakefulness as defined using an awareness classification system (see
Table 1): class 2
"No patient had explicit recall of any events during the period when the tape was played. The patients
in the propofol group who heard the tape during surgery had significant implicit recall of the word as-
sociations..."

Notes $\begin{aligned} & \text { Non-randomized portion of anaesthetic: parts of IV (opioid-based anaesthesia)/ } \mathbf{N}_{\mathbf{2}} \mathbf{O} \mathbf{~ n o} / \mathbf{n a r} \text { - } \\ & \text { cotics/hypnotics bolus } \mathbf{M C l} / \mathbf{m u s c l e ~ r e l a x a n t s ~ i n d u c t i o n ~ y e s / m a i n t e n a n c e ~ y e s ~}\end{aligned}$
Anaesthesia induction: midazolam $(2 \mathrm{mg})+$ fentanyl $(15 \mathrm{\mu g} / \mathrm{kg})+$ pancuronium $(0.14 \mathrm{mg} / \mathrm{kg})$
Anaesthesia maintenance: drug infusion; atracurium $50 \mathrm{mg}$ and droperidol $5 \mathrm{mg}$ were administered on
initiation of cardiopulmonary bypass (CPB)
Time of outcome determination: between 36 and $48 \mathrm{~h}$ after surgery
Method of outcome determination: interview
Comment: this implicit memory was lost when re-tested in ICU with sedation
No email address available for ROB survey

\section{Risk of bias}

\begin{tabular}{|c|c|c|}
\hline Bias & Authors' judgement & Support for judgement \\
\hline $\begin{array}{l}\text { Random sequence genera- } \\
\text { tion (selection bias) }\end{array}$ & Unclear risk & Quote: "...were allocated randomly..." \\
\hline $\begin{array}{l}\text { Allocation concealment } \\
\text { (selection bias) }\end{array}$ & Unclear risk & Comment: no information provided \\
\hline $\begin{array}{l}\text { Blinding of participants } \\
\text { and personnel (perfor- } \\
\text { mance bias) } \\
\text { All outcomes }\end{array}$ & Unclear risk & Comment: no information provided \\
\hline $\begin{array}{l}\text { Blinding of outcome as- } \\
\text { sessment (detection bias) } \\
\text { All outcomes }\end{array}$ & Unclear risk & $\begin{array}{l}\text { Comment: pre- and postoperative interviewer was blinded to assignment - im- } \\
\text { plicit study tape }\end{array}$ \\
\hline $\begin{array}{l}\text { Incomplete outcome data } \\
\text { (attrition bias) } \\
\text { All outcomes }\end{array}$ & Low risk & $\begin{array}{l}\text { Quote: "Data from one patient in the propofol group were mislaid and had } \\
\text { been omitted from the analysis" }\end{array}$ \\
\hline
\end{tabular}


Bethune 1992 (Continued)

Selective reporting (re- Low risk Comment: awareness outcome part of inclusion criteria porting bias)

Other bias Unclear risk Comment: insufficient information provided

Bhawna 2012

\begin{tabular}{ll}
\hline Methods & Study design: randomized parallel groups \\
& Study dates: January 2007 to December 2008 \\
\hline Participants & Country: India \\
& Sex: male and female \\
Age: 25 and 65 years of age \\
ASA: I-II \\
Procedure: lower abdominal surgeries \\
Study size: 50
\end{tabular}

\section{Interventions $\quad$ Randomized portion of anaesthetic: cardiac drug vs placebo}

Intervention 1: $(\mathrm{N}=25)$ esmolol infusion

Intervention 2: $(\mathrm{N}=25)$ saline infusion

Entropy: 40 to 60

Quote: "...loading dose of randomly selected study drug infusion $(0.5 \mathrm{mg} / \mathrm{kg})$ over $5 \mathrm{~min}, 20 \mathrm{~min}$ before induction followed by a continuous infusion of the study drug at $0.5 \mathrm{mg} / \mathrm{kg} / \mathrm{min}$ till the closure of skin incision"

Primary outcomes: "...absolute isoflurane requirement between the two groups to keep the entropy
values between 40 and 60 during the peri-operat i ve period"
Secondary outcome: awareness/wakefulness as defined using an awareness classification system (see
Table 1): class 1
Quote: "No incidence of intra-operat i ve awareness was reported by any patient from either of
the groups"

Notes

Non-randomized portion of anaesthetic: parts of volatile agent: $\mathrm{N}_{2} \mathrm{O}$ no/narcotics/hypnotics bolus/muscle relaxants induction yes/maintenance PRN/ADM: entropy

Induction: fentanyl ( $3.0 \mu \mathrm{gg} / \mathrm{kg}) / \mathrm{propofol}(1.25 \mathrm{mg}$ to $2.0 \mathrm{mg} / \mathrm{kg})$ titratedentropy 40 to 60 /atracurium $(0.5 \mathrm{mg} / \mathrm{kg})$ then PRN/oxygen $\left(\mathrm{FIO}_{2}\right)$ at 0.4 /isoflurane/target RE/SE entropy

sukhminder_bajwa2001@yahoo.com 5 February 2015 response

\section{Risk of bias}

\begin{tabular}{lll}
\hline Bias & Authors' judgement & Support for judgement \\
\hline $\begin{array}{l}\text { Random sequence genera- } \\
\text { tion (selection bias) }\end{array}$ & Unclear risk & Quote from ROB survey response: "Simple randomization" \\
\hline $\begin{array}{l}\text { Allocation concealment } \\
\text { (selection bias) }\end{array}$ & Low risk & $\begin{array}{l}\text { Quote from ROB survey response: "By use of sequentially numbered opaque } \\
\text { sealed envelopes (SNOSE)" }\end{array}$ \\
\hline $\begin{array}{l}\text { Blinding of participants } \\
\begin{array}{l}\text { and personnel (perfor- } \\
\text { mance bias) }\end{array}\end{array}$ & Low risk & $\begin{array}{l}\text { Quote from ROB survey response: "Patient, Anesthesiologist, Awareness out- } \\
\text { come assessor (interviewer)" }\end{array}$ \\
\hline
\end{tabular}


Bhawna 2012 (Continued)

All outcomes Comment: infusions used same rate

Blinding of outcome as-
sessment (detection bias) $\quad$ Low risk Quote from ROB survey response: as above

sessment (detection bias)

All outcomes

\begin{tabular}{lll}
\hline $\begin{array}{l}\text { Incomplete outcome data } \\
\text { (attrition bias) } \\
\text { All outcomes }\end{array}$ & Low risk & $\begin{array}{l}\text { Quote from ROB survey response: "No such attrition/exclusions were reported } \\
\text { in the study" }\end{array}$ \\
\hline $\begin{array}{l}\text { Selective reporting (re- } \\
\text { porting bias) }\end{array}$ & Low risk & $\begin{array}{l}\text { Quote from ROB survey response: "All specified outcomes have been well ad- } \\
\text { dressed in the study"; "No significant difference in MAC was observed at inter- } \\
\text { vals other than } 30 \text { min, } 40 \text { min and } 105 \text { min intervals" }\end{array}$ \\
& Comment: awareness outcome part of inclusion criteria \\
\hline Other bias & Low risk & $\begin{array}{l}\text { Quote from ROB survey response: "Study did not have any bias potential as } \\
\text { the design of the study was conceived after thorough discussion among all re- } \\
\text { searchers" }\end{array}$ \\
\hline
\end{tabular}

Blendinger 1976

\begin{tabular}{ll}
\hline Methods & Study design: randomized parallel groups \\
& Study dates: not stated \\
\hline Participants & Country: Germany \\
Sex: both & Age: not stated \\
ASA: not stated \\
Procedure: open heart surgery \\
Study size: 15 in test group; control group not stated, assume 15 as per translator
\end{tabular}

Interventions

\section{Randomized portion of anaesthetic: parts of intravenous (IV) anaesthesia $\mathrm{MCI}$}

Intervention 1: control group no etomidate: average fentanyl dose $30 \mu \mathrm{g} / \mathrm{kg} / \mathrm{min}$

Intervention 2: experimental group average etomidate dose $\mathbf{2 . 5 5} \mathbf{~ m g / k g}$; average fentanyl dose $12 \mu \mathrm{g} /$ $\mathrm{kg} / \mathrm{min}$

Primary outcomes: anaesthesia consumption, postoperative recovery parameters
Secondary outcome: awareness/wakefulness as defined using an awareness classification system (see
Table 1): class 1
Comment: none of the subjects reported any memories

Notes
Non-randomized portion of anaesthetic: parts of intravenous (IV) anaesthesia: $\mathrm{N}_{2} \mathrm{O}$ yes/narcotics and/or hypnotics bolus $\mathrm{MCl} /$ muscle relaxants induction yes/maintenance yes

Muscle relaxation, intubation; maintenance:controlled respiration $/ \mathrm{N}_{2} \mathrm{O}(2: 1)$ fentanyl was intermittently injected

Comment: high-dose fentanyl anaesthesia with and without etomidate supplementation

Comment: details of anaesthetic unclear to translator; translator Lore Schultheiss

No email address available for ROB survey 
Blendinger 1976 (Continued)

\section{Risk of bias}

\begin{tabular}{|c|c|c|}
\hline Bias & Authors' judgement & Support for judgement \\
\hline $\begin{array}{l}\text { Random sequence genera- } \\
\text { tion (selection bias) }\end{array}$ & Unclear risk & Comment: unclear to translator \\
\hline $\begin{array}{l}\text { Allocation concealment } \\
\text { (selection bias) }\end{array}$ & Unclear risk & Comment: no information provided \\
\hline $\begin{array}{l}\text { Blinding of participants } \\
\text { and personnel (perfor- } \\
\text { mance bias) } \\
\text { All outcomes }\end{array}$ & Unclear risk & Comment: no information provided \\
\hline $\begin{array}{l}\text { Blinding of outcome as- } \\
\text { sessment (detection bias) } \\
\text { All outcomes }\end{array}$ & Unclear risk & Comment: no information provided \\
\hline $\begin{array}{l}\text { Incomplete outcome data } \\
\text { (attrition bias) } \\
\text { All outcomes }\end{array}$ & Low risk & Comment: no apparent dropout \\
\hline $\begin{array}{l}\text { Selective reporting (re- } \\
\text { porting bias) }\end{array}$ & Low risk & Comment: awareness outcome part of inclusion criteria \\
\hline Other bias & Unclear risk & Comment: insufficient information provided \\
\hline
\end{tabular}

\section{Block 1991}

\begin{tabular}{ll}
\hline Methods & Study design: randomized parallel groups \\
& Study dates: not stated \\
\hline Participants & Country: USA \\
Sex: female \\
Age: mean 34-38-35 (by group) \\
ASA: I-II-III \\
Procedure: operations on the fallopian rubes for infertility, vertical banding gastroplasty for morbid \\
obesity, total abdominal hysterectomy, cholecystectomy, other small groups \\
Study size: 72
\end{tabular}

Interventions

\section{Randomized portion of anaesthetic: parts of IV $+\mathrm{N}_{2} \mathrm{O}$ vs parts of volatile agent}

Intervention 1: inhalation group:

Isoflurane ET $1.0 \mathrm{MAC} / 70 \% \mathrm{~N}_{2} \mathrm{O} / \mathrm{O}_{2}, \mathrm{~N}=12$

Isoflurane ET $1.3 \mathrm{MAC} / 70 \% \mathrm{~N}_{2} \mathrm{O} / \mathrm{O}_{2}, \mathrm{~N}=24$

Isoflurane $\mathrm{ET} 1.5 \mathrm{MAC} / 70 \% \mathrm{~N}_{2} \mathrm{O} / \mathrm{O}_{2}, \mathrm{~N}=12$

Bolus PRN: $0.75 \mu \mathrm{g} / \mathrm{kg}$ fentanyl/equivalent sufentanil: systolic BP $15 \%$ baseline

Intervention 2; 70\% $\mathrm{N}_{2} \mathrm{O} / \mathrm{O}_{2} 2$ doses of opioids, $\mathrm{N}=24$

Induction: fentanyl $7.5 \mu \mathrm{g}$ induction/equivalent opioids, thiopentone 
Block 1991 (Continued)

Maintenance: $70 \% \mathrm{~N}_{2} \mathrm{O} / \mathrm{O}_{2}$

Outcomes Primary/secondary outcomes: awareness/wakefulness as defined using an awareness classification system (see Table 1): class 1

Comment: no implicit/explicit memory

Quote: "determine if learning occurs during general anaesthesia"

Notes

\section{Non-randomized portion of anaesthetic: parts of IV $+\mathrm{N}_{2} \mathrm{O}$ vs parts of volatile agent $\mathrm{N}_{2} \mathrm{O}$ yes/nar- cotics/hypnotics bolus $\mathrm{MCl} /$ muscle relaxants induction yes/maintenance unclear}

Thiopentone $3.0 \mathrm{mg} / \mathrm{kg}$

Bolus fentanyl $2.5 \mu \mathrm{g} / \mathrm{kg}$ for systolic BP > 15\% baseline or patient moved

Induction/maintenance: alfentanil $50 \mu \mathrm{g} / \mathrm{kg}$ (equivalent dose other opioids) then $1 \mu \mathrm{g}$ to $1.5 \mu \mathrm{g} / \mathrm{kg} / \mathrm{min}$; $70 \% \mathrm{~N}_{2} \mathrm{O} / \mathrm{O}_{2}$, infusion: assumed sufentanil $1 \mu \mathrm{g}$, fentanyl $5 \mu \mathrm{g}$, and alfentanil $25 \mu \mathrm{g}$ to be equivalent doses

No email address available for ROB survey

\section{Risk of bias}

\begin{tabular}{lll}
\hline Bias & Authors' judgement & Support for judgement \\
\hline $\begin{array}{l}\text { Random sequence genera- } \\
\text { tion (selection bias) }\end{array}$ & Unclear risk & $\begin{array}{l}\text { Quote: "Patients were allocated blindly and randomly to one of two anesthesia } \\
\text { methods..." }\end{array}$ \\
\hline $\begin{array}{l}\text { Allocation concealment } \\
\text { (selection bias) }\end{array}$ & Unclear risk & Comment: see above \\
\hline $\begin{array}{l}\text { Blinding of participants } \\
\text { and personnel (perfor- } \\
\text { mance bias) } \\
\text { All outcomes }\end{array}$ & Unclear risk & Comment: anaesthesiologist: no information provided \\
\hline
\end{tabular}

Blinding of outcome as-
sessment (detection bias) $\quad$ Unclear risk Comment: insufficient information provided

All outcomes

Incomplete outcome data Low risk Comment: no missing outcome data
(attrition bias)
All outcomes

\begin{tabular}{lll}
\hline $\begin{array}{l}\text { Selective reporting (re- } \\
\text { porting bias) }\end{array}$ & Low risk & Comment: awareness outcome part of inclusion criteria \\
\hline Other bias & Unclear risk & Comment: insufficient information provided \\
\hline
\end{tabular}

Bonato 2001

\begin{tabular}{ll} 
Methods & $\begin{array}{l}\text { Study design: randomized parallel groups } \\
\text { Study dates: not stated }\end{array}$ \\
\hline Participants & Country: Italy
\end{tabular}


Bonato 2001 (Continued)

Sex: female and male

Age: mean age 64 and 63 years (range 28 to 75 )

ASA: cardiac surgery: II-IV

Procedure: cardiac surgery

Study size: 93

\begin{tabular}{|c|c|}
\hline \multirow[t]{7}{*}{ Interventions } & Randomized portion of anaesthetic: ADM BIS 60 vs 40 : implicit memory test \\
\hline & Control group: $\mathrm{N}=20$ \\
\hline & 73 subjects (experimental group) \\
\hline & Group A: N = 35 \\
\hline & Group B: N = 38 \\
\hline & Intervention 1: BIS 60 (word list played) \\
\hline & Intervention 2: BIS 40 \\
\hline \multirow[t]{2}{*}{ Outcomes } & $\begin{array}{l}\text { Primary/secondary outcomes: awareness/wakefulness as defined using an awareness classification } \\
\text { system (see Table 1): class } 2\end{array}$ \\
\hline & $\begin{array}{l}\text { Quote: "significant intraoperative implicit memory was found }(P<0.005) \text {, but no patient had sponta- } \\
\text { neous or directed recall of intraoperative events" }\end{array}$ \\
\hline \multirow[t]{5}{*}{ Notes } & $\begin{array}{l}\text { Non-randomized portion of anaesthetic: parts of TIVA: } \mathrm{N}_{2} \mathrm{O} \text { no/narcotics/hypnotics bolus } \mathrm{MCl} / \\
\text { muscle relaxants induction yes/maintenance yes }\end{array}$ \\
\hline & Remifentanil-propofol-vecuronium-vecuronium, CPB \\
\hline & $\begin{array}{l}\text { The mean dose of propofol group A was } 1.9 \mathrm{mg} / \mathrm{kg} / \mathrm{h} \text {, group B } 2.3 \mathrm{mg} / \mathrm{kg} / \mathrm{h} \text {; remifentanil mean dose re- } \\
\text { quired in the } 2 \text { groups is the same: } 0.45 \mathrm{mg} / \mathrm{kg} / \mathrm{min}\end{array}$ \\
\hline & Translated by AM \\
\hline & No email address available for ROB survey \\
\hline
\end{tabular}

Risk of bias

\begin{tabular}{|c|c|c|}
\hline Bias & Authors' judgement & Support for judgement \\
\hline $\begin{array}{l}\text { Random sequence genera- } \\
\text { tion (selection bias) }\end{array}$ & Unclear risk & Quote: "...prospective, randomised study" \\
\hline $\begin{array}{l}\text { Allocation concealment } \\
\text { (selection bias) }\end{array}$ & Unclear risk & Comment: inadequate information \\
\hline $\begin{array}{l}\text { Blinding of participants } \\
\text { and personnel (perfor- } \\
\text { mance bias) } \\
\text { All outcomes }\end{array}$ & High risk & $\begin{array}{l}\text { Comment: anaesthesiologists targeted anaesthesia to } 2 \text { different endpoints, } \\
\text { BIS } 60 \text { and } 40\end{array}$ \\
\hline $\begin{array}{l}\text { Blinding of outcome as- } \\
\text { sessment (detection bias) } \\
\text { All outcomes }\end{array}$ & Unclear risk & $\begin{array}{l}\text { Quote: "a standardised interview was conducted to determine the extent of in- } \\
\text { traoperative explicit memory and a Word Stem" }\end{array}$ \\
\hline
\end{tabular}


Bonato 2001 (Continued)

Incomplete outcome data Low risk Comment: no missing data
(attrition bias)

All outcomes

Selective reporting (re- Low risk porting bias)

Comment: primary outcome: implicit memory; secondary outcome: awareness

Comment: awareness outcome part of inclusion criteria

Other bias Unclear risk Comment: inadequate information

Browne 1973

\begin{tabular}{ll} 
Methods & Study design: randomized parallel groups \\
& Study dates: not stated \\
\hline Participants & Country: Canada \\
& Sex: female \\
& Age: 20 to 76 \\
ASA: I-II & Procedure: gynaecological operations \\
& Study size: 112
\end{tabular}

Randomized portion of anaesthetic: parts of intravenous (IV) (neurolept) anaesthesia/induction
Interventions
Intervention 1 : induction: thiopentone ( $250 \mathrm{mg}$ to $500 \mathrm{mg}), \mathrm{N}=56$
novar $(0.5 \mathrm{~mL}$ to $1 \mathrm{~mL}), \mathrm{PRN}$ signs light anaesthesia, $\mathrm{N}=56$
\begin{tabular}{ll}
\hline Outcomes & Primary outcomes: awareness/wakefulness as defined using an awareness classification system (see \\
& Table 1): class 4
\end{tabular}

Quote: "Recall of music appeared to be definite in two patients in Group I"

Quote: "This study is concerned with the assessment of the patient's awareness for events occurring during and after surgery, when using two types of light anaesthesia"

Notes

\begin{abstract}
Non-randomized portion of anaesthetic: parts of intravenous (IV) (neurolept) anaesthesia: $\mathrm{N}_{2} \mathrm{O}$ yes/narcotics and/or hypnotics bolus muscle relaxants induction yes/maintenance PRN

Maintenance: $60 \% \mathrm{~N}_{2} \mathrm{O}$ /curare or pancuronium PRN; patients were exposed to a fixed auditory stimulus (music)

Comment: Innovar had less movement; see Dryad

Time of outcome determination: within $48 \mathrm{~h}$

Method of outcome determination: interview

No email address available for ROB survey
\end{abstract}

\title{
Risk of bias
}

\begin{tabular}{lll}
\hline Bias & Authors' judgement & Support for judgement \\
\hline $\begin{array}{l}\text { Random sequence genera- } \\
\text { tion (selection bias) }\end{array}$ & Unclear risk & Quote: "The patients were then divided at random into two groups" \\
\hline
\end{tabular}


Browne 1973 (Continued)

Allocation concealment Unclear risk $\quad$ Comment: no information provided
(selection bias)

Blinding of participants Unclear risk Comment: insufficient information provided
and personnel (perfor-
mance bias)
All outcomes

\begin{tabular}{lll}
\hline Blinding of outcome as- & Unclear risk & Comment: assessor: no information provided \\
sessment (detection bias)
\end{tabular}

All outcomes

\begin{tabular}{lll}
\hline $\begin{array}{l}\text { Incomplete outcome data } \\
\text { (attrition bias) } \\
\text { All outcomes }\end{array}$ & Low risk & Comment: no missing outcome data \\
\hline $\begin{array}{l}\text { Selective reporting (re- } \\
\text { porting bias) }\end{array}$ & Low risk & Comment: awareness outcome part of inclusion criteria \\
\hline Other bias & Unclear risk & Comment: insufficient information provided \\
\hline
\end{tabular}

\section{Bruhn 2005}

\begin{tabular}{ll}
\hline Methods & Study design: randomized parallel groups \\
& Study dates: Quote: "2001-2003" (email bias survey) \\
\hline Participants & Country: Germany \\
& Sex: both \\
& Age: 18 to 80 \\
& ASA: I-III \\
Procedure: minor surgery $>1 \mathrm{~h}$ \\
Study size: 200
\end{tabular}

\section{Interventions $\quad$ Randomized portion of anaesthetic: volatile agent types ADM (BIS) vs SCP}

Intervention 1: BIS controlled desflurane-remifentanil, $\mathrm{N}=71$

Intervention 2: AAI controlled desflurane-remifentanil, $\mathrm{N}=58$

Intervention 3: clinical parameters controlled desflurane-remifentanil; maintenance: desflurane increase $0.5 \%$ if needed, $\mathrm{N}=71$

\begin{tabular}{ll}
\hline Outcomes & Primary outcomes: recovery times and drug consumption: BIS vS SCP \\
& Secondary outcome: awareness/wakefulness as defined using an awareness classification system (see \\
Table 1 ): class 4 \\
Quote: "No patient complained of intraoperative recall" \\
20 patients remembered dreaming during surgery \\
\hline Notes \\
Non-randomized portion of anaesthetic: parts of volatile agent: $\mathbf{N}_{\mathbf{2}} \mathbf{O}$ no/narcotics/hypnotics bolus \\
$\mathbf{M C l}$ /muscle relaxants induction yes/maintenance no/ADM BIS or AAI
\end{tabular}


Induction: remifentanil $0.4 \mu \mathrm{g} / \mathrm{kg} / \mathrm{min}+$ propofol $2 \mathrm{mg} / \mathrm{kg}+$ cis-atracurium $0.1 \mathrm{mg} / \mathrm{kg}+$ remifentanil increased $0.05 \mu \mathrm{g} / \mathrm{kg} / \mathrm{min}$ if needed

Maintenance: remifentanil reduced to $0.2 \mu \mathrm{g} / \mathrm{kg} / \mathrm{min}+$ desflurane $3 \% \mathrm{ET}$ in $\mathrm{O}_{2}$ and air. No more neuromuscular blocking agents were given intraoperatively

Time of outcome determination: 1 and 3 days postoperatively

Method of determination: interview

Primary author responded to email bias survey 31 March 2011. See bias table below for responses

Survey response: 31 March 2011 J. Bruhnj.bruhn@anes.umcn.nl

\section{Risk of bias}

\begin{tabular}{|c|c|c|}
\hline Bias & Authors' judgement & Support for judgement \\
\hline $\begin{array}{l}\text { Random sequence genera- } \\
\text { tion (selection bias) }\end{array}$ & Low risk & $\begin{array}{l}\text { Quote: "The patients were randomised by drawing lots from a closed box." (E- } \\
\text { mail bias survey) }\end{array}$ \\
\hline $\begin{array}{l}\text { Allocation concealment } \\
\text { (selection bias) }\end{array}$ & High risk & $\begin{array}{l}\text { Quote: "Anaesthesiologist: Due to the study design, the anaesthesiologist had } \\
\text { to know to what group a patient was randomised." (Email bias survey) }\end{array}$ \\
\hline $\begin{array}{l}\text { Blinding of participants } \\
\text { and personnel (perfor- } \\
\text { mance bias) } \\
\text { All outcomes }\end{array}$ & High risk & Quote: "Patient" (email bias survey, see notes) \\
\hline $\begin{array}{l}\text { Blinding of outcome as- } \\
\text { sessment (detection bias) } \\
\text { All outcomes }\end{array}$ & Unclear risk & $\begin{array}{l}\text { Quote: "In post-operative period, investigators interviewed patients about } \\
\text { awareness with an informal interview." (Email bias survey) }\end{array}$ \\
\hline $\begin{array}{l}\text { Incomplete outcome data } \\
\text { (attrition bias) } \\
\text { All outcomes }\end{array}$ & Low risk & $\begin{array}{l}\text { Quote: "The outcome data were complete, there were no exclusions from the } \\
\text { analysis." (Email bias survey) }\end{array}$ \\
\hline $\begin{array}{l}\text { Selective reporting (re- } \\
\text { porting bias) }\end{array}$ & Low risk & $\begin{array}{l}\text { Quote: "...non-significant results from the study, i.e. no differences between } \\
\text { the groups were reported." (Email bias survey) } \\
\text { Comment: awareness outcome part of inclusion criteria }\end{array}$ \\
\hline Other bias & Unclear risk & Comment: no information (Email bias survey) \\
\hline
\end{tabular}

\section{Casati 1999}

\begin{tabular}{ll} 
Methods & Study design: randomized parallel groups \\
& Study dates: not stated \\
\hline Participants & Country: Italy \\
Sex: "healthy women" \\
Age: 18 to 70 \\
ASA: I-II
\end{tabular}


Casati 1999 (Continued)

Procedure: ultrasound guided oocyte retrieval for in vitro fertilization procedures

Study size: 60

Notes

\section{Randomized portion of anaesthetic: parts of IV}

Intervention 1: induction/maintenance: propofol/fentanyl

Intervention 2: induction/maintenance: midazolam/remifentanil

\section{Non-randomized portion of anaesthetic: parts of IV: $\mathrm{N}_{2} \mathrm{O}$ no/narcotics/hypnotics bolus $\mathrm{MCl} / \mathrm{mus}$ - cle relaxants induction no/maintenance no}

Midazolam/remifentanil group, ( $\mathrm{N}=30$ ) IV midazolam $(0.05 \mathrm{mg} / \mathrm{kg})$ infusion remifentanil; propofol/fentanyl group, $\mathrm{N}=30$, IV fentanyl $(1.5 \mathrm{mg} / \mathrm{kg}$ )/propofol ( $1 \mathrm{mg} / \mathrm{kg}$ ) than propofol ( $2 \mathrm{mg}$ to $4 \mathrm{mg} / \mathrm{kg} / \mathrm{h})$. SR $50 \%$ oxygen if pulse oxygen sat. $<=90 \%$ manually assisted using an oral airway-facemask

No email address available for ROB survey

\section{Risk of bias}

\begin{tabular}{|c|c|c|}
\hline Bias & Authors' judgement & Support for judgement \\
\hline $\begin{array}{l}\text { Random sequence genera- } \\
\text { tion (selection bias) }\end{array}$ & Unclear risk & Quote: "were then randomly divided in two groups according" \\
\hline $\begin{array}{l}\text { Allocation concealment } \\
\text { (selection bias) }\end{array}$ & Unclear risk & Comment: inadequate information provided \\
\hline $\begin{array}{l}\text { Blinding of participants } \\
\text { and personnel (perfor- } \\
\text { mance bias) } \\
\text { All outcomes }\end{array}$ & Unclear risk & Comment: inadequate information provided \\
\hline $\begin{array}{l}\text { Blinding of outcome as- } \\
\text { sessment (detection bias) } \\
\text { All outcomes }\end{array}$ & Unclear risk & Comment: inadequate information provided \\
\hline $\begin{array}{l}\text { Incomplete outcome data } \\
\text { (attrition bias) } \\
\text { All outcomes }\end{array}$ & Low risk & Comment: no missing data \\
\hline $\begin{array}{l}\text { Selective reporting (re- } \\
\text { porting bias) }\end{array}$ & Low risk & Comment: awareness outcome part of inclusion criteria \\
\hline Other bias & Unclear risk & Comment: inadequate information provided \\
\hline
\end{tabular}

Methods Study design: randomized parallel groups


Celebioglu 2002 (Continued)

Study dates: April to September 1999

Participants
Sex: both
Age: 54,51
ASA: NA
Procedure: open heart surgery
Study size: 59

Randomized portion of anaesthetic: maintenance: CPB: (IV) vs volatile agent (inhalational anaes-
thesia): music explicit/implicit memory test
Intervention 1: maintenance during CPB: fentanyl $10 \mu \mathrm{g} / \mathrm{kg}+$ dehydrobenzperidol $5 \mathrm{mg}+5 \mathrm{mg}$ boluses
PRN, $\mathrm{N}=30$
Intervention 2: maintenance during CPB: fentanyl $10 \mu \mathrm{g} / \mathrm{kg}+$ sevoflurane $2 \%, \mathrm{~N}=29$

Primary outcomes: awareness/wakefulness as defined using an awareness classification system (see
Table 1): class 4
Group 1: 5 cases of awareness: $5 / 30(17 \%)$
Group 2: 0 cases of awareness: $0 / 29$
Awareness $5 / 59(9 \%)$

\title{
Notes
}

Non-randomized portion of anaesthetic: parts of volatile agent $/ \mathrm{N}_{2} \mathrm{O}$ yes + narcotics + muscle relaxant(s) induction yes/maintenance explicit yes/implicit memory test

\begin{abstract}
** IV vs sevoflurane only during CPB rest of case sevoflurane ${ }^{\star \star \star}$ Classify as IV techniques compared to volatile techniques because of the unique phase of anaesthesia, CPB
\end{abstract}

Comment: difficult to classify type of anaesthetic technique: IV agents vs volatile during CPB with volatile technique pre and post CPB

Induction: etomidate $(0.3 \mathrm{mg} / \mathrm{kg})+$ dehydrobenzperidol $(5 \mathrm{mg})+$ fentanyl $(5 \mu \mathrm{g} / \mathrm{kg})+$ vecuronium $(0.1$ $\mathrm{mg} / \mathrm{kg}$ )

Maintenance: sevoflurane $2 \%$ in $50 \% \mathrm{~N}_{2} \mathrm{O}+$ fentanyl $(5 \mu \mathrm{g} / \mathrm{kg})+$ additional vecuronium was given during surgery

Quote: "...three different audiotapes were played during the operation: one containing radio static and assorted noises such as ringing telephones during the pre-bypass period, a tape of a famous Turkish folk music singer during the actual period of bypass, followed by classical music during the post bypass period"

Time of outcome determination: 8 and $24 \mathrm{~h}$ after surgery

Method of outcome determination: interview

Bilge Celebioglu, bilgesel@superonline.com.tr survey 4 February 2013 - failed to deliver

\section{Risk of bias}

\begin{tabular}{lll}
\hline Bias & Authors' judgement & Support for judgement \\
\hline $\begin{array}{l}\text { Random sequence genera- } \\
\text { tion (selection bias) }\end{array}$ & High risk & $\begin{array}{l}\text { Quote: "Random allocation was done by assigning the first 10 patients to } \\
\text { Group 1, the next 10 patients to Group 2, and so on" }\end{array}$ \\
\hline \hline
\end{tabular}


Celebioglu 2002 (Continued)

$\begin{array}{ll}\begin{array}{l}\text { Allocation concealment } \\ \text { (selection bias) }\end{array} & \text { High risk } \\ \end{array}$
(selection bias)

Unclear risk

Comment: anaesthesiologist: no information provided

Blinding of participants and personnel (performance bias)

All outcomes

Blinding of outcome as- $\quad$ Unclear risk $\quad$ Comment: assessor: no information provided
sessment (detection bias)

(detion bias)

All outcomes

Incomplete outcome data Low risk Comment: no missing outcome data
(attrition bias)

All outcomes

Selective reporting (re- Low risk Comment: awareness outcome part of inclusion criteria
porting bias)

\begin{tabular}{ll}
\hline Other bias $\quad$ Unclear risk $\quad$ Comment: insufficient information provided \\
\hline
\end{tabular}

\section{Celleno 1993}

\begin{tabular}{ll}
\hline Methods & Study design: randomized parallel groups \\
& Study dates: "1992" (email survey) \\
\hline Participants & Country: Italy \\
& Sex: female \\
Age: mean 31 \\
ASA: Quote: "Ninety healthy women at term ..." implied: I and II \\
Procedure: elective caesarean section \\
Study size: 90
\end{tabular}

Interventions

\section{Randomized portion of anaesthetic: volatile agent types: IV induction hypnotics}

Intervention 1: induction: thiopental $15 \mathrm{mg} / \mathrm{kg}, \mathrm{N}=30$

Intervention 2: induction: propofol $2.4 \mathrm{mg} / \mathrm{kg}, \mathrm{N}=30$

Intervention 3: induction: midazolam $0.3 \mathrm{mg} / \mathrm{kg}, \mathrm{N}=30$

Outcomes

Primary outcomes: maternal/fetal anaesthesia drug consumption, APGAR, surgical/anaesthesia times, quality of anaesthesia assessed: standard somatic, sympathetic, and haemodynamic signs. Tearing, sweating, or opening eyes considered to indicate light plane of anaesthesia

Secondary outcome: awareness/wakefulness as defined using an awareness classification system (see Table 1): class 1

Quote: "None of the patients reported any recall of the intraoperative period"

Comment: dreams during surgery were reported in $17 \%$ of the propofol group and $3 \%$ of the thiopental group

Notes

Non-randomized portion of anaesthetic: parts of volatile agent: $\mathrm{N}_{\mathbf{2}} \mathrm{O}$ yes/narcotics/hypnotics bolus/muscle relaxants induction ys/maintenance PRN

Anaesthesia induction: group specific induction regimen (see above) + succinylcholine $1.5 \mathrm{mg} / \mathrm{kg}+\mathrm{in}$ tubation 
Anaesthesia maintenance $50 \% \mathrm{~N}_{2} \mathrm{O}$ in oxygen $+0.75 \%$ isoflurane; after the umbilical cord clamped: $\mathrm{N}_{2} \mathrm{O}$ $60 \%+$ infusion of oxytocin $0.02 \mathrm{U} / \mathrm{mL}+$ atracurium as necessary

Time of outcome determination: first postoperative day

Method of outcome determination: interview

Survey response: 24 January 2011, Capogna dipartimento.anestesia@gruppogarofalo.com

Email about postoperative interviewer 21 January 2013

Emailed again to clarify postoperative blinding 4 March 2013

\section{Risk of bias}

\begin{tabular}{|c|c|c|}
\hline Bias & Authors' judgement & Support for judgement \\
\hline \multirow[t]{2}{*}{$\begin{array}{l}\text { Random sequence genera- } \\
\text { tion (selection bias) }\end{array}$} & Low risk & $\begin{array}{l}\text { Quote: "Patients were randomized, according to a computerized randomiza- } \\
\text { tion code, to one of three groups of } 30 \text { patients each to receive thiopental } 15 \\
\mathrm{mg} / \mathrm{kg} \text {, propofol } 12.4 \mathrm{mg} / \mathrm{kg} \text {, or midazolam } 0.3 \mathrm{mg} / \mathrm{kg} \text { " }\end{array}$ \\
\hline & & Quote: "Computerized randomization code" (email survey) \\
\hline $\begin{array}{l}\text { Allocation concealment } \\
\text { (selection bias) }\end{array}$ & Low risk & $\begin{array}{l}\text { Quote: "The investigator was not involved in the anesthesia administration } \\
\text { and not aware of the induction agent used" (email survey) }\end{array}$ \\
\hline $\begin{array}{l}\text { Blinding of participants } \\
\text { and personnel (perfor- } \\
\text { mance bias) } \\
\text { All outcomes }\end{array}$ & Low risk & $\begin{array}{l}\text { Quote: "Two anesthesiologists were assigned to each patient, one who was } \\
\text { blinded to the induction drug administered to the mother and was conducting } \\
\text { the investigation and another who was administering the anesthesia. A neurol- } \\
\text { ogist and technician-neurologist performing the maternal electroencephalo- } \\
\text { gram (EEG), as well as the neonatologist who performed the neonatal exami- } \\
\text { nations, also were blinded to the maternal treatment" }\end{array}$ \\
\hline
\end{tabular}

\section{Blinding of outcome as- High risk} sessment (detection bias) All outcomes

Quote: "The day after surgery, all patients were asked about the occurrence of intraoperative dreams, awareness, or discomfort at the time of injection of the induction drug"

Quote: "Patient, Anesthesiologist" (email survey)

Email about postoperative interviewer 21 January 2013

Emailed again to clarify postoperative blinding 4 March 2013

Incomplete outcome data Low risk
(attrition bias)

Quote: "No patient was excluded from the study or the analysis, main outcome All outcomes data are published" (email survey)

Selective reporting (re- Low risk porting bias)

Quote: "The original study protocol and the original data are no more available: we performed this study more than 15 years ago and the meantime we also moved to another hospital!" (email survey)

Comment: awareness outcome part of inclusion criteria

Other bias Low risk Comment: none identified by author response to survey

Chen 2009

Methods Study design: randomized parallel groups


Chen 2009 (Continued)

Study dates: not provided

\begin{tabular}{|c|c|}
\hline \multirow[t]{6}{*}{ Participants } & Country: Germany \\
\hline & Sex: both \\
\hline & Age: 25 to 56 \\
\hline & ASA: I and II \\
\hline & Procedure: ENT surgery \\
\hline & Study size: 50 \\
\hline \multirow[t]{4}{*}{ Interventions } & Randomized portion of anaesthetic: parts of TIVA TCI vs MCI \\
\hline & Intervention 1: $\mathrm{TCl}$ induction/maintenance propofol $4 \mu \mathrm{g} / \mathrm{mL}$ than remifentanil $0.3 \mu \mathrm{g} / \mathrm{kg} / \mathrm{min}, \mathrm{N}=25$ \\
\hline & $\begin{array}{l}\text { Intervention 2: } \mathrm{MCl} \text { induction/maintenance bolus propofol } 2 \mathrm{mg} / \mathrm{kg} \text { than continuous propofol } 5 \mathrm{mg} / \\
\mathrm{kg} / \mathrm{h}+\text { remifentanil } 0.3 \mu \mathrm{g} / \mathrm{kg} / \mathrm{min}, \mathrm{N}=25\end{array}$ \\
\hline & Auditory-evoked potential/BIS \\
\hline \multirow[t]{3}{*}{ Outcomes } & Primary outcomes: anaesthesia and recovery parameters, propofol and remifentanil consumption \\
\hline & $\begin{array}{l}\text { Secondary outcome: awareness/wakefulness as defined using an awareness classification system (see } \\
\text { Table 1): class } 1\end{array}$ \\
\hline & Comment: no recall \\
\hline
\end{tabular}

Notes

Non-randomized portion of anaesthetic: parts of TIVA: $\mathrm{N}_{2} \mathrm{O}$ no/narcotics/hypnotics bolus $\mathrm{MCl} /$ muscle relaxants induction yes/maintenance no: ADM: BIS/MLAEPs

Induction: propofol $20 \mathrm{mg}$ (if BIS not $<60$ during induction) + rocuronium $0.6 \mathrm{mg} / \mathrm{kg}$, no other relaxants were injected during maintenance of anaesthesia. Maintenance: maintain BIS 40 to 60 and MAP within $20 \%$ of baseline values

Total dose table: page 931. Total propofol dosages and anaesthesia times available

Time of outcome determination: on the day after surgery

Method of outcome determination: interview

Correspondence to Berthold Bein, MD

Email: bein@anethesie.uni·kiel.de

\section{Risk of bias}

\begin{tabular}{lll}
\hline Bias & Authors' judgement & Support for judgement \\
\hline $\begin{array}{l}\text { Random sequence genera- } \\
\text { tion (selection bias) }\end{array}$ & Unclear risk & $\begin{array}{l}\text { Quote: "Patients were randomly allocated to one of two groups by opening of } \\
\text { a sealed envelope" }\end{array}$ \\
\hline $\begin{array}{l}\text { Allocation concealment } \\
\text { (selection bias) }\end{array}$ & Unclear risk & $\begin{array}{l}\text { Quote: "Patients were randomly allocated to one of two groups by opening of } \\
\text { a sealed envelope" }\end{array}$ \\
\hline $\begin{array}{l}\text { Blinding of participants } \\
\text { and personnel (perfor- } \\
\text { mance bias) }\end{array}$ & Unclear risk & Comment: not downgraded for not using the word "opaque" \\
\begin{tabular}{l} 
All outcomes \\
\hline
\end{tabular} & \\
\hline
\end{tabular}


Chen 2009 (Continued)

Blinding of outcome as- Low risk Quote: assessor "On the day after surgery, all patients were interviewed about sessment (detection bias) awareness and memory during the perioperative period by an anaesthesioloAll outcomes gist unaware of the type of anaesthesia performed"

Incomplete outcome data Low risk Comment: no missing outcome data
(attrition bias)

All outcomes

\begin{tabular}{lll}
\hline $\begin{array}{l}\text { Selective reporting (re- } \\
\text { porting bias) }\end{array}$ & Low risk & Comment: awareness outcome part of inclusion criteria \\
\hline Other bias & Unclear risk & Comment: insufficient information provided \\
\hline
\end{tabular}

Cheun 1987

\begin{tabular}{ll}
\hline Methods & Study design: randomized parallel groups \\
& Study dates: not stated \\
\hline Participants & Country: Korea \\
& Sex: both \\
Age: NA \\
ASA: NA \\
Procedure: open heart surgery \\
Study size: 180
\end{tabular}

Interventions Randomized portion of anaesthetic: regional anaesthesia: spinal

Intervention 1: spinal anaesthesia $0.1 \mathrm{mg} / \mathrm{kg}$ of morphine, $\mathrm{N}=60$

Intervention 2: spinal panaesthesia $1.5 \mathrm{mg} / \mathrm{kg}$ of meperidine to $55, \mathrm{~N}=60$

Intervention 3: spinal anaesthesia mixture of morphine and meperidine to 30 patients, $\mathrm{N}=60$

To eliminate intraoperative awareness, lorazepam $0.1 \mathrm{mg} / \mathrm{kg}$ or diazepam $10 \mathrm{mg}$ to $20 \mathrm{mg} / \mathrm{kg}$

Outcomes

Primary outcomes: haemodynamics (blood pressure) and duration of anaesthesia

Secondary outcome: awareness/wakefulness as defined using an awareness classification system (see Table 1): class 1

Comment: Table 4. Complications list 16 awareness events but probably data entry error and that was myalgias and awareness is 0 not myalgias; text zero events

Quote: "No one complained of intraoperative awareness, and almost all of the patients were comfortable during the surgery and recovery periods"

\section{Notes}

\section{Non-randomized portion of anaesthetic: parts of TIVA anaesthesia/ $\mathrm{N}_{2} \mathrm{O}$ no: muscle relaxants yes - both induction/maintenance}

Adjuvants: diazepam $10 \mathrm{mg}$ to $20 \mathrm{mg}$ or lorazepam $4 \mathrm{mg}$ to $8 \mathrm{mg}$

Premedication: morphine $0.1 \mathrm{mg}$ IM lorazepam $3 \mathrm{mg}$ to $5 \mathrm{mg}$ glycopyrrolate $0.005 \mathrm{mg}$ IM

Anaesthesia induction: thiopental $5 \mathrm{mg} / \mathrm{kg}+$ succinylcholine $1 \mathrm{mg} / \mathrm{kg} /, 100 \% \mathrm{O}_{2}$ maintenance: $100 \%$

$\mathrm{O}_{2}$, lorazepam, pancuronium $0.1 \mathrm{mg} / \mathrm{kg}, 0.1 \mathrm{mg} / \mathrm{kg}$ or diazepam $0.4 \mathrm{mg} / \mathrm{kg}$ for intraoperative amnesia

No titration anaesthetic strategy for light anaesthesia given in paper 
Cheun 1987 (Continued)

Time of outcome determination: first postoperative day

Method of outcome determination: interview

No email address available for ROB survey

\section{Risk of bias}

\begin{tabular}{|c|c|c|}
\hline Bias & Authors' judgement & Support for judgement \\
\hline $\begin{array}{l}\text { Random sequence genera- } \\
\text { tion (selection bias) }\end{array}$ & Unclear risk & $\begin{array}{l}\text { Quote: "Open heart surgery patients, who were suitable for spinal anaesthesia } \\
\text { were randomly selected" }\end{array}$ \\
\hline $\begin{array}{l}\text { Allocation concealment } \\
\text { (selection bias) }\end{array}$ & Unclear risk & Comment: no information provided \\
\hline $\begin{array}{l}\text { Blinding of participants } \\
\text { and personnel (perfor- } \\
\text { mance bias) } \\
\text { All outcomes }\end{array}$ & Unclear risk & Comment: anaesthesiologist: no information provided \\
\hline $\begin{array}{l}\text { Blinding of outcome as- } \\
\text { sessment (detection bias) } \\
\text { All outcomes }\end{array}$ & Unclear risk & Comment: assessor: no information provided \\
\hline $\begin{array}{l}\text { Incomplete outcome data } \\
\text { (attrition bias) } \\
\text { All outcomes }\end{array}$ & Low risk & Comment: no missing outcome data \\
\hline $\begin{array}{l}\text { Selective reporting (re- } \\
\text { porting bias) }\end{array}$ & Low risk & Comment: awareness outcome part of inclusion criteria \\
\hline Other bias & Unclear risk & Comment: insufficient information provided \\
\hline
\end{tabular}

\section{Chin 2004}

\begin{tabular}{ll}
\hline Methods & Study design: randomized parallel groups \\
& Study dates: not stated \\
\hline Participants & Country: Singapore \\
& Sex: female and male \\
Age: parturients & ASA: I-II \\
Procedure: caesarean delivery surgery \\
Study size: 23 enrolled and completed study
\end{tabular}

Interventions

\section{Randomized portion of anaesthetic: volatile agent types}

Intervention 1: maintenance: ET 1\% sevoflurane

Intervention 2: ET 1.5\% sevoflurane

Successful BIS outcome N = 12; unsuccessful BIS outcome N=11, N = 23 
Chin 2004 (Continued)

The up-down allocation method randomized each subsequent patient's ET dose based on the previous patients ET dose being judged as successful or unsuccessful based on BIS criteria explained in ROB table

Primary outcomes: anaesthesia and recovery parameters, APGAR, successful BIS response to random-
ized ET sevoflurane and relationships between sevoflurane concentration and other outcome variables
Secondary outcome: awareness/wakefulness as defined using an awareness classification system (see
Table 1): class 1
Quote: "There were no instances of intraoperative recall"

\section{Notes}

\section{Non-randomized portion of anaesthetic: parts of volatile agent: $\mathrm{N}_{2} \mathrm{O}$ yes/narcotics/hypnotics bo- lus/muscle relaxants induction yes/maintenance yes: ADM BIS}

IV sodium thiopental $4 \mathrm{mg} / \mathrm{kg}$ and succinylcholine $1 \mathrm{mg}$ to $1.5 \mathrm{mg} / \mathrm{kg}$ intubation

Maintained $\mathrm{N}_{2} \mathrm{O} 3 \mathrm{~L} / \mathrm{min} / \mathrm{O}_{2} 3 \mathrm{~L} / \mathrm{min}$. Atracurium bolus of $30 \mathrm{mg}+10 \mathrm{mg}$ PRN

Patients were mechanically ventilated end-tidal concentration $0.5 \mathrm{MAC}$ in $50 \%$

Quote: "Our aim was to determine the BIS values achieved with the equivalent end-tidal concentration of sevoflurane and to determine if a larger concentration would consistently maintain BIS values 60"

$\mathrm{N}_{2} \mathrm{O}$ throughout surgery. Morphine $0.1 \mathrm{mg}$ to $0.15 \mathrm{mg} / \mathrm{kg}$ was after delivery

ROB survey 7 January 2014. Email: gasgetJie@yahoo.co.uk

\section{Risk of bias}

\begin{tabular}{lll}
\hline Bias & Authors' judgement & Support for judgement \\
\hline $\begin{array}{l}\text { Random sequence genera- } \\
\text { tion (selection bias) }\end{array}$ & Low risk & $\begin{array}{l}\text { Quote: "The end-tidal concentration (ETC) of sevoflurane administered to each } \\
\text { patient was decided using an up down sequential allocation design, wherein } \\
\text { each patient's dose was determined by the previous patient's BIS response" }\end{array}$ \\
& $\begin{array}{l}\text { Comment: this "up down sequential method" is debated in (Benhamou 2003; } \\
\text { Lacassie 2004) }\end{array}$
\end{tabular}

Allocation concealment Low risk Comment see above

(selection bias)

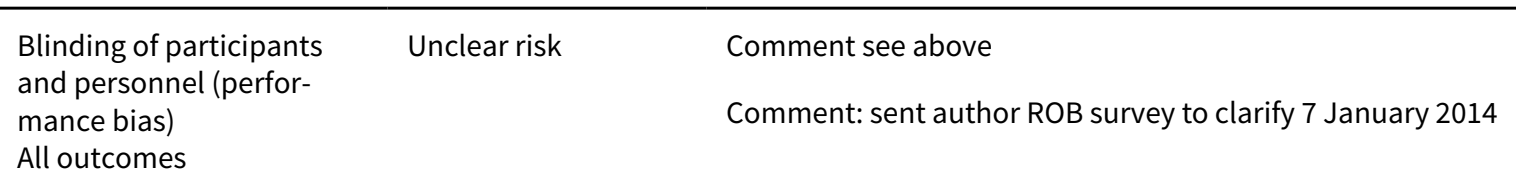

All outcomes

\begin{tabular}{lll}
$\begin{array}{l}\text { Blinding of outcome as- } \\
\text { sessment (detection bias) } \\
\text { All outcomes }\end{array}$ & Unclear risk & \\
\hline $\begin{array}{l}\text { Incomplete outcome data } \\
\text { (attrition bias) }\end{array}$ & Low risk & Comment: no missing data \\
All outcomes & &
\end{tabular}

Selective reporting (re- Low risk Comment: awareness outcome part of inclusion criteria
porting bias)

\begin{tabular}{lll}
\hline Other bias & Unclear risk & Comment: inadequate information \\
\hline
\end{tabular}


Choi 2012

\begin{tabular}{ll}
\hline Methods & Study design: randomized parallel groups \\
& Study dates: December 2010 and February 2011 \\
\hline Participants & Country: USA and Korea \\
Sex: female \\
Age: mean 31 to 32 \\
ASA: I-II \\
Procedure: caesarean delivery \\
Study size: 70 enrolled, 64 recruited, 61 completed study \\
\hline
\end{tabular}

Interventions

Randomized portion of anaesthetic: volatile agent types

Intervention 1: $(\mathrm{N}=15)$ control 1

Intervention 2: $(\mathrm{N}=15)$ control 2

Intervention 3: ( $\mathrm{N}=16)$ pre-sevoflurane 1 group - 1.2 to $1.3 \mathrm{vol}$ (control 2) end-tidal sevoflurane; but were also pre-exposed to 1 vol\% sevoflurane for the final $1 \mathrm{~min}$ of the pre-oxygenation period

Intervention 4: ( $\mathrm{N}=15)$ pre-sevoflurane 2 groups - 1.0 to 1.1 vol (control 1) end-tidal sevoflurane; but were also pre-exposed to 1 vol\% sevoflurane for the final $1 \mathrm{~min}$ of the pre-oxygenation period

Outcomes

Primary outcomes: BIS values, non-invasive arterial pressure, and heart rate

Secondary outcome: awareness/wakefulness as defined using an awareness classification system (see Table 1): class 1

Quote: "no patient reported intraoperative recall"

Notes

\section{Non-randomized portion of anaesthetic: parts of volatile agent: $\mathrm{N}_{2} \mathrm{O}$ yes/narcotics/hypnotics bo- lus/muscle relaxants induction yes/maintenance yes: ADM: BIS recorded}

Induction: thiopental sodium $4 \mathrm{mg} / \mathrm{kg} /$ trachea intubated after muscle paralysis with succinylcholine $1.5 \mathrm{mg} / \mathrm{kg}$, with rocuronium $0.5 \mathrm{mg} / \mathrm{kg}$ muscle relaxation. Anaesthesia was maintained with either 1.0 to 1.1 or 1.2 to 1.3 vol\% ET sevoflurane/50\% $\mathrm{N}_{2} \mathrm{O} /$ oxygen. After delivery, $\mathrm{N}_{2} \mathrm{O} / \mathrm{O}_{2}: 2: 1 /$ sevoflurane $\mathrm{ET} 0.8$ vol\% minimize uterine tocolysis. Midazolam $0.05 \mathrm{mg}$ to $0.1 \mathrm{mg} / \mathrm{kg}$ and fentanyl $1.0 \mathrm{mg}$ to $3.0 \mathrm{mg} / \mathrm{kg} / \mathrm{se}-$ dation or analgesia to the end of surgery. Lung ventilation $\mathrm{ET} \mathrm{CO}_{2} 30$ to $35 \mathrm{mmHg}$

ROB survey. We emailed sjinwoo@hotmail.com on 22 March 2015; multiple emails sent in 2013

\section{Risk of bias}

\begin{tabular}{lll}
\hline Bias & Authors' judgement & Support for judgement \\
\hline $\begin{array}{l}\text { Random sequence genera- } \\
\text { tion (selection bias) }\end{array}$ & Low risk & $\begin{array}{l}\text { Quote: "This prospective, randomized, controlled trial... registered with the } \\
\text { Clinical Research Information Service (code number KCT0000069)" }\end{array}$ \\
& $\begin{array}{l}\text { Quote: "Patients were randomly divided into one of the four groups using a } \\
\text { computer-generated randomization schedule; the randomized block size was } \\
\text { eight (http://www.randomization.com); randomization was achieved using } \\
\text { sealed envelopes prepared by our consultant statistician" }\end{array}$
\end{tabular}

\begin{tabular}{lll}
\hline $\begin{array}{l}\text { Allocation concealment } \\
\text { (selection bias) }\end{array}$ & Unclear risk & Comment: using sealed envelopes \\
\hline $\begin{array}{l}\text { Blinding of participants } \\
\begin{array}{l}\text { and personnel (perfor- } \\
\text { mance bias) }\end{array}\end{array}$ & High risk & $\begin{array}{l}\text { Quote: "The anesthetist controlling sevoflurane concentration was blinded to } \\
\text { the BIS value" }\end{array}$ \\
All outcomes & Comment: BIS not randomized; sevoflurane concentrations were randomized
\end{tabular}


Choi 2012 (Continued)

Blinding of outcome as- Unclear risk Quote: "Each patient was asked on discharge from the postoperative care unit sessment (detection bias) and $24 \mathrm{~h}$ after the operation, whether she could recall any events during the All outcomes operation"

Incomplete outcome data Low risk (attrition bias)

All outcomes

Quote: "Of the 70 subjects initially enrolled in the study, six were excluded because they requested regional anaesthesia. Thus, 64 subjects were randomized into the four groups, and 61 completed the study..."

Comment: no high-risk exclusions

Comment: 2 exclusions from control group 2/30 vs 1 from experimental group 1/30: not significantly different, Peto OR 0.48 (0.05 to 4.85)

\begin{tabular}{lll}
\hline $\begin{array}{l}\text { Selective reporting (re- } \\
\text { porting bias) }\end{array}$ & Low risk & $\begin{array}{l}\text { Comment: as above } \\
\text { Comment: awareness outcome part of inclusion criteria }\end{array}$ \\
\hline Other bias & Unclear risk & Comment: inadequate information \\
\hline
\end{tabular}

\section{Clyburn 1986}

\begin{tabular}{ll}
\hline Methods & Study design: randomized parallel groups \\
& Study dates: "From memory, during 1984. Completed by end of 1984" (email bias survey, see notes) \\
\hline Participants & Country: UK \\
& Sex: female \\
Age: mean: 29 and 26 \\
ASA: I-II \\
Procedure: minor gynaecological surgery \\
Study size: 60
\end{tabular}

\section{Interventions Randomized portion of anaesthetic: parts of intravenous (IV) anaesthesia}

Intervention 1: induction: midazolam $70 \mu \mathrm{g} / \mathrm{kg}, \mathrm{N}=30$

Intervention 2: induction: diazepam $150 \mu \mathrm{g} / \mathrm{kg}, \mathrm{N}=30$

Outcomes Primary outcomes: pain on injection, nausea/vomiting, recovery time

Secondary outcome: awareness/wakefulness as defined using an awareness classification system (see Table 1): class 1

Comment: no awareness

"Patients were asked to volunteer comments on unpleasant aspects of the procedure"

Induction: etomidate $300 \mu \mathrm{g} / \mathrm{kg}+$ fentanyl $1.5 \mu \mathrm{g} / \mathrm{kg}+$ group-specific study drug (see above)

Maintenance: $66 \% \mathrm{~N}_{2} \mathrm{O}$ in $34 \% \mathrm{O}_{2}$ with intermittent boluses of etomidate as needed

Quote: "Relaxation was deemed unsatisfactory in eight of the 60 patients, but in each this was corrected by a further increment of etomidate."

Survey response: 17 January 2011 Paul Clyburn clyburn@cf.ac.uk 
Clyburn 1986 (Continued)

Emailed author 26 December 2013 to clarify allocation

\section{Risk of bias}

\section{Bias Authors' judgement Support for judgement}

Random sequence genera- Low risk tion (selection bias)

Quote: "The patients were randomly allocated to one of two anaesthetic techniques"

Quote: "I believe we used randomisation tables with sealed envelopes." (email survey)

\begin{tabular}{|c|c|c|}
\hline $\begin{array}{l}\text { Allocation concealment } \\
\text { (selection bias) }\end{array}$ & Low risk & $\begin{array}{l}\text { Quote: "Sequential envelope opening" (email survey) } \\
\text { Dr Clyburn responded to email survey requesting clarification of allocation } \\
\text { process on } 28 \text { December } 2013 \\
\text { Quote: "Yes we used opaque envelopes" }\end{array}$ \\
\hline $\begin{array}{l}\text { Blinding of participants } \\
\text { and personnel (perfor- } \\
\text { mance bias) } \\
\text { All outcomes }\end{array}$ & High risk & Quote: "No blinding occurred" (email survey) \\
\hline $\begin{array}{l}\text { Blinding of outcome as- } \\
\text { sessment (detection bias) } \\
\text { All outcomes }\end{array}$ & High risk & Quote: "No blinding occurred" (email survey) \\
\hline $\begin{array}{l}\text { Incomplete outcome data } \\
\text { (attrition bias) } \\
\text { All outcomes }\end{array}$ & Low risk & $\begin{array}{l}\text { Quote: "There were no exclusions or attrition of patients studied" (email sur- } \\
\text { vey) }\end{array}$ \\
\hline $\begin{array}{l}\text { Selective reporting (re- } \\
\text { porting bias) }\end{array}$ & Low risk & $\begin{array}{l}\text { Quote: "Protocol no longer available but text does report all expected out- } \\
\text { comes" (email bias survey, see notes) } \\
\text { Quote: "Basically, there were no differences between the two studied groups } \\
\text { i.e. negative findings only" (email survey) } \\
\text { Comment: awareness outcome part of inclusion criteria }\end{array}$ \\
\hline Other bias & Low risk & Quote: "Not aware of any other sources of bias" (email survey) \\
\hline
\end{tabular}

Coates 1987

\begin{tabular}{ll} 
Methods & Study design: randomized parallel groups \\
& Study dates: not stated \\
\hline Participants & Country: UK \\
Sex: female and male & Age: 39 to 57 \\
ASA: I-II & Procedure: Quote: "body surface surgery" \\
& Study size: 17
\end{tabular}


Coates 1987 (Continued) Interventions

\section{Randomized portion of anaesthetic: parts of IV: $\mathrm{MCI}$ hypnotic}

Intervention 1: maintenance: infusion propofol $54 \mu \mathrm{g} / \mathrm{kg} / \mathrm{min}, \mathrm{N}=9$

Intervention 2: propofol $108 \mu \mathrm{g} / \mathrm{kg} / \mathrm{min}, \mathrm{N}=8$

\begin{tabular}{ll}
\hline Outcomes & Primary outcomes: haemodynamic effects \\
& Secondary outcome: awareness/wakefulness as defined using an awareness classification system (see \\
Table 1): class 1 & \\
Quote: "None of the patients, including those who had moved in response to the first incision or the in \\
troduction of IPPV, had any recall of these events or suggestion of awareness during the procedure"
\end{tabular}

Premedicated with morphine, $0.15 \mathrm{mg} / \mathrm{kg}$. Anaesthesia was induced: propofol, $2 \mathrm{mg} / \mathrm{kg} / \mathrm{succinyl}$ choline $1 \mathrm{mg} / \mathrm{kg}$ for intubation and then $0.3 \mathrm{mg} / \mathrm{kg}$ PRN during surgery/intermittent supplement $67 \%$ $\mathrm{N}_{2} \mathrm{O}$. Positive pressure ventilation (IPPV) to maintain the end-tidal CO, at $4.8 \%$ to $5.4 \%$

No email address available for ROB survey

\section{Risk of bias}

\begin{tabular}{|c|c|c|}
\hline Bias & Authors' judgement & Support for judgement \\
\hline $\begin{array}{l}\text { Random sequence genera- } \\
\text { tion (selection bias) }\end{array}$ & Unclear risk & $\begin{array}{l}\text { Quote: "Normotensive patients (ASA I or } 11 \text { ) scheduled for body surface } \\
\text { surgery were randomly allocated to group } 1 \text { (propofol infusion rate: ( } 54 \mathrm{mcg} / \\
\mathrm{kg} / \mathrm{min} \text { ) or group } 2 \text { ( } 108 \mathrm{mcg} / \mathrm{kg} / \mathrm{min}) "\end{array}$ \\
\hline $\begin{array}{l}\text { Allocation concealment } \\
\text { (selection bias) }\end{array}$ & Unclear risk & Comment: no information provided \\
\hline $\begin{array}{l}\text { Blinding of participants } \\
\text { and personnel (perfor- } \\
\text { mance bias) } \\
\text { All outcomes }\end{array}$ & Unclear risk & Comment: no information \\
\hline $\begin{array}{l}\text { Blinding of outcome as- } \\
\text { sessment (detection bias) } \\
\text { All outcomes }\end{array}$ & Unclear risk & $\begin{array}{l}\text { Quote: "Patients were questioned about their experience during induction, } \\
\text { maintenance and recovery with specific attention to the possibility of aware- } \\
\text { ness" }\end{array}$ \\
\hline $\begin{array}{l}\text { Incomplete outcome data } \\
\text { (attrition bias) } \\
\text { All outcomes }\end{array}$ & Low risk & Comment: no missing data \\
\hline $\begin{array}{l}\text { Selective reporting (re- } \\
\text { porting bias) }\end{array}$ & Low risk & Comment: awareness outcome part of inclusion criteria \\
\hline Other bias & Unclear risk & Comment: no information provided; no ROB survey data \\
\hline
\end{tabular}

Collins 1996

Methods $\quad$ Study design: randomized parallel groups
Study dates unknown


Collins 1996 (Continued)

Participants
Seuntry: Australia
Age: 25 to 39
ASA: I-II
Procedure: laparoscopic gynaecological surgery
Study size: 30

\begin{abstract}
Interventions $\quad$ Randomized portion of anaesthetic: parts of TIVA vs parts of volatile agent $+\mathrm{N}_{\mathbf{2}} \mathrm{O}$
Intervention 1: maintenance: ventilated oxygen/air mix $\mathbf{F I O}_{\mathbf{2}}=\mathbf{0 . 3}$ and infusion of propofol (110 $\mathrm{mg} /$ $\mathrm{mL}$ ) mixed with $4 \mathrm{~mL}$ of alfentanil $(0.5 \mathrm{mg} / \mathrm{mL})$, starting rate $1.5 \mathrm{~mL} / \mathrm{kg} / \mathrm{h}, \mathrm{N}=15$

Intervention 2: maintenance: oxygen/ $\mathbf{N}_{\mathbf{2}} \mathrm{O}$ FIO 0.3 isoflurane starting with inspired $1 \%$ adjusted pert response to surgical stimulation, $\mathrm{N}=15$
\end{abstract}

\begin{tabular}{ll}
\hline Outcomes & Primary outcomes: recovery characteristics \\
& Secondary outcome: awareness/wakefulness as defined using an awareness classification system (see \\
& Table 1): class 1 \\
& "No patient experienced any awareness"
\end{tabular}

Notes $\begin{aligned} & \text { Non-randomized portion of anaesthetic: parts of TIVA vs parts of volatile agent } \mathbf{N}_{\mathbf{2}} \mathbf{O} \text { no/nar- } \\ & \text { cotics/hypnotics bolus } \mathrm{MCl} / \text { muscle relaxants induction yes/maintenance unclear }\end{aligned}$
Induction: propofol $2 \mathrm{mg} \mathrm{to} 3 \mathrm{mg} / \mathrm{kg}-1+$ alfentanil $7.5 \mu \mathrm{gg}+$ vecuronium $75 \mu \mathrm{gg} / \mathrm{intubation}+\mathrm{ketoro-}$
lac $30 \mathrm{mg} \mathrm{LV}+$ droperidol $0.5 \mathrm{mg}+$ glycopyrronium bromide $3 \mu \mathrm{gg}$; residual muscle paralysis was re-
versed
No email address available for ROB survey

\title{
Risk of bias
}

\begin{tabular}{lll}
\hline Bias & Authors' judgement & Support for judgement \\
\hline $\begin{array}{l}\text { Random sequence genera- } \\
\text { tion (selection bias) }\end{array}$ & Unclear risk & $\begin{array}{l}\text { Quote: "Thirty patients undergoing laparoscopic gynaecological sterilization. } \\
\text { as day-cases, were randomly allocated to receive either total intravenous } \\
\text { anaesthesia (TIVA) with a propofol and alfentanil mixture or a standard inhala- } \\
\text { tional technique" }\end{array}$ \\
\hline
\end{tabular}

Allocation concealment Unclear risk Comment: no information provided

(selection bias)

Blinding of participants Unclear risk Comment: anaesthesiologist: no information provided

and personnel (perfor-

mance bias)

All outcomes

\begin{tabular}{|c|c|c|}
\hline $\begin{array}{l}\text { Blinding of outcome as- } \\
\text { sessment (detection bias) } \\
\text { All outcomes }\end{array}$ & Low risk & $\begin{array}{l}\text { Quote: assessor "On arrival in recovery, a second investigator, blinded to the } \\
\text { type of anaesthesia received. assessed the times to eye opening, obeying com- } \\
\text { mand/hand squeeze) and orientation (giving the correct date of birth)...Pa- } \\
\text { tients were specifically asked about awareness" }\end{array}$ \\
\hline
\end{tabular}

$\begin{array}{ll}\text { Incomplete outcome data Low risk } & \text { Quote: "One patient in each group was given post-operative pethidine prior to } \\ \text { (attrition bias) } & \text { the assessments and they were therefore excluded from the final analysis" }\end{array}$

All outcomes

Comment: $2 / 30=7 \%$ possibly high-risk awareness balanced exclusion

Selective reporting (re- Low risk $\quad$ Comment: awareness outcome part of inclusion criteria
porting bias)


Collins 1996 (Continued)

Other bias Unclear risk Comment: insufficient information provided

Crawford 1985

Methods Study design: randomized parallel groups

Study dates: not stated

\begin{tabular}{ll}
\hline Participants & Country: England \\
& Sex: female \\
& Age: parturients \\
ASA: not stated & Procedure: emergency caesarean section \\
& Enrolled and completed study size: $237+540=777$
\end{tabular}

\begin{tabular}{ll}
\hline Interventions & Randomized portion of anaesthetic: volatile agent types \\
Intervention 1: maintenance: trichloroethylene 0.2 vol. $\%, \mathrm{~N}=135$ \\
Intervention 2: maintenance: trichloroethylene $0.3 \mathrm{vol} . \%, \mathrm{~N}=128$ \\
Intervention 3: maintenance: halothane (0.2 vol. \%), $\mathrm{N}=129$ \\
Intervention 4: maintenance: halothane (0.3 vol. \%), $\mathrm{N}=129$ \\
Intervention 5: maintenance: halothane (0.4 vol. \%), $\mathrm{N}=127$ \\
Intervention 6: maintenance: halothane (0.5 vol. \%), $\mathrm{N}=129$
\end{tabular}

Outcomes

Primary outcomes: intra and postoperative parameters specific to C-sections: anaesthesia consumption and time to surgical/anaesthesia endpoints such as entry of uterus and delivery of fetus, blood loss, surgical/anaesthesia duration, fetal wellbeing parameters and maternal recovery parameters (table IV, table V)

Secondary outcome: awareness and unpleasant dreams (table VI), awareness/wakefulness as defined using an awareness classification system (see Table 1): class 4

Comment: Table VI: 22 awareness events; dreams: 13

Low dose: trichloroethylene $0.2+\mathrm{H} 0.2+\mathrm{H} 0.3=19$ aware/393 vs high dose: trichloroethylene $0.3+\mathrm{H}$ $0.4+\mathrm{H} 0.5=3$ aware $/ 384$

Quote: "Our results clearly show that trichloroethylene 0.2 vol.\%, halothane 0.2 vol. $\%$ or halothane 0.3 vol.\% [low dose]...produces an unacceptably high incidence of "awareness plus unpleasant dreams"

Notes

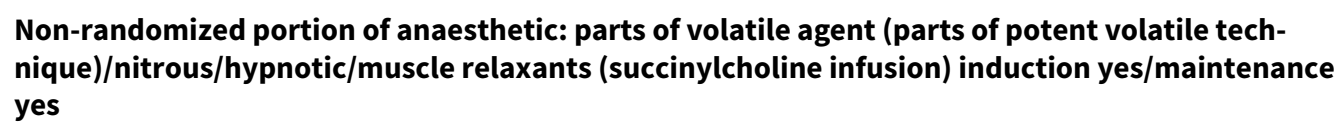

The incidence of maternal awareness unpleasant dreams was unacceptably high in the lower concentrations were used, and it is recommended that either trichloroethylene $0.3 \mathrm{vol}$. $\%$ or halothane 0.4 or 0.5 vol. $\%$ be used 
Comment: since the mechanism of intraoperative dreams is controversial, we simulated a reduction of $50 \%$ in patient awareness/dream reports balanced across both groups as a method to exclude a portion of dream reports and the significant difference between low and high-dose inhalation agents persisted (2/384 vs 9/393), Peto OR 0.28 (95\% $\mathrm{Cl} 0.09$ to 0.93$)$

No email address available for ROB survey

\section{Risk of bias}

\begin{tabular}{|c|c|c|}
\hline Bias & Authors' judgement & Support for judgement \\
\hline $\begin{array}{l}\text { Random sequence genera- } \\
\text { tion (selection bias) }\end{array}$ & Low risk & $\begin{array}{l}\text { Quote: "The choice of volatile agent was made by reference to a series of ran- } \\
\text { domised numbers..." }\end{array}$ \\
\hline $\begin{array}{l}\text { Allocation concealment } \\
\text { (selection bias) }\end{array}$ & Unclear risk & Comment: no information provided \\
\hline $\begin{array}{l}\text { Blinding of participants } \\
\text { and personnel (perfor- } \\
\text { mance bias) } \\
\text { All outcomes }\end{array}$ & High risk & Comment: inadequate information \\
\hline $\begin{array}{l}\text { Blinding of outcome as- } \\
\text { sessment (detection bias) } \\
\text { All outcomes }\end{array}$ & Unclear risk & $\begin{array}{l}\text { Comment: assessor: no information provided } \\
\text { Quote: "On the day following operation, the mother was asked if she had had } \\
\text { any dreams during the operation. If the answer was affirmative, the possibility } \\
\text { of "awareness" was pursued...The entire series showed a significantly higher } \\
\text { incidence of awareness or unpleasant dreams, or both, when.." }\end{array}$ \\
\hline $\begin{array}{l}\text { Incomplete outcome data } \\
\text { (attrition bias) } \\
\text { All outcomes }\end{array}$ & Low risk & Comment: no missing outcome data \\
\hline $\begin{array}{l}\text { Selective reporting (re- } \\
\text { porting bias) }\end{array}$ & Low risk & Comment: awareness outcome part of inclusion criteria \\
\hline Other bias & Unclear risk & Comment: insufficient information provided \\
\hline
\end{tabular}

\section{Crawford ME 1984}

\begin{tabular}{|c|c|}
\hline Methods & $\begin{array}{l}\text { Study design: randomized parallel groups } \\
\text { Study dates: not stated }\end{array}$ \\
\hline Participants & $\begin{array}{l}\text { Country: Denmark } \\
\text { Sex: female } \\
\text { Age: } 27 \text { and } 25 \\
\text { ASA: I-II } \\
\text { Procedure: termination of pregnancy (day case surgery) } \\
\text { Study size: } 100\end{array}$ \\
\hline Interventions & $\begin{array}{l}\text { Randomized portion of anaesthetic: parts of intravenous (IV) anaesthesia } \\
\text { Intervention 1: induction: midazolam } 0.2 \mathrm{mg} / \mathrm{kg}+\text { midazolam } 0.1 \mathrm{mg} / \mathrm{kg} \text { if needed; maintenance: mida- } \\
\text { zolam } 0.15 \mathrm{mg} / \mathrm{kg} \text {, fentanyl } 0.1 \mathrm{mg} \text {, and } / \mathrm{or} \text { both as needed, } \mathrm{N}=50 \\
\text { Intervention } 2: \text { induction: thiopentone } 4 \mathrm{mg} / \mathrm{kg}+\text { supplementary dose }(2 \mathrm{mg} / \mathrm{kg}) \text { as needed; mainte- } \\
\text { nance: thiopentone } 3 \mathrm{mg} / \mathrm{kg} \text {, fentanyl } 0.1 \mathrm{mg} \text {, and/or both as needed, } \mathrm{N}=50\end{array}$ \\
\hline
\end{tabular}


Crawford ME 1984 (Continued)

Outcomes

Primary outcomes: haemodynamic effects, anaesthetic consumption, nausea, vomiting and dizziness, degree of amnesia

Awareness/wakefulness as defined using an awareness classification system (see Table 1): class 1

Quote: "no patient was able to remember any part of the operation"

Notes

\section{Non-randomized portion of anaesthetic: parts of intravenous (IV) anaesthesia: $\mathrm{N}_{2} \mathrm{O}$ yes/narcotics and/or hypnotics bolus/muscle relaxants induction no/maintenance no}

Non-randomized anaesthetics: premedication droperidol $0.5 \mathrm{mg} \mathrm{IM}$, both groups $30 \mathrm{~min}$ before surgery. Group A ( $\mathrm{N}=50$ ), induction midazolam $0.2 \mathrm{mg} / \mathrm{kg}$ IV, midazolam $0.1 \mathrm{mg} / \mathrm{kg}$, midazolam 0.15 $\mathrm{mg} / \mathrm{kg}$ and/or fentanyl $0.10 \mathrm{mg}$ : PRN eyelash reflex present $3 \mathrm{~min}$ after the initial dose, after loss consciousness, fentanyl $0.15 \mathrm{mg}$, maintenance $67 \% \mathrm{~N}_{2} \mathrm{O}$ /oxygen. PRN: movement, peripheral vasoconstriction, lacrimation, sweating, change heart rate or arterial pressure), Group $B(N=50)$, induction thiopentone $4 \mathrm{mg} / \mathrm{kg}$ IV and PRN $2 \mathrm{mg} / \mathrm{kg}$ after $3 \mathrm{~min}$, fentanyl $0.15 \mathrm{mg}$ IV; maintenance: 67\% $\mathrm{N}_{2} \mathrm{O}$ /oxygen, supplemented by thiopentone $3 \mathrm{mg} / \mathrm{kg}$ and/or fentanyl $0.10 \mathrm{mg}$

Comment: balanced anaesthesia describes IV technique in this RCT

No email address available for ROB survey

\section{Risk of bias}

\begin{tabular}{lll}
\hline Bias & Authors' judgement & Support for judgement \\
\hline $\begin{array}{l}\text { Random sequence genera- } \\
\text { tion (selection bias) }\end{array}$ & Unclear risk & Quote: "allocated randomly to one of two groups (A and B)"
\end{tabular}

tion (selection bias)

Allocation concealment $\quad$ Unclear risk $\quad$ Comment: no information provided
(selection bias)

Blinding of participants Unclear risk Comment: anaesthesiologist: no information provided
and personnel (performance bias)

All outcomes

\begin{tabular}{lll}
\hline $\begin{array}{l}\text { Blinding of outcome as- } \\
\text { sessment (detection bias) } \\
\text { All outcomes }\end{array}$ & Unclear risk & Comment: assessor: no information provided \\
\hline $\begin{array}{l}\text { Incomplete outcome data } \\
\begin{array}{l}\text { (attrition bias) } \\
\text { All outcomes }\end{array}\end{array}$ & Low risk & Comment: no missing outcome data \\
\hline $\begin{array}{l}\text { Selective reporting (re- } \\
\text { porting bias) }\end{array}$ & Low risk & Comment: awareness outcome part of inclusion criteria \\
\hline Other bias & Unclear risk & Comment: insufficient information provided \\
\hline
\end{tabular}

Czarko 2013

\begin{tabular}{ll}
\hline Methods & $\begin{array}{l}\text { Study design: randomized parallel groups } \\
\text { Study dates: not stated }\end{array}$ \\
\hline Participants & $\begin{array}{l}\text { Country: Poland } \\
\text { Sex: female }\end{array}$ \\
\hline
\end{tabular}


Czarko 2013 (Continued)

Age:aged: 31 to 50

ASA: I-II

Procedure: elective gynaecological procedures, short gynaecological procedures, and caesarean section patients

Study size: 337

Interventions

Randomized portion of anaesthetic: TIVA ( $\mathrm{TCl}$ ) vs parts volatile agent + infusion narcotics (TCI)

Intervention 1: ( $\mathrm{N}=51)$ group A, TIVA/TCI remifentanil incremental doses to plasma $8.5 \mathrm{ng} \mathrm{mL}-1$, then infusion propofol to of $8 \mu \mathrm{g} \mathrm{mL}-1$. Maintained infusion remifentanil/propofol pre-set doses of $3 \mathrm{ng}$ to 6 $\mathrm{ng} / \mathrm{mL}-1$ and $2 \mu \mathrm{g}$ to $4 \mu \mathrm{g} / \mathrm{mL}-1$

Intervention 2: ( $\mathrm{N}=95)$ group $\mathrm{B}$ - thiopentone ( $5 \mathrm{mg} / \mathrm{kg}$-1), fentanyl ( $3 \mu \mathrm{g}$ to $5 \mu \mathrm{g} / \mathrm{kg}$ - 1$)$, cisatracurium ( $0.1 \mathrm{mg} / \mathrm{kg}-1)$, sevoflurane (1 to 2 vol\%)

Intervention 3: ( $\mathrm{N}=16)$ group $\mathrm{C}$ - propofol $(2 \mathrm{mg} / \mathrm{kg}-1)$, fentanyl ( $3 \mu \mathrm{g}$ to $5 \mu \mathrm{g} / \mathrm{kg}$ - 1 ) sevoflurane (1 to 2 vol\%), cisatracurium

Intervention 4: ( $\mathrm{N}=175)$ group D intravenous (IV) thiopentone (5 mg/kg-1), suxamethonium (1 mg/ $\mathrm{kg}-1$ ), fentanyl ( $3 \mu \mathrm{g}$ to $5 \mu \mathrm{g} / \mathrm{kg}-1)$ and cisatracurium $(0.05 \mathrm{mg} / \mathrm{kg}-1)$ after foetus extraction

All patients: $\mathbf{N}_{\mathbf{2}} \mathbf{O}$ and $\mathrm{O}_{2} ; \mathrm{FIO}_{2}$ 0.33; auditory evoked potentials: AEP target range: 15 to 25

Group A, B, C: elective gynaecological procedures; Group D: caesarean section

Quote: "All of the patients received a mixture of $\mathrm{N}_{2} \mathrm{O}$ and $\mathrm{O}_{2} ; \mathrm{FiO}_{2}$ was maintained at the level of 0.33 "

Outcomes

Primary: outcomes: intraoperative sensations

Secondary outcomes: awareness/wakefulness as defined using an awareness classification system (see Table 1): class 4

Quote: "3 cases, the descriptions of intraoperative events suggested intraoperative awareness"

Comment: sensations usually associated with intraoperative dreams were reported by $14 \%$ (46/337); this is evidence that dreams maybe related to light planes of anaesthesia as suggested by other authors over decades

Notes Non-randomized portion of anaesthetic: TIVA vs parts of volatile agent/ $\mathrm{N}_{2} \mathrm{O} /$ infusion of narcotics (TCI) + muscle relaxants induction yes/maintenance yes/ADM AEP (15 to 25)

In group A total intravenous anaesthesia: target controlled infusion (TCI), cisatracurium, $(0.1 \mathrm{mg} / \mathrm{kg}-1)$, infusion of remifentanil incremental doses until reaching plasma concentration $8.5 \mathrm{ng} / \mathrm{mL}-1$, infusion propofol to plasma concentration $8 \mu \mathrm{g} / \mathrm{mL}-1$. TCI maintained infusion remifentanil/propofol preset doses $3 \mathrm{ng}$ to $6 \mathrm{ng} / \mathrm{mL}-1$ and $2 \mu \mathrm{g}$ to $4 \mu \mathrm{g} / \mathrm{mL}-1$; remaining groups, combined general anaesthesia: Group B - thiopentone ( $5 \mathrm{mg} / \mathrm{kg}$-1), fentanyl ( $3 \mu \mathrm{g}$ to $5 \mu \mathrm{g} / \mathrm{kg}-1)$, cisatracurium $(0.1 \mathrm{mg} / \mathrm{kg}-1)$, sevoflurane (1 to 2 vol\%)

Group C - propofol (2 mg/kg-1), fentanyl (3 $\mu$ g to $5 \mu \mathrm{g} / \mathrm{kg}-1$ ), sevoflurane (1 to 2 vol\%); group D thiopentone ( $5 \mathrm{mg} / \mathrm{kg}-1)$, suxamethonium ( $1 \mathrm{mg} / \mathrm{kg}-1)$, fentanyl ( $3 \mu \mathrm{g}$ to $5 \mu \mathrm{g} / \mathrm{kg}-1$ ) and cisatracurium $(0.05 \mathrm{mg} / \mathrm{kg}-1)$ after foetus extraction. All received $\mathrm{N}_{2} \mathrm{O}$ and $\mathrm{O}_{2} ; \mathrm{FIO}_{2} 0.33$; sleep depth: measuring auditory evoked potentials: AEP monitor, A-line auditory evoked potential index was kept within range 15 to 25

Comment: Annexe: questionnaire for assessment of intraoperative awareness: 22 questions assess recall/pain/dreams/tactile/auditory sensations

Quote: "...Group A received total intravenous anaesthesia with $\mathrm{TCI}$, and groups $\mathrm{B}, \mathrm{C}$ and $\mathrm{D}$ received balanced anaesthesia. The depth of anaesthesia was monitored with an AEP monitor. Blinded structured"

Comment: see Dryad topic sensations associated with dreams 
Czarko 2013 (Continued)

ROB survey.We emailed on 22 March 2015 kate.czarko@wp.pl

\section{Risk of bias}

\begin{tabular}{|c|c|c|}
\hline Bias & Authors' judgement & Support for judgement \\
\hline $\begin{array}{l}\text { Random sequence genera- } \\
\text { tion (selection bias) }\end{array}$ & Unclear risk & $\begin{array}{l}\text { Quote: "patients were enrolled in the study and randomly allocated to } 4 \\
\text { groups according to the type of general anaesthesia performed...." }\end{array}$ \\
\hline $\begin{array}{l}\text { Allocation concealment } \\
\text { (selection bias) }\end{array}$ & Unclear risk & Comment: no information \\
\hline $\begin{array}{l}\text { Blinding of participants } \\
\text { and personnel (perfor- } \\
\text { mance bias) } \\
\text { All outcomes }\end{array}$ & High risk & Comment: no blinding \\
\hline $\begin{array}{l}\text { Blinding of outcome as- } \\
\text { sessment (detection bias) } \\
\text { All outcomes }\end{array}$ & Low risk & $\begin{array}{l}\text { Quote: "Patients were surveyed three times: } 2 \mathrm{~h} \text { after anaesthesia and on post- } \\
\text { anaesthesia days } 7 \text { and } 30 \text { (by phone). Postoperative surveys were conducted } \\
\text { by a person not involved in anaesthesia" }\end{array}$ \\
\hline $\begin{array}{l}\text { Incomplete outcome data } \\
\text { (attrition bias) } \\
\text { All outcomes }\end{array}$ & Low risk & Comment: no dropouts \\
\hline $\begin{array}{l}\text { Selective reporting (re- } \\
\text { porting bias) }\end{array}$ & Low risk & Comment: awareness outcome part of inclusion criteria \\
\hline Other bias & Unclear risk & Comment: no information \\
\hline
\end{tabular}

\section{De Kock 1995}

\begin{tabular}{|c|c|}
\hline Methods & $\begin{array}{l}\text { Study design: randomized parallel groups } \\
\text { Study dates: not stated }\end{array}$ \\
\hline Participants & $\begin{array}{l}\text { Country: NA } \\
\text { Sex: female and male } \\
\text { Age: } 35.3 \pm 9.2 \\
\text { ASA: NA } \\
\text { Procedure: abdominal surgery colic resection } \\
\text { Study size: } 40\end{array}$ \\
\hline Interventions & $\begin{array}{l}\text { Randomized portion of anaesthetic: regional anaesthesia: epidural: } 2 \text { infusion rates } \\
\text { Intervention 1: induction epidural clonidine }(4 \mu \mathrm{g} / \mathrm{kg} \text { in } 10 \mathrm{~mL}) \text { infused in } 20 \text { min followed by a } 2 \mu \mathrm{g} / \mathrm{kg} \\
\text { infusion }(5 \mathrm{~mL} / \mathrm{h} \text { ) during } 12 \mathrm{~h} \text { (Group } 1) \\
\text { Intervention 2: induction epidural sufentanil ( } 0.5 \mathrm{mug} / \mathrm{kg} \text { in } 10 \mathrm{~mL}) \text { in } 20 \text { min followed by a } 0.25 \mu \mathrm{g} / \mathrm{kg} \\
\text { infusion }(5 \mathrm{~mL} / \mathrm{h}) \text { during } 12 \mathrm{~h} \text { (Group 2) }\end{array}$ \\
\hline
\end{tabular}

Outcomes

Primary outcomes: efficacy and side effects of epidural clonidine and sufentanil 
Secondary outcome: awareness/wakefulness as defined using an awareness classification system (see Table 1): class 4

Comment: 2 awareness reports Group 1 (clonidine)

Notes

\section{Non-randomized portion of anaesthetic: IV $\mathrm{N}_{2} \mathrm{O}$ propofol $\mathrm{MCl} /$ muscle relaxants: both induc- tion/maintenance}

Before anaesthesia, epidural catheter inserted L1-L2; induction and maintenance: propofol/ $\mathrm{N}_{2} \mathrm{O}$, propofol bolus $(0.5 \mathrm{mg} / \mathrm{kg}$ ) PRN if inadequate, then bolus sufentanil $0.035 \mu \mathrm{g} / \mathrm{kg}$. Neuromuscular block: infusion atracurium ( $5 \mathrm{pg} / \mathrm{kg} / \mathrm{min}$ ). Atracurium infusion was discontinued at the beginning of the closure of the peritoneum. Anaesthesia was maintained with a propofol infusion of $3 \mathrm{mg} / \mathrm{kg} / \mathrm{h}$ and $50 \%$ $\mathrm{N}_{2} \mathrm{O}$ in oxygen. Neuromuscular block maintained infusion atracurium $(5 \mathrm{pg} / \mathrm{kg} / \mathrm{min})$

ROB survey email sent 3 January 2014 dekock@anes.ucl.ac.be; response 10 January 2014

\section{Risk of bias}

\begin{tabular}{|c|c|c|}
\hline Bias & Authors' judgement & Support for judgement \\
\hline \multirow[t]{2}{*}{$\begin{array}{l}\text { Random sequence genera- } \\
\text { tion (selection bias) }\end{array}$} & Low risk & $\begin{array}{l}\text { ROB survey response by Dr Marc de Kock: "computer generated randomization } \\
\text { list" }\end{array}$ \\
\hline & & $\begin{array}{l}\text { Quote: "At this time, patients were randomly assigned to receive either epidur- } \\
\text { al clonidine (Group 1) or epidural sufentanil..." }\end{array}$ \\
\hline $\begin{array}{l}\text { Allocation concealment } \\
\text { (selection bias) }\end{array}$ & Low risk & $\begin{array}{l}\text { ROB survey response: "study drugs were prepared by an anesthesiologist not } \\
\text { involved in patient's care and were blinded to the anesthesiologist in charge" }\end{array}$ \\
\hline $\begin{array}{l}\text { Blinding of participants } \\
\text { and personnel (perfor- } \\
\text { mance bias) }\end{array}$ & Low risk & $\begin{array}{l}\text { ROB survey response: "Patient, Anesthesiologist, Awareness outcome assessor } \\
\text { (interviewer)" }\end{array}$ \\
\hline All outcomes & & $\begin{array}{l}\text { Quote: "At this time, patients were randomly assigned to receive either epidur- } \\
\text { al clonidine (Group 1) or epidural sufentanil (Group 2)" }\end{array}$ \\
\hline
\end{tabular}

Blinding of outcome as- Low risk Comment: see above
sessment (detection bias)

All outcomes

$\begin{array}{ll}\begin{array}{l}\text { Incomplete outcome data } \\ \text { (attrition bias) }\end{array} & \text { Low risk } \\ \text { All outcomes } & \begin{array}{l}\text { Quote: "One patient in Group } 2 \text { presented with an immediate postoperative } \\ \text { respiratory depression that required prolonged ventilatory support and was } \\ \text { therefore excluded from the postoperative study protocol..." }\end{array} \\ & \begin{array}{l}\text { Comment: respiratory depression: epidural narcotic effect: sign of deep anaes- } \\ \text { thesia hence a low risk of awareness }\end{array}\end{array}$

\begin{tabular}{ll}
\hline $\begin{array}{l}\text { Selective reporting (re- } \\
\begin{array}{l}\text { porting bias) }\end{array}\end{array}$ & $\begin{array}{l}\text { ROB survey response: "the study protocol is available and all the outcome da- } \\
\text { ta are reported" }\end{array}$ \\
& Comment: awareness outcome part of inclusion criteria
\end{tabular}

\begin{tabular}{ll}
\hline Other bias $\quad$ Low risk $\quad$ ROB survey response: "no particular bias" \\
\hline
\end{tabular}

\section{Deeprose 2005}

$\begin{array}{ll}\text { Methods } & \text { Study design: randomized parallel groups } \\ \text { Study dates: not stated }\end{array}$


Deeprose 2005 (Continued)

$\begin{array}{ll}\text { Participants } & \text { Country: UK } \\ \text { Sex: both } \\ \text { Age: } 16 \text { to } 72 \\ \text { ASA: I } \\ \text { Procedure: orthopaedic } \\ \text { Study size: } 64 \text { enrolled, } 62 \text { completed study }\end{array}$

Interventions

Randomized portion of anaesthetic: parts of IV/narcotics (fentanyl vs no fentanyl) induction/implicit memory word test

Intervention 1: induction: fentanyl $1.5 \mu \mathrm{g} / \mathrm{kg}$ + "sleep" dose of propofol, $\mathrm{N}=32$

Intervention 2: induction: no fentanyl + propofol, $\mathrm{N}=30$

Primary outcomes: relationship between BIS (mean-BIS and max-BIS) and memory scores
Secondary outcome: awareness/wakefulness as defined using an awareness classification system (see
Table 1): class 2
Comment: no patients reported awareness; i mplicit memory was present in both groups
Quote: "Patients were interviewed for awareness using the structured interview of intraoperative
events (based on Russell and Wang, 1997). There was no evidence for spontaneous or prompted recall"

Notes

Randomized portion of anaesthetic: parts of IV: induction: hypnotic/maintenance: propofol TCI
nitrous/SR: LMA/no muscle relaxants/ADM BIS open not target

Induction: see interventions ('sleep' dose of propofol)/narcotics(randomized group yes/no fentanyl); maintenance: $3 \mathrm{mg}$ to $6 \mathrm{mg} / \mathrm{kg} / \mathrm{h}$ infusion rate + nitrous $66 \%$ and $\mathrm{O}_{2} 33 \%$; no titration anaesthetic strategy for light anaesthesia given in paper. Maintained TCI target-controlled infusion $3 \mathrm{mg}$ and 9 mg/kg-1 h-1: clinical judgement. $\mathrm{N}_{2} \mathrm{O} 66 \%$ and oxygen $33 \%$ spontaneously laryngeal mask. BIS not blinded but also not used to guide titration of anaesthetic

Quote: "Priming remained above zero when data from the six patients with above-chance performance on the yes-no recognition test and the 25 patients with max-BIS $>60$ were excluded from the analysis"

Comment see Dryad: evidence for and against implicit memory

c.deeprose@shefac.uk emailed 2011

Jackie Andrade jackie.andrade@plymouth.ac.uk emailed 1 February 2013

Responded to survey: 4 June 2013 Catherine Deeprose catherine.deeprose@plymouth.ac.uk

\section{Risk of bias}

\begin{tabular}{lll}
\hline Bias & Authors' judgement & Support for judgement \\
\hline $\begin{array}{l}\text { Random sequence genera- } \\
\text { tion (selection bias) }\end{array}$ & Low risk & $\begin{array}{l}\text { Quote: "Patients were assigned randomly to a fentanyl or no-fentanyl study } \\
\text { group to which the experimenter (CD) was blinded" }\end{array}$ \\
& $\begin{array}{l}\text { Quote survey response by Dr Deeprose: "Simple randomization in which ei- } \\
\text { ther "fentanyl" or "no-fentanyl" was drawn from a bag for each patient. A total } \\
\text { of } 64 \text { (32 per group) slips of paper indicating "fentanyl" or "no-fentanyl" were } \\
\text { created before the study commenced. The sample size was based on power } \\
\text { calculations (see point 7 below)" }\end{array}$
\end{tabular}

Allocation concealment High risk

(selection bias)
Experimenter $(C D)$ was blinded to anaesthetic assignment Anaesthetist was not blinded to anaesthetic protocol, but was not involved in memory testing"

Comment: experimenter did intra and postoperative management of protocol not the anaesthesiologist 
Deeprose 2005 (Continued)

Blinding of participants and personnel (performance bias)

All outcomes
High risk Quote survey response by Dr Deeprose: "The experimenter was blinded to anaesthetic technique. The study completed the proposed sample size based on our pilot work using the auditory word stem completion tasks and previous published research (Deeprose and Andrade, 2004) ...."

Comment: the protocol for this review (Messina 2008), includes implicit memory tests in the classification of outcomes (class 2). But, interventions to decrease wakefulness/awareness are defined as anaesthetic regimens and ADMs. The anaesthesiologist, although blinded to the word tests, was not blinded to the randomized anaesthetics.
Blinding of outcome as- Low risk sessment (detection bias)

All outcomes
Quote: assessor: "Patients were assigned randomly to a fentanyl or no-fentanyl study group to which the experimenter (CD) was blinded"

Comment: experimenter did postoperative interviews

Incomplete outcome data Low risk
(attrition bias)
All outcomes

Incomplete outcome data Low risk

Comment we analysed 2 total and 1 high-risk awareness dropout(s) from the no fentanyl group and found no significant difference between groups: $(2 / 30)$ vs (0/32), Peto OR 8.18 (0.50 to 133.94$) ;(1 / 30)$ vs (0/32) Peto OR 7.90 (0.16 to 398.87)

Selective reporting (re- Low risk
porting bias)
porting bias)
Quote: "The study is described in full in my Phd thesis which presents the rational for the expected outcomes as described in the published paper. There are no unreported outcome variables"

Comment: awareness outcome part of inclusion criteria

Comment: underpowered study which was identified by author ROB survey response as a source of other bias is a source of imprecision, which is not covered in this domain. No other sources of internal biases identified by author

Author sent ROB table grades for comment 7 December 2013 catherine.deeprose@plymouth.ac.uk

Deshpande 2009

\begin{tabular}{|c|c|}
\hline Methods & $\begin{array}{l}\text { Study design: randomized parallel groups } \\
\text { Study dates: not stated }\end{array}$ \\
\hline Participants & $\begin{array}{l}\text { Country: India } \\
\text { Sex: female and male } \\
\text { Age: } 15 \text { to } 50 \\
\text { ASA: >= III } \\
\text { Procedure: open heart surgery: valvular and simple congenital heart disease surgery } \\
\text { Study size: } 100,98\end{array}$ \\
\hline Interventions & $\begin{array}{l}\text { Randomized portion of anaesthetic: volatile agent types: IV narcotics } \\
\text { Intervention 1: sufentanil group: induction sufentanil } 0.5 \mu \mathrm{g} / \mathrm{kg} \text {; maintenance: sufentanil } 0.1 \mu \mathrm{g} / \mathrm{kg} \text { PRN } \\
\text { Intervention 2: fentanyl group: induction fentanyl } 3 \mu \mathrm{g} / \mathrm{kg} \text {; maintenance: fentanyl } 1 \mu \mathrm{g} / \mathrm{kg}\end{array}$ \\
\hline
\end{tabular}


Deshpande 2009 (Continued)

Outcomes
Primary outcomes: anaesthetic consumption and recovery parameters, mean ventilation time between groups

Secondary outcome: awareness/wakefulness as defined using an awareness classification system (see Table 1): class 4

Comment: sufentanil group 1 patient awareness event at sternotomy lus $\mathrm{MCl} /$ muscle relaxants induction yes/maintenance yes

Induction: midazolam $0.05 \mathrm{mg} / \mathrm{kg}$ sleep dose thiopental vecuronium $0.1 \mathrm{mg} / \mathrm{kg}$ for intubation; maintenance: $\mathbf{N}_{\mathbf{2}} \mathbf{O}$ isoflurane ET $0.8 \%$ to $1 \%$ midazolam and vecuronium PRN before and after CPB with goal of stable haemodynamics; CPB: infusion propofol $4 \mathrm{mg}$ to $5 \mathrm{mg} / \mathrm{kg} / \mathrm{h}$; sufentanil $0.1 \mu \mathrm{g} / \mathrm{kg}$ PRN or fentanyl $1 \mu \mathrm{g} / \mathrm{kg}$, max doses for case sufentanil fentanyl midazolam 1 and $6 \mu \mathrm{g} / \mathrm{kg}$ and $5 \mathrm{mg}$ respectively

Emailed ROB survey 2 January 2014and asked Dr Deshpande to clarify the reason for referral of awareness patient to psychiatrist for an accurate classification category Table 1 desh56@hotmail.com

\section{Risk of bias}

\begin{tabular}{|c|c|c|}
\hline Bias & Authors' judgement & Support for judgement \\
\hline $\begin{array}{l}\text { Random sequence genera- } \\
\text { tion (selection bias) }\end{array}$ & Unclear risk & "...prospective randomized double blind study..." \\
\hline $\begin{array}{l}\text { Allocation concealment } \\
\text { (selection bias) }\end{array}$ & Unclear risk & Comment: inadequate information provided \\
\hline $\begin{array}{l}\text { Blinding of participants } \\
\text { and personnel (perfor- } \\
\text { mance bias) } \\
\text { All outcomes }\end{array}$ & Unclear risk & Comment: inadequate information provided \\
\hline $\begin{array}{l}\text { Blinding of outcome as- } \\
\text { sessment (detection bias) } \\
\text { All outcomes }\end{array}$ & Unclear risk & Comment: inadequate information provided \\
\hline $\begin{array}{l}\text { Incomplete outcome data } \\
\text { (attrition bias) } \\
\text { All outcomes }\end{array}$ & Low risk & $\begin{array}{l}\text { Comment: } 100 \text { patients, } 50 \text { in each group, "another } 2 \text { patients were excluded } \\
\text { from study because of prolonged ventilation }>6 \text { hours secondary to surgical } \\
\text { complication" } \\
\text { Comment: no significant difference between groups if exclusions were in one } \\
\text { or both groups ( } 2 / 50 \text { vs } 0 / 50) \text {, Peto OR } 7.54(0.47 \text { to } 122.28)\end{array}$ \\
\hline $\begin{array}{l}\text { Selective reporting (re- } \\
\text { porting bias) }\end{array}$ & Low risk & Comment: awareness outcome part of inclusion criteria \\
\hline Other bias & Unclear risk & Comment: inadequate information provided \\
\hline
\end{tabular}

Dhadphale 1979

\begin{tabular}{ll}
\hline Methods & $\begin{array}{l}\text { Study design: randomized parallel groups } \\
\text { Study dates: not stated }\end{array}$ \\
\hline Participants & $\begin{array}{l}\text { Country: USA } \\
\text { Sex: both }\end{array}$ \\
\hline
\end{tabular}


Dhadphale 1979 (Continued)

Age: 49,52

ASA: not given

Procedure: mitral or aortic valve replacement

Study size: 32 enrolled, 30 completed study

Interventions Randomized portion of anaesthetic: parts of intravenous (IV) anaesthesia

Intervention 1: induction: diazepam $0.4 \mathrm{mg} / \mathrm{kg}+$ ketamine $2 \mathrm{mg} / \mathrm{kg}, \mathrm{N}=16$

Intervention 2: induction: morphine $3 \mathrm{mg} / \mathrm{kg}, \mathrm{N}=16$

\begin{tabular}{ll} 
Outcomes & Primary outcomes: circulatory responses (heart rate, mean arterial blood pressure, $\mathrm{PaCO}_{2}$ ) \\
& Secondary outcome: awareness/wakefulness as defined using an awareness classification system (see \\
Table 1 ): class 1 & \\
& No intraoperative awareness occurred in either group \\
\hline Notes & $\begin{array}{l}\text { Non-randomized portion of anaesthetic: parts of intravenous (IV) anaesthesia: } \mathbf{N}_{\mathbf{2}} \mathbf{O} \text { yes/narcotics } \\
\text { and/or hypnotics bolus } \mathbf{M C l} / \text { muscle relaxants induction yes/maintenance yes }\end{array}$
\end{tabular}

Premedication: morphine $5 \mathrm{mg}$ to $10 \mathrm{mg}$ + scopolamine $0.2 \mathrm{mg}$ to $0.4 \mathrm{mg}$; induction: succinylcholine 1.5 $\mathrm{mg} / \mathrm{kg}$; maintenance: nitrous $50 \%$ + pancuronium $0.1 \mathrm{mg} / \mathrm{kg}+$ ketamine $1 \mathrm{mg} / \mathrm{kg} / \mathrm{h}$

No email address available for ROB survey

\section{Risk of bias}

\begin{tabular}{|c|c|c|}
\hline Bias & Authors' judgement & Support for judgement \\
\hline $\begin{array}{l}\text { Random sequence genera- } \\
\text { tion (selection bias) }\end{array}$ & Unclear risk & Quote: "randomly selected patients were given..." \\
\hline $\begin{array}{l}\text { Allocation concealment } \\
\text { (selection bias) }\end{array}$ & Unclear risk & Comment: no information provided \\
\hline $\begin{array}{l}\text { Blinding of participants } \\
\text { and personnel (perfor- } \\
\text { mance bias) } \\
\text { All outcomes }\end{array}$ & Unclear risk & Comment: anaesthesiologist: no information provided \\
\hline $\begin{array}{l}\text { Blinding of outcome as- } \\
\text { sessment (detection bias) } \\
\text { All outcomes }\end{array}$ & Unclear risk & $\begin{array}{l}\text { Quote: "All patients were seen postoperatively and questioned specifically } \\
\text { about possible awareness..." }\end{array}$ \\
\hline $\begin{array}{l}\text { Incomplete outcome data } \\
\text { (attrition bias) } \\
\text { All outcomes }\end{array}$ & Low risk & $\begin{array}{l}\text { Quote: "Two deaths occurred, both in Group I." } \\
\text { Comment: group } 1 \text { (ketamine) patients at increased risk of awareness }(2 / 16) \\
\text { were not significantly different from morphine group }(0 / 16) \text {, Peto OR } 7.90(0.47 \\
\text { to } 132.20)\end{array}$ \\
\hline $\begin{array}{l}\text { Selective reporting (re- } \\
\text { porting bias) }\end{array}$ & Low risk & Comment: awareness outcome part of inclusion criteria \\
\hline Other bias & Unclear risk & Comment: insufficient information provided \\
\hline
\end{tabular}

Drover 2002

Methods Study design: randomized parallel groups


Drover 2002 (Continued)

Study dates: 18 May 1999 to 4 January 2000 (ROB survey)

Participants
Country: USA
Sex: males and females
Age: 18 to 80 years
ASA: I-III
Procedure: elective surgical procedures scheduled for at least 30 min
Study size: 347 (102 controls +245 randomized), 306 completed study ( 82 controls +224 randomized
patients)

\begin{tabular}{ll} 
Interventions & Randomized portion of anaesthetic: parts of IV: ADM: PSI (25 to 50$)$ \\
& $\begin{array}{l}\text { Intervention } 1: \text { PSI guidance, } \mathrm{N}=123 \\
\text { Intervention 2: standard practice guidelines, } \mathrm{N}=122\end{array}$ \\
\hline Outcomes & Primary outcomes: drug dosage, recovery times \\
& Secondary outcome: awareness/wakefulness as defined using an awareness classification system (see \\
& Table 1 ): class 1 \\
& Quote: "There was no incidence of reported awareness or memories in any patient in any group"
\end{tabular}

Notes

\section{Non-randomized portion of anaesthetic: parts of IV: $\mathrm{N}_{2} \mathrm{O}$ yes/narcotics/hypnotics bolus $\mathrm{MCl} / \mathrm{NMBs}$ induction PRN/maintenance PRN: SR/LMA or CV/ETT ADM EEG}

Premedication: midazolam $1 \mathrm{mg}$ to $2 \mathrm{mg}$; induction: propofol $1 \mathrm{mg}$ to $3 \mathrm{mg} / \mathrm{kg}+$ alfentanil </- $30 \mu \mathrm{g} / \mathrm{kg}$; maintenance: propofol $140 \mu \mathrm{g} / \mathrm{kg} / \mathrm{min}+$ alfentanil $0.5 \mu \mathrm{g} / \mathrm{kg} / \mathrm{min}+$ nitrous 50\%; muscle relaxation PRN

Quote: "...consciousness, patients breathed via a laryngeal mask airway or a muscle relaxant was administered and an endotracheal tube placed."

Comment: the isolated-arm technique was used to evaluate patient movement after administration of the neuromuscular blocking agent. The authors used a historic control group in the comparison with the experimental group.

Comment: wakefulness defined by response to complex command was not used; somatic responses only were recorded; also, patients were not given additional doses of anaesthesia until autonomic responses stopped but until target range of ADM reached

Author responded to the email bias survey response: 8 August 2011, David Drover ddrover@stanford.edu

Email sent to author to clarify these issues ddrover@stanford.edu 7 December 2013

Email sent to clarify these issues: ddrover@stanford.edu 7 December 2013; responded 8 December 2013

\section{Risk of bias}

\begin{tabular}{lll}
\hline Bias & Authors' judgement & Support for judgement \\
\hline $\begin{array}{l}\text { Random sequence genera- } \\
\text { tion (selection bias) }\end{array}$ & Low risk & $\begin{array}{l}\text { Quote: "Randomization was determined prior to start of the study was by the } \\
\text { coordinating company. Randomization was performed using MS Excel and } \\
\text { randomization assignments were placed in sealed envelops that were opened } \\
\text { once the subject entered the study." (Email bias survey, see notes) }\end{array}$ \\
\hline $\begin{array}{l}\text { Allocation concealment } \\
\text { (selection bias) }\end{array}$ & Unclear risk & $\begin{array}{l}\text { Quote from ROB survey response: "The assignment was in a sealed envelope } \\
\text { and was not opened until anesthesia was to begin..." }\end{array}$ \\
& Comment: await author clarification on the use opaque, sealed envelopes
\end{tabular}


Drover 2002 (Continued)

Blinding of participants High risk Comment: readers can view a detailed description by the author, Dr Drover and personnel (performance bias)

All outcomes

Quote from ROB survey response: "Patient, Anesthesiologist... For the SPC group, anesthesiologists... were blinded to the PSI information... PSI group were guided by the PSI measure...One of the goals of the study was to see change in behavior of the anesthesiologist with respect to drug use. If the anesthesiologist was blinded, he could not see the output from the monitor, otherwise, if unblinded, he had full access to the monitor. The patient was always blinded"

Comment: both groups not blinded to SCPS

Blinding of outcome as- High risk sessment (detection bias) All outcomes
Quote: "Postoperative interview was not conducted by a blinded investigator. Awareness was a secondary endpoint." (email bias survey)
Incomplete outcome data Low risk (attrition bias)

All outcomes
Comment: Table 1 enrolled 347 is correct and methods section 306 is an error per ROB survey response; 347 enrolled -306 completed study $=41 / 347=$ $12 \%$ dropout; but, $347-102$ controls and PSI training group $=245$ randomized to PSI vS SCP - 41 total dropouts - 20 controls/training dropouts $=21 / 245(9 \%)$ dropouts study sample. Reasons for not completing protocol: SCP vs PSI: no high-risk dropouts

Comment: Table 1: SCP exclusions 10/122 vs PSI 11/123, Peto OR 1.10 (0.45 to 2.68): no significant difference between groups

Email sent to clarify these issues: ddrover@stanford.edu 7 December 2013; Dr. Drover responded 8 December 2013

$\begin{array}{ll}\begin{array}{l}\text { Selective reporting (re- } \\ \text { porting bias) }\end{array} & \text { Low risk } \\ & \text { Comment: awareness outcome part of inclusion criteria }\end{array}$

Other bias Low risk

Quote: "One of the goals of the study was to see change in behavior of the anesthesiologist with respect to drug use"

Dunnett 1977

\begin{tabular}{ll} 
Methods & Study design: randomized parallel groups \\
& Study dates: not stated \\
\hline Participants & Country: USA \\
Sex: both & Age: adult patients \\
ASA: not given, "good health" \\
Procedure: no surgery identification \\
Study size: 77 \\
Randomized portion of anaesthetic: parts of volatile agent (balanced) with intravenous (IV) in- \\
duction agents
\end{tabular}

Intervention 1: induction: thiopentone $3 \mathrm{mg} / \mathrm{kg}, \mathrm{N}=38$

Intervention 2: induction: ketamine $2 \mathrm{mg} / \mathrm{kg}, \mathrm{N}=39$

Outcomes

Primary outcomes: awareness/wakefulness as defined using an awareness classification system (see Table 1): class 4 
Quote: "One patient in the thiopentone group remembered an unpleasant sensation of a tube being put into his throat and associated this with gagging"

\section{Notes}

Non-randomized portion of anaesthetic: parts of volatile agent (balanced) $\mathrm{N}_{2} \mathrm{O}$ yes/narcotics and/ or hypnotics bolus/muscle relaxants induction yes/maintenance yes

Premedication: tubocurarine $3 \mathrm{mg}$; induction: intervention + suxamethonium $1 \mathrm{mg} / \mathrm{kg}$; maintenance: nitrous in $\mathrm{O}_{2}$ + halothane + pancuronium; no anaesthetic strategy for light anaesthesia described

Quote from discussion section, see Dryad: "The possibility of retrograde amnesia..."

No email address available for ROB survey

\section{Risk of bias}

\begin{tabular}{lll}
\hline Bias & Authors' judgement & Support for judgement \\
\hline $\begin{array}{l}\text { Random sequence genera- } \\
\text { tion (selection bias) }\end{array}$ & Unclear risk & $\begin{array}{l}\text { Quote: "Patients were allocated at random to induction of anaesthesia with ei- } \\
\text { ther a barbiturate or ketamine..." }\end{array}$ \\
\hline $\begin{array}{l}\text { Allocation concealment } \\
\text { (selection bias) }\end{array}$ & Unclear risk & Comment: no information provided \\
\hline
\end{tabular}

Blinding of participants Unclear risk Comment: no information provided

and personnel (perfor-

mance bias)

All outcomes

\begin{tabular}{lll}
\hline $\begin{array}{l}\text { Blinding of outcome as- } \\
\text { sessment (detection bias) }\end{array}$ & Low risk & $\begin{array}{l}\text { Quote: "The same interviewer was used throughout the series and was not } \\
\text { aware which induction agent had been used in a given patient" }\end{array}$
\end{tabular}

All outcomes

Incomplete outcome data Low risk Comment: no missing outcome data
(attrition bias)

All outcomes

Selective reporting (re- Low risk Comment: awareness outcome part of inclusion criteria
porting bias)

Other bias Unclear risk Comment: insufficient information provided

\section{Echevarria 1998}

\begin{tabular}{ll}
\hline Methods & Study design: randomized parallel groups \\
& Study dates: "17 months" (email bias survey, see notes) \\
\hline Participants & Country: Spain \\
& Sex: male and female \\
Age: 18 to 60 \\
ASA: I-II \\
Procedure: elective surgery \\
Study size: 100 enrolled, 98 completed study \\
Randomized portion of anaesthetic: TIVA MCl vs volatile agent types \\
Intervention 1: desflurane $/ \mathrm{N}_{2} \mathrm{O}$ induction: atropine $0.5 \mathrm{mg}+$ fentanyl $2 \mu \mathrm{\mu g} / \mathrm{kg}+$ atracurium $0.5 \mathrm{mg} / \mathrm{kg} ;$ \\
maintenance: nitrous $60 \%+$ desflurane, $\mathrm{N}=25$
\end{tabular}


Echevarria 1998 (Continued)

Intervention 2: isoflurane $/ \mathrm{N}_{2} \mathrm{O}$ induction: atropine $0.5 \mathrm{mg}+$ fentanyl $2 \mu \mathrm{g} / \mathrm{kg}+$ atracurium $0.5 \mathrm{mg} / \mathrm{kg}$; maintenance: nitrous $60 \%+$ isoflurane, $\mathrm{N}=25$

Intervention 3: IV anaesthesia fentanyl/ $\mathrm{N}_{2} \mathrm{O}$ induction: atropine $0.5 \mathrm{mg}+$ fentanyl $2 \mu \mathrm{g} / \mathrm{kg}+$ atracurium $0.5 \mathrm{mg} / \mathrm{kg}$; maintenance: nitrous $60 \%+$ fentanyl $3 \mu \mathrm{g} / \mathrm{kg}, \mathrm{N}=25$

Intervention 4: total intravenous anaesthesia induction: alfentanil $15 \mu \mathrm{g} / \mathrm{kg}$ + propofol; maintenance:

$\mathrm{O}_{2}+$ propofol $6 \mathrm{mg} / \mathrm{kg} / \mathrm{h}+$ alfentanil $50 \mu \mathrm{g} / \mathrm{kg}$ then $1.5 \mu \mathrm{g} / \mathrm{kg} / \mathrm{min}, \mathrm{N}=25$

All groups: taped music followed by an order requiring a non-verbal response

Primary outcomes: evidence of implicit memory (taped music followed by an order requiring a non ver-
bal response)
Secondary outcome: awareness/wakefulness as defined using an awareness classification system (see
Table 1): class 2
Comment: no explicit memories of intraoperative events; evidence for implicit memory in isoflurane
group

Notes

Non-randomized portion of anaesthetic: parts of volatile agent: $\mathrm{N}_{2} \mathrm{O}$ yes/narcotics/hypnotics bolus/muscle relaxants induction yes/maintenance unclear/music memory and non-verbal response

Music not word test (Isabel Dufano - translator)

Author responded to the email bias survey on 22 January 2011. Responses are recorded in the 'Risk of bias' table. Author's responses were translated by translator Brett Smith/translator Isabelle Dufano

Survey response: 22 January 2011, Mercedes Echevarria mercedes.etxeba@terra.es

\begin{tabular}{|c|c|c|}
\hline \multicolumn{3}{|l|}{ Risk of bias } \\
\hline Bias & Authors' judgement & Support for judgement \\
\hline $\begin{array}{l}\text { Random sequence genera- } \\
\text { tion (selection bias) }\end{array}$ & Low risk & $\begin{array}{l}\text { Comment: author ROB survey response that sequence allocation was per- } \\
\text { formed by using Statgraphics software }\end{array}$ \\
\hline $\begin{array}{l}\text { Allocation concealment } \\
\text { (selection bias) }\end{array}$ & Low risk & $\begin{array}{l}\text { Comment: author ROB survey response that an anaesthesiologist who was } \\
\text { blinded to the anaesthetic administration performed the allocation conceal- } \\
\text { ment and postoperative interview }\end{array}$ \\
\hline $\begin{array}{l}\text { Blinding of participants } \\
\text { and personnel (perfor- } \\
\text { mance bias) } \\
\text { All outcomes }\end{array}$ & Unclear risk & Comment: difficult to blind infusion pump sound vs inhaled agent \\
\hline $\begin{array}{l}\text { Blinding of outcome as- } \\
\text { sessment (detection bias) } \\
\text { All outcomes }\end{array}$ & Low risk & Comment: see above \\
\hline $\begin{array}{l}\text { Incomplete outcome data } \\
\text { (attrition bias) } \\
\text { All outcomes }\end{array}$ & Low risk & $\begin{array}{l}\text { Quote: "In recruiting only } 1 \text { patient refused to participate in the study. During } \\
\text { the study one patient was excluded from group } 3 \text { (fentanyl and nitrous oxide) } \\
\text { due to hospital discharged at } 12 \text { hours." (email bias survey, see notes) } \\
\text { Comment: dropout unrelated to risks of awareness }\end{array}$ \\
\hline $\begin{array}{l}\text { Selective reporting (re- } \\
\text { porting bias) }\end{array}$ & Low risk & $\begin{array}{l}\text { Quote ROB survey response: "The article described the entire protocol and re- } \\
\text { sults of the analysis of both research, as well as secondary outcomes of the } \\
\text { study." (email bias survey, see notes) } \\
\text { Comment: awareness outcome part of inclusion criteria }\end{array}$ \\
\hline
\end{tabular}


Echevarria 1998 (Continued)

Other bias Low risk Quote: "No" (email bias survey, see notes)

Elhakim 2010

\begin{tabular}{ll}
\hline Methods & Study design: randomized parallel groups \\
& Study dates: "2008-2009" (email ROB survey) \\
\hline Participants & Country: Egypt \\
& Sex: male \\
& Age: 40 to 60 \\
& ASA: II-III \\
& Procedure: thoracic surgery with one-lung ventilation \\
& Study size: 50 \\
& Randomized portion of anaesthetic: regional anaesthesia: epidural: induction \\
& Intervention $1:$ post-induction/maintenance: epidural: dexmedetomidine $1 \mu \mathrm{mg} / \mathrm{kg}+$ bupivacaine $0.5 \%$ \\
& 30 mg to $40 \mathrm{mg}$ (Group DB), $\mathrm{N}=25$ \\
& Intervention 2: post- induction/maintenance: epidural: bupivacaine $0.5 \% 30 \mathrm{mg}$ to $40 \mathrm{mg}$ (Group B), $\mathrm{N}=$ \\
& 25
\end{tabular}

\title{
Outcomes
}

Primary outcomes: compare analgesic effect, BIS, haemodynamics, blood gases

Secondary outcome: awareness/wakefulness as defined using an awareness classification system (see Table 1): class 4

Quote: "Two patients (8\%) in group B reported possible intraoperative awareness"

Notes

\begin{abstract}
Non-randomized portion of anaesthetic: parts of volatile agent isoflurane: $\mathrm{N}_{2} \mathrm{O}$ no/narcotics/hypnotics bolus/muscle relaxants induction yes/maintenance unclear/ADM BIS recorded
\end{abstract}

Anaesthesia induction: fentanyl $3 \mu \mathrm{g} / \mathrm{kg}$ + thiopental $3 \mathrm{mg}$ to $5 \mathrm{mg} / \mathrm{kg}$ + pancuronium $0.1 \mathrm{mg} / \mathrm{kg}$; anaesthesia maintenance: isoflurane $0.3 \%$ to $0.5 \% \mathrm{ET}$; anaesthetic/epidural drugs adjusted BIS: 40 and 60

Time of outcome determination: $24 \mathrm{~h}, 72 \mathrm{~h}, 30$ days

Method of outcome determination: interview

Authors report definite and possible cases of awareness. Note Table A1 2 patient awareness reports adjudicated as possible

Author responded to the email bias survey on 12 February 2011: "Two (8\%) patients in group B reported dreams or nightmares (see Appendix 1). In two patients (cases 1 and 2), the initial BIS after induction of anaesthesia was 37 and 39, the average BIS during the surgical procedure was 44 and 48 and the highest recorded value was 51 and 53, respectively."

Survey response: 12 February 2011, Prof. Dr. Mokhtar Elhakim mokhtar.elhakim@gmail.com

\section{Risk of bias}

Bias Authors' judgement Support for judgement


Elhakim 2010 (Continued)

Random sequence genera- Low risk Quote ROB survey response Dr Elhakim: "Patients were randomly divided intion (selection bias)

to two equal groups using computer-generated random numbers with the closed-sealed envelope, to receive either control or study drugs"

\section{Allocation concealment Low risk} (selection bias)

Quote ROB survey response Dr Elhakim: "To insure the study was blinded, the anaesthetist who prepared or administered the study drugs was not involved in patient care"

\begin{tabular}{|c|c|c|}
\hline $\begin{array}{l}\text { Blinding of participants } \\
\text { and personnel (perfor- } \\
\text { mance bias) }\end{array}$ & Low risk & $\begin{array}{l}\text { Quote ROB survey: "Patient, Anesthesiologist, Awareness outcome assessor } \\
\text { (interviewer)" }\end{array}$ \\
\hline All outcomes & & $\begin{array}{l}\text { Comment: both epidurals contained local anaesthetic. Hence, blinding possi- } \\
\text { ble. }\end{array}$ \\
\hline
\end{tabular}

\begin{tabular}{|c|c|c|}
\hline $\begin{array}{l}\text { Blinding of outcome as- } \\
\text { sessment (detection bias) } \\
\text { All outcomes }\end{array}$ & Low risk & $\begin{array}{l}\text { Quote: "Intraoperative awareness in the period from induction of anaesthesia } \\
\text { till recovery was assessed by experts who were unaware of the patient group } \\
\text { assignments" }\end{array}$ \\
\hline
\end{tabular}

Incomplete outcome data Low risk Quote: "All our patients completed the study." (Email ROB survey)
(attrition bias)

(attrition bias)

All outcomes

\begin{tabular}{|c|c|c|}
\hline $\begin{array}{l}\text { Selective reporting (re- } \\
\text { porting bias) }\end{array}$ & Low risk & Comment: awareness outcome part of inclusion criteria \\
\hline Other bias & Low risk & $\begin{array}{l}\text { Quote ROB survey: "The main limitation of the present study is the short na- } \\
\text { ture of the study period, and the small number of cases that were reviewed, } \\
\text { decreasing the confidence in our results and conclusion" }\end{array}$ \\
\hline
\end{tabular}

\section{Ellingson 1977}

\begin{tabular}{ll}
\hline Methods & Study design: randomized parallel groups \\
& Study dates: not stated \\
\hline Participants & Country: Norway \\
Sex: female & Age: 18 to 33 years \\
ASA: not given \\
Procedure: forceps delivery \\
Study size: 26
\end{tabular}


Ellingson 1977 (Continued)

Notes
Non-randomized portion of anaesthetic: parts of intravenous (IV) anaesthesia: $\mathrm{N}_{2} \mathrm{O}$ yes/narcotics
and/or hypnotics bolus/muscle relaxants induction no/maintenance no

Premedication: atropine $0.6 \mathrm{mg}$

Induction: see interventions; mask cases

Maintenance: none

No email address available for ROB survey

\section{Risk of bias}

\begin{tabular}{lll}
\hline Bias & Authors' judgement & Support for judgement \\
\hline $\begin{array}{l}\text { Random sequence genera- } \\
\text { tion (selection bias) }\end{array}$ & Unclear risk & $\begin{array}{l}\text { Quote: "Twenty-six patients, in whom forceps delivery was indicated, were al- } \\
\text { located at random into two groups of } 13 \text { each" }\end{array}$ \\
\hline
\end{tabular}

\begin{tabular}{lll}
\hline $\begin{array}{l}\text { Allocation concealment } \\
\text { (selection bias) }\end{array}$ & Unclear risk & Comment: only above information provided \\
\hline $\begin{array}{l}\text { Blinding of participants } \\
\text { and personnel (perfor- }\end{array}$ & Unclear risk & Comment: personnel knew treatment group assignment \\
mance bias) & & \\
All outcomes & &
\end{tabular}

\begin{tabular}{lll}
\hline $\begin{array}{l}\text { Blinding of outcome as- } \\
\text { sessment (detection bias) } \\
\text { All outcomes }\end{array}$ & Unclear risk & Comment: assessor: no information provided \\
\hline $\begin{array}{l}\text { Incomplete outcome data } \\
\text { (attrition bias) } \\
\text { All outcomes }\end{array}$ & Low risk & Comment: no missing outcome data \\
\hline $\begin{array}{l}\text { Selective reporting (re- } \\
\text { porting bias) }\end{array}$ & Low risk & Comment: awareness outcome part of inclusion criteria \\
\hline Other bias & Unclear risk & Comment: insufficient information provided \\
\hline
\end{tabular}

\section{Fehr 2001}

\begin{tabular}{ll}
\hline Methods & Study design: randomized, double-blind, placebo-controlled \\
& Study dates: not stated \\
\hline Participants & Country: Switzerland \\
& Sex: male and female \\
Age: 18 to 70 \\
ASA: I-II \\
Procedure: superficial surgical procedures expected to last at least 45 min \\
Study size: 50
\end{tabular}


Fehr 2001 (Continued)

Intervention 1: maintenance: clonidine $4 \mu \mathrm{g} / \mathrm{kg}, \mathrm{N}=25$

Intervention 2: maintenance: placebo in $0.9 \% \mathrm{NaCl} 100 \mathrm{~mL}, \mathrm{~N}=25$

Outcomes
Primary outcomes: clonidine's impact on depth of anaesthesia as measured by BIS, BIS guided propo-
Secondary: awareness/wakefulness as defined using an awareness classification system (see Table 1):
class 1
Quote: "No patient had any free recall either of the presented items or of any other pre- or intra-opera-
tive events."
Comment: no evidence of explicit or implicit memory
Non-randomized portion of anaesthetic: parts of TIVA $\mathbf{N}_{2} \mathbf{O}$ no/hypnotic (propofol TCI) infusions
MCI/narcotics infusion (remifentanil MCI): muscle relaxants maintenance yes induction/mainte-
nance unclear/ADM BIS recorded
Induction: propofol (TCI pump target plasma concentration incremental steps until patient uncon-
scious) + rocuronium 0.6 mg/kg + 40\% oxygen
Maintenance: propofol (target concentration) + remifentanil MCI between $0.01 \mu \mathrm{g}$ to $1 \mu \mathrm{gg} / \mathrm{kg} / \mathrm{min}$ main-
tain BIS and haemodynamic stability
Notes: atropine 0.5 mg was administered if the heart rate fell below 40 beats per min
Survey was sent to Donat Spahn, corresponding author, on 14 January 2011. No response

Risk of bias

\begin{tabular}{lll}
\hline Bias & Authors' judgement & Support for judgement \\
\hline $\begin{array}{l}\text { Random sequence genera- } \\
\text { tion (selection bias) }\end{array}$ & Unclear risk & Quote: "...we allocated the patients randomly..." \\
\hline $\begin{array}{l}\text { Allocation concealment } \\
\text { (selection bias) }\end{array}$ & Unclear risk & Comment: see above quote \\
\hline $\begin{array}{l}\text { Blinding of participants } \\
\text { and personnel (perfor- } \\
\text { mance bias) } \\
\text { All outcomes }\end{array}$ & Low risk & $\begin{array}{l}\text { Comment: anaesthesiologist: no information provided. However, clonidine or } \\
\text { placebo was infused after a steady state was reached post intubation; the use } \\
\text { of placebo is a form of blinding }\end{array}$ \\
\hline
\end{tabular}

Blinding of outcome as- Unclear risk Comment: assessor: no information provided

sessment (detection bias)

All outcomes

Incomplete outcome data Low risk Comment: no missing outcome data
(attrition bias)
All outcomes

\begin{tabular}{lll}
\hline $\begin{array}{l}\text { Selective reporting (re- } \\
\text { porting bias) }\end{array}$ & Low risk & Comment: awareness outcome part of inclusion criteria \\
\hline Other bias & Unclear risk & Comment: insufficient information provided \\
\hline
\end{tabular}


Forestier 2003

\begin{tabular}{ll}
\hline Methods & $\begin{array}{l}\text { Study design: randomized parallel groups } \\
\text { Study dates: September } 1999 \text { to December } 2000\end{array}$ \\
\hline Participants & Country: France \\
& Sex: male and female \\
& Age: mean 61 (SD 9) years \\
ASA: II-III & Procedure: coronary artery bypass grafting \\
& Study size: 110 intention-to-treat, 111 enrolled
\end{tabular}

Interventions

\section{Randomized portion of anaesthetic: parts of TIVA: sufentanil TCI}

Intervention 1: maintenance: sufentanil effect site concentrations (Ce) of $0.5 \mu \mathrm{g} / \mathrm{mL}$ decreased by a third after sternotomy, $\mathrm{N}=21$

Intervention 2:maintenance: sufentanil effect site concentrations (Ce) of $0.75 \mu \mathrm{g} / \mathrm{mL}$ decreased by a third after sternotomy, $\mathrm{N}=23$

Intervention 3: maintenance: sufentanil effect site concentrations (Ce) of $1.0 \mu \mathrm{g} / \mathrm{mL}$ decreased by a third after sternotomy, $\mathrm{N}=23$

Intervention 4: maintenance: sufentanil effect site concentrations (Ce) of $1.25 \mu \mathrm{g} / \mathrm{mL}$ decreased by a third after sternotomy, $\mathrm{N}=21$

Intervention 5: maintenance: sufentanil effect site concentrations (Ce) of $1.5 \mu \mathrm{g} / \mathrm{mL}$ decreased by a third after sternotomy, $\mathrm{N}=23$

propofol and sufentanil, both administered by computer-controlled infusion, were titrated on the bispectral index (BIS) values

Outcomes

Primary outcomes: cardiovascular stability, time to tracheal extubation, patient satisfaction

Secondary outcome: awareness/wakefulness as defined using an awareness classification system (see Table 1): class 1

Comment: awareness not defined as a dichotomous variable but a continuous one. The authors used a scoring system found in the appendix. Intraoperative dreams scored as awareness; dreams reported but not clear whether intraoperative or postoperative. We had difficulty interpreting this scoring system in regard to the number of patient awareness/dream reports that the author are defining as consistent with recall/dreams. Author contacted for clarification.

Comment: score 3 consistent with recall during surgery; page 342 indicates that the range of scores identified recall/dream in group 1 and 3 (maximal score $=3)$, group $2(\max =7)$, group $4(\max =4)$, group $5(\max =6)$. We have assumed that Table 6 represents 4 patients who scored $>3$ that the authors defined as on the spectrum of recall/dreams; we will revise in updated version if the authors clarify

\section{Notes}

\section{Non-randomized portion of anaesthetic: parts of TIVA: $\mathrm{N}_{2} \mathrm{O}$ no/narcotics/hypnotics bolus $\mathrm{MCl} /$ muscle relaxants induction yes/maintenance PRN/ADM BIS}

Induction: sufentanil $5 \mu \mathrm{g} / \mathrm{mL}$ in saline + propofol $1.5 \mu \mathrm{g} / \mathrm{mL}(\mathrm{TCl})+$ intubation BIS $<60$ pancuronium $0.1 \mathrm{mg} / \mathrm{kg}$; maintenance: propofol $1 \mu \mathrm{g} / \mathrm{mL}$ (TCl); pancuronium PRN

Comment: classify as TIVA as per rules Appendix 8; might be informative to correlate the target blood levels of propofol and sufentanil with wakefulness using IFT

Email survey sent 4 February 2013 to d.longrois@chu-nancy.fr - email failed

Second email sent on 7 December 2013 for ROB table feedback

\section{Risk of bias}


Forestier 2003 (Continued)

\begin{tabular}{lll} 
Bias & Authors' judgement & Support for judgement \\
\hline $\begin{array}{l}\text { Random sequence genera- } \\
\text { tion (selection bias) }\end{array}$ & Low risk & $\begin{array}{l}\text { Quote: "computer generated random numbers in closed envelopes opened } \\
\text { when the patient arrived in the OpR" }\end{array}$ \\
\hline $\begin{array}{l}\text { Allocation concealment } \\
\text { (selection bias) }\end{array}$ & Unclear risk & $\begin{array}{l}\text { Quote: "computer generated random numbers in closed envelopes opened } \\
\text { when the patient arrived in the OpR" }\end{array}$ \\
\hline $\begin{array}{l}\text { Blinding of participants } \\
\text { and personnel (perfor- } \\
\text { mance bias) }\end{array}$ & Unclear risk & Comment: anaesthesiologist: no information provided \\
All outcomes & & \\
\hline
\end{tabular}

Blinding of outcome as- Unclear risk Comment: assessor: no information provided

sessment (detection bias)

All outcomes

$\begin{array}{ll}\begin{array}{l}\text { Incomplete outcome data } \\ \text { (attrition bias) }\end{array} & \text { Low risk } \\ \text { All outcomes } & \begin{array}{l}\text { Comment: all protocol violations but one (occurred prior to induction and was } \\ \text { excluded from study) were included in outcomes analysis; both postoperative } \\ \text { patient deaths occurred after the first awareness interview; therefore, no high- } \\ \text { risk awareness patients excluded }\end{array}\end{array}$

Author sent characteristics and ROB tables for comment 7 December 2013: d.longrois@chu-nancy.fr. There was no response from this author to our survey.

\begin{tabular}{lll}
\hline $\begin{array}{l}\text { Selective reporting (re- } \\
\text { porting bias) }\end{array}$ & Low risk & Comment: awareness outcome part of inclusion criteria \\
\hline Other bias & Unclear risk & Comment: insufficient information provided \\
\hline
\end{tabular}

\section{Fragen 1981}

\begin{tabular}{ll} 
Methods & Study design: randomized parallel groups \\
& Study dates: 1981 \\
\hline Participants & Country: USA \\
& Sex: female \\
& Age: 19 to 60 \\
& ASA: I-II \\
& Procedure: short gynaecological operations \\
& Study size: 99 \\
& Randomized portion of anaesthetic: IV: premedication: narcotic vs benzodiazepine vs barbiturate \\
& vs placebo \\
& Intervention 1: premedication: fentanyl $1.5 \mu \mathrm{g} / \mathrm{kg}+$ induction: midazolam $0.175 \mathrm{mg} / \mathrm{kg}, \mathrm{N}=25$ \\
& Intervention 2: premedication: saline $1.5 \mu \mathrm{g} / \mathrm{kg}$ (placebo) + induction: midazolam $0.175 \mathrm{mg} / \mathrm{kg}, \mathrm{N}=26$ \\
& Intervention 3: premedication: fentanyl $1.5 \mu \mathrm{g} / \mathrm{kg}+$ thiopental $3.75 \mathrm{mg} / \mathrm{kg}, \mathrm{N}=25$ \\
& Intervention 4: premedication: saline $1.5 \mu \mathrm{g} / \mathrm{kg}$ (placebo) + thiopental $3.75 \mathrm{mg} / \mathrm{kg}, \mathrm{N}=23$ \\
& Maintenance: doses equal to one-fourth the initial induction dose were given IV when signs of awaken- \\
ing or movement appeared
\end{tabular}


Fragen 1981 (Continued)

Outcomes
Primary outcomes: speed/quality of recovery (awakening characteristics)

Secondary outcome: awareness/wakefulness as defined using an awareness classification system (see Table 1): class 1

Comment: anterograde amnesia means no recall of intraoperative events as per author survey response (see notes)

(Above from table 3 in study)
Non-randomized portion of anaesthetic: parts of intravenous (IV) anaesthesia: $\mathrm{N}_{2} \mathrm{O}$ yes/narcotics and/or hypnotics bolus/muscle relaxants induction no/maintenance no

Induction: midazolam $0.175 \mathrm{mg} / \mathrm{kg}$ or thiopental $3.75 \mathrm{mg} / \mathrm{kg}$. If 2 of 3 consecutive patients receiving midazolam remained awake after $0.175 \mathrm{mg} / \mathrm{kg}$, the dose was increased by $0.025 \mathrm{mg} / \mathrm{kg}$ such that most patients in the midazolam + saline group were induced with a dose of $0.25 \mathrm{mg} / \mathrm{kg}$. Maintenance: $\mathrm{N}_{2} \mathrm{O} 67 \%$

Time of outcome determination: $24 \mathrm{~h}$ postoperative

Method of outcome determination: recall of pictures shown the previous day

Comment: ROB survey Fragen states that anterograde amnesia indicates that no patient had recall of intraoperative events

Survey response: 17 January 2011, RJ Fragen r-fragen@northwestern.edu

Third email sent to Robert Fragen rfragen@yahoo.com 4 February 2013

\section{Risk of bias}

\begin{tabular}{|c|c|c|}
\hline Bias & Authors' judgement & Support for judgement \\
\hline $\begin{array}{l}\text { Random sequence genera- } \\
\text { tion (selection bias) }\end{array}$ & Low risk & $\begin{array}{l}\text { Quote: "According to a random number table, fentanyl...or an equivalent vol- } \\
\text { ume of saline was given..." }\end{array}$ \\
\hline $\begin{array}{l}\text { Allocation concealment } \\
\text { (selection bias) }\end{array}$ & Unclear risk & Comment: no information provided \\
\hline $\begin{array}{l}\text { Blinding of participants } \\
\text { and personnel (perfor- } \\
\text { mance bias) } \\
\text { All outcomes }\end{array}$ & Low risk & $\begin{array}{l}\text { Comment: Dr Fragen's response to ROB survey stated that the anaesthesiolo- } \\
\text { gist was blinded to the premedication randomized drug }\end{array}$ \\
\hline $\begin{array}{l}\text { Blinding of outcome as- } \\
\text { sessment (detection bias) } \\
\text { All outcomes }\end{array}$ & Unclear risk & Comment: assessor: no information provided \\
\hline $\begin{array}{l}\text { Incomplete outcome data } \\
\text { (attrition bias) } \\
\text { All outcomes }\end{array}$ & Low risk & Comment: no missing outcome data \\
\hline $\begin{array}{l}\text { Selective reporting (re- } \\
\text { porting bias) }\end{array}$ & Low risk & Comment: awareness outcome part of inclusion criteria \\
\hline Other bias & Unclear risk & Comment: insufficient information provided \\
\hline
\end{tabular}


Gaitini 1995

\begin{tabular}{ll}
\hline Methods & $\begin{array}{l}\text { Study design: randomized parallel groups } \\
\text { Study dates: not stated }\end{array}$ \\
\hline Participants & Country: Israel \\
Sex: female \\
Age: 44 \\
ASA: I \\
Procedure: elective caesarean section \\
Study size: 50
\end{tabular}

\section{Interventions Randomized portion of anaesthetic: IV parts of volatile agent induction}

Intervention 1: induction: thiopentone $(4 \mathrm{mg} / \mathrm{kg}), \mathrm{N}=25$

Intervention 2: induction: ketamine (1 mg/kg), N = 25

Outcomes Primary outcomes: correlation between EEG separately for those patients with responsiveness to verbal commands and for those without

Secondary outcome: awareness/wakefulness as defined using an awareness classification system (see Table 1): class 2

Quote: "None of the patients recalled anything of the surgery"

Comment: implicit memory: 13/25 thiopentone, 5/25 ketamine

Notes Non-randomized portion of anaesthetic: parts of volatile agent: $\mathrm{N}_{2} \mathrm{O}$ yes/narcotics/hypnotics bo-
lus/muscle relaxants induction yes/maintenance unclear/EEG SEF90

Anaesthesia induction: succinylcholine $(1.5 \mathrm{mg} / \mathrm{kg})$

Anaesthesia maintenance: $50 \% \mathrm{~N}_{2} \mathrm{O} 50 \%$ oxygen with end-tidal halothane $0.5 \mathrm{MAC}$; relationship between EEG (spectral edge frequency 90 - SEF90) and occurrence of awareness

Time of outcome determination: $24 \mathrm{~h}$ postoperatively

Method of outcome determination: interview

Comment: IFT used, awareness = wakefulness, recall = explicit memory

Quote: "In the thiopentone group, 13 of 25 patients (52\%), moved their hands in response to the anaesthetist's instruction, before delivery. The pre-delivery movements in response to command occurred at an average SEF90 value of $18.09+3.1 \mathrm{~Hz}$. In the ketamine group, five of 25 patients $(24 \%)$ moved their hands in response to command before delivery at an average SEF90 of 12.0"

No email address available for ROB survey

\section{Risk of bias}

\begin{tabular}{lll}
\hline Bias & Authors' judgement & Support for judgement \\
\hline $\begin{array}{l}\text { Random sequence genera- } \\
\text { tion (selection bias) }\end{array}$ & Low risk & $\begin{array}{l}\text { Quote: "The patients were assigned by a randomised code to receive either } \\
\text { thiopentone }(4 \mathrm{mg} \text { ' kg) or ketamine (l mg kg) for induction of anaesthesia" }\end{array}$ \\
\hline $\begin{array}{l}\text { Allocation concealment } \\
\text { (selection bias) }\end{array}$ & Unclear risk & Comment: no information provided \\
\hline
\end{tabular}


Gaitini 1995 (Continued)
Blinding of participants
Unclear risk
Comment: anaesthesiologist: no information provided and personnel (performance bias)

All outcomes

\begin{tabular}{lll}
\hline $\begin{array}{l}\text { Blinding of outcome as- } \\
\text { sessment (detection bias) }\end{array}$ & Unclear risk & Comment: assessor: no information pro \\
All outcomes & & \\
\hline $\begin{array}{l}\text { Incomplete outcome data } \\
\text { (attrition bias) }\end{array}$ & Low risk & Comment: no missing outcome data \\
All outcomes & &
\end{tabular}

\begin{tabular}{lll}
\hline $\begin{array}{l}\text { Selective reporting (re- } \\
\text { porting bias) }\end{array}$ & Low risk & Comment: awareness outcome part of inclusion criteria \\
\hline Other bias & Unclear risk & Comment: insufficient information provided \\
\hline
\end{tabular}

Gale 2001

\begin{tabular}{ll}
\hline Methods & $\begin{array}{l}\text { Study design: randomized parallel groups } \\
\text { Study dates: June } 2000 \text { to January } 2001\end{array}$ \\
\hline Participants & Country: Australia \\
Sex: both & Age: 44 \\
ASA: I-III & Procedure: elective surgery \\
Study size: 40
\end{tabular}

Interventions

Randomized portion of anaesthetic: parts of IV: induction: MCI vs TCI hypnotic (propofol)

Intervention 1: induction: manually controlled infusion of propofol at $\sim 2 \mathrm{mg} / \mathrm{kg}$ at $1200 \mathrm{~mL} / \mathrm{h}$ maintenance: propofol 3 to $10 \mathrm{mg} / \mathrm{kg}, \mathrm{N}=20$

Intervention 2: induction: target controlled infusion of propofol of $3 \mu \mathrm{g}$ to $8 \mu \mathrm{g} / \mathrm{mL}$; maintenance: propofol $2 \mu \mathrm{g}$ to $5 \mu \mathrm{g} / \mathrm{mL}, \mathrm{N}=20$

Outcomes

Primary outcomes: BIS median absolute performance error; the total dose of propofol infused and the number of changes in target concentration or infusion rate were also noted

Secondary outcome: awareness/wakefulness as defined using an awareness classification system (see Table 1): class 1

Quote: "No patient reported awareness of intraoperative events"

Notes
relaxants induction yes/maintenance yes ADM BIS

Anaesthesia induction: midazolam $0.03 \mu \mathrm{g} / \mathrm{kg}+$ fentanyl $2 \mu \mathrm{g} / \mathrm{kg}+$ rocuronium. Anaesthesia maintenance: nitrous $66 \%$ propofol, rocuronium, fentanyl as needed; BIS recorded 


\section{Risk of bias}

\begin{tabular}{lll}
\hline Bias & Authors' judgement & Support for judgement \\
\hline $\begin{array}{l}\text { Random sequence genera- } \\
\text { tion (selection bias) }\end{array}$ & Low risk & $\begin{array}{l}\text { Quote: "Randomization to } \mathrm{TCl} \text { or MCl was achieved using random number } \\
\text { tables and sealed opaque envelope allocation after consent had been ob- } \\
\text { tained."(email bias survey, see notes) }\end{array}$ \\
\hline $\begin{array}{l}\text { Allocation concealment } \\
\text { (selection bias) }\end{array}$ & Low risk & $\begin{array}{l}\text { Quote: "Sealed opaque envelope allocation after consent had been ob- } \\
\text { tained" (email bias survey, see notes) }\end{array}$ \\
\hline $\begin{array}{l}\text { Blinding of participants } \\
\begin{array}{l}\text { and personnel (perfor- } \\
\text { mance bias) }\end{array}\end{array}$ & High risk & $\begin{array}{l}\text { Quote: "Patient, Awareness outcome assessor (interviewer)" (email bias sur- } \\
\text { vey, see notes) }\end{array}$ \\
\hline
\end{tabular}

\begin{tabular}{|c|c|c|}
\hline $\begin{array}{l}\text { Blinding of outcome as- } \\
\text { sessment (detection bias) } \\
\text { All outcomes }\end{array}$ & Low risk & $\begin{array}{l}\text { Quote: "Patient, Awareness outcome assessor (interviewer)" (email bias sur- } \\
\text { vey, see notes) }\end{array}$ \\
\hline $\begin{array}{l}\text { Incomplete outcome data } \\
\text { (attrition bias) } \\
\text { All outcomes }\end{array}$ & Low risk & $\begin{array}{l}\text { Quote: "40 patients consented and were randomised. There were no attrition } \\
\text { after consent or after randomisation. Data for all main outcomes was com- } \\
\text { plete. These details were not reported in the paper." (email bias survey, see } \\
\text { notes) }\end{array}$ \\
\hline \multirow[t]{2}{*}{$\begin{array}{l}\text { Selective reporting (re- } \\
\text { porting bias) }\end{array}$} & Low risk & $\begin{array}{l}\text { Quote: "The study protocol is not available, but the protocol is clear from the } \\
\text { published report." (email bias survey, see notes) }\end{array}$ \\
\hline & & Comment: awareness outcome part of inclusion criteria \\
\hline Other bias & Low risk & Quote: "none" (email bias survey, see notes) \\
\hline
\end{tabular}

\section{Ghaly 1988}

\begin{tabular}{ll}
\hline Methods & $\begin{array}{l}\text { Study design: randomized parallel groups } \\
\text { Study dates: not stated }\end{array}$ \\
\hline Participants & Country: England \\
& Sex: female \\
Age: 28 & Procedure: elective caesarean section for cephalopelvic disproportion \\
Study size: 50
\end{tabular}

\section{Interventions \\ Randomized portion of anaesthetic: parts of volatile agent}

Intervention 1: maintenance: halothane $0.5 \%, \mathrm{~N}=25$

Intervention 2: maintenance: Isoflurane $0.75 \%, \mathrm{~N}=25$

Outcomes Primary outcomes: anaesthesia recovery, APGAR scores, blood gases


Ghaly 1988 (Continued)

Secondary outcome: awareness/wakefulness as defined using an awareness classification system (see Table 1): class 1

Comment: none of the mothers complained of intraoperative dreams or awareness

Notes

Non-randomized portion of anaesthetic: parts of volatile agent $\mathrm{N}_{2} \mathrm{O}$ yes/narcotics/hypnotics bolus/muscle relaxants induction yes/maintenance yes

Anaesthesia induction: thiopentone $(3 \mathrm{mg}$ to $5 \mathrm{mg} / \mathrm{kg})+$ suxamethonium $100 \mathrm{mg}$. Anaesthesia maintenance: $50: 50 \mathrm{~N}_{2} \mathrm{O}: \mathrm{O}_{2}+$ group-specific volatile agent; post-delivery: alfentanil $1.0 \mathrm{mg} \mathrm{IV} / \mathrm{N}_{2} \mathrm{O} 70 \% / \mathrm{sux}$ amethonium $0.1 \%$ rate just sufficient to abolish diaphragmatic movement

Time of outcome determination: first postoperative day

Method of outcome determination: interview

No email address available for ROB survey

\section{Risk of bias}

\begin{tabular}{|c|c|c|}
\hline Bias & Authors' judgement & Support for judgement \\
\hline $\begin{array}{l}\text { Random sequence genera- } \\
\text { tion (selection bias) }\end{array}$ & Unclear risk & $\begin{array}{l}\text { Quote: "They were randomly allocated to either the isoflurane or halothane } \\
\text { group" }\end{array}$ \\
\hline $\begin{array}{l}\text { Allocation concealment } \\
\text { (selection bias) }\end{array}$ & Unclear risk & Comment: no information provided \\
\hline $\begin{array}{l}\text { Blinding of participants } \\
\text { and personnel (perfor- } \\
\text { mance bias) } \\
\text { All outcomes }\end{array}$ & Unclear risk & Comment: anaesthesiologist: no information provided \\
\hline $\begin{array}{l}\text { Blinding of outcome as- } \\
\text { sessment (detection bias) } \\
\text { All outcomes }\end{array}$ & Unclear risk & Comment: assessor: no information provided \\
\hline $\begin{array}{l}\text { Incomplete outcome data } \\
\text { (attrition bias) } \\
\text { All outcomes }\end{array}$ & Low risk & Comment: no missing outcome data \\
\hline $\begin{array}{l}\text { Selective reporting (re- } \\
\text { porting bias) }\end{array}$ & Low risk & Comment: awareness outcome part of inclusion criteria \\
\hline Other bias & Unclear risk & Comment: insufficient information provided \\
\hline
\end{tabular}

Ghoneim 2000

\begin{tabular}{ll}
\hline Methods & $\begin{array}{l}\text { Study design: randomized parallel groups } \\
\text { Study dates: not stated }\end{array}$ \\
\hline Participants & Country: USA \\
Sex: both \\
Age: 23 \\
ASA: I-III
\end{tabular}


Ghoneim 2000 (Continued)

Procedure: elective surgery

Study size: 180,179

$\begin{array}{ll}\text { Interventions } & \text { Randomized portion of anaesthetic: parts of IV vs parts of volatile agent: opioid bolus vs opioid } \\ \text { infusion } \mathrm{MCl} \text { vs volatile agent }\end{array}$

Opioid bolus: intervention 1: induction: fentanyl $7.5 \mu \mathrm{g} / \mathrm{kg}$, after $5 \mathrm{~min}$, thiopental sleep dose (incremental dose until fall asleep), maintenance: $70 \% \mathrm{~N}_{2} \mathrm{O} / \mathrm{O}_{2}$ and muscle relaxant; $2.5 \mu \mathrm{g} / \mathrm{kg}$ fentanyl supplements as needed, $\mathrm{N}=100$

Opioid infusion: intervention 2: induction: alfantenil $50 \mu \mathrm{g} / \mathrm{kg}+$ alfentanil $1.5 \mu \mathrm{g} / \mathrm{kg} / \mathrm{min}$; after $90 \mathrm{sec}$ onds, thiopental sleep dose (incremental dose until fall asleep), maintenance: $70 \% \mathrm{~N}_{2} \mathrm{O} / \mathrm{O}_{2}$ and muscle relaxant; alfentanil $1.0 \mu \mathrm{g}$ to $1.5 \mathrm{\mu g} / \mathrm{kg} / \mathrm{min}$ titrated to patient response to noxious stimuli, $\mathrm{N}=40$

Volatile agent: isoflurane $0.3 \%$ : intervention 3: induction: fentanyl $1 \mu \mathrm{g} / \mathrm{kg}$ after $5 \mathrm{~min}$, thiopental sleep dose (incremental dose until fall asleep), maintenance: $70 \% \mathrm{~N}_{2} \mathrm{O} / \mathrm{O}_{2}$ and muscle relaxant; isoflurane $0.3 \% \mathrm{ET}+$ fentanyl up to $1 \mu \mathrm{g} / \mathrm{kg} / \mathrm{h}$ as needed, $\mathrm{N}=16$

Isoflurane $0.7 \%$ : intervention 4 : similar to the preceding group except that isoflurane maintained $0.7 \%$ $\mathrm{ET}, \mathrm{N}=24$

Secondary outcome: awareness/wakefulness as defined using an awareness classification system (see Table 1): class 4

Quote: "Six patients showed explicit recall of intraoperative events: All received the opioid bolus regimen"

Quote: "None of the patients gave evidence of awareness when they were asked initially the simple four questions mentioned above. However, with further prompting cue questions they gave evidence of awareness" cotics/hypnotics bolus/muscle relaxants induction yes/maintenance yes/ADM AER recorded

Anaesthesia induction: thiopental sleep dose + nitrous $70 \%$ with muscle relaxant

Anaesthesia maintenance: $\mathrm{N}_{2} \mathrm{O} 70 \%$ in oxygen

Comment: 10 tapes (5 of each story) were randomized to maintain blinded conditions and assessed the AER. Each story contained target words

Comment: opioid anaesthesia is a light anaesthetic with more dreams consistent with Utting's view

Comment: extended interview identifies more patient awareness reports than the standardized interview (p133 see for interview protocol)

Time of outcome determination: at most 4 days postoperatively

ROB survey: we emailed on 16 June 2015

\section{Risk of bias}

\begin{tabular}{lll}
\hline Bias & Authors' judgement & Support for judgement \\
\hline $\begin{array}{l}\text { Random sequence genera- } \\
\text { tion (selection bias) }\end{array}$ & Low risk & $\begin{array}{l}\text { Quote: "decided to allocate most patients to the opioid bolus regimen ( } \mathrm{N}=100) \\
\text { and a lesser number to the opioid infusion regimen }(\mathrm{N}=40), \text { isoflurane } 0.7 \% \\
(\mathrm{~N}=24) \text { and isoflurane } 0.3 \% \text { regimen }(\mathrm{N}=16), \text { using randomization tables" }\end{array}$ \\
\hline
\end{tabular}


Ghoneim 2000 (Continued)

$\begin{aligned} & \text { Allocation concealment } \\ & \text { (selection bias) }\end{aligned} \quad$ Unclear risk Comment: no information provided

Blinding of participants Unclear risk Comment: anaesthesiologist: no information provided
and personnel (perfor-
mance bias)
All outcomes

\begin{tabular}{|c|c|c|}
\hline $\begin{array}{l}\text { Blinding of outcome as- } \\
\text { sessment (detection bias) } \\
\text { All outcomes }\end{array}$ & Low risk & $\begin{array}{l}\text { Quote: assessor: "Ten tapes (five of each story) were randomized to maintain } \\
\text { blinded conditions for the investigators, who interviewed the patients postop- } \\
\text { eratively and assessed the AER...The research assistant was also "blinded" to } \\
\text { the method of anesthesia and to the specific story which was played" }\end{array}$ \\
\hline
\end{tabular}

\begin{tabular}{|c|c|c|}
\hline $\begin{array}{l}\text { Incomplete outcome data } \\
\text { (attrition bias) }\end{array}$ & Low risk & $\begin{array}{l}\text { Quote: "one male receiving isoflurane } 0.7 \% \text { had to be eliminated from the AER } \\
\text { analyses because of equipment failure" }\end{array}$ \\
\hline
\end{tabular}

\begin{tabular}{lll}
\hline $\begin{array}{l}\text { Selective reporting (re- } \\
\text { porting bias) }\end{array}$ & Low risk & Comment: awareness outcome part of inclusion criteria \\
\hline Other bias & Unclear risk & Comment: insufficient information provided \\
\hline
\end{tabular}

Ghosh 2008

\begin{tabular}{ll}
\hline Methods & $\begin{array}{l}\text { Study design: randomized parallel groups } \\
\text { Study dates: Quote: "2005-06" (email bias survey, see notes) }\end{array}$ \\
\hline Participants & Country: India \\
Sex: 86 male, 4 female \\
Age: mean 29.1 \\
ASA: I-II \\
Procedure: peripheral nerve repair surgery \\
Study size: 90
\end{tabular}

\section{Interventions Randomized portion of anaesthetic: cardiac drug vs placebo}

Intervention 1: premedication (1 h before surgery): group I: metoprolol $100 \mathrm{mg}, \mathrm{N}=30$

Intervention 2: premedication: Group II: placebo control, $\mathrm{N}=30$

Intervention 3: premedication: Group III: clonidine $200 \mu \mathrm{g}, \mathrm{N}=30$

Primary outcomes: anaesthetic consumption, haemodynamic effects
Secondary outcome: awareness/wakefulness as defined using an awareness classification system (see
Table 1): class 1
Quote: "... none of the patients had free recall of any intraoperative event"

\section{Notes Non-randomized portion of anaesthetic: parts of IV: $\mathrm{N}_{\mathbf{2}} \mathrm{O}$ no/narcotics/hypnotics bolus $\mathrm{MCl} / \mathrm{mus}$ - cle relaxants induction no/maintenance no/ADM: BIS}


Ghosh 2008 (Continued)

Anaesthesia induction: fentanyl $(2 \mu \mathrm{g} / \mathrm{kg})+$ propofol until loss of response; anaesthesia maintenance: fentanyl infusion $(1 \mu \mathrm{g} / \mathrm{kg} / \mathrm{h})+$ propofol infusion titrated to BIS 40 to $60+\mathrm{N}_{2} \mathrm{O}$ in oxygen (2:1) LMA, BIS

40 to 50

Time of outcome determination: $2 \mathrm{~h}$ postoperatively

Method of outcome determination: interview

Survey response: 17 February 2011, Parmod Kumar Bithal bithal.parmod@gmail.com

\section{Risk of bias}

\begin{tabular}{lll}
\hline Bias & Authors' judgement & Support for judgement \\
\hline $\begin{array}{l}\text { Random sequence genera- } \\
\text { tion (selection bias) }\end{array}$ & Low risk & $\begin{array}{l}\text { Quote: "After we had obtained approval from the institutional ethics com- } \\
\text { mittee and informed consent from the patients, they were divided into three } \\
\text { groups, of } 30 \text { each, by the use of computer-generated block randomisation } \\
\text { numbers" }\end{array}$ \\
& $\begin{array}{l}\text { Quote: "Computer generated randomisation sequence of } 90 \text { patients in } 3 \\
\text { blocks of } 30 \text { patients each" (email bias survey, see notes) }\end{array}$ \\
\hline $\begin{array}{l}\text { Allocation concealment } \\
\text { (selection bias) }\end{array}$ & Low risk & $\begin{array}{l}\text { Quote: "Identical opaque sealed envelops were used for the study drugs.All } \\
\text { envelops were labelled and contained drug according to sequence generat- } \\
\text { ed by computer. Envelops were prepared by person not a part of investigating } \\
\text { team" (email bias survey, see notes) }\end{array}$
\end{tabular}

Blinding of participants Low risk Quote: "Patient, Anaesthesiologist, Awareness outcome assessor"
and personnel (perfor-
mance bias)
All outcomes

\begin{tabular}{lll}
\hline $\begin{array}{l}\text { Blinding of outcome as- } \\
\text { sessment (detection bias) } \\
\text { All outcomes }\end{array}$ & Low risk & $\begin{array}{l}\text { Quote: "Patient, Anaesthesiologist, Awareness outcome assessor (interview- } \\
\text { er)" (email bias survey, see notes) }\end{array}$ \\
\hline $\begin{array}{l}\text { Incomplete outcome data } \\
\begin{array}{l}\text { attrition bias) } \\
\text { All outcomes }\end{array}\end{array}$ & Low risk & $\begin{array}{l}\text { Quote: "All patients completed the study and none was excluded from final } \\
\text { analysis" (email bias survey, see notes) }\end{array}$ \\
\hline $\begin{array}{l}\text { Selective reporting (re- } \\
\text { porting bias) }\end{array}$ & Low risk & $\begin{array}{l}\text { Quote: "All primary and secondary end points have been reported" (email bias } \\
\text { survey, see notes) } \\
\text { "No results however insignificant have been selectively withheld from publica- } \\
\text { tion" (email bias survey, see notes) }\end{array}$ \\
& Comment: awareness outcome part of inclusion criteria \\
\hline Other bias & Low risk & $\begin{array}{l}\text { Quote: "None that we are aware of In the post operative period all" (email bias } \\
\text { survey, see notes) }\end{array}$ \\
&
\end{tabular}

Girardi 1994

\begin{tabular}{ll}
\hline Methods & $\begin{array}{l}\text { Study design: randomized parallel groups } \\
\text { Study dates: not stated }\end{array}$ \\
\hline Participants & Country: Italy \\
\hline
\end{tabular}


Girardi 1994 (Continued)

Sex: female and male

Age: 40 to 54

ASA: I

Procedure: saphenectomy surgery

Study size: 51

\section{Interventions Randomized portion of anaesthetic: volatile agent types}

Intervention 1: group 1 (26 patients), 5\% isoflurane in air, by mask; maintenance: group 1, 2\% isoflurane in air

Intervention 2: group 2 (25 patients), $3 \%$ isoflurane and $60 \% \mathrm{~N}_{2} \mathrm{O}$, by mask; maintenance: group 2, $1.2 \%$ isoflurane and $60 \% \mathrm{~N}_{2} \mathrm{O}$

\begin{tabular}{|c|c|}
\hline Outcomes & $\begin{array}{l}\text { Primary outcomes: control the depth, the quality of recovery, recovery time } \\
\text { Secondary outcome: awareness/wakefulness as defined using an awareness classific } \\
\text { Table 1): class } 1 \\
\text { Comment: no patient recall of surgical events }\end{array}$ \\
\hline Notes & $\begin{array}{l}\text { Non-randomized portion of anaesthetic: parts of volatile agent: } \mathrm{N}_{\mathbf{2}} \mathbf{O} \text { no/narcotic } \\
\text { lus/muscle relaxants induction no/maintenance no/ADM EEG and Evans test } \\
\text { Induction: thiopental ( } 3.5 \mathrm{mg} / \mathrm{kg} \text { ), atracurium ( } 0.6 \mathrm{mg} / \mathrm{kg} \text { ) IV } \\
\text { Comment: manual mask induction then ventilator with equipotent isoflurane dose; } \\
\text { inhalational agents only; authors conclude that pure inhalational anaesthesia achie } \\
\text { anaesthesia as long as you use the appropriate concentrations } \\
\text { Quote: "Isoflurane anesthesia in air, in adequate concentrations, provides a sufficien } \\
\text { sia, hypnosis, amnesia, without clinical side effects" } \\
\text { Standardized interview } 1 \mathrm{~h} \text { after anaesthesia and } 24 \mathrm{~h} \text { later } \\
\text { Both groups: EEG compressed spectral array, and clinical signs of pain by Evans test } \\
\text { Translated by AM } \\
\text { No email address available for ROB survey }\end{array}$ \\
\hline
\end{tabular}

Risk of bias

\begin{tabular}{lll}
\hline Bias & Authors' judgement & Support for judgement \\
\hline $\begin{array}{l}\text { Random sequence genera- } \\
\text { tion (selection bias) }\end{array}$ & Unclear risk & Quote: "Patients were randomly assigned to: group..." \\
\hline $\begin{array}{l}\text { Allocation concealment } \\
\text { (selection bias) }\end{array}$ & Unclear risk & Comment: no information provided; no ROB survey data \\
\hline $\begin{array}{l}\text { Blinding of participants } \\
\text { and personnel (perfor- } \\
\text { mance bias) }\end{array}$ & Unclear risk & Comment: no information provided \\
All outcomes & & \\
\hline
\end{tabular}

Blinding of outcome as-
sessment (detection bias) $\quad$ Unclear risk Comment: no information provided


Girardi 1994 (Continued)

All outcomes

Incomplete outcome data Low risk Comment: no missing data
(attrition bias)

All outcomes

\begin{tabular}{lll}
\hline $\begin{array}{l}\text { Selective reporting (re- } \\
\text { porting bias) }\end{array}$ & Low risk & Comment: awareness outcome part of inclusion criteria \\
\hline Other bias & Unclear risk & Comment: no information provided \\
\hline
\end{tabular}

\section{Gokce 2009}

\begin{tabular}{ll}
\hline Methods & $\begin{array}{l}\text { Study design: randomized parallel groups } \\
\text { Study dates: not stated }\end{array}$ \\
\hline Participants & Country: Turkey \\
Sex: both & Age: 29 \\
ASA: I & Procedure: elective septorhinoplasty \\
Study size: 40
\end{tabular}

Interventions

Randomized portion of anaesthetic: cardiac drug + IV vs IV anaesthesia: hypotensive anaesthesia: induction/maintenance

Comment: remifentanil-propofol induced hypotensive anaesthesia (group RP) or remifentanil-propofol-esmolol induced hypotensive anaesthesia (group RP-E): hypotensive technique with safe lower limits of 80 systolic and mean $50 \mathrm{mmHg}$, both groups titrated to SNAP index score $\mathbf{4 0 \%}$ to $60 \%$

Intervention 1: No esmolol: induction: remifentanil bolus $\mathrm{mg} / \mathrm{kg}$ + infusion $0.1 \mu \mathrm{g}$ to $0.5 \mu \mathrm{g} / \mathrm{kg} / \mathrm{min}$; maintenance: remifentanil $0.1 \mu \mathrm{g}$ to $0.5 \mu \mathrm{g} / \mathrm{kg} / \mathrm{min}$ (control), $\mathrm{N}=20$

Intervention 2: Yes esmolol: as intervention 1 plus: induction: esmolol bolus $100 \mu \mathrm{g}$ to $300 \mu \mathrm{g} / \mathrm{kg} / \mathrm{min}$ infusion; maintenance: esmolol $100 \mu \mathrm{g}$ to $300 \mu \mathrm{g} / \mathrm{kg} / \mathrm{min}, \mathrm{N}=20$

Outcomes

Primary outcomes: recovery times, haemodynamic effects, anaesthetic consumption

Secondary outcome: awareness/wakefulness as defined using an awareness classification system (see Table 1): class 4

Comment: 1 awareness patient in group RP

Notes Non-randomized portion of anaesthetic: parts of $\mathrm{IV} \mathrm{N}_{2} \mathrm{O}$ no/narcotics/hypnotics bolus $\mathrm{MCl} / \mathrm{muscle}$
relaxants induction yes/maintenance unclear PRN/ADM: SNAP $(40 \%$ to $60 \%)$
Premed: midazolam ( $0.03 \mathrm{mg} / \mathrm{kg} \mathrm{IV}$ ); induction: propofol bolus ( $2 \mathrm{mg}$ to $2.5 \mathrm{mg} / \mathrm{kg}$ ) + rocuronium (0.6 $\mathrm{mg} / \mathrm{kg}$ ) $+\mathrm{O}_{2} 50 \%$ + rocuronium (table 2); maintenance: propofol $4 \mathrm{mg}$ to $10 \mathrm{mg} / \mathrm{kg} / \mathrm{h}+$ remifentanil infu- sion $(0.1 \mu \mathrm{g}$ to $0.5 \mu \mathrm{g} / \mathrm{kg} / \mathrm{h})$
Quote: "Depth of anaesthesia was measured by depth of anaesthesia (SNAP index score) (Nicolet Bio- medical, VIASYS Healthcare, Madison, Wisconsin, USA)"
Time of outcome determination: in recovery room 
Gokce 2009 (Continued)

Method of outcome determination: interview time NA

Dr Lale Karabrysk, email: karabiyik@gazi.edu.tr

\section{Risk of bias}

\begin{tabular}{|c|c|c|}
\hline Bias & Authors' judgement & Support for judgement \\
\hline $\begin{array}{l}\text { Random sequence genera- } \\
\text { tion (selection bias) }\end{array}$ & Low risk & $\begin{array}{l}\text { Quote: "The patients were equally assigned via computer-generated random } \\
\text { numbers" }\end{array}$ \\
\hline $\begin{array}{l}\text { Allocation concealment } \\
\text { (selection bias) }\end{array}$ & Unclear risk & Comment: no information provided \\
\hline $\begin{array}{l}\text { Blinding of participants } \\
\text { and personnel (perfor- } \\
\text { mance bias) } \\
\text { All outcomes }\end{array}$ & Unclear risk & Comment: anaesthesiologist: no information provided \\
\hline $\begin{array}{l}\text { Blinding of outcome as- } \\
\text { sessment (detection bias) } \\
\text { All outcomes }\end{array}$ & Low risk & $\begin{array}{l}\text { Quote: assessor: "After the extubation, the patients were transferred to the } \\
\text { postanaesthesia care unit (PACU), where further recordings were carried out } \\
\text { by an independent observer blinded to the anaesthetic regimen" }\end{array}$ \\
\hline $\begin{array}{l}\text { Incomplete outcome data } \\
\text { (attrition bias) } \\
\text { All outcomes }\end{array}$ & Low risk & Comment: no missing outcome data \\
\hline $\begin{array}{l}\text { Selective reporting (re- } \\
\text { porting bias) }\end{array}$ & Low risk & Comment: awareness outcome part of inclusion criteria \\
\hline Other bias & Unclear risk & Comment: insufficient information provided \\
\hline
\end{tabular}

Goto 2000

\begin{tabular}{ll} 
Methods & $\begin{array}{l}\text { Study design: randomized parallel groups } \\
\text { Study dates: Quote: "From July } 71998 \text { to January 25, 1999" (email bias survey, see notes) }\end{array}$ \\
\hline Country: Japan \\
Sex: female \\
Age: 38 to 56 \\
ASA: I and II \\
Procedure: elective total abdominal or vaginal hysterectomy \\
Study size: 20
\end{tabular}

Interventions

\section{Randomized portion of anaesthetic: volatile agent types}

Intervention 1: maintenance: xenon: $56 \%$ xenon (0.8 MAC), N = 10

Intervention 2: maintenance: isoflurane: $1.0 \%$ to $1.5 \%$ in $6 \mathrm{~L} / \mathrm{min}$ flow of oxygen, $\mathrm{N}=10$

Bls in both groups 
Goto 2000 (Continued)

Secondary outcome: awareness/wakefulness as defined using an awareness classification system (see Table 1): class 1

Comment: zero patient awareness reports; 4 patients had wakefulness at BIS 50 with xenon post end surgery

\section{Notes \\ Non-randomized portion of anaesthetic: regional anaesthesia: epidural: induction/maintenance: parts of volatile agent: $\mathrm{N}_{2} \mathrm{O}$ no/narcotics/hypnotics bolus/muscle relaxants induction yes/mainte- nance unclear/ADM: BIS recorded}

Anaesthesia induction: epidural $10 \mathrm{~mL}$ mepivacaine $1.5 \%$ with $1: 200,000$ epinephrine, propofol $2.5 \mathrm{mg} /$ $\mathrm{kg} \mathrm{IV} \mathrm{+} \mathrm{5 \%} \mathrm{sevoflurane} \mathrm{+} \mathrm{vecuronium} 10 \mathrm{mg}$ IV; anaesthesia maintenance: see interventions; muscle relaxant reversed at end surgery

Time of outcome determination: $2 \mathrm{~h}$ postoperative

Method of outcome determination: interview

Comment: after surgery...asked to open their eyes and squeeze the anaesthetists hand. For xenon, in some patients this occurred at BIS $<50$. None remembered wakefulness

Survey response: 2 March 2011, Takahisa Goto takigoto@yokohama-cu.ac.jp

Survey questionnaire 25 February 2011

\section{Risk of bias}

\begin{tabular}{lll}
\hline Bias & Authors' judgement & Support for judgement \\
\hline $\begin{array}{l}\text { Random sequence genera- } \\
\text { tion (selection bias) }\end{array}$ & Low risk & $\begin{array}{l}\text { Quote: "The envelop method. Before starting the whole study, we made } 11 \text { and } \\
9 \text { cards with Xe or Iso, respectively, and put each card to an identical envelop } \\
\text { and sealed. Before induction of anaesthesia, the anaesthetist selected one en- } \\
\text { velop, opened it, and gave either xenon or isoflurane according to what the } \\
\text { card said. We made a little more cards of xenon than those of isoflurane simply } \\
\text { because xenon was a newer drug" (email survey) }\end{array}$
\end{tabular}

Allocation concealment Low risk (selection bias)
Quote: "As described in the randomized method, we decided allocation just before induction of anesthesia. After randomization, we did not tell the participants whether they would be receiving xenon or isoflurane. Similarly, the investigator who enrolled the participants had no means to know in advance if they would be allocated to xenon or isoflurane. The anesthetists who actually conducted anesthesia were NOT blinded to the anesthetics given. Blinding was virtually impossible" (email survey)

\begin{tabular}{l}
\hline Blinding of participants High risk Quote: "Patient, Awareness outcome assessor (interviewer)" (email survey) \\
and personnel (perfor- \\
mance bias)
\end{tabular}


Goto 2000 (Continued)

Comment: awareness outcome part of inclusion criteria

\begin{tabular}{ll}
\hline Other bias $\quad$ Low risk $\quad$ Quote: "I cannot think of any other potential bias" (email survey) \\
\hline
\end{tabular}

Gruenewald 2007

\begin{tabular}{ll}
\hline Methods & $\begin{array}{l}\text { Study design: randomized parallel groups } \\
\text { Study dates: not stated }\end{array}$ \\
\hline Participants & Country: Germany \\
Sex: female \\
Age: 33,38 \\
ASA: I and II \\
Procedure: elective gynaecological laparoscopy \\
Study size: 72
\end{tabular}

\section{Interventions $\quad$ Randomized portion of anaesthetic: TIVA ADM (M-entropy) vs SCP}

Intervention 1: standard clinical practice

Intervention 2: M-entropy monitoring $\mathbf{4 0}$ and $\mathbf{6 0}$

\section{Outcomes}

Primary outcomes: consumption of anaesthetics, recovery times

Secondary outcome: awareness/wakefulness as defined using an awareness classification system (see Table 1): class 4

Comment: 1 patient in SCP reported awareness

Notes

\section{Non-randomized portion of anaesthetic: parts of TIVA: $\mathrm{N}_{2} \mathrm{O}$ no/narcotics/hypnotics bolus $\mathrm{MCl} /$ muscle relaxants induction yes/maintenance unclear/ADM BIS recorded}

Anaesthesia induction: propofol $(2 \mathrm{mg} / \mathrm{kg})+$ remifentanil $(0.3 \mu \mathrm{g}$ to $0.5 \mu \mathrm{g} / \mathrm{kg} / \mathrm{min})+$ rocuronium $(0.6$ $\mathrm{mg} / \mathrm{kg}$ ); maintenance: propofol + remifentanil

Comment: blinding anaesthetist, learning bias according to 2 opposing views of Roizen and Lindholm

Time of outcome determination: first postoperative day

Method of outcome determination: interview

Email: gruenewald@anaesthesie.uni-kiel.de; ROB survey - we emailed on 11 April 2015

\section{Risk of bias}

Bias Authors' judgement Support for judgement

Random sequence genera- Unclear risk Quote: "Randomisation to the two treatment groups (standard practice or ention (selection bias) tropy) was done by opening a sealed envelope"

$\begin{aligned} & \text { Allocation concealment } \\ & \text { (selection bias) }\end{aligned}$
$\begin{aligned} & \text { Unclear risk } \\ & \text { tropy) was done by opening a sealed envelope" }\end{aligned}$




\begin{tabular}{|c|c|c|}
\hline $\begin{array}{l}\text { Blinding of participants } \\
\text { and personnel (perfor- } \\
\text { mance bias) } \\
\text { All outcomes }\end{array}$ & High risk & $\begin{array}{l}\text { Comment: both groups used BIS and M-entropy; in SCP group both were blind- } \\
\text { ed and in experimental group entropy was not blinded }\end{array}$ \\
\hline $\begin{array}{l}\text { Blinding of outcome as- } \\
\text { sessment (detection bias) } \\
\text { All outcomes }\end{array}$ & Low risk & $\begin{array}{l}\text { Quote: assessor: "On the first postoperative day, all patients were asked by a } \\
\text { blinded anaesthetist if they had any memory or awareness during different } \\
\text { stages..." }\end{array}$ \\
\hline $\begin{array}{l}\text { Incomplete outcome data } \\
\text { (attrition bias) } \\
\text { All outcomes }\end{array}$ & Low risk & Quote: "All patients were included into the final analysis" \\
\hline $\begin{array}{l}\text { Selective reporting (re- } \\
\text { porting bias) }\end{array}$ & Low risk & Comment: awareness outcome part of inclusion criteria \\
\hline Other bias & Unclear risk & Comment: insufficient information provided \\
\hline
\end{tabular}

Grundmann 2001

\begin{tabular}{ll}
\hline Methods & $\begin{array}{l}\text { Study design: randomized parallel groups } \\
\text { Study dates: not stated }\end{array}$ \\
\hline Participants & Country: Germany \\
Sex: male and female & Age: 23 to 65 \\
ASA: I and II \\
Procedure: elective laparoscopic cholecystectomy \\
Study size: 50
\end{tabular}

\section{Interventions Randomized portion of anaesthetic: parts of TIVA vs parts of volatile agent}

Intervention 1: maintenance: Group R/P: propofol $4 \mathrm{mg} / \mathrm{kg} / \mathrm{h}, \mathrm{N}=25$

Intervention 2: maintenance: Group R/D: desflurane 3\% ET, N = 25

Outcomes Primary outcomes: haemodynamic responses, recovery profile

Secondary outcome: awareness/wakefulness as defined using an awareness classification system (see Table 1): class 1

Quote: "None of the patients showed any signs of wakefulness in response to surgical procedures or had postoperative recall of intraoperative events"

Notes

Non-randomized portion of anaesthetic: parts of TIVA vs parts of volatile agent $\mathrm{N}_{2} \mathrm{O}$ no + infusion of narcotics $\mathrm{MCl}+$ muscle relaxant(s) induction yes/maintenance unclear

Premed: $10 \mathrm{mg}$ diazepam; induction: remifentanil infusion $\mathrm{MCl}(0.5 \mu \mathrm{g} / \mathrm{kg} / \mathrm{min})$ until patient felt dazed + propofol IV $(2 \mathrm{mg} / \mathrm{kg})+$ atracurium $(0.5 \mathrm{mg} / \mathrm{kg})+$ ventilation oxygen $2 \mathrm{~L} / \mathrm{min}$ in air

Anaesthesia maintenance: remifentanil infusion $\mathrm{MCl}$ reduced $0.25 \mu \mathrm{g} / \mathrm{kg} / \mathrm{min}$ 
Grundmann 2001 (Continued)

Comment: see Dryad author's definition of anaesthesia

Time of outcome determination: after recovery

Method of outcome determination: interview

ROB survey. We emailed on 11 April 2015

Dr. Grundmann email: aiugru@krzsun.med-rz.uni-sb.de

\section{Risk of bias}

\begin{tabular}{|c|c|c|}
\hline Bias & Authors' judgement & Support for judgement \\
\hline $\begin{array}{l}\text { Random sequence genera- } \\
\text { tion (selection bias) }\end{array}$ & Unclear risk & Quote: "Fifty patients (ASA I-II, 23-65 yr) were randomly assigned" \\
\hline $\begin{array}{l}\text { Allocation concealment } \\
\text { (selection bias) }\end{array}$ & Unclear risk & Comment: inadequate information provided \\
\hline $\begin{array}{l}\text { Blinding of participants } \\
\text { and personnel (perfor- } \\
\text { mance bias) } \\
\text { All outcomes }\end{array}$ & Unclear risk & Comment: anaesthesiologist: no information provided \\
\hline $\begin{array}{l}\text { Blinding of outcome as- } \\
\text { sessment (detection bias) } \\
\text { All outcomes }\end{array}$ & Low risk & $\begin{array}{l}\text { Quote: assessor: "...the patients were directly transferred to the postanaesthe- } \\
\text { sia care unit (PACU), where further recordings were done by an independent, } \\
\text { blinded observer, who was unaware of the administered anaesthesia regimen" }\end{array}$ \\
\hline $\begin{array}{l}\text { Incomplete outcome data } \\
\text { (attrition bias) } \\
\text { All outcomes }\end{array}$ & Low risk & Comment: no missing outcome data \\
\hline $\begin{array}{l}\text { Selective reporting (re- } \\
\text { porting bias) }\end{array}$ & Low risk & Comment: awareness outcome part of inclusion criteria \\
\hline Other bias & Unclear risk & Comment: insufficient information provided \\
\hline
\end{tabular}

Gupta 1992

\begin{tabular}{ll}
\hline Methods & $\begin{array}{l}\text { Study design: randomized parallel groups } \\
\text { Study dates: not stated }\end{array}$ \\
\hline Participants & Country: Sweden \\
& Sex: both \\
& Age: 17 to 49, mean: $33.2 \pm 10,27.5 \pm 6$ \\
& ASA: I and II \\
& Procedure: outpatient arthroscopic procedures of the knee \\
& Study size: 30
\end{tabular}

Interventions

Randomized portion of anaesthetic: volatile agent types: IV induction hypnotics

Intervention 1: induction: thiopentone $5 \mathrm{mg}$ to $6 \mathrm{mg} / \mathrm{kg}, \mathrm{N}=14$ 
Outcomes Primary outcomes: psychomotor recovery; differences between isoflurane and propofol groups at each measurement, dream frequency

Secondary outcome: awareness/wakefulness as defined using an awareness classification system (see Table 1): class 1

Comment: assessment for dreams and awareness was in methods. Results section reports only dreams does not mention awareness; awareness reported

\section{Non-randomized portion of anaesthetic: parts of volatile agent: $\mathrm{N}_{2} \mathrm{O}$ no/narcotics/hypnotics bo- lus/muscle relaxants induction no/maintenance no}

Anaesthesia induction: alfentanil $0.25 \mathrm{mg}$; maintenance: isoflurane $(0.5 \%$ to $2 \%)$ in oxygen and air + alfentanil $0.25 \mathrm{mg}$ plus additional doses every $15 \mathrm{~min}$; spontaneous breathing with mask; ventilation was controlled if there was apnoea exceeding $30 \mathrm{~s}$

Time of outcome determination: prior to discharge

Method of outcome determination: interview

No email address available for ROB survey

\section{Risk of bias}

\begin{tabular}{|c|c|c|}
\hline Bias & Authors' judgement & Support for judgement \\
\hline $\begin{array}{l}\text { Random sequence genera- } \\
\text { tion (selection bias) }\end{array}$ & Unclear risk & Quote: "The patients were randomly divided into two groups" \\
\hline $\begin{array}{l}\text { Allocation concealment } \\
\text { (selection bias) }\end{array}$ & Unclear risk & Comment: no information provided \\
\hline $\begin{array}{l}\text { Blinding of participants } \\
\text { and personnel (perfor- } \\
\text { mance bias) } \\
\text { All outcomes }\end{array}$ & Unclear risk & Comment: anaesthesiologist: no information provided \\
\hline $\begin{array}{l}\text { Blinding of outcome as- } \\
\text { sessment (detection bias) } \\
\text { All outcomes }\end{array}$ & Unclear risk & $\begin{array}{l}\text { Comment: assessor: no information provided } \\
\text { Quote: "The patients were interviewed prior to discharge as to whether they } \\
\text { had any dreams or were aware during the procedure..." }\end{array}$ \\
\hline $\begin{array}{l}\text { Incomplete outcome data } \\
\text { (attrition bias) } \\
\text { All outcomes }\end{array}$ & Low risk & Comment: no missing outcome data \\
\hline $\begin{array}{l}\text { Selective reporting (re- } \\
\text { porting bias) }\end{array}$ & Low risk & Comment: awareness outcome part of inclusion criteria \\
\hline Other bias & Unclear risk & Comment: insufficient information provided \\
\hline
\end{tabular}

Gurman 1994

$\begin{array}{ll}\text { Methods } & \text { Study design: randomized parallel groups } \\ \text { Study dates: "year of 1992" (email bias survey, see notes) }\end{array}$


Gurman 1994 (Continued)

Country: Israel
Sex: male and female
Age: mean 18 to 70
ASA: I-II
Procedure: surgical procedures lasting at least 30 min
Study size: 48 enrolled; 43 completed study

Randomized portion of anaesthetic: parts of TIVA vs parts of volatile agent
Intervention 1: maintenance: propofol varying between $3 \mathrm{mg}$ to $6 \mathrm{mg} / \mathrm{kg} / \mathrm{h}, \mathrm{N}=24$
Intervention 2: maintenance: isoflurane $1 \%$ to $1.75 \%, \mathrm{~N}=24$
Both isoflurane and propofol dosage as well as the amount of fluids administered were adjusted in or-
der to maintain a SEF between $8 \mathrm{~Hz}$ and $12 \mathrm{~Hz}$ and mean blood pressure and heart rate within normal
limits

Outcomes Primary outcomes: haemodynamic effects, recovery effects, differences anaesthetics consumed, SEF variation

Secondary outcome: awareness/wakefulness as defined using an awareness classification system (see Table 1): class 1

Quote: "No patients in either group showed any evidence of awareness during maintenance of anaesthesia (by raising the isolated arm) or by postoperative recall of intra-operative events"

Notes Non-randomized portion of anaesthetic: parts of TIVA vs parts of volatile agent $\mathrm{N}_{2} \mathrm{O}$ yes/nar-
cotics/hypnotics bolus/muscle relaxants induction yes/maintenance PRN/ADM: SEF recorded

Premedication: oral diazepam $5 \mathrm{mg}$ to $10 \mathrm{mg}$

Induction: vecuronium $1 \mathrm{mg}$ + fentanyl $0.2 \mathrm{mg}$ + thiopentone $5 \mathrm{mg} / \mathrm{kg}$ + suxamethonium $5 \mathrm{mg} / \mathrm{kg}$

Maintenance: $\mathrm{N}_{2} \mathrm{O} / \mathrm{O}_{2} 2: 1$ litre/min + vecuronium and fentanyl when needed

Author responded to the email bias survey on 25 January 2011

Survey response: 25 January 2011, Gabriel M. Gurman MD gurman@bgu.ac.il

Emailed author on 8 December 2013 for feedback about characteristics table and ROB domains; responded 12December 2013: "I have nothing to comment"

\section{Risk of bias}

\begin{tabular}{|c|c|c|}
\hline Bias & Authors' judgement & Support for judgement \\
\hline \multirow[t]{2}{*}{$\begin{array}{l}\text { Random sequence genera- } \\
\text { tion (selection bias) }\end{array}$} & High risk & $\begin{array}{l}\text { Quote: "the patients were randomised into two groups according to the last } \\
\text { digit of their identity number" }\end{array}$ \\
\hline & & Quote: "last digit ID number" (email survey) \\
\hline $\begin{array}{l}\text { Allocation concealment } \\
\text { (selection bias) }\end{array}$ & Low risk & $\begin{array}{l}\text { Quote: "There was only one of us (MS) who dealt with randomisation and he } \\
\text { did not take part to the results analysis" (email survey) }\end{array}$ \\
\hline $\begin{array}{l}\text { Blinding of participants } \\
\text { and personnel (perfor- } \\
\text { mance bias) } \\
\text { All outcomes }\end{array}$ & Low risk & $\begin{array}{l}\text { Quote: "Patient, Anaesthesiologist, Awareness outcome assessor (interview- } \\
\text { er)" (email survey) }\end{array}$ \\
\hline $\begin{array}{l}\text { Blinding of outcome as- } \\
\text { sessment (detection bias) } \\
\text { All outcomes }\end{array}$ & Low risk & Above \\
\hline
\end{tabular}


Gurman 1994 (Continued)

Incomplete outcome data Unclear risk (attrition bias)

All outcomes
Comment: (5/48) $11 \%$ of study group dropped out but unclear what that distribution was across the 2 groups

Quote: "Three were eventually excluded due to lack of complete data. Two other cases were eliminated because of the need for naloxone to treat prolonged postoperative respiratory depression"

Comment: naloxone group not at high risk of awareness

Comment: unclear risk because we cannot determine if imbalanced exclusions If 5 exclusions in 1 group that is a significant difference, Peto OR 0.11 ( 0.02 to 0.70)

\section{Selective reporting (re- Low risk} porting bias)

Quote: "The study protocol is not available but it is clear that the published report includes all expected outcomes, including those that were pre-specified." (email survey)

Comment: awareness outcome part of inclusion criteria

$\begin{array}{ll}\text { Other bias } \quad \text { Low risk } & \begin{array}{l}\text { Quote: "No problems like those described above" (email bias survey, see } \\ \text { notes) }\end{array}\end{array}$

Hachero 2001

\begin{tabular}{ll}
\hline Methods & $\begin{array}{l}\text { Study design: randomized parallel groups } \\
\text { Study dates: not stated }\end{array}$ \\
\hline Participants & Country: Spain \\
Sex: female & Age: 18 to 65 \\
ASA: I-II \\
Procedure: major gynaecological surgery \\
Study size: 40
\end{tabular}

Interventions

\section{Randomized portion of anaesthetic: ADM (BIS) vs SCP}

Intervention 1: BIS: maintenance: propofol doses to keep BIS maintained between $\mathbf{4 0}$ to $\mathbf{6 0}, \mathrm{N}=20$

Intervention 2: standard clinical practices (SCP): maintenance: propofol $10 \mathrm{mg} / \mathrm{kg} / \mathrm{h}$ for $5 \mathrm{~min}, 8 \mathrm{mg} /$ $\mathrm{kg} / \mathrm{h} 5 \mathrm{~min}, 6 \mathrm{mg} / \mathrm{kg} / \mathrm{h}$ until end + fentanyl $150 \mu \mathrm{g}$ or $75 \mu \mathrm{g}$ when needed, $\mathrm{N}=20$

Primary outcomes: anaesthetic consumption, recovery times, haemodynamic effects, BIS changes
Secondary outcome: awareness/wakefulness as defined using an awareness classification system (see
Table 1): class 1
$\begin{aligned} & \text { Quote: "En ningun caso las pacientes refirieron recuerdo explicito intraoperatorio." Translation: "In no } \\ & \text { case patients reported explicit recall intraoperatively" }\end{aligned}$

Notes
Non-randomized portion of anaesthetic: $\mathrm{TIVA} / \mathrm{N}_{2} \mathrm{O}$ no/induction: muscle relaxants: infusions propofol/induction yes/maintenance yes 
Hachero 2001 (Continued)

Premedication: midazolam $0.05 \mathrm{mg} / \mathrm{kg}$ + atropine $0.01 \mathrm{mg} / \mathrm{kg}+$ dehydrobenzperidol $40 \mathrm{\mu g} / \mathrm{kg}+$ fentanyl $2 \mu \mathrm{g} / \mathrm{kg}$

Induction: propofol $2 \mathrm{mg}$ to $2.5 \mathrm{mg} / \mathrm{kg}+$ mivacurium $0.2 \mathrm{mg} / \mathrm{kg}$

Maintenance: mivacurium $0.5 \mathrm{mg} / \mathrm{kg} / \mathrm{h}+$ fentanyl $75 \mu \mathrm{g}$ to $150 \mu \mathrm{g}$ PRN BP/h > 20\% baseline

Translated by Brett Smith

No email address available for ROB survey

\section{Risk of bias}

\begin{tabular}{|c|c|c|}
\hline Bias & Authors' judgement & Support for judgement \\
\hline \multirow[t]{2}{*}{$\begin{array}{l}\text { Random sequence genera- } \\
\text { tion (selection bias) }\end{array}$} & Low risk & $\begin{array}{l}\text { Quote: "Mediante una tabla generada por ordenador las pacientes fueron asig- } \\
\text { nadas de formas aleatoria a dos grupos..." }\end{array}$ \\
\hline & & $\begin{array}{l}\text { Translation: "Using a computer-generated table patients were randomly as- } \\
\text { signed to two groups..." }\end{array}$ \\
\hline $\begin{array}{l}\text { Allocation concealment } \\
\text { (selection bias) }\end{array}$ & Unclear risk & Comment: no information provided \\
\hline $\begin{array}{l}\text { Blinding of participants } \\
\text { and personnel (perfor- } \\
\text { mance bias) } \\
\text { All outcomes }\end{array}$ & Unclear risk & Comment: anaesthesiologist: no information provided \\
\hline $\begin{array}{l}\text { Blinding of outcome as- } \\
\text { sessment (detection bias) } \\
\text { All outcomes }\end{array}$ & Low risk & $\begin{array}{l}\text { Translation: assessor: "upon arriving in the PACU a nurse that was unaware of } \\
\text { the anaesthetic group that they belonged to about their pain...The possibility } \\
\text { of intraoperative awareness was investigated in all patients through an inter- } \\
\text { view given } 24 \text { hours post-op" }\end{array}$ \\
\hline $\begin{array}{l}\text { Incomplete outcome data } \\
\text { (attrition bias) } \\
\text { All outcomes }\end{array}$ & Low risk & Comment: no missing outcome data \\
\hline $\begin{array}{l}\text { Selective reporting (re- } \\
\text { porting bias) }\end{array}$ & Low risk & Comment: awareness outcome part of inclusion criteria \\
\hline Other bias & Unclear risk & Comment: insufficient information provided \\
\hline
\end{tabular}

\section{Hackner 2003}

\begin{tabular}{ll}
\hline Methods & Study design: randomized parallel groups \\
& Study dates: NA \\
\hline Participants & Country: Germany \\
Sex: both \\
Age: 18 to 73 \\
ASA: I-III \\
Procedure: elective panendoscopy, microlaryngoscopy, or tonsillectomy \\
Study size: 44 enrolled, 43 completed study
\end{tabular}


Hackner 2003 (Continued)

Intervention 1 maintenance: propofol-pronounced: propofol $100 \mu \mathrm{g} / \mathrm{kg} / \mathrm{min}$, remifentanil $\mathbf{0 . 1 5} \boldsymbol{\mu \mathrm { g } / \mathrm { kg } /}$ $\min ), \mathrm{N}=22$

Intervention 2 maintenance: remifentanil-pronounced: propofol $\mathbf{5 0} \boldsymbol{\mu g} / \mathrm{kg} / \mathrm{min}$, remifentanil $\mathbf{0 . 4 5} \boldsymbol{\mu g}$ / $\mathrm{kg} / \mathrm{min}), \mathrm{N}=22$

Outcomes Primary outcomes: halogenated agents and the acid base status, cbc chemistry, urine analysis etc; values of MAP, $\mathrm{HR}, \mathrm{SpO}_{2}$, and $\mathrm{BIS}$

Secondary outcome: awareness/wakefulness as defined using an awareness classification system (see Table 1): class 1

"...No intra-operative awareness with recall was reported..."

\section{Notes \\ Non-randomized portion of anaesthetic: parts of TIVA: $\mathrm{N}_{2} \mathrm{O}$ no/narcotics/hypnotics bolus $\mathrm{MCl} /$ muscle relaxants induction yes/maintenance PRN/ADM: BIS}

Anaesthesia induction: remifentanil ( $0.4 \mathrm{mg} / \mathrm{kg} \pm 1$ over $30 \mathrm{sec})$, followed by propofol $(2.0 \mathrm{mg} / \mathrm{kg} \pm 1$ over $30 \mathrm{sec})$ and mivacurium $(0.2 \mathrm{mg} / \mathrm{kg} \pm 1)$; maintenance: propofol: remifentanil combo $(100 \mu \mathrm{g} / \mathrm{kg} /$ $\min : 0.15 \mu \mathrm{g} / \mathrm{kg} / \mathrm{min})$ or $(50 \mu \mathrm{g} / \mathrm{kg} / \mathrm{min}: 0.45 \mu \mathrm{g} / \mathrm{kg} / \mathrm{min})$, mivacurium PRN surgical requirements. BIS > 55

Time of outcome determination: $24 \mathrm{~h}$ postoperative

Method of outcome determination: interview recovery room and on the day after anaesthesia

ROB survey. We emailed on 12 April 2015

Email: o.detsch@lrz.tum.de

\section{Risk of bias}

\begin{tabular}{|c|c|c|}
\hline Bias & Authors' judgement & Support for judgement \\
\hline $\begin{array}{l}\text { Random sequence genera- } \\
\text { tion (selection bias) }\end{array}$ & Unclear risk & Quote: "Before induction, patients were randomised to receive either..." \\
\hline $\begin{array}{l}\text { Allocation concealment } \\
\text { (selection bias) }\end{array}$ & Unclear risk & Comment: insufficient information provided \\
\hline $\begin{array}{l}\text { Blinding of participants } \\
\text { and personnel (perfor- } \\
\text { mance bias) } \\
\text { All outcomes }\end{array}$ & Low risk & $\begin{array}{l}\text { Quote: anaesthesiologist/assessor: "The anaesthetist providing anaesthesia } \\
\text { and the interviewer recording all variables were blinded to the drug concen- } \\
\text { trations" }\end{array}$ \\
\hline $\begin{array}{l}\text { Blinding of outcome as- } \\
\text { sessment (detection bias) } \\
\text { All outcomes }\end{array}$ & Low risk & $\begin{array}{l}\text { Quote: anaesthesiologist/assessor: "The anaesthetist providing anaesthesia } \\
\text { and the interviewer recording all variables were blinded to the drug concen- } \\
\text { trations" }\end{array}$ \\
\hline $\begin{array}{l}\text { Incomplete outcome data } \\
\text { (attrition bias) } \\
\text { All outcomes }\end{array}$ & Low risk & $\begin{array}{l}\text { Quote: "one patient was excluded because of changes in the surgical proce- } \\
\text { dure" }\end{array}$ \\
\hline $\begin{array}{l}\text { Selective reporting (re- } \\
\text { porting bias) }\end{array}$ & Low risk & Comment: awareness outcome part of inclusion criteria \\
\hline Other bias & Unclear risk & Comment: insufficient information provided \\
\hline
\end{tabular}


Haimeur 1997

\begin{tabular}{ll}
\hline Methods & Study design: randomized parallel groups \\
& Study dates: not stated \\
\hline Participants & Country: Maroc \\
Sex: female & Age: mean 27 to 30 in 3 groups \\
ASA: NA & Procedure: caesarean section surgery \\
Study size: 30
\end{tabular}

Interventions $\quad$ Randomized portion of anaesthetic: parts of intravenous (IV) anaesthesia vs volatile agent types

Intervention 1: induction: thiopental $4 \mathrm{mg} / \mathrm{kg}$ maintenance: $\mathbf{N}_{\mathbf{2}} \mathbf{O} / \mathrm{O}_{2} 50 \%+$ halothane $0.5 \% ; \mathrm{N}=10$

Intervention 2: induction: ketamine $1 \mathrm{mg} / \mathrm{kg}$ maintenance: $\mathbf{N}_{\mathbf{2}} \mathbf{O} / \mathrm{O}_{2} 50 \% ; \mathrm{N}=10$

Intervention 3: induction: ketamine $1 \mathrm{mg} / \mathrm{kg}$ maintenance: $\mathbf{N}_{\mathbf{2}} \mathbf{O} / \mathrm{O}_{2} 50 \%+$ halothane $0.5 \% ; \mathrm{N}=10$

Primary outcomes: wakefulness, haemodynamic parameters, time to loss of consciousness between
thiopental and ketamine, incisions to delivery time, APGAR scores
Secondary outcome: awareness/wakefulness as defined using an awareness classification system (see
Table 1): class 5
Comment: positive wakefulness: group 1: 4 events, group 2: 2 events, group 3: 1 event; 2 patient aware-
ness reports and 1 postoperative nightmare report; see Dryad for translation
Non-randomized portion of anaesthetic: parts of intravenous (IV) anaesthesia vs volatile agent
types: $\mathbf{N}_{\mathbf{2}} \mathbf{O}$ yes/narcotics and/or hypnotics bolus/muscle relaxants induction yes/maintenance un-
clear/ADM: response to command (IFT)
Vecuronium for intubation
Isolated forearm technique
Translated by Anthony Messina
No email address available for ROB survey

Risk of bias

\begin{tabular}{lll}
\hline Bias & Authors' judgement & Support for judgement \\
\hline $\begin{array}{l}\text { Random sequence genera- } \\
\text { tion (selection bias) }\end{array}$ & Unclear risk & $\begin{array}{l}\text { Quote: "For induction...are randomly distributed in one of the following three } \\
\text { groups " }\end{array}$ \\
\hline $\begin{array}{l}\text { Allocation concealment } \\
\text { (selection bias) }\end{array}$ & Unclear risk & Comment: inadequate information provided \\
\hline $\begin{array}{l}\text { Blinding of participants } \\
\text { and personnel (perfor- } \\
\text { mance bias) } \\
\text { All outcomes }\end{array}$ & Unclear risk & Comment: inadequate information provided \\
\hline
\end{tabular}


Haimeur 1997 (Continued)

All outcomes

Incomplete outcome data Low risk Comment: no missing data
(attrition bias)

(attrition bias)

All outcomes

Selective reporting (re- Low risk Comment: awareness outcome part of inclusion criteria
porting bias)
porting bias)

Other bias Unclear risk Comment: inadequate information provided; no ROB survey data

Haram 1981

\begin{tabular}{ll}
\hline Methods & Study design: randomized parallel groups \\
& Study dates: not stated \\
\hline Participants & Country: Norway \\
& Sex: women \\
Age: 19 to 44 \\
ASA: not given \\
Procedure: elective caesarean section \\
Study size: 97 enrolled, 82 completed surgery, 79 had complete data for analysis \\
In 2 groups of 43 and 39 women, respectively
\end{tabular}

Interventions Randomized portion of anaesthetic: parts of intravenous (IV) anaesthesia

Intervention 1: thiopentone induction $3 \mathrm{mg} / \mathrm{kg}$ + additional bolus doses $(25 \mathrm{mg}$ to $50 \mathrm{mg}$ ) if needed; $\mathrm{N}=$ 43

Intervention 2: diazepam induction $0.3 \mathrm{mg} / \mathrm{kg}$ + additional bolus doses ( $5 \mathrm{mg}$ to $15 \mathrm{mg}$ ); $\mathrm{N}=39$

Outcomes Primary outcomes: APGAR scores, acid-base balance; times from injection of the induction agent to sleep; loss of ciliary reflexes

Secondary outcome: awareness/wakefulness as defined using an awareness classification system (see Table 1): class 4

Comment: Table 3: group 1: awareness 5: awareness with noise 1, pain 1, unpleasant dreams 3, no awareness $35=40=\mathrm{N}$

Group 2: awareness 0: awareness with noise 0 , pain 0 , unpleasant dreams 0 , no awareness $39=\mathrm{N}$; the term wakefulness is used to describe postoperative memory of intraoperative events, awareness

Notes

Non-randomized portion of anaesthetic: parts of intravenous (IV) anaesthesia: $\mathrm{N}_{2} \mathrm{O}$ yes/narcotics and/or hypnotics bolus/muscle relaxants induction yes/maintenance yes

Induction: atropine $0.6 \mathrm{mg}+\mathrm{N}_{2} \mathrm{O} / \mathrm{O}_{2} 4: 2+$ boluses hypnotic sedative drugs

Maintenance: suxamethonium $50 \mathrm{mg}$ to $100 \mathrm{mg}+\mathrm{N}_{2} \mathrm{O} / \mathrm{O}_{2} 4: 2+$ analgesic (pethidine $50 \mathrm{mg}$ to $100 \mathrm{mg}$ IV) after delivery

No email address available for ROB survey

\section{Risk of bias}


Haram 1981 (Continued)

Random sequence genera- Unclear risk Quote: "They were randomly allocated to two groups" tion (selection bias)

Allocation concealment
(selection bias)

\begin{tabular}{ll}
\hline $\begin{array}{l}\text { Blinding of participants } \\
\text { and personnel (perfor- }\end{array}$ & $\begin{array}{l}\text { Quote: "The anaesthetist providing anaesthesia and the interviewer recording } \\
\text { all variables were blinded to the drug concentrations" }\end{array}$ \\
All outcomes &
\end{tabular}

\begin{tabular}{lll}
$\begin{array}{l}\text { Blinding of outcome as- } \\
\begin{array}{l}\text { sessment (detection bias) } \\
\text { All outcomes }\end{array}\end{array}$ & Low risk & $\begin{array}{l}\text { Quote: assessor: "On first postoperative day, the patients were interviewed by } \\
\text { one of the authors }(\mathrm{KH}), \text { who was not aware which induction agent had been } \\
\text { used" }\end{array}$ \\
\hline $\begin{array}{l}\text { Incomplete outcome data } \\
\text { (attrition bias) }\end{array}$ & $\begin{array}{l}\text { Unclear risk } \\
\text { All outcomes }\end{array}$ & $\begin{array}{l}\text { Comment: enrolled } 97 \text { minus } 15 \text { excluded due to obstetrical criteria; } 97 \text { started } \\
\text { surgery, } 82 \text { completed surgery; } 79 \text { had complete study data for analysis; hence } \\
(18 / 97) 19 \% \text { dropouts but no dropout for reasons that defined them as high- } \\
\text { risk awareness cases: dropouts for SCP data (unable to collect); no awareness } \\
\text { interview dropouts }\end{array}$ \\
& $\begin{array}{l}\text { Comment: inadequate information to determine if exclusions were balanced } \\
\text { between groups }\end{array}$
\end{tabular}

\begin{tabular}{lll}
\hline $\begin{array}{l}\text { Selective reporting (re- } \\
\text { porting bias) }\end{array}$ & Low risk & Comment: awareness outcome part of inclusion criteria \\
\hline Other bias & Unclear risk & Comment: insufficient information provided \\
\hline
\end{tabular}

\begin{tabular}{ll} 
Hug 1988 & \\
\hline Methods & $\begin{array}{l}\text { Study design: randomized parallel groups } \\
\text { Study dates: not stated }\end{array}$ \\
\hline Participants & Country: USA \\
& Sex: female/male \\
& Age: 58 to 61 \\
ASA: NA \\
Procedure: CABG \\
Study size: 19
\end{tabular}

\section{Interventions $\quad$ Randomized portion of anaesthetic: TIVA (MCI)}

Alfentanil infusion rate (prime/maintenance $(\mu \mathrm{g} / \mathrm{kg} / \mathrm{min}))$

Intervention 1: $(\mathrm{N}=6) 60 / 4.5 \mu \mathrm{g} / \mathrm{kg} / \mathrm{min}$

Intervention 2: $(\mathrm{N}=4) 60 / 5.4 \mu \mathrm{g} / \mathrm{kg} / \mathrm{min}$

Intervention 3: $(\mathrm{N}=5) 72 / 6.6 \mu \mathrm{g} / \mathrm{kg} / \mathrm{min}$

Intervention 4: $(\mathrm{N}=4) 86 / 7.8 \mu \mathrm{g} / \mathrm{kg} / \mathrm{min}$

Outcomes

Primary: outcomes: plasma concentration of alfentanil, somatic and haemodynamic responses

Secondary outcomes: awareness/wakefulness as defined using an awareness classification system (see Table 1): class 1 
Hug 1988 (Continued)

Quote: "No patient had recall of intraoperative events when interviewed 1 to 3 days after surgery

Notes

Non-randomized portion of anaesthetic: $\mathrm{TIVA} / \mathrm{N}_{2} \mathrm{O}$ no/infusion of narcotics $(\mathrm{MCl})+$ muscle relaxants induction yes//maintenance yes PRN

Lorazepam $0.08 \mathrm{mg} / \mathrm{kg}$ (intervention 1), $0.04 \mathrm{mg} / \mathrm{kg}$ (intervention 2 to 4), PO premed

Metocurine $0.05 \mathrm{mg} / \mathrm{kg}$ while breathing $100 \%$ oxygen, suxamethonium and PRN after intubation

Comment: no MR use after induction to view somatic response

Quote: "The highest plasma concentration of alfentanil to prevent response to a stimulus other than tracheal intubation was different between the two studies $(P<0.05)$. We conclude that alfentanil alone is insufficient to suppress haemodynamic and somatic motor responses to noxious stimulation during CABG and that the role of premedication is significant..." "Rigidity on induction of anaesthesia occurred in 14 of the 19 patients and was promptly relieved by suxamethonium. Suxamethonium was again required in 12 patients to facilitate opening of the sternum"

No email address

\section{Risk of bias}

\begin{tabular}{lll}
\hline Bias & Authors' judgement & Support for judgement \\
\hline $\begin{array}{l}\text { Random sequence genera- } \\
\text { tion (selection bias) }\end{array}$ & Unclear risk & Quote: "chosen randomly from one of three different options (table II)" \\
\hline $\begin{array}{l}\text { Allocation concealment } \\
\text { (selection bias) }\end{array}$ & Unclear risk & Comment: inadequate information \\
\hline $\begin{array}{l}\text { Blinding of participants } \\
\text { and personnel (perfor- } \\
\text { mance bias) }\end{array}$ & Unclear risk & Comment: inadequate information \\
All outcomes & & \\
\hline
\end{tabular}

Blinding of outcome as- Unclear risk Comment: inadequate information

sessment (detection bias)

All outcomes

\begin{tabular}{lll}
\hline $\begin{array}{l}\text { Incomplete outcome data } \\
\text { (attrition bias) } \\
\text { All outcomes }\end{array}$ & Low risk & \\
\hline $\begin{array}{l}\text { Selective reporting (re- } \\
\text { porting bias) }\end{array}$ & Low risk & Comment: awareness outcome part of inclusion criteria \\
\hline Other bias & Unclear risk & Comment: inadequate information \\
\hline
\end{tabular}

\section{Hung 1992}

\begin{tabular}{ll}
\hline Methods & Study design: randomized parallel groups \\
& Study dates: not stated \\
\hline Participants & Country: Canada, USA \\
& Sex: male \\
Age: aged: 30 to 79 \\
ASA: I-II \\
Procedure: not specified \\
\hline
\end{tabular}


Hung 1992 (Continued)

$$
\text { Study size: } 26
$$

Interventions $\quad$ Randomized portion of anaesthetic: IV hypnotic (thiopental) (TCI) infusion serum levels

Intervention 1: thiopental serum concentrations $10 \mu \mathrm{g}$ to $30 \mu \mathrm{g} / \mathrm{mL} 5 / 26$ had noxious stimulation because they were arousable and responded to verbal command

Intervention 2: higher, randomly assigned target serum concentration of $40 \mu \mathrm{g}$ to $90 \mu \mathrm{g} / \mathrm{mL}$ tracheas of 6 could not be intubated due to inability to intubate without muscle relaxants

Primary: outcomes: association thiopental serum concentrations and clinical signs anaesthetic depth
as defined by EEG and several perioperative stimuli (verbal command, tetanic nerve stimulation,
trapezius muscle squeeze, and laryngoscopy)
Secondary outcomes: awareness/wakefulness as defined using an awareness classification system (see
Table 1): class 1
Quote: "When interviewed $24 \mathrm{~h}$ postoperatively, none of the subjects could recall the events that oc-
curred during the study"

Notes Non-randomized portion of anaesthetic: ADM EEG recorded

No post-intubation anaesthetic technique described: classified as "other" technique

Quote: "A positive response was recorded if purposeful extremity movement or coughing was observed the probability of no movement to each stimulus was characterized using logistic regression. The biphasic thiopental concentration-EEG relationship and the isoelectric EEG at the high serum thiopental concentrations needed to prevent purposeful movement responses limit the utility of the EEG as a measure of anaesthetic depth when thiopental is used alone ...The movement responses may be associated with spinal (brain stem in the case of laryngoscopy and intubation) reflexes to peripheral noxious stimuli. However, they also may be associated with light anaesthesia and inadequate cortical CNS suppression, since most of these movement responses were associated with an increase of mean arterial pressure and heart rate. It is not possible for us to separate the cortical from spinal components of a movement or cough response.... Laryngoscopy followed by intubation can be considered the most noxious stimulus that has been quantitated with available methodology in humans. Because of the concurrent peri operative use of anaesthetic drugs with specific actions...traditional clinical signs of anaesthetic depth such as movement and hemodynamic responses to noxious stimuli become less interpretable"

No email survey

\section{Risk of bias}

\begin{tabular}{lll}
\hline Bias & Authors' judgement & Support for judgement \\
\hline $\begin{array}{l}\text { Random sequence genera- } \\
\text { tion (selection bias) }\end{array}$ & Unclear risk & $\begin{array}{l}\text { Quote: "The first randomly assigned target serum concentration of 10-30 mcg/ } \\
\text { ml was maintained ..." }\end{array}$ \\
\hline $\begin{array}{l}\text { Allocation concealment } \\
\text { (selection bias) }\end{array}$ & Unclear risk & Comment: inadequate information \\
\hline $\begin{array}{l}\text { Blinding of participants } \\
\text { and personnel (perfor- } \\
\text { mance bias) } \\
\text { All outcomes }\end{array}$ & Unclear risk & Comment: inadequate information \\
\hline $\begin{array}{l}\text { Blinding of outcome as- } \\
\text { sessment (detection bias) } \\
\text { All outcomes }\end{array}$ & Unclear risk & Comment: inadequate information \\
\hline
\end{tabular}


Hung 1992 (Continued)

Incomplete outcome data Low risk Comment: no dropouts
(attrition bias)

All outcomes

\begin{tabular}{lll}
\hline $\begin{array}{l}\text { Selective reporting (re- } \\
\text { porting bias) }\end{array}$ & Low risk & Comment: awareness outcome part of inclusion criteria \\
\hline Other bias & Unclear risk & Comment: inadequate information \\
\hline
\end{tabular}

Ibraheim 2008

\begin{tabular}{|c|c|}
\hline Methods & $\begin{array}{l}\text { Study design: randomized parallel groups } \\
\text { Study dates: not stated }\end{array}$ \\
\hline \multirow[t]{6}{*}{ Participants } & Country: Saudi Arabia \\
\hline & Sex: both \\
\hline & Age: 41, 39 \\
\hline & ASA: I-II \\
\hline & Procedure: laparoscopic gastric banding \\
\hline & Study size: 30 \\
\hline \multirow[t]{3}{*}{ Interventions } & Randomized portion of anaesthetic: volatile agent types/ADM \\
\hline & Intervention 1: maintenance: sevoflurane BIS between $\mathbf{4 0}$ to $\mathbf{6 0}, \mathrm{N}=15$ \\
\hline & Intervention 2: maintenance: sevoflurane SCP, N = 15 \\
\hline \multirow[t]{3}{*}{ Outcomes } & Primary outcomes: recovery times, anaesthetic consumption \\
\hline & $\begin{array}{l}\text { Secondary outcome: awareness/wakefulness as defined using an awareness classification system (see } \\
\text { Table 1): class } 1\end{array}$ \\
\hline & $\begin{array}{l}\text { Quote: "There was no recall or dreaming reported by any patient in Recovery room or } 24 \text { hours after } \\
\text { surgery in both groups" }\end{array}$ \\
\hline \multirow[t]{5}{*}{ Notes } & $\begin{array}{l}\text { Non-randomized portion of anaesthetic: parts of volatile agent: } \mathrm{N}_{2} \mathrm{O} \text { no/narcotics/hypnotics bo- } \\
\text { lus/muscle relaxants induction yes/maintenance yes }\end{array}$ \\
\hline & $\begin{array}{l}\text { Induction: fentanyl } 2 \mu \mathrm{g} / \mathrm{kg}+\text { propofol } 1.5 \mathrm{mg} \text { to } 2.0 \mathrm{mg} / \mathrm{kg}+\text { succinylcholine } 1.0 \mathrm{mg} \text { to } 1.5 \mathrm{mg} / \mathrm{kg} \text {; main- } \\
\text { tenance: sevoflurane } 2 \% \text { in } 2 \mathrm{~L} / \mathrm{min}+\text { fentanyl } 100 \mu \mathrm{g} \text { + atracurium }\end{array}$ \\
\hline & Time of outcome determination: discharge from recovery room and $24 \mathrm{~h}$ postoperative \\
\hline & Method of determination: interview \\
\hline & Email: osamaibraheim@yahoo.com; awaiting email bias survey response \\
\hline
\end{tabular}

\section{Risk of bias}

\begin{tabular}{lll}
\hline Bias & Authors' judgement & Support for judgement \\
\hline $\begin{array}{l}\text { Random sequence genera- } \\
\text { tion (selection bias) }\end{array}$ & Unclear risk & Quote: "Patients were randomly assigned to two groups" \\
\hline
\end{tabular}


Ibraheim 2008 (Continued)

$\begin{aligned} & \text { Allocation concealment } \\ & \text { (selection bias) }\end{aligned}$
Unclear risk $\quad$ Comment: no information provided

Blinding of participants

High risk

Quote: "BIS Group: the anaesthesiologist had access to the monitor and adand personnel (perforjusted the concentration of sevoflurane to achieve a target BIS in the range mance bias) 40-60. Non BIS (control group) the anaesthesiologist adjusted the sevoflurane All outcomes concentration purely according to the clinical signs"

Comment: anaesthesiologists were not blinded to inhalational agent nor to SCPS

Blinding of outcome as- Low risk Quote: assessor: "Blinded study personnel recorded..." sessment (detection bias) All outcomes

\begin{tabular}{l}
\hline Incomplete outcome data Low risk Comment: no missing outcome data \\
(attrition bias) \\
All outcomes
\end{tabular}

Selective reporting (re- Low risk Comment: awareness outcome part of inclusion criteria
porting bias)

\begin{tabular}{lll}
\hline Other bias $\quad$ Unclear risk $\quad$ Comment: insufficient information provided \\
\hline
\end{tabular}

Inoue 2005

Methods Study design: randomized parallel groups

Study dates: not stated

\begin{tabular}{ll}
\hline Participants & Country: USA \\
& Sex: men and women \\
& Age: 37 to 76 \\
ASA: I-II \\
Procedure: cervical spine surgery \\
Study size: 75
\end{tabular}

$\begin{array}{ll}\text { Interventions } & \text { Randomized portion of anaesthetic: parts of IV vs parts of volatile agent: TCI vs supplemental } \\ \text { volatile vs solely volatile }\end{array}$

Intervention FP 1: induction and maintenance: fentanyl $50 \mu \mathrm{g}$ intermittent boluses + propofol $1.5 \mu \mathrm{g}$ to $3.5 \mu \mathrm{g} / \mathrm{mL}$ TCl , both titrated against clinical signs, $\mathrm{N}=25$

Intervention Fs 2: induction: fentanyl $100 \mu \mathrm{g}$ + propofol $1 \mathrm{mg}$ to $3 \mathrm{mg} / \mathrm{kg}$; maintenance: fentanyl $50 \mu \mathrm{g}$ intermittent boluses + supplementary sevoflurane $(0.5 \%$ to $1.0 \% \mathrm{ET}), \mathrm{N}=25$

Intervention S 3: induction: fentanyl $100 \mu \mathrm{g}$ + propofol $1 \mathrm{mg}$ to $2 \mathrm{mg} / \mathrm{kg}$; maintenance: solely with sevoflurane $\mathbf{1 . 5} \%$ to $2.5 \% \mathrm{ET}, \mathrm{N}=25$

Outcomes Primary outcomes: the time to extubation, bucking scores, and pain scores

Secondary outcome: awareness/wakefulness as defined using an awareness classification system (see Table 1): class 0

Quote: "There were no light anesthesia responses such as hazardous involuntary movements, bucking, or awareness during surgery" 
Comment: no awareness events; all patients were paralysed for induction and a portion of the sample were paralysed during maintenance

\section{Notes}

\section{Non-randomized portion of anaesthetic: parts of IV/ $\mathrm{N}_{2} \mathrm{O}$ yes vs parts of volatile agent: $\mathrm{N}_{2} \mathrm{O}$ yes/ muscle relaxants induction yes/maintenance yes}

Premedication: $25 \mathrm{mg}$ hydroxyzine $+0.5 \mathrm{mg}$ atropine; anaesthesia induction: vecuronium; maintenance: vecuronium as needed + nitrous $60 \%, \mathrm{O}_{2} 40 \%$

Time of outcome determination: $24 \mathrm{~h}$ postoperative Method of outcome determination: interview

Emailed author 27 December 2010 for risk of bias information; no response received

\section{Risk of bias}

\begin{tabular}{|c|c|c|}
\hline Bias & Authors' judgement & Support for judgement \\
\hline $\begin{array}{l}\text { Random sequence genera- } \\
\text { tion (selection bias) }\end{array}$ & Unclear risk & Quote: "Patients were randomly assigned into one of three groups" \\
\hline $\begin{array}{l}\text { Allocation concealment } \\
\text { (selection bias) }\end{array}$ & Unclear risk & Comment: no information provided \\
\hline $\begin{array}{l}\text { Blinding of participants } \\
\text { and personnel (perfor- } \\
\text { mance bias) } \\
\text { All outcomes }\end{array}$ & Unclear risk & Comment: anaesthesiologist: no information provided \\
\hline $\begin{array}{l}\text { Blinding of outcome as- } \\
\text { sessment (detection bias) } \\
\text { All outcomes }\end{array}$ & Low risk & $\begin{array}{l}\text { Quote: assessor: "the extent of awareness and readiness for the neurological } \\
\text { examination were assessed using a predetermined scoring scale by a nurse ob- } \\
\text { server blinded to the method of anesthesia" }\end{array}$ \\
\hline $\begin{array}{l}\text { Incomplete outcome data } \\
\text { (attrition bias) } \\
\text { All outcomes }\end{array}$ & Low risk & Comment: no missing outcome data \\
\hline $\begin{array}{l}\text { Selective reporting (re- } \\
\text { porting bias) }\end{array}$ & Low risk & Comment: awareness outcome part of inclusion criteria \\
\hline Other bias & Unclear risk & Comment: insufficient information provided \\
\hline
\end{tabular}

\section{Jensen 1995}

\begin{tabular}{ll}
\hline Methods & Study design: randomized parallel groups \\
& Study dates: 1987 (email bias survey, see notes) \\
\hline Participants & Country: Denmark \\
Sex: female & Age: mean 42 to 47 \\
ASA: I-II \\
Procedure: major elective gynaecologic surgery \\
Study size: 80,74 complete data postoperative \\
Randomized portion of anaesthetic: parts of: neurolept (IV) vs TIVA reversal flumazenil vs no re- \\
versal flumazenil $\pm \mathbf{N}_{\mathbf{2}} \mathbf{O}$
\end{tabular}


TIVA using midazolam-alfentanil intervention 1 and 2, with or without reversal with flumazenil vs standardized neurolept anaesthesia with $\mathbf{N}_{\mathbf{2}} \mathbf{O}$, intervention 3

Intervention 1: TIVA induction: alfentanil $50 \mu \mathrm{g} / \mathrm{kg}+$ midazolam $150 \mu \mathrm{g} / \mathrm{kg}+$ alfentanil $10 \mu \mathrm{g} / \mathrm{kg} / \mathrm{min} 10$ min, $2 \mu \mathrm{g} / \mathrm{kg} / \mathrm{min} 20 \mathrm{~min}+$ midazolam $8 \mu \mathrm{g} / \mathrm{kg} / \mathrm{min} 10 \mathrm{~min}, 3.3 \mu \mathrm{g} / \mathrm{kg} / \mathrm{min} 20 \mathrm{~min}$; maintenance: alfentanil $1 \mu \mathrm{g} / \mathrm{kg} / \mathrm{min}+$ midazolam $2 \mu \mathrm{g} / \mathrm{kg} / \mathrm{min}$ + atracurium $7 \mu \mathrm{g} / \mathrm{kg} / \mathrm{min}$; reversal flumazenil $2 \mathrm{mg}, \mathrm{N}=$ 20

Intervention 2: TIVA induction: alfentanil $50 \mu \mathrm{g} / \mathrm{kg}+$ midazolam $150 \mu \mathrm{g} / \mathrm{kg}+$ alfentanil $10 \mu \mathrm{g} / \mathrm{kg} / \mathrm{min} 10$ $\min , 2 \mu \mathrm{g} / \mathrm{kg} / \mathrm{min} 20 \mathrm{~min}+$ midazolam $8 \mu \mathrm{g} / \mathrm{kg} / \mathrm{min} 10 \mathrm{~min}, 3.3 \mu \mathrm{g} / \mathrm{kg} / \mathrm{min} 20 \mathrm{~min}$; maintenance: alfentanil $1 \mu \mathrm{g} / \mathrm{kg} / \mathrm{min}+$ midazolam $2 \mu \mathrm{g} / \mathrm{kg} / \mathrm{min}+$ atracurium $7 \mu \mathrm{g} / \mathrm{kg} / \mathrm{min} ; 202 \mathrm{mg}, \mathrm{N}=\mathbf{2 0} \mathbf{- 1}=\mathbf{1 9}$

Reversal placebo

Intervention 3: neurolept induction: fentanyl $5 \mu \mathrm{g} / \mathrm{kg}+$ droperidol $250 \mu \mathrm{g} / \mathrm{kg}$ + thiopental $4 \mathrm{mg} / \mathrm{kg}$ and supplemental doses $50 \mathrm{mg}$; maintenance: $\mathbf{N}_{\mathbf{2}} \mathbf{O}$ in $33 \% \mathrm{O}_{2}+$ fentanyl and droperidol doses as needed, $\mathrm{N}$

$=\mathbf{4 0}-\mathbf{1}=\mathbf{3 9}$

Outcomes

Primary outcomes: recovery characteristics

Quote: "Recovery after Midazolam-Alfentanil Anaesthesia with and without Reversal with Flumazenil, and Standardized Neurolept Anaesthesia"

Secondary outcome: awareness/wakefulness as defined using an awareness classification system (see Table 1): class 4

Comment: the dynamic nature of postoperative memory was demonstrated by a patient who had immediate postoperative recall of skin incision as a "burning sensation", but the next day the patient "failed to recall the event." This is evidence that RCTs that interview patients after the immediate postoperative period underestimate the frequency of awareness

Comment: naloxone needed in 11/40 patients in TIVA groups with and without reversal and 0/40 patients in neurolept group. Significantly more naloxone used in TIVA groups 1 and $2(11 / 40)$ vs neurolept group (0/40), Peto OR 9.87 (2.79 to 34.97)

Notes

\section{Non-randomized portion of anaesthetic: parts of: neurolept (IV) vs TIVA/ $\mathrm{N}_{2} \mathrm{O}$ no/narcotics/hyp- notics bolus $\mathrm{MCl} /$ muscle relaxants induction yes/maintenance yes}

Premedication: midazolam $0.1 \mathrm{mg} / \mathrm{kg}$; induction/maintenance: group-specific maintenance regimen. See above. Intubation and relaxation: atracurium $0.5 \mathrm{mg} / \mathrm{kg} \mathrm{IV}$, infusion $7 \mu \mathrm{g} / \mathrm{kg} / \mathrm{min}$ : TOF ratio, aim one tactile twitch until skin suture, end of surgery/residual neuromuscular blockade reversed atropine $1 \mathrm{mg}$ and neostigmine $2.5 \mathrm{mg}$ IV

Time of outcome determination: before discharge

Method of outcome determination: interview

Emailed author on 27 December 2010 for risk of bias information

Author responded to the email bias survey on 18 January 2011

Survey response: 18 January 2011, Anders G. Jensen anders.gadegaard.jensen@ouh.regionsyddanmark.dk

\section{Risk of bias}

\begin{tabular}{lll}
\hline Bias & Authors' judgement & Support for judgement \\
\hline $\begin{array}{l}\text { Random sequence genera- } \\
\text { tion (selection bias) }\end{array}$ & Low risk & Quote: "The patients were randomized by sealed envelopes into three groups" \\
& $\begin{array}{l}\text { Quote: "Sealed, numbered envelopes were used. Patients were given the } \\
\text { next number when they were enrolled in the study. Envelopes prepared and } \\
\text { randomisation performed in advance by a person not participating in the } \\
\text { study." (Email bias survey, see notes) }\end{array}$ \\
\hline
\end{tabular}


Jensen 1995 (Continued)

Allocation concealment Low risk (selection bias)
Quote: "The Anaesthesiologist knew, that the patient was given either TIVA (Group 1 and 2) or Neurolept anaesthesia (Group 3). Placebo or flumazenil was drawn from blinded, numbered ampoules. Hence, the Anaesthesiologist was unaware of allocation to group 1 or $2 "$

Quote: "Outcome was assessed by an investigator blinded to group allocation. This investigator did not have access to the patients files." (Email survey)

Comment: anaesthesiologists not blinded to anaesthetic technique but blinded to reversal drug vs placebo drug

Blinding of participants Low risk
and personnel (perfor-
mance bias)
All outcomes

Quote: "Patient, Anaesthesiologist, Awareness outcome assessor (interviewer)" (email survey)

Quote: "There were 3 groups in the study:

1) TIVA with reversal with flumazenil

2) TIVA with reversal with placebo

3) Standardized neurolept anaesthesia

Quote: "The Anaesthesiologist knew, that the patient was given either TIVA (Group 1 and 2) or Neurolept anaesthesia (Group 3). Placebo or flumazenil was drawn from blinded, numbered ampoules. Hence, the Anaesthesiologist was unaware of allocation to group 1 or 2." survey

Comment: complicated protocol in regard to blinding and allocation. We will not downgrade because both TIVA groups were blinded to placebo vs study drug and group 3 was blinded to groups 1 and 2 .
Blinding of outcome as- Low risk sessment (detection bias) All outcomes
Quote: "Outcome was assessed by an investigator blinded to group allocation. This investigator did not have access to the patients files"
Incomplete outcome data Low risk (attrition bias)

All outcomes
Comment: from table 6 and Dr Jensen's response to ROB survey: $2 / 40$ patients from TIVA groups and 4/40 patients from neurolept groups excluded due to lack of data; this is imbalanced between groups but not significantly different, Peto OR 0.49 (0.09 to 2.56)

Author sent characteristics and ROB tables for comment 12/7 and 8/13: Anders G. Jensen anders.gadegaard.jensen@ouh.regionsyddanmark.dk

Quote: "The study was performed more than 20 years ago. The study protocol is no longer available" (email bias survey, see notes)

Quote: "All results from our study were reported. That includes the non-significant ones" (email survey)

Comment: awareness outcome part of inclusion criteria
Selective reporting (re- Low risk porting bias)

\begin{tabular}{ll}
\hline Other bias $\quad$ Low risk $\quad$ Quote: "I do not find any risk of bias" (email survey) \\
\hline
\end{tabular}

\section{Jiahai 2012}

\begin{tabular}{ll}
\hline Methods & $\begin{array}{l}\text { Study design: randomized parallel groups } \\
\text { Study dates: not stated }\end{array}$ \\
\hline Participants & Country: China \\
& Sex: female/male \\
& Age: mean 59 to 60 \\
ASA: unknown but must be $>=$ III \\
Procedure: OPCAB surgery
\end{tabular}


Jiahai 2012 (Continued)

Study size: 70

\begin{tabular}{|c|c|}
\hline Interventions & $\begin{array}{l}\text { Randomized portion of anaesthetic: TIVA ADM (Entropy) vs SCP } \\
\text { Intervention 1: ( } \mathrm{N}=35 \text { ) entropy values ( } 45 \text { to } 55 \text { ) visible (the entropy group) } \\
\text { Intervention 2: ( } \mathrm{N}=35 \text { ) without the entropy values visible (the control group) }\end{array}$ \\
\hline Outcomes & $\begin{array}{l}\text { Primary outcomes: adrenocorticotropic hormone (ACTH) and cortisol levels } \\
\text { Secondary outcomes: awareness/wakefulness as defined using an awareness classification system (see } \\
\text { Table 1): class } 1\end{array}$ \\
\hline & $\begin{array}{l}\text { Quote: "None of the patients in the } 2 \text { groups reported intraoperative recall in the postoperative inter- } \\
\text { view" }\end{array}$ \\
\hline
\end{tabular}

Notes

Non-randomized portion of anaesthetic: parts of TIVA: $\mathrm{N}_{2} \mathrm{O}$ no/narcotics/hypnotics bolus $\mathrm{MCl} /$ muscle relaxants induction yes/maintenance yes

Induction midazolam, $0.1 \mathrm{mg} / \mathrm{kg}$; etomidate, $0.1 \mathrm{mg} / \mathrm{kg}$; sufentanil, $1 \mu \mathrm{g} / \mathrm{kg}$, intubation pancuronium, $0.1 \mathrm{mg} / \mathrm{kg}$. After intubation, infusion propofol, $4 \mathrm{mg}$ to $8 \mathrm{mg} / \mathrm{kg} / \mathrm{h}$, and sufentanil, $0.5 \mu \mathrm{g}$ to $2.0 \mu \mathrm{g} / \mathrm{kg} / \mathrm{h}$, ventilated $\mathrm{ET} \mathrm{CO}_{2} 32 \mathrm{mmHg}$ to $42 \mathrm{mmHg}$. Additional pancuronium, $0.03 \mathrm{mg} / \mathrm{kg}$ given; filling pressures and fluid balance maintained lactated Ringer's solution and $6 \%$ hydroxyeth. starch; entropy group, propofol infusion rate titrated SE value 45 to 55; bolus propofol, 20 to $50 \mathrm{mg}$ PRN abrupt SE increase; sufentanil infusion adjusted so RE-SE difference remain within $10 \mathrm{U}$

Ma Jiahai, MD, Email: mjh-214@163.com

ROB survey: we emailed mjh-214@163.com on 22 March 2015

\section{Risk of bias}

\begin{tabular}{|c|c|c|}
\hline Bias & Authors' judgement & Support for judgement \\
\hline $\begin{array}{l}\text { Random sequence genera- } \\
\text { tion (selection bias) }\end{array}$ & Unclear risk & $\begin{array}{l}\text { Quote: "prospective, randomized, controlled study was conducted on } 70 \text { pa- } \\
\text { tients undergoing first-time OPCAB surgery" }\end{array}$ \\
\hline $\begin{array}{l}\text { Allocation concealment } \\
\text { (selection bias) }\end{array}$ & Unclear risk & Comment: no information \\
\hline $\begin{array}{l}\text { Blinding of participants } \\
\text { and personnel (perfor- } \\
\text { mance bias) } \\
\text { All outcomes }\end{array}$ & Unclear risk & Comment: no information \\
\hline $\begin{array}{l}\text { Blinding of outcome as- } \\
\text { sessment (detection bias) } \\
\text { All outcomes }\end{array}$ & Unclear risk & $\begin{array}{l}\text { Quote: "A standardized questionnaire (Appendix } 1 \text { ) to measure explicit intra- } \\
\text { operative recall was completed immediately after tracheal extubation and } 3 \\
\text { days later" }\end{array}$ \\
\hline $\begin{array}{l}\text { Incomplete outcome data } \\
\text { (attrition bias) } \\
\text { All outcomes }\end{array}$ & Low risk & Comment: no dropouts \\
\hline $\begin{array}{l}\text { Selective reporting (re- } \\
\text { porting bias) }\end{array}$ & Low risk & Comment: awareness outcome part of inclusion criteria \\
\hline Other bias & Unclear risk & Comment: no information \\
\hline
\end{tabular}


Kamal 1990

\begin{tabular}{ll}
\hline Methods & Study design: randomized parallel groups \\
& Study dates: not stated \\
\hline Participants & Country: Pakistan \\
Sex: both & Age: 41 \\
ASA: I-II \\
Procedure: cholecystectomy \\
Study size: 36
\end{tabular}

Interventions

Randomized portion of anaesthetic: parts of TIVA: narcotic dose

Intervention 1: induction buprenorphine $2.5 \mu \mathrm{g} / \mathrm{kg}$ bolus, $\mathrm{N}=18$

Intervention 2: induction buprenorphine $5 \mu \mathrm{g} / \mathrm{kg}$ bolus, $\mathrm{N}=18$

Primary outcomes: duration of anaesthesia, arterial blood pressure and heart rate data, incidence of
side effects within the 2 groups
Secondary outcome: awareness/wakefulness as defined using an awareness classification system (see
Table 1): class 1
Quote: "None of the patients reported any awareness"

\section{Notes}

\section{Non-randomized portion of anaesthetic: parts of TIVA: $\mathrm{N}_{2} \mathrm{O}$ no/narcotics/hypnotics bolus $\mathrm{MCl} /$ muscle relaxants induction yes/maintenance yes} ade at the end of surgery was reversed with neostigmine
Anaesthesia maintenance: propofol infusion $(6 \mathrm{mg} / \mathrm{kg} / \mathrm{h})$
Comment: see Dryad: advantages of total intravenous anaesthesia
Time of outcome determination: $2 \mathrm{~h}$ postoperative
Method of outcome determination: interview
No email address available for ROB survey

Premedication: diazepam $0.15 \mathrm{mg} / \mathrm{kg}$; anaesthesia induction: propofol $(1 \mathrm{mg} / \mathrm{kg})$ followed by $10 \mathrm{~min}$ infusion at $(10 \mathrm{mg} / \mathrm{kg} / \mathrm{h})$ followed by 10 min infusion at $(8 \mathrm{mg} / \mathrm{kg} / \mathrm{h})+$ pancuronium $(0.1 \mathrm{mg} / \mathrm{kg})+$ group-specific bolus of buprenorphine (agonist-partial antagonist (narcotic)) neuromuscular block-

\begin{tabular}{lll}
\hline Risk of bias & & \\
\hline Bias & Authors' judgement & Support for judgement \\
\hline $\begin{array}{l}\text { Random sequence genera- } \\
\text { tion (selection bias) }\end{array}$ & Unclear risk & Quote "patients were randomly allocated into two groups of 18 each" \\
\hline $\begin{array}{l}\text { Allocation concealment } \\
\text { (selection bias) }\end{array}$ & Unclear risk & Comment: no information provided \\
\hline $\begin{array}{l}\text { Blinding of participants } \\
\text { and personnel (perfor- } \\
\text { mance bias) }\end{array}$ & Low risk & $\begin{array}{l}\text { Quote: anaesthesiologist: "An anaesthetist unconnected with the study gave } \\
\text { a bolus of intravenous buprenorphine so that the observer was blinded to the } \\
\text { dose received" }\end{array}$ \\
\hline
\end{tabular}


Kamal 1990 (Continued)

All outcomes

Blinding of outcome as-
sessment (detection bias) $\quad$ Unclear risk Comment: assessor: no information provided

All outcomes

\begin{tabular}{lll}
\hline $\begin{array}{l}\text { Incomplete outcome data } \\
\text { (attrition bias) } \\
\text { All outcomes }\end{array}$ & Low risk & \\
\hline $\begin{array}{l}\text { Selective reporting (re- } \\
\text { porting bias) }\end{array}$ & Low risk & Comment: awareness outcome part of inclusion criteria \\
\hline Other bias & Unclear risk & Comment: insufficient information provided \\
\hline
\end{tabular}

\section{Kasmacher 1996}

\begin{tabular}{ll}
\hline Methods & $\begin{array}{l}\text { Study design: randomized parallel groups } \\
\text { Study dates: not stated }\end{array}$ \\
\hline Participants & Country: Germany \\
& Sex: both \\
& ASA: I and II \\
& Study size: 230 \\
& Procedure: minor elective surgery \\
& Randomized portion of anaesthetic: TIVA vs volatile agent types ("balanced anaesthesia") \\
& Intervention $1:$ induction: etomidate $2 \mathrm{mg} / \mathrm{kg} ;$ maintenance: $0.8 \%$ to $1.5 \%$ enflurane, $\mathrm{N}=109$ \\
Intervention $2:$ induction: propofol $2 \mathrm{mg} / \mathrm{kg}+$ after saturation phase of $10 \mathrm{mg} / \mathrm{kg} / \mathrm{h}$, then followed \\
with 5 mg to 6 mg/kg/h \\
Interventions 121
\end{tabular}

Outcomes

Primary: dreaming, haemodynamics

Secondary outcome: awareness/wakefulness as defined using an awareness classification system (see Table 1): class 1

Comment: no evidence intraoperative awareness

Sensory experiences during propofol anaesthesia are not stimulus-related perceptions or awareness but dreams similar to normal ones

Dreams: $60 \%$ (73/121) vs propofol $11 \%(12 / 109)$ enflurane anaesthesia"): $\mathrm{N}_{\mathbf{2}} \mathrm{O}$ no/narcotics/hypnotics bolus $\mathrm{MCl} /$ muscle relaxants induction yes/maintenance yes ADM BIS recorded

Maintenance both groups: supplemented fentanyl, vecuronium and $\mathrm{N}_{2} \mathrm{O}$ ("balanced anaesthesia"); BIS Maintenance both groups: enflurane $0.8 \%$ to $1.5 \%$, supplemented fentanyl, vecuronium and $\mathrm{N}_{2} \mathrm{O}$

("balanced anaesthesia") 
Kasmacher 1996 (Continued)

Comment: Kasmacher's view: propofol intraoperative dreams: unrelated to surgery; intraoperative dream incidence: $.60^{\star} 121=73$ propofol; $11^{\star} 109=12$ enflurane; no email address available for ROB survey

\section{Risk of bias}

\begin{tabular}{lll}
\hline Bias & Authors' judgement & Support for judgement \\
\hline $\begin{array}{l}\text { Random sequence genera- } \\
\text { tion (selection bias) }\end{array}$ & Unclear risk & Quote: "...randomly assigned to one of two groups..." p147 \\
\hline $\begin{array}{l}\text { Allocation concealment } \\
\text { (selection bias) }\end{array}$ & Unclear risk & Comment: no information provided \\
\hline $\begin{array}{l}\text { Blinding of participants } \\
\text { and personnel (perfor- } \\
\text { mance bias) } \\
\text { All outcomes }\end{array}$ & Unclear risk & Comment: anaesthesiologist: no information provided \\
\hline
\end{tabular}

Blinding of outcome as- Unclear risk Comment: assessor: no information provided

sessment (detection bias)

All outcomes

\begin{tabular}{lll}
\hline $\begin{array}{l}\text { Incomplete outcome data } \\
\text { (attrition bias) } \\
\text { All outcomes }\end{array}$ & Low risk & Comment: no missing outcome data \\
\hline $\begin{array}{l}\text { Selective reporting (re- } \\
\text { porting bias) }\end{array}$ & Low risk & Comment: awareness outcome part of inclusion criteria \\
\hline Other bias & Unclear risk & Comment: insufficient information provided \\
\hline
\end{tabular}

\section{Kerssens 2005b}

\begin{tabular}{ll}
\hline Methods & $\begin{array}{l}\text { Study design: randomized parallel groups } \\
\text { Study dates: } 2001-2002\end{array}$ \\
\hline Participants & Country: USA \\
Sex: both & ASA: I and II \\
Study size: $106-90=16$ dropouts \\
Procedure: elective (ambulatory) surgery
\end{tabular}

\section{Interventions Randomized portion of anaesthetic: TIVA vs volatile agent types}

Group 1: maintenance of anaesthesia with propofol (propofol group, $\mathrm{N}=48$ ) or

Group 2: isoflurane (isoflurane group, $\mathrm{N}=42$ )

Word stem completion test

Outcomes Primary: word test implicit memory associated with preoperative anxiety score 
Secondary outcome: awareness/wakefulness as defined using an awareness classification system (see Table 1): class 0

Quote: "None of the patients consciously recalled the intraanesthetic period on interview...absence of both implicit and explicit memory function in this study"

Notes

\section{Non-randomized portion of anaesthetic: parts of TIVA vs parts of volatile agent types: $\mathrm{N}_{2} \mathrm{O}$ yes/ narcotics/hypnotics bolus/muscle relaxants induction yes/maintenance yes ADM BIS 50 to 55}

Induction: lidocaine (1 mg/kg), fentanyl $(2 \mathrm{~g} / \mathrm{kg})$ and propofol $(2 \mathrm{mg} / \mathrm{kg})$. Succinylcholine $(1.5 \mathrm{mg} / \mathrm{kg})$ intubation. Maintenance: neuromuscular blockade was maintained at the discretion of the anaesthesiologist, using vecuronium PRN train-of-four at 1:4. $\mathrm{N}_{2} \mathrm{O}$ in oxygen $\left(\mathrm{FIO}_{2} \mathrm{0.4}\right.$ ). Anaesthetics titrated as close to BIS 50 to 55 (mean BIS during word presentation in the trauma study 54). Additional fentanyl $(50 \mathrm{~g} 100 \mathrm{~g})$ if heart rate or blood pressure changed as described previously

Survey response from ckerssens@simpleC.com 10 March 2011

\section{Risk of bias}

\begin{tabular}{lll}
\hline Bias & Authors' judgement & Support for judgement \\
\hline $\begin{array}{ll}\text { Random sequence genera- } \\
\text { tion (selection bias) }\end{array}$ & Low risk & $\begin{array}{l}\text { ROB survey Dr Kerssens: "a computer-generated assignment to both study list } \\
(1 \text { in 4) and memory test (different versions)" }\end{array}$ \\
\hline
\end{tabular}

Allocation concealment Unclear risk

(selection bias)

ROB survey Dr Kerssens: "Everything was computer programmed. All we did as investigators was type in patient study number and the computer determined which list to play plus test to use. It was completely blinded. Everybody knew words would be played but WHICH words were unknown to all."

Comment: no information regarding anaesthetic allocation

\begin{tabular}{|c|c|c|}
\hline $\begin{array}{l}\text { Blinding of participants } \\
\text { and personnel (perfor- }\end{array}$ & High risk & $\begin{array}{l}\text { ROB survey Dr Kerssens: "Patient, Anesthesiologist, Awareness outcome asses- } \\
\text { sor (interviewer)" }\end{array}$ \\
\hline All outcomes & & Comment: blinding for word list not anaesthetics \\
\hline
\end{tabular}

\begin{tabular}{lll}
\hline $\begin{array}{l}\text { Blinding of outcome as- } \\
\text { sessment (detection bias) }\end{array} \quad$ Low risk & $\begin{array}{l}\text { ROB survey Dr Kerssens: " Patient, Anesthesiologist, Awareness outcome as- } \\
\text { sessor (interviewer)" }\end{array}$
\end{tabular}
All outcomes

\section{Incomplete outcome data Low risk} (attrition bias)

All outcomes
Quote: "...excluded 16 patients because of anesthetic (drug) protocol violations ( $\mathrm{n} 8$ ), because critical stimuli could not be presented during anesthesia ( $n$ 4), or because patients had left the hospital before they were tested ( $n 4)$, resulting in 90 evaluable patients. Study group size was chosen to approximate the same number of patients ( $\mathrm{n} 96$ ) as in our previous study"

ROB survey Dr Kerssens: "Outcome data was complete. Exclusions are listed in the paper but did not affect anesthesia treatment groups differentially"

\begin{tabular}{ll}
\hline $\begin{array}{l}\text { Selective reporting (re- } \quad \text { Low risk } \\
\text { porting bias) }\end{array}$ & ROB survey Dr Kerssens: "yes"
\end{tabular}
porting bias)

Other bias Unclear risk $\quad$ ROB survey Dr Kerssens: "No, all results were reported"




\begin{tabular}{l} 
Country: USA \\
Sex: both \\
Age: $61.2,63.9$ \\
Procedure: joint replacement surgery \\
Study size: 167 enrolled, 128 completed study \\
\hline
\end{tabular}

Randomized portion of anaesthetic: volatile agent types: ADM: BIS $\mathbf{5 0}$ to $\mathbf{6 0}$ vs SCPs
Intervention 1: BIS monitor used to guide anaesthetic, maintained between $\mathbf{5 0}$ to $\mathbf{6 0}, \mathrm{N}=67$
Intervention 2: BIS not seen, standard clinical signs to guide anaesthetic, $\mathrm{N}=61$

Primary outcomes: effect of BIS-guided anaesthesia vs SCP on memory recognition function
Secondary outcome: awareness/wakefulness as defined using an awareness classification system (see
Table 1 ): class 1
Quote: "When interviewed postoperatively, three patients $(2.3 \%)$ reported recall of the time period be-
tween falling asleep and waking up from anaesthesia"
Comment: 2 patients were in BIS group and 1 in SCP group. There was evidence of implicit memory in
the BIS guided group compared to the SCP group.

\section{Notes \\ Non-randomized portion of anaesthetic: parts of volatile agent: $\mathrm{N}_{\mathbf{2}} \mathrm{O}$ no/narcotics/hypnotics bolus} $\mathrm{MCl} /$ muscle relaxants induction yes/maintenance PRN

Anaesthesia induction: propofol $2 \mathrm{mg} / \mathrm{kg}+$ fentanyl $3 \mu \mathrm{g} / \mathrm{kg}$ + vecuronium bromide $(0.1 \mathrm{mg} / \mathrm{kg})$ tracheal intubation, additional doses as necessary; maintenance: sevoflurane in oxygen using standard ventilation parameters + fentanyl $50 \mu \mathrm{g}$ to $100 \mu \mathrm{g}+$ esmolol $0.5 \mathrm{mg} / \mathrm{kg}+$ phenylephrine $100 \mu \mathrm{g}+$ fentanyl $50 \mu \mathrm{g}$ to $100 \mu \mathrm{g} / \mathrm{kg}$ as needed. Physiologic parameters recorded: BIS, end-tidal gas concentrations (but actual ET data reported) (every $5 \mathrm{~s}$ ) and vital signs (every $3 \mathrm{~min}$ )

Time of outcome determination: $6 \mathrm{~h}$ postoperative

Method of outcome determination: interview questions

Comment: see Dryad topics BIS and implicit memory vs SCPs and dreams

Survey response: 10 March 2011, Chantal Kerssens ckerssens@simpleC.com

Author sent characteristics and ROB tables for comment 7 December 2013: ckerssens@simpleC.com

\section{Risk of bias}

\begin{tabular}{lll}
\hline Bias & Authors' judgement & Support for judgement \\
\hline $\begin{array}{l}\text { Random sequence genera- } \\
\text { tion (selection bias) }\end{array}$ & Low risk & $\begin{array}{l}\text { Quote: "Patients were randomly assigned to one of two anaesthetic manage- } \\
\text { ment groups using a computer-generated list linking subject study numbers to } \\
\text { group assignment" }\end{array}$ \\
\hline $\begin{array}{l}\text { Allocation concealment } \\
\text { (selection bias) }\end{array}$ & Unclear risk & Comment: no information provided \\
\hline $\begin{array}{l}\text { Blinding of participants } \\
\text { and personnel (perfor- } \\
\text { mance bias) }\end{array}$ & Unclear risk & Comment: no information provided \\
\hline
\end{tabular}


Kerssens 2009 (Continued)

All outcomes

$\begin{array}{lll}\begin{array}{l}\text { Blinding of outcome as- } \\ \text { sessment (detection bias) }\end{array} & \text { Low risk } & \begin{array}{l}\text { Quote: assessor: "Outcome assessors were blinded to study group allocation } \\ \text { and tested patients postoperatively for recall and recognition memory. Recall } \\ \text { All outcomes }\end{array} \\ \text { was assessed approximately } 6 \mathrm{~h} \text { after surgery with five questions" }\end{array}$

All outcomes was assessed approximately $6 \mathrm{~h}$ after surgery with five questions"

Incomplete outcome data Low risk
(attrition bias)

Quote: "Numbers are reported in the paper. The ratios and reasons for ex-

All outcomes clusion/attrition were comparable between groups." (email bias survey, see notes)

Author sent characteristics and ROB tables for comment 7 December 2013: ckerssens@simpleC.com

\begin{tabular}{lll}
\hline $\begin{array}{l}\text { Selective reporting (re- } \\
\text { porting bias) }\end{array}$ & Low risk & $\begin{array}{l}\text { Quote: "True" (email bias survey, see notes) } \\
\text { Comment: awareness outcome part of inclusion criteria }\end{array}$ \\
\hline Other bias & Low risk & $\begin{array}{l}\text { Quote: "Yes. We stopped enrolment/testing when the main study -unrelated to } \\
\text { memory function - reached it's target enrolment number." (email bias survey, } \\
\text { see notes) }\end{array}$
\end{tabular}

\section{Kim 2007}

\begin{tabular}{ll}
\hline Methods & $\begin{array}{l}\text { Study design: randomized parallel groups } \\
\text { Study dates: not stated }\end{array}$ \\
\hline Participants & Country: South Korea \\
Sex: both & Age: 38 \\
ASA: I & Procedure: elective orthopaedic or gynaecological surgery \\
Study size: 40
\end{tabular}

\section{Interventions $\quad$ Randomized portion of anaesthetic: cardiac drug vs placebo}

Intervention 1: induction: saline control $(\mathrm{N}=20)$

Intervention 2: induction: nicardipine $15 \mu \mathrm{g} / \mathrm{kg}(\mathrm{N}=20)$

Outcomes Primary outcomes: effect of IV nicardipine on haemodynamic and BIS responses

Secondary outcome: awareness/wakefulness as defined using an awareness classification system (see Table 1): class 1

Quote: "No patient in either group had any recall of the procedure"

Notes

\section{Non-randomized portion of anaesthetic: parts of volatile agent: $\mathrm{N}_{2} \mathrm{O}$ yes/narcotics/hypnotics bo- lus/muscle relaxants induction yes/maintenance unclear/ADM: BIS recorded}

Anaesthesia induction: thiopental $(5 \mathrm{mg} / \mathrm{kg})+$ fentanyl $(1.5 \mu \mathrm{g} / \mathrm{kg})+$ rocuronium $(0.6 \mathrm{mg} / \mathrm{kg}) .30 \mathrm{sec}$ post-induction saline or nicardipine $(15 \mu \mathrm{g} / \mathrm{kg})$ administered

Anaesthesia maintenance: $1.0 \%$ inspired concentration of sevoflurane and $50 \% \mathrm{~N}_{2} \mathrm{O}$ in $\mathrm{O}_{2} \mathrm{BIS}$ recorded

Time of outcome determination: in recovery room 
Kim 2007 (Continued)
Method of outcome determination: interview
Bias survey sent via email to author. No response received
DrYoon-Sook Lee yslee4719@gmail.com
Re-sent 13 April 2015

\section{Risk of bias}

\begin{tabular}{|c|c|c|}
\hline Bias & Authors' judgement & Support for judgement \\
\hline $\begin{array}{l}\text { Random sequence genera- } \\
\text { tion (selection bias) }\end{array}$ & Unclear risk & $\begin{array}{l}\text { Quote: "The patients were randomly allocated, by sealed envelope assign- } \\
\text { ment, into two groups..." }\end{array}$ \\
\hline $\begin{array}{l}\text { Allocation concealment } \\
\text { (selection bias) }\end{array}$ & Unclear risk & $\begin{array}{l}\text { Comment: sealed-envelope technique } \\
\text { COMMENT: as described in previous tables }\end{array}$ \\
\hline $\begin{array}{l}\text { Blinding of participants } \\
\text { and personnel (perfor- } \\
\text { mance bias) } \\
\text { All outcomes }\end{array}$ & Unclear risk & Comment: anaesthesiologist: no information provided \\
\hline $\begin{array}{l}\text { Blinding of outcome as- } \\
\text { sessment (detection bias) } \\
\text { All outcomes }\end{array}$ & Unclear risk & Comment: assessor: no information provided \\
\hline $\begin{array}{l}\text { Incomplete outcome data } \\
\text { (attrition bias) } \\
\text { All outcomes }\end{array}$ & Low risk & Comment: no missing outcome data \\
\hline $\begin{array}{l}\text { Selective reporting (re- } \\
\text { porting bias) }\end{array}$ & Low risk & Comment: awareness outcome part of inclusion criteria \\
\hline Other bias & Unclear risk & Comment: insufficient information provided \\
\hline
\end{tabular}

Kiyama 1997

\begin{tabular}{ll}
\hline Methods & Study design: randomized parallel groups \\
& Study dates: not stated \\
\hline Participants & Country: Japan \\
Sex: female & Age: 44 to 48 years mean each group \\
ASA: I & Procedure: gynaecological surgery: total abdominal hysterectomy \\
& Study size: 20 \\
Randomized portion of anaesthetic: regional anaesthesia: epidural: induction/maintenance \\
Intervention $1:$ with pre-incisional (before induction) epidural: $1.5 \%$ lignocaine with $1: 200,00$ epi 20 mL \\
after test dose: T4 dermatome to pinprick; $\mathrm{N}=10$
\end{tabular}


Kiyama 1997 (Continued)

Intervention 2: maintenance: 15 minutes post-incisional epidural: 1.5\% lignocaine with 1:200,00 epi 20 $\mathrm{mL}$ after test dose; $\mathrm{N}=10$

\begin{tabular}{ll}
\hline Outcomes & $\begin{array}{l}\text { Primary outcomes: effects surgical stimuli on EEG; haemodynamic effects andEEG variables } \\
\text { Secondary outcome: awareness/wakefulness as defined using an awareness classification system (see } \\
\text { Table } 1 \text { ): class } 1\end{array}$ \\
Comment: no patient-reported intraoperative recall in the immediate postoperative period and $24 \mathrm{~h}$ \\
later
\end{tabular}

\section{Risk of bias}

\begin{tabular}{|c|c|c|}
\hline Bias & Authors' judgement & Support for judgement \\
\hline $\begin{array}{l}\text { Random sequence genera- } \\
\text { tion (selection bias) }\end{array}$ & Unclear risk & Quote: "...allocated randomly..." \\
\hline $\begin{array}{l}\text { Allocation concealment } \\
\text { (selection bias) }\end{array}$ & Unclear risk & Comment: above \\
\hline $\begin{array}{l}\text { Blinding of participants } \\
\text { and personnel (perfor- } \\
\text { mance bias) } \\
\text { All outcomes }\end{array}$ & Low risk & $\begin{array}{l}\text { Comment: blinded to epidural drug but anaesthesiologists could deduce } \\
\text { which intervention group they were managing based on haemodynamic } \\
\text { changes (table 2) }\end{array}$ \\
\hline $\begin{array}{l}\text { Blinding of outcome as- } \\
\text { sessment (detection bias) } \\
\text { All outcomes }\end{array}$ & High risk & Comment: not blinded \\
\hline $\begin{array}{l}\text { Incomplete outcome data } \\
\text { (attrition bias) } \\
\text { All outcomes }\end{array}$ & Low risk & Comment: no missing data \\
\hline $\begin{array}{l}\text { Selective reporting (re- } \\
\text { porting bias) }\end{array}$ & Low risk & Comment: awareness outcome part of inclusion criteria \\
\hline Other bias & Unclear risk & Comment: inadequate information provided \\
\hline
\end{tabular}

Kreuer 2003

\begin{tabular}{ll}
\hline Methods & Study design: randomized parallel groups \\
& Study dates: not stated \\
\hline Participants & Country: Germany \\
& Sex: male/female
\end{tabular}


Kreuer 2003 (Continued)

Age: 18 to 80

ASA: I, II or III

Procedure: minor orthopaedic

Study size: 120

\section{Interventions Randomized portion of anaesthetic: ADM (BIS 50 Narcotrend D0) vs SCP}

Intervention 1: monitor type: Narcotrend target D0

Intervention 1: monitor type: BIS target 50

Intervention 1: monitor type: standard clinical parameter (SCP)

Primary outcomes: anaesthetic consumption, recovery times (eye opening/extubation)
Secondary outcome: awareness/wakefulness as defined using an awareness classification system (see
Table 1): class 1
Quote: "Finally, all patients were visited in the postanaesthesia care unit and on the first and third post-
operative day and were interviewed about intraoperative recall"
Quote: "No patient reported intraoperative recall"

Notes

\section{Non-randomized portion of anaesthetic: parts of TIVA $\mathrm{N}_{2} \mathrm{O}$ no: propofol-remifentanil TCI $\mathrm{MCl} /$ muscle relaxants induction yes/maintenance unclear (atracurium)}

Premedicated diazepam $0.15 \mathrm{mg} / \mathrm{kg}$ PO

Induction/maintenance non-randomized portion of anaesthetic: TIVA

Anaesthesia induction: remifentanil $\mathrm{MCl} 0.4 \mu \mathrm{g} / \mathrm{kg} / \mathrm{min}+5 \mathrm{~min}$ later, propofol $\mathrm{TCl} 3.5 \mu \mathrm{g} / \mathrm{mL}+$ atracurium $0.1 \mathrm{mg} / \mathrm{kg}$ intubated $3 \mathrm{~min}$ later, ventilated $\mathrm{ET} \mathrm{CO}_{2} 35 \mathrm{mmHg}$, remifentanil reduced $0.2 \mu \mathrm{g} / \mathrm{kg} / \mathrm{min}$, whereas propofol $\mathrm{TCl}$ adjusted

\section{BIS vs Narcotrend target values vs SCP}

Comment: see Dryad topic inadequate anaesthesia

Time of outcome determination: first and third day postoperative. Method of outcome determination: interview

Email sent to secondary author, Wilhelm, on 1 April 2011: no response Dr. Wilhelm: wolfram.wilhelm@uniklinik-saarland.de

\section{Risk of bias}

\begin{tabular}{lll}
\hline Bias & Authors' judgement & Support for judgement \\
\hline $\begin{array}{l}\text { Random sequence genera- } \\
\text { tion (selection bias) }\end{array}$ & Unclear risk & $\begin{array}{l}\text { Quote: "were randomized to receive a propofol-remifentanil anaesthetic con- } \\
\text { trolled by Narcotrend, by BIS }{ }^{\circledR}, \text { or solely by clinical parameters" }\end{array}$ \\
\hline $\begin{array}{l}\text { Allocation concealment } \\
\text { (selection bias) }\end{array}$ & Unclear risk & Comment: no information provided \\
\hline $\begin{array}{l}\text { Blinding of participants } \\
\text { and personnel (perfor- } \\
\text { mance bias) } \\
\begin{array}{l}\text { All outcomes } \\
\hline\end{array}\end{array}$ & Unclear risk & Comment: insufficient information provided \\
\hline
\end{tabular}


Kreuer 2003 (Continued)

Blinding of outcome as- Unclear risk Comment: assessor: no information provided sessment (detection bias)

All outcomes

Incomplete outcome data Low risk Comment: no missing outcome data
(attrition bias)

All outcomes

Selective reporting (re- Low risk Comment: awareness outcome part of inclusion criteria

porting bias)

Other bias Unclear risk Comment: insufficient information provided

\section{Kreuer 2005}

\begin{tabular}{|c|c|}
\hline Methods & $\begin{array}{l}\text { Study design: randomized parallel groups } \\
\text { Study dates: not stated }\end{array}$ \\
\hline Participants & $\begin{array}{l}\text { Country: Germany } \\
\text { Sex: both } \\
\text { Age: } 18 \text { to } 80 \\
\text { ASA: I-III } \\
\text { Procedure: minor orthopaedic surgery expected to last at least } 1 \mathrm{~h} \\
\text { Study size: } 120\end{array}$ \\
\hline Interventions & $\begin{array}{l}\text { Randomized portion of anaesthetic: volatile agent types: ADM: BIS 50/Narcotrend DO vs SCPs } \\
\text { Intervention 1: induction and maintenance: } \mathrm{SP}(\mathrm{N}=40) \text { - control } \\
\text { Intervention 2: induction and maintenance: } \mathrm{BIS} 50(\mathrm{~N}=40) \\
\text { Intervention 3: induction and maintenance: Narcotrend D0 }(\mathrm{N}=40)\end{array}$ \\
\hline Outcomes & $\begin{array}{l}\text { Primary outcomes: Quote: "The primary end-point of this study was defined as the time taken to spon- } \\
\text { taneous opening of eye" } \\
\text { Secondary outcome: awareness/wakefulness as defined using an awareness classification system (see } \\
\text { Table 1): class } 1 \\
\text { Quote: "Complaints of intraoperative recall were not reported" }\end{array}$ \\
\hline
\end{tabular}

All patients were premedicated with midazolam $7.5 \mathrm{mg}$ orally

Induction/maintenance non-randomized portion of anaesthetic: balanced anaesthesia defined by IV (propofol/remifentanil) and inhalation (desflurane)

Remifentanil infusion at $0.4 \mu \mathrm{g} / \mathrm{kg}+2 \mathrm{mg} / \mathrm{kg}$ propofol, oxygen was given by face mask ventilation +0.5 $\mathrm{mg} / \mathrm{kg}$ atracurium, trachea was intubated, ventilated $\mathrm{ET} \mathrm{CO}_{2} 35 \mathrm{mmHg}$, maintenance: remifentanil reduced $0.2 \mu \mathrm{g} / \mathrm{kg} / \mathrm{min}$, desflurane adjusted: BIS vs Narcotrend target values vs SCP

Comment: see Dryad inadequate anaesthesia 
Kreuer 2005 (Continued)

Bias survey not sent to author due to incorrect email address

Care Medicine, Sascha Kreuer, MD email to sascha.kreuer@uniklinik-saarland.de

ROB survey. We re-emailed on 13 April 2015; responded 13 April 2015 sascha.kreuer@uks.eu

\section{Risk of bias}

\begin{tabular}{lll}
\hline Bias & Authors' judgement & Support for judgement \\
\hline $\begin{array}{l}\text { Random sequence genera- } \\
\text { tion (selection bias) }\end{array}$ & Low risk & $\begin{array}{l}\text { Quote: "adult patients were randomised to receive...After enrolment, patients } \\
\text { were randomised by drawing lots from a closed box" }\end{array}$ \\
& $\begin{array}{l}\text { ROB survey Dr Kreuer: "Patients were randomised by drawing lots from a } \\
\text { closed box" }\end{array}$ \\
\hline $\begin{array}{l}\text { Allocation concealment } \\
\text { (selection bias) }\end{array}$ & $\begin{array}{l}\text { Comment: no information provided. RCTs that are included in this review and } \\
\text { indicate that CONSORT criteria are part of their methods, have unblinded } \\
\text { anaesthesiologists. Hence, we cannot assume that other ROB domains are low } \\
\text { risk without ROB survey input }\end{array}$ \\
$\begin{array}{l}\text { ROB survey response: "In all patients, irrespective of the individual Group as- } \\
\text { signment, both BIS values and Narcotrend Levels were continuously record- } \\
\text { ed in intervals of } 5 \text { min by a second independent investigator (LA). In the Stan- } \\
\text { dard practice group, both monitors were covered behind a curtain and invisi- } \\
\text { ble for the attending anaesthesiologist (CS), whereas, in the EEG groups, either } \\
\text { only the Narcotrend or only the BIS monitor was uncovered" }\end{array}$
\end{tabular}

\begin{tabular}{|c|c|c|}
\hline $\begin{array}{l}\text { Blinding of participants } \\
\text { and personnel (perfor- } \\
\text { mance bias) } \\
\text { All outcomes }\end{array}$ & High risk & $\begin{array}{l}\text { Comment: anaesthesia titrated to ADMs x } 2 \text { vs SCP } \\
\text { ROB survey response: "Patient, Anaesthesiologist, Awareness outcome asses- } \\
\text { sor (interviewer)" }\end{array}$ \\
\hline
\end{tabular}

\begin{tabular}{ll}
\hline Blinding of outcome as- \\
sessment (detection bias)
\end{tabular} Low risk $\quad$ Quote: "Recovery times were recorded by a blinded investigator (MS)"

All outcomes

\begin{tabular}{|c|c|c|}
\hline $\begin{array}{l}\text { Incomplete outcome data } \\
\text { (attrition bias) } \\
\text { All outcomes }\end{array}$ & Low risk & $\begin{array}{l}\text { Comment: no missing outcome data } \\
\text { ROB survey response: "No Patient was excluded from data Analysis" }\end{array}$ \\
\hline $\begin{array}{l}\text { Selective reporting (re- } \\
\text { porting bias) }\end{array}$ & Low risk & $\begin{array}{l}\text { Comment: awareness outcome part of inclusion criteria } \\
\text { ROB survey response: "The study protocol is available. All results are reported } \\
\text { in the manuscript" }\end{array}$ \\
\hline Other bias & Low risk & $\begin{array}{l}\text { Comment: as above } \\
\text { ROB survey response: "There is no Bias like described above" }\end{array}$ \\
\hline
\end{tabular}

Krissel 1994

\begin{tabular}{ll}
\hline Methods & $\begin{array}{l}\text { Study design: randomized parallel groups } \\
\text { Study dates: not stated }\end{array}$ \\
\hline Participants & Country: Germany \\
& Sex: female
\end{tabular}


Krissel 1994 (Continued)

ASA: not given, "healthy women"

Age: 30

Procedure: elective caesarean section

Study size: 75

\section{Interventions \\ Randomized portion of anaesthetic: parts of intravenous (IV) anaesthesia vs volatile agent types:} induction/maintenance

Intervention 1: (Group A) Induction: thiopentone $(4 \mathrm{mg} / \mathrm{kg}$ ) maintenance: ventilation $2+2$ litre/min $\mathrm{N}_{2} \mathrm{O} / \mathrm{O}_{2}$ mix with $0.8 \%$ enflurane $(\mathrm{N}=25)$

Intervention 2: (Group B) Induction: thiopentone $(2 \mathrm{mg} / \mathrm{kg})+$ ketamine maintenance: $(0.5 \mathrm{mg} / \mathrm{kg})$ ventilation $2+2$ litre/min $\mathrm{N}_{2} \mathrm{O} / \mathrm{O}_{2}$ mix with $0.8 \%$ enflurane $(\mathrm{N}=25)$

Intervention 3: (Group C) Induction: ketamine (1 mg/kg) maintenance: no enflurane ( $\mathrm{N}=25)$

Outcomes
Awimary outcomes: maternal blood pressure, neonate muscle tone, UID intervals
Quote: "Intra-operative consciousness was reported only by patients in the thiopentone group [1 pa-
tient awareness report], unpleasant dreams only in the ketamine group and pleasant dreams in both
the ketamine and the thiopentone/ketamine groups"

\begin{tabular}{|c|c|}
\hline \multirow[t]{8}{*}{ Notes } & $\begin{array}{l}\text { Non-randomized portion of anaesthetic: parts of IV vs parts of volatile agent } \mathrm{N}_{2} \mathrm{O} \text { yes/nar- } \\
\text { cotics/hypnotics bolus/muscle relaxant induction yes/maintenance yes }\end{array}$ \\
\hline & Induction/maintenance non-randomized portion of anaesthetic: \\
\hline & $\begin{array}{l}\text { Anaesthesia induction: alcuronium ( } 0.1 \mathrm{mg} \text { pre-curization). Group-specific induction regimen + suc- } \\
\text { cinylcholine }(1.5 \mathrm{mg} / \mathrm{kg})+\text { alcuronium }(0.1 \mathrm{mg} / \mathrm{kg})\end{array}$ \\
\hline & $\begin{array}{l}\text { After delivery: all groups: nitrous } 67 \% \mathrm{O}_{2} 33 \%+\text { enflurane } 1 \% \text { to } 1.5 \% \text { with alcuronium and ketamine } \\
0.25 \mathrm{mg} / \mathrm{kg} \text { if needed }\end{array}$ \\
\hline & Note the various definitions of inhalation vs IV \\
\hline & Time of outcome determination: $24 \mathrm{~h}$ postoperative \\
\hline & Method of outcome determination: interview \\
\hline & Comment: no email found for author; bias survey not sent \\
\hline
\end{tabular}

\section{Risk of bias}

\begin{tabular}{lll}
\hline Bias & Authors' judgement & Support for judgement \\
\hline $\begin{array}{l}\text { Random sequence genera- } \\
\text { tion (selection bias) }\end{array}$ & Unclear risk & Quote: "...randomly allocated..." \\
\hline $\begin{array}{l}\text { Allocation concealment } \\
\text { (selection bias) }\end{array}$ & Unclear risk & Comment: no information provided \\
\hline $\begin{array}{l}\text { Blinding of participants } \\
\text { and personnel (perfor- } \\
\text { mance bias) } \\
\text { All outcomes }\end{array}$ & Unclear risk & Comment: anaesthesiologist: no information provided \\
\hline
\end{tabular}


Krissel 1994 (Continued)

Blinding of outcome as- Unclear risk Comment: assessor: no information provided sessment (detection bias)

All outcomes

Incomplete outcome data Low risk Comment: no missing outcome data
(attrition bias)

All outcomes

Selective reporting (re- Low risk Comment: awareness outcome part of inclusion criteria

porting bias)

Other bias Unclear risk Comment: insufficient information provided

Kudoh 1999

\begin{tabular}{ll}
\hline Methods & $\begin{array}{l}\text { Study design: randomized parallel groups } \\
\text { Study dates: not stated }\end{array}$ \\
\hline Participants & Country: Japan \\
Sex: both & Age: 25 \\
ASA: NA & Procedure: orthopaedic \\
Study size: 40
\end{tabular}

$\begin{array}{ll}\text { Interventions } & \text { Randomized portion of anaesthetic: parts of TIVA MCI vs bolus maintenance } \\ & \text { Intervention 1: (group A) maintenance: fentanylinfusion }(5 \mu \mathrm{g} / \mathrm{kg} / \mathrm{h} \text { ) for the first } 60 \mathrm{~min} \text { and } 3 \mu \mathrm{g} / \mathrm{kg} / \mathrm{h} \\ \text { for the next } 90 \mathrm{~min} ;(\mathrm{N}=20) \\ \text { Intervention 2: (group B) maintenance: fentanyl bolus } 50 \mu \mathrm{g} \text { to } 100 \mu \mathrm{g} \text { at signs of light anaesthesia; ( } \mathrm{N}= \\ \text { 20) }\end{array}$

\begin{tabular}{|c|c|}
\hline \multirow[t]{3}{*}{ Outcomes } & $\begin{array}{l}\text { Primary outcomes: } 1 \text { - TIVA (ketamine/droperidol/fentanyl) impact on MLAEP and explicit memory; } 2 \\
\text { impact of differences in infusion methods on dream frequency }\end{array}$ \\
\hline & Awareness/wakefulness as defined using an awareness classification system (see Table 1): class 1 \\
\hline & $\begin{array}{l}\text { Comment: no explicit memories; several patients had intraoperative dreaming; group } A=5 \text { dreams } \\
\text { group } B=10 \text { (see table } 1 \text { ) }\end{array}$ \\
\hline
\end{tabular}

Notes
Non-randomized portion of anaesthetic: parts of TIVA $\mathrm{N}_{2} \mathrm{O}$ no/narcotics/hypnotics bolus/muscle relaxant induction yes/maintenance unclear PRN/ADM: MLAEP recorded

Total intravenous anaesthesia: droperidol, ketamine, and fentanyl: middle latency auditory evoked potentials

Anaesthesia induction: ketamine $(2 \mathrm{mg} / \mathrm{kg})+$ fentanyl $(5 \mu \mathrm{g} / \mathrm{kg})+$ droperidol $(0.1 \mathrm{mg} / \mathrm{kg})+$ suxamethonium $(1 \mathrm{mg} / \mathrm{kg})$ intubation

Anaesthesia maintenance: group-specific regimen (see above) + ketamine $(2 \mathrm{mg} / \mathrm{kg} / \mathrm{h}$ )

Comment: study of explicit memory: affirmative message and auditory stimulation by pop music during surgery using a tape recorder 
Kudoh 1999 (Continued)

Comment: see Dryad: dreams associated with lower levels anaesthesia

Comment: see Dryad topic advantages TIVA

Time of outcome determination: 1 to 3 days postoperative

No email address available for ROB survey

\section{Risk of bias}

\begin{tabular}{|c|c|c|}
\hline Bias & Authors' judgement & Support for judgement \\
\hline $\begin{array}{l}\text { Random sequence genera- } \\
\text { tion (selection bias) }\end{array}$ & Unclear risk & $\begin{array}{l}\text { Comment: groups were randomized. No discussion of method of randomiza- } \\
\text { tion }\end{array}$ \\
\hline $\begin{array}{l}\text { Allocation concealment } \\
\text { (selection bias) }\end{array}$ & Unclear risk & Comment: no information provided \\
\hline $\begin{array}{l}\text { Blinding of participants } \\
\text { and personnel (perfor- } \\
\text { mance bias) } \\
\text { All outcomes }\end{array}$ & Unclear risk & Comment: anaesthesiologist: no information provided \\
\hline $\begin{array}{l}\text { Blinding of outcome as- } \\
\text { sessment (detection bias) } \\
\text { All outcomes }\end{array}$ & Unclear risk & Comment: assessor: no information provided \\
\hline $\begin{array}{l}\text { Incomplete outcome data } \\
\text { (attrition bias) } \\
\text { All outcomes }\end{array}$ & Low risk & Comment: no missing outcome data \\
\hline $\begin{array}{l}\text { Selective reporting (re- } \\
\text { porting bias) }\end{array}$ & Low risk & Comment: awareness outcome part of inclusion criteria \\
\hline Other bias & Unclear risk & Comment: insufficient information provided \\
\hline
\end{tabular}

Kwon 2013

\begin{tabular}{ll}
\hline Methods & Study design: randomized parallel groups \\
& Study dates: not stated \\
\hline Participants & Country: Korea \\
& Sex: female/male \\
Age: 18 to $70 ;$ mean 40 to 45 \\
ASA: I-II \\
Procedure: elective surgery \\
Study size: 40
\end{tabular}

Interventions

\section{Randomized portion of anaesthetic: muscle relaxants: rocuronium vs succinylcholine: mainte- nance: no information}

Intervention 1 : $(\mathrm{N}=20) 0.6 \mathrm{mg} / \mathrm{kg}$ rocuronium followed by $1.5 \mathrm{mg} / \mathrm{kg}$ propofol: intubated just after confirming loss of consciousness

Intervention 2: $(\mathrm{N}=20) 1.5 \mathrm{mg} / \mathrm{kg}$ propofol and $1.5 \mathrm{mg} / \mathrm{kg}$ succinylcholine: intubated 1 minute after injecting succinylcholine 


Primary outcome: acceptable intubation conditions
Secondary outcomes: awareness/wakefulness as defined using an awareness classification system (see
Table 1): class 1
Quote: "None of the patients complained awareness of the intubation procedure or had respiratory dif-
ficulty during a postoperative interview"

\section{Notes}

\section{Non-randomized portion of anaesthetic: hypnotic sedative/narcotic/lidocaine induction agents, muscle relaxants yes/maintenance: no information; other techniques}

Induction: all patients received $1.5 \mu \mathrm{g} / \mathrm{kg}$ fentanyl intravenously with pre-oxygenation for 2 minutes and were randomized to receive $0.6 \mathrm{mg} / \mathrm{kg}$ rocuronium followed by $1.5 \mathrm{mg} / \mathrm{kg}$ propofol or $1.5 \mathrm{mg} / \mathrm{kg}$ propofol and $1.5 \mathrm{mg} / \mathrm{kg}$ succinylcholine

\section{Maintenance: no information}

Comment: no information about maintenance phase of the study; Jaegyok Song, MD, email: drjack@nate.com

ROB survey: we emailed drjack@nate.com on 22 March 2015

\section{Risk of bias}

\begin{tabular}{|c|c|c|}
\hline Bias & Authors' judgement & Support for judgement \\
\hline $\begin{array}{l}\text { Random sequence genera- } \\
\text { tion (selection bias) }\end{array}$ & Unclear risk & $\begin{array}{l}\text { Quote: "Patients were randomly assigned to receive rocuronium (group l) or } \\
\text { succinylcholine (group 2)" }\end{array}$ \\
\hline $\begin{array}{l}\text { Allocation concealment } \\
\text { (selection bias) }\end{array}$ & Unclear risk & Comment: no information \\
\hline $\begin{array}{l}\text { Blinding of participants } \\
\text { and personnel (perfor- } \\
\text { mance bias) } \\
\text { All outcomes }\end{array}$ & High risk & Comment: no apparent blinding \\
\hline $\begin{array}{l}\text { Blinding of outcome as- } \\
\text { sessment (detection bias) } \\
\text { All outcomes }\end{array}$ & Low risk & $\begin{array}{l}\text { Quote: "All patients were interviewed by a blinded investigator 6-24 } \mathrm{h} \text { after } \\
\text { surgery" }\end{array}$ \\
\hline $\begin{array}{l}\text { Incomplete outcome data } \\
\text { (attrition bias) } \\
\text { All outcomes }\end{array}$ & Low risk & Comment: no dropouts \\
\hline $\begin{array}{l}\text { Selective reporting (re- } \\
\text { porting bias) }\end{array}$ & Low risk & Comment: awareness outcome part of inclusion criteria \\
\hline Other bias & Unclear risk & Comment: no information \\
\hline
\end{tabular}

Lallemand 2003

\begin{tabular}{ll}
\hline Methods & $\begin{array}{l}\text { Study design: randomized parallel groups } \\
\text { Study dates: March, April } 2002 \text { survey }\end{array}$ \\
\hline Participants & Country: France \\
\hline
\end{tabular}


Lallemand 2003 (Continued)

Sex: both

Age: 30

ASA: I

Procedure: elective surgery

Study size: 30

$\begin{array}{ll}\text { Interventions } & \text { Randomized portion of anaesthetic: parts of } \\ \text { Intervention 1: etomidate } 0.2 \mathrm{mg} / \mathrm{kg}(\mathrm{N}=10) \\ \text { Intervention 2: etomidate } 0.3 \mathrm{mg} / \mathrm{kg}(\mathrm{N}=10) \\ \text { Intervention 3: etomidate } 0.4 \mathrm{mg} / \mathrm{kg}(\mathrm{N}=10)\end{array}$

Outcomes Primary outcomes: times to disappearance of the eyelash reflex, to a decrease in the BIS to 50, and to tracheal intubation were compared. The BIS values 30 s following tracheal intubation, and mean arterial pressure (MAP) and heart rate $(\mathrm{h})$ at all time points

Secondary outcome: awareness/wakefulness as defined using an awareness classification system (see Table 1): class 1

Quote: "No awareness was recorded"

Notes

Non-randomized portion of anaesthetic: parts of volatile agent: $\mathrm{N}_{2} \mathrm{O}$ yes/narcotics/hypnotics bolus/muscle relaxant induction yes/maintenance unclear/ADM: BIS

Anaesthesia induction: etomidate (by group) + rocuronium $0.6 \mathrm{mg} / \mathrm{kg}$

Anaesthesia maintenance: sufentanil + isoflurane $+\mathrm{BIS}<=\mathbf{5 0}$ for intubation

Comment nitrous not identified in methods but described in results: "One patient who received etomidate $0.4 \mathrm{mg} \mathrm{kg} \pm 1$ did not require any additional drug administration after sufentanil $10 \mathrm{mg}$ had been given in accordance with the study design, and underwent surgery with a BIS value of 30 . He recovered consciousness with no recall when nitrous oxide was discontinued"

Quote: "The number of patients for the present study was based on the fact that similar investigations used at the most 30 patients...."

Time of outcome determination: day after surgery

Method of outcome determination: interview

Survey response: 5 February 2011, C Lentschenerclaude.lentschener@cch.aphp.fr

Author sent characteristics and ROB table grades for comment 8 December 2013: claude.lentschener@cch.aphp.fr

\section{Risk of bias}

\begin{tabular}{lll}
\hline Bias & Authors' judgement & Support for judgement \\
\hline $\begin{array}{l}\text { Random sequence genera- } \\
\text { tion (selection bias) }\end{array}$ & Low risk & $\begin{array}{l}\text { Quote ROB survey: "... nurse not involved in the assessment (a) performed the } \\
\text { randomisation ... sealed opaque envelopes that contained the group assign- } \\
\text { ments according to a previously computer-generated random list" }\end{array}$ \\
\hline $\begin{array}{l}\text { Allocation concealment } \\
\text { (selection bias) }\end{array}$ & Low risk & Comment: sealed-envelope technique \\
\hline
\end{tabular}


Lallemand 2003 (Continued)

Blinding of participants Low risk Quote: "Patient, Anaesthesiologist, Awareness outcome assessor (interviewand personnel (perforer)...(b) prepared ...syringes containing... etomidate; and (c) activated the mance bias)

All outcomes pump infusing...etomidate dose...anaesthetist...took care of BIS monitoring and tracheal intubation, but remained unaware of the etomidate dose administered"

\begin{tabular}{|c|c|c|}
\hline $\begin{array}{l}\text { Blinding of outcome as- } \\
\text { sessment (detection bias) }\end{array}$ & Low risk & $\begin{array}{l}\text { Quote: "Patient, Anaesthesiologist, Awareness outcome assessor (interview- } \\
\text { er)" (email survey) }\end{array}$ \\
\hline
\end{tabular}

All outcomes

Incomplete outcome data Low risk (attrition bias)

All outcomes
Quote: ROB survey: "...One patient in the $0.2 \mathrm{mg} \mathrm{kg}-1$ etomidate group was still aware 10 minutes following etomidate administration. This patient was withdrawn from further assessment....that this patient had a high BIS value $10 \mathrm{~min}$ following etomidate administration. ..."

Comments: this excluded patient is at increased risk of awareness. However, there was a significant difference between groups regarding dropouts: $(1 / 10)$ etomidate $0.2 \mathrm{mg}$ vs etomidate 0.3 and $0.4 \mathrm{mg}(0 / 20)$, Peto OR 0.05 (0.00 to 3.18)

Author sent characteristics and ROB table grades for comment 8 December 2013: claude.lentschener@cch.aphp.fr

\section{Selective reporting (re- Low risk} porting bias)
Quote: "I don't understand this query. The study protocol is clear. Every necessary information is provided. If you wish any additional information in this respect tell me in an additional mail. Sorry. CL" (email bias survey, see notes)

Comment: see rules for grading selective reporting for a list of examples of this type of ROB

Comment: awareness outcome part of inclusion criteria

\begin{tabular}{ll}
\hline Other bias & Quote: "In my opinion, there is not any risk of bias Investigators were blinded \\
& to group allocation. Data were honestly collected. All recorded data are pro- \\
duced. Excluded patient is reported. I don't see any problem; neither did the \\
Editor" (email survey)
\end{tabular}

Lam 2013

\begin{tabular}{ll} 
Methods & Study design: randomized parallel groups \\
& Study dates: 1 March 2012 to 31 May 2012 \\
\hline Participants & Country: Taiwan (Republic of China) \\
Sex: female/male & Age: 18 to 59 \\
ASA: I-II & \\
Obese patients with a body mass index (BMI) of $30 \mathrm{~kg} / \mathrm{m}^{2}$ or greater \\
Procedure: bariatric surgery (laparoscopic gastric banding, sleeve gastrectomy, and Roux-en-Y bypass \\
Surgery) \\
Study size: 40 enrolled; 38
\end{tabular}

Interventions

\section{Randomized portion of anaesthetic: parts of volatile agent: IV hypnotic agents: induction}

I nduction single bolus propofol $2 \mathrm{mg} / \mathrm{kg}$ calculated from:

Intervention 1 - total body weight (TBW; 20 patients) 
Lam 2013 (Continued)

Intervention 2 - corrected body weight 60\% (CBW60; 18 patients)

Outcomes Primary outcomes: hypotension, complete blood count, coagulation profile, liver function, renal function, electrolytes, total cholesterol, triglyceride, high-density lipoprotein, uric acid, or blood sugar data, BIS values

Secondary outcomes: awareness/wakefulness as defined using an awareness classification system (see Table 1): class 1

Quote: "none reported intraoperative awareness or recall"

Notes

\section{Non-randomized portion of anaesthetic: parts of volatile agent: $\mathrm{N}_{2} \mathrm{O}$ no/narcotics/hypnotics bo- lus/muscle relaxant induction yes/maintenance yes/ADM: BIS recorded}

All received: fentanyl ( $2 \mu \mathrm{g}$ to $3 \mu \mathrm{g} / \mathrm{LBW}$ ) and lidocaine (100 mg)

The onset of loss of consciousness: patient dropped the syringe... asked to open...eyes and the eyelash test by the blinded medical personnel... bolus propofol loss consciousness/succinylcholine (1 mg/ TBW): endotracheal intubation. Anaesthesia maintained: $3 \%$ sevoflurane $50 \%$ oxygen-air mixture (6 L/ min) first 5 minutes... BIS monitor

Cisatracurium to maintain neuromuscular blockade

Quote: "We also defined a bispectral index (BIS) value of greater than 60 as indicative of possible intraoperative awareness"

ROB survey: we emailed on 2 April 2015; email address: lin.soon@gmail.com (C-S Lin)

\section{Risk of bias}

\begin{tabular}{lll}
\hline Bias & Authors' judgement & Support for judgement \\
\hline $\begin{array}{l}\text { Random sequence genera- } \\
\text { tion (selection bias) }\end{array}$ & Unclear risk & $\begin{array}{l}\text { Quote: "We performed a prospective, randomized controlled study to evaluate } \\
\text { the clinical efficacy of two different dosages of propofol" }\end{array}$ \\
\hline $\begin{array}{l}\text { Allocation concealment } \\
\text { (selection bias) }\end{array}$ & Unclear risk & Comment: no information \\
\hline $\begin{array}{l}\text { Blinding of participants } \\
\text { and personnel (perfor- } \\
\text { mance bias) } \\
\text { All outcomes }\end{array}$ & High risk & $\begin{array}{l}\text { Quote: "Except for the anesthesiologist who administered the induction dose } \\
\text { of propofol, all other medical personnel and the patients were blinded to the } \\
\text { propofol induction dose protocol." Email survey: requested details } 2 \text { April 2015 }\end{array}$
\end{tabular}

\begin{tabular}{|c|c|c|}
\hline $\begin{array}{l}\text { Blinding of outcome as- } \\
\text { sessment (detection bias) }\end{array}$ & Unclear risk & $\begin{array}{l}\text { Quote: "On questioning the patients during the postoperative interview, none } \\
\text { reported intraoperative awareness or recall" }\end{array}$ \\
\hline
\end{tabular}

\begin{tabular}{|c|c|c|}
\hline $\begin{array}{l}\text { Incomplete outcome data } \\
\text { (attrition bias) } \\
\text { All outcomes }\end{array}$ & Low risk & $\begin{array}{l}\text { Quote: "Two patients were excluded because of incomplete data collection } \\
\text { or because they had undergone multiple endotracheal intubation attempt- } \\
\text { s." (CBW } 2 / 20 \text { vs } 0 / 20 \text { TBW). Although imbalanced, there were no significant } \\
\text { difference between groups, Peto OR } 7.79 \text { (0.47 to } 129.11)\end{array}$ \\
\hline
\end{tabular}

Selective reporting (re- Low risk $\quad$ Comment: awareness outcome part of inclusion criteria
porting bias)

\begin{tabular}{ll}
\hline Other bias $\quad$ Unclear risk & Comment: no information \\
\hline
\end{tabular}


Lehmann 1985

\begin{tabular}{ll}
\hline Methods & Study design: randomized parallel groups \\
Study dates: Quote: "1984" (email bias survey, see notes)
\end{tabular}

Country: Germany
Sex: both
Age: $37,41,40$
ASA: I and II
Procedure: elective orthopaedic or abdominal surgery
Study size: 40

Interventions $\quad$ Randomized portion of anaesthetic: parts of volatile agent: IV hypnotic agents: maintenance:
supplemental narcotic vs placebo

Intervention 1: maintenance: placebo infusion $(0.9 \% \mathrm{NaCl})(\mathrm{N}=20)$

intervention 2: maintenance: tramadol infusion $13 \mathrm{mg} / \mathrm{kg} / \mathrm{h}$ for $20 \mathrm{~min}$, then $1 \mathrm{mg} / \mathrm{kg} / \mathrm{h}(\mathrm{N}=20)$

Primary outcomes: relative cumulative enflurane times (tramadol, placebo), frequency enflurane giv-
en as PRN dose, MAP, HR, postoperative recovery time and pain scales, anaesthesiologists judgement
of the quality of anaesthesia
Secondary outcome: awareness/wakefulness as defined using an awareness classification system (see
Table 1): class 4
Comment: see Dryad spontaneous memory; dreams associated with memory; partial amnesia, pain yet
satisfied with surgery

Non-randomized portion of anaesthetic: parts of volatile agent: $\mathrm{N}_{2} \mathrm{O}$ no/narcotics/hypnotics bolus $\mathrm{MCl} /$ muscle relaxant induction yes/maintenance yes

Induction: methohexitone $100 \mathrm{mg}$ + succinylcholine $1 \mathrm{mg} / \mathrm{kg}$ + pancuronium $4 \mathrm{mg}$

Maintenance: $\mathrm{N}_{2} \mathrm{O} / \mathrm{O}_{2} 79: 21,4$ breaths/min and enflurane (0.5\% to 1.5 vol.\%) PRN

Comment: see Dryad topic for awareness and lower level of anaesthesia; SCPs not predictive of awareness; translated by Lora Schulteiss

Survey response: 4 March 2011, Klaus A klaus.@uni-koeln.de

\section{Risk of bias}

\begin{tabular}{lll}
\hline Bias & Authors' judgement & Support for judgement \\
\hline $\begin{array}{l}\text { Random sequence genera- } \\
\text { tion (selection bias) }\end{array}$ & Low risk & $\begin{array}{l}\text { Quote: "computer generated randomisation list...the randomisation plan was } \\
\text { designed by the manufacturer "Firma Gruenenthal", and was not accessible to } \\
\text { any persons involved in the clinical study. only after the study was finished, the } \\
\text { codes were revealed" }\end{array}$ \\
& $\begin{array}{l}\text { Computer-generated randomization list (email bias survey, see notes) } \\
\begin{array}{l}\text { Allocation concealment } \\
\text { (selection bias) }\end{array}\end{array} \quad$ Low risk & $\begin{array}{l}\text { Quote: "coded ampoules according to randomisation plan, provided by Grue- } \\
\text { nenthal; randomised music presentation according to an own computer gen- } \\
\text { erated randomisation list." (email bias survey, see notes) }\end{array}$ \\
\hline
\end{tabular}


Lehmann 1985 (Continued)

Blinding of participants Low risk Quote: "Patient, Anaesthesiologist, Awareness outcome assessor (interviewand personnel (perforer)" (email bias survey, see notes) mance bias)

All outcomes

\begin{tabular}{ll}
\hline $\begin{array}{l}\text { Blinding of outcome as- } \\
\text { sessment (detection bias) }\end{array}$ & Low risk
\end{tabular}$\quad \begin{aligned} & \text { Quote: "Patient, Anaesthesiologist, Awareness outcome assessor (interview- } \\
& \text { er)" (email bias survey, see notes) }\end{aligned}$

All outcomes

\begin{tabular}{ll}
\hline Incomplete outcome data Low risk & Quote: "no dropouts for any parameter" (email bias survey, see notes) \\
(attrition bias)
\end{tabular}

(attrition bias)

All outcomes

\begin{tabular}{lll}
\hline $\begin{array}{l}\text { Selective reporting (re- } \\
\text { porting bias) }\end{array}$ & Low risk & Quote: "no" (email bias survey, see notes) \\
& Comment: awareness outcome part of inclusion criteria \\
\hline Other bias & Low risk & Quote: "I can not remember any bias." (email bias survey, see notes) \\
\hline
\end{tabular}

Lehmann 1992

\begin{tabular}{ll}
\hline Methods & $\begin{array}{l}\text { Study design: randomized parallel groups } \\
\text { Study dates: Quote: "1991" (email bias survey, see notes) }\end{array}$ \\
\hline Participants & Country: Germany \\
Sex: female & Age: 27 to 66 \\
& ASA: I and II \\
& Procedure: elective gynaecologic surgeries \\
& Study size: 60 \\
Randomized portion of anaesthetic: parts of IV vs parts of volatile light: balanced anaesthesia I IV \\
induction narcotics vs dissociate agent \\
Intervention $1:$ induction: fentanyl $(5 \mu \mathrm{kg}) ;$ maintenance: $2 \mu \mathrm{mg} / \mathrm{kg} / \mathrm{h}(\mathrm{N}=20)-$ control \\
Intervention $2:$ induction: pentazocine $(2 \mathrm{mg} / \mathrm{kg}) ;$ maintenance: $0.8 \mathrm{mg} / \mathrm{kg} / \mathrm{h}(\mathrm{N}=19)$ \\
Intervention 3: induction: ketamine $(2 \mathrm{mg} / \mathrm{kg}) ;$ maintenance: $0.8 \mathrm{mg} / \mathrm{kg} / \mathrm{h}(\mathrm{N}=20)$
\end{tabular}

Outcomes

Primary outcomes: vegetative parameters relative cumulative enflurane times ( $F, P, K)$, frequency enflurane given as PRN dose, MAP, HR, postoperative recovery time and pain scales, retrospective anaesthesiologist's judgement of the quality of anaesthesia

Secondary outcome: incidence of dreams and recollection of music

Awareness/wakefulness as defined using an awareness classification system (see Table 1): class 4

Comment: see Dryad topic dreams precede awareness, definitions of awareness and memory

Notes

Randomized portion of anaesthetic: parts of IV vs parts of volatile light: balanced anaesthesia I $\left(\mathrm{N}_{2} \mathrm{O}\right.$ yes narcotics + muscle relaxant $+\mathrm{PRN}$ volatile inhalation agent)/muscle relaxant induction yes/maintenance unclear 
Anaesthesia induction: alcuronium $(2 \mathrm{mg}+8 \mathrm{mg})+$ methohexital $(1.5 \mathrm{mg} / \mathrm{kg})+$ succinylcholine $(1 \mathrm{mg} /$ $\mathrm{kg}$ ) + bolus of randomized narcotic (fentanyl or pentazocine)/anaesthetic (ketamine) bolus and infusion; maintenance: $\mathrm{N}_{2} \mathrm{O}: \mathrm{O}_{2} 75: 25$ + inadequate anaesthesia: enflurane $(0.5 \%$ to $2 \%$ vol) for short periods if insufficient anaesthesia indicated; muscle relaxant reversed: neostigmine/atropine

Comment: see Dryad definition: balanced anaesthesia see Appendix 8, definitions of negative dreams, wakefulness, recall of music or words

Interviewed after extubation and POD 1

Lore Schultheiss was translator

Survey response: 4 March 2011, Klaus A klaus.@uni-koeln.de

\section{Risk of bias}

\begin{tabular}{lll}
\hline Bias & Authors' judgement & Support for judgement \\
\hline $\begin{array}{ll}\text { Random sequence genera- } \\
\text { tion (selection bias) }\end{array}$ & Low risk & Quote: "....randomised double blind study to evaluate...." \\
& $\begin{array}{l}\text { Quote: "same design and evaluation as in previous message, concerning } \\
\text { PubMed PMID: } 3883843 \text { but no help from industry (which means, we prepared } \\
\text { all the solutions our self according to a self generated computer randomisa- } \\
\text { tion list; the syringes with either fentanyl, pentazocine or ketamine were given } \\
\text { to the anaesthesiologist by a colleague not involved in performing or evaluat- } \\
\text { ing the study)" (email bias survey, see notes) }\end{array}$
\end{tabular}

$\begin{array}{ll}\begin{array}{l}\text { Allocation concealment } \\ \text { (selection bias) }\end{array} & \text { Quote: "see PubMed PMID: } 3883843 \text { 'coded ampoules according to randomisa- } \\ & \text { tion plan, provided by Gruenenthal; randomised music presentation accord- } \\ \text { ing to an own computer generated randomisation list'" (email bias survey, see } \\ \text { notes) }\end{array}$

Blinding of participants Low risk and personnel (perforComment: yes blind data collection: research nurse administered the randommance bias)

All outcomes

\begin{tabular}{|c|c|c|}
\hline $\begin{array}{l}\text { Blinding of outcome as- } \\
\text { sessment (detection bias) }\end{array}$ & Low risk & $\begin{array}{l}\text { Quote: "Patient, Anaesthesiologist, Awareness outcome assessor (interview- } \\
\text { er)" (email bias survey, see notes) }\end{array}$ \\
\hline
\end{tabular}

All outcomes

Incomplete outcome data Low risk Comment: no dropouts

(attrition bias)

All outcomes

Selective reporting (re- Low risk $\quad$ Quote: "no" (email bias survey, see notes)
porting bias)

\begin{tabular}{ll}
\hline Other bias $\quad$ Low risk $\quad$ Quote: "I cannot remember any bias" (email bias survey, see notes) \\
\hline
\end{tabular}

\section{Lehmann 2007}

\begin{tabular}{ll}
\hline Methods & Study design: randomized parallel groups \\
Study dates: "2004" (email bias survey, see notes)
\end{tabular}

Participants Country: Germany


Lehmann 2007 (Continued)

Sex: both

Age: 65

Procedure: coronary artery bypass grafting

Study size: 66

\begin{tabular}{ll}
\hline Interventions & Randomized portion of anaesthetic: ADM vs SCP \\
& Intervention 1: BIS 50 ( 45 to 55$) \mathrm{N}=33$ \\
& Intervention 2: BIS 40 (35 to 45$) \mathrm{N}=33$ \\
& Simultaneously, state entropy and response entropy were recorded \\
\hline Outcomes & Primary outcomes: Quote: "designed and powered to compare differences in the values of BIS and \\
spectral entropy" \\
Secondary outcome: awareness/wakefulness as defined using an awareness classification system (see \\
Table 1): class 1 \\
Comment: no recall
\end{tabular}

\section{Notes}

\section{Non-randomized portion of anaesthetic: parts of IV $\mathrm{N}_{2} \mathrm{O}$ no/narcotics/hypnotics bolus $\mathrm{MCl} / \mathrm{muscle}$} relaxant induction yes/maintenance yes ADM entropy measured

BIS 50 group induction: midazolam $(0.07 \mathrm{mg} / \mathrm{kg})+$ sufentanil $(1 \mu \mathrm{g} / \mathrm{kg})+$ pancuronium $(0.1 \mathrm{mg} / \mathrm{kg})$; maintenance: sufentanil $1.5 \mu \mathrm{g}$ to $2 \mu \mathrm{g} / \mathrm{kg} / \mathrm{h}+$ midazolam $0.03 \mathrm{mg}$ to $0.07 \mathrm{mg} / \mathrm{kg}$ and sufentanil $0.5 \mu \mathrm{g}$ to $1 \mu \mathrm{g} / \mathrm{kg}$ as needed

BIS 40 group induction: midazolam $(0.1 \mathrm{mg} / \mathrm{kg})+\operatorname{sufentanil}(1.5 \mu \mathrm{g} / \mathrm{kg})+$ pancuronium $(0.1 \mathrm{mg} / \mathrm{kg})$ : maintenance: sufentanil $0.5 \mu \mathrm{g}$ to $1.5 \mu \mathrm{g} / \mathrm{kg} / \mathrm{h}+$ midazolam $0.05 \mu \mathrm{g}$ to $0.1 \mu \mathrm{g} / \mathrm{kg}$ and sufentanil $1 \mu \mathrm{g}$ to 2 $\mu \mathrm{g} / \mathrm{kg}$ as needed

Anaesthesia maintenance: $\mathrm{O}_{2}$ in air $50 \%+$ pancuronium $0.03 \mathrm{mc} / \mathrm{kg}$ as needed

The spectral entropy parameters RE and SE were measured

Comment: see Dryad topic reduction in inotropic support

Time of outcome determination: third day after surgery

Method of outcome determination: interview

Survey response: 18 January 2011, andreasa@klilu.de

\section{Risk of bias}

\begin{tabular}{lll}
\hline Bias & Authors' judgement & Support for judgement \\
\hline $\begin{array}{l}\text { Random sequence genera- } \\
\text { tion (selection bias) }\end{array}$ & Low risk & Quote: "flipping coin" (email bias survey, see notes) \\
\hline $\begin{array}{l}\text { Allocation concealment } \\
\text { (selection bias) }\end{array}$ & High risk & Quote: "No concealment" (email bias survey, see notes) \\
& $\begin{array}{l}\text { Comment: the randomization is to an open BIS endpoint of } 40 \text { and } 50 \text { and } \\
\text { anaesthesia is targeted to a specific BIS endpoint value of } 40 \text { or } 50 . \text { As in other } \\
\text { RCTs merged into a meta-analysis in this review, there would be no downgrade } \\
\text { for this method of allocation in determining the quality of evidence. }\end{array}$ \\
\hline
\end{tabular}


Lehmann 2007 (Continued)

Blinding of participants High risk Quote: "Patient" (email bias survey, see notes) and personnel (performance bias)

All outcomes

\section{Blinding of outcome as-} sessment (detection bias)

All outcomes

All outcomes

\begin{tabular}{|c|c|c|}
\hline $\begin{array}{l}\text { Selective reporting (re- } \\
\text { porting bias) }\end{array}$ & Low risk & $\begin{array}{l}\text { Quote: "Study protocol is available; primary and secondary outcomes have } \\
\text { been reported. Study was not designed to detect awareness" (email bias sur- } \\
\text { vey, see notes) }\end{array}$ \\
\hline & & $\begin{array}{l}\text { Quote: "Hemodynamics, mixed venous oxygen saturation were recorded but } \\
\text { not reported" (email bias survey, see notes) }\end{array}$ \\
\hline Other bias & Low risk & $\begin{array}{l}\text { Quote: "BIS and entropy values were manually recorded" (email bias survey, } \\
\text { see notes) }\end{array}$ \\
\hline
\end{tabular}

$\operatorname{Lim} 1992$

\begin{tabular}{ll}
\hline Methods & $\begin{array}{l}\text { Study design: randomized parallel groups } \\
\text { Study dates: not stated }\end{array}$ \\
\hline Participants & Country: Singapore \\
& Sex: both \\
Age: 18 \\
ASA: I and II \\
Procedure: removal of impacted or buried teeth \\
Study size: 50
\end{tabular}

\section{Interventions Randomized portion of anaesthetic: parts of TIVA vs parts of volatile agent}

Intervention 1: induction: (TIVA) propofol $(2 \mathrm{mg} / \mathrm{kg}$ ) at $40 \mathrm{mg} / 10 \mathrm{sec}$ maintenance: propofol infusion reduced to $6 \mathrm{mg} / \mathrm{kg} / \mathrm{h}$ by reducing flow manually $2 \mathrm{mg} / \mathrm{kg} / \mathrm{h}$ every 10 minutes + propofol bolus $(0.5 \mathrm{mg} /$ $\mathrm{kg}$ ) no narcotics as needed oxygen/air, $\mathrm{N}=25$

Intervention 2: induction: (thiopentone/isoflurane/ $\left.\mathbf{N}_{\mathbf{2}} \mathbf{O}\right)$, thiopentone $(4 \mathrm{mg} / \mathrm{kg})$; maintenance: $66 \%$ $\mathrm{N}_{\mathbf{2}} \mathrm{O}$ in oxygen $+0.5 \%$ isoflurane, $\mathrm{N}=25$

\begin{tabular}{ll}
\hline Outcomes & Primary outcomes: recovery characteristics \\
& Secondary outcome: awareness/wakefulness as defined using an awareness classification system (see \\
Table 1$)$ : class 1 & \\
Comment: no awareness reported & $\begin{array}{l}\text { Non-randomized portion of anaesthetic: parts of TIVA vs parts of volatile agent } \mathbf{N}_{\mathbf{2}} \mathrm{O} \text { yes } / \text { nar- } \\
\text { cotics/hypnotics bolus } \mathbf{M C l} / \mathbf{m u s c l e} \text { relaxant induction yes } / \mathbf{m a i n t e n a n c e ~ u n c l e a r} \\
\text { Induction: suxamethonium }(1.0 \mathrm{mg} \text { to } 1.5 \mathrm{mg} / \mathrm{kg})+\text { atracurium }(0.5 \mathrm{mg} / \mathrm{kg})+\text { supplementary dose }(0.1 \\
\mathrm{mg} / \mathrm{kg})\end{array}$
\end{tabular}


Lim 1992 (Continued)

$$
\begin{aligned}
& \text { Air/oxygen with TIVA and } \mathrm{N}_{2} \mathrm{O} \text { with isoflurane } \\
& \text { Method of outcome determination: interview } \\
& \text { Bias survey sent to author }
\end{aligned}
$$

\begin{tabular}{|c|c|c|}
\hline Bias & Authors' judgement & Support for judgement \\
\hline $\begin{array}{l}\text { Random sequence genera- } \\
\text { tion (selection bias) }\end{array}$ & Unclear risk & $\begin{array}{l}\text { Quote: "scheduled for surgical removal of impacted or buried teeth were ran- } \\
\text { domly allocated to receive either TIVA using propofol" }\end{array}$ \\
\hline $\begin{array}{l}\text { Allocation concealment } \\
\text { (selection bias) }\end{array}$ & Unclear risk & Comment: no information provided \\
\hline $\begin{array}{l}\text { Blinding of participants } \\
\text { and personnel (perfor- } \\
\text { mance bias) } \\
\text { All outcomes }\end{array}$ & Unclear risk & Comment: anaesthesiologist: no information provided \\
\hline $\begin{array}{l}\text { Blinding of outcome as- } \\
\text { sessment (detection bias) } \\
\text { All outcomes }\end{array}$ & Unclear risk & $\begin{array}{l}\text { Quote: "The patients were interviewed by an anaesthetic trainee for complica- } \\
\text { tions of anaesthesia ..." }\end{array}$ \\
\hline $\begin{array}{l}\text { Incomplete outcome data } \\
\text { (attrition bias) } \\
\text { All outcomes }\end{array}$ & Low risk & Comment: no missing outcome data \\
\hline $\begin{array}{l}\text { Selective reporting (re- } \\
\text { porting bias) }\end{array}$ & Low risk & Comment: awareness outcome part of inclusion criteria \\
\hline Other bias & Unclear risk & Comment: insufficient information provided \\
\hline
\end{tabular}

\section{Risk of bias}

Lin 2011

\begin{tabular}{ll}
\hline Methods & Study design: randomized parallel groups \\
& Study dates: not stated \\
\hline Participants & Country: Taiwan \\
& Sex: female and male \\
Age: mean $56 \pm 15$ & ASA: I-II \\
Procedure: orthopaedic surgery: total hip replacement $(T H R)(N=20)$, the Girdlestone procedure $(N=$ \\
2), revision of a THR ( $N=6)$, revision of a total knee replacement $(N=1)$, or knee arthroscopy $(\mathrm{N}=1)$ \\
Study size: 30 enrolled and completed study
\end{tabular}

Interventions

\section{Randomized portion of anaesthetic: volatile agent types}

Intervention 1: induction: sevoflurane group inhaled $6 \%$ sevoflurane and $4 \mathrm{~L} / \mathrm{min} \mathrm{O}_{2}$ for 3 minutes before intubation, $\mathrm{N}=15$ 
Lin 2011 (Continued)

Intervention 2: induction: non-sevoflurane group was given $\mathbf{4} \mathbf{L} / \mathbf{m i n} \mathbf{O}_{\mathbf{2}}$ alone with IV induction, $\mathrm{N}=$ 15

AAl used in both groups

Primary outcomes: differences in BP, HR, and AAI during intubation between groups
Secondary outcome: awareness/wakefulness as defined using an awareness classification system (see
Table 1): class 1
Comment: no awareness events reported

Notes

Non-randomized portion of anaesthetic: parts of volatile agent: $\mathrm{N}_{2} \mathrm{O}$ no/narcotics/hypnotics bolus $\mathrm{MCI} /$ muscle relaxant induction yes/maintenance unclear/ADM AAI recorded

Both groups: induction: $3 \mu \mathrm{g} / \mathrm{kg}$ fentanyl, $4 \mathrm{mg} / \mathrm{kg}$ thiamylal, and $0.2 \mathrm{mg} / \mathrm{kg}$ cis-atracurium and maintenance: $2.5 \%$ sevoflurane and $4 \mathrm{~L} \mathrm{O}_{2}$

ROB survey.Email: yangcy@adm.cgmh.org.tw, mazuifeng@adm.cgmh.org.tw 7 January 2014

\section{Risk of bias}

\begin{tabular}{lll}
\hline Bias & Authors' judgement & Support for judgement \\
\hline $\begin{array}{l}\text { Random sequence genera- } \\
\text { tion (selection bias) }\end{array}$ & Unclear risk & $\begin{array}{l}\text { Quote: "Subjects were assigned to either the sevoflurane or non-sevoflurane } \\
\text { group, according to designations randomly selected by the researcher from } \\
\text { a pool that contained } 15 \text { assignments to the sevoflurane group and } 15 \text { to the } \\
\text { non-sevoflurane group..." }\end{array}$ \\
\hline
\end{tabular}

\begin{tabular}{lll}
\hline $\begin{array}{l}\text { Allocation concealment } \\
\text { (selection bias) }\end{array}$ & Unclear risk & Comment: inadequate information \\
\hline $\begin{array}{l}\text { Blinding of participants } \\
\text { and personnel (perfor- } \\
\text { mance bias) }\end{array}$ & Unclear risk & $\begin{array}{l}\text { Quote: "All study procedures were prepared and performed by an anaesthesi- } \\
\text { ologist and an anaesthetic nurse. The same doctor administered anaesthesia } \\
\text { for all surgical procedures. The other researcher was responsible for recording } \\
\text { the study results for each patient and monitoring vital signs" }\end{array}$ \\
\hline
\end{tabular}

\begin{tabular}{|c|c|c|}
\hline $\begin{array}{l}\text { Blinding of outcome as- } \\
\text { sessment (detection bias) } \\
\text { All outcomes }\end{array}$ & Unclear risk & $\begin{array}{l}\text { Quote: "they were interviewed to determine their state of awareness during } \\
\text { the intubation and operative procedures. No patients in either group were } \\
\text { aware of these } \\
\text { events" }\end{array}$ \\
\hline
\end{tabular}

Incomplete outcome data Low risk Comment: no missing data
(attrition bias)

All outcomes

\begin{tabular}{lll}
\hline $\begin{array}{l}\text { Selective reporting (re- } \\
\text { porting bias) }\end{array}$ & Low risk & Comment: awareness outcome part of inclusion criteria \\
\hline Other bias & Unclear risk & Comment: inadequate information \\
\hline
\end{tabular}

Lindholm 2008

\begin{tabular}{ll}
\hline Methods & $\begin{array}{l}\text { Study design: randomized parallel groups } \\
\text { Study dates: Quote: "030423-041126" (email bias survey, see notes) }\end{array}$ \\
\hline Participants & Country: Sweden
\end{tabular}


Lindholm 2008 (Continued)

Sex: both

Age: 50

ASA: I-III

Procedure: non-cardiac surgery

Study size: 320

\section{Interventions $\quad$ Randomized portion of anaesthetic: ADM vs SCP BIS 40 to 60}

Intervention 1: SCP blinded to BIS, N = 110

Intervention 2: open to BIS $\mathbf{4 0}$ to $\mathbf{6 0}, \mathrm{N}=110$

Induction: automatic closed-loop titration of propofol (closed loop group, $\mathrm{N}=20$ )

Manually target controlled infusion of propofol (target control infusion ( $\mathbf{T C I}$ ) group, $\mathrm{N}=20$ )

Outcomes Primary outcomes: BIS levels, anaesthetic gas consumption, fentanyl use, and subjective opinions on utility and reliability

Secondary outcome: awareness/wakefulness as defined using an awareness classification system (see Table 1): class 1

Comment no explicit recall

Notes

\section{Non-randomized portion of anaesthetic: parts of volatile agent: $\mathrm{N}_{\mathbf{2}} \mathrm{O}$ yes/narcotics/hypnotics bo- lus $\mathrm{MCl} \mathrm{TCl} /$ muscle relaxant induction yes/maintenance yes}

Anaesthesia induction: thiopental or propofol; anaesthesia maintenance: fentanyl + sevoflurane in $\mathrm{N}_{2} \mathrm{O}$; relaxant anaesthesia; for both groups, remifentanil was administered by a $\mathbf{T C l}$ target $2 \mathrm{ng} / \mathrm{mL}$ as propofol infusion $1.5 \mathrm{\mu g} / \mathrm{L}$ anxiolysis

Comment: see Dryad topic learning bias

Survey response: 14 February 2011, Maj-Lis Lindholm MajLisL@LTKalmar.se

Clarification missing data email sent 27 December 2013

\section{Risk of bias}

\begin{tabular}{|c|c|c|}
\hline Bias & Authors' judgement & Support for judgement \\
\hline \multirow[t]{4}{*}{$\begin{array}{l}\text { Random sequence genera- } \\
\text { tion (selection bias) }\end{array}$} & Low risk & $\begin{array}{l}\text { Quote: "A closed envelope was drawn for each study patient, containing a note } \\
\text { saying "open" which meant access to the BIS-monitoring, or "closed" meaning } \\
\text { that the monitor should be covered." (email bias survey, see notes) }\end{array}$ \\
\hline & & $\begin{array}{l}\text { Quote: "It is impossible to blind anyone to the fact that the BIS data is avail- } \\
\text { able or not." (email bias survey, see notes) }\end{array}$ \\
\hline & & $\begin{array}{l}\text { Quote: "The sequence of treatments was determined in blocks of } 10 \text { (five man- } \\
\text { ual TCl and five closed-loop group) using a random number generator..." }\end{array}$ \\
\hline & & $\begin{array}{l}\text { Comment: induction regimen is low-risk randomization protocol; technically, } \\
\text { the RCT is designed primarily to track the impact of learning with BIS open and } \\
\text { closed }\end{array}$ \\
\hline
\end{tabular}

Allocation concealment High risk

(selection bias)
Quote: "In the first part of the study, the ten first patients for each nurse were anaesthetized without available BIS..." (email bias survey, see notes) 
Lindholm 2008 (Continued)

Comment: Cochrane policy requires downgrade to high risk despite the evidence provided in this RCT that thelearning bias is not always related to nonblinded anaesthesiologists and despite author's statement above

\begin{tabular}{|c|c|c|}
\hline $\begin{array}{l}\text { Blinding of participants } \\
\text { and personnel (perfor- }\end{array}$ & High risk & $\begin{array}{l}\text { Quote: "It is impossible to blind anyone to the fact that the BIS data is avail- } \\
\text { able or not." (email bias survey, see notes) }\end{array}$ \\
\hline
\end{tabular}
mance bias)

All outcomes

Blinding of outcome as- Unclear risk Comment: no information

sessment (detection bias)

All outcomes

Incomplete outcome data Low risk

(attrition bias)

All outcomes

Quote: "One patient was not possible to reach because he hade no telephone.....The only exclusions made were done after the case was completed, and if so, only because of technical failure..." (email bias survey, see notes)

Comment: 1 patient could not be reached for interview to assess awareness $1 / 320=0.3 \%$ dropout frequency

Comment: for awareness outcome, although this lack of follow-up could be for non-relevant reasons, this could possibly be a high-risk awareness case avoiding interaction with medical staff. The patient had no phone. There was no difference between both groups with 1 dropout.

\begin{tabular}{|c|c|c|}
\hline $\begin{array}{l}\text { Selective reporting (re- } \\
\text { porting bias) }\end{array}$ & Low risk & $\begin{array}{l}\text { Quote: "The study protocol is available and was followed." "No we did not" (e- } \\
\text { mail bias survey, see notes) }\end{array}$ \\
\hline & & Comment: awareness outcome part of inclusion criteria \\
\hline Other bias & Low risk & $\begin{array}{l}\text { Quote: "We can not see any obvious bias in the study" (email bias survey, see } \\
\text { notes) }\end{array}$ \\
\hline
\end{tabular}

Liu 2013

$\begin{array}{ll}\text { Methods } & \text { Study design: randomized parallel groups } \\ \text { Study dates: NA }\end{array}$

\begin{tabular}{ll}
\hline Participants & Country: USA/France \\
Sex: $M / F$ \\
Age: 49 to 73 range \\
ASA: I-IV \\
Procedure: rigid bronchoscopic procedures \\
Study size: 70 enrolled; 67 completed study
\end{tabular}

\section{Interventions Randomized portion of anaesthetic: parts of TIVA: MCI vs BIS dual loop: induction/maintenance \\ Intervention 1: ( $\mathrm{N}=34)$ manual target-controlled infusion of propofol and remifentanil (manual TCI group) BIS 40 to 60}

Intervention 2: ( $\mathrm{N}=33$ ) dual-loop group with automatic titration guided by the BIS (dual-loop group) 40 to 60

\section{Outcomes}

Primary outcomes: Quote: "The primary outcome was the time spent with adequate anaesthesia, defined by a BIS value of $40-60$, expressed as a percentage of time during the maintenance period"

Secondary outcomes: awareness/wakefulness as defined using an awareness classification system (see Table 1): class 1 
Liu 2013 (Continued)

"No case of intraoperative awareness was detected"

Notes

Non-randomized portion of anaesthetic: part TIVA: $\mathrm{N}_{2} \mathrm{O}$ no/narcotics/hypnotics bolus/muscle relaxant induction yes/maintenance yes

Comment: indications for muscle relaxants in bronchoscopy

M. Fischler MD email: m.fischler@hopital-foch.org

ROB survey: we emailed m.fischler@hopital-foch.org on 22 March 2015

\section{Risk of bias}

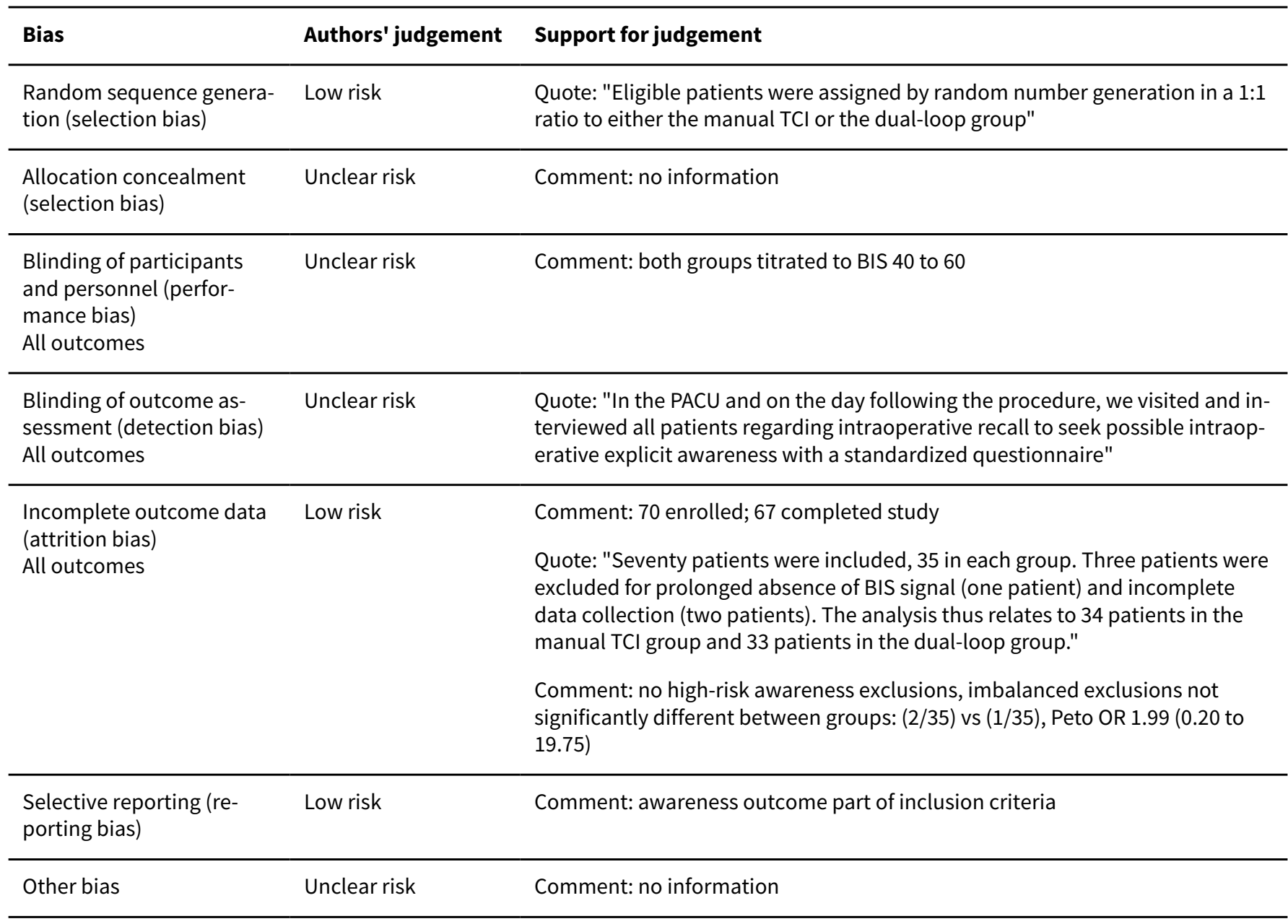

Lu 2005

\begin{tabular}{ll}
\hline Methods & Study design: randomized parallel groups \\
& Study dates: not given \\
\hline Participants & Country: France \\
& Sex: both \\
Age: 58,59 & ASA: I-III \\
\hline
\end{tabular}


Lu 2005 (Continued)

Procedure: elective minor or major surgery

Study size: 164

\begin{tabular}{|c|c|}
\hline Interventions & $\begin{array}{l}\text { Randomized portion of anaesthetic: regional anaesthesia: epidural: induction } \\
\text { Intervention 1: Group GE: induction: } 15 \mathrm{~mL} \text { of } 2 \% \text { lidocaine epidurally, } \mathrm{N}=82 \\
\text { Intervention 2: Group GS: induction: saline epidural, } \mathrm{N}=82\end{array}$ \\
\hline Outcomes & $\begin{array}{l}\text { Primary outcomes: differences in the desflurane concentration between groups } \\
\text { Secondary outcome: awareness/wakefulness as defined using an awareness classification system (see } \\
\text { Table 1): class } 1 \\
\text { Comment: no patient-reported intraoperative awareness }\end{array}$ \\
\hline Notes & $\begin{array}{l}\text { Non-randomized portion of anaesthetic: parts of volatile agent } \mathbf{N}_{\mathbf{2}} \mathbf{O} \text { no + supplemental narcotics } \\
\text { (balanced anaesthesia)/muscle relaxants induction yes/maintenance unclear/PRN ADM AAI } 20 \pm \mathbf{5} \\
\text { Anaesthesia induction: thiopental ( } 5 \mathrm{mg} / \mathrm{kg})+ \text { rocuronium }(0.6 \mathrm{mg} / \mathrm{kg}) \\
\text { Anaesthesia maintenance: desflurane titrated in } 100 \% \text { oxygen with target AAI } \mathbf{2 0 \pm 5} \\
\text { Time of outcome determination: in recovery room and before discharge } \\
\text { Method of outcome determination: interview } \\
\text { Survey response: } 26 \text { January } 2011 \text {, Chih-Shung Wongw82556@gmail.com }\end{array}$ \\
\hline
\end{tabular}

Risk of bias

\begin{tabular}{lll}
\hline Bias & Authors' judgement & Support for judgement \\
\hline $\begin{array}{l}\text { Random sequence genera- } \\
\text { tion (selection bias) }\end{array}$ & Low risk & Comment: randomly allocated, by selection of sealed envelopes \\
& $\begin{array}{l}\text { Quote: "Patient assignments were generated using a computer random num- } \\
\text { ber generator and stored in sealed envelopes before initiation of the study pro- } \\
\text { tocol." (email bias survey, see notes) }\end{array}$ \\
\hline
\end{tabular}

Allocation concealment Low risk Comment: sealed envelopes

(selection bias)

Quote: "The pharmacy department independently prepared sterile syringes of either epidural lidocaine or epidural saline with assigned random numbers. The envelopes were opened immediately after induction of anaesthesia." (email bias survey, see notes)

Comment: Cochrane policy emphasizes the need for opaque, sealed envelopes; we graded it low risk because even if the investigators could see through the envelope they could not know in advance the association of a random number and the drug, which could not be differentiated between placebo and lidocaine

\begin{tabular}{|c|c|c|}
\hline Blinding of participants & Low risk & $\begin{array}{l}\text { Quote: "Patient, Anaesthesiologist, Awareness outcome assessor (interview- } \\
\text { er)." (email bias survey, see notes) }\end{array}$ \\
\hline All outcomes & & $\begin{array}{l}\text { Quote: "The anaesthesiologist in charge of the anaesthesia was not aware of } \\
\text { the epidural study drug or who controlled the desflurane titration during the } \\
\text { whole procedure. The epidural solutions were prepared and injected by a dif- } \\
\text { ferent anaesthesiologist who did not participate in the anaesthesia care or } \\
\text { evaluation of the patients" }\end{array}$ \\
\hline
\end{tabular}


Lu 2005 (Continued)

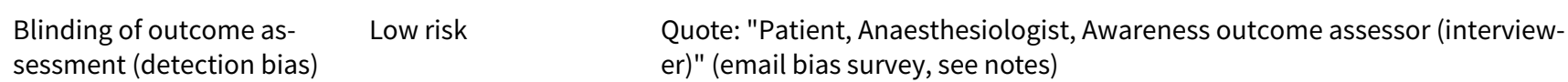
All outcomes

\begin{tabular}{|c|c|c|}
\hline $\begin{array}{l}\text { Incomplete outcome data } \\
\text { (attrition bias) } \\
\text { All outcomes }\end{array}$ & Low risk & $\begin{array}{l}\text { Quote: "All patients of both groups completed the study protocol" (email bias } \\
\text { survey, see notes) }\end{array}$ \\
\hline $\begin{array}{l}\text { Selective reporting (re- } \\
\text { porting bias) }\end{array}$ & Low risk & $\begin{array}{l}\text { Quote: "The study protocol was clear. No other non-significant results was } \\
\text { available" (email bias survey, see notes) }\end{array}$ \\
\hline Other bias & Low risk & $\begin{array}{l}\text { Quote: "Although the anaesthesiologist in charge of the anaesthesia was not } \\
\text { aware of the epidural study drugs, he also could predict it with the changes of } \\
\text { vital signs and the desflurane titration" (email bias survey, see notes) }\end{array}$ \\
\hline
\end{tabular}

Maattanen 2002

\begin{tabular}{ll}
\hline Methods & Study design: randomized parallel groups \\
& Study dates: not stated \\
\hline Participants & Country: Sweden \\
Age: 44 and $49 \pm 13$ and 10 \\
ASA: I-II \\
Procedure: elective open spine surgery \\
Study size: 30
\end{tabular}

Interventions

\section{Randomized portion of anaesthetic: ADM vs SCP}

Intervention 1: Group I ( $\mathrm{N}=15)$, maintenance: desflurane and $50 \% \mathrm{~N}_{2} \mathrm{O}$, was titrated with a target AAIindex of $\mathbf{2 0} \pm \mathbf{5}$

Intervention 2: Group II (N = 15), maintenance: desflurane and 50\% $\mathrm{N}_{2} \mathrm{O}$, titrated according to routine clinical signs (SCP): heart rate, blood pressure, sweating and tears. No pre-defined fixed MAC-multiple was administered

Outcomes

Primary outcomes: anaesthetic consumption determination (desflurane vaporiser was filled and weighed and re-weighed at end)

Secondary outcome: awareness/wakefulness as defined using an awareness classification system (see Table 1): class 1

Quote: "no patients showed signs of awareness or had any recall postoperatively"

\begin{tabular}{|c|c|}
\hline Notes & $\begin{array}{l}\text { Non-randomized portion of anaesthetic: parts of inhalation or volatile agent } / \mathrm{N}_{2} \mathrm{O} \text { yes }+ \text { sup- } \\
\text { plemental narcotics (balanced anaesthesia)/muscle relaxant induction yes/maintenance un- } \\
\text { clear/random ADM (AAI: 20) vs SCP AAI-index of } 20 \pm 5\end{array}$ \\
\hline
\end{tabular}

ADM (AAI: 20) vs SCP: inhalational: desflurane $/ \mathrm{N}_{2} \mathrm{O}$

Premed betamethasone $8 \mathrm{mg}$ IV, induction: propofol as needed, fentanyl $0.5 \mathrm{mg}$ and vecuronium/intubation, controlled ventilation, fentanyl $50 \mu \mathrm{g}$ PRN and then $2 \%$ desflurane if needed 
Maattanen 2002 (Continued)

Fentanyl 50mg PRN both groups if need haemodynamic control after sequential $2 \%$ increase in desflurane....No other drugs were given during the desflurane anaesthesia

Comment see Dryad topic definition Evan's score and AAI targets with and without muscle relaxants

ROB survey emailed 03 January 2014 jan.jacobsson@mm-medical.se; delivery failed

\section{Risk of bias}

\begin{tabular}{|c|c|c|}
\hline Bias & Authors' judgement & Support for judgement \\
\hline $\begin{array}{l}\text { Random sequence genera- } \\
\text { tion (selection bias) }\end{array}$ & Unclear risk & Quote: "Patients were randomised by the envelope technique" \\
\hline $\begin{array}{l}\text { Allocation concealment } \\
\text { (selection bias) }\end{array}$ & Unclear risk & Comment: see above \\
\hline $\begin{array}{l}\text { Blinding of participants } \\
\text { and personnel (perfor- } \\
\text { mance bias) } \\
\text { All outcomes }\end{array}$ & High risk & $\begin{array}{l}\text { Quote: "The same anaesthetist }(\mathrm{JJ}) \text {, with } 1 \text { year's experience with the A-line } \\
\text { monitor, performed all anaesthesia's and, by the nature of the study, was non- } \\
\text { blinded. The postoperative nursing staff was blinded" }\end{array}$ \\
\hline $\begin{array}{l}\text { Blinding of outcome as- } \\
\text { sessment (detection bias) } \\
\text { All outcomes }\end{array}$ & Low risk & $\begin{array}{l}\text { Quote: "grading by nurses otherwise not involved in the study...interviewed in } \\
\text { the recovery room...explicit memories from surgery or anaesthesia" }\end{array}$ \\
\hline $\begin{array}{l}\text { Incomplete outcome data } \\
\text { (attrition bias) } \\
\text { All outcomes }\end{array}$ & Low risk & Comment: no missing data \\
\hline $\begin{array}{l}\text { Selective reporting (re- } \\
\text { porting bias) }\end{array}$ & Low risk & Comment: awareness outcome part of inclusion criteria \\
\hline Other bias & Unclear risk & Comment: inadequate information provided \\
\hline
\end{tabular}

\section{Mashour 2012}

\begin{tabular}{|c|c|}
\hline Methods & $\begin{array}{l}\text { Study design: randomized parallel groups } \\
\text { Study dates: May } 2008 \text { until May } 2010\end{array}$ \\
\hline \multirow[t]{6}{*}{ Participants } & Country: USA \\
\hline & Sex: both \\
\hline & Age: $>18$ years \\
\hline & ASA: I-IV \\
\hline & Procedure: all surgical cases \\
\hline & Study size: enrolled 21,601 completed study 18,836 \\
\hline \multirow[t]{2}{*}{ Interventions } & $\begin{array}{l}\text { Randomized portion of anaesthetic: ADM }(B I S<60) \text { vs SCP (MAC }>0.5 \text { ) parts inhalation (majority } \\
98 \% \text { ), parts TIVA (minority } 2 \% \text { cases) }\end{array}$ \\
\hline & $\begin{array}{l}\text { Alert if the bispectral index value }(B I S)>60 \text { and/or if the age-adjusted minimum alveolar concentration } \\
(\mathrm{MAC})<0.5, \mathrm{BIS} \text { group } N=9460 \text {, anaesthetic concentration (MAC) group } N=9376\end{array}$ \\
\hline
\end{tabular}




Primary outcome: awareness/wakefulness as defined using an awareness classification system (see Ta-
ble 1): class 4
Comment: modified intention-to-treat analysis: definite awareness $11 / 9376$ or $0.12 \%(95 \% \mathrm{Cl} 0.07 \%$ to
$0.21 \%)$
Combined incidence of definite and possible awareness cases:
$0.08 \%$ BIS monitoring
$0.20 \%$ MAC group
$0.38 \%$ no intervention group

Notes Non-randomized portion of anaesthetic: $A D M(B I S<60)$ vs SCP $(M A C>0.5)$ parts inhalation (ma-
jority $98 \%$ ), parts TIVA (minority $2 \%$ cases): $\mathrm{N}_{2} \mathrm{O}$ unclear/narcotics/hypnotics bolus $\mathrm{MCI}$ un-
clear/muscle relaxant induction yes/maintenance unclear/random $(\mathrm{BIS})>60$

The study was terminated because of futility

Discretion of anaesthesiologist

Inhalation technique $98 \%$ and TIVA $2 \%$ of cases

Brice interview: screened one time 28 to 30 days after surgery by telephone or written form of the interview

Comment: see Dryad topic definition Michigan Awareness Classification and other conclusions from RCT; gmashour@med.umich.edu: multiple email communications from 31 January 2013 to 21 February 2015. Topics: ROB survey, clarification of missing data, adjudicated awareness reports

\section{Risk of bias}

Bias Authors' judgement Support for judgement

Random sequence genera- Low risk Quote: "Randomization was performed using a random-number, computtion (selection bias) $\quad$ er-generated block scheme based on even or odd operating room number"

Quote: "A detailed description of the experimental protocol for the Michigan Awareness Control Study (ClinicalTrials.gov No. NCT00689091) has been previously reported (Mashour 2009). The conduct of the study and the reporting of results followed the Consolidated Standards of Reporting Trials guidelines" (Schulz 2010)

\begin{tabular}{lll}
\hline $\begin{array}{l}\text { Allocation concealment } \\
\text { (selection bias) }\end{array}$ & Low risk & Comment: Schulz 2010 \\
\hline $\begin{array}{l}\text { Blinding of participants } \\
\text { and personnel (perfor- } \\
\text { mance bias) } \\
\begin{array}{l}\text { All outcomes } \\
\text { Blinding of outcome as- }\end{array}\end{array}$ & High risk & Comment: SCPs exposed to both groups \\
\hline $\begin{array}{l}\text { sessment (detection bias) } \\
\text { All outcomes }\end{array}$ & & Quote: "Blinded, trained interviewers used the modified Brice interview..." \\
\hline $\begin{array}{l}\text { Incomplete outcome data } \\
\text { (attrition bias) } \\
\text { All outcomes }\end{array}$ & Low risk & \\
\hline
\end{tabular}


Mashour 2012 (Continued)

Selective reporting (re- Low risk $\quad$ Quote author ROB response: "...we reported both significant and non-signifiporting bias) cant findings"

Comment: awareness outcome part of inclusion criteria

Other bias Low risk Quote: as was detailed in the article, the study was terminated due to futility

Masuda 2002

\begin{tabular}{ll}
\hline Methods & Study design: randomized parallel groups \\
Study dates: 1999 to 2000
\end{tabular}

Country: Japan
Sex: both
Age: aged 18 to 65
ASA: I-II (Quote: "were free from hypertension and obesity $(\mathrm{BMI}<28$ ")
Procedure:elective surgery for 2 to $3 \mathrm{~h}$
Study size: 46

Interventions Randomized portion of anaesthetic: ADM BIS (40 to 60) vs SCP

Intervention 1: blinded to BIS (40 to 60 ), $\mathrm{N}=20$

Intervention 2: SCP, $\mathrm{N}=19$

Outcomes

Primary outcomes: propofol infusion rates, total amount of propofol, recovery times for both groups

Secondary outcome: awareness/wakefulness as defined using an awareness classification system (see Table 1): class 1

Quote: in regard to awareness test: "We used a standard questionnaire. We did not find any suspected cases of intraoperative awareness"

\section{Notes Non-randomized portion of anaesthetic: parts of TIVA $\mathrm{N}_{\mathbf{2}} \mathrm{O}$ no induction/muscle relaxant induc- tion/maintenance PRN}

Premed: atropine $(0.01 \mathrm{mg} / \mathrm{kg}$ ) and midazolam $(0.05 \mathrm{mg} / \mathrm{kg}$, max $3 \mathrm{mg})$. Induction: fentanyl ( $1 \mu \mathrm{g}$ to $2 \mu \mathrm{g} / \mathrm{kg}$ ), vecuronium $(0.1 \mathrm{mg} / \mathrm{kg}$ ), propofol ( $1.5 \mathrm{mg}$ to $2 \mathrm{mg} / \mathrm{kg}$ ) fentanyl (at each anaesthesiologist's discretion), vecuronium (added by $1 \mathbf{~ m g}$ to $\mathbf{2} \mathbf{~ m g}$ targeting the TOF count of 1). Maintenance: propofol (decreased from $10 \mathrm{mg}$ to $6 \mathrm{mg} / \mathrm{kg} / \mathrm{h}$ and titrated between $4 \mathrm{mg}$ to $6 \mathrm{mg} / \mathrm{kg} / \mathrm{h}$ targeting the BIS value 40 to 60$)$, balance of anaesthetics that were not randomized

Neither of the induction doses of propofol nor the total doses of fentanyl differed between the BIS and the control groups as indicated in their Table 2. Only the total propofol consumption and the average rate of propofol infusion showed a significant difference as indicated in their Table 3.

Translated by Jiro Kurata MD

Survey response: 1 September 2011, Messina, Kurata, Masuda jkurata@plum.plala.or.jp

\section{Risk of bias}

Bias Authors' judgement Support for judgement


Masuda 2002 (Continued)

Random sequence genera- Unclear risk Quote: "We randomly allocated all the patients that underwent elective tion (selection bias) surgery for 2-3 hours, aged 18-65 years, had the ASA PS of 1-2, and were free from hypertension and obesity $(\mathrm{BMI}<28)$. She did not mention the method of randomizations. They did not find any statistical differences between the BIS and control groups (Table 2)."

Allocation concealment Low risk
(selection bias)

Quote: "The other anaesthesiologists than myself allocated an attending anaesthesiologist to each case. (I did not do such allocation.) Each attending anaesthesiologist was handed a data sheet to fill in during the case without being informed of the purpose of the study. (My residents and I made a preoperative visit to each patient, obtained informed consent, and prepared for BIS monitoring)"

Anaesthesiologists were not informed of either the purpose of the study or the group allocation of their patients

Blinding of participants High risk Comment: See ROB rule
and personnel (perfor-
mance bias)

\begin{tabular}{|c|c|c|}
\hline $\begin{array}{l}\text { Blinding of outcome as- } \\
\text { sessment (detection bias) }\end{array}$ & Low risk & Quote: \\
\hline All outcomes & & $\begin{array}{l}\text { 1) Patients: blinded (they were not able to see the presence or absence of a BIS } \\
\text { monitor) }\end{array}$ \\
\hline
\end{tabular}

2) Attending anaesthesiologists: they were not blinded to the usage of a BIS monitor

3) Interviewers: blinded. They did not manage the cases in the OpR

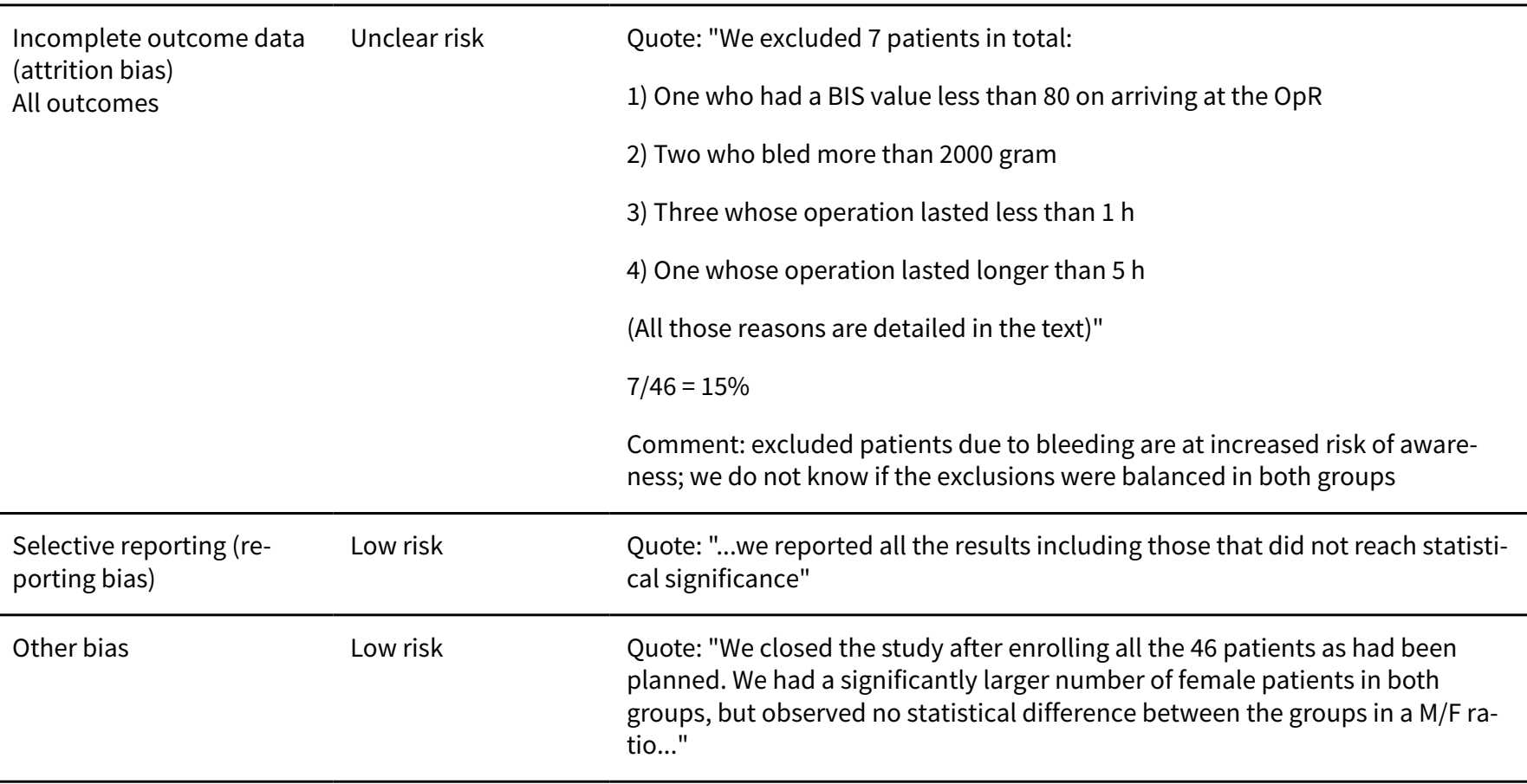

Methods Study design: randomized parallel groups


McNulty 1995 (Continued)

Study dates: not provided

Country: USA
Sex: both
Age: 48 to 78
ASA: III and IV
Procedure: elective coronary artery bypass or valve replacement
Study size: 96

Interventions Randomized portion of anaesthetic: parts of volatile light (volatile PRN dosing): balanced anaesthesia I IV induction benzodiazepines vs placebo

Intervention 1: maintenance (CPB): midazolam low dose $0.05 \mathrm{mg} / \mathrm{kg}, \mathrm{N}=25$

Intervention 2: maintenance (CPB): midazolam high dose $0.1 \mathrm{mg} / \mathrm{kg}, \mathrm{N}=10$

Intervention 3: maintenance (CPB): lorazepam low dose $0.05 \mathrm{mg} / \mathrm{kg}, \mathrm{N}=26$

Intervention 4: maintenance (CPB): lorazepam high dose $0.1 \mathrm{mg} / \mathrm{kg}, \mathrm{N}=10$

Intervention 5: maintenance (CPB): placebo, $\mathrm{N}=25$

Outcomes
Primary outcomes: recovery times
Secondary outcome: awareness/wakefulness as defined using an awareness classification system (see
Table 1): class 4
Quote: "there were three patients in the placebo group who had sensory experiences consistent with
intraoperative awareness. Two of these patients described sensations that were consistent with aware-
ness during CPB (rewarming and cardioversion). The third patient reported awareness during laryn-
goscopy only"
Randomized portion of anaesthetic: parts of volatile light: balanced anaesthesia I ( $\mathbf{N}_{\mathbf{2}} \mathbf{O}$ yes nar-
cotics + muscle relaxant + PRN volatile inhalation agent)/muscle relaxants induction yes/mainte-
nance yes

Premedication: morphine $0.05 \mathrm{mg}$ to $0.10 \mathrm{mg} / \mathrm{kg} \mathrm{IM}+$ scopolamine $0.2 \mathrm{mg}$ to $0.3 \mathrm{mg} \mathrm{IM}+$ diazepam 0.08 $\mathrm{mg}$ to $0.10 \mathrm{mg} / \mathrm{kg}$ OS 90 minutes before induction

Anaesthesia induction: fentanyl $35 \mu \mathrm{g}$ to $50 \mu \mathrm{g} / \mathrm{kg}$ + pancuronium $0.1 \mathrm{mg} / \mathrm{kg}$; anaesthesia maintenance: fentanyl + enflurane PRN to treat HTN up to 5 min prior to CPB and after CPB

Comment: balanced anaesthesia definitions, see Lehmann 1992

Time of outcome determination: no evidence

Method of outcome determination: interview

Bias survey sent but not response received

\section{Risk of bias}

\begin{tabular}{lll}
\hline Bias & Authors' judgement & Support for judgement \\
\hline $\begin{array}{l}\text { Random sequence genera- } \\
\text { tion (selection bias) }\end{array}$ & Unclear risk & $\begin{array}{l}\text { Quote: "The study drugs were randomized and prepared by the pharmacy in } \\
\text { unlabeled syringes" }\end{array}$ \\
\hline
\end{tabular}


McNulty 1995 (Continued)

$\begin{aligned} & \text { Allocation concealment } \\ & \text { (selection bias) }\end{aligned}$
Unclear risk

\begin{tabular}{|c|c|c|}
\hline $\begin{array}{l}\text { Blinding of participants } \\
\text { and personnel (perfor- } \\
\text { mance bias) } \\
\text { All outcomes }\end{array}$ & Low risk & $\begin{array}{l}\text { Comment: syringes were unlabelled } \\
\text { Quote: "All individuals involved in the patient's care were blinded to the identi- } \\
\text { ty of the study drug" }\end{array}$ \\
\hline
\end{tabular}

\begin{tabular}{|c|c|c|}
\hline $\begin{array}{l}\text { Blinding of outcome as- } \\
\text { sessment (detection bias) } \\
\text { All outcomes }\end{array}$ & Unclear risk & Comment: insufficient information provided \\
\hline
\end{tabular}

\begin{tabular}{lll}
\hline $\begin{array}{l}\text { Incomplete outcome data } \\
\text { (attrition bias) } \\
\text { All outcomes }\end{array}$ & Low risk & Comment: no missing outcome data \\
\hline $\begin{array}{l}\text { Selective reporting (re- } \\
\text { porting bias) }\end{array}$ & Low risk & Comment: awareness outcome part of inclusion criteria \\
\hline Other bias & Unclear risk & Comment: insufficient information provided \\
\hline
\end{tabular}

\section{Menigaux 2002}

\begin{tabular}{ll}
\hline Methods & Study design: randomized parallel groups \\
& Study dates: not given \\
\hline Participants & Country: France \\
& Sex: both \\
Age: 18 to 70 & ASA: I-II \\
Procedure: elective non-cranial surgery \\
Study size: 50
\end{tabular}

$\begin{array}{ll}\text { Interventions } & \text { Randomized portion of anaesthetic: cardiac drug vs placebo } \\ \text { Intervention } 1 \text { : induction esmolol } 1 \mathrm{mg} / \mathrm{kg}+250 \mu \mathrm{g} / \mathrm{kg} / \mathrm{min}, \mathrm{N}=25 \\ \text { Intervention 2: saline solution of equal volume, } \mathrm{N}=25\end{array}$

Outcomes Primary outcomes: changes in BIS, heart rate and MAP with orotracheal intubation (DBIS, DHR, and DMAP, respectively)

Secondary outcome: awareness/wakefulness as defined using an awareness classification system (see Table 1): class 1

Quote: "None of the patients reported recall of intraoperative events"

Notes
maintenance unclear/TCI/IFT/ADM: BIS recorded
Anaesthesia induction: propofol was administered via a computer-assisted, $\mathbf{T C I}$, infusion; propofol 4
$\mathrm{mg} / \mathrm{mL}$ (i.e. $2 \mathrm{mg} / \mathrm{kg}$ bolus followed by $225 \mathrm{mg} / \mathrm{kg} / \mathrm{min}$ ) during the entire study period + vecuronium 0.1
$\mathrm{mg} / \mathrm{kg}$


IFT: patient movement to intubation; positive response gross purposeful movement arm with the tourniquet attached within $1 \mathrm{~min}$ intubation; study ended 16 min after starting the propofol

Anaesthesia maintenance: no information

Time of outcome determination: day after operation

Method of outcome determination: interview POD 1

ROB survey. Email: marcel.chauvin@apr.ap-hop-paris.fr. We emailed on 16 April 2015

\section{Risk of bias}

\begin{tabular}{|c|c|c|}
\hline Bias & Authors' judgement & Support for judgement \\
\hline $\begin{array}{l}\text { Random sequence genera- } \\
\text { tion (selection bias) }\end{array}$ & Low risk & Quote: "Group allocations were based on computer-generated codes" \\
\hline $\begin{array}{l}\text { Allocation concealment } \\
\text { (selection bias) }\end{array}$ & Low risk & $\begin{array}{l}\text { Quote: "Patients and personnel involved in patient management and data col- } \\
\text { lection were unaware of the group assignment" }\end{array}$ \\
\hline $\begin{array}{l}\text { Blinding of participants } \\
\text { and personnel (perfor- } \\
\text { mance bias) } \\
\text { All outcomes }\end{array}$ & Low risk & $\begin{array}{l}\text { Quote: "Patients and personnel involved in patient management and data col- } \\
\text { lection were unaware of the group assignment" }\end{array}$ \\
\hline $\begin{array}{l}\text { Blinding of outcome as- } \\
\text { sessment (detection bias) } \\
\text { All outcomes }\end{array}$ & Low risk & $\begin{array}{l}\text { Quote: "Patients and personnel involved in patient management and data col- } \\
\text { lection were unaware of the group assignment" }\end{array}$ \\
\hline $\begin{array}{l}\text { Incomplete outcome data } \\
\text { (attrition bias) } \\
\text { All outcomes }\end{array}$ & Low risk & Comment: no missing outcome data \\
\hline $\begin{array}{l}\text { Selective reporting (re- } \\
\text { porting bias) }\end{array}$ & Low risk & Comment: awareness outcome part of inclusion criteria \\
\hline Other bias & Unclear risk & Comment: insufficient information provided (email bias survey sent) \\
\hline
\end{tabular}

\section{Mertens 2003}

\begin{tabular}{ll}
\hline Methods & Study design: randomized parallel groups \\
& Study dates: not given \\
\hline Participants & Country: Netherlands \\
& Sex: female \\
Age: 18 to 65 & ASA: I or II \\
Procedure: lower abdominal surgery \\
Study size: 30
\end{tabular}


Mertens 2003 (Continued)

Intervention 1: propofol target concentration $2 \mu \mathrm{g} / \mathrm{mL}+$ remifentanil, $\mathrm{N}=10$

Intervention 1: propofol target concentration $4 \mu \mathrm{g} / \mathrm{mL}+$ remifentanil, $\mathrm{N}=10$

Intervention 1: propofol target concentration $6 \mu \mathrm{g} / \mathrm{mL}+$ remifentanil, $\mathrm{N}=10$

3 laryngoscopies in protocol: attempt identify 1 responder and 1 non responder

Outcomes Primary outcomes: mean measured blood, propofol, and blood remifentanil concentrations, BIS, spectral edge frequency, systolic and diastolic blood pressures, and heart rate

Secondary outcome: awareness/wakefulness as defined using an awareness classification system (see Table 1): class 1

Quote: "Twenty-four hours postoperatively, the patients were interviewed to evaluate possible side effects and any recall of intraoperative events...None of the patients reported awareness of intraoperative events"

Notes

\section{Non-randomized portion of anaesthetic: parts of TIVA/ $\mathrm{N}_{2} \mathrm{O}$ no: muscle relaxant induction yes/ maintenance yes ADM BIS recorded/TCI}

Anaesthesia induction: propofol infusion group-specific target concentrations (TCI) + atracurium (0.4 $\mathrm{mg} / \mathrm{kg})+$ remifentanil infusion target concentration $2 \mathrm{ng} / \mathrm{mL}$

Anaesthesia maintenance: group-specific propofol infusion + remifentanil infusion adjusted to maintain LOC;BIS monitor; inadequate anaesthesia accepted if verified by all 3 observers. To facilitate identification of somatic responses, atracurium given at the minimal dose necessary for surgery (train-offour levels 1 to 3 )

Time of outcome determination: $24 \mathrm{~h}$ postoperative

Method of outcome determination: interview

ROB survey. Email: m.j.mertens@lumc.nl. We emailed on 16 April 2015: email address rejected.

\section{Risk of bias}

\begin{tabular}{lll}
\hline Bias & Authors' judgement & Support for judgement \\
\hline $\begin{array}{l}\text { Random sequence genera- } \\
\text { tion (selection bias) }\end{array}$ & Unclear risk & $\begin{array}{l}\text { Quote: "The patients were randomly assigned to one of three study groups to } \\
\text { receive, in a double-blind manner" }\end{array}$ \\
\hline $\begin{array}{l}\text { Allocation concealment } \\
\text { (selection bias) }\end{array}$ & Unclear risk & Comment: no information provided \\
\hline $\begin{array}{l}\text { Blinding of participants } \\
\begin{array}{l}\text { and personnel (perfor- } \\
\text { mance bias) } \\
\text { All outcomes }\end{array}\end{array}$ & Unclear risk & Comment: anaesthesiologist: no information provided \\
\hline
\end{tabular}

Blinding of outcome as-
sessment (detection bias) $\quad$ Unclear risk Comment: assessor: no information provided

All outcomes

Incomplete outcome data Low risk (attrition bias)

All outcomes

\begin{abstract}
Quote: "One patient in group $\mathrm{C}$ had to be excluded from the study due to improper handling of the blood samples"
\end{abstract}

Comment: $33 \%$ (1/30) dropout; imbalanced among groups but this was the highest dose group so likelihood of awareness should be lowest. The difference between groups was not significant ( $1 / 20$ vs $0 / 10)$ Peto OR 4.48 (0.07 to 286.49) 
Mertens 2003 (Continued)

Selective reporting (re- Low risk Comment: awareness outcome part of inclusion criteria porting bias)

Other bias Unclear risk Comment: insufficient information provided

Miller 1996

\begin{tabular}{ll}
\hline Methods & Study design: randomized parallel groups \\
Study dates: not given
\end{tabular}

\section{Participants}

Country: Canada

Sex: both

Age: 18 to 65

ASA: I-II

Procedure: arthroscopic knee or laparoscopic procedures

Study size: 90

Interventions

Randomized portion of anaesthetic: parts of TIVA: pre-induction hypnotic vs placebo

Intervention 1: pre-induction saline $0.1 \mathrm{~mL} / \mathrm{kg}, \mathrm{N}=21$

Intervention 2: pre-induction midazolam $15 \mu \mathrm{g} / \mathrm{kg}, \mathrm{N}=24$

Intervention 3: pre-induction midazolam $30 \mu \mathrm{g} / \mathrm{kg}, \mathrm{N}=23$

Intervention 4: pre-induction midazolam $45 \mu \mathrm{g} / \mathrm{kg}, \mathrm{N}=22$

Outcomes Primary outcomes: effects of midazolam-propofol: evaluated amount propofol required to induce anaesthesia and infusion rates propofol during maintenance and SCPS

Secondary outcome: awareness/wakefulness as defined using an awareness classification system (see Table 1): class 4

Quote: "The study was discontinued prematurely, as six patients unexpectedly experienced intraoperative awareness with recall $(4 / 21=19.1 \%$ PLAC vs $2 / 692.9 \%$ midazolam groups, $\mathrm{P}=0.038) "$

Notes Non-randomized portion of anaesthetic: parts of TIVA bolus $\mathrm{MCI} / \mathrm{N}_{2} \mathrm{O}$ no/muscle relaxant induc-
tion yes/maintenance yes/placebo

Surgical day care procedures: unpremedicated, anaesthesia induction: atracurium $0.03 \mu \mathrm{g} / \mathrm{kg}$ then $0.1 \mathrm{~mL} / \mathrm{kg}$ study drug + alfentanil $20 \mu \mathrm{g} / \mathrm{kg}+$ propofol up to $1 \mathrm{mg} / \mathrm{kg}+$ propofol $10 \mathrm{mg}$ IV bolus PRN + atracurium $0.47 \mathrm{mg} / \mathrm{kg}+$ intubation

Anaesthesia maintenance: air/oxygen 2:1 + propofol $100 \mu \mathrm{g} / \mathrm{kg} / \mathrm{min}$ (range: 80 to $200 \mu \mathrm{g} / \mathrm{kg} / \mathrm{min}$ PRN light anaesthesia) + propofol $300 \mu \mathrm{g} / \mathrm{kg}$ when infusion rate changed + alfentanil infusion $(0.5 \mu \mathrm{g} / \mathrm{kg} /$ $\mathrm{min}$ ) prior to skin incision + atracurium to maintain 1 to 2 twitches TOF

Time of outcome determination: 24 to $48 \mathrm{~h}$ postoperative

Method of outcome determination: interview

Quote: "The study was terminated prematurely due to an unexpectedly high incidence of intraoperative awareness with recall" 
Miller 1996 (Continued)

Comment: authors state patients with awareness with pain were satisfied with anaesthetic. This patient response contrasts with what anaesthesiologists as patients prefer (Girgirah 2006); no email

found

\section{Risk of bias}

\begin{tabular}{|c|c|c|}
\hline Bias & Authors' judgement & Support for judgement \\
\hline $\begin{array}{l}\text { Random sequence genera- } \\
\text { tion (selection bias) }\end{array}$ & Low risk & $\begin{array}{l}\text { Quote: "Patients were then block-randomised (in five blocks of } 20 \text { ) into one of } \\
\text { four study groups, according to a computer-generated randomisation sched- } \\
\text { ule" }\end{array}$ \\
\hline \multirow[t]{2}{*}{$\begin{array}{l}\text { Allocation concealment } \\
\text { (selection bias) }\end{array}$} & Unclear risk & $\begin{array}{l}\text { Quote: "Allocation concealment was achieved with the use of sealed en- } \\
\text { velopes" }\end{array}$ \\
\hline & & Comment: opaque not mentioned \\
\hline $\begin{array}{l}\text { Blinding of participants } \\
\text { and personnel (perfor- } \\
\text { mance bias) } \\
\text { All outcomes }\end{array}$ & Low risk & $\begin{array}{l}\text { Quote: "Blinding was established by preparing midazolam in coded syringes, } \\
\text { on the morning of surgery, in concentrations of either } 0.15,0.30 \text {, or } 0.45 \mathrm{mg} . \mathrm{ml} \\
\text {-I (for groups } \mathrm{M}-15, \mathrm{M}-30 \text { and } \mathrm{M}-45 \text {, respectively). This allowed for study drug/ } \\
\text { saline preparations to be delivered in a volume of } 0.1 \mathrm{ml} \text {. } \mathrm{kg}-1 \mathrm{iv} \text {, in order to } \\
\text { prevent group identification" }\end{array}$ \\
\hline $\begin{array}{l}\text { Blinding of outcome as- } \\
\text { sessment (detection bias) } \\
\text { All outcomes }\end{array}$ & Unclear risk & Comment: assessor: no information provided \\
\hline $\begin{array}{l}\text { Incomplete outcome data } \\
\text { (attrition bias) } \\
\text { All outcomes }\end{array}$ & Low risk & Comment: no missing outcome data \\
\hline $\begin{array}{l}\text { Selective reporting (re- } \\
\text { porting bias) }\end{array}$ & Low risk & Comment: insufficient information provided \\
\hline Other bias & Unclear risk & Comment: insufficient information provided \\
\hline
\end{tabular}

Miranda 1992

\begin{tabular}{ll}
\hline Methods & Study design: randomized parallel groups \\
& Study dates: not given \\
\hline Participants & Country: Malaysia \\
& Sex: female \\
& Age: $33.2,31.45$ \\
& ASA: I \\
Procedure: elective caesarean section \\
Study size: 30
\end{tabular}

\section{Interventions Randomized portion of anaesthetic: parts of volatile: balanced anaesthesia II IV induction}

Intervention 1: induction methohexitone $1 \%, \mathrm{~N}=15$ 


Primary outcomes: recovery parameters
Secondary outcome: awareness/wakefulness as defined using an awareness classification system (see
Table 1): class 1
Comment: there was no recall in all patients

\begin{tabular}{|c|c|}
\hline \multirow[t]{8}{*}{ Notes } & $\begin{array}{l}\text { Non-randomized portion of anaesthetic: parts of volatile: balanced anaesthesia II (volatile agent } \\
\text { continuous dosing + supplemental narcotics } \pm \text { muscle relaxant)/ } \mathrm{N}_{2} \mathrm{O} \text { yes/muscle relaxant induc- } \\
\text { tion yes/maintenance yes }\end{array}$ \\
\hline & Premedication: ranitidine $150 \mathrm{mg} 12 \mathrm{~h}$ before + ranitidine $50 \mathrm{mg}$ + metaclopropamide $10 \mathrm{mg}$ \\
\hline & Anaesthesia induction: suxamethonium $1 \mathrm{mg} / \mathrm{kg}$ \\
\hline & Anaesthesia maintenance: $\mathrm{N}_{2} \mathrm{O} 60 \%$ in oxygen $40 \%+$ enflurane $1 \%+$ atracurium $0.4 \mathrm{mg} / \mathrm{kg}$ \\
\hline & Post-delivery syntocinon 10 units + fentanyl $3 \mu \mathrm{g} / \mathrm{kg}$ \\
\hline & Time of outcome determination: day after surgery \\
\hline & Method of outcome determination: interview \\
\hline & No email address available for ROB survey \\
\hline
\end{tabular}

\section{Risk of bias}

\begin{tabular}{|c|c|c|}
\hline Bias & Authors' judgement & Support for judgement \\
\hline $\begin{array}{l}\text { Random sequence genera- } \\
\text { tion (selection bias) }\end{array}$ & Unclear risk & Quote: "Patients were randomised into two groups..." \\
\hline $\begin{array}{l}\text { Allocation concealment } \\
\text { (selection bias) }\end{array}$ & Unclear risk & Comment: no information provided \\
\hline $\begin{array}{l}\text { Blinding of participants } \\
\text { and personnel (perfor- } \\
\text { mance bias) } \\
\text { All outcomes }\end{array}$ & Unclear risk & Comment: anaesthesiologist: no information provided \\
\hline $\begin{array}{l}\text { Blinding of outcome as- } \\
\text { sessment (detection bias) } \\
\text { All outcomes }\end{array}$ & Low risk & $\begin{array}{l}\text { Quote: assessor: "Both the recovery staff and the doctor at the recovery were } \\
\text { 'blinded' as regards to the induction agent" } \\
\text { Quote: assessor: "The medical officer was not aware of the induction agents } \\
\text { used" }\end{array}$ \\
\hline $\begin{array}{l}\text { Incomplete outcome data } \\
\text { (attrition bias) } \\
\text { All outcomes }\end{array}$ & Low risk & Comment: no missing outcome data \\
\hline $\begin{array}{l}\text { Selective reporting (re- } \\
\text { porting bias) }\end{array}$ & Low risk & Comment: awareness outcome part of inclusion criteria \\
\hline Other bias & Unclear risk & Comment: insufficient information provided \\
\hline
\end{tabular}


Monedero 1994

\begin{tabular}{ll}
\hline Methods & Study design: randomized parallel groups \\
& Study dates: not given \\
\hline Participants & Sex: male and female \\
Age: 18 to 60 \\
ASA: I-II \\
Procedure: elective breast, lumbar, gynaecological surgery \\
Study size: 63
\end{tabular}

\section{Interventions $\quad$ Randomized portion of anaesthetic: parts of TIVA vs parts of balanced anaesthesia II (volatile agent + supplemental narcotics \pm muscle relaxant)}

Intervention 1: induction: midazolam perfusion $0.3 \mathrm{mg} / \mathrm{kg} / \mathrm{h}$ (Group M); maintenance: midazolam perfusion $0.12 \mathrm{mg} / \mathrm{kg} / \mathrm{h}, \mathrm{N}=21$

Intervention 2: induction: propofol $2.5 \mathrm{mg} / \mathrm{kg}$ (group P); maintenance: propofol perfusion $7 \mathrm{mg} / \mathrm{kg} / \mathrm{h}$ + pre-incision dose $1.5 \mathrm{mg} / \mathrm{kg} / \mathrm{h}$ (Group P), N = 21

Intervention 3: induction: thiopental $3 \mathrm{mg} / \mathrm{kg}$ (group I); maintenance: isoflurane $1.15 \%$ (Group I), N = 21

Outcomes Primary outcomes: intraoperative signs of inadequate anaesthesia and recovery parameters

Secondary outcome: awareness/wakefulness as defined using an awareness classification system (see Table 1): class 1

Quote: "No patients manifested having memories(awareness) of the intra-operative period"

Notes

Non-randomized portion of anaesthetic: parts of TIVA vs parts of volatile: balanced anaesthesia II (volatile agent continuous dosing + supplemental narcotics \pm muscle relaxant) $/ \mathrm{N}_{2} \mathrm{O}$ no/muscle relaxant induction yes/maintenance yes/MCl

TIVA (group M and P) vs inhalational (group 1): midazolam or propofol infusion vs isoflurane $1.15 \%$ : alfentanil/vecuronium

Induction: all patients $50 \mu \mathrm{g} / \mathrm{kg}$ alfentanil and vecuronium bromide $0.12 \mathrm{mg} / \mathrm{kg} / \mathrm{h}$

Maintenance: the 3 groups also received one pre-incision dose of alfentanil $25 \mu \mathrm{g} / \mathrm{kg}$ and post-incision perfusion at $60 \mu \mathrm{g} / \mathrm{kg} / \mathrm{h}$. alfentanil changed $20 \mu \mathrm{g} / \mathrm{kg} / \mathrm{h}$ PRN After surgery group M flumazenil $0.5 \mathrm{mg}$ IV and a perfusion of flumazenil $0.5 \mathrm{mg}$ over $60 \mathrm{~min}$

Quote: "Conclusions: None of the TIVA techniques proved superior in all the parameters studied during anaesthetic maintenance when compared with balanced isoflurane/alfentanil, although the propofol-alfentanil combination was found to be superior to that of midazolam-alfentanil. After anaesthesia, however, recovery was better with the association of propofol-alfentanil and adverse side effects were fewer. Flumazenil at the doses used was ineffective for preventing re sedation due to midazolam"

Brett Smith: translator from Spanish

No email address available for ROB survey

\section{Risk of bias}

\begin{tabular}{lll}
\hline Bias & Authors' judgement & Support for judgement \\
\hline $\begin{array}{l}\text { Random sequence genera- } \\
\text { tion (selection bias) }\end{array}$ & Unclear risk & $\begin{array}{l}\text { Quote from translator Brett Smith: "... Whereas there is no indication of ran- } \\
\text { domization in the abstract (English or Spanish), within the body of the paper }\end{array}$ \\
\hline
\end{tabular}


I found that the authors did indeed randomize the patients to the three different intervention groups. Here is where l located the reference: under the section heading "Pacientes y metedos".

Quote: "...Los pacientes se distribuyeron de forma aleatoria ('The patients were allocated in a random way') en 3 grupos de 21 pacientes: midazolam (grupo M). propofol (grupo P) o induccion con tiopental (grupo l)"

\begin{tabular}{|c|c|c|}
\hline $\begin{array}{l}\text { Allocation concealment } \\
\text { (selection bias) }\end{array}$ & Unclear risk & $\begin{array}{l}\text { Quote from translator Brett Smith: "the authors did report allocation conceal- } \\
\text { ment of patients to the } 3 \text { intervention groups }(\mathrm{M}, \mathrm{P}, \mathrm{I}) \text {, although they don't say } \\
\text { how they randomized the allocation, i.e. random number generator, etc. As far } \\
\text { as the other biases, I didn't see any evidence of blinding...authors didn't report } \\
\text { any participant attrition..." }\end{array}$ \\
\hline
\end{tabular}

Blinding of participants $\quad$ Unclear risk $\quad$ Comment: see above
and personnel (perfor-
mance bias)
All outcomes

\begin{tabular}{lll}
\hline $\begin{array}{l}\text { Blinding of outcome as- } \\
\text { sessment (detection bias) } \\
\text { All outcomes }\end{array}$ & Unclear risk & Comment: see above \\
\hline $\begin{array}{l}\text { Incomplete outcome data } \\
\begin{array}{l}\text { (attrition bias) } \\
\text { All outcomes }\end{array}\end{array}$ & Low risk & Comment: see above \\
\hline $\begin{array}{l}\text { Selective reporting (re- } \\
\text { porting bias) }\end{array}$ & Low risk & Comment: awareness outcome part of inclusion criteria \\
\hline Other bias & Unclear risk & Comment: inadequate information provided \\
\hline
\end{tabular}

\section{Morimoto 2002}

\begin{tabular}{ll}
\hline Methods & Study design: randomized parallel groups \\
Study dates: data discarded
\end{tabular}

\section{Participants}

Country: Japan

Sex: male and female

Age: $56 \pm 9,53 \pm 12$ (range 18 to 70 )

ASA: I-II

Procedure: mixed type elective surgery

Study size: 60, 14 excluded, 46 completed study, 23\% dropout

Interventions Randomized portion of anaesthetic: ADM BIS (40 to 60) vs SCP

Intervention 1: SCP blinded to BIS, $\mathrm{N}=21$

Intervention 2: open to BIS (40 to 60 ), $\mathrm{N}=25$

Total $\mathrm{N}$ completed study $=46,14$ dropouts 
Morimoto 2002 (Continued)

Secondary outcome: awareness/wakefulness as defined using an awareness classification system (see

Table 1): class 1

Comment: no awareness

Notes

Non-randomized portion of anaesthetic: parts of volatile agent/ $\mathrm{N}_{2} \mathrm{O}$ yes + supplemental narcotics + muscle relaxant induction yes/maintenance unclear

Quote: "Sixty patients (ASA physical status 1 or 2 ) undergoing various surgical procedures under sevoflurane/nitrous oxide anaesthesia were studied..... In the BIS group, sevoflurane concentration was adjusted to achieve target BIS values between 40-60 during surgery and 60-75 during the final.."

Premed: atropine $(0.5 \mathrm{mg}$ ) plus midazolam $(2 \mathrm{mg}$, if $<60$ years old) or hydroxyzine $(50 \mathrm{mg}$, if $>=60$ years old). Induction: thiopental ( $5 \mathrm{mg} / \mathrm{kg}$ ), vecuronium $(0.1 \mathrm{mg} / \mathrm{kg}$ ). Maintenance: sevoflurane (as shown in the abstract) $/ \mathbf{N}_{\mathbf{2}} \mathbf{O}$, balance of anaesthetics that were not randomized, fentanyl (control: $129 \pm 64$; BIS: $132 \pm 80 \mu \mathrm{g}$ ), vecuronium (control: $16 \pm 5 ; 14 \pm 4 \mathrm{mg}$ ), pentazocine (control: $2.4 \pm 5.6 ; 4.2 \pm 6.9 \mathrm{mg}$ )

Quote: "Table 1 shows the discharge criteria from PACU. Table 2 shows demographics. The line means Age, Sex(male/female), Weight, Anaesthetic time, Operation time, Blood loss, Total doses of fentanyl, Total doses of vecuronium, Doses of sevoflurane, Incidence of Hypertension, Incidence of bradycardia or hypotension, Incidence of nausea and vomiting, Total doses of pentazocine in PACU. The left column shows control group and right column shows BIS group"

Quote: "The important limitation of this study is not double blinded design. The anaesthesiologists [were] aware [of] the patients' group during the surgery"

Comment: nonetheless, the control group were blinded to BIS values

Jiro Kurata MD translator

Survey response: 1 September 2011, Messina, Kurata, Morimoto jkurata@plum.plala.or.jp

\section{Risk of bias}

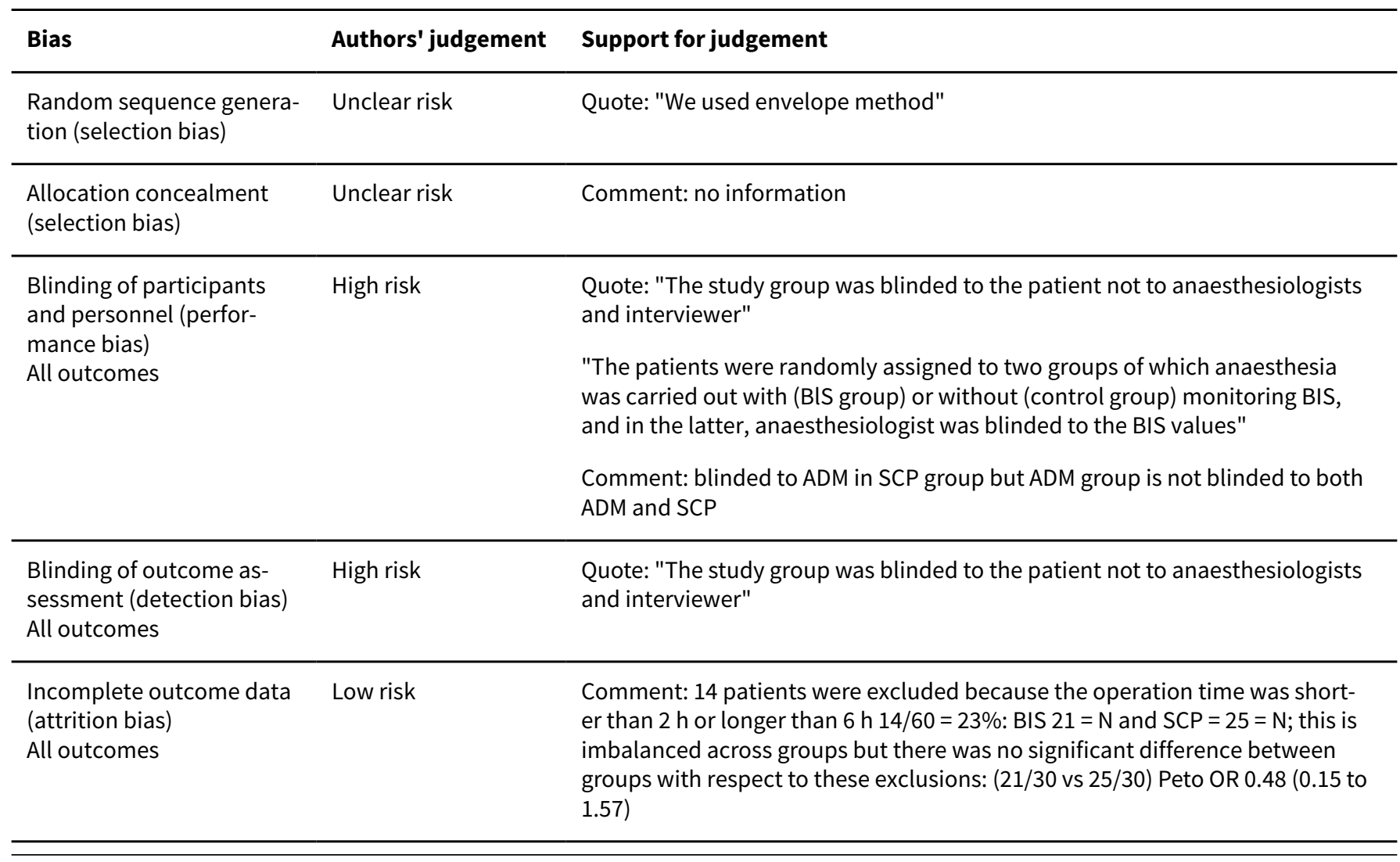


Morimoto 2002 (Continued)

Selective reporting (re- Low risk Comment based on the translator's verbal and written response: no porting bias)

Other bias Low risk Comment based on the translator's verbal and written response: no

\section{Mozafari 2014}

\begin{tabular}{ll}
\hline Methods & Study design: randomized parallel groups \\
& Study dates: not stated \\
\hline Participants & Country: Iran \\
& Sex: male/female \\
& Age: mean 47 and 48; range 18 to 65 \\
& ASA: I-III \\
Procedure: elective abdominal surgery (laparoscopy, cholecystectomy) \\
Study size: 392 enrolled, 333 completed study \\
Randomized portion of anaesthetic: ADM BIS values (target range: 45 to 65) vs SCP: volatile agent \\
Intervention 1: BIS monitoring (N = 163) BIS values (target range: 45 to 65) \\
Intervention 2: routine monitoring (N = 170)
\end{tabular}

\section{Outcomes}

Primary outcomes: BIS values and vital parameters including systolic blood pressure (SBP), diastolic blood pressure (DBP), heart rate (HR), and $\mathrm{SPO}_{2}$

Secondary outcomes: awareness/wakefulness as defined using an awareness classification system (see Table 1): class 4

Quote: "The overall incidence of awareness in the BIS and routine monitoring groups were $5.5 \%$ and $4.1 \%$, which was not significantly different"

Comment: total awareness events 16

Notes

\section{Randomized portion of anaesthetic: parts of volatile agent $/ \mathrm{N}_{\mathbf{2}} \mathrm{O}$ yes + supplemental narcotics + muscle relaxant induction yes/maintenance unclear}

Anaesthesia induced: sufentanil $0.1 \mu \mathrm{g}$ to $0.2 \mu \mathrm{g} / \mathrm{kg}$, thiopental $3 \mathrm{mg}$ to $5 \mathrm{mg} / \mathrm{kg}$ and atracurium $0.5 \mathrm{mg} /$ $\mathrm{kg}$ maintained isoflurane or halothane/ $\mathbf{N}_{\mathbf{2}} \mathbf{O} / \mathbf{B I S}$

Comment: the reported awareness events from this RCT suggests that there is something unusual about the method of administration of anaesthesia compared to other RCTs in this review from other countries with similar interventions but lower awareness rates or the criteria or protocol that other studies use to identify or include patient awareness reports is different. The difference maybe related to 1 ) the percentage of illiterate patients in study and/or 2) the validated awareness questionnaire specific to Persian culture (Malek 2010a)

Quote: "However, it seems that the incidence of this phenomenon and its complications are exactly dependent on the quality of postoperative interview by specialists. It has been shown that detection of awareness depends on the technique, timing and structure of interview ..."

Comment: Brice interview is NOT validated

Author: Amir Asadi Fakhr, Department of Anesthesiology, School of Paramedicine, Hamadan University of Medical Sciences, Hamadan, IR Iran. Tel: +98-9183159883, Email: asadi@umsha.ac.ir

ROB survey. We emailed asadi@umsha.ac.ir on 22 March 2015; no response 17 April 2015 
Mozafari 2014 (Continued)

Risk of bias

\begin{tabular}{|c|c|c|}
\hline Bias & Authors' judgement & Support for judgement \\
\hline $\begin{array}{l}\text { Random sequence genera- } \\
\text { tion (selection bias) }\end{array}$ & Low risk & $\begin{array}{l}\text { Quote: "We considered about } 196 \text { samples for each group. Patients were allo- } \\
\text { cated to BIS monitoring }(n=163) \text { and routine monitoring }(n=170) \text { groups us- } \\
\text { ing the permuted block randomization method" }\end{array}$ \\
\hline $\begin{array}{l}\text { Allocation concealment } \\
\text { (selection bias) }\end{array}$ & Unclear risk & Comment: no information \\
\hline $\begin{array}{l}\text { Blinding of participants } \\
\text { and personnel (perfor- } \\
\text { mance bias) } \\
\text { All outcomes }\end{array}$ & High risk & Comment: personnel knew treatment group assignment \\
\hline $\begin{array}{l}\text { Blinding of outcome as- } \\
\text { sessment (detection bias) } \\
\text { All outcomes }\end{array}$ & Unclear risk & $\begin{array}{l}\text { Quote: "In addition, information related to the awareness during anesthesia } \\
\text { was collected by a special questionnaire including formalized set of open-end- } \\
\text { ed questions" }\end{array}$ \\
\hline $\begin{array}{l}\text { Incomplete outcome data } \\
\text { (attrition bias) } \\
\text { All outcomes }\end{array}$ & Low risk & $\begin{array}{l}\text { Quote: "We considered about } 196 \text { samples for each group. Patients were allo- } \\
\text { cated to BIS monitoring }(n=163 \text { ) and routine monitoring }(n=170) \text { groups us- } \\
\text { ing the permuted block randomization method. Nevertheless, } 30 \text { and } 26 \text { per- } \\
\text { sons disagreed to participate in the study (BIS monitoring } n=163 \text { and routine } \\
\text { monitoring } n=170) " \\
\text { Comment: exclusions before surgery started; no exclusions between groups } \\
\text { that started and finished surgery }\end{array}$ \\
\hline $\begin{array}{l}\text { Selective reporting (re- } \\
\text { porting bias) }\end{array}$ & Low risk & Comment: awareness outcome part of inclusion criteria \\
\hline Other bias & Unclear risk & Comment: no information \\
\hline
\end{tabular}

Muralidhar 2008

\begin{tabular}{ll}
\hline Methods & Study design: randomized parallel groups \\
Study dates: not given
\end{tabular}

$\begin{array}{ll}\text { Participants } & \text { Country: India } \\ \text { Sex: both } \\ \text { Age: mean } 50 \\ \text { ASA: III-IV } \\ \text { Procedure: off-pump coronary artery bypass grafting (CABG) } \\ \text { Study size: } 40 \\ \text { Randomized portion of anaesthetic: parts of TIVA vs parts of volatile agent ADM vs SCP } \\ \text { intervention 1: isoflurane BIS open vs closed (SP), } N=20 \\ \text { intervention 2: propofol BIS open vs closed (SP), } N=20\end{array}$


Muralidhar 2008 (Continued)

Group A (I - no BIS): isoflurane in $\mathrm{O}_{2}$; ETAC $1 \%$ to $1.2 \%$

Group B (I - BIS): isoflurane inspired concentration adjusted BIS $\mathbf{5 0} \pm 5$

Group C ( $P$ - no BIS): maintained propofol infusion (after a $50 \mathrm{bmg}$ bolus) at $6 \mathrm{mg}$ to $8 \mathrm{mg} / \mathrm{kg} / \mathrm{h}$ to sternotomy and $4 \mathrm{mg}$ to $6 \mathrm{mg} / \mathrm{kg} / \mathrm{h}$ thereafter

Group D (P - BIS): maintained (after a 50 mg bolus) titrated to a BIS value of $\mathbf{5 0} \pm \mathbf{5}$

Primary outcomes: anaesthesia consumption
Secondary outcome: awareness/wakefulness as defined using an awareness classification system (see
Table 1): class 1
$\begin{aligned} & \text { Quote: "The patients who experienced recall were reevaluated and determined by a senior author } \\ & \text { and in his judgement none of the awareness reports were valid" }\end{aligned}$

Notes
Non-randomized portion of anaesthetic: parts of TIVA $\mathrm{N}_{2} \mathrm{O}$ no vs parts of volatile agent + supple- mental narcotics + muscle relaxant induction yes/maintenance unclear

General anaesthesia induced, $100 \% \mathrm{O}_{2}$ facemask, fentanyl $2 \mu \mathrm{g} / \mathrm{kg}$, midazolam $100 \mu \mathrm{g} / \mathrm{kg} / \mathrm{sleep}$ dose of thiopentone

Endotracheal intubation/pancuronium $0.15 \mathrm{mg} / \mathrm{kg}$ and mechanical ventilation

Quote: "If patient suggested that he suffered from awareness under anaesthesia he/she was visited by the senior author and the attending anaesthesiologist to discuss, explain the peri-operative events, answer patient's questions sympathetically and refer the patient for psychological counselling, if necessary"

Comment: senior author was sole adjudicator of patient awareness reports. He classified all reports as not valid awareness

No email address available for ROB survey

\section{Risk of bias}

\begin{tabular}{|c|c|c|}
\hline Bias & Authors' judgement & Support for judgement \\
\hline $\begin{array}{l}\text { Random sequence genera- } \\
\text { tion (selection bias) }\end{array}$ & Unclear risk & Quote: "randomly divided into four groups by a sealed envelope technique" \\
\hline $\begin{array}{l}\text { Allocation concealment } \\
\text { (selection bias) }\end{array}$ & Unclear risk & Quote: "randomly divided into four groups by a sealed envelope technique" \\
\hline $\begin{array}{l}\text { Blinding of participants } \\
\text { and personnel (perfor- } \\
\text { mance bias) } \\
\text { All outcomes }\end{array}$ & Unclear risk & Comment: anaesthesiologist: no information provided \\
\hline $\begin{array}{l}\text { Blinding of outcome as- } \\
\text { sessment (detection bias) } \\
\text { All outcomes }\end{array}$ & Unclear risk & Comment: assessor: no information provided \\
\hline $\begin{array}{l}\text { Incomplete outcome data } \\
\text { (attrition bias) } \\
\text { All outcomes }\end{array}$ & Low risk & Comment: no missing outcome data \\
\hline $\begin{array}{l}\text { Selective reporting (re- } \\
\text { porting bias) }\end{array}$ & Low risk & Comment: awareness outcome part of inclusion criteria \\
\hline
\end{tabular}


Muralidhar 2008 (Continued)

Other bias Unclear risk Comment: insufficient information provided

Myles 1997

$\begin{array}{ll}\text { Methods } & \text { Study design: randomized parallel groups } \\ \text { Study dates: not stated }\end{array}$

Country: Australia
Sex: female and male
Age: $64 \pm 10$
ASA: NA
Procedure: CABG surgery
Study size: 124 patients (34 with poor ventricular function), 119

Interventions
Randomized portion of anaesthetic: parts of TIVA vs parts of volatile agent + supplemental nar- cotics

Intervention 1: TIVA: maintenance: propofol-based $(5 \mathrm{mg} / \mathrm{kg} / \mathrm{h}$ prior to sternotomy, than $3 \mathrm{mg} / \mathrm{kg} / \mathrm{h}$ thereafter; $\mathrm{N}=58$ )

Intervention 2: inhalation balanced anaesthesia: enflurane-based $0.2 \%$ to $1.0 \%$, fentanyl boluses (5 $\mu \mathrm{g} / \mathrm{kg}$ ) sternotomy, CPB; midazolam $0.1 \mathrm{mg} / \mathrm{kg}$ CPB, enflurane BP.85 MAP; no enflurane on CPB ( $\mathrm{N}=$ 66)

Primary outcomes: recovery parameters (e.g. average time to extubation)
Secondary outcome: awareness/wakefulness as defined using an awareness classification system (see
Table 1): class 1
Comment: no awareness events reported

Notes
Non-randomized portion of anaesthetic: parts of TIVA/ $\mathrm{N}_{2} \mathrm{O}$ no vs parts of volatile agent + supple- mental narcotics + muscle relaxant induction yes/PRN maintenance
Induction: fentanyl $15 \mu \mathrm{g} / \mathrm{kg}$ and midazolam $0.05 \mathrm{mg} / \mathrm{kg}$
enflurane group: additional bolus of fentanyl $5 \mu \mathrm{g} / \mathrm{kg}$ prior to sternotomy and fentanyl $10 \mu \mathrm{g} / \mathrm{kg}$ with midazolam $0.1 \mathrm{mg} / \mathrm{kg}$ at (CPB)
Comment: identical induction technique, IV midazolam $0.05 \mathrm{mg} / \mathrm{kg} /$ fentanyl $15 \mu \mathrm{g} / \mathrm{kg}$. Endotracheal intubation/muscle relaxation/IV pancuronium $0.12 \mathrm{mg} / \mathrm{kg}$. PRN: IV vecuronium $2 \mathrm{mg}$ to $-4 \mathrm{mg}$ Mainte- nance of anaesthesia differed
5 patients excluded: due to intraoperative complications
ROB survey sent p.myles@alfred.org.au

\section{Risk of bias}

Bias Authors' judgement Support for judgement


Myles 1997 (Continued)

Random sequence genera- Unclear risk Quote: "we randomized patients after stratification according to the surgeon's tion (selection bias) angiographic assessment of contractility ...Randomization was determined by a table of random numbers"

\section{Allocation concealment High risk}

(selection bias)
Quote: "An acknowledged deficiency of our study was that the investigators were not blinded to treatment allocation...We retained details of intraoperative drug treatment until after extubation, so that ICU staff were unaware of group allocation, and so decisions were minimally biased..."

Blinding of participants High risk Comment: inhalation vs TIVA
and personnel (perfor-

\begin{tabular}{|c|c|c|}
\hline $\begin{array}{l}\text { Blinding of outcome as- } \\
\text { sessment (detection bias) }\end{array}$ & Unclear risk & Comment: see above \\
\hline All outcomes & & $\begin{array}{l}\text { Quote: "within } 3 \text { days of surgery and queried about any recall of intraoperative } \\
\text { events" }\end{array}$ \\
\hline
\end{tabular}

Incomplete outcome data Low risk (attrition bias)

Comment: based on our reading of the results section, we assume that the 129

All outcomes patients that started surgery and the 5 exclusions before the end of surgery were distributed as follows: propofol (4/62) vs enflurane (1/67), Peto OR 3.75 (0.63 to 22.27); hence, although the exclusions, which were due to death or change in surgical plans due to severe disease, were imbalanced, there was no significant difference between groups

\begin{tabular}{lll}
\hline $\begin{array}{l}\text { Selective reporting (re- } \\
\text { porting bias) }\end{array}$ & Low risk & $\begin{array}{l}\text { Comment: primary outcome: recovery parameters (e.g. average time to extu- } \\
\text { bation); secondary outcome: awareness; no ROB survey data }\end{array}$ \\
& Comment: awareness outcome part of inclusion criteria \\
\hline Other bias & Unclear risk & Comment: inadequate information provided \\
\hline
\end{tabular}

\section{Myles 2004}

\begin{tabular}{ll}
\hline Methods & Study design: randomized parallel groups \\
& Study dates: not given \\
\hline
\end{tabular}

Participants Country: Australia, China

Sex: both

Age: mean $58 \mathrm{BIS}$ and $57 \mathrm{SCP}$

High risk of awareness

ASA: I-IV (> 80\% patients ASA III-IV)

ASA: I-V

Procedure: elective and emergency

Study size: enrolled 2503, completed study 2463

Interventions

Randomized portion of anaesthetic: ADM BIS 40 to 60 vs SCP: parts inhalation ( $53 \%$ of cases) or TIVA techniques ( $43 \%$ of cases)

Intervention 1: BIS monitor, maintain BIS 40 to $60(\mathrm{~N}=1225)$ 
Myles 2004 (Continued)

Intervention 2: SCP No BIS monitor ( $\mathrm{N}=1238)$

Outcomes Primary outcomes: awareness/wakefulness as defined using an awareness classification system (see Table 1): class 4

Quote: "There were 22 reports of confirmed or possible awareness in the BIS group (1.8\%) and 27 reports in the routine care group $(2.2 \% ; \mathrm{P}=0.49)$ "

\section{Notes}

Non-randomized portion of anaesthetic: parts of TIVA MCI ( $43 \%$ of cases) vs parts of volatile agent $(57 \%$ of cases $) / \mathrm{N}_{2} \mathrm{O}$ yes + supplemental narcotics + muscle relaxant induction yes/PRN maintenance

Anaesthesia induction/maintenance: anaesthetic drugs: clinical judgement

Comment: Table 4: TIVA was used on $\mathbf{4 3} \%$ in BIS group and $\mathbf{4 2} \%$ in SCP group. So balanced anaesthesia (inhaled agents with IV agents) used in $57 \%$ and $58 \%$, respectively

Time of outcome determination: 2 to $4 \mathrm{~h}, 24$ to $36 \mathrm{~h}$, and 30 PODs

Method of outcome determination: structured interview

Comment: $22 \%$ (11/49) of definite and possible adjudicated patient awareness reports had pain

Comment: Table 3: 50\% (18/36) adjudicated possible awareness reports are intraoperative dream reports. Some of these may have been in postoperative period; up to $50 \%(9 / 18)$ of these dreams could be interpreted as being associated with pain/distress; see Dryad appendix

Quote: "Dreamt about aliens and thought aliens had taken over the operation (theatre staff had had a conversation about aliens during surgery)"

Comment: this one intraoperative dream report was corroborated by OpRstaff. It is proof that patient dream reports that do not contain content consistent with events during surgery should not be interpreted as proof that they do not represent fragments of intraoperative memory as part of a portion of patient reports of intraoperative dreams

Paul Myles p.myles@alfred.org.au on 14 January 2011: ROB survey not received. Multiple email communications about the following topics were exchanged from 14 January 2011 to 5 April 2015: adjudication of patient awareness reports by expert panel

\section{Risk of bias}

\begin{tabular}{lll}
\hline Bias & Authors' judgement & Support for judgement \\
\hline $\begin{array}{ll}\text { Random sequence genera- } \\
\text { tion (selection bias) }\end{array}$ & Low risk & $\begin{array}{l}\text { Quote: "perioperative care were unaffected. After consent was obtained and } \\
\text { immediately before induction of anaesthesia the anaesthetist rang the co-or- } \\
\text { dination centre to obtain a computer-generated random group allocation" }\end{array}$ \\
\hline
\end{tabular}

\begin{tabular}{|c|c|c|}
\hline $\begin{array}{l}\text { Allocation concealment } \\
\text { (selection bias) }\end{array}$ & Low risk & Comment: see random sequence allocation \\
\hline $\begin{array}{l}\text { Blinding of participants } \\
\text { and personnel (perfor- } \\
\text { mance bias) } \\
\text { All outcomes }\end{array}$ & Unclear risk & Comment: insufficient information provided \\
\hline $\begin{array}{l}\text { Blinding of outcome as- } \\
\text { sessment (detection bias) } \\
\text { All outcomes }\end{array}$ & Low risk & $\begin{array}{l}\text { Quote: assessor: "Follow-up was undertaken by a blinded observer, with a } \\
\text { structured interview, and an independent endpoint adjudication committee } \\
\text { was established" }\end{array}$ \\
\hline $\begin{array}{l}\text { Incomplete outcome data } \\
\text { (attrition bias) } \\
\text { All outcomes }\end{array}$ & Low risk & $\begin{array}{l}\text { Comment: } 2503 \text { enrolled - } 40 \text { excluded before surgery started = } 2463 \text { started } \\
\text { surgery; } 65 \text { patients (BIS group 30, routine care group 35) did not provide any }\end{array}$ \\
\hline
\end{tabular}


Myles 2004 (Continued)

interview data, mainly because of critical illness or death in the postoperative period

Peto OR: not interviewed:

(30/1225 vs 35/1238) $100.0 \%$; 0.86 ( 0.53 to 1.41 )

number of patients able to be interviewed at each of the three time periods were:

(23/1252 vs $17 / 1251) 100.0 \% ; 1.36$ (0.73 to 2.53$)$

Selective reporting (re- Low risk Comment: awareness outcome part of inclusion criteria
porting bias)

\begin{tabular}{ll}
\hline Other bias $\quad$ Unclear risk & Comment: insufficient information provided \\
\hline
\end{tabular}

Myles 2007

\begin{tabular}{ll}
\hline Methods & Study design: randomized parallel groups \\
& Study dates: April 2003 and November 2004 \\
\hline Participants & Country: worldwide \\
& Sex: both \\
& Age: $>18$, average age $55.8,54.6$ \\
& ASA: I-IV \\
& Procedure: major surgery expected to last at least $2 \mathrm{~h}$ \\
& Study size: 2050,2012
\end{tabular}

Interventions

\section{Randomized portion of anaesthetic: $\mathrm{N}_{\mathbf{2}} \mathrm{O}$ vs $\mathrm{N}_{2} \mathrm{O}$-free}

Intervention 1: maintenance oxygen $80 \%+$ nitrogen $20 \%(\mathrm{~N}=997)$

Intervention 2: maintenance: $\mathrm{N}_{2} \mathrm{O} 70 \%+$ oxygen $30 \%(\mathrm{~N}=1015)$ control

Outcomes

Primary outcomes: duration of hospital stay

Secondary outcome: awareness/wakefulness as defined using an awareness classification system (see Table 1): class 4

Comment: 2 awareness reports in $\mathrm{N}_{2} \mathrm{O}$ group

\section{Notes}

\section{Non-randomized portion of anaesthetic: $\mathrm{N}_{2} \mathrm{O}$ vs $\mathrm{N}_{2} \mathrm{O}$-free: parts of TIVA and parts of volatile agent + supplemental narcotics + muscle relaxant induction yes/PRN maintenance ADM BIS subgroup recorded}

Anaesthesia induction: standard anaesthetic care, anaesthetic depth adjusted clinical judgement and, if available, bispectral index monitoring

Comment: restricted the secondary analysis to the $\mathrm{N}_{2} \mathrm{O}$-free group to minimize the possibility of selection (Berksonian) bias. Additional regression analyses: explore the effect of possible covariate imbalance

Comment: despite the decrease in postoperative complications, did not observe a meaningful difference in duration of hospital stay between groups 
Myles 2007 (Continued)

Comment: $\mathrm{N}_{2} \mathrm{O}$-free anaesthetic: less myocardial infarction and death, but could be atype II error be-

cause study not of sufficient size/rare in unselected patients: follow-up trial in 7000 patients at risk of coronary artery disease (the ENIGMA II trial)

Time of outcome determination: $24 \mathrm{~h}$ and 30 days postoperative

Method of outcome determination: structured questionnaire

Bias email survey sent. No response received

ROB survey sent p.myles@alfred.org.au

\section{Risk of bias}

\begin{tabular}{lll}
\hline Bias & Authors' judgement & Support for judgement \\
\hline $\begin{array}{l}\text { Random sequence genera- } \\
\text { tion (selection bias) }\end{array}$ & Low risk & $\begin{array}{l}\text { Quote: "Patients were randomly assigned to ...using a computer-generated } \\
\text { code, accessed via an automated telephone voice recognition service..." }\end{array}$ \\
\hline $\begin{array}{l}\text { Allocation concealment } \\
\text { (selection bias) }\end{array}$ & Unclear risk & $\begin{array}{l}\text { Quote: "Treatment assignment was stratified by site and elective/emergency } \\
\text { status of the surgery, using permuted blocks" }\end{array}$ \\
\hline
\end{tabular}

Blinding of participants High risk and personnel (performance bias)

All outcomes
Quote: "All patients otherwise received standard anaesthetic care and monitoring. Choice of other anaesthetic drugs and intravenous fluids was at the discretion of the attending anaesthesiologist"

\section{Blinding of outcome as- Low risk} sessment (detection bias) All outcomes

\begin{abstract}
Quote: "At the end of the procedure, the intraoperative case report form and documentation of group identity were faxed to the data management centre and then placed in an opaque envelope by the anaesthesiologist. The envelope was then sealed to ensure blinding of research staff conducting the postoperative follow-ups....All patients were seen by a research assistant on the day after surgery to assess their quality of recovery and to detect awareness"

Quote: assessor: "Patients and observers were blind to group identity"

Comment: figure 1: 4035 undergoing surgery $>2 \mathrm{~h} \mathrm{GA,} 1696$ excluded before surgery for non-medical reasons, 3187 patient eligible for study, 2274 excluded before surgery after eligible: no obvious factor for exclusion increased risk of awareness, 2050 randomized, 1020 assigned $\mathrm{N}_{2} \mathrm{O}$-free group: 23 developed exclusion criterion: 997 assessed for primary endpoint (of whom 5 received $\mathrm{N}_{2} \mathrm{O}$ ): $23 / 1020=2.3 \%, 1030$ assigned $\mathrm{N}_{2} \mathrm{O}$ group: 15 developed exclusion criterion: 1015 assessed for primary endpoint (of whom 9 did not receive $\mathrm{N}_{2} \mathrm{O}$ ): 15/1030 $=1.5 \%$. If we assess these exclusions as an outcome in data analysis table using Peto OR: (23/1020) vs 15/1030), Peto OR 1.55 (0.82 to 2.95$)$. That is, there is no significant difference between the 2 groups
\end{abstract}

Incomplete outcome data Low risk (attrition bias)

All outcomes

Selective reporting (re- Low risk $\quad$ Comment: awareness outcome part of inclusion criteria
porting bias)
porting bias)

Other bias Unclear risk Comment: insufficient information provided

\section{Navarro 2000}

$\begin{array}{ll}\text { Methods } & \begin{array}{l}\text { Study design: randomized parallel groups } \\ \text { Study dates: not stated }\end{array}\end{array}$


Navarro 2000 (Continued)

Country: Germany
Sex: female
Age: 25 to $26 \pm 5$ to 5.5
ASA: I-II
Procedure: caesarean section
Study size: 75 enrolled and completed study and data collection

\section{Interventions $\quad$ Randomized portion of anaesthetic: volatile vs volatile}

Intervention 1: $(\mathrm{N}=25)$ desflurane $2.5 \%$

Intervention 2: $(\mathrm{N}=25)$ isoflurane $0.5 \%$

Intervention 3: $(\mathrm{N}=25)$ epidural $15 \mathrm{~mL}$ ropivacaine $7.5 \mathrm{mg} / \mathrm{mL}$ with fentanyl $100 \mu \mathrm{g}$

Outcomes

Primary: outcomes: recovery time (recovery period), intraoperative haemodynamic changes, blood loss, APGAR scores, neurologic adaptive capacity scores, umbilical vein blood gas analysis

Secondary outcomes: awareness/wakefulness as defined using an awareness classification system (see Table 1): class 1

Quote: "The patients were interviewed about intraoperative awareness 24 and $48 \mathrm{~h}$ after the operation. None of them reported awareness during the operation"

\section{Notes}

\section{Non-randomized portion of anaesthetic: parts of volatile agent $/ \mathrm{N}_{\mathbf{2}} \mathrm{O} /$ muscle relaxant induction yes/maintenance yes}

Thiopental (4 mg/kg IV) and succinylcholine (1.0 mg to $1.5 \mathrm{mg} / \mathrm{kg}$ ) IV

$\mathrm{N}_{2} \mathrm{O}$ to $50 \%$ in oxygen $\left(\mathrm{O}_{2}\right)$, pancuronium

Alfentanil $15 \mu \mathrm{g}$ to $25 \mu \mathrm{g} / \mathrm{kg}$ after birth PRN, oxytocin, neostigmine, and atropine antagonized muscle relaxants

ROB survey no email address available

\section{Risk of bias}

\begin{tabular}{lll}
\hline Bias & Authors' judgement & Support for judgement \\
\hline $\begin{array}{l}\text { Random sequence genera- } \\
\text { tion (selection bias) }\end{array}$ & Unclear risk & $\begin{array}{l}\text { Quote: "...were randomly divided into two groups of 25 patients who received } \\
\text { either desflurane or isoflurane" }\end{array}$ \\
\hline $\begin{array}{l}\text { Allocation concealment } \\
\text { (selection bias) }\end{array}$ & Unclear risk & Comment: inadequate information \\
\hline $\begin{array}{l}\text { Blinding of participants } \\
\text { and personnel (perfor- } \\
\text { mance bias) }\end{array}$ & Unclear risk & Comment: inadequate information \\
All outcomes & \\
\hline $\begin{array}{l}\text { Blinding of outcome as- } \\
\text { sessment (detection bias) } \\
\text { All outcomes }\end{array}$ & Unclear risk & Comment: inadequate information \\
\hline $\begin{array}{l}\text { Incomplete outcome data } \\
\text { (attrition bias) } \\
\begin{array}{l}\text { All outcomes } \\
\hline\end{array}\end{array}$ & Low risk & Comment: no dropouts \\
\hline
\end{tabular}


Navarro 2000 (Continued)

Selective reporting (re- Low risk Comment: awareness outcome part of inclusion criteria porting bias)

Other bias Unclear risk Comment: inadequate information

Nayar 2009

\begin{tabular}{ll}
\hline Methods & Study design: randomized parallel groups \\
Study dates: November 2005 to December 2007
\end{tabular}

Participants
Sex: female
Age: 24
ASA: I-II
Procedure: caesarean section
Study size: 60

\section{Interventions Randomized portion of anaesthetic: parts of volatile agent (IV induction agents of inhalational anaesthesia)}

Intervention 1: induction: thiopentone $(5 \mathrm{mg} / \mathrm{kg})(\mathrm{N}=20)$

Intervention 2: induction: ketamine $(1 \mathrm{mg} / \mathrm{kg})(\mathrm{N}=20)$

Intervention 3: induction: ketamine $(0.5 \mathrm{mg} / \mathrm{kg})+$ thiopentone $(2.5 \mathrm{mg} / \mathrm{kg})(\mathrm{N}=20)$

Primary outcomes: APGAR, haemodynamics
Secondary outcome: awareness/wakefulness as defined using an awareness classification system (see
Table 1): class 1
Quote: "None of our patients reported intraoperative awareness or dreams"

\section{Notes Randomized portion of anaesthetic: parts of volatile agent $/ \mathrm{N}_{\mathbf{2}} \mathrm{O}$ yes + supplemental narcotics + muscle relaxant induction yes/maintenance yes}

Premedication: ranitidine $150 \mathrm{mg}+30 \mathrm{~mL}$ of $0.3 \mathrm{M}$ sodium citrate

Anaesthesia induction: study specific drug (see above) + suxamethonium (1.5 mg/kg)

Anaesthesia maintenance: ventilation with $\mathbf{N}_{\mathbf{2}} \mathbf{O}$, oxygen, and halothane $(0.5 \%)$, vecuronium

Time of outcome determination: $3 \mathrm{~h}$ and $24 \mathrm{~h}$ postoperative

Method of outcome determination: interview

Email survey sent, no response received

ROB survey: Dr Nayar anesthesia62@hotmail.com We emailed on 18 April 2015.

\section{Risk of bias}


Nayar 2009 (Continued)

Random sequence genera- Unclear risk Quote: "following which they were randomly assigned to 3 groups..." tion (selection bias)

Allocation concealment $\quad$ Unclear risk
(selection bias)

Blinding of participants Unclear risk Comment: anaesthesiologist: no information provided

and personnel (perfor-

mance bias)

All outcomes

$\begin{array}{ll}\begin{array}{l}\text { Blinding of outcome as- } \\ \text { sessment (detection bias) }\end{array} & \text { Low risk } \\ \begin{array}{l}\text { All outcomes } \\ \text { tient group..." }\end{array}\end{array}$

All outcomes

Incomplete outcome data Low risk Comment: no missing outcome data

(attrition bias)

All outcomes

\begin{tabular}{lll}
\hline $\begin{array}{l}\text { Selective reporting (re- } \\
\text { porting bias) }\end{array}$ & Low risk & Comment: awareness outcome part of inclusion criteria \\
\hline Other bias & Unclear risk & Comment: insufficient information provided \\
\hline
\end{tabular}

\section{Ngan 1997}

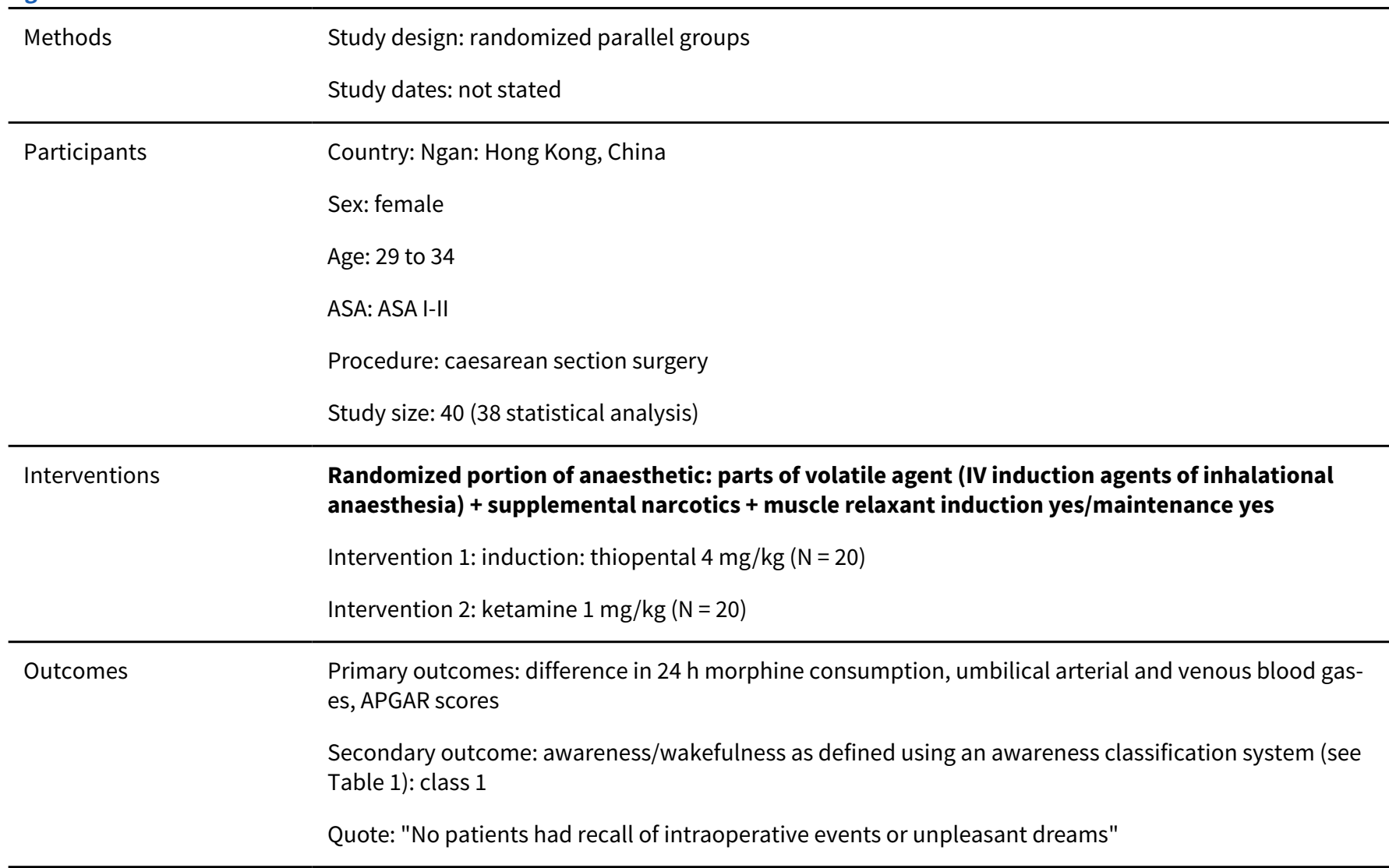


Ngan 1997 (Continued)

Notes

\section{Non-randomized portion of anaesthetic: parts of volatile agent $\mathrm{N}_{2} \mathrm{O}$ yes + supplemental narcotics + muscle relaxant induction yes/maintenance yes}

Rapid-sequence induction using study drug, succinylcholine $1.5 \mathrm{mg} / \mathrm{kg}$, ventilated $50 \% \mathbf{N}_{\mathbf{2}} \mathbf{O}$ in oxygen ET CO 2 4.2\%. Isoflurane ET 0.5\%, atracurium. After delivery $10 \mathrm{IU}$ oxytocin and morphine $0.15 \mathrm{mg} / \mathrm{kg}$, $\mathrm{N}_{2} \mathrm{O}$ increased to $70 \%$, and isoflurane reduced ET $0.3 \%$

No email address available for ROB survey

\section{Risk of bias}

\begin{tabular}{lll}
\hline Bias & Authors' judgement & Support for judgement \\
\hline $\begin{array}{l}\text { Random sequence genera- } \\
\text { tion (selection bias) }\end{array}$ & Low risk & Quote: "Patients were randomized by drawing of shuffled coded envelopes" \\
\hline $\begin{array}{l}\text { Allocation concealment } \\
\text { (selection bias) }\end{array}$ & Unclear risk & Comment: no information provided \\
\hline $\begin{array}{l}\text { Blinding of participants } \\
\text { and personnel (perfor- } \\
\text { mance bias) } \\
\text { All outcomes }\end{array}$ & Low risk & $\begin{array}{l}\text { Comment: no evidence of blinding } \\
\text { Quote: "... An anesthesiologist not involved with patient assessments calcu- } \\
\text { lated each induction dose, diluted it to } 20 \text { mL with saline, and covered the sy- } \\
\text { ringe with opaque adhesive tape" }\end{array}$
\end{tabular}

\begin{tabular}{ll}
\hline Blinding of outcome as- & Unclear risk
\end{tabular} Quote: "No patient reported recall of intraoperative events"

All outcomes

Incomplete outcome data Low risk
(attrition bias)

All outcomes

Comment: 2 dropouts ketamine group (2/20) vs thiopental group (0/20); uneven distribution of high-risk dropouts but no significant difference between groups, Peto OR 7.79 (0.47 to 129.11)

Quote: "patients in the ketamine group were excluded, one because of massive intraoperative haemorrhage that required hysterectomy and postoperative ventilation and one because of technical problems with the PCA device"

\begin{tabular}{lll}
\hline $\begin{array}{l}\text { Selective reporting (re- } \\
\text { porting bias) }\end{array}$ & Low risk & $\begin{array}{l}\text { Comment: primary outcome: morphine consumption; secondary outcome: } \\
\text { awareness; no ROB survey data }\end{array}$ \\
& Comment: awareness outcome part of inclusion criteria \\
\hline Other bias & Unclear risk & Comment: no information provided; no ROB survey data \\
\hline
\end{tabular}

Ngan Kee 2002

\begin{tabular}{l} 
Methods $\quad \begin{array}{l}\text { Study design: randomized parallel groups } \\
\text { Study dates: "Oct-1998 to Apr-2001" (email bias survey, see notes) }\end{array}$ \\
\hline
\end{tabular}

Participants
Sex: female
Age: 26 to 43
ASA: I and II


Ngan Kee 2002 (Continued)

Procedure: elective caesarian section

Study size: 60

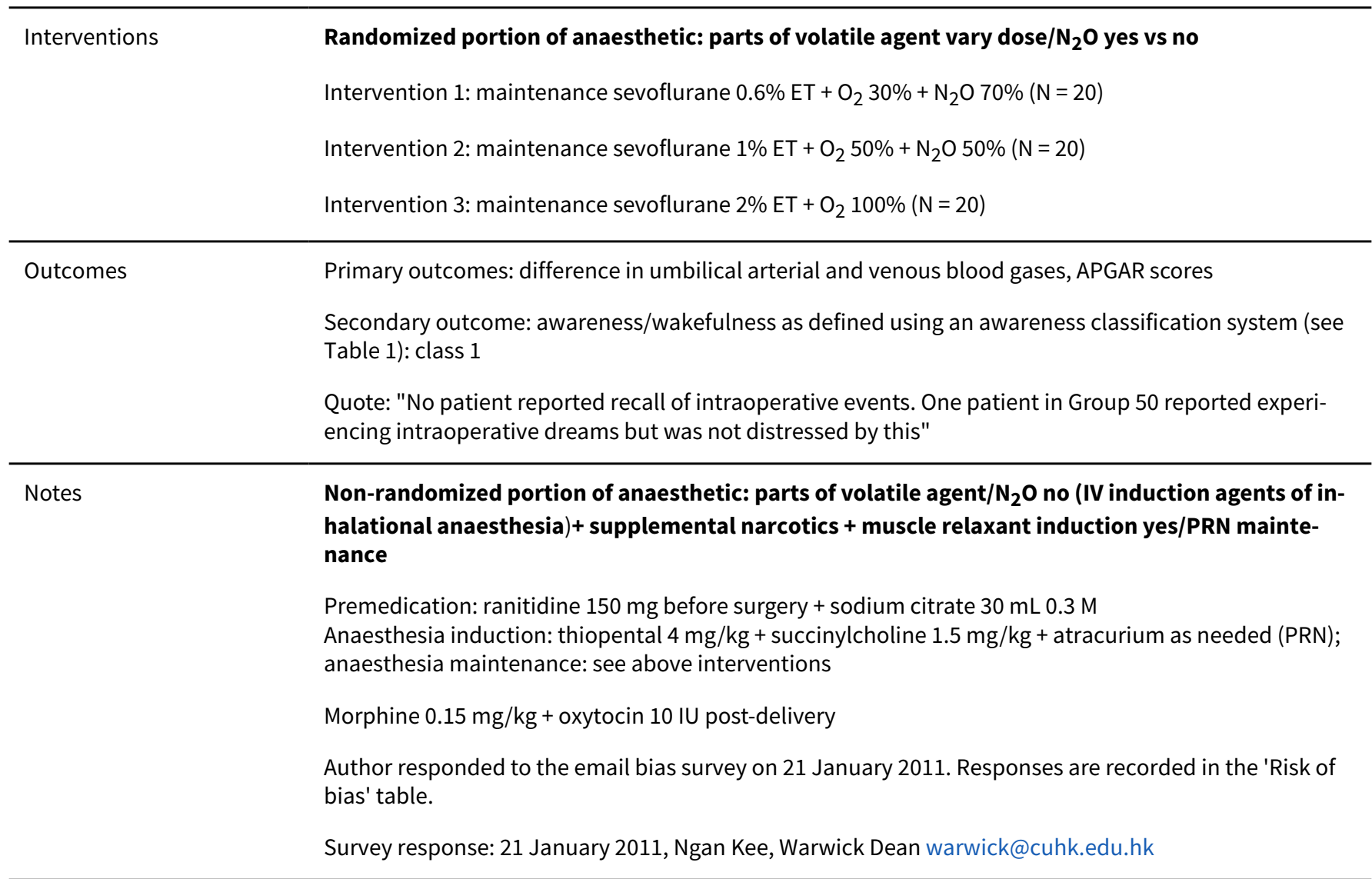

\section{Risk of bias}

\begin{tabular}{|c|c|c|}
\hline Bias & Authors' judgement & Support for judgement \\
\hline $\begin{array}{l}\text { Random sequence genera- } \\
\text { tion (selection bias) }\end{array}$ & Low risk & $\begin{array}{l}\text { Quote: "Computer-generated randomisation code held in sealed opaque en- } \\
\text { velopes" (email bias survey, see notes) }\end{array}$ \\
\hline $\begin{array}{l}\text { Allocation concealment } \\
\text { (selection bias) }\end{array}$ & Low risk & Comment above (email bias survey, see notes) \\
\hline $\begin{array}{l}\text { Blinding of participants } \\
\text { and personnel (perfor- } \\
\text { mance bias) } \\
\text { All outcomes }\end{array}$ & Low risk & $\begin{array}{l}\text { Quote: "Separate investigators applied intervention (oxygen) and adminis- } \\
\text { tered anaesthesia while different investigators performed data collection. } \\
\text { Anaesthesia machine turned away from investigators collecting data so they } \\
\text { were unable to see settings" }\end{array}$ \\
\hline $\begin{array}{l}\text { Blinding of outcome as- } \\
\text { sessment (detection bias) } \\
\text { All outcomes }\end{array}$ & Low risk & $\begin{array}{l}\text { "Patient, Awareness outcome assessor (interviewer)" (email bias survey, see } \\
\text { notes) }\end{array}$ \\
\hline $\begin{array}{l}\text { Incomplete outcome data } \\
\text { (attrition bias) } \\
\text { All outcomes }\end{array}$ & Low risk & $\begin{array}{l}\text { Comment: no missing outcome data } \\
\text { Quote: "No attrition or exclusions" (email bias survey, see notes) }\end{array}$ \\
\hline $\begin{array}{l}\text { Selective reporting (re- } \\
\text { porting bias) }\end{array}$ & Low risk & $\begin{array}{l}\text { Quote: "yes" (email bias survey, see notes). Unclear - probably meant "no" lan } \\
\text { guage barrier. }\end{array}$ \\
\hline
\end{tabular}


Ngan Kee 2002 (Continued)

Comment: awareness outcome part of inclusion criteria

Other bias Low risk Lute: "yes" (email bias survey, see notes)

Comment same as selection bias

Oddby-Muhrbeck 1993

\begin{tabular}{ll}
\hline Methods & Study design: randomized parallel groups \\
& Study dates: $1991-1992$ \\
\hline Participants & Country: Sweden \\
& Sex: female \\
Age: 30,32 \\
ASA: I \\
Procedure: laparoscopy \\
Study size: 60
\end{tabular}

Interventions Randomized portion of anaesthetic: parts of TIVA propofol vs parts of volatile agent isoflurane/IFT/music memory

Intervention 1: maintenance: propofol $10 \mathrm{mg} / \mathrm{kg}, 8 \mathrm{mg} / \mathrm{kg}$, and $5 \mathrm{mg}$ to $8 \mathrm{mg} / \mathrm{kg}$ as needed $(\mathrm{N}=30)$

Intervention 2: maintenance: isoflurane 1.5 to 2 MAC 3 to 6 min then set as needed $(N=30)$

Patients 2 groups randomly assigned 3 subgroups listening: soft music, hard rock music or no music at all. Isolated forearm technique detect insufficient anaesthesia.

12 patients in each group were randomly assigned hear one piece of soft music (Cavatine by Stanley Myer). Another 12 patients one piece of hard rock music (Prowler by Iron Maiden). 6 patients in each group played blank tape - control groups

Outcomes Primary outcomes: awareness/wakefulness as defined using an awareness classification system (see Table 1): class 1

Comment: no patient in any of the groups had memories of operation or moved the isolated arm in response to command or surgery

Comment: none of the 60 patients moved the isolated arm in response to commands or surgery

Quote: "...two patients picked the correct piece of music. It is impossible to say if they were guessing, dreaming or if they really did recall the music that was played"

Notes
Non-randomized portion of anaesthetic: parts of TIVA/ $\mathrm{N}_{2} \mathrm{O}$ yes vs parts of volatile agent + supple- mental narcotics + muscle relaxants induction yes/maintenance yes
Premedication: midazolam IM (4 $\mathrm{mg}$ below $70 \mathrm{~kg}$ and $5 \mathrm{mg}$ above)
Anaesthesia induction: fentanyl $1.5 \mu \mathrm{g}$ to $2 \mu \mathrm{g} / \mathrm{kg}$ + propofol $1 \mathrm{mg}$ to $3 \mathrm{mg} / \mathrm{kg}$ + suxamethonium chlo- ride $1 \mathrm{mg}$ to $1.5 \mathrm{mg} / \mathrm{kg}$
Anaesthesia maintenance: $66 \% \mathbf{N}_{\mathbf{2}} \mathbf{O}$ in $\mathrm{O}_{2}$ + atracurium $0.15 \mathrm{mg}$ to $2.0 \mathrm{mg} / \mathrm{kg} /$ fentanyl PRN
Comment: important issues in this paper are 1-4 stages of unconsciousness and TIVA defined to include $\mathrm{N}_{2} \mathrm{O}$ : see Dryad topic 
Time of outcome determination: $24 \mathrm{~h}$ postoperative

Method of outcome determination: questionnaire

This paper design with volunteers and breakdown of music guessing should be model to compare other music papers

Survey response: 21 January 2011, jan jakobsson jan.jakobsson@ki.se

Survey response: 8 August 2011, jan jakobsson jan.jakobsson@ki.se

Survey response: 21 January 2013 re. method of randomization

\section{Risk of bias}

\begin{tabular}{|c|c|c|}
\hline Bias & Authors' judgement & Support for judgement \\
\hline $\begin{array}{l}\text { Random sequence genera- } \\
\text { tion (selection bias) }\end{array}$ & Unclear risk & Quote: "Thirty patients, randomly selected, received propofol infusion..." \\
\hline $\begin{array}{l}\text { Allocation concealment } \\
\text { (selection bias) }\end{array}$ & Low risk & $\begin{array}{l}\text { Quote survey: "Envelopes with group assignment: Envelopes provided ran- } \\
\text { domly and a nurse otherwise not involved in the study broke an envelope after } \\
\text { that the patient had been screed and provided written and oral consent" }\end{array}$ \\
\hline $\begin{array}{l}\text { Blinding of participants } \\
\text { and personnel (perfor- } \\
\text { mance bias) } \\
\text { All outcomes }\end{array}$ & Low risk & $\begin{array}{l}\text { Quote: "Patient, Anaesthesiologist, Awareness outcome assessor (interview- } \\
\text { er)" (email bias survey, see notes) }\end{array}$ \\
\hline $\begin{array}{l}\text { Blinding of outcome as- } \\
\text { sessment (detection bias) } \\
\text { All outcomes }\end{array}$ & Low risk & $\begin{array}{l}\text { Quote: "Patient, Anaesthesiologist, Awareness outcome assessor (interview- } \\
\text { er)" (email bias survey, see notes) }\end{array}$ \\
\hline $\begin{array}{l}\text { Incomplete outcome data } \\
\text { (attrition bias) } \\
\text { All outcomes }\end{array}$ & Low risk & $\begin{array}{l}\text { Quote: "Eight patients were excluded because the laparoscopy was followed } \\
\text { by laparotomy or other surgical procedures such as tubotomy through the la- } \\
\text { paroscope." } \\
\text { Comment: } 13 \% \text { dropout (8/60); dropout related to surgical findings }\end{array}$ \\
\hline $\begin{array}{l}\text { Selective reporting (re- } \\
\text { porting bias) }\end{array}$ & Low risk & $\begin{array}{l}\text { Quote: "The study protocol is not available but it is clear that the published re- } \\
\text { port include all expected outcomes" (email bias survey, see notes) } \\
\text { Quote: "No all results associated to the study protocol are reported" (email } \\
\text { bias survey, see notes) } \\
\text { Comment: awareness outcome part of inclusion criteria }\end{array}$ \\
\hline Other bias & Low risk & Quote: "No obvious bias" (email bias survey, see notes) \\
\hline
\end{tabular}

\section{Panousis 2009}

\begin{tabular}{ll} 
Methods & Study design: randomized parallel groups \\
& Study dates: not stated \\
\hline Participants & Country: Germany \\
& Sex: both
\end{tabular}


Panousis 2009 (Continued)

Age: 51 to 66

ASA: II-III

Procedure: major abdominal surgery

Study size: 45,43

Interventions Randomized portion of anaesthetic: regional anaesthesia: epidural: local anaesthetic, ropiva-
caine vs placebo

Intervention 1: Group 1: pre-induction: ropivacaine $10 \mathrm{~mL}$ of $0.5 \%$ every $60 \mathrm{~min}+$ sufentanil $(0.5 \mu \mathrm{g} /$ $\mathrm{mL}), \mathrm{N}=15$

Intervention 2: Group 2: pre-induction: ropivacaine $10 \mathrm{~mL}$ of $0.2 \%$ every $60 \mathrm{~min}+$ sufentanil $(0.5 \mu \mathrm{g} / \mathrm{mL})$, $\mathrm{N}=13$

Intervention 3: Group 3: pre-induction: placebo (saline) control group, N = 15

Outcomes Primary outcomes: awareness/wakefulness as defined using an awareness classification system (see Table 1)

Quote: "During the postoperative interviews, no patient reported intraoperative awareness or recall"

Notes Non-randomized portion of anaesthetic: parts of volatile agent/ $\mathrm{N}_{\mathbf{2}} \mathrm{O}$ yes + supplemental narcotics + muscle relaxant induction yes/PRN maintenance BIS 55, even without changes in the PRST

Anaesthesia induction: propofol $(1.5 \mathrm{mg} / \mathrm{kg})+$ sufentanil $(0.5 \mu \mathrm{g} / \mathrm{kg})+$ rocuronium $(0.5 \mathrm{mg} / \mathrm{kg})$

Comment: see Dryad topic definition PSRT score

Anaesthesia maintenance: desflurane in $60 \% \mathbf{N}_{\mathbf{2}} \mathbf{O}$ at 1 MAC + additional remifentanil; desflurane administration was adjusted to the actual demand under continuous BIS and PRST score monitoring

An increase in BIS 55, even without changes in the PRST score, was treated by increasing the endtidal concentration of desflurane until a maximum end-tidal desflurane concentration of an age-adapted 1 MAC

Time of outcome determination: $2 \mathrm{~h}$ and 2 days postoperative

Method of outcome determination: Brice questionnaire

Bias survey sent via email to author. No response received yet.

\section{Risk of bias}

\begin{tabular}{|c|c|c|}
\hline Bias & Authors' judgement & Support for judgement \\
\hline $\begin{array}{l}\text { Random sequence genera- } \\
\text { tion (selection bias) }\end{array}$ & Low risk & $\begin{array}{l}\text { Quote: "The solutions were prepared by a nurse according to a computer de- } \\
\text { rived block randomization list" }\end{array}$ \\
\hline $\begin{array}{l}\text { Allocation concealment } \\
\text { (selection bias) }\end{array}$ & Low risk & $\begin{array}{l}\text { Quote: "Syringes were delivered to the operating room (OpR) merely labelled } \\
\text { with "TEAMAC-Study" and the consecutive patient number" }\end{array}$ \\
\hline $\begin{array}{l}\text { Blinding of participants } \\
\text { and personnel (perfor- } \\
\text { mance bias) } \\
\text { All outcomes }\end{array}$ & Low risk & $\begin{array}{l}\text { Quote: "The attending anaesthesiologist was blinded to patient randomiza- } \\
\text { tion" }\end{array}$ \\
\hline $\begin{array}{l}\text { Blinding of outcome as- } \\
\text { sessment (detection bias) } \\
\text { All outcomes }\end{array}$ & Unclear risk & $\begin{array}{l}\text { Quote: "To detect intraoperative awareness or recall, patients were inter- } \\
\text { viewed using the Brice questionnaire immediately after surgery, and } 2 \text { days } \\
\text { later when they were discharge..." }\end{array}$ \\
\hline
\end{tabular}


Panousis 2009 (Continued)

Incomplete outcome data Low risk (attrition bias)

All outcomes
Quote: "Because of protocol violations in terms of remifentanil administration at desflurane levels $<1 \mathrm{MAC}$, two patients from Group 2 were withdrawn from the database"

Comment: $4.5 \%$ (2/45) imbalanced dropout rate across groups, but protocol violation was due to giving more remifentanil than required; hence, no increase awareness risk associated with dropouts

Selective reporting (re- Low risk Comment: awareness outcome part of inclusion criteria porting bias)

Other bias

Unclear risk

Comment: insufficient information provided

Pauls 2009

\begin{tabular}{ll}
\hline Methods & Study design: randomized parallel groups \\
& Study dates: "October 10, 2007 - April 1, 2008"(email bias survey, see notes) \\
\hline Participants & Country: Canada \\
Sex: both & Age: $49.9,59.6$ \\
ASA: I-IV \\
Procedure: neurosurgery \\
Study size: 23,21
\end{tabular}

Interventions

\section{Randomized portion of anaesthetic: ADMs: EEG vs BIS}

Intervention 1: only EEG monitor visible to anaesthesiologist for maintenance, $\mathrm{N}=8$

Intervention 2: only BIS monitor visible to anaesthesiologist for maintenance, $\mathrm{N}=8$

Continuously measured/time to burst suppression

Outcomes

Primary outcomes: an assessment of quality of emergence

Quote (ClinicalTrials.gov): "This study is designed to test the hypothesis that the EEGo monitor will be superior to the BIS monitor to assess emergence following neuroanesthesia"

Secondary outcome: awareness/wakefulness as defined using an awareness classification system (see Table 1): class 1

Quote: "...none of the patients reported evidence of intraoperative awareness at $24 \mathrm{~h}$ post-surgery"

Notes

\section{Non-randomized portion of anaesthetic: parts of volatile agent $/ \mathrm{N}_{2} \mathrm{O}$ no + supplemental narcotics $\mathrm{MCl}+$ muscle relaxant induction yes/PRN maintenance}

Premedication: midazolam $1 \mathrm{mg}$

Anaesthesia induction: remifentanil $1 \mu \mathrm{g} / \mathrm{kg}$ + propofol $1.5 \mathrm{mg}$ to $2.5 \mathrm{mg} / \mathrm{kg}$ + lidocaine $1.5 \mathrm{mg} / \mathrm{kg}+$ rocuronium $0.6 \mathrm{mg} / \mathrm{kg}$

Anaesthesia maintenance: desflurane 0.5 to $1.5 \mathrm{MAC}+$ remifentanil $0.05 \mu \mathrm{g}$ to $0.1 \mu \mathrm{g} / \mathrm{kg} / \mathrm{min}$ + propofol up to $50 \mu \mathrm{g} / \mathrm{kg} / \mathrm{min}$ + phenylephrine $0.1 \mu \mathrm{g}$ to $0.5 \mu \mathrm{g} / \mathrm{kg} / \mathrm{min}+$ morphine $0.1 \mathrm{mg} / \mathrm{kg}$ 
Pauls 2009 (Continued)

Time of outcome determination: $24 \mathrm{~h}$ postoperative

Comment: see Dryad discussion differences BIS vs EEG

Method of outcome determination: interview

Quote: "Author responded to the email bias survey on 12 February 2011. Responses are recorded in the 'Risk of bias' table

Survey response: 12 February 2011, Wac Mutch wacmutch@shaw.ca

https://clinicaltrials.gov/ct2/show/NCT00443807

\section{Risk of bias}

\begin{tabular}{lll}
\hline Bias & Authors' judgement & Support for judgement \\
\hline $\begin{array}{l}\text { Random sequence genera- } \\
\text { tion (selection bias) }\end{array}$ & Low risk & $\begin{array}{l}\text { Quote: "Both the BIS monitor and the EEG signals were...measured...the clini- } \\
\text { cian was given access to only one of the monitors, as randomly allocated by a } \\
\text { third party with a coin toss to either EEGo (heads) or BIS (tails)" }\end{array}$ \\
\hline
\end{tabular}

\begin{tabular}{|c|c|c|}
\hline $\begin{array}{l}\text { Allocation concealment } \\
\text { (selection bias) }\end{array}$ & Unclear risk & $\begin{array}{l}\text { Quote: "Not assigned until all patients were induced with both monitors ap- } \\
\text { plied and functional. Then randomized as above" (email bias survey, see } \\
\text { notes) }\end{array}$ \\
\hline
\end{tabular}
notes)

\begin{tabular}{|c|c|c|}
\hline $\begin{array}{l}\text { Blinding of participants } \\
\text { and personnel (perfor- } \\
\text { mance bias) }\end{array}$ & High risk & $\begin{array}{l}\text { Quote: "Patient, Anesthesiologist, Awareness outcome assessor (interview- } \\
\text { er)" (email bias survey, see notes) }\end{array}$ \\
\hline
\end{tabular}

\begin{tabular}{|c|c|c|}
\hline $\begin{array}{l}\text { Blinding of outcome as- } \\
\text { sessment (detection bias) } \\
\text { All outcomes }\end{array}$ & Low risk & $\begin{array}{l}\text { Quote: "Twenty-four hours following surgery, a survey of patient satisfac- } \\
\text { tion and a query regarding awareness were completed by an anesthesiologist } \\
\text { blinded to the mode of EEG monitoring" }\end{array}$ \\
\hline
\end{tabular}

Incomplete outcome data Low risk Quote: "All 21 recruited patients completed the protocol... cerebral aneurysm (attrition bias) clipping...MVD for trigeminal neuralgia. The two surgical groups behaved very All outcomes differently on emergence....were not compared with the MVD patients to assess emergence criteria..." (email bias survey, see notes)

Comment: cerebral aneurysm clipping surgery can not be assessed for awareness due to surgery on brain; there was no dropout in regard to awareness assessment

\begin{tabular}{|c|c|c|}
\hline \multirow[t]{3}{*}{$\begin{array}{l}\text { Selective reporting (re- } \\
\text { porting bias) }\end{array}$} & Low risk & $\begin{array}{l}\text { Quote: "The study protocol was listed at ClinicalTrials.gov with identifier NC- } \\
\text { T00443807." (email bias survey, see notes) }\end{array}$ \\
\hline & & $\begin{array}{l}\text { Quote: "There was commentary contained within the study of an episode of } \\
\text { patient arousal." (email bias survey, see notes) }\end{array}$ \\
\hline & & Comment: awareness outcome part of inclusion criteria \\
\hline Other bias & Low risk & $\begin{array}{l}\text { Quote: "Each patient had both monitors applied. They were compared pos- } \\
\text { hoc with no inherent bias" (email bias survey, see notes) }\end{array}$ \\
\hline
\end{tabular}


Paventi 2001 (Continued)

Study dates

Country: Italy
Sex: both
Age: mean: 42,48 (18 to 75$)$
ASA: I-IV
Procedure: abdominal surgery (greater than 30 minutes)
Study size: 90

\begin{tabular}{|c|c|}
\hline Interventions & $\begin{array}{l}\text { Randomized portion of anaesthetic: ADM (BIS) vs SCP } \\
\text { intervention 1: BIS40 to } 60, N=45 \\
\text { intervention 2: SCP (BIS blinded), N = 45 }\end{array}$ \\
\hline Outcomes & $\begin{array}{l}\text { Primary outcomes: anaesthetic consumption, recovery times } \\
\text { Secondary outcome: awareness/wakefulness as defined using an awareness classification system (see } \\
\text { Table 1): class } 1\end{array}$ \\
\hline
\end{tabular}

Notes

Non-randomized portion of anaesthetic: parts of volatile agent $/ \mathrm{N}_{2} \mathrm{O}$ no, air yes + infusion of narcotics $\mathrm{MCl}+$ muscle relaxant(s) induction yes/maintenance yes

Premed: diazepam $5 \mathrm{mg}$ to $10 \mathrm{mg}$ PO; anaesthetics given per anaesthesia

All patients: induction and maintenance: remifentanil $1(\mu \mathrm{g} / \mathrm{kg}$ ) and TPS ( $4 \mathrm{mg}$ to $8 \mathrm{mg} / \mathrm{kg}$ ) vecuronium $0.1 \mathrm{mg} / \mathrm{kg}$ for intubation and for maintaining neuromuscular blockade during maintenance

Maintenance: remifentanil mean $0.4 \mu \mathrm{g} / \mathrm{kg} / \mathrm{min}$ and sevoflurane $0.5 \mathrm{MAC}$ air 50\%; after skin closure at the end of surgery, residual neuromuscular blockade was reversed

Email survey sent to author, paventi@iol.it, no response received

\section{Risk of bias}

\begin{tabular}{lll}
\hline Bias & Authors' judgement & Support for judgement \\
\hline $\begin{array}{l}\text { Random sequence genera- } \\
\text { tion (selection bias) }\end{array}$ & Unclear risk & Quote: "randomly allocated" \\
\hline $\begin{array}{l}\text { Allocation concealment } \\
\text { (selection bias) }\end{array}$ & Unclear risk & Comment: no information provided \\
\hline $\begin{array}{l}\text { Blinding of participants } \\
\begin{array}{l}\text { and personnel (perfor- } \\
\text { mance bias) } \\
\text { All outcomes }\end{array}\end{array}$ & Unclear risk & Comment: anaesthesiologist: no information provided \\
\hline
\end{tabular}

Blinding of outcome as-
sessment (detection bias) $\quad$ Unclear risk Comment: assessor: no information provided

All outcomes

Incomplete outcome data Low risk Comment: no missing outcome data
(attrition bias)


Paventi 2001 (Continued)

All outcomes

Selective reporting (re- Low risk Comment: awareness outcome part of inclusion criteria
porting bias)

Other bias Unclear risk Comment: insufficient information provided

\section{Pedersen 1992}

\begin{tabular}{|c|c|}
\hline Methods & $\begin{array}{l}\text { Study design: randomized parallel groups } \\
\text { Study dates: not given }\end{array}$ \\
\hline Participants & $\begin{array}{l}\text { Country: Denmark } \\
\text { Sex: female } \\
\text { Age: } 31,29 \\
\text { ASA: NA } \\
\text { Procedure: emergency or elective caesarean section } \\
\text { Study size: } 51\end{array}$ \\
\hline Interventions & $\begin{array}{l}\text { Randomized portion of anaesthetic: volatile agent doses } \pm \mathbf{N}_{\mathbf{2}} \mathrm{O} \\
\text { Intervention 1: maintenance oxygen } \mathbf{2} \text { litres/min }+\mathbf{N}_{\mathbf{2}} \mathbf{O} \mathbf{2} \text { litres/min + halothane } \mathbf{0 . 5} \%, \mathrm{~N}=26 \\
\text { Intervention 2: maintenance oxygen } \mathbf{4} \text { litres/min + halothane } \mathbf{2} \% \text { maintenance changed to oxygen } 2 \\
\text { litres/min }+\mathrm{N}_{\mathbf{2}} \mathbf{O} \mathbf{2} \text { litres/min + halothane } \mathbf{0 . 5} \%, \mathrm{~N}=25\end{array}$ \\
\hline Outcomes & $\begin{array}{l}\text { Primary outcomes: difference in the duration of anaesthesia, recovery time } \\
\text { Secondary outcome: awareness/wakefulness as defined using an awareness classification system (see } \\
\text { Table 1): class } 4 \\
\text { Comment: } 15 \% \text { of the mothers receiving } 0.5 \% \text { halothane had some recall. No maternal reminiscence } \\
\text { was seen using } 2 \% \text { halothane. }\end{array}$ \\
\hline Notes & $\begin{array}{l}\text { Non-randomized portion of anaesthetic: IV hypnotic/PRN narcotic/muscle relaxant parts of } \\
\text { volatile (potent inhalation) technique/ } \mathbf{N}_{\mathbf{2}} \mathbf{O} \text { no/muscle relaxants induction yes/PRN maintenance } \\
\text { Pre-oxygenation atropine } 0.5 \mathrm{mg}+\text { oxygen } 10 \mathrm{litres} / \mathrm{min} \times 3 \text { mins, manual hand controlled ventilation, } \\
\text { anaesthesia induction: thiopentone } 4 \mathrm{mg} \text { to } 5 \mathrm{mg} / \mathrm{kg}+\text { suxamethonium } 1.5 \mathrm{mg} / \mathrm{kg} / \text { intubation, mainte- } \\
\text { nance (randomized inhalational agents) pre-delivery; post cord clamp, Syntocinon infusion ( } 40 \mathrm{IU} / 1 \mathrm{~L} \\
\text { solution)+ pethidine + gallamine PRN } \\
\text { Time of outcome determination: day after operation } \\
\text { Method of outcome determination: interview } \\
\text { No email address available for ROB survey }\end{array}$ \\
\hline
\end{tabular}

\section{Risk of bias}


Pedersen 1992 (Continued)

Random sequence genera- Unclear risk Quote: "the choice of anesthesia was made by drawing an envelope randomtion (selection bias)

izing the patient to one of...the volatile anaesthetic mixture was administered according to the randomized pre-induction allocation"

Allocation concealment $\quad$ Unclear risk $\quad$ Comment: insufficient information provided
(selection bias)

Blinding of participants Low risk and personnel (perfor-

Quote: "The patients were manually ventilated by an anaesthesiologist who mance bias)

All outcomes was completely unaware of the anaesthetic gas mixture delivered"

\begin{tabular}{|c|c|c|}
\hline $\begin{array}{l}\text { Blinding of outcome as- } \\
\text { sessment (detection bias) } \\
\text { All outcomes }\end{array}$ & Unclear risk & Comment: no information \\
\hline $\begin{array}{l}\text { Incomplete outcome data } \\
\text { (attrition bias) } \\
\text { All outcomes }\end{array}$ & Low risk & Comment: no missing outcome data \\
\hline $\begin{array}{l}\text { Selective reporting (re- } \\
\text { porting bias) }\end{array}$ & Low risk & Comment: awareness outcome part of inclusion criteria \\
\hline Other bias & Unclear risk & Comment: insufficient information provided \\
\hline
\end{tabular}

Persec 2012

\begin{tabular}{ll}
\hline Methods & Study design: randomized parallel groups \\
& Study dates: February to July 2011 \\
\hline Participants & Country: Croatia \\
Sex: 21 male and 19 female \\
Age: median 65 years (25 to 84 years) \\
ASA: II-III \\
Procedure: major abdominal surgery (explorative laparotomy and colostomy/colectomy) \\
Study size: 45,40
\end{tabular}

Interventions Randomized portion of anaesthetic: ADM (BIS) vs SCP

Intervention 1: routine anaesthesia care: non BIS-guided group

Intervention 2: BIS-guided anaesthesia $\mathbf{5 0}$ and $\mathbf{6 0}$

Outcomes Primary outcomes: BIS levels, measurement of heart rate (HR), systolic blood pressure (sBP), end-tidal $\mathrm{CO}_{2}(\mathrm{ET} \mathrm{CO})$, operation time, and extubation time

Secondary outcomes: awareness/wakefulness as defined using an awareness classification system (see Table 1): class 1

"None of the patients reported explicit awareness"

Notes

\section{Non-randomized portion of anaesthetic: volatile (potent inhalation) $+\mathrm{N}_{\mathbf{2}} \mathrm{O}$ technique: IV hypnot- ic/PRN narcotic/muscle relaxant both induction/maintenance}

The operation was performed under general anaesthesia using midazolam $(0.15 \mathrm{mg} / \mathrm{kg}$ ), fentanyl (2 $\mu \mathrm{g} / \mathrm{kg})$, and vecuronium $(0.1 \mathrm{mg} / \mathrm{kg})$ to facilitate endotracheal intubation, and 1.5 to $2.5 \mathrm{MAC}$ of sevoflu- 
Persec 2012 (Continued)

rane, $\mathbf{N}_{\mathbf{2}} \mathbf{O} 50 \%$ in oxygen, boluses of fentanyl and vecuronium for maintenance. Intraoperatively, after induction doses of fentanyl, anaesthesia was mainly balanced with sevoflurane

Correspondence: Jasminka Persec, MD, PhD, Clinical Department of Anesthesiology, Reanimatology and Intensive Care Medicine, University Hospital Dubrava, Av. G. Suska 6, HR-Zagreb, Croatia

ROB survey. We emailed jpersec@net.amis.hr on 22 March 2015.

ClinicalTrials.gov (NCT01470898) - no information on web page https://clinicaltrials.gov/ct2/re-

sults?term=NCT01470898

\section{Risk of bias}

\begin{tabular}{|c|c|c|}
\hline Bias & Authors' judgement & Support for judgement \\
\hline \multirow[t]{2}{*}{$\begin{array}{l}\text { Random sequence genera- } \\
\text { tion (selection bias) }\end{array}$} & Unclear risk & $\begin{array}{l}\text { Quote: "The investigation was also registered on ClinicalTrials.gov (NC- } \\
\text { T01470898)...According to a computer generated randomisation list... " }\end{array}$ \\
\hline & & $\begin{array}{l}\text { Comment: ClinicalTrials.gov (NCT01470898) - no information on web page } \\
\text { https://clinicaltrials.gov/ct2/results?term=NCT01470898 }\end{array}$ \\
\hline $\begin{array}{l}\text { Allocation concealment } \\
\text { (selection bias) }\end{array}$ & Unclear risk & Comment: see above \\
\hline \multirow[t]{2}{*}{$\begin{array}{l}\text { Blinding of participants } \\
\text { and personnel (perfor- } \\
\text { mance bias) } \\
\text { All outcomes }\end{array}$} & High risk & $\begin{array}{l}\text { Quote: "The non BIS-guided group ... was blinded to the anaesthesiologist in } \\
\text { charge. All values were recorded by the younger anaesthesiologist, who was } \\
\text { not involved in the anaesthesia maintenance. All other aspects of peri-opera- } \\
\text { tive treatment were similar, including choice of anaesthetic agents and moni- } \\
\text { toring" }\end{array}$ \\
\hline & & $\begin{array}{l}\text { Comment: as explained in previous RCT domains, the SCP group is NOT blind- } \\
\text { ed to both groups. We use this as an example that indicates that specific as- } \\
\text { pects of RCT methods can result in high risk domains in the ROB table. Hence, } \\
\text { unless explicitly described we do not assume that trial registration leads to } \\
\text { low ROB domain grades }\end{array}$ \\
\hline
\end{tabular}

Blinding of outcome as- Unclear risk Comment: as above

sessment (detection bias)

All outcomes

\begin{tabular}{lll}
\hline $\begin{array}{l}\text { Incomplete outcome data } \\
\text { (attrition bias) } \\
\text { All outcomes }\end{array}$ & Low risk & $\begin{array}{l}\text { Quote: "Out of } 45 \text { patients recruited for the study, } 5 \text { patients were excluded be- } \\
\text { cause of an inoperative malignant process found intra-operatively" }\end{array}$ \\
\hline $\begin{array}{l}\text { Selective reporting (re- } \\
\text { porting bias) }\end{array}$ & Low risk & Comment: awareness outcome part of inclusion criteria \\
\hline Other bias & Unclear risk & Comment: see above \\
\hline
\end{tabular}

\section{Piggott 1990}

Methods Study design: randomized parallel groups

Study dates: "Late 1988 - late 1989" (email bias survey, see notes)

Participants Country: Wales

Sex: female 
Piggott 1990 (Continued)

Age: not given

ASA: NA

Procedure: elective or emergency caesarean section

Study size: 200, 197

\begin{tabular}{ll}
\hline Interventions & Randomized portion of anaesthetic: volatile agent doses $\pm \mathbf{N}_{\mathbf{2}} \mathbf{O}$ \\
& Intervention 1: maintenance isoflurane $1.8 \%$ in $100 \%$ oxygen was reduced to $1.2 \%$ after 5 min, $\mathrm{N}=100$ \\
& Intervention 2: maintenance isoflurane $1.2 \%$ in $50 \% \mathbf{N}_{\mathbf{2}} \mathbf{O}$ in oxygen was reduced to $0.6 \%$ after 5 min, $\mathrm{N}$ \\
& $=100$
\end{tabular}

Outcomes

Primary outcomes: umbilical venous and arterial blood, samples

Secondary outcome: awareness/wakefulness as defined using an awareness classification system (see Table 1): class 1

Comment: there were no instances of awareness

Comment: 4 patients ( 2 in each group) recalled dreaming on direct questioning ( 2 had moved the isolated arm and 2 had not)

Quote: "One patient (group 50) reported a sensation of painful pressure, but believed she had been dreaming. She had not moved her arm."

Comment: the patient in group 50 could also have been classified as awareness, 2 moved their arms presumably not in response to complex command; many would call this non-purposeful movement; see discussion of non-purposeful movement

Comment: this is evidence that a portion of dreams are a variant of intraoperative memory

Notes Non-randomized portion of anaesthetic: volatile (randomized) (potent inhalation) technique continuous then PRN: IV hypnotic/PRN narcotic/muscle relaxants both induction/maintenance

Anaesthesia induction: thiopentone $3 \mathrm{mg}$ to $4 \mathrm{mg} / \mathrm{kg}$ + suxamethonium $1.5 \mathrm{mg} / \mathrm{kg}$ + pancuronium $4 \mathrm{mg}$ to $6 \mathrm{mg}$

Anaesthesia maintenance: isoflurane increased $50 \%$ for 5 min added as needed

Quote: "...no taped message was played to the anaesthetized patients, and they were not asked beforehand to move the hand if they felt pain, as it was considered that this would add to existing stress"

Comment: see Dryad topic non-purposeful vs purposeful movement with IFT and topic of air oxygen paralysis only in neonates

Time of outcome determination: postoperative before discharge

Method of outcome determination: interview

Author responded to the email bias survey on 7 February 2011. Responses are recorded in the 'Risk of bias' table.

Survey response: 7 February 2011, David George Bogod david.bogod@nottingham.ac.uk

\section{Risk of bias}

\begin{tabular}{lll}
\hline Bias & Authors' judgement & Support for judgement \\
\hline $\begin{array}{l}\text { Random sequence genera- } \\
\text { tion (selection bias) }\end{array}$ & High risk & $\begin{array}{l}\text { Quote: "Alternate groups for alternate weeks...Randomisation was far from } \\
\text { ideal by current standards!" (email bias survey, see notes) }\end{array}$ \\
\hline
\end{tabular}


Piggott 1990 (Continued)

Allocation concealment High risk Quote: "Participants unaware of allocation sequence. Investigators aware" (e(selection bias)

Blinding of participants and personnel (performance bias)

All outcomes

\section{Blinding of outcome as- Low risk} sessment (detection bias)

All outcomes

\author{
mail bias survey, see notes)
}

Quote: "Patient, Awareness outcome assessor (interviewer)" (email bias survey, see notes)
Quote: "Patient, Awareness outcome assessor (interviewer)" (email bias survey, see notes)

\section{Incomplete outcome data Low risk} (attrition bias)

All outcomes

Quote: "Uncertain so long after the study. Not fully addressed in the paper. 197 out of 200 analysed for indication for Caesarean section, and $100 \%$ of neonates followed-up. From what I recall, data were very largely complete, as subjects were in-patients during follow-up" (email bias survey, see notes)

Comment: unclear about distribution of 3 patient dropouts

Comment: assume the most imbalanced variant and there is no significant difference between groups: ( $3 / 50$ vs (0/50), Peto OR 7.70 (0.78 to 75.76 )

Selective reporting (re- Low risk
porting bias)
porting bias)

Quote: "Protocol no longer available (this was 31 years ago!). I can only say that, from what I recall, it was followed fully" (email bias survey, see notes)

Quote: "All results reported" (email bias survey, see notes)

Comment: awareness outcome part of inclusion criteria

\begin{tabular}{ll}
\hline Other bias & Comment: no exclusions listed \\
& $\begin{array}{l}\text { Quote: "Randomisation was far from ideal by current standards! Other forms } \\
\text { of bias were, to the best of my knowledge so long after the event, excluded" }\end{array}$ \\
\hline
\end{tabular}

Plourde 1996

\begin{tabular}{ll} 
Methods & Study design: randomized parallel groups \\
& Study dates: Quote: "Jan to Oct 1991" (email bias survey, see notes) \\
\hline Participants & Country: Canada \\
& Sex: female 19 to 50 \\
& ASA: I-II \\
& Procedure: reduction mammoplasty \\
& Study size: 12
\end{tabular}

Interventions

\section{Randomized portion of anaesthetic: volatile agent doses $\pm \mathrm{N}_{2} \mathrm{O}$}

Intervention 1: maintenance $\mathrm{N}_{2} \mathrm{O}(66 \%$ end-tidal $(\mathrm{ET})$ ) enflurane $0.5 \% \mathrm{ET}, \mathrm{N}=4$

Intervention 2: maintenance $\mathrm{N}_{2} \mathrm{O}(66 \%$ end-tidal (ET)) enflurane $0.8 \% \mathrm{ET}, \mathrm{N}=4$

Intervention 3: maintenance $\mathrm{N}_{2} \mathrm{O}(66 \%$ end-tidal (ET)) enflurane $1.1 \% \mathrm{ET}, \mathrm{N}=4$ 
Plourde 1996 (Continued)
Outcomes

Primary outcomes: $40 \mathrm{~Hz}$ ASSR/AML, AMLR amplitude, latency, or phase data

Secondary outcome: awareness/wakefulness as defined using an awareness classification system (see Table 1): class 1

Comment: no patient had any recollection of intraoperative events

Notes

\section{Non-randomized portion of anaesthetic: volatile (randomized) (potent inhalation) technique: IV hypnotic/PRN narcotic/muscle relaxants both induction/maintenance ADM AMLR recorded}

Anaesthesia induction: fentanyl $3 \mu \mathrm{g} / \mathrm{kg}$ + thiopental $3 \mathrm{mg}$ to $5 \mathrm{mg} / \mathrm{kg}$ + vecuronium $0.08 \mathrm{mg} / \mathrm{kg}$

Anaesthesia maintenance: fentanyl $1.0 \mu \mathrm{g} / \mathrm{kg}$ as needed + vecuronium $0.01 \mathrm{mg} / \mathrm{kg}$

Time of outcome determination: 4 to 8 weeks postoperative

Method of outcome determination: interview

Neostigmine $40 \mu \mathrm{g} / \mathrm{kg}+$ glycopyrrolate $10 \mu \mathrm{g} / \mathrm{kg}$ used to reverse muscle paralysis

Primary author responded to email bias survey. Responses are recorded in 'Risk of bias' table below.

Comment: study was not powered to assess for awareness but electrophysiology (author's response to survey)

Survey response: 13 February 2011, Gilles Plourde gilles.plourde@mcgill.ca

\section{Risk of bias}

\section{Bias Authors' judgement Support for judgement}

Random sequence genera- Low risk tion (selection bias)
Quote paper: "four patients per concentration; random assignment..."

Quote survey: "Assignment (concentration of enflurane, recording order i.e. ASSR or AMLR first) written on cards which were shuffled and individually places in a sealed envelope by the department secretary who was familiar with these procedures" (email bias survey, see notes)

\begin{tabular}{|c|c|c|}
\hline $\begin{array}{l}\text { Allocation concealment } \\
\text { (selection bias) }\end{array}$ & Unclear risk & $\begin{array}{l}\text { Quote: "Anaesthesiologist did not keep track of cases done. So each envelope } \\
\text { brought a surprise" (email bias survey, see notes) }\end{array}$ \\
\hline
\end{tabular}

\begin{tabular}{|c|c|c|}
\hline $\begin{array}{l}\text { Blinding of participants } \\
\text { and personnel (perfor- } \\
\text { mance bias) } \\
\text { All outcomes }\end{array}$ & High risk & $\begin{array}{l}\text { Quote: "Patient, Awareness outcome assessor (interviewer), Data analyst" (e- } \\
\text { mail bias survey, see notes) }\end{array}$ \\
\hline
\end{tabular}

Blinding of outcome as- Low risk sessment (detection bias) Quote: "Patient, Awareness outcome assessor (interviewer), Data analyst" (email bias survey, see notes)

\begin{tabular}{ll}
\hline $\begin{array}{l}\text { Incomplete outcome data } \\
\text { (attrition bias) }\end{array}$ & Low risk \\
All outcomes & Qurvey, see notes) \\
\hline
\end{tabular}

$\begin{array}{ll}\begin{array}{l}\text { Selective reporting (re- } \\ \begin{array}{l}\text { porting bias) }\end{array}\end{array} & \begin{array}{l}\text { Quote: "Main goal of study was electrophysiology. Awareness was only out- } \\ \text { come examined...Yes. Some findings did not reach significance" (email bias } \\ \text { survey, see notes) }\end{array} \\ \text { Comment: awareness outcome part of inclusion criteria }\end{array}$

Other bias Low risk Quote: "No obvious bias" (email bias survey, see notes (email)


Puri 2003

\begin{tabular}{|c|c|}
\hline Methods & $\begin{array}{l}\text { Study design: randomized parallel groups } \\
\text { Study dates: not stated }\end{array}$ \\
\hline Participants & $\begin{array}{l}\text { Country: India } \\
\text { Sex: both } \\
\text { Age: } 18 \text { to } 70 \\
\text { ASA: NA but by type of surgery ASA III-IV } \\
\text { Procedure: valve replacement or coronary artery grafting under cardiopulmonary bypass } \\
\text { Study size: } 30\end{array}$ \\
\hline Interventions & 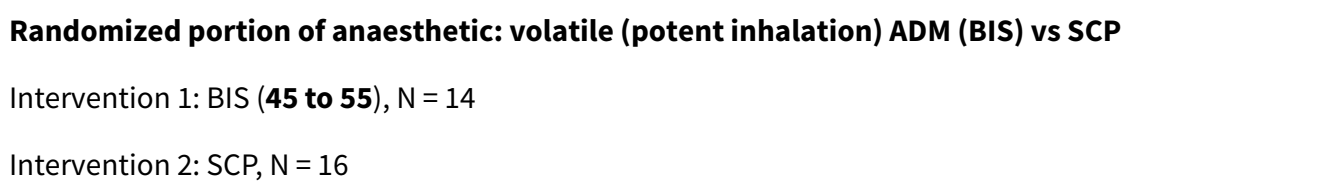 \\
\hline Outcomes & $\begin{array}{l}\text { Primary outcomes: haemodynamic disturbances, time to recovery } \\
\text { Secondary outcome: awareness/wakefulness as defined using an awareness classification system (see } \\
\text { Table 1): class } 4 \\
\text { Quote: "None of the patients in the study group had recall of intraoperative events when interviewed } \\
\text { on the first postoperative day, while one patient in the control group had awareness during the ster- } \\
\text { notomy" }\end{array}$ \\
\hline
\end{tabular}
ic/PRN narcotic/muscle relaxants both induction/maintenance (CPB)

Anaesthesia induction: morphine $0.2 \mathrm{mg} / \mathrm{kg} 1+$ midazolam $0.05 \mathrm{mg} / \mathrm{kg}$ + thiopental + vecuronium 0.08 $\mathrm{mg} / \mathrm{kg}$

Maintenance induction titrated to keep BIS between 45 and 55 emergence 65 to $75+$ morphine $0.05 \mathrm{mg}$ to $0.1 \mathrm{mg} / \mathrm{kg}$ as needed, $\mathrm{N}=15$

Anaesthesia maintenance: isoflurane $+\mathrm{N}_{2} \mathrm{O}\left(66 \% \mathrm{O}_{2}\right.$ before $\left.\mathbf{C P B}\right)+$ morphine $0.025 \mathrm{mg} / \mathrm{kg} / \mathrm{h}+$ morphine $3 \mathrm{mg}+$ midazolam $1 \mathrm{mg}$ + vecuronium $0.5 \mathrm{mg}$

Quote: "...while in the study group, the anaesthesiologist adjusted the vasoactive drugs to maintain pressure while keeping the BIS constant"

Comment: this is the method cardiac anaesthesiologists use to maintain what they judge to be an appropriate depth of anaesthesia without lightening the anaesthetic as the main or supplemental intervention to treat hypotension. This cause and method of avoiding awareness is rarely described in papers.

Comment: senior author adjudicated patient awareness reports as not valid without expert panel; studying this phenomena

Time of outcome determination: $24 \mathrm{~h}$ after operation

Method of outcome determination: interview

gdpuri007@hotmail.com

\section{Risk of bias}


Puri 2003 (Continued)

\begin{tabular}{|c|c|c|}
\hline Bias & Authors' judgement & Support for judgement \\
\hline $\begin{array}{l}\text { Random sequence genera- } \\
\text { tion (selection bias) }\end{array}$ & Low risk & $\begin{array}{l}\text { Quote: "...were randomized into either a study group (using BIS) or a control } \\
\text { group (no BIS) using computer generated numbers...." }\end{array}$ \\
\hline $\begin{array}{l}\text { Allocation concealment } \\
\text { (selection bias) }\end{array}$ & Unclear risk & Comment: no information provided \\
\hline $\begin{array}{l}\text { Blinding of participants } \\
\text { and personnel (perfor- } \\
\text { mance bias) } \\
\text { All outcomes }\end{array}$ & Unclear risk & Comment: insufficient information provided \\
\hline $\begin{array}{l}\text { Blinding of outcome as- } \\
\text { sessment (detection bias) } \\
\text { All outcomes }\end{array}$ & Unclear risk & $\begin{array}{l}\text { Comment: insufficient information provided } \\
\text { Quote: "Every patient was interviewed to determine any recall on the first } \\
\text { postoperative day after the trachea had been extubated" }\end{array}$ \\
\hline $\begin{array}{l}\text { Incomplete outcome data } \\
\text { (attrition bias) } \\
\text { All outcomes }\end{array}$ & Low risk & Comment: no missing outcome data \\
\hline $\begin{array}{l}\text { Selective reporting (re- } \\
\text { porting bias) }\end{array}$ & Low risk & Comment: awareness outcome part of inclusion criteria \\
\hline Other bias & Unclear risk & Comment: insufficient information provided \\
\hline
\end{tabular}

Puri 2007

\begin{tabular}{ll}
\hline Methods & Study design: randomized parallel groups \\
& Study dates: "Feb 2003 to Dec 2004" (email bias survey, see notes) \\
\hline Participants & Country: India \\
Sex: both & Age: 39 \\
Procedure: elective non-cardiac surgery \\
Study size: 40
\end{tabular}

Interventions Randomized portion of anaesthetic: TIVA + CLADS vs TIVA + ADM: BIS 50

Intervention 1: closed loop anaesthesia delivery system (CLADS): propofol $5.03 \pm 1.68 \mathrm{mg} / \mathrm{kg}-1$, h-1

Intervention 2: manual infusion control: $7.33 \pm 2.07 \mathrm{mg} / \mathrm{kg}-1$, h-1 propofol titrated to BIS $=50$

Outcomes

Primary outcomes: induction time (the time required to achieve target BIS after start of infusion), induction dose, minimum BIS within 30 seconds of induction, total dose propofol, median duration of closed loop control or manual control, and median time interval between end of closed-loop control (or end propofol infusion in manual control) and extubation

Secondary outcome: awareness/wakefulness as defined using an awareness classification system (see Table 1): class 1

Comment: no awareness cases 
Puri 2007 (Continued)

Notes

\section{Non-randomized portion of anaesthetic: parts of TIVA/ $\mathrm{N}_{2} \mathrm{O}$ no: narcotics $\mathrm{MCl} /$ muscle relaxants in- duction yes/maintenance yes (CPB)}

Anaesthesia induction: fentanyl $(2 \mu \mathrm{g} / \mathrm{kg}$ ) prior to induction than fentanyl $1 \mu \mathrm{g} / \mathrm{kg}-1$, h-1 continuous infusion for the duration of surgery; endotracheal intubation $/ 0.1 \mathrm{mg} / \mathrm{kg}$ vecuronium

Anaesthesia maintenance: fentanyl infusion $(1 \mu \mathrm{g} / \mathrm{kg} / \mathrm{h})$

Time of outcome determination: at discharge, 1 day, and 1 week postoperative

Method of outcome determination: modified Brice questionnaire

Survey response: 16 February 2011, Dr Goverdhan Dutt Puri gdpuri007@hotmail.com

\section{Risk of bias}

\begin{tabular}{lll}
\hline Bias & Authors' judgement & Support for judgement \\
\hline $\begin{array}{l}\text { Random sequence genera- } \\
\text { tion (selection bias) }\end{array}$ & Low risk & $\begin{array}{l}\text { Quote ROB survey response, Dr Puri: "Computer generated" (email bias sur- } \\
\text { vey, see notes) }\end{array}$ \\
\hline $\begin{array}{l}\text { Allocation concealment } \\
\text { (selection bias) }\end{array}$ & High risk & $\begin{array}{l}\text { Quote ROB survey response, Dr Puri: "Anaesthesiologist conducting anaes- } \\
\text { thesia knew of the group the patient belong. But anaesthesiologist assessing } \\
\text { awareness post-op did not know the group to which patient belong" (email } \\
\text { bias survey, see notes) }\end{array}$
\end{tabular}

\begin{tabular}{|c|c|c|}
\hline $\begin{array}{l}\text { Blinding of participants } \\
\text { and personnel (perfor- }\end{array}$ & High risk & $\begin{array}{l}\text { Comment: given the closed vs open loop systems used, like Pedersen 1992, it } \\
\text { is possible to blind the anaesthesiologist but requires extra manpower }\end{array}$ \\
\hline
\end{tabular}

mance bias)

All outcomes

\begin{tabular}{|c|c|c|}
\hline $\begin{array}{l}\text { Blinding of outcome as- } \\
\text { sessment (detection bias) } \\
\text { All outcomes }\end{array}$ & Low risk & $\begin{array}{l}\text { Quote ROB survey response, Dr Puri: "Patient, Awareness outcome assessor } \\
\text { (interviewer), Data analyst...But anaesthesiologist assessing awareness post- } \\
\text { op did not know the group to which patient belong" (email bias survey, see } \\
\text { notes) }\end{array}$ \\
\hline
\end{tabular}

\begin{tabular}{ll}
\hline Incomplete outcome data Low risk & Quote ROB survey response, Dr Puri: "all data reported" \\
(attrition bias)
\end{tabular}

(attrition bias)

All outcomes

\begin{tabular}{|c|c|c|}
\hline $\begin{array}{l}\text { Selective reporting (re- } \\
\text { porting bias) }\end{array}$ & Low risk & $\begin{array}{l}\text { Quote ROB survey response, Dr Puri: "...don't think any non significant results } \\
\text { of any importance to the study relevant were excluded" (email bias survey, see } \\
\text { notes) }\end{array}$ \\
\hline & & Comment: awareness outcome part of inclusion criteria \\
\hline Other bias & Low risk & $\begin{array}{l}\text { Quote ROB survey response, Dr Puri: "free of bias as all patients had anaesthe- } \\
\text { sia to be controlled on target BIS numbers" (email bias survey, see notes) }\end{array}$ \\
\hline
\end{tabular}

\section{Rehberg 2007}

\begin{tabular}{ll}
\hline Methods & Study design: randomized parallel groups \\
& Study dates: "5/2005-10/2005" (email bias survey, see notes) \\
\hline Participants & Country: Germany \\
& Sex: both \\
\hline
\end{tabular}


Rehberg 2007 (Continued)

Age: 49,55

ASA: I-III

Procedure: elective minor urological or gynaecological surgery

Study size: 92

Interventions Randomized portion of anaesthetic: TIVA: MCI vs TCI propofol

Intervention 1: induction propofol $\mathrm{MCl}$ no restriction of dose; maintenance propofol no dose restriction; both manual TIVA N = $46-2(2 / 46=5 \%)$ (unplanned ICU stay $=44)$

Intervention 2: induction propofol TCI $7 \mathbf{~ m g}$ to $\mathbf{1 0} \mathbf{~ m g / m L ; ~ m a i n t e n a n c e ~ p r o p o f o l ~ T C l ~} 2.5 \mathrm{mg}$ to $4.5 \mathrm{mg}$ / $\mathrm{mL} ; \mathrm{N}=46-4(4 / 46=9 \%)$ (unplanned ICU stay $=42)$

Outcomes

Primary outcomes: proportion of priming words identified and the BS values

Secondary outcome: awareness/wakefulness as defined using an awareness classification system (see Table 1): class 1

Quote: "none of our patients expressed explicit memory"

Notes

\section{Non-randomized portion of anaesthetic: parts of TIVA/ $\mathrm{N}_{2} \mathrm{O}$ no/muscle relaxants induction yes/ maintenance no/BIS blinded}

Midazolam ( $0.1 \mathrm{mg} / \mathrm{kg}$ ) premed; induction: fentanyl bolus $1 \mathrm{mg}$ to $3 \mathrm{mg} / \mathrm{kg}$, neuromuscular blockers only induction if intubation; LMA used also; maintenance: manual dosing of fentanyl

Bispectral index recorded in a blinded manner

Quote: "Neuromuscular blockers were given only during anaesthesia induction to facilitate intubation, and no further intraoperative doses were given"

Quote: "Participating anaesthesiologists were allowed to perform total IV propofol anaesthesia supplemented by fentanyl but without nitrous oxide"

Time of outcome determination: $12 \mathrm{~h}$ to $24 \mathrm{~h}$ postoperative

Method of outcome determination: interview

Benno Rehberg benno.rehberg-klug@hcuge.ch

8 December 2013: responded 9 December 2013, 10 March 2011, 24 January 2011 re. muscle relaxant use; dropout rate, characteristics table

\section{Risk of bias}

\begin{tabular}{lll}
\hline Bias & Authors' judgement & Support for judgement \\
\hline $\begin{array}{l}\text { Random sequence genera- } \\
\text { tion (selection bias) }\end{array}$ & Low risk & $\begin{array}{l}\text { Quote from Dr. Rehberg: "computer-generated list of consecutive allocation to } \\
\text { the groups, no blocks" (email bias survey, see notes) }\end{array}$ \\
\hline $\begin{array}{l}\text { Allocation concealment } \\
\text { (selection bias) }\end{array}$ & Unclear risk & $\begin{array}{l}\text { Quote from Dr. Rehberg: "concealed envelopes, opened immediately before } \\
\text { induction" (email bias survey, see notes) }\end{array}$ \\
\hline $\begin{array}{l}\text { Blinding of participants } \\
\text { and personnel (perfor- } \\
\text { mance bias) } \\
\begin{array}{l}\text { All outcomes } \\
\text { Comment: unclear if sealed and opaque }\end{array}\end{array}$ & High risk & Quote: "Anaesthesiologists, who were blinded towards the BIS..." \\
\hline
\end{tabular}


Rehberg 2007 (Continued)

Blinding of outcome as- High risk Quote from Dr. Rehberg: "Potential bias: Assessors were not blinded to treatsessment (detection bias) ment" (email bias survey)

All outcomes

Incomplete outcome data Low risk (attrition bias)

All outcomes
Comment: outcome data are missing in both intervention groups, imbalanced as percentage units because of unplanned ICU transfer. TIVA: $(2 / 46=5 \%)$ vs manual controlled infusion ( $4 / 46=9 \%)$ : but no significant difference between both groups in dropouts, Peto OR 9.85 (0.51 to 188.36); severely ill patients not interviewed are at higher risk of awareness due to their unstable intraoperative clinical condition (see secondary outcomes), which frequently results in the anaesthesiologist lightening the anaesthetic as part of the treatment of that unstable condition that is often manifest by a common final pathway of hypotension

Author sent characteristics and ROB table grades for comment 8 December 2013: Benno Rehberg benno.rehberg-klug@hcuge.ch

Quote from Dr. Rehberg 9 December 2013: "I agree with your assessment in general. Although none of the patients admitted to the ICU were unstable during surgery, it is difficult to assess their risk of awareness in comparison to the other patients in retrospect (which was not our primary outcome)"

Quote: "Based on performing a statistical analysis and information from Dr. Rehberg we have changed the grade to low risk"

Selective reporting (re- Low risk
porting bias)
Quote from Dr. Rehberg: "The study protocol is available, but written in German language. However, the published report includes all pre-specified outcomes" (email bias survey, see notes)

Quote: "The main (and other) outcome reported was actually non-significant" (email bias survey, see notes)

Comment: awareness outcome part of inclusion criteria
Quote from Dr. Rehberg: "Potential bias: Assessors were not blinded to treatment." (email bias survey)

Comment: that bias is accounted for in the "Blinding of outcome assessment (detection bias)" domain. However, no other risk identified.

Renna 2000

\begin{tabular}{ll}
\hline Methods & Study design: randomized parallel groups \\
& Study dates: not given \\
\hline Participants & Country: UK \\
& Sex: female \\
& Age: mean 41.7 \\
& ASA: NA \\
& Procedure: minor gynaecological surgery \\
& Study size: 48 \\
\hline $\begin{array}{l}\text { Randomized portion of anaesthetic: volatile agent different doses/word test: implicit memo- } \\
\text { ry/positive and neutral suggestion }\end{array}$ \\
\hline Interventions
\end{tabular}


Renna 2000 (Continued)

Intervention 1: sevoflurane $1.2 \% \mathrm{ET}+$ either word list $\mathrm{A}$ or $\mathrm{B}+$ either positive or neutral suggestion, $\mathrm{N}=$ 16

Intervention 2: sevoflurane 1.5\% ET + either word list A or B + either positive or neutral suggestion, $\mathrm{N}=$ 16

Intervention 3: sevoflurane $2 \% \mathrm{ET}+$ either word list A or B + either positive or neutral suggestion, $\mathrm{N}=16$

\begin{tabular}{ll}
\hline Outcomes & Primary outcomes: primary outcome implicit memory; secondary outcome: awareness \\
& BIS, word lists, neutral suggestion \\
& Secondary outcome: awareness/wakefulness as defined using an awareness classification system (see \\
& Table 1 ): class 2 \\
& Quote: "...there was evidence of implicit memory...There was no evidence of a therapeutic effect of \\
positive suggestion...The bispectral index ...not... statistical significance ....indicator... susceptibility to \\
priming....no patient had recall of priming or intra-operative events"
\end{tabular}

Breathing induction and maintenance: sevoflurane and $\mathbf{O}_{\mathbf{2}}$ only with facemask; at each of the 3 target ET points in induction word tests and suggestion transmitted by headphones

Quote: "Anaesthesia was induced by inhalation ofsevoflurane in oxygen via a facemask. At loss of eyelid reflex...After the target end-tidal concentration...stable...bi spectral index ...noted, headphones ...common two-syllable words ...prime implicit memory... then ...neutral ('You will be having your operation today') or the positive ('You will feel great after the operation!') suggestion...Surgical anaesthesia ...established ...operation performed. At no point during surgery did patients receive drugs other than sevoflurane and oxygen"

Comment: one of the few volatile agent only anaesthetics

No email address available for ROB survey

\section{Risk of bias}

\begin{tabular}{lll}
\hline Bias & Authors' judgement & Support for judgement \\
\hline $\begin{array}{l}\text { Random sequence genera- } \\
\text { tion (selection bias) }\end{array}$ & Low risk & $\begin{array}{l}\text { Quote: "Allocation was randomised by drawing a code from a hat, which en- } \\
\text { sured 16 patients in each concentration group and equal numbers of A and B, } \\
\text { and of positive and neutral suggestion, within each concentration group" }\end{array}$ \\
\hline $\begin{array}{l}\text { Allocation concealment } \\
\text { (selection bias) }\end{array}$ & Unclear risk & $\begin{array}{l}\text { Quote: "Each patient was allocated to one of three groups characterised by } \\
\text { their target end-tidal sevoflurane concentration (1.2, } 1.5 \text { or } 2 \%), \text { then to a sub- } \\
\text { group, A or B, to balance the test of perceptual facilitation, and finally, to a sec- } \\
\text { ond subgroup for positive or neutral suggestion (a stimulus requiring semantic } \\
\text { processing)..." }\end{array}$ \\
\hline
\end{tabular}

Blinding of participants High risk Comment: not blinded to sevoflurane doses and personnel (performance bias)

All outcomes

Blinding of outcome as- Unclear risk sessment (detection bias)

All outcomes

\begin{abstract}
Quote: "...Two to three hours after the operation, each patient was interviewed and asked if they remembered hearing anything while they were asleep"
\end{abstract}


Renna 2000 (Continued)

Incomplete outcome data Low risk Quote: "One patient was not included in the analysis because she required (attrition bias)

All outcomes al induction" propofol to control her movements during the excitement phase of inhalation-

Comment: dropout rate $1 / 48$ (2\%): high-risk awareness dropout; imbalanced across groups but no significant difference between groups:sevoflurane $1.2 \%$ (1/16) vs sevoflurane $2.5 \%$ and $2 \%$ (0/32), Peto OR 0.05 (0.00 to 3.18 )

Selective reporting (re- Low risk Comment: awareness outcome part of inclusion criteria porting bias)

Other bias Unclear risk Comment: insufficient information provided

Rinaldi 2005

Study design: randomized parallel groups
Study dates: not stated

\begin{tabular}{|c|c|}
\hline \multirow[t]{6}{*}{ Participants } & Country: Italy \\
\hline & Sex: both \\
\hline & Age: 49,52 \\
\hline & ASA: I-II \\
\hline & Procedure: major abdominal surgery \\
\hline & Study size: 100 \\
\hline \multirow[t]{3}{*}{ Interventions } & $\begin{array}{l}\text { Randomized portion of anaesthetic: volatile (potent inhalation) technique ADM AAI (AAI } 20 \pm 5 \text { ) vS } \\
\text { SCP }\end{array}$ \\
\hline & Intervention 1: sevoflurane titrated AAI (AAI 20 $\mathbf{5}$ ) + fentanyl $1 \mu \mathrm{g} / \mathrm{kg}$ PRN, $\mathrm{N}=50$ \\
\hline & Intervention 2: sevoflurane titrated clinical signs (SCPs) + fentanyl $1 \mu \mathrm{g} / \mathrm{kg}$ PRN, $N=50$ \\
\hline \multirow[t]{4}{*}{ Outcomes } & Primary outcomes: sevoflurane consumption, time to recovery, memory \\
\hline & $\begin{array}{l}\text { Secondary outcome: awareness/wakefulness as defined using an awareness classification system (see } \\
\text { Table 1): class } 1\end{array}$ \\
\hline & Comment: no patients showed signs of awareness or had any recall postoperatively \\
\hline & $\begin{array}{l}\text { Quote: "No patients experienced explicit memory and there was not significant difference in implicit } \\
\text { memory between Groups A and } B(P=0.107) \ldots 11 \text { patients had intraoperative dreams and patients had } \\
\text { implicit memory of word tests" }\end{array}$ \\
\hline
\end{tabular}

Notes

\section{Non-randomized portion of anaesthetic: volatile (potent inhalation) technique/ $\mathrm{N}_{\mathbf{2}} \mathrm{O}$ no: IV hyp- notic/PRN narcotic/muscle relaxants both induction/maintenance}

Premed: diazepam $0.1 \mathrm{mg} / \mathrm{kg}$; induction: fentanyl $2 \mu \mathrm{g} / \mathrm{kg}$ + propofol $1.5 \mathrm{mg}$ to $2 \mathrm{mg} / \mathrm{kg}$ + atracurium $0.6 \mathrm{mg} / \mathrm{kg}+3 \mathrm{~min} \mathrm{FIO}_{2} 80 \%$ + intubation

Anaesthetic maintenance: sevoflurane oxygen/air (titrated to randomized groups); atracurium $0.4 \mathrm{mg} /$ $\mathrm{kg} / \mathrm{h}$ up to $30 \mathrm{~min}$ before the end of surgery/morphine $0.07 \mathrm{mg} / \mathrm{kg}$ plus ketorolac $0.4 \mathrm{mg} / \mathrm{kg}$ as preventive analgesia, and ondansetron $8 \mathrm{mg}$ for postoperative nausea, maintain target AAI 205

Time of outcome determination: $2 \mathrm{~h}$ postoperative 
Rinaldi 2005 (Continued)

Method of outcome determination: interview

No email address available for ROB survey

\section{Risk of bias}

\begin{tabular}{lll}
\hline Bias & Authors' judgement & Support for judgement \\
\hline $\begin{array}{l}\text { Random sequence genera- } \\
\text { tion (selection bias) }\end{array}$ & Unclear risk & $\begin{array}{l}\text { Quote: "Patients were randomised using the closed envelope technique in two } \\
\text { groups" }\end{array}$ \\
\hline
\end{tabular}

\begin{tabular}{ll}
\hline $\begin{array}{l}\text { Allocation concealment } \\
\text { (selection bias) }\end{array}$ & $\begin{array}{l}\text { Quote: "Patients were randomised using the closed envelope technique in two } \\
\text { groups" }\end{array}$ \\
& Comment: we assume this is referring to allocation \\
\hline
\end{tabular}

\begin{tabular}{lll}
\hline $\begin{array}{l}\text { Blinding of participants } \\
\text { and personnel (perfor- } \\
\text { mance bias) }\end{array}$ & High risk & $\begin{array}{l}\text { Quote: "anaesthetist... performed all anaesthetic procedures and, by the na- } \\
\text { ture of the study, was not blinded" }\end{array}$ \\
\hline $\begin{array}{l}\text { Blinding of outcome as- } \\
\text { sessment (detection bias) } \\
\text { All outcomes }\end{array}$ & Low risk & $\begin{array}{l}\text { Quote: "Implicit and explicit memory has been evaluated by the physician } \\
\text { whose voice had been recorded for the implicit memory test. This physician } \\
\text { did not perform or neither know the anaesthetic technique, so memory testing } \\
\text { was blinded" }\end{array}$ \\
\hline
\end{tabular}

Incomplete outcome data Low risk Comment: no missing outcome data

(attrition bias)

All outcomes

\begin{tabular}{lll}
\hline $\begin{array}{l}\text { Selective reporting (re- } \\
\text { porting bias) }\end{array}$ & Low risk & Comment: awareness outcome part of inclusion criteria \\
\hline Other bias & Unclear risk & Comment: insufficient information provided \\
\hline
\end{tabular}

\section{Russell 1986}

\begin{tabular}{ll}
\hline Methods & Study design: randomized parallel groups \\
& Study dates: "1982-1984" (email bias survey, see notes) \\
\hline Participants & Country: UK \\
Sex: female & Age: 19 to 74 \\
ASA: NA & Procedure: gynaecological surgery \\
& Study size: 55 \\
Randomized portion of anaesthetic: TIVA vs "inhaled nitrous oxide with IV fentanyl increments \\
("balanced" regimen)" otherwise described as intravenous anaesthesia \\
Intervention $1:$ TIVA: etomidate $100 \mathrm{\mu g} / \mathrm{kg} / \mathrm{min}$ for 10 min then... $\mathrm{O}_{2} /$ air, $100 \mathrm{mc} / \mathrm{kg} / \mathrm{min}$ for rest of proce- \\
dure + fentanyl bolus, $\mathrm{N}=25$
\end{tabular}


Secondary outcome: awareness/wakefulness as defined using an awareness classification system (see Table 1): class 1

Comments: no recall, 3 dreams, $7 \%$ wakeful in the etomidate group, and one 9 dreams; $44 \%$ occurrence of recall in the $\mathrm{N}_{2} \mathrm{O}$ group ments ("balanced" regimen)" otherwise described as intravenous anaesthesia: muscle relaxants induction yes/maintenance PRN

Premedication: temazepam $10 \mathrm{mg}$ to $20 \mathrm{mg}+$ fentanyl $250 \mu \mathrm{g}$

Anaesthesia induction: thiopentone suxamethonium $1 \mathrm{mg}$ to $1.5 \mathrm{mg} / \mathrm{kg}$

Anaesthesia maintenance: $\mathrm{N}_{2} \mathrm{O}: \mathrm{O}_{2}$ 2:1 vecuronium $4 \mathrm{mg}+$ vecuronium $2 \mathrm{mg}$ as needed + fentanyl 100 $\mu \mathrm{g}$ as needed

When patient responded to command: thiopentone $100 \mathrm{mg}+$ fentanyl $100 \mu \mathrm{g}$ or etomidate $5 \mathrm{mg}+100$ mc fentanyl; nitrous required significantly more fentanyl boluses and hence is defined as the "light" anaesthesia group

Comment: balanced anaesthesia is defined as inhalational agents with small-dose narcotics; others define it as a regimen based on inhaled $\mathrm{N}_{2} \mathrm{O}$ with IV fentanyl increments; TIVA anaesthetic is defined as based on a 2-stage infusion of etomidate plus increments of fentanyl; other definitions of balanced anaesthesia: Lallemand 2003; Lehmann 1985; Lehmann 1992; Myles 1997

Comment: see Dryad topics: definition of light and inadequate anaesthesia; isolated forearm technique (IFT)

Comment: wakefulness during anaesthesia has been recognized for many years since Artusio 1955 described this state in spontaneously breathing patients under ether anaesthesia. Using the IFT, Wilson 1980 found some $30 \%$ of patients were wakeful

Time of outcome determination: before discharge

Method of outcome determination: interview

Author responded to the email bias survey on 4 February 2011. Responses are recorded in the 'Risk of bias' table

Survey response: 4 February 2011, Ian F i.f.@hull.ac.uk

\section{Risk of bias}

Random sequence genera- High risk tion (selection bias)
Quote: "Patients were randomised according to whether their unit number was odd or even...no one has control over the unit number assigned to a patient. It is true that the unit number was known before inclusion in the study, but since all patients meeting the entry criteria were included and received their appropriate anaesthetic, I do not think this method of randomisation introduced bias" (email bias survey, see notes)

Comment: other experts disagree with Dr. Russell Myles 2015 (personal communication). Despite the $4 / 7$ domains in this RCT having a 'high' risk, we have given this RCT an overall ROB rating that is acceptable for use in our metaanalysis in this review 
Russell 1986 (Continued)

Allocation concealment High risk Quote: "I was the sole investigator and anaesthetist. Allocation could not be (selection bias) concealed" (email bias survey, see notes)

Comment: if the anaesthesiologist is not blinded to the drugs then the lack of allocation concealment will not change the impact of the unblinded state of the anaesthesiologist on the ROB

Blinding of participants High risk Quote: "Patient" (email bias survey)
and personnel (perfor-
mance bias)

\begin{tabular}{lll}
$\begin{array}{l}\text { Blinding of outcome as- } \\
\text { sessment (detection bias) } \\
\text { All outcomes }\end{array}$ & High risk & Comment: not blinded \\
\hline $\begin{array}{l}\text { Incomplete outcome data } \\
\text { (attrition bias) }\end{array}$ & Low risk & $\begin{array}{l}\text { Comment: } 3 \text { patients had partial data due to uncontrolled hypertension; } 2 \text { in } \\
\text { one group, } 1 \text { in the other. All patients }(\mathrm{N}=55) \text { were included in the awareness } \\
\text { evaluation (email bias survey, see notes) }\end{array}$ \\
\hline
\end{tabular}

Selective reporting (re- Low risk Quote: "The study protocol is no longer available as this was over 25 years ago. porting bias) But all of the study's pre-specified (primary and secondary) outcomes that are of interest in the review have been reported" (email bias survey, see notes)

Quote: "Yes. While all the primary outcomes were significant, some secondary outcomes were not significant" (email bias survey, see notes)

Comment: awareness outcome part of inclusion criteria

$\begin{array}{ll}\text { Other bias } \quad \text { Low risk } & \begin{array}{l}\text { Comment: from author survey responses: the author believes that for reasons } \\ \text { explain above, there were no other biases }\end{array}\end{array}$

\section{Samarkandi 2004}

\begin{tabular}{ll}
\hline Methods & Study design: randomized parallel groups \\
& Study dates: not given \\
\hline Participants & Country: Saudi Arabia \\
& Sex: both \\
& Age: 58 \\
Procedure: off-pump coronary bypass surgery \\
Study size: 40
\end{tabular}

Interventions $\quad$ Randomized portion of anaesthetic: ADM BIS 40 to 60 vs SCP

Intervention 1: SCP, $\mathrm{N}=20$

Intervention 2: BIS 40 to $60, \mathrm{~N}=20$

Outcomes

Primary outcomes: anaesthetic consumption, haemodynamics

Secondary outcome: awareness/wakefulness as defined using an awareness classification system (see Table 1): class 1 

muscle relaxant + PRN volatile inhalation agent) $/ \mathrm{N}_{2} \mathrm{O}$ no/muscle relaxants both induction/maintenance

Anaesthesia induction: sufentanil $1 \mu \mathrm{g}$ to $1.5 \mu \mathrm{g} / \mathrm{kg}$ + midazolam $0.05 \mathrm{mg}$ to $0.1 \mathrm{mg} / \mathrm{kg}$ + rocuronium 0.9 $\mathrm{mg} / \mathrm{kg}$

Anaesthesia maintenance: sufentanil $0.2 \mu \mathrm{g} / \mathrm{kg} / \mathrm{h}+$ midazolam $1.5 \mu \mathrm{g} / \mathrm{kg} / \mathrm{h}+$ rocuronium $0.5 \mathrm{mg} / \mathrm{kg} / \mathrm{h}+$ sevoflurane PRN

Anaesthesia was induced with sufentanil $1 \mu \mathrm{g}$ to $1.5 \mu \mathrm{g} / \mathrm{kg}$, midazolam $0.05 \mathrm{mg}$ to $0.1 \mathrm{mg} / \mathrm{kg}$ and rocuronium $0.9 \mathrm{mg} / \mathrm{kg}$ then a maintenance sufentanil $0.2 \mu \mathrm{g} / \mathrm{kg} / \mathrm{h}$, midazolam $1.5 \mu \mathrm{g} / \mathrm{kg} / \mathrm{h}$ and rocuronium $0.5 \mathrm{mg} / \mathrm{kg} / \mathrm{h}$ supplemented with sevoflurane as required. Induction doses as well as anaesthetic maintenance supplementation doses were guided by the BIS range 40 to 60; Group 2 control group, only clinical judgement was used to titrate

Comment: postoperative standardized questionnaire uses the memory of intraoperative dreams as the starting point to assess explicit memory as do other authors like Pedersen 1992

Comment: author seems to state that the administration of a volatile agent was used for inadequate anaesthesia (PRN) in both groups; emailed author but no response for clarification of this issue; if this is the case, this is another example of the variable definitions of TIVA

Comment: see appendix for discussion of the definitions of balanced anaesthesia

Time of outcome determination: 2 days postoperative

Method of outcome determination: standardized questionnaire

Dr. Mohamed Essam Abdel-Meguid, email: memeguid@hotmail.com ROB survey. We emailed on 19 April 2015: recipient failed permanently.

\section{Risk of bias}

\begin{tabular}{|c|c|c|}
\hline Bias & Authors' judgement & Support for judgement \\
\hline $\begin{array}{l}\text { Random sequence genera- } \\
\text { tion (selection bias) }\end{array}$ & High risk & $\begin{array}{l}\text { Quote: "Randomisation was performed using patient's medical record num- } \\
\text { ber, being odds related to Group I and evens related to Group II" }\end{array}$ \\
\hline $\begin{array}{l}\text { Allocation concealment } \\
\text { (selection bias) }\end{array}$ & Unclear risk & Comment: no information provided \\
\hline $\begin{array}{l}\text { Blinding of participants } \\
\text { and personnel (perfor- } \\
\text { mance bias) } \\
\text { All outcomes }\end{array}$ & Unclear risk & Comment: anaesthesiologist: no information provided \\
\hline $\begin{array}{l}\text { Blinding of outcome as- } \\
\text { sessment (detection bias) } \\
\text { All outcomes }\end{array}$ & Low risk & $\begin{array}{l}\text { Quote: assessor: "Postoperatively, patients were visited on the } 2 \text { nd postoper- } \\
\text { ative day by one of the medical staff who was blinded about the grouping and } \\
\text { they were asked to answer a standardized questionnaire including" }\end{array}$ \\
\hline $\begin{array}{l}\text { Incomplete outcome data } \\
\text { (attrition bias) } \\
\text { All outcomes }\end{array}$ & Low risk & Comment: no missing outcome data \\
\hline
\end{tabular}

Selective reporting (re- Low risk Comment: awareness outcome part of inclusion criteria
porting bias)

Other bias Unclear risk Comment: insufficient information provided


Sareen 1997

\begin{tabular}{|c|c|}
\hline Methods & $\begin{array}{l}\text { Study design: randomized parallel groups } \\
\text { Study dates: not given }\end{array}$ \\
\hline Participants & $\begin{array}{l}\text { Country: Canada } \\
\text { Sex: both } \\
\text { Age: } 63 \pm 9 ; 65 \pm 7 \\
\text { ASA: not given } \\
\text { Procedure: elective CABG } \\
\text { Study size: } 34\end{array}$ \\
\hline Interventions & $\begin{array}{l}\text { Randomized portion of anaesthetic: TIVA or "balanced" narcotic portion: } 2 \text { doses compared } \\
\text { Intervention } 1 \text { induction: Group L: sufentanil } 3 \mu \mathrm{g} / \mathrm{kg}, \mathrm{N}=17 \\
\text { Intervention } 2 \text { induction: Group H: sufentanil } 15 \mu \mathrm{g} / \mathrm{kg}, \mathrm{N}=17\end{array}$ \\
\hline Outcomes & $\begin{array}{l}\text { Primary outcomes: haemodynamics, EEG } \\
\text { Quote: "effect of a five-fold variation in sufentanil dose on the haemodynamic and electroencephalo- } \\
\text { graphic (EEG) response to anaesthetic induction and tracheal intubation" } \\
\text { Secondary outcome: awareness/wakefulness as defined using an awareness classification system (see } \\
\text { Table 1): class } 1 \\
\text { Quote: "no patient had awareness" }\end{array}$ \\
\hline Notes & $\begin{array}{l}\text { Non-randomized portion of anaesthetic: TIVA or volatile I "balanced" anaesthesia I (narcotics + } \\
\text { muscle relaxant + PRN volatile inhalation agent)/ } \mathbf{N}_{\mathbf{2}} \mathbf{O} \text { no/muscle relaxants both induction/main- } \\
\text { tenance/ADM EEG spectral edge LIFESCAN recorded } \\
\text { Premedication: } 60 \mathrm{\mu g} / \mathrm{kg} \text { lorazepam PO induction and maintenance: sufentanil + vecuronium } 0.15 \mathrm{mg} / \\
\mathrm{kg}, 0.15 \mathrm{mg} / \mathrm{kg} \text { vecuronium, Neurometrics (Lifescan) aperiodic analysis used as ADM } \\
\text { Comment: nomenclature between RCTs is confusing } \\
\text { Time of outcome determination: NA } \\
\text { Method of outcome determination: interview } \\
\text { Email survey sent to author, no response received ithomson@sbrc.umanitoba.ca }\end{array}$ \\
\hline
\end{tabular}

\section{Risk of bias}

\begin{tabular}{lll}
\hline Bias & Authors' judgement & Support for judgement \\
\hline $\begin{array}{l}\text { Random sequence genera- } \\
\text { tion (selection bias) }\end{array}$ & Unclear risk & Quote: "Patients were randomly assigned to one of two groups" \\
\hline $\begin{array}{l}\text { Allocation concealment } \\
\text { (selection bias) }\end{array}$ & Unclear risk & Comment: no information provided \\
\hline $\begin{array}{l}\text { Blinding of participants } \\
\text { and personnel (perfor- } \\
\text { mance bias) }\end{array}$ & Low risk & Quote: "Sufentanil was prepared by our pharmacy in concentrations of either \\
\end{tabular}


Sareen 1997 (Continued)

All outcomes

Blinding of outcome as-
sessment (detection bias) $\quad$ Unclear risk Comment: assessor: no information provided

All outcomes

\begin{tabular}{lll}
\hline $\begin{array}{l}\text { Incomplete outcome data } \\
\text { (attrition bias) } \\
\text { All outcomes }\end{array}$ & Low risk & Comment: no missing outcome data \\
\hline $\begin{array}{l}\text { Selective reporting (re- } \\
\text { porting bias) }\end{array}$ & Low risk & Comment: awareness outcome part of inclusion criteria \\
\hline Other bias & Unclear risk & Comment: insufficient information provided \\
\hline
\end{tabular}

\section{Schultetus 1986}

\begin{tabular}{ll}
\hline Methods & $\begin{array}{l}\text { Study design: randomized parallel groups } \\
\text { Study dates: not stated }\end{array}$ \\
\hline Participants & Country: USA \\
& Sex: female \\
& Age: $23.5,25.5$ \\
& ASA: I-II \\
& Procedure: elective caesarean section \\
& Study size: 36
\end{tabular}

Interventions

Randomized portion of anaesthetic: IV: opioid - intravenous technique

Intervention 1: induction ketamine $1 \mathrm{mg} / \mathrm{kg}, \mathrm{N}=12$

Intervention 2: induction thiopental $4 \mathrm{mg} / \mathrm{kg}, \mathrm{N}=13$

Intervention 3: induction ketamine $0.5 \mathrm{mg} / \mathrm{kg}+$ thiopental $2 \mathrm{mg} / \mathrm{kg}, \mathrm{N}=11$

Outcomes Primary outcomes: haemodynamics, fetal blood gas tensions, APGAR

Secondary outcome: awareness/wakefulness as defined using an awareness classification system (see Table 1): class 1

Comment: 3 patients (8\%): awareness: 1 in thiopental group and 2 in combination group. 4 had intraoperative dreams: 2 thiopental and 2 combination groups; 12 followed commands (wakefulness): 1 from ketamine, 7 thiopental, 4 combinations; 17 reaching movements: 9 from thiopental and 8 from combinations

Notes

Non-randomized portion of anaesthetic: IV: opioid - intravenous technique/muscle relaxants yes both induction/maintenance/ $\mathrm{N}_{2} \mathrm{O}$ yes

Preoperatively sodium citrate $30 \mathrm{~mL}$ of $0.3 \mathrm{M}+\mathrm{d}$-tubocurarine chloride $0.07 \mathrm{mg} / \mathrm{kg}$; induction: succinylcholine $2 \mathrm{mg} / \mathrm{kg}$ than continuous infusion succinylcholine; anaesthesia maintenance: $70 \% \mathrm{~N}_{2} \mathrm{O}$ in $\mathrm{O}_{2}+$ succinylcholine chloride $2 \mathrm{mg} / \mathrm{min}$; after delivery fentanyl $(100 \mu \mathrm{g})$ was given 
Schultetus 1986 (Continued)

\section{Comment: "balanced" means "inhaled" agent $\mathrm{N}_{2} \mathrm{O}$ not volatile, by our rules define this as IV anaesthesia}

Time of outcome determination: postoperative

Method of outcome determination: interview

No email address available for ROB survey

\section{Risk of bias}

\begin{tabular}{|c|c|c|}
\hline Bias & Authors' judgement & Support for judgement \\
\hline $\begin{array}{l}\text { Random sequence genera- } \\
\text { tion (selection bias) }\end{array}$ & Low risk & $\begin{array}{l}\text { Quote: "scheduled for elective cesarean section and general anesthesia were } \\
\text { assigned by a randomized code to receive..." }\end{array}$ \\
\hline $\begin{array}{l}\text { Allocation concealment } \\
\text { (selection bias) }\end{array}$ & Unclear risk & Comment: no information provided \\
\hline $\begin{array}{l}\text { Blinding of participants } \\
\text { and personnel (perfor- } \\
\text { mance bias) } \\
\text { All outcomes }\end{array}$ & Unclear risk & Comment: anaesthesiologist: no information provided \\
\hline $\begin{array}{l}\text { Blinding of outcome as- } \\
\text { sessment (detection bias) } \\
\text { All outcomes }\end{array}$ & Unclear risk & Comment: assessor: no information provided \\
\hline $\begin{array}{l}\text { Incomplete outcome data } \\
\text { (attrition bias) } \\
\text { All outcomes }\end{array}$ & Low risk & Comment: no missing outcome data \\
\hline $\begin{array}{l}\text { Selective reporting (re- } \\
\text { porting bias) }\end{array}$ & Low risk & Comment: awareness outcome part of inclusion criteria \\
\hline Other bias & Unclear risk & Comment: insufficient information provided \\
\hline
\end{tabular}

\section{Schwender 1994}

\begin{tabular}{ll}
\hline Methods & Study design: randomized parallel groups \\
& Study dates: not stated \\
\hline Participants & Country: Germany \\
Sex: both & Age: $57.4,61.6,61.2,56.8$ \\
& ASA: NA \\
& Procedure: elective cardiac surgery \\
& Study size: 45 \\
Randomized portion of anaesthetic: parts of IV: opioid vs TIVA vs parts of balanced anaesthesia II \\
(volatile agent + supplemental narcotics \pm muscle relaxant) induction/maintenance:
\end{tabular}


IV vs TIVA vs volatile agent continuous administration (balanced II) + music implicit memory tests/MCI

Intervention 1: induction flunitrazepam $0.01 \mathrm{mg} / \mathrm{kg}$ + fentanyl $0.01 \mathrm{mg} / \mathrm{kg}$; maintenance flunitrazepam $1.2 \mathrm{mg} / \mathrm{h}, \mathrm{N}=10$

Intervention 2: induction etomidate $0.25 \mathrm{mg} / \mathrm{kg}$ and fentanyl $0.005 \mathrm{mg} / \mathrm{kg}$; maintenance isoflurane $(0.6$ to 1.2 vol\%), $\mathrm{N}=10$

Intervention 3: induction etomidate $0.25 \mathrm{mg} / \mathrm{kg}$ and fentanyl $0.005 \mathrm{mg} / \mathrm{kg}$; maintenance propofol $4 \mathrm{mg}$ to $8 \mathrm{mg} / \mathrm{kg} / \mathrm{h}, \mathrm{N}=10$

Intervention 4: the group 4 patients werenot exposed to the audiotape and those patients were assigned randomly to 1 of the 3 anaesthetic regimes, $N=15$

Audiotape with implicit memory task using the Robinson Crusoe story

Outcomes

Primary outcomes: implicit memory interview, MLAEP

Quote: "The main goals of this study were to determine whether explicit or implicit memory is present during cardiac surgery, and if so, whether memory functions can be related to specific characteristics of MLAEP."

Secondary outcome: awareness/wakefulness as defined using an awareness classification system (see Table 1): class 2

Quote: "No patient had a clear explicit memory of intraoperative events. However, there were statistically significant differences in the incidence of implicit recall among the groups. Five patients in the flunitrazepam- fentanyl group, 1 patient in the isoflurane-fentanyl group, 1 patient in the propofol-fentanyl group, and no patient in the control group showed an implicit memory"

Comment: implicit recall was related to continued presence of MLAEP

Notes

Randomized portion of anaesthetic: nitrous N/parts of IV: opioid vs TIVA vs parts of balanced anaesthesia II (volatile agent + supplemental narcotics \pm muscle relaxant)/muscle relaxants yes both induction/maintenance: ADM MLAEP

IV vs TIVA vs volatile agent continuous administration (balanced II) \pm music implicit memory tests/ADM MLAEP recorded

Premedication: benzodiazepine (flunitrazepam $1 \mathrm{mg}$ to $2 \mathrm{mg}$ orally) 45 to $60 \mathrm{~min}$ before anaesthesia. Anaesthesia maintenance: high-dose fentanyl analgesia $1.2 \mathrm{mg} / \mathrm{h}+$ pancuronium $0.1 \mathrm{mg} / \mathrm{kg}$. In addition, group 1 received flunitrazepam $(1.2 \mathrm{mg} / \mathrm{h})$, group 2 isoflurane ( 0.6 to $1.2 \mathrm{vol} \%)$, and group 3 propofol ( 4 to $8 \mathrm{mg} / \mathrm{kg} / \mathrm{h}$ ) to maintain general anaesthesia, pancuronium $0.1 \mathrm{mg} / \mathrm{kg}$. The patients of group $4(n=15)$ were randomly assigned to 1 of the 3 anaesthetic regimes. MALEP

Comment: see Dryad topic: details regarding this RCT's control group; implicit memory test, portions of novel Robinson Crusoe used as a parable; and associated with "Friday" and postoperative recovery

Comment: the ability to retrieve thememory of implicit tasks are a more sensitive measure of memory during anaesthesia than explicit tasks

Time of outcome determination: 3 to 5 hours in postoperative period

Method of outcome determination: interview

No email address available for ROB survey

\section{Risk of bias}


Schwender 1994 (Continued)
Random sequence genera- Unclear risk
Quote: "those patients were assigned randomly to one of the anaesthetic tion (selection bias)
regimes..."

\begin{tabular}{lll}
$\begin{array}{l}\text { Allocation concealment } \\
\text { (selection bias) }\end{array}$ & Unclear risk & Comment: no information provided \\
\hline $\begin{array}{l}\text { Blinding of participants } \\
\text { and personnel (perfor- } \\
\text { mance bias) }\end{array}$ & High risk & Comment: anaesthesiologist: see below \\
All outcomes & &
\end{tabular}

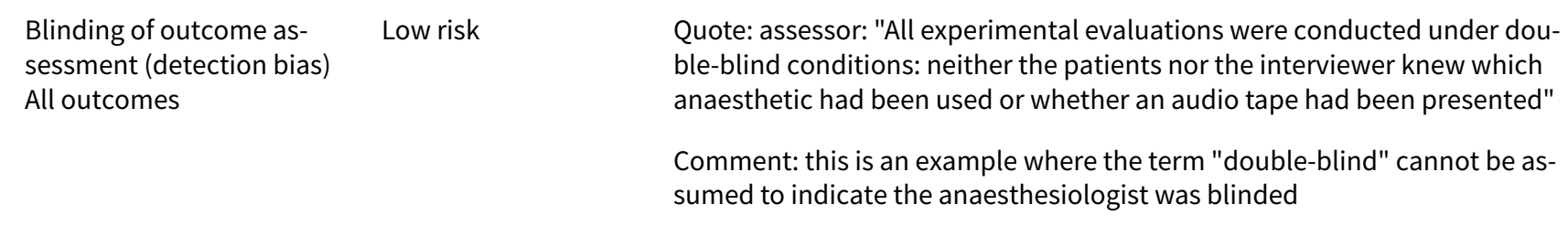

Incomplete outcome data Low risk $\quad$ Comment: no missing outcome data
(attrition bias)

All outcomes

\begin{tabular}{lll}
\hline $\begin{array}{l}\text { Selective reporting (re- } \\
\text { porting bias) }\end{array}$ & Low risk & Comment: awareness outcome part of inclusion criteria \\
\hline Other bias & Unclear risk & Comment: insufficient information provided \\
\hline
\end{tabular}

Schwender 1996

\begin{tabular}{ll}
\hline Methods & Study design: randomized parallel groups \\
& Study dates: not stated \\
\hline Participants & Country: Germany \\
Sex: both & Age: 21 to 79 \\
ASA: I-II & Procedure: elective gynaecological or urological laparotomy \\
Study size: 47
\end{tabular}

Randomized portion of anaesthetic: IV vs volatile agent
Comment: as per rules: $\mathbf{N}_{\mathbf{2}} \mathbf{O}$ used hence IV not TIVA anaesthesia
Intervention 1: induction: epidural + thiopentone $5 \mathrm{mg} / \mathrm{kg}$; maintenanceisoflurane 0.4 to $1.2 \mathrm{vol} \%, \mathrm{~N}=$
23
Intervention 2: induction: epidural + propofol $2 \mathrm{mg} / \mathrm{kg}$; maintenance propofol $3 \mathrm{mg}$ to $5 \mathrm{mg} / \mathrm{kg} / \mathrm{h}, \mathrm{N}=$
24

Outcomes

Primary outcomes: sensitivity of movement/specificity adequate anaesthesia associated with threshold levels of SEF 90 
Schwender 1996 (Continued)

Secondary outcome: awareness/wakefulness as defined using an awareness classification system (see Table 1): class 1

Quote: "No patient had explicit recall of intraoperative events"

Notes

Non-randomized portion of anaesthetic: regional anaesthesia: epidural and GETGA parts of TI-

VA vs parts of volatile agent/ $\mathrm{N}_{2} \mathrm{O}$ yes + supplemental narcotics + muscle relaxants yes both induction/maintenance ADM SEF recorded

Comment: as per rules: $\mathrm{N}_{\mathbf{2}} \mathrm{O}$ used hence IV not TIVA anaesthesia

Premedication: oral clorazepate (benzodiazepine) 45 to 60 minutes before surgery; anaesthesia induction: epidural + randomized inhalation vs IV + vecuronium $0.1 \mathrm{mg} / \mathrm{kg}+\mathbf{N}_{\mathbf{2}} \mathbf{O} 50 \%+\mathrm{O}_{2}$

Anaesthesia maintenance: see intervention maintenance; no muscle relaxants for maintenance

Comment: PSRT>2 or spontaneous movements defined light anesthesia

Comment: sensitivity $\mathbf{7 2} \%$ is number successfully predicted movements/total movements; specificity $\mathbf{8 2} \%$ number correctly predicted situations of adequate anaesthesia/number situations of adequate anaesthesia threshold $14 \mathrm{~Hz}$ GETA + epidural to minimize pain

Comment: there was no correlation between haemodynamic data and patient movement Comment epidural blocks spinal cord and ablates reflex movement

Comment: see Dryad topic purposeful movement in setting of NO reflex movement

Comment: see Dryad topic: wide range of BIS levels associated with transition into unconsciousness and consciousness under anaesthesia

No email address available for ROB survey

\section{Risk of bias}

\begin{tabular}{lll}
\hline Bias & Authors' judgement & Support for judgement \\
\hline $\begin{array}{l}\text { Random sequence genera- } \\
\text { tion (selection bias) }\end{array}$ & Unclear risk & Quote: "patients allocated randomly to 2 groups" \\
\hline $\begin{array}{l}\text { Allocation concealment } \\
\text { (selection bias) }\end{array}$ & Unclear risk & Comment: no information provided \\
\hline $\begin{array}{l}\text { Blinding of participants } \\
\text { and personnel (perfor- } \\
\text { mance bias) }\end{array}$ & Unclear risk & Comment: anaesthesiologist: no information provided \\
All outcomes & & \\
\hline
\end{tabular}

Blinding of outcome as- Unclear risk Comment: assessor: no information provided

sessment (detection bias)

All outcomes

Incomplete outcome data Low risk Comment: no missing outcome data
(attrition bias)
All outcomes

Selective reporting (re- Low risk Comment: awareness outcome part of inclusion criteria
porting bias)

Other bias Unclear risk Comment: insufficient information provided


Shin 2012

\begin{tabular}{|c|c|}
\hline Methods & $\begin{array}{l}\text { Study design: randomized parallel groups } \\
\text { Study dates: not stated }\end{array}$ \\
\hline Participants & $\begin{array}{l}\text { Country: Korea } \\
\text { Sex: female and male } \\
\text { Age: } 37-38 \\
\text { ASA: I } \\
\text { Procedure: elective orthopaedic or extremity surgeries } \\
\text { Study size: } 90\end{array}$ \\
\hline Interventions & $\begin{array}{l}\text { Randomized portion of anaesthetic: parts of volatile agent } 3 \text { doses } \pm \text { infusion of narcotics (TCI) } \\
\text { Intervention 1: maintenance: } 4 \% \text { to } 6 \% \text { inspired desflurane + target-controlled concentration (TCI) } 1 \\
\mathrm{ng} / \mathrm{mL}, \mathrm{N}=30 \\
\text { Intervention 2: maintenance: } 4 \% \text { to } 6 \% \text { inspired desflurane }+(\mathrm{TCl}) 2 \mathrm{ng} / \mathrm{mL} \text { remifentanil, } \mathrm{N}=30-2=28 \\
\text { Intervention } 3: 7 \% \text { to } 9 \% \text { inspired desflurane only without remifentanil infusion } \\
\text { BIS both groups, } \mathrm{N}=30\end{array}$ \\
\hline
\end{tabular}

Outcomes Primary outcomes: Quote: "optimal target-controlled concentration of remifentanil combined with desflurane, by using a more widely and decreasing end-tidal concentration of desflurane"

Secondary outcome: awareness/wakefulness as defined using an awareness classification system (see Table 1): class 1

Comment: awareness events: none

\section{Notes}

Non-randomized portion of anaesthetic: parts of volatile agent $/ \mathrm{N}_{2} \mathrm{O}$ no + muscle relaxants yes for both induction/maintenance/ADM BIS recorded

Induction propofol $2 \mathrm{mg} / \mathrm{kg}$ and lidocaine $0.5 \mathrm{mg} / \mathrm{kg}$, vecuronium $0.15 \mathrm{mg} / \mathrm{kg}$ IV intubation vecuronium $0.02 \mathrm{mg} /$ per stimulator algorithm

Comment: inhalation vs inhalation (balanced anaesthesia): desflurane vary ET with varied infusion rate remifentanil: BIS both groups

Comment: infusion remifentanil allows a wider range of volatile gent: see Dryad topic

Emailed Dr Shin, smkeun311@yahoo.co.kr, the ROB survey 3 January 2014

\section{Risk of bias}

\begin{tabular}{lll}
\hline Bias & Authors' judgement & Support for judgement \\
\hline $\begin{array}{l}\text { Random sequence genera- } \\
\text { tion (selection bias) }\end{array}$ & Low risk & $\begin{array}{l}\text { Quote: "Randomization into one of the three groups was based on an Excel } \\
\text { random-number generation" }\end{array}$ \\
\hline $\begin{array}{l}\text { Allocation concealment } \\
\text { (selection bias) }\end{array}$ & Unclear risk & $\begin{array}{l}\text { Comment: inadequate information provided } \\
\text { Quote: "...were registered and randomly allocated to receive either a tar- } \\
\text { get-controlled concentration" }\end{array}$ \\
\hline
\end{tabular}


Shin 2012 (Continued)
Blinding of participants
Unclear risk
Comment: no evidence of blinding. TIVA vs volatile agent. and personnel (performance bias)

All outcomes

\begin{tabular}{lll}
\hline $\begin{array}{l}\text { Blinding of outcome as- } \\
\text { sessment (detection bias) } \\
\text { All outcomes }\end{array}$ & Unclear risk & Comment: inadequate information provided \\
\hline $\begin{array}{l}\text { Incomplete outcome data } \\
\text { (attrition bias) }\end{array}$ & Low risk & $\begin{array}{l}\text { Comment: } 2 \text { patients excluded: systolic blood pressure was below } 90 \text { mmHg } \\
\text { (1 in group R2) and BIS }>60>=2 \text { min (1 in group R2) treated immediately. Post- } \\
\text { operative interview: no awareness report; following up with the awareness in- } \\
\text { terview in these } 2 \text { excluded patients allowed us to grade the missing data as } \\
\text { low risk. There was no significant difference between groups due to exclusions } \\
(2 / 60 \text { vs } 0 / 30), \text { Peto OR } 4.56(0.24 \text { to } 87.68)(P=0.31)\end{array}$ \\
\hline
\end{tabular}

\begin{tabular}{lll}
\hline $\begin{array}{l}\text { Selective reporting (re- } \\
\text { porting bias) }\end{array}$ & Low risk & Comment: awareness outcome part of inclusion criteria \\
\hline Other bias & Unclear risk & Comment: inadequate information provided \\
\hline
\end{tabular}

Sidi 1990

\begin{tabular}{ll}
\hline Methods & Study design: randomized parallel groups \\
Study dates: not stated
\end{tabular}

\begin{tabular}{ll}
\hline Participants & Country: Israel and USA \\
Sex: female and male \\
Age: 18 to 70 \\
ASA: III or IV \\
Procedure: elective cardiac surgery with cardiopulmonary bypass (CPB): CABG, aortic valve replace- \\
ment with/without mitral valve replacement, and mitral valve replacement with tricuspid valve valvu- \\
loplasty \\
Study size: 32,29 \\
Randomized portion of anaesthetic: parts of intravenous (IV) anaesthesia for intubation only: \\
ADM: EEG/CSA vs SCP \\
Intervention $1:$ induction: fentanyl $50 \mu \mathrm{g} / \mathrm{kg}$ with no EEG monitoring, $\mathrm{N}=16$ \\
Intervention $2:$ induction: fentanyl 25 to $50 \mu \mathrm{g}$ based on changes in EEG, $\mathrm{N}=16$ \\
\hline $\begin{array}{l}\text { Primary outcomes: EEG associated haemodynamic changes secondary to induction/laryngoscopy } \\
\text { Secondary outcome: awareness/wakefulness as defined using an awareness classification system (see } \\
\text { Table } 1): \text { class } 1\end{array}$ \\
Quote: "No patient in either group had recall”
\end{tabular}

Notes

Non-randomized portion of anaesthetic: parts of intravenous (IV) anaesthesia for intubation on$\mathrm{ly} / \mathrm{N}_{2} \mathrm{O}$ no: muscle relaxants induction yes 
Sidi 1990 (Continued)

Premed: morphine $10 \mathrm{mg}$ IM/diazepam $10 \mathrm{mg}$ PO; induction:midazolam ( 0.015 to $0.03 \mathrm{mg} / \mathrm{kg}$ ), and fentanyl ( 25 to $50 \mu \mathrm{g} / \mathrm{kg}$ )/pancuronium $(0.15 \mathrm{mg} / \mathrm{kg}) 100 \% \mathrm{O}_{2}$, volatile anaesthetics were not used before endotracheal intubation

Comment: IV anaesthesia intubation titrated to fentanyl; dose based on EEGs vs control: fixed dose; IV vs IV: ADM: EEG: CSA: open/closed

Comment: authors describe technique as IV anaesthesia for induction; no post intubation description of maintenance anaesthesia

\section{Inadequate anaesthesia protocol (see Dryad)}

No email address available for ROB survey

\section{Risk of bias}

\begin{tabular}{|c|c|c|}
\hline Bias & Authors' judgement & Support for judgement \\
\hline $\begin{array}{l}\text { Random sequence genera- } \\
\text { tion (selection bias) }\end{array}$ & Unclear risk & $\begin{array}{l}\text { Quote: "16 were randomly assigned to be monitored with continuous EEG } \\
\text { starting immediately before anesthetic induction. The remaining patients } \\
\text { were monitored as the others but without EEG" }\end{array}$ \\
\hline $\begin{array}{l}\text { Allocation concealment } \\
\text { (selection bias) }\end{array}$ & Unclear risk & Comment: inadequate information provided \\
\hline $\begin{array}{l}\text { Blinding of participants } \\
\text { and personnel (perfor- } \\
\text { mance bias) } \\
\text { All outcomes }\end{array}$ & Unclear risk & Comment: inadequate information provided \\
\hline $\begin{array}{l}\text { Blinding of outcome as- } \\
\text { sessment (detection bias) } \\
\text { All outcomes }\end{array}$ & Unclear risk & $\begin{array}{l}\text { Quote: "None of the patients in the two groups reported recall of induction, in- } \\
\text { tubation, or intraoperative events" }\end{array}$ \\
\hline $\begin{array}{l}\text { Incomplete outcome data } \\
\text { (attrition bias) } \\
\text { All outcomes }\end{array}$ & Low risk & $\begin{array}{l}\text { Comment: if hypertension persisted or tachycardia occurred before or during } \\
\text { induction, the patient was excluded from the study } \\
\text { EEG group } 2 \text { exclusions with missing data; SCP group (fixed fentanyl dose) } 3 \\
\text { exclusions } 1 \text { hypertension peri-intubation, } 2 \text { died on CPB; NS }(2 / 16 \text { vs } 3 / 16) \text {, } \\
\text { Peto OR } 0.63(0.10 \text { to } 4.13)(P=0.63) \text {; NS also for high-risk awareness analysed } \\
\text { as a subgroup: }(0 / 16 \text { vs } 3 / 16) \text { Peto OR } 0.12 \text { ( } 0.01 \text { to } 1.22)(P=0.07)\end{array}$ \\
\hline $\begin{array}{l}\text { Selective reporting (re- } \\
\text { porting bias) }\end{array}$ & Low risk & Comment: awareness outcome part of inclusion criteria \\
\hline Other bias & Unclear risk & Comment: inadequate information provided \\
\hline
\end{tabular}

Smith 1999

\begin{tabular}{ll}
\hline Methods & Study design: randomized parallel groups \\
& Study dates: not stated \\
\hline Participants & Country: USA \\
Sex: male and female \\
ASA: I-II
\end{tabular}


Smith 1999 (Continued)

\author{
Age: 18 to 65 \\ Procedure: any elective surgery \\ Study size: 101 enrolled, 81 completed surgery 20\% (20/101) dropped out
}

\begin{tabular}{|c|c|}
\hline \multirow[t]{6}{*}{ Interventions } & $\begin{array}{l}\text { Randomized portion of anaesthetic: parts of intravenous (IV) - TIVA vs inhalational anaest } \\
\text { midazolam vs sevoflurane }\end{array}$ \\
\hline & Intervention 1: maintenance: midazolam $0.540 \mu \mathrm{g} / \mathrm{kg}+$ fentanyl $4.5 \mu \mathrm{g} / \mathrm{kg} / \mathrm{h}+\mathrm{N}_{2} \mathrm{O} 50 \%, \mathrm{~N}=23$ \\
\hline & Intervention 2: intervention $1+$ word test, $\mathrm{N}=28$ \\
\hline & Intervention 3: maintenance: $1.4 \%$ ET sevoflurane + fentanyl $+50 \% \mathrm{~N}_{2} \mathrm{O}, \mathrm{N}=25$ \\
\hline & Intervention 4: intervention $3+$ word test given and correlated with, $\mathrm{N}=25$ \\
\hline & Auditory middle latency response (AMLR) recorded all groups \\
\hline
\end{tabular}

Outcomes Primary outcomes: response from stem-word completion test

Secondary outcome: awareness/wakefulness as defined using an awareness classification system (see Table 1): class 4

Comment: awareness: 2 midazolam group: 1 heard auditory clicks, 1 felt drill pressing into his leg

Comment: implicit memory (defined: completion of word stem test) compared to control group: patient scores: sevoflurane no relationship $(P=0.07)$; midazolam $(P=0.07)$

\title{
Notes
}

\section{Non-randomized portion of anaesthetic: $\mathrm{N}_{2} \mathrm{O}$ yes/parts of intravenous (IV) vs inhalational anaes- thesia: midazolam vs sevoflurane/muscle relaxants induction yes/PRN maintenance: AMLR recorded: implicit memory test}

IV group: induction: lidocaine $20 \%$, propofol $1.5 \mathrm{mg}$ to $2.5 \mathrm{mg} / \mathrm{kg}$, fentanyl $1.0 \mu \mathrm{g}$ to $3.5 \mu \mathrm{g} / \mathrm{kg}$, succinylcholine $1.5 \mathrm{mg} / \mathrm{kg}$ or atracurium $0.4 \mathrm{mg} / \mathrm{kg} /$ intubation; maintenance: midazolam $0.54 \mu \mathrm{g} / \mathrm{kg}$, fentanyl $4.5 \mathrm{\mu g} / \mathrm{h}, 50 \% \mathbf{N}_{\mathbf{2}} \mathbf{O} 50 \% \mathrm{O}_{2}$, all infusions except atracurium PRN

Inhalational group: maintenance: sevoflurane $1.4 \% \mathrm{ET}$, fentanyl $1.4 \mu \mathrm{g} / \mathrm{kg} / \mathrm{h}, \mathrm{N}_{2} \mathrm{O} 50 \%$

Comment: see Dryad topics: AMLRs association to implicit memory, defined IV anaesthesia includes $\mathrm{N}_{2} \mathrm{O}$

No email address available for ROB survey

\section{Risk of bias}

\begin{tabular}{lll}
\hline Bias & Authors' judgement & Support for judgement \\
\hline $\begin{array}{l}\text { Random sequence genera- } \\
\text { tion (selection bias) }\end{array}$ & Unclear risk & Quote: "randomly assigned" \\
\hline $\begin{array}{l}\text { Allocation concealment } \\
\text { (selection bias) }\end{array}$ & Unclear risk & Comment: no information \\
\hline $\begin{array}{l}\text { Blinding of participants } \\
\begin{array}{l}\text { and personnel (perfor- } \\
\text { mance bias) }\end{array}\end{array}$ & Unclear risk & Quote: "double blinded" \\
All outcomes & \\
\hline $\begin{array}{l}\text { Blinding of outcome as- } \\
\text { sessment (detection bias) }\end{array}$ & Unclear risk & Quote: "double blinded" \\
\hline
\end{tabular}


Smith 1999 (Continued)

All outcomes

Incomplete outcome data Low risk (attrition bias)

All outcomes
Comment: $18 \%$ of patients enrolled were excluded from statistical analysis: of 101, 12 eliminated due technical issues related to AMLR recording and memory testing; 6 excluded due to lack of preoperative implicit memory tests (groups not specified) - these do not impact awareness rate; 2 midazolam patients excluded: postoperative explicit memory (awareness)

There is no significant difference between groups if we analyse the awareness rates by adding the 2 patient awareness reports to the midazolam group in an intention-to-treat analysis ( $\mathrm{N}=101$, Peto OR 7.39 (0.46 to 119.86)) and after the non-high awareness risk patients were excluded ( $N=89$, Peto OR 6.79 ( 0.42 to 110.77), $\mathrm{N}=83$, Peto OR 6.75 (0.41 to 110.34 ))

\begin{tabular}{lll}
\hline $\begin{array}{l}\text { Selective reporting (re- } \\
\text { porting bias) }\end{array}$ & Low risk & Comment: awareness outcome part of inclusion criteria \\
\hline Other bias & Unclear risk & Comment: no information \\
\hline
\end{tabular}

\section{Song 1997}

\begin{tabular}{ll}
\hline Methods & Study design: randomized parallel groups \\
& Study dates: not stated \\
\hline Participants & Country: USA \\
Sex: female & Age: 27,28 \\
Procedure: laparoscopic tubal ligation \\
Study size: 60
\end{tabular}

Interventions

Randomized portion of anaesthetic: parts of volatile agent/ADM (BIS 60) vs SCP

Groups I and II: maintenance: desflurane, $2 \%$ to $5 \%$, BIS open (60) vs closed (SCP), N = 30

Group III and IV: maintenance: sevoflurane, $0.7 \%$ to $2 \%$, BIS open (60) vs closed (SCP), N = 30

Outcomes

Primary outcomes: times to awakening and extubation

Secondary outcome: awareness/wakefulness as defined using an awareness classification system (see Table 1): class 1

Quote: "None of the patients reported recall of intraoperative events when questioned at the time of discharge from the hospital"

\section{Notes Non-randomized portion of anaesthetic: parts of volatile agent $/ \mathrm{N}_{2} \mathrm{O} /$ supplemental nar-
cotics/muscle relaxants yes for both induction/maintenance/ADM (BIS) vs SCP}

Control groups (Groups I and III), volatile anaesthetics administered: standard clinical practice, anaesthesiologists blinded to BIS value

Induction: midazolam (2 mg), fentanyl $1 \mu \mathrm{g} / \mathrm{kg}$, propofol $2 \mathrm{mg} / \mathrm{kg}$, succinylcholine, $1 \mathrm{mg} / \mathrm{kg}$, and lidocaine $4 \%(4 \mathrm{~mL})$

Maintenance: group assignment $+\mathrm{N}_{2} \mathrm{O} 1 \mathrm{~L} / \mathrm{min}(65 \%)$, in oxygen, $0.7 \mathrm{~L} / \mathrm{min}$, mivacurium used 
In the BIS-titrated groups (Groups II and IV): the volatile anaesthetics were titrated toBIS $\mathbf{6 0}$

All patients were mechanically ventilated

Comment: BIS 60 as titration endpoint used in Vakkuri 2000

See Dryad topic light anaesthesia with BIS; underpowered studies and type II error

Emailed ROB survey pwhite@medner.swmed.edu 03 January 2014 - failed

\section{Risk of bias}

\begin{tabular}{|c|c|c|}
\hline Bias & Authors' judgement & Support for judgement \\
\hline $\begin{array}{l}\text { Random sequence genera- } \\
\text { tion (selection bias) }\end{array}$ & Low risk & Quote: "computer-generated random numbers table" \\
\hline $\begin{array}{l}\text { Allocation concealment } \\
\text { (selection bias) }\end{array}$ & Unclear risk & Comment: no information provided \\
\hline $\begin{array}{l}\text { Blinding of participants } \\
\text { and personnel (perfor- } \\
\text { mance bias) } \\
\text { All outcomes }\end{array}$ & High risk & $\begin{array}{l}\text { Quote: "One of the criticisms of this study is the possibility of bias as a result of } \\
\text { the lack of a double-blind design. However, this clinical investigation was con- } \\
\text { ducted in the context of standard clinical practice, and routine blinding proce- } \\
\text { dures would not be appropriate" }\end{array}$ \\
\hline $\begin{array}{l}\text { Blinding of outcome as- } \\
\text { sessment (detection bias) } \\
\text { All outcomes }\end{array}$ & Unclear risk & Comment: assessor: no information provided \\
\hline $\begin{array}{l}\text { Incomplete outcome data } \\
\text { (attrition bias) } \\
\text { All outcomes }\end{array}$ & Low risk & Comment: no missing outcome data \\
\hline $\begin{array}{l}\text { Selective reporting (re- } \\
\text { porting bias) }\end{array}$ & Low risk & Comment: awareness outcome part of inclusion criteria \\
\hline Other bias & Unclear risk & Comment: insufficient information provided \\
\hline
\end{tabular}

\section{Sorbara 1995}

\begin{tabular}{ll}
\hline Methods & Study design: randomized parallel groups \\
& Study dates: not stated \\
\hline Participants & Country: Italy \\
Sex: both & Age: 37 to 70 \\
ASA: NA & Procedure: CABG: normal-moderately impaired LV function (ejection fraction $\sim 40 \%)$ as assessed by pre- \\
operative LV cineangiography and LV end-diastolic pressure $<=18 \mathrm{mmHg}$ \\
Study size: 30
\end{tabular}


Sorbara 1995 (Continued) Interventions

Randomized portion of anaesthetic: parts of volatile agent

Intervention 1: maintenance before sternotomy propofol $3 \mathrm{mg} / \mathrm{kg} / \mathrm{h}(\mathrm{N}=15)$

Intervention 2: maintenance before sternotomy isoflurane $0.6 \%$ (IF group) ( $N=15$ )

Primary outcomes: assessment of LV contractility
Secondary outcome: awareness/wakefulness as defined using an awareness classification system (see
Table 1): class 1
Comment: no patient of either group experienced dreaming or had any recall of operative events when
questioned

Notes
Non-randomized portion of anaesthetic: $\mathrm{N}_{2} \mathrm{O}$ yes/parts of volatile agent + supplemental narcotics + muscle relaxants: yes both induction/maintenance

Premedication flunitrazepam $2 \mathrm{mg}$, orally 90 minutes before surgery

Anaesthesia induction: thiopental $1 \mathrm{mg} / \mathrm{kg}$, fentanyl $20 \mu \mathrm{g} / \mathrm{kg}$, and vecuronium $0.1 \mathrm{mg} / \mathrm{kg}$

Maintenance after sternotomy boluses $(5 \mu \mathrm{g} / \mathrm{kg}$ ) fentanyl (max maintenance dose $30 \mu \mathrm{g} / \mathrm{kg}$ ): prophylactic: blunt/intense periods pain/autonomic stimulation (e.g. sternal splitting and spread, aortic mobilization, cannulation, decannulation, and sternal closure) $0.025 \mathrm{mg} / \mathrm{kg}$ pancuronium $/ \mathrm{h}$

Comment: light anaesthesia techniques resulted from the need to use a ceiling dose of IV moderate to long acting anaesthetics in order to extubate the patient at the end of the case; ceiling dose

Time of outcome determination: 2 days and 1 week postoperative

Method of outcome determination: interview

ROB survey sent via email to secondary author on 17 January 2011. No response received yet.

\section{Risk of bias}

\begin{tabular}{|c|c|c|}
\hline Bias & Authors' judgement & Support for judgement \\
\hline $\begin{array}{l}\text { Random sequence genera- } \\
\text { tion (selection bias) }\end{array}$ & Unclear risk & $\begin{array}{l}\text { Quote: "On the day before surgery, the patients were randomly allocated to ei- } \\
\text { ther the PF }(N=15) \text { or IF }(N=15) \text { group" }\end{array}$ \\
\hline $\begin{array}{l}\text { Allocation concealment } \\
\text { (selection bias) }\end{array}$ & Unclear risk & Comment: no information provided \\
\hline $\begin{array}{l}\text { Blinding of participants } \\
\text { and personnel (perfor- } \\
\text { mance bias) } \\
\text { All outcomes }\end{array}$ & Unclear risk & Comment: anaesthesiologist: no information provided \\
\hline $\begin{array}{l}\text { Blinding of outcome as- } \\
\text { sessment (detection bias) } \\
\text { All outcomes }\end{array}$ & Unclear risk & $\begin{array}{l}\text { Quote: "All patients were questioned } 2 \text { days and I week postoperatively about } \\
\text { dreaming or recall of operative events" }\end{array}$ \\
\hline $\begin{array}{l}\text { Incomplete outcome data } \\
\text { (attrition bias) } \\
\text { All outcomes }\end{array}$ & Low risk & Comment: no missing outcome data \\
\hline $\begin{array}{l}\text { Selective reporting (re- } \\
\text { porting bias) }\end{array}$ & Low risk & Comment: awareness outcome part of inclusion criteria \\
\hline
\end{tabular}


Sorbara 1995 (Continued)

Other bias Unclear risk Comment: insufficient information provided

Soyannwo 1988

Methods Study design: randomized parallel groups

Study dates: NA

Country: Nigeria
Sex: female
Age: $28-29$
ASA: all patients were classified as ASA I or II
Procedure: elective or emergency caesarian section
Study size: 150

Interventions

Randomized portion of anaesthetic: parts of intravenous (IV) anaesthesia: pethidine (meperidine) $(25 \mathrm{mg}$ ) and pethidine ( $25 \mathrm{mg}$ ) plus flunitrazepam (benzodiazepine)

Intervention 1: maintenance Group A - 25 mg pethidine (control), N = 50

Intervention 2: maintenance Group B - $25 \mathrm{mg}$ pethidine + flunitrazepam $0.015 \mathrm{mg} / \mathrm{kg}$ body weight (experiment subcat 1$), \mathrm{N}=50$

Intervention 3: maintenance Group C - $25 \mathrm{mg}$ pethidine + flunitrazepam $0.030 \mathrm{mg} / \mathrm{kg}$ body weight (experiment subcat 2), $\mathrm{N}=50$

\section{Outcomes}

Primary outcomes: Quote: "Effect of flunitrazepam (Rohypnol) on awareness during anaesthesia for Caesarian section". Awareness/wakefulness as defined using an awareness classification system (see Table 1): class 4

Comment: awareness - Group A 14/50 (28\%), Group B - 10/50 (20\%), Group C - 2/50 (4\%); total awareness incidence $17 \%(26 / 150)$

Quote: "...six felt pain at the beginning of surgery while three felt pain throughout the procedure"

Non-randomized portion of anaesthetic: $\mathrm{N}_{2} \mathrm{O}$ yes/parts of intravenous (IV) anaesthesia: $\mathrm{N}_{2} \mathrm{O} /$ nar-
cotic/hypnotic/muscle relaxants yes both induction/maintenance

Anaesthesia induction: $250 \mathrm{mg}$ thiopentone sodium intravenously $+0.6 \mathrm{mg}$ atropine $+100 \mathrm{mg}$ suxamethonium chloride. Anaesthesia maintenance: $\mathbf{N}_{\mathbf{2}} \mathbf{O}$ and oxygen $41: 21 / \mathrm{min}$, and pancuronium bromide or fazadinium bromide in appropriate doses. After delivery pethidine (analgesic) + flunitrazepam

Comment: the technique using intravenous agents and $\mathrm{N}_{2} \mathrm{O}$ is not described by author as intravenous technique etc.

The incidence of awareness during obstetric anaesthesia: see Dryad topic frequency awareness with nitrous-based techniques

Time of outcome determination: within $72 \mathrm{~h}$

Method of outcome determination: questionnaire

No email address available for ROB survey 
Soyannwo 1988 (Continued)

\begin{tabular}{|c|c|c|}
\hline Bias & Authors' judgement & Support for judgement \\
\hline $\begin{array}{l}\text { Random sequence genera- } \\
\text { tion (selection bias) }\end{array}$ & Unclear risk & Quote: "They were randomly divided into three groups of 50 patients each" \\
\hline $\begin{array}{l}\text { Allocation concealment } \\
\text { (selection bias) }\end{array}$ & Unclear risk & Comment: no information provided \\
\hline $\begin{array}{l}\text { Blinding of participants } \\
\text { and personnel (perfor- } \\
\text { mance bias) } \\
\text { All outcomes }\end{array}$ & Unclear risk & Comment: anaesthesiologist: no information provided \\
\hline $\begin{array}{l}\text { Blinding of outcome as- } \\
\text { sessment (detection bias) } \\
\text { All outcomes }\end{array}$ & Unclear risk & Comment: assessor: no information provided \\
\hline $\begin{array}{l}\text { Incomplete outcome data } \\
\text { (attrition bias) } \\
\text { All outcomes }\end{array}$ & Low risk & Comment: no missing outcome data \\
\hline $\begin{array}{l}\text { Selective reporting (re- } \\
\text { porting bias) }\end{array}$ & Low risk & Comment: awareness outcome part of inclusion criteria \\
\hline Other bias & Unclear risk & Comment: insufficient information provided \\
\hline
\end{tabular}

Staikou 2013

$\begin{array}{ll}\text { Methods } & \text { Study design: randomized parallel groups } \\ & \text { Study dates: } 3 \text { November } 2008 \text { to } 14 \text { July } 2011 \\ \text { Participants } & \text { Country: Greece } \\ & \text { Sex: male/female } \\ & \text { Age: } 20 \text { to } 70 \text { years old } \\ \text { ASA: I-II } & \text { Procedure: surgery under general anaesthesia (specific type not described) } \\ & \text { Study size: } 84 \\ & 84 \text { enrolled - } 78 \text { started - } 72 \text { completed study }\end{array}$

\begin{tabular}{ll}
\hline Interventions & Randomized portion of anaesthetic: parts of intravenous (IV) anaesthesia for intubation only: li- \\
docaine vs placebo (saline)
\end{tabular}

Intervention 1: normal saline

Intervention 2: lidocaine 1.5 mg/kg

\begin{tabular}{|c|c|}
\hline \multirow[t]{3}{*}{ Outcomes } & $\begin{array}{l}\text { Primary outcomes: the impact of lidocaine pretreatment on BIS values on rapid sequence induction } \\
\text { and intubation (RSII) }\end{array}$ \\
\hline & $\begin{array}{l}\text { Secondary outcomes: awareness/wakefulness as defined using an awareness classification system (see } \\
\text { Table 1): class } 1\end{array}$ \\
\hline & Comment: "none of the patients reported awareness/recall of the procedure" \\
\hline Notes & $\begin{array}{l}\text { Non-randomized portion of anaesthetic: parts of intravenous (IV) anaesthesia for intubation/ } \mathrm{N}_{2} \mathrm{O} \\
\text { yes only: maintenance: no information BIS recorded }\end{array}$ \\
\hline
\end{tabular}




\section{No post-intubation anaesthetic technique described: classified as "other" technique}

Propofol $2 \mathrm{mg} / \mathrm{kg}$, lidocaine or normal saline and rocuronium $1 \mathrm{mg} / \mathrm{kg}$, trachea was intubated; difficult intubation excluded

ET CO 35 to $40 \mathrm{mmHg}$ and sevoflurane $1 \% \mathrm{ET} / \mathbf{N}_{\mathbf{2}} \mathbf{O}$-oxygen mixture $\left(\mathrm{FIO}_{2}: 0.45\right)$. Opioids spared during the study period; BIS scores recorded by investigator blinded to patient's allocation group

Chryssoula Staikou MD email: c_staikou@yahoo.gr; ROB survey email sent 25 January 2015; email query re: maintenance anaesthetic, signs of light anaesthesia 22 March 2015; response on 24 March 2015

\section{Risk of bias}

Bias Authors' judgement Support for judgement

Random sequence genera- Unclear risk tion (selection bias)
Quote: "The study is also registered in the ClinicalTrials.gov protocol registration system (NCT01238718)"

Quote from ROB survey response: "Patients were randomly assigned by the use of sealed envelopes describing the group of assignment"

\begin{tabular}{|c|c|c|}
\hline $\begin{array}{l}\text { Allocation concealment } \\
\text { (selection bias) }\end{array}$ & Unclear risk & $\begin{array}{l}\text { Quote from ROB survey response: "Patients were randomly assigned by the } \\
\text { use of sealed envelopes describing the group of assignment" }\end{array}$ \\
\hline
\end{tabular}

Blinding of participants Low risk and personnel (performance bias)

All outcomes

Quote from ROB survey response: "The patients received either lidocaine $1.5 \mathrm{mg} / \mathrm{kg}$ or normal saline, both prepared... an independent investigator ...The anaesthesiologist (other investigator) was blinded to group allocation...Recordings were made by the anaesthesiologist who was blinded to patient's allocation group"

Comment: assume that the syringes are blinded

\begin{tabular}{|c|c|c|}
\hline $\begin{array}{l}\text { Blinding of outcome as- } \\
\text { sessment (detection bias) }\end{array}$ & Unclear risk & $\begin{array}{l}\text { Quote from ROB survey response: "...investigators interviewed patients about } \\
\text { awareness during surgery with an informal interview..." }\end{array}$ \\
\hline
\end{tabular}

Incomplete outcome data Low risk Comment: 84 patients enrolled, 6 excluded: 4 for technical reasons and 2 (attrition bias) for airway problems during intubation that made them high-risk awareness All outcomes dropouts. The 2 were balanced between both groups; hence no downgrade, Peto OR 0.89 (0.05 to 14.63 )

\begin{tabular}{|c|c|c|}
\hline $\begin{array}{l}\text { Selective reporting (re- } \\
\text { porting bias) }\end{array}$ & Low risk & $\begin{array}{l}\text { Quote from ROB survey response: "The study protocol is available and all of } \\
\text { the study's pre-specified (primary and secondary) outcomes that are of inter- } \\
\text { est in the review have been reported in the pre-specified way." } \\
\text { Comment: awareness outcome part of inclusion criteria }\end{array}$ \\
\hline Other bias & Low risk & $\begin{array}{l}\text { Quote from ROB survey response: "all results were reported. There may be } \\
\text { some limitations in the study: the lag time of the used monitor... we do not } \\
\text { consider that it affected our results... timing of administration of the drug (li- } \\
\text { docaine = intervention) ...clearly described in the manuscript ... " }\end{array}$ \\
\hline
\end{tabular}

Methods Study design: randomized parallel groups


Stoppe 2012 (Continued)

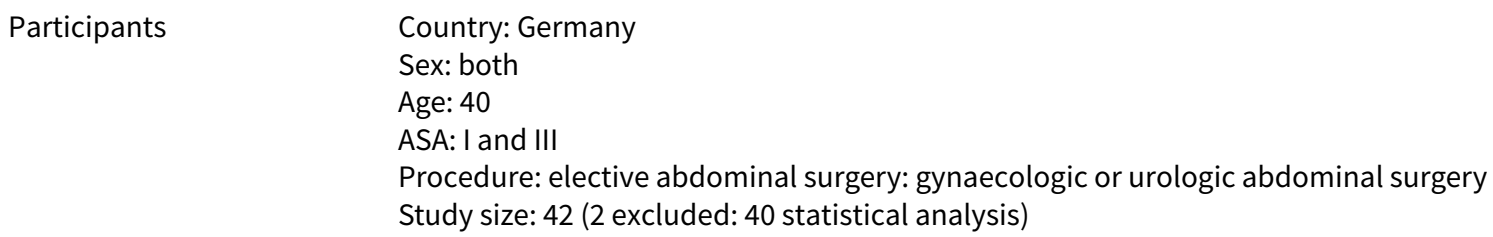

Secondary outcome: awareness/wakefulness as defined using an awareness classification system (see Table 1): class 1

Quote: "After clinical observation and postoperative Brice interview, no signs of awareness were recorded"

\section{Notes}

\section{Non-randomized portion of anaesthetic: $\mathrm{N}_{2} \mathrm{O}$ no/parts of volatile agent + infusion of narcotics + muscle relaxant(s) induction yes/maintenance unclear/ADM (BIS/AEP) vs SCP recorded simultane- ously}

Balanced volatile inhalation (narcotic supplementation, remifentanil infusion): ADM (AEP) vs SCP: xenon vs sevoflurane (AeP compared BIS)/remifentanil infusion

Induction: propofol/remifentanil infusion/rocuronium; maintained by remifentanil $(0.15 \mu \mathrm{g} / \mathrm{kg} / \mathrm{m})$ and either sevoflurane (1 to 1.4 vol\% MAC) or xenon (53 to 56 vol\% MAC)

Intraoperative awareness Brice questionnaire at $2 \mathrm{~h}$ and $12 \mathrm{~h}$ after anaesthesia

Primary outcome: "auditory-evoked potentials as assessed by aepEX monitor...xenon...aepEX-derived values: compared: BIS and control group with sevoflurane"

Secondary endpoints: relevant outcome and recovery parameters: "Aldrete and Myles score and assessment: intraoperative awareness"

ROB survey response mcoburn@ukaachen.de

\section{Risk of bias}

\begin{tabular}{lll}
\hline Bias & Authors' judgement & Support for judgement \\
\hline $\begin{array}{ll}\text { Random sequence genera- } \\
\text { tion (selection bias) }\end{array}$ & Low risk & $\begin{array}{l}\text { Comment: the study was registered at the European Medicines Agency (Eu- } \\
\text { draCT number: 2008-004132-20) and at ClinicalTrials.gov (NCT number: }\end{array}$ \\
& $\begin{array}{l}\text { 00793663). Nonetheless, there are no details about the method of random- } \\
\text { ized allocation and other domains; ROB survey: "computer based random- } \\
\text { ization" }\end{array}$
\end{tabular}

\begin{tabular}{|c|c|c|}
\hline $\begin{array}{l}\text { Allocation concealment } \\
\text { (selection bias) }\end{array}$ & Unclear risk & $\begin{array}{l}\text { Comment: ADMs are blinded to anaesthesiologist; description of sealed } \\
\text { opaque envelope or similar concealment protocols not clear; emailed on } 20 \\
\text { April } 2015 \text { for clarification }\end{array}$ \\
\hline
\end{tabular}

Blinding of participants High risk
and personnel (perfor-
mance bias)
Quote: "The performing attending anaesthetist was blinded to the BIS and
aepEX values"

Comment: not blinded to SCPS 
Stoppe 2012 (Continued)

All outcomes

\begin{tabular}{|c|c|c|}
\hline $\begin{array}{l}\text { Blinding of outcome as- } \\
\text { sessment (detection bias) }\end{array}$ & Low risk & $\begin{array}{l}\text { Quote: "...Brice questionnaire was performed at } 2 \text { and } 12 \mathrm{~h} \text { after end of anaes- } \\
\text { thesia by an independent physician" }\end{array}$ \\
\hline
\end{tabular}

All outcomes

\begin{tabular}{|c|c|c|}
\hline $\begin{array}{l}\text { Incomplete outcome data } \\
\text { (attrition bias) } \\
\text { All outcomes }\end{array}$ & Low risk & $\begin{array}{l}\text { Comment: } 1 \text { high-risk awareness dropout in xenon group is not significantly } \\
\text { different from control group if we assume that dropout would have submitted } \\
\text { an awareness report, Peto OR } 7.39 \text { ( } 0.15 \text { to } 372.38)\end{array}$ \\
\hline
\end{tabular}

\begin{tabular}{|c|c|c|}
\hline $\begin{array}{l}\text { Selective reporting (re- } \\
\text { porting bias) }\end{array}$ & Low risk & $\begin{array}{l}\text { Comment: ROB survey: states that there was no selective reporting } \\
\text { Comment: awareness outcome part of inclusion criteria }\end{array}$ \\
\hline Other bias & Low risk & $\begin{array}{l}\text { Quote ROB survey: "1. xenon anaesthesia ...not commonly used... 3...BIS mon- } \\
\text { itoring ...shown to provide reliable measurement of hypnotic depth, the va- } \\
\text { lidity of this monitoring remains controversial. Therefore ...AepEX monitoring } \\
\text { does not necessarily reflect a true assessment of anaesthetic depth but can } \\
\text { only state that hypnotic depth monitoring using aepEx was comparable to BIS } \\
\text { measurement and clinical evaluation" }\end{array}$ \\
\hline & & $\begin{array}{l}\text { Comment: these can be described as possible causes of diversity rather than } \\
\text { form of internal bias (other bias) }\end{array}$ \\
\hline
\end{tabular}

\section{Stuttmann 2010}

\begin{tabular}{ll} 
Methods & Study design: randomized parallel groups \\
& Study date: Quote: "1/2003 - 12/2004" (email bias survey, see notes) \\
\hline Participants & Country: Germany \\
Sex: both & Age: 40 \\
ASA: I and II \\
Procedure: lumpectomy, mammoplasty, liposuction, arthroscopy \\
Study size: 61
\end{tabular}

$\begin{array}{ll}\text { Interventions } & \text { Randomized portion of anaesthetic: volatile agent types } \\ \text { Intervention 1: maintenance: } x e n o n(E T 63 \%)(\mathrm{N}=31) \\ \text { Intervention 2: maintenance: isoflurane in } \mathrm{N}_{2} \mathrm{O}(\mathrm{ET} 0.6 \%)(\mathrm{N}=30)\end{array}$

\section{Outcomes}

Primary outcomes: compare xenon with isoflurane anaesthesia impact on early cognitive recovery with the syndrome short test (SST)

Secondary outcome: awareness/wakefulness as defined using an awareness classification system (see Table 1): class 0

Quote: "no patient reported awareness on the visit one day postoperatively"

Notes

Non-randomized portion of anaesthetic: $\mathrm{N}_{2} \mathrm{O}$ yes/parts of volatile agent + infusion of narcotics $\mathrm{MCI}+$ muscle relaxant(s) induction yes/maintenance none/BIS 40 
Stuttmann 2010 (Continued)

Anaesthesia induction: propofol ( $1 \mathrm{mg}$ to $2 \mathrm{mg} / \mathrm{kg} \mathrm{IV}$ ) + propofol, $0.003 \mathrm{mg} / \mathrm{kg}$ fentanyl and $0.6 \mathrm{mg} / \mathrm{kg}$ + rocuronium

Anaesthesia maintenance: see interventions; infused propofol/fentanyl ( $0.0015 \mathrm{mg} / \mathrm{kg} \mathrm{BW}) \mathrm{PRN}$.

Rocuronium bromide was not repeated during the operation

Time of outcome determination: 1 day after surgery

Method of outcome determination: interview

ROB survey email sent 21 February 2011

Email survey response: 25 February 2011, Stuttmann ralph.stuttmann@bergmannstrost.com

Author sent characteristics and ROB table grades for comment 8 December 2013: ralph.stuttmann@bergmannstrost.com

\section{Risk of bias}

\begin{tabular}{lll}
\hline Bias & Authors' judgement & Support for judgement \\
\hline $\begin{array}{l}\text { Random sequence genera- } \\
\text { tion (selection bias) }\end{array}$ & Low risk & $\begin{array}{l}\text { Quote: "Patients were randomised in variable blocks of 4-8 patients in order to } \\
\text { balance the groups using simple self-programmed software..." }\end{array}$ \\
\hline $\begin{array}{l}\text { Allocation concealment } \\
\text { (selection bias) }\end{array}$ & Unclear risk & $\begin{array}{l}\text { Quote: "...cards were in envelops signed with numbers to recognize different } \\
\text { block size. Randomization was done by Rolf Lefering, IFOM in cologne, a very } \\
\text { experienced statistical experts in medical studies." (email bias survey, see } \\
\text { notes) }\end{array}$ \\
$\begin{array}{l}\text { Comment: unclear if opaque, sealed envelopes } \\
\text { Comment: no details regarding the } 7 \text { domains at http://www.controlled-trial- } \\
\text { s.com/search?q=01110844 }\end{array}$
\end{tabular}

\begin{tabular}{|c|c|c|}
\hline $\begin{array}{l}\text { Blinding of participants } \\
\text { and personnel (perfor- }\end{array}$ & High risk & $\begin{array}{l}\text { Quote: "Patient, Awareness outcome assessor (interviewer)" (email bias sur- } \\
\text { vey, see notes) }\end{array}$ \\
\hline
\end{tabular}

mance bias)

All outcomes

\begin{tabular}{|c|c|c|}
\hline $\begin{array}{l}\text { Blinding of outcome as- } \\
\text { sessment (detection bias) }\end{array}$ & Low risk & $\begin{array}{l}\text { Quote: "Patient, Awareness outcome assessor (interviewer)" (email bias sur- } \\
\text { vey, see notes) }\end{array}$ \\
\hline All outcomes & & $\begin{array}{l}\text { Comment: assessor: the investigator measuring the SST pre- and postopera- } \\
\text { tively was a medical assistant and was blinded for the inhalational anaesthetic } \\
\text { utilized }\end{array}$ \\
\hline
\end{tabular}

Incomplete outcome data Low risk

(attrition bias)

Quote: "...one patient was excluded because of intra-operative hypertension.

All outcomes The method to conduct anaesthesia was changed in this case" (email bias survey, see notes)

Comment: there is no significant difference in awareness rates between both groups if we assume the hypertensive dropout at high risk of awareness is placed in the experimental or control group; when Peto OR analysis is applied there is no significant difference with exclusion in either group: Peto OR 0.13 (0.00 to 6.60$)$

Author sent characteristics and ROB table grades for comment 8 December 2013: ralph.stuttmann@bergmannstrost.com

\begin{tabular}{|c|c|c|}
\hline $\begin{array}{l}\text { Selective reporting (re- } \\
\text { porting bias) }\end{array}$ & Low risk & $\begin{array}{l}\text { Quote: "the study protocol is available and all primary and secondary outcome } \\
\text { data were recorded completely in the pre-specified way..." (email bias survey, } \\
\text { see notes) }\end{array}$ \\
\hline
\end{tabular}


Trial registration: the trial was registered with the number ISRCTN01110844 at http://www.controlled-trials.com/isrctn/pf/01110844

Comment: awareness outcome part of inclusion criteria

\begin{tabular}{ll}
\hline Other bias & Quote: "there was...no baseline imbalance because a block design was used to \\
& select patients. The test to prove cognitive function ...A learning effect in the \\
& test was compensated by using two different test designs. In our opinion there \\
& was no important risk of bias." (email bias survey, see notes)
\end{tabular}

Toft 1987

\begin{tabular}{ll}
\hline Methods & Study design: randomized parallel groups \\
Study dates: not stated
\end{tabular}

Participants
Sex: both
Age: $52.8,53.5$
ASA: not given
Procedure: bronchoscopy, mediastinoscopy or laryngoscopy, or combinations of these procedures
Study size: 50
Randomized portion of anaesthetic: parts of intravenous (IV) anaesthesia (neurolept i.e. keta-
mine dissociative) induction
Intervention 1: induction infusion ketamine $250 \mathrm{mg}+$ midazolam $12.5 \mathrm{mg}$ in $250 \mathrm{~mL}$ of $0.9 \% \mathrm{NaCl}, \mathrm{N}=$
25
Interventions

Outcomes

Primary outcomes: compare midazolam with diazepam using total intravenous anaesthesia with ketamine/benzodiazepine-fentanyl: anaesthetic consumption, duration, time to recovery

Secondary outcome: awareness/wakefulness as defined using an awareness classification system (see Table 1): class 1

Comment: "No awareness during anaesthesia was reported"

Premedicated with intramuscular morphine $7.5 \mathrm{mg}$ and scopolamine $0.3 \mathrm{mg}$, pancuronium $0.01 \mathrm{mg} / \mathrm{kg}$ and fentanyl $100 \mu \mathrm{g}$ to $150 \mu \mathrm{g} 5$ minutes before the induction of anaesthesia
Anaesthesia induction: interventions 1 and 2, succinylcholine $1.5 \mathrm{mg} / \mathrm{kg}$; maintenance:ketamine-ben- zodiazepine solution + fentanyl 50-100 $\mu \mathrm{g}$ PRN as indicated by HR/BP;MR
Time of outcome determination: postoperative before discharge
Method of outcome determination: interview
ROB survey/questionnaire email was sent to author on 14 February 2011 to palle.toft@ouh.regionsyd- danmark.dk: no response received


Toft 1987 (Continued)

Risk of bias

\begin{tabular}{|c|c|c|}
\hline Bias & Authors' judgement & Support for judgement \\
\hline $\begin{array}{l}\text { Random sequence genera- } \\
\text { tion (selection bias) }\end{array}$ & Unclear risk & $\begin{array}{l}\text { Quote: "Patients were allocated in a random and double-blind fashion two } \\
\text { groups of } 25 \text { patients each" }\end{array}$ \\
\hline $\begin{array}{l}\text { Allocation concealment } \\
\text { (selection bias) }\end{array}$ & Unclear risk & Comment: above \\
\hline $\begin{array}{l}\text { Blinding of participants } \\
\text { and personnel (perfor- } \\
\text { mance bias) } \\
\text { All outcomes }\end{array}$ & Low risk & Quote: "The patient, the anaesthetist and the observer were all blinded" \\
\hline $\begin{array}{l}\text { Blinding of outcome as- } \\
\text { sessment (detection bias) } \\
\text { All outcomes }\end{array}$ & Low risk & $\begin{array}{l}\text { Quote: "The patient, the anaesthetist and the observer were all blinded" } \\
\text { Quote: "Before leaving the hospital the patients were asked by one of the in- } \\
\text { vestigators if they had experienced any dreaming, visual disturbances, or } \\
\text { awareness during the anaesthetic" }\end{array}$ \\
\hline $\begin{array}{l}\text { Incomplete outcome data } \\
\text { (attrition bias) } \\
\text { All outcomes }\end{array}$ & Low risk & Comment: no missing outcome data \\
\hline $\begin{array}{l}\text { Selective reporting (re- } \\
\text { porting bias) }\end{array}$ & Low risk & Comment: awareness outcome part of inclusion criteria \\
\hline Other bias & Unclear risk & Comment: insufficient information provided \\
\hline
\end{tabular}

\section{Toscano 2007}

\begin{tabular}{ll}
\hline Methods & $\begin{array}{l}\text { Study design: randomized parallel groups } \\
\text { Study date: "2000" (email bias survey, see notes) }\end{array}$ \\
\hline Participants & Country: Italy \\
& Sex: female \\
Age: 27 & ASA: I and II \\
Procedure: minor gynaecologic surgery \\
Study size: 100
\end{tabular}

\section{Interventions $\quad$ Randomized portion of anaesthetic: IV: premedication}

Intervention 1: pre-medication scopolamine IM $(2.5 \mu \mathrm{g} / \mathrm{kg} \mathrm{IM})(\mathrm{N}=50)$

Intervention 2: pre-medication atropine IM $(10 \mu \mathrm{g} / \mathrm{kg} \mathrm{IM})(\mathrm{N}=50)$

Outcomes

Primary outcomes: incidence of dreams, anaesthetic consumption

Secondary outcome: awareness/wakefulness as defined using an awareness classification system (see Table 1): class 1 
Comment: although the paper has no mention of patients being asked about recall of intraoperative events after surgery or awareness, the author states in the author's response to our ROB survey: "none had awareness after asking them"

Notes

\section{Non-randomized portion of anaesthetic: parts of intravenous (IV) anaesthesia: $\mathrm{N}_{\mathbf{2}} \mathrm{O} / \mathrm{SR}$}

Anaesthesia induction: propofol bolus $(2.5 \mathrm{mg} / \mathrm{kg})$

Anaesthesia maintenance: propofol infusion (12 mg/kg/h) $\mathrm{N}_{2} \mathrm{O}$ propofol as a $2.5 \mathrm{mg} / \mathrm{kg}$ bolus, followed by $12 \mathrm{mg} / \mathrm{kg}$

Time of outcome determination: $20 \mathrm{~min}$ and $6 \mathrm{~h}$ after surgery

Ventilation was assisted manually $70 \% \mathrm{~N}_{2} \mathrm{O} / \mathrm{O}^{2}$ with facemask until the end of surgery

Comment: see Dryad topic - propofol activates basal forebrain cholinergic

Method of outcome determination: interview

Survey response: 14 February 2011, Carlo Pancaro carlopancaro@hotmail.com

\section{Risk of bias}

\begin{tabular}{lll}
\hline Bias & Authors' judgement & Support for judgement \\
\hline $\begin{array}{l}\text { Random sequence genera- } \\
\text { tion (selection bias) }\end{array}$ & Low risk & Quote: "computer generated, then envelopes" (email bias survey, see notes) \\
\hline $\begin{array}{l}\text { Allocation concealment } \\
\text { (selection bias) }\end{array}$ & Unclear risk & Quote: "computer generated, then envelopes" (email bias survey, see notes) \\
\hline
\end{tabular}

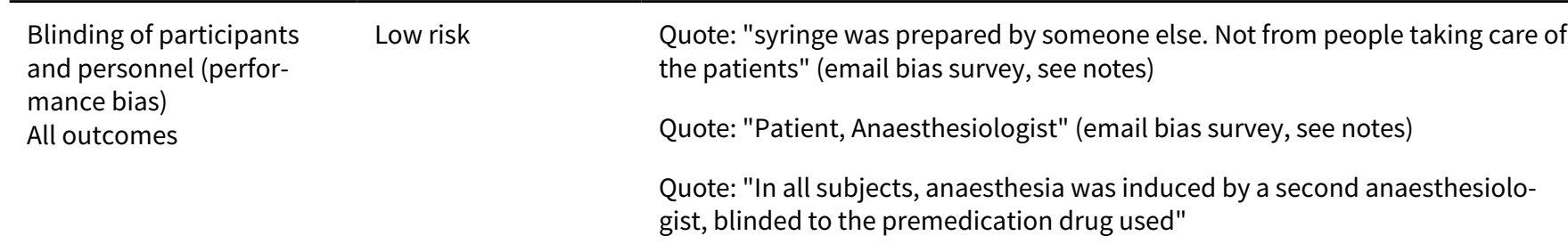

\begin{tabular}{lll}
\hline Blinding of outcome as- & Unclear risk & Quote: "Patient, Anaesthesiologist" (email bias survey, see notes) \\
sessment (detection bias) & & $\begin{array}{l}\text { Comment: paper indicates blinded observer for dream interview; survey re- } \\
\text { All outcomes }\end{array}$ \\
& sponse does not address this \\
\hline
\end{tabular}

Incomplete outcome data Low risk Comment: 3\% (3/100) dropout rate

(attrition bias)

All outcomes

\section{Comment: 3\% (3/100) dropout rate}

Quote: "2 patients received inhalational agents, 1 patient received morphine intraoperatively;...these three patients were excluded from the analysis since inhalational agents and morphine can suppress dream activity. However, none of these three patients reported any dreams or awareness" (email bias survey, see notes)

Comment: since author assessed the dropouts for awareness, there are no missing data in regard to this outcome

$\begin{array}{ll}\begin{array}{l}\text { Selective reporting (re- } \\ \text { porting bias) }\end{array} & \text { Quote: "we reported everything" (email bias survey, see notes) } \\ & \text { Quote: "none had awareness after asking them" } \\ & \text { Comment: awareness outcome part of inclusion criteria }\end{array}$


Toscano 2007 (Continued)

Other bias Low risk Quote: "free of bias" (email bias survey, see notes)

Tsai 2001

$\begin{array}{ll}\text { Methods } & \text { Study design: randomized parallel groups } \\ \text { Study dates: NA }\end{array}$

Country: Taiwan
Sex: female
Age: 22 to 46
ASA: I and II
Procedure: elective caesarean section
Study size: 24

Interventions

Randomized portion of anaesthetic: parts of volatile agent anaesthesia: post-delivery: volatile agent vs hypnotic: propofol

Intervention 1: maintenance post-delivery isoflurane ET 0.5, N = 12

Intervention 2: maintenance post-delivery propofol $8 \mathrm{mg} / \mathrm{kg} / \mathrm{h}, \mathrm{N}=12$

Primary outcomes: BIS values, haemodynamics
Secondary outcome: awareness/wakefulness as defined using an awareness classification system (see
Table 1): class 1
Quote: "None of the patients in either group subsequently reported recall of events during th entire
course of delivery"

Notes

Non-randomized portion of anaesthetic: parts of volatile agent anaesthesia: $\mathrm{N}_{2} \mathrm{O} /$ narcotic/hypnotic/muscle relaxants yes for both induction/maintenance: BIS target $<75$

Volatile agent technique supplemented post-delivery with propofol vs isoflurane; classify as other - sevoflurane pre-delivery then post-delivery random propofol vs isoflurane

Anaesthesia induction: pentothal $(4 \mathrm{mg} / \mathrm{kg})+$ succinylcholine $(1 \mathrm{mg} / \mathrm{kg})+$ atracurium $(0.5 \mathrm{mg} / \mathrm{kg})$. Anaesthesia maintenance: isoflurane (ET 1.15\%) in 50\% $\mathrm{N}_{2} \mathrm{O} / 50 \% \mathrm{O}_{2}+$ post-delivery: fentanyl $3 \mathrm{\mu g} / \mathrm{kg}+$ droperidol $5 \mathrm{mg}+67 \% \mathrm{~N}_{2} \mathrm{O}$ in $\mathrm{O}_{2}+$ atracurium group-specific drug (see above)

Comment: this is very light anaesthesia with BIS target $<\mathbf{7 5}$

BIS target $<\mathbf{7 5}$, if BIS $>=75>5$ mins anaesthesia increased; if MAP $<65>=3$ min after RX bolus $500 \mathrm{~mL}$ fluid, decrease isoflurane or propofol; if uterine contraction poor increase oxytocin

Time of outcome determination: day after surgery

Method of outcome determination: interview

Email for ROB table sent to author on 22 February 2011. No email response received yet.

\section{Risk of bias}

Bias Authors' judgement Support for judgement


Tsai 2001 (Continued)

Random sequence genera- Unclear risk Quote: "...patients were randomly assigned to either of two groups..." tion (selection bias)

\begin{tabular}{lll}
\hline $\begin{array}{l}\text { Allocation concealment } \\
\text { (selection bias) }\end{array}$ & Unclear risk & Comment: no information provided \\
\hline $\begin{array}{l}\text { Blinding of participants } \\
\text { and personnel (perfor- } \\
\text { mance bias) }\end{array}$ & Unclear risk & Comment: anaesthesiologist: no information provided \\
All outcomes & &
\end{tabular}

\begin{tabular}{|c|c|c|}
\hline $\begin{array}{l}\text { Blinding of outcome as- } \\
\text { sessment (detection bias) }\end{array}$ & Low risk & $\begin{array}{l}\text { Quote: assessor: "The effects ... were detected by a helper ... who was blinded } \\
\text { to the anaesthetic given" }\end{array}$ \\
\hline
\end{tabular}

All outcomes

\begin{tabular}{|c|c|c|}
\hline $\begin{array}{l}\text { Incomplete outcome data } \\
\text { (attrition bias) }\end{array}$ & Low risk & $\begin{array}{l}\text { Quote: "Therefore, there was no exclusion of patients who were initially in- } \\
\text { cluded in the study..." }\end{array}$ \\
\hline All outcomes & & Comment: no missing outcome data \\
\hline
\end{tabular}

\begin{tabular}{lll}
\hline $\begin{array}{l}\text { Selective reporting (re- } \\
\text { porting bias) }\end{array}$ & Low risk & Comment: awareness outcome part of inclusion criteria \\
\hline Other bias & Unclear risk & Comment: insufficient information provided \\
\hline
\end{tabular}

Tunstall 1989

\begin{tabular}{ll}
\hline Methods & Study design: randomized parallel groups \\
& Study dates: not given \\
\hline Participants & Country: Scotland \\
Sex: female & Age: not given, mean \\
ASA: NA \\
Procedure: elective and semi-elective caesarian section \\
Study size: 113
\end{tabular}

Interventions

\section{Randomized portion of anaesthetic: volatile agent types: enflurane vs isoflurane}

Pilot study completed; followed by this protocol:

Intervention 1: maintenance 3 min enflurane $3 \%$ + enflurane $1.5 \%$ + post-delivery enflurane $0.5 \%, \mathrm{~N}=$ 50

Intervention 2: maintenance $3 \mathrm{~min}$ isoflurane $3 \%+$ isoflurane $1.25 \%+$ post-delivery isoflurane $0.5 \%, \mathrm{~N}=$ 63

Outcomes

Primary outcomes: effects withdrawing $\mathbf{N}_{\mathbf{2}} \mathbf{O}$ for increased inspired concentration: enflurane or isoflurane; depth anaesthesia: isolated forearm technique: wakefulness (as first defined by Tunstall)

Awareness/wakefulness as defined using an awareness classification system (see Table 1): class 1 
Tunstall 1989 (Continued)

Quote: "No mother experienced awareness (that is, postoperative recall) and no mother experienced dreams. Wakefulness was observed in 24 patients who received enflurane and in 23 who received isoflurane at the 2-min interval..."

Comment: $48 \%(24 / 50)$ enflurane group and $37 \%(23 / 63)$ isoflurane group

Non-randomized portion of anaesthetic: $\mathbf{N}_{\mathbf{2}} \mathbf{O} / \mathbf{p a r t s}$ of potent inhalational technique (volatile
agent)/hypnotic/supplemental narcotics/muscle relaxants induction yes/maintenance yes/IFT:
response to command (wakefulness)/ $\mathbf{N}_{\mathbf{2}} \mathbf{O}$ yes - no pre-delivery and yes post-delivery: study - en-
flurane vs isoflurane
Anaesthesia induction: thiopentone $250 \mathrm{mg}+$ suxamethonium $100 \mathrm{mg}+$ oxygen $100 \%$; anaesthe-
sia maintenance: atracurium $25 \mathrm{mg}$ to $30 \mathrm{mg}+$ post-delivery oxytocin 10 units + $66 \% \mathbf{N}_{\mathbf{2}} \mathbf{O}+$ metoclo-
pramide $10 \mathrm{mg}+$ papaveretum $20 \mathrm{mg}$
Comment: conclusion of RCT: the new volatile agents studied, $1.5 \%$ enflurane/1.25\% isoflurane in oxy-
gen only, were acceptable as sole maintenance agent
Comment: see Dryad topic movement scores figures 1-4; if the anaesthetist's hand was gripped with-
out being released on the command to open and shut the hand, it was classified as reflex grip
Time of outcome determination: before discharge
Method of outcome determination: interview
Comment: see Dryad topic movement scores figures 1-4
Email: $\mathrm{m}$.e.tunstall@abdn.ac.uk

Risk of bias

\begin{tabular}{lll}
\hline Bias & Authors' judgement & Support for judgement \\
\hline $\begin{array}{l}\text { Random sequence genera- } \\
\text { tion (selection bias) }\end{array}$ & Unclear risk & Quote: "...allocated randomly to receive either enflurane or isoflurane" \\
\hline $\begin{array}{l}\text { Allocation concealment } \\
\text { (selection bias) }\end{array}$ & Unclear risk & Comment: no information provided \\
\hline $\begin{array}{l}\text { Blinding of participants } \\
\text { and personnel (perfor- } \\
\text { mance bias) }\end{array}$ & Unclear risk & Comment: anaesthesiologist: no information provided \\
All outcomes & & \\
\hline
\end{tabular}

\begin{tabular}{lll}
\hline $\begin{array}{l}\text { Blinding of outcome as- } \\
\text { sessment (detection bias) } \\
\text { All outcomes }\end{array}$ & Unclear risk & Comment: assessor: no information provided \\
\hline $\begin{array}{l}\text { Incomplete outcome data } \\
\begin{array}{l}\text { (attrition bias) } \\
\text { All outcomes }\end{array}\end{array}$ & Low risk & Comment: no missing outcome data \\
\hline $\begin{array}{l}\text { Selective reporting (re- } \\
\text { porting bias) }\end{array}$ & Low risk & Comment: awareness outcome part of inclusion criteria \\
\hline Other bias & Unclear risk & Comment: insufficient information provided \\
\hline
\end{tabular}


Vakkuri 2005

\begin{tabular}{ll} 
Methods & Study design: randomized parallel groups \\
& Study dates: Quote: "8/7/2002 - 27/2/2003" (email bias survey, see notes) \\
\hline Participants & Country: Finland, Sweden, Norway \\
Sex: both & Age: 18 to 80 \\
Procedure: elective surgery procedures 45 min $<$ time $<150$ min \\
Study size: 335
\end{tabular}

Interventions

Randomized portion of anaesthetic: ADM (Entropy 45 to 65 ) vs SCP (target ADM < 65)

Intervention 1: entropy values shown group, $\mathrm{N}=160$

Intervention 2: entropy values shown not control group, $\mathrm{N}=160$

Outcomes

Primary outcomes: Quote: "hypothesis that intraoperative monitoring of entropy would decrease propofol consumption during propofol-nitrous oxide-alfentanil anaesthesia"

Secondary outcome: awareness/wakefulness as defined using an awareness classification system (see Table 1): class 1

Quote: "None of the patients reported any anaesthesia- or surgery- related memories in the two postoperative interviews"

\section{Notes}

\section{Non-randomized portion of anaesthetic: parts of $\mathrm{IV} \mathrm{MCl} / \mathrm{N}_{2} \mathrm{O} /$ muscle relaxants induction yes/ maintenance PRN: alfentanil/propofol/ $\mathrm{N}_{2} \mathrm{ON}_{2} \mathrm{O} /$ endotracheal tube or laryngeal mask/muscle re- laxants when "appropriate"}

Induction: alfentanil >= $30 \mu \mathrm{g} / \mathrm{kg}$ + propofol $1.0 \mathrm{mg}$ to $2.5 \mathrm{mg} / \mathrm{kg}$; maintenance: mixture of oxygen (35\% to $50 \%$ ) and $\mathbf{N}_{\mathbf{2}} \mathbf{O}$ (50\% to $65 \%$ ), infusions: alfentanil max. dose $30 \mu \mathrm{g} / \mathrm{kg} / \mathrm{h}+$ propofol max dose $9 \mathrm{mg} /$ $\mathrm{kg} / \mathrm{h}$

Inadequate anaesthesia: alfentanil and propofol boluses and/or muscle relaxant choice of anaesthesiologist when considered "appropriate" when entropy indices increased, suggesting impending awakening; note the use of muscle relaxants in the protocol to treat a clinical judgement of impending awakening rather than vasoactive drugs and more anaesthesia; this is a commonly used protocol

Comment: see discussion facial frontal muscle activation less sensitive to the effects of neuromuscular blocking drugs than are the hand muscles. Part of the depth of anaesthesia monitoring was defining the degree of paralysis

Time of outcome determination: in PACU and $24 \mathrm{~h}$ postoperative

Method of determination: interview

Author survey email sent (Yli-Hankal) on 27 January 2011 to arvi.yli-hankala@uta.fi, no response received. Survey response: 15 February 2011, Anne Vakkuri anne.vakkuri@hus.fi. Author sent characteristics and ROB table grades for comment 8 December 2013: anne.vakkuri@hus.fi; email topic incomplete data 14 June 2015

\section{Risk of bias}

Bias Authors' judgement Support for judgement


van der Maaten 1996 (Continued)

Study dates: Quote: "in 1994" (email bias survey, see notes)

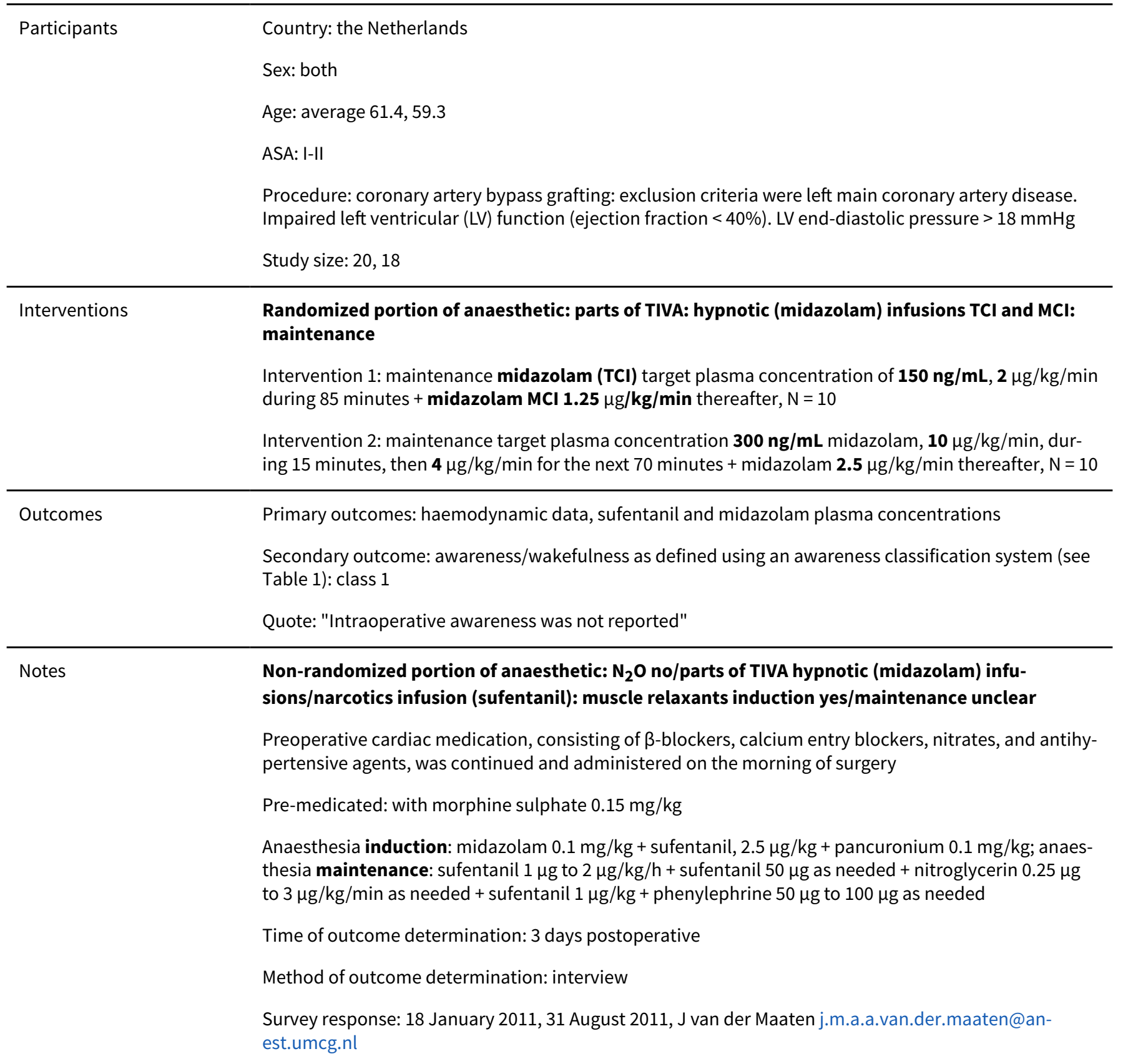

\section{Risk of bias}

\begin{tabular}{lll}
\hline Bias & Authors' judgement & Support for judgement \\
\hline $\begin{array}{l}\text { Random sequence genera- } \\
\text { tion (selection bias) }\end{array}$ & Low risk & $\begin{array}{l}\text { Quote: "Patients were randomly assigned to receive midazolam at a target } \\
\text { plasma concentration of } 150 \mathrm{ng} / \mathrm{mL} \text { (group 1) or } 300 \mathrm{ng} / \mathrm{mL}(\mathrm{group} 2) "\end{array}$ \\
& $\begin{array}{l}\text { Quote: "Computer-generated block randomization (10x group1 and } 10 \mathrm{x} \\
\text { group2)." (email bias survey, see notes) }\end{array}$ \\
\hline $\begin{array}{l}\text { Allocation concealment } \\
\text { (selection bias) }\end{array}$ & Low risk & $\begin{array}{l}\text { Quote survey: "The concentration of the study drug (midazolam, } 1 \mathrm{mg} / \mathrm{ml}) \text { in } \\
\text { the syringe was the same for both study groups" }\end{array}$ \\
\hline
\end{tabular}


van der Maaten 1996 (Continued)

Blinding of participants Unclear risk Quote survey: "Considering the difference in infusion rate for both groups, the and personnel (perforanaesthesiologist could have been aware of the assignment to one group or the other" (email bias survey, see notes)

mance bias

All outcomes

Comment: rule; infusions can not be blinded due to differences in infusion rates

\section{Blinding of outcome as- Low risk} sessment (detection bias)

All outcomes

Quote: "Three days after surgery, the patients were interviewed to detect recollection of auditory or other forms of awareness of intraoperative events..."

Quote: "Patient, Awareness outcome assessor (interviewer)" (email bias survey, see notes)

Incomplete outcome data Low risk

(attrition bias)

Quote: "There were no missing values and no attrition, exclusions or re-inclu-

All outcomes sions. Data set was complete, including the plasma drug concentration samples"

Quote (email bias survey, see notes): "There were 10 patients in each study group. All data were complete, except for the samples for midazolam and sufentanil plasma concentrations there were two missing values in each sample set $(2$ missing values on 110 samples for the midazolam and sufentanil respectively)"

Comment: there was no significant difference between groups: (2/10 vs 0/10), Peto OR 8.26 (0.48 to 142.43 )

Selective reporting (re- Low risk porting bias)

Quote: "The study protocol is available and outcomes of interest have been reported" (email bias survey, see notes)

Comment: awareness outcome part of inclusion criteria

Other bias Low risk Quote: "Free of other bias" (email bias survey, see notes)

van Leeuwen 1990

\begin{tabular}{|c|c|}
\hline Methods & $\begin{array}{l}\text { Study design: randomized parallel groups } \\
\text { Study dates: not stated }\end{array}$ \\
\hline Participants & $\begin{array}{l}\text { Country: the Netherlands } \\
\text { Sex: both } \\
\text { Age: aged } 15 \text { to } 72 \text { years } \\
\text { ASA: I and II } \\
\text { Procedure: orthopaedic or ophthalmic operations } \\
\text { Study size: } 30\end{array}$ \\
\hline
\end{tabular}


van Leeuwen 1990 (Continued)

Outcomes
Primary outcomes: cardiovascular parameters between groups; duration of anaesthesia, mean total doses (induction and maintenance) of both propofol and alfentanil

Secondary outcome: awareness/wakefulness as defined using an awareness classification system (see Table 1): class 1

Quote: "Awareness did not occur in any patient"

\section{Non-randomized portion of anaesthetic: $\mathrm{N}_{2} \mathrm{O}$ no parts of TIVA hypnotic (propofol) infusions $\mathrm{MCl}$ narcotics infusion (alfentanil): maintenance/muscle relaxants induction yes/maintenance no}

All patients received premedication with diazepam $10 \mathrm{mg}$ orally 1 to $1.5 \mathrm{~h}$ before surgery. Anaesthesia induction: propofol $2 \mathrm{mg} / \mathrm{kg}$ + alfentanil $10 \mu \mathrm{g} / \mathrm{kg} / \mathrm{min}+$ vecuronium bromide $0.1 \mathrm{mg} / \mathrm{kg}$. A single dose of vecuronium $0.1 \mathrm{mg} / \mathrm{kg}$ was used as the muscle relaxant; anaesthesia maintenance: alfentanil infusion $1 \mu \mathrm{g} / \mathrm{kg} / \mathrm{min}+$ propofol $20 \mathrm{mg} / \mathrm{kg}$ and alfentanil $1 \mathrm{mg}$ was administered as needed. Oxygen in air $\left(\mathrm{FIO}_{2}\right.$ 0.35). Neuromuscular block was reversed with atropine + neostigmine + naloxone $0.2 \mathrm{mg}$ to 0.4 $\mathrm{mg}$, if respiratory depression was present

Time of outcome determination: day and month after operation

Method of outcome determination: interview

Email survey sent to author, no response received

\section{Risk of bias}

\begin{tabular}{|c|c|c|}
\hline Bias & Authors' judgement & Support for judgement \\
\hline $\begin{array}{l}\text { Random sequence genera- } \\
\text { tion (selection bias) }\end{array}$ & Unclear risk & $\begin{array}{l}\text { Quote: "The patients were randomly allocated into three groups of ten pa- } \\
\text { tients each, Groups A, B, and C. All..." }\end{array}$ \\
\hline $\begin{array}{l}\text { Allocation concealment } \\
\text { (selection bias) }\end{array}$ & Unclear risk & Comment: no information provided \\
\hline $\begin{array}{l}\text { Blinding of participants } \\
\text { and personnel (perfor- } \\
\text { mance bias) } \\
\text { All outcomes }\end{array}$ & Unclear risk & $\begin{array}{l}\text { Comment: anaesthesiologist: no information provided } \\
\text { Comment: different infusion rates difficult to blind to anaesthesiologist (ROB } \\
\text { survey van der Maaten 1996) }\end{array}$ \\
\hline $\begin{array}{l}\text { Blinding of outcome as- } \\
\text { sessment (detection bias) } \\
\text { All outcomes }\end{array}$ & Unclear risk & $\begin{array}{l}\text { Quote: "The patients were questioned by the anaesthetist about intraoper- } \\
\text { ative awareness. This was done in the recovery room, the day after and one } \\
\text { month after the operation" }\end{array}$ \\
\hline $\begin{array}{l}\text { Incomplete outcome data } \\
\text { (attrition bias) } \\
\text { All outcomes }\end{array}$ & Low risk & Comment: no missing outcome data \\
\hline $\begin{array}{l}\text { Selective reporting (re- } \\
\text { porting bias) }\end{array}$ & Low risk & Comment: awareness outcome part of inclusion criteria \\
\hline Other bias & Unclear risk & Comment: insufficient information provided \\
\hline
\end{tabular}

Wang 2013

$\begin{array}{ll}\text { Methods } & \text { Study design: randomized parallel groups } \\ \text { Study dates: January } 2010 \text { to October } 2011\end{array}$


Wang 2013 (Continued)

Country: China
Sex: female
Age: aged 15 to 75 years, $52.9(9.8), 53.3(9.6)$
ASA: I-III
Procedure: breast cancer surgery including modified radical mastectomy, total mastectomy, lumpec-
tomy, breast-conserving surgery and breast reconstruction
Study size: 920 enrolled, 908 completed study

\begin{tabular}{ll}
\hline Interventions & Randomized portion of anaesthetic: parts of TIVA: premedication (phencyclidine) vs placebo \\
Intervention 2: premedication ( $N=456)$ phencyclidine $(\mathrm{PHC}) 0.01 \mathrm{mg} / \mathrm{kg}$ \\
Intervention 2: premedication ( $\mathrm{N}=452)$ placebo (saline) \\
BIS-guided total intravenous anaesthesia \\
\hline Primary outcomes: awareness/wakefulness as defined using an awareness classification system (see \\
Table 1$)$ \\
Quote: "The primary outcome was to evaluate the effect of PHC on intra-operative awareness." \\
Quote: "A committee of three experts, blinded to the study conditions, independently scrutinised \\
all reported recollections...PHC group, none of the patients had recall of intra-operative events (0\%), \\
saline group, five of 452 patients reported intra-operative awareness (1.1\%)"
\end{tabular}

Notes

Non-randomized portion of anaesthetic: $\mathrm{N}_{2} \mathrm{O}$ no/parts of TIVA hypnotic (propofol TCl and bolus midazolam)/narcotics (bolus sufentanil): maintenance/muscle relaxants induction yes/maintenance PRN/BIS 40 to 60

General anaesthesia was induced by propofol (TCI) plasma target-controlled infusion (a target plasma concentration of 3.5 to $4.5 \mathrm{lg} / \mathrm{mL} 1)$ /bolus midazolam $(0.03 \mathrm{mg} / \mathrm{kg} 1) /$ bolus sufentanil $(0.3 \mathrm{lg} / \mathrm{kg} 1) / \mathrm{in}$ tubation $0.2 \mathrm{mg} / \mathrm{kg} 1$ cisatracurium BIS $<45$. TCl adjusted maintain BIS 40 to 60/neuromuscular blockade: cisatracurium PRN Interventions: cardiovascular instability: if blood pressure deviated $>30 \%$ baseline value for $>5$ min Correspondence to: ZM Tan Email:zmtan166@163.com

ROB survey: we emailed zmtan166@163.com on 22 March 2015

\section{Risk of bias}

\begin{tabular}{|c|c|c|}
\hline Bias & Authors' judgement & Support for judgement \\
\hline $\begin{array}{l}\text { Random sequence genera- } \\
\text { tion (selection bias) }\end{array}$ & Low risk & $\begin{array}{l}\text { Quote: "Random assignment of patients was established by computer-gener- } \\
\text { ated codes. Allocation concealment was established by placing the randomi- } \\
\text { sation sequence in consecutively numbered, opaque envelopes" }\end{array}$ \\
\hline $\begin{array}{l}\text { Allocation concealment } \\
\text { (selection bias) }\end{array}$ & Unclear risk & Comment: unclear if sealed; await author's response to ROB survey \\
\hline $\begin{array}{l}\text { Blinding of participants } \\
\text { and personnel (perfor- } \\
\text { mance bias) } \\
\text { All outcomes }\end{array}$ & Low risk & $\begin{array}{l}\text { Quote: "The PHC group received } 0.01 \mathrm{mg} . \mathrm{kg} 1 \mathrm{PHC} \text { intravenously, whereas the } \\
\text { saline group patients received saline intravenously as placebo. Penehyclidine } \\
\text { hydrochloride or saline solutions were prepared in a syringe by the first anaes- } \\
\text { thesiologist, who was also responsible for subject grouping. The PHC was di- } \\
\text { luted ( } 1 \mathrm{mg} \text { in } 1 \mathrm{ml} \text { )...This second anaesthesiologist was also responsible for } \\
\text { the anaesthetic manage" }\end{array}$ \\
\hline $\begin{array}{l}\text { Blinding of outcome as- } \\
\text { sessment (detection bias) }\end{array}$ & Low risk & $\begin{array}{l}\text { Quote: "The third anaesthesiologist served as the postoperative interviewer. } \\
\text { Awareness was defined as recall of intra-operative events" }\end{array}$ \\
\hline
\end{tabular}


Wang 2013 (Continued)

All outcomes

Incomplete outcome data Low risk (attrition bias)

All outcomes
Quote: "Patients' data were not included if: two consecutive recorded BIS values were outside the target range 40-60; the time of surgery was longer than $10 \mathrm{~h}$ or shorter than $30 \mathrm{~min}$; and patients required ephedrine or atropine because of circulatory instability. In all, data from 12 patients were not analysed (four in the PHC group, eight in the saline group), which left 908 patients' data (456 in the PHC group and 452 in the saline group) available for analysis (Fig. 1)"

Comment: Figure 1: PHC group: excluded 4: $\mathrm{BIS}<40 \mathrm{~N}=1,>60 \mathrm{~N}=1$, ephedrine $N=2$, atropine $N=0$; saline group: excluded 8: $\mathrm{BIS}<40 \mathrm{~N}=3,>60 \mathrm{~N}$ $=2$, ephedrine $\mathrm{N}=2$, atropine $\mathrm{N}=1$; high-risk awareness exclusions: $\mathrm{BIS}>60 \mathrm{~N}$ $=1$ for PHC and 2 for saline groups; $2 \%(1 / 460)$ vs $4 \%$ (2/460); since the saline group has increased awareness events and high-risk awareness exclusions vs $\mathrm{PHC}$ group, there is no downgrade

In addition, there was no significant difference between groups, Peto OR 0.75 (0.17 to 3.32 )
Selective reporting (re-
Low risk
Comment: awareness outcome part of inclusion criteria porting bias)

Other bias Unclear risk Comment: no information

White 2003

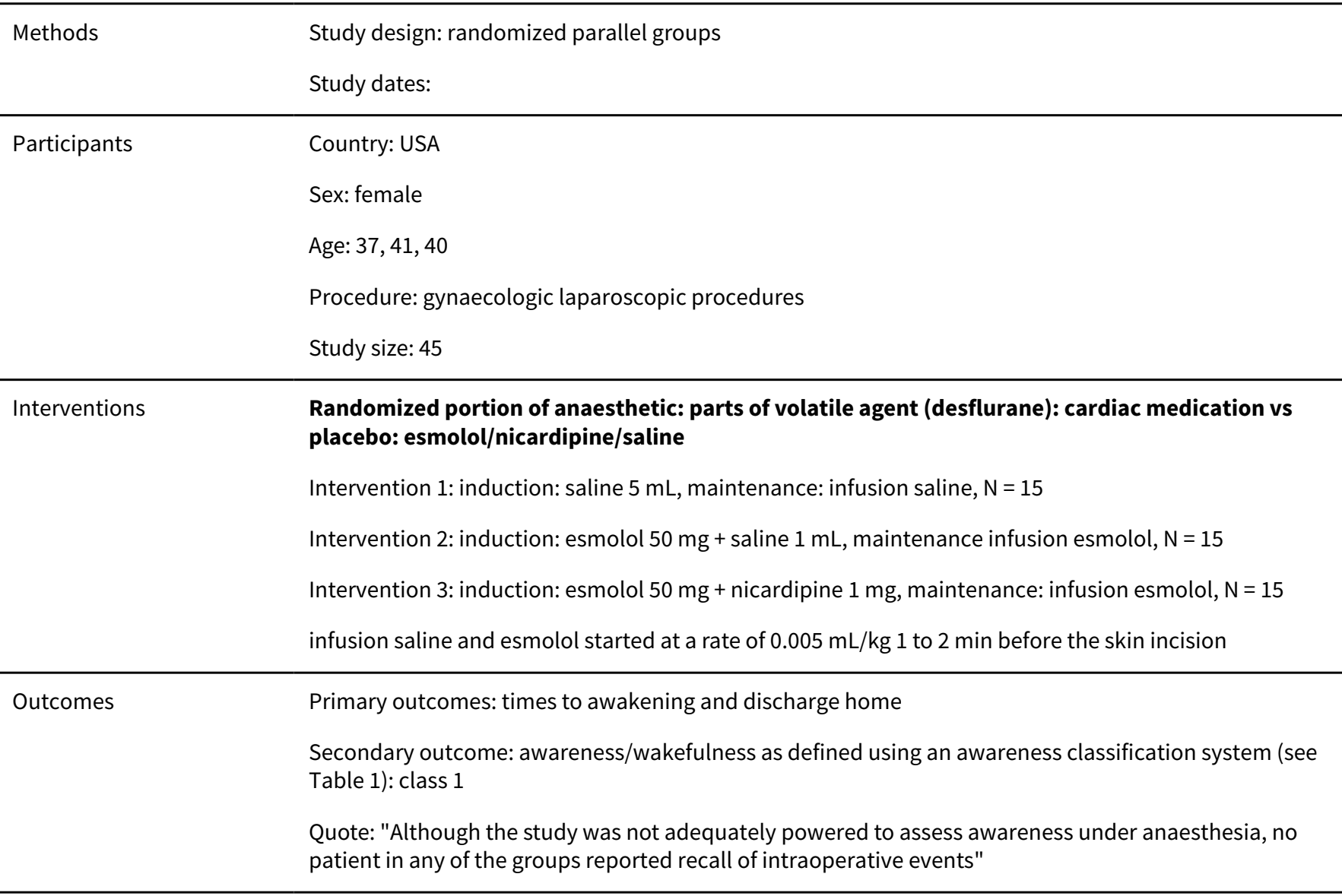


White 2003 (Continued)

Notes

\title{
Non-randomized portion of anaesthetic: parts of volatile agent (desflurane)/ $\mathrm{N}_{\mathbf{2}} \mathrm{O} /$ hypnotic (propofol) bolus narcotics (fentanyl) + muscle relaxant(s) (vecuronium) induction yes/PRN main- tenance ADM (BIS) blinded
}

Anaesthesia induction: fentanyl $1.5 \mu \mathrm{g} / \mathrm{kg}+$ propofol $2 \mathrm{mg} / \mathrm{kg}$ + vecuronium $0.12 \mathrm{mg} / \mathrm{kg}+$ group-specific study drug; anaesthesia maintenance: desflurane $2 \%$ (inspired) and $\mathrm{N}_{2} \mathrm{O} 67 \%$ in oxygen + vecuronium $1 \mathrm{mg}$ to $2 \mathrm{mg}$ PRN; BIS blinded

Pneumoperitoneum maintained at 15 to $20 \mathrm{mmHg} /$ Trendelenburg position; MAP maintained 15\% of the pre-induction baseline value by increasing/decreasing the infusion rate study medication $50 \%$ to $100 \%$

Email survey sent, no response received

\section{Risk of bias}

\begin{tabular}{|c|c|c|}
\hline Bias & Authors' judgement & Support for judgement \\
\hline $\begin{array}{l}\text { Random sequence genera- } \\
\text { tion (selection bias) }\end{array}$ & Unclear risk & Quote: "...were randomly assigned to 1 of 3 treatment groups..." \\
\hline $\begin{array}{l}\text { Allocation concealment } \\
\text { (selection bias) }\end{array}$ & Unclear risk & Comment: no information provided \\
\hline $\begin{array}{l}\text { Blinding of participants } \\
\text { and personnel (perfor- } \\
\text { mance bias) } \\
\text { All outcomes }\end{array}$ & Unclear risk & Comment: anaesthesiologist: no information provided \\
\hline $\begin{array}{l}\text { Blinding of outcome as- } \\
\text { sessment (detection bias) } \\
\text { All outcomes }\end{array}$ & Unclear risk & $\begin{array}{l}\text { Quote: "Finally, none of the patients in the study reported recall of intraopera- } \\
\text { tive events when questioned at the time of discharge" }\end{array}$ \\
\hline $\begin{array}{l}\text { Incomplete outcome data } \\
\text { (attrition bias) } \\
\text { All outcomes }\end{array}$ & Low risk & Comment: no missing outcome data \\
\hline $\begin{array}{l}\text { Selective reporting (re- } \\
\text { porting bias) }\end{array}$ & Low risk & Comment: awareness outcome part of inclusion criteria \\
\hline Other bias & Unclear risk & Comment: insufficient information provided \\
\hline
\end{tabular}

White 2004

Methods Study design: randomized parallel groups

Study dates: not given

Participants

\author{
Country: USA \\ Sex: female \\ Age: $48,54,50$ \\ ASA: |-III
}

Procedure: gynaecologic laparoscopic surgery 
White 2004 (Continued)

Study size: 60

Randomized portion of anaesthetic: $\mathbf{A D M}$ (AAI $\mathbf{1 5}$ to $\mathbf{2 5 ,} \mathbf{N}=\mathbf{2}$
Intervention 1: maintenance: SCP, blinded to BIS or AAI, N = 20
Intervention 2: maintenance BIS 50 to $60, \mathrm{~N}=20$
Intervention 3: maintenance AAI 15 to $25, \mathrm{~N}=20$
Value in the range of 50 to 60 or 15 to 25 , respectively

Outcomes Primary outcomes: relationship between BIS and PSI values during the induction and emergence periods, BIS and PSI values and the probability of unconsciousness

Secondary outcome: awareness/wakefulness as defined using an awareness classification system (see Table 1): class 1

Quote: "None of the patients reported recall of intraoperative events when questioned at the time of discharge from the hospital or during the follow-up telephone interview at $24 \mathrm{~h}$ after surgery"

Notes

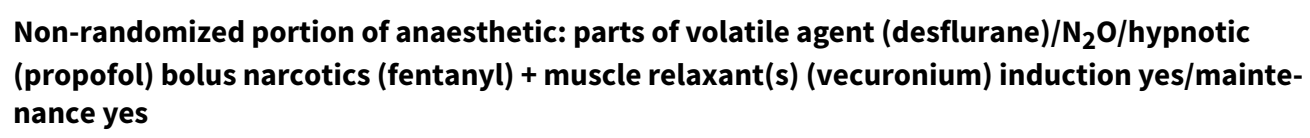

Premedication: midazolam $2 \mathrm{mg}$; anaesthesia induction: propofol $1.5 \mathrm{mg}$ to $2.5 \mathrm{mg} / \mathrm{kg}+$ fentanyl $1 \mu \mathrm{g}$ to $1.5 \mu \mathrm{g} / \mathrm{kg}$ + succinylcholine $1 \mathrm{mg}$ to $1.5 \mathrm{mg} / \mathrm{kg}$; anaesthesia maintenance: desflurane $3 \%$ with $60 \%$ $\mathrm{N}_{2} \mathrm{O}$ in oxygen $1.5 \mathrm{~L} / \mathrm{min} / 1 \mathrm{~L} / \mathrm{min}+$ cisatracurium $10 \mathrm{mg}$ to $20 \mathrm{mg}+$ esmolol $10 \mathrm{mg}$ as needed + neostigmine $0.05 \mathrm{mg} / \mathrm{kg}+$ glycopyrrolate $0.01 \mathrm{mg}$

Clinical signs of excessive anaesthetic effect (e.g. a decrease in MAP 20\% pre-incision value), desflurane decreased by $2 \%$; residual neuromuscular blockade reversed

Comment: correlation coefficients for eye opening with respect to AAI/BIS and desflurane ET concentration poor

Time of outcome determination: before discharge and $24 \mathrm{~h}$ postoperative

Method of outcome determination: interview

Email survey sent, no response received. ROB survey: we emailed DrWhite paul.white@utsouthwestern.edu on 30 April 2015; email rejected: "Delivery to the following recipient failed permanently"

\section{Risk of bias}

\begin{tabular}{|c|c|c|}
\hline Bias & Authors' judgement & Support for judgement \\
\hline $\begin{array}{l}\text { Random sequence genera- } \\
\text { tion (selection bias) }\end{array}$ & Unclear risk & Quote: "...were randomly assigned to one of three groups" \\
\hline $\begin{array}{l}\text { Allocation concealment } \\
\text { (selection bias) }\end{array}$ & Unclear risk & Comment: no information provided \\
\hline $\begin{array}{l}\text { Blinding of participants } \\
\text { and personnel (perfor- } \\
\text { mance bias) } \\
\text { All outcomes }\end{array}$ & High risk & Comment: SCP exposed to both groups \\
\hline $\begin{array}{l}\text { Blinding of outcome as- } \\
\text { sessment (detection bias) } \\
\text { All outcomes }\end{array}$ & Unclear risk & $\begin{array}{l}\text { Quote: "At the time of discharge from the hospital and during the follow-up } \\
\text { telephone interview at } 24 \mathrm{~h} \text { after surgery, patients were asked whether they re- } \\
\text { called any events during the intraoperative period" }\end{array}$ \\
\hline
\end{tabular}


White 2004 (Continued)

Incomplete outcome data Low risk Comment: no missing outcome data
(attrition bias)

All outcomes

Selective reporting (re- Low risk Comment: awareness outcome part of inclusion criteria porting bias)

\begin{tabular}{ll}
\hline Other bias $\quad$ Unclear risk & Comment: insufficient information provided \\
\hline
\end{tabular}

Wong 2002

\begin{tabular}{ll} 
Methods & Study design: randomized parallel groups \\
& Study date: "1998-2000" (email bias survey, see notes) \\
\hline Participants & Country: Canada \\
Sex: both & Age: 76,71 \\
ASA: I-III & Procedure: elective orthopaedic knee or hip replacement surgery \\
Study size: 68
\end{tabular}

\section{Interventions $\quad$ Randomized portion of anaesthetic: ADM (BIS 50 to 60) vs SCP}

Intervention 1: BIS guided titration of anaesthesia (BIS 50 to 60 ), $\mathrm{N}=34$

Intervention 2: standard clinical practice of anaesthesia (SP), $\mathrm{N}=34$

Primary outcomes: BIS values, haemodynamics, anaesthetic consumption, recovery time
Awareness/wakefulness as defined using an awareness classification system (see Table 1)
Secondary outcome: awareness/wakefulness as defined using an awareness classification system (see
Table 1): class 0
Quote: "None of the patients reported awareness"
No patient had intraoperative dreams
fol/midazolam) bolus narcotics (fentanyl) + muscle relaxant(s) (rocuronium) induction yes/maintenance yes

Anaesthesia induction: propofol $1 \mathrm{mg}$ to $2 \mathrm{mg} / \mathrm{kg}$ + fentanyl $2 \mathrm{mg}$ to $3 \mathrm{mg} / \mathrm{kg}+$ midazolam $1 \mathrm{mg}$ + rocuronium $0.6 \mathrm{mg} / \mathrm{kg}$

Anaesthesia maintenance: isoflurane and $60 \%$ to $70 \% \mathrm{~N}_{2} \mathrm{O}$ in oxygen at $3 \mathrm{~L} / \mathrm{min}$ for 5 minutes, then decreased to $1.5 \mathrm{~L} / \mathrm{min}$

Reversal of neuromuscular blockade 5 minutes prior to the discontinuation of inhalational agents

Comment see Dryad topic for light anaesthesia protocol

Comment: haemodynamic stability, rapid recover,y and quick discharge time are the 3 most common parameters that many of the included RCTs use to guide their dosing of anaesthesia to patients 
Wong 2002 (Continued)

Time of outcome determination: $72 \mathrm{~h}+14$ days postoperative

Method of outcome determination: interview

Survey emailed to jean_wong@yahoo.com on 6 December 2013

\section{Risk of bias}

Bias Authors' judgement Support for judgement

Random sequence genera- Low risk tion (selection bias)

Quote: "...block randomization with concealed varying block sizes was performed with computer generated random numbers"

Survey: "computer generated random numbers with varying block sizes"

Allocation concealment Low risk
(selection bias)

Quote: "The assignments were kept in sealed envelopes by a research assistant not involved with the study"

Comment: await author response as to whether envelope was sealed

\begin{tabular}{|c|c|c|}
\hline $\begin{array}{l}\text { Blinding of participants } \\
\text { and personnel (perfor- } \\
\text { mance bias) }\end{array}$ & High risk & $\begin{array}{l}\text { Quote: "In the standard practice (SP) group... anaesthesiologist was blinded to } \\
\text { the BIS value..." }\end{array}$ \\
\hline All outcomes & & Comment: SCP exposed to both groups \\
\hline
\end{tabular}

Blinding of outcome as- Low risk sessment (detection bias)

Quote: "At the 72-h interview, the patients were asked a series of questions reAll outcomes lating to whether they had any recall of intraoperative events (Appendix)"

Quote: "Patient, Awareness outcome assessor (interviewer)"

Incomplete outcome data Low risk

(attrition bias)

Quote: "all patients were included"

All outcomes

68 patients were enrolled in this study; however, 8 patients ( 3 from the SP group, and 5 from the BIS group) were excluded from the analysis for protocol violations. 2 patients had bipolar disorder; 2 patients received propofol near the end of surgery; 2 patients received excessive fentanyl near the end of surgery; and 1 patient desaturated necessitating discontinuation of $\mathrm{N}_{2} \mathrm{O}$ intraoperatively

There was no difference in demographic data between the 2 groups (Table I)

$\begin{array}{ll}\begin{array}{l}\text { Selective reporting (re- } \\ \text { porting bias) }\end{array} & \text { Low risk } \\ \end{array}$

Other bias Low risk Quote survey: "no other risk of bias"

Wu 2001

\begin{tabular}{ll}
\hline Methods & Study design: randomized parallel groups \\
& Study date: not given \\
\hline Participants & Country: Taiwan \\
& Sex: female \\
Age: 36 & ASA: I and II
\end{tabular}


Wu 2001 (Continued)

Procedure: elective gynaecologic surgeries

Study size: 40

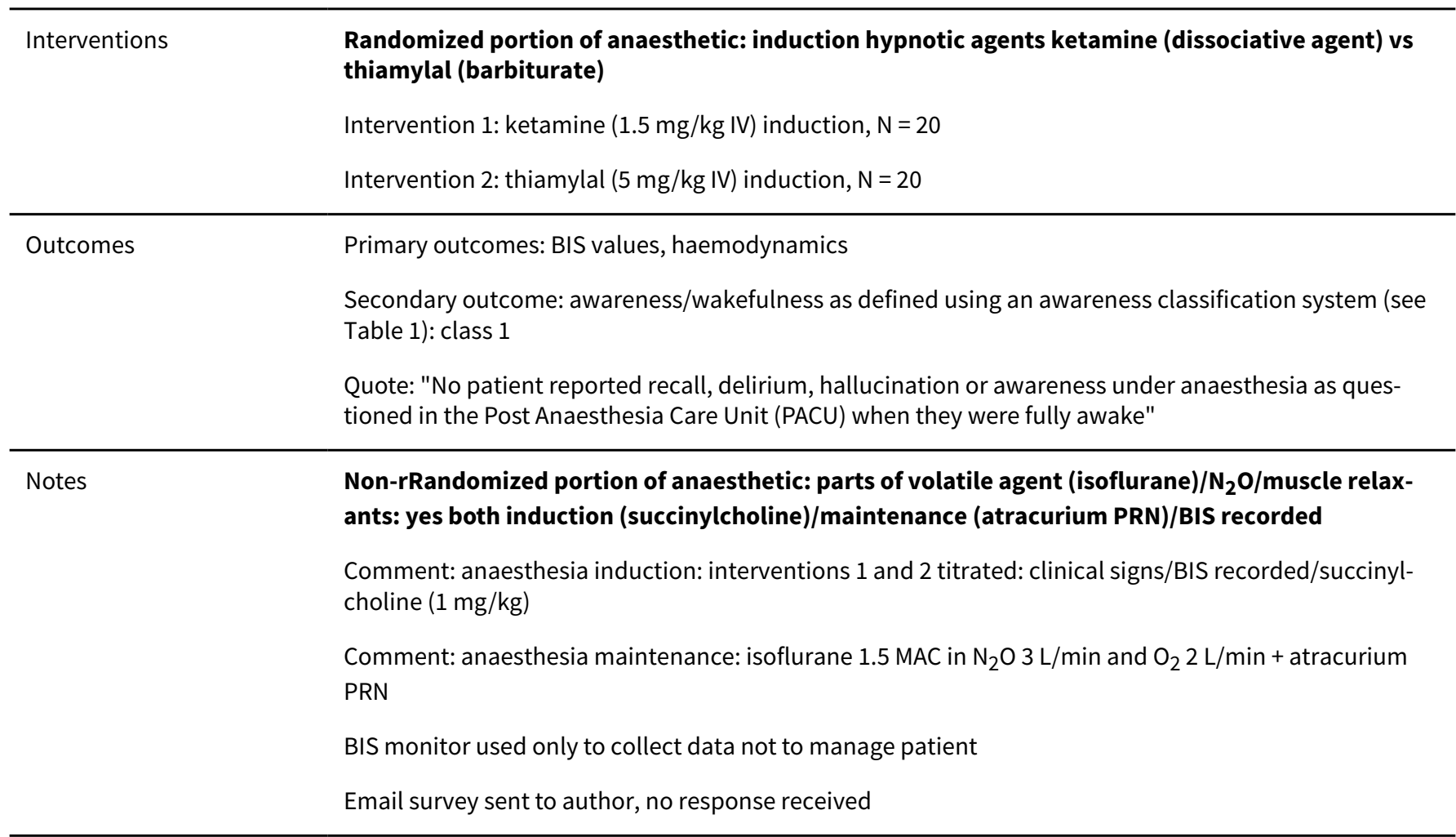

\section{Risk of bias}

\begin{tabular}{|c|c|c|}
\hline Bias & Authors' judgement & Support for judgement \\
\hline $\begin{array}{l}\text { Random sequence genera- } \\
\text { tion (selection bias) }\end{array}$ & Unclear risk & Quote: "The patients were then divided randomly into two groups: Group K ...." \\
\hline $\begin{array}{l}\text { Allocation concealment } \\
\text { (selection bias) }\end{array}$ & Unclear risk & Comment: no information provided \\
\hline $\begin{array}{l}\text { Blinding of participants } \\
\text { and personnel (perfor- } \\
\text { mance bias) } \\
\text { All outcomes }\end{array}$ & Unclear risk & Comment: anaesthesiologist: no information provided \\
\hline $\begin{array}{l}\text { Blinding of outcome as- } \\
\text { sessment (detection bias) } \\
\text { All outcomes }\end{array}$ & Unclear risk & $\begin{array}{l}\text { Quote: "No patient reported recall, delirium, hallucinations or awareness un- } \\
\text { der anaesthesia..." }\end{array}$ \\
\hline $\begin{array}{l}\text { Incomplete outcome data } \\
\text { (attrition bias) } \\
\text { All outcomes }\end{array}$ & Low risk & Comment: no missing data \\
\hline $\begin{array}{l}\text { Selective reporting (re- } \\
\text { porting bias) }\end{array}$ & Low risk & Comment: awareness outcome part of inclusion criteria \\
\hline Other bias & Unclear risk & Comment: insufficient information provided \\
\hline
\end{tabular}


Yildiz 2002

\begin{tabular}{ll} 
Methods & Study design: randomized parallel groups \\
& Study date: not given \\
\hline Participants & Country: Turkey \\
Sex: both & Age: 42 \\
& ASA: I-II \\
& Procedure: laparoscopic cholecystectomy \\
& Study size: 50 \\
Randomized portion of anaesthetic: parts of TIVA anaesthesia/narcotic (alfentanil and remifen- \\
tanil) \\
Intervention $1:$ induction: alfentanil $10 \mathrm{mg} / \mathrm{kg}, \mathrm{N}=25$ \\
Intervention 2: induction: remifentanil $1.5 \mathrm{mg} / \mathrm{kg}, \mathrm{N}=25$ \\
Cards with pictures presented to patients
\end{tabular}

Outcomes

Primary outcomes: BIS values, haemodynamics, "delayed memory recall test"

Secondary outcome: awareness/wakefulness as defined using an awareness classification system (see Table 1): class 2

Quote: "After gained consciousness none of the patients in both groups did not have any awareness according to the meetings with the patients"

Comment: class 2: negative explicit recall, positive implicit memory for word/image/music stimuli but no emotional sequelae; both groups had "delayed memory recall test [?implicit memory ?]" of cards with images and there were significantly fewer "error points" with the remifentanil vs alfentanil group

Notes

Non-randomized portion of anaesthetic: parts of TIVA anaesthesia: air/narcotic (randomized: alfentanil and remifentanil)/hypnotic (propofol)/muscle relaxants induction yes/maintenance unclear (atracurium)/BIS recorded

Anaesthesia induction: (randomized: alfentanil (10 $\mu \mathrm{g} / \mathrm{kg})$ or remifentanil $(1 \mu \mathrm{g} / \mathrm{kg})$ )/propofol (2 mg/ $\mathrm{kg}$ )/atracurium $(0.6 \mathrm{mg} / \mathrm{kg})$; anaesthesia maintenance: (randomized: alfentanil $(1 \mu \mathrm{g} / \mathrm{kg} / \mathrm{min}$ ) or remifentanil $(0.25 \mu \mathrm{g} / \mathrm{kg} / \mathrm{min})) /$ propofol $(9 \mathrm{mg} / \mathrm{kg} / \mathrm{h}) /$ ventilation $\mathrm{O}_{2}$ :air $1: 1$, residual neuromuscular block antagonized/BIS monitor used

Time of outcome determination: $24 \mathrm{~h}$ postoperative

Method of outcome determination: interview

Learning test: delayed memory test - pictures

Murat translator

No email address to send survey

\section{Risk of bias}


Yildiz 2002 (Continued)

Random sequence genera- Unclear risk Quote: "....randomly separated into two groups" tion (selection bias)

\begin{tabular}{lll}
\hline $\begin{array}{l}\text { Allocation concealment } \\
\text { (selection bias) }\end{array}$ & Unclear risk & Comment: no information provided \\
\hline $\begin{array}{l}\text { Blinding of participants } \\
\text { and personnel (perfor- } \\
\text { mance bias) }\end{array}$ & Unclear risk & Comment: anaesthesiologist: no information provided \\
All outcomes & &
\end{tabular}

Blinding of outcome as- Unclear risk $\quad$ Comment: assessor: no information provided
sessment (detection bias)
All outcomes

All outcomes

Incomplete outcome data Low risk Comment: no missing outcome data

(attrition bias)

All outcomes

\begin{tabular}{lll}
\hline $\begin{array}{l}\text { Selective reporting (re- } \\
\text { porting bias) }\end{array}$ & Low risk & Comment: awareness outcome part of inclusion criteria \\
\hline Other bias & Unclear risk & Comment: insufficient information provided \\
\hline
\end{tabular}

\section{Yoshitani 2003}

\begin{tabular}{ll}
\hline Methods & $\begin{array}{l}\text { Study design: randomized parallel groups } \\
\text { Study dates: "From October, } 1998 \text { to July, 1999." (email bias survey, see notes) }\end{array}$ \\
\hline Country: Japan \\
Sex: both \\
Age: 37 to 85 \\
ASA: not stated \\
Procedure: cardiac surgery \\
Study size: 45
\end{tabular}

\begin{tabular}{ll} 
Randerventions & Ramized portion of anaesthetic: parts of IV: hypnotic (propofol) infusions TCI \\
Intervention 1: maintenance: propofol $4 \mathrm{mg} / \mathrm{kg} / \mathrm{h}, \mathrm{N}=15$ \\
Intervention 2: maintenance: propofol $5 \mathrm{mg} / \mathrm{kg} / \mathrm{h}, \mathrm{N}=15$ \\
Intervention 3: maintenance: propofol $6 \mathrm{mg} / \mathrm{kg} / \mathrm{h}, \mathrm{N}=15$ \\
\hline Outcomes & Primary outcomes: BIS values, anaesthetic consumption, haemodynamic parameters \\
& Secondary outcome: awareness/wakefulness as defined using an awareness classification system (see \\
Table 1 ): class 1 & \\
Quote: "No patient reported awareness of intraoperative events"
\end{tabular}


Yoshitani 2003 (Continued) Notes

\section{Non-randomized portion of anaesthetic: parts of intravenous (IV) anaesthesia: $\mathrm{N}_{\mathbf{2}} \mathrm{O} /$ narcotic (fen- tanyl)/hypnotic (propofol)/muscle relaxants induction yes/maintenance yes (vecuronium): EEG recorded}

Anaesthesia induction: fentanyl $10 \mathrm{mg} / \mathrm{kg}+$ propofol $3 \mu \mathrm{g} / \mathrm{mL}+$ vecuronium $0.2 \mathrm{mg} / \mathrm{kg}$

Anaesthesia maintenance: fentanyl $5 \mu \mathrm{g} / \mathrm{kg} / \mathrm{h}$ (to a total of $30 \mu \mathrm{g} / \mathrm{kg}$ ) + oxygen $50 \%$ and $\mathrm{N}_{2} \mathrm{O} 50 \%$

The EEG was monitored continuously from induction of anaesthesia to emergence

Author responded to the email bias survey on 3 February 2011. Responses are recorded in the 'Risk of bias' table.

Survey response: 3 February 2011, Kenji Yoshitani ykenji@kfz.biglobe.ne.jp

Emailed author 29 December 2013 to clarify allocation concealment

\section{Risk of bias}

\begin{tabular}{lll}
\hline Bias & Authors' judgement & Support for judgement \\
\hline $\begin{array}{ll}\text { Random sequence genera- } \\
\text { tion (selection bias) }\end{array}$ & Low risk & $\begin{array}{l}\text { Quote: "Patients were randomly assigned to receive propofol at 4 (Group A), } \\
5 \text { (Group B), or } 6 \mathrm{mg} / \mathrm{kg} / \mathrm{h} \text { IV (Group C) using the sealed envelope technique in } \\
\text { block randomization with } 15 \text { in each group" }\end{array}$ \\
& &
\end{tabular}

\begin{tabular}{ll}
\hline $\begin{array}{l}\text { Allocation concealment } \\
\text { (selection bias) }\end{array}$ & Unclear risk \\
& $\begin{array}{l}\text { Comment: emailed author } 29 \text { December } 2013 \text { to clarify; await author response } \\
\text { regarding the use of opaque envelopes }\end{array}$
\end{tabular}

\begin{tabular}{|c|c|c|}
\hline $\begin{array}{l}\text { Blinding of participants } \\
\text { and personnel (perfor- } \\
\text { mance bias) }\end{array}$ & High risk & $\begin{array}{l}\text { Quote: "This study was an open label study. To change propofol dosage ac- } \\
\text { cording to the assignment was difficult to blind. However, patients did not } \\
\text { know the group assignment" }\end{array}$ \\
\hline
\end{tabular}

\begin{tabular}{lll}
\hline $\begin{array}{l}\text { Blinding of outcome as- } \\
\text { sessment (detection bias) } \\
\text { All outcomes }\end{array}$ & Low risk & Quote survey: "Patient, Awareness outcome assessor (interviewer)" \\
\hline $\begin{array}{l}\text { Incomplete outcome data } \\
\text { (attrition bias) } \\
\text { All outcomes }\end{array}$ & Low risk & $\begin{array}{l}\text { Quote: "All outcome was completed in the study. There was no exclusion be- } \\
\text { cause of single center small study" (email bias survey, see notes) }\end{array}$ \\
\hline $\begin{array}{l}\text { Selective reporting (re- } \\
\text { porting bias) }\end{array}$ & Low risk & $\begin{array}{l}\text { Quote: "The study protocol is available and all of the study's pre-specified out- } \\
\text { comes that are of interest in the review have been reported in the pre-speci- } \\
\text { fied way" (email bias survey, see notes) }\end{array}$ \\
& \begin{tabular}{l} 
Comment: awareness outcome part of inclusion criteria \\
\hline
\end{tabular}
\end{tabular}

\begin{tabular}{ll}
\hline Other bias $\quad$ Low risk & $\begin{array}{l}\text { Quote: "We did not have any risk of bias. We did not have a design related to } \\
\text { the specific study design, stop early and so on" }\end{array}$
\end{tabular}

\section{Zhang 2011}

\begin{tabular}{|c|c|}
\hline Methods & Study design: randomized parallel groups \\
\hline
\end{tabular}


Zhang 2011 (Continued)

Country: China
Sex: both
Age: $>=18$ years
ASA: I to III with significantly sicker patients in BIS guided group (P<0.0 $)$
Procedure:
Type of operation: $1=$ neurosurgery, $2=$ craniofacial and cervical surger
cologic and obstetrics surgery, $5=$ chest and abdomen surgery, $6=$ urinary
surgery, $8=$ others
Study size: enrolled 5309 , completed study 5228 patients
Randomized portion of anaesthetic: ADM (BIS 40 to 60$)$ vs SCP: TIVA
TIVA:
BIS guided (40 to 60$), \mathrm{N}=2309$
BIS blinded, $\mathrm{N}=2919$

Outcomes Primary outcomes: awareness/wakefulness as defined using our 'Classification of intra-operative cognitive states' Table 1: class 4

BIS-guided group vs BIS blinded (control group)

Confirmed awareness: $4 / 2919(0.14 \%)$ vs $15 / 2309$ (0.65\%) ( $P=0.002$, OR $0.21,95 \% \mathrm{Cl} 0.07$ to 0.63$)$

Possible awareness: 4/2919 (0.14\%) vs 6/2309 (0.26\%) $(P=0.485)$

Dreaming: $3.1 \%$ vs $3.1 \%(P=0.986)$

Non-randomized portion of anaesthetic: parts of TIVA/ $\mathrm{N}_{2} \mathrm{O}$ unclear hypnotic (midazolam + propofol infusion)/narcotics: other anaesthetics (analgesics and muscle relaxants): discretion of the anaesthetist

\section{Comment: TIVA not defined}

No premedication

Induction: midazolam + propofol infusion

Maintenance: propofol infusion and other anaesthetics (analgesics and muscle relaxants): discretion of the anaesthetist

Comment: this is one of the most detailed stratifications of patient awareness reports in this review

\section{Comment: see Dryad topic: explanation of awareness events}

Conclusion: authors agree with Ghoneim 2009 and Schwender 1995: "light anaesthesia was the main reason for awareness"

\section{Comment: authors describe one of the most complete lists of causes of awareness}

Email communications: yueyun@hotmail.com, zhch1127@sina.com: 31 January 2013 through 14 November 2014; topics: ROB survey, missing data, adjudicated awareness reports including non-published data; 13 June $2015 \mathrm{~N}_{2} \mathrm{O}$

\section{Risk of bias}


Zhang 2011 (Continued)

\section{Bias Authors' judgement Support for judgement}

Random sequence genera- High risk tion (selection bias)
ROB survey response by Dr Zhang, Quote: "Randomization was carried out in each individual center through computer-generated random numbers to develop randomized program..."

Comment: there is an unexplained large discrepancy in the sample sizes for the 2 interventions: 2309 vs 2919

\begin{tabular}{ll}
\hline $\begin{array}{l}\text { Allocation concealment } \\
\text { (selection bias) }\end{array}$ & ROBclear risk \\
& $\begin{array}{l}\text { blinded to the group allocation. We have independent investigators who did } \\
\text { not know the patient allocation and did not participant in anesthesia proce- } \\
\text { dure. The anesthesiologists were not blinded, for they have to maintain anes- } \\
\text { thesia depth by BIS or not according to the allocation" }\end{array}$ \\
\end{tabular}

Blinding of participants High risk Comment: SCPs exposed to both groups and infusion rates difficult to blind and personnel (perfor-

mance bias)

All outcomes

\begin{tabular}{lll}
\hline $\begin{array}{l}\text { Blinding of outcome as- } \\
\text { sessment (detection bias) } \\
\text { All outcomes }\end{array}$ & Low risk & Quote: "Interviewers and patients were blinded to the group allocation" \\
\hline $\begin{array}{l}\text { Incomplete outcome data } \\
\text { (attrition bias) }\end{array}$ & Low risk & $\begin{array}{l}\text { ROB survey response: "Outcome data was collected from } 5309 \text { patients. Fifty- } \\
\text { four cases were withdrawn because the information of group allocation was } \\
\text { unavailable (without awareness cases), another } 21 \text { patients were excluded due } \\
\text { to younger than } 18 \text { years (11 cases in Group A, and } 10 \text { cases in Group B), and a } \\
\text { further } 6 \text { patients were excluded because of failure to be interviewed at any of } \\
\text { the two times (2 cases in Group A, } 2 \text { cases in Group B; } 1 \text { patient died postoper- } \\
\text { atively, operation was cancelled in } 1 \text { case after anaesthesia induction). Thus, a } \\
\text { total of } 5228 \text { cases were enrolled in the final statistical analysis with 2919 cas- } \\
\text { es in Group A and } 2309 \text { cases in Group B" }\end{array}$
\end{tabular}

Selective reporting (re- Low risk $\quad$ Quote: "No" porting bias)

Comment: awareness outcome part of inclusion criteria

Zhou 2008

ROB survey response: "There was one bias related to our study design that the anesthesiologists were not blinded to the group allocation"

\begin{tabular}{ll}
\hline Methods & Study design: randomized parallel groups \\
& Study dates: NA \\
\hline Participants & Country: China \\
& Sex: female \\
& Age: mean age $39 \pm 7$ \\
ASA: I-II & Procedure: gynaecologic laparoscopy \\
Study size: 45
\end{tabular}


Zhou 2008 (Continued)

\section{Interventions \\ Randomized portion of anaesthetic: parts of TIVA (TCI propofol/propofol bolus) vs parts of volatile agent (sevoflurane)}

Intervention 1: induction and maintenance: sevoflurane 6\%: induction; 4\%: maintenance MAC, N = 15

Intervention 2: induction: $\mathrm{TCl}$ propofol $3 \mathrm{mg} / \mathrm{mL}, \mathrm{N}=15$

Intervention 3: induction: propofol bolus $2 \mathrm{mg} / \mathrm{kg}, \mathrm{N}=15$

Outcomes

Primary outcomes: BIS values and haemodynamics peri-intubation

Awareness/wakefulness as defined using an awareness classification system (see Table 1): class 1

Quote: "no adverse reaction concerning memory was observed in three groups"

\section{Notes}

\section{Non-randomized portion of anaesthetic: nitrous N/parts of TIVA vs volatile agent (sevoflurane) + narcotics (sufentanil) + muscle relaxant(s) (rocuronium) induction yes/maintenance unclear/ADM BIS 60}

Induction: sufentanil $0.5 \mu \mathrm{g} / \mathrm{kg}$ + sevoflurane $6 \mathrm{MAC}$ + rocuronium bromide $0.6 \mathrm{mg} / \mathrm{kg} / \mathrm{BIS}$

Comment: intubation at BIS $\mathbf{6 0}$ is example of light anaesthesia

Zancong Shen translator

ROB survey sent yueyun@hotmail.com

\section{Risk of bias}

\begin{tabular}{lll}
\hline Bias & Authors' judgement & Support for judgement \\
\hline $\begin{array}{l}\text { Random sequence genera- } \\
\text { tion (selection bias) }\end{array}$ & Low risk & $\begin{array}{l}\text { Quote survey: "Patients were randomized by their assigned random num- } \\
\text { bers, however after randomization each group was given different treatment } \\
\text { drugs...And or anesthesia depth monitors like BIS (BIS is the key depth moni- } \\
\text { toring endpoint (60) when intubation was applied for all patients),Narcotrend, } \\
\text { AAl, etc. All 45 patients had in GYN laparoscopy" }\end{array}$ \\
\hline $\begin{array}{l}\text { Allocation concealment } \\
\text { (selection bias) }\end{array}$ & Unclear risk & Comment: no information provided \\
\hline $\begin{array}{l}\text { Blinding of participants } \\
\text { and personnel (perfor- } \\
\text { mance bias) } \\
\text { All outcomes }\end{array}$ & Unclear risk & Comment: difficult to blind infusion-based anaesthetic and volatile agent \\
\hline
\end{tabular}

Blinding of outcome as- Unclear risk Comment: assessor: no information provided
sessment (detection bias)

All outcomes

\begin{tabular}{|c|c|c|}
\hline $\begin{array}{l}\text { Incomplete outcome data } \\
\text { (attrition bias) } \\
\text { All outcomes }\end{array}$ & Low risk & $\begin{array}{l}\text { Comment: no missing data } \\
\text { Quote: "They followed up with all patients post surgery for any adverse reac- } \\
\text { tion related to memory, but did not find any)" }\end{array}$ \\
\hline $\begin{array}{l}\text { Selective reporting (re- } \\
\text { porting bias) }\end{array}$ & Low risk & Comment: awareness outcome part of inclusion criteria \\
\hline Other bias & Unclear risk & Comment: insufficient information provided \\
\hline
\end{tabular}


Zohar 2006

\begin{tabular}{|c|c|}
\hline Methods & $\begin{array}{l}\text { Study design: randomized parallel groups } \\
\text { Study dates: NA }\end{array}$ \\
\hline \multirow[t]{6}{*}{ Participants } & Country: Israel and USA \\
\hline & Sex: female \\
\hline & Age: geriatric $>65$ \\
\hline & ASA: \\
\hline & Procedure: short elective transurethral surgical procedures \\
\hline & Study size: 50 \\
\hline \multirow[t]{3}{*}{ Interventions } & Randomized portion of anaesthetic: ADM (BIS 50 to 60 ) vs SCP \\
\hline & 1) Standard practice (control) group, $\mathrm{N}=25$ \\
\hline & 2) Experimental (BIS) group (50 to 60 ), $\mathrm{N}=25$ \\
\hline \multirow[t]{3}{*}{ Outcomes } & $\begin{array}{l}\text { Primary outcomes: anaesthetic and analgesic requirements, times to eye opening, and other recovery } \\
\text { parameters }\end{array}$ \\
\hline & $\begin{array}{l}\text { Secondary outcome: awareness/wakefulness as defined using an awareness classification system (see } \\
\text { Table 1): class } 1\end{array}$ \\
\hline & Comment: no awareness events reported \\
\hline
\end{tabular}

\section{Notes}

\section{Randomized portion of anaesthetic: parts of volatile agent/hypnotic/(propofol)/(sevoflu- rane)/ $\mathrm{N}_{2} \mathrm{O} /$ narcotic (fentanyl)/spontaneous respiration, laryngeal mask airway: hence, no muscle relaxant(s)}

No preanaesthetic medication

Induction: fentanyl $1.0 \mu \mathrm{g}$ to $1.5 \mu \mathrm{g} / \mathrm{kg}$ + propofol $1.5 \mathrm{mg}$ to $2.0 \mathrm{mg} / \mathrm{kg}$

Maintenance: sevoflurane $1.5 \%$ with $60 \% \mathrm{~N}_{2} \mathrm{O}$ in oxygen, fentanyl $25 \mu \mathrm{g}$ IV PRN tachypnoea; LMA; BIS 50 to 60

Comment: supplemental "rescue" doses of fentanyl $(25 \mu \mathrm{g}$ IV) were significantly more in SCP vs BIS group

Comment: see Dryad topic calculation of sevoflurane minimum alveolar concentration (MAC) during the maintenance period

No email address available for ROB survey

\section{Risk of bias}

\begin{tabular}{lll}
\hline Bias & Authors' judgement & Support for judgement \\
\hline $\begin{array}{l}\text { Random sequence genera- } \\
\text { tion (selection bias) }\end{array}$ & Unclear risk & $\begin{array}{l}\text { Quote: "written informed consent, 50 geriatric outpatients were enrolled in } \\
\text { this prospective, randomized, assessor-blinded study involving two treatment } \\
\text { groups" }\end{array}$ \\
\hline $\begin{array}{l}\text { Allocation concealment } \\
\text { (selection bias) }\end{array}$ & Unclear risk & Comment: no information provided \\
\hline
\end{tabular}


Zohar 2006 (Continued)
Blinding of participants
High risk
Comment: SCPs exposed to both groups and personnel (perfor- mance bias)
All outcomes

\begin{tabular}{|c|c|c|}
\hline $\begin{array}{l}\text { Blinding of outcome as- } \\
\text { sessment (detection bias) } \\
\text { All outcomes }\end{array}$ & Low risk & $\begin{array}{l}\text { Quote: assessor: "Early recovery endpoints were recorded at one minute inter- } \\
\text { vals following discontinuation of the maintenance anesthetics by a 'blinded' } \\
\text { observer" }\end{array}$ \\
\hline
\end{tabular} observer"

Incomplete outcome data Low risk Comment: no missing outcome data
(attrition bias)

All outcomes

\begin{tabular}{lll}
$\begin{array}{l}\text { Selective reporting (re- } \\
\text { porting bias) }\end{array}$ & Low risk & Comment: awareness outcome part of inclusion criteria \\
\hline Other bias & Unclear risk & Comment: insufficient information provided \\
\hline
\end{tabular}

Acronyms and abbreviations

$\mathrm{AAI}=\mathrm{A}$-line $\mathrm{ARX}$ index; $\mathrm{ADM}=$ anaesthesia depth monitor; $\mathrm{AEP}=$ auditory evoked potential; $\mathrm{AER}$ = auditory evoked response; $\mathrm{AMLR}$ auditory middle-latency response; AP = arterial pressure; APGAR = Appearance, Pulse, Grimace, Activity, and Respiration developed in 1952 by an anaesthesiologist named Virginia Apgar; AML = auditory middle latency response; ASA = American Society of Anesthesiology; ASSR = auditory steady-state response; BAG-RECALL = BIS or Anaesthetic Gas to Reduce Explicit Recall trial; BIS = Bispectral Index; BP = blood pressure; $C A B G=$ coronary artery graft surgery; $c b c=$ complete blood count; $C B W=$ corrected body weight; $C I=$ confidence interval; $C L A D S$ = closed-loop anaesthesia delivery system; CPB = cardiopulmonary bypass; CV = cardiovascular; DBIS, DBP, DHR, DMAP = changes in BIS, heart rate and MAP; EEG = electroencephalogram; ENT = ear, nose and throat; $E T$ = end-tidal; $E T A G$ = end-tidal panaesthesia gas; $E T T$ = endotracheal tube; $\mathrm{FIO}_{2}$ = fraction of inspired oxygen; $\mathrm{GA}=$ general anaesthesia; GETA = general endotracheal anaesthesia; GETGA = general endotracheal general anaesthesia; $h=$ hours; $\mathrm{HBI}=$ pulse plethysmography; $\mathrm{mmHg}=$ millimetres of mercury; $\mathrm{h}=\mathrm{hour} ; \mathrm{HR}=\mathrm{heart}$ rate; $\mathrm{HTN}=$ hypertension; $\mathrm{Hz}=$ hertz; ICU = intensive care unit; IFT = isolated forearm technique; IM = intramuscular; IPPV = intermittent positive pressure ventilation; IU = international unit; IV = intravenous; $\mathrm{L}=$ litres; $\mathrm{LMA}=$ laryngeal mask airway; $\mathrm{LOC}=$ loss of consciousness; LV = left ventricular; $\mathrm{kg}=$ kilogram; $\mathrm{MAC}=$ minimal alveolar concentration; $\mu \mathrm{g}=$ micrograms; $\mathrm{MCl}=$ manually controlled infusion; $\mathrm{mg}=\mathrm{milligram} ; \mathrm{min}$ = minute; $\mu \mathrm{g} / \mathrm{kg} / \mathrm{min}$ = micrograms per kilogram per minute; $\mathrm{MLAEP}=$ middle latency auditory evoked potentials; MLAER = middle latency auditory evoked responses; $\mathrm{MVD}=$ microvascular decompression; $\mathrm{N}=$ sample size; $\mathrm{NA}=$ not available; $\mathrm{NaCl}$ : saline; $\mathrm{NS}$ not significant; $\mathrm{N}_{2} \mathrm{O}$ = nitrous oxide; $\mathrm{NMB}=$ neuromuscular blocking agents; $\mathrm{OPCAB}=$ off pump coronary artery bypass; $\mathrm{OR}=$ odds ratio; OpR = operating room; $\mathrm{Pa}=$ waveform part of auditory evoked potentials; $\mathrm{PACU}=$ post-anaesthesia care unit; $\mathrm{PHC}=$ phencyclidine; $\mathrm{PO}=\mathrm{per}$ ora $(\mathrm{by}$ mouth); $\mathrm{POD}=$ postoperative day; PPG = photo plethysmography; PRN = pro re nata (as the occasion arises) 'as needed'; PRST = P (systolic blood Pressure), $\mathrm{R}$ (heart Rate), $\mathrm{S}$ (Sweating) and $\mathrm{T}$ (Tears); $\mathrm{PSI}=$ pound per square inch; RCT = randomized controlled trial; RE = response entropy; ROB = risk of bias; RSII[AM1] = rapid sequence induction and intubation; $\mathrm{S}=\mathrm{S}$ - (+)-ketamine is more potent than its racemic mixture; $\mathrm{SBP}=$ systolic blood pressure; SCP = standard clinical practice; SD = standard deviation; SE = state entropy; SEF = spectral edge frequency; SNAP = sensory nerve action potentials; SNOSE = sequentially numbered, opaque, sealed envelopes; SPI = surgical pleth index; SR = spontaneous respiration; sys = systolic; TBW = total body weight; TCI = target-controlled infusions; THR = total hip replacement; TIVA = total intravenous anaesthesia; TOF = train-of-four; TP termination of pregnancy; TPS Paventi 2000 no definition; UID = uterine incision to delivery interval; vs $=$ versus

${ }^{\star *}$ acronym used twice

Characteristics of excluded studies [ordered by study ID]

\begin{tabular}{ll}
\hline Study & Reason for exclusion \\
\hline Abboud 1990 & Not general anaesthesia \\
\hline Abdel-Meguid 2005 & No awareness test \\
\hline Abott 1980 & No randomization of medications \\
\hline Abouleish 1976 & No randomization of medications \\
\hline
\end{tabular}




\begin{tabular}{|c|c|}
\hline Study & Reason for exclusion \\
\hline Absalom 2002 & No randomization of medications \\
\hline Acil 2004 & No awareness test \\
\hline Adams 1998 & No randomization of medications \\
\hline Adams 2003 & $\begin{array}{l}\text { Not general anaesthesia. Survey response: } 24 \text { January 2011, Prof. Dr med. Hans Anton Adams } \\
\text { adams.ha@mh-hannover.de }\end{array}$ \\
\hline Ahmad 2003 & No awareness test \\
\hline Ahonen 2007 & No awareness test \\
\hline Al-Ruzzeh 2006 & No awareness test \\
\hline Alexander 1999a & No awareness test \\
\hline Alexander 1999b & No awareness test \\
\hline Alvarez 2000 & No randomization of medications \\
\hline Andelman 2004 & No randomization of medications \\
\hline Anderson 2003 & No randomization of medications \\
\hline Anderson 2004 & No randomization of medications \\
\hline Andrade 2001 & No randomization of medications \\
\hline Aono 1999 & No randomization of medications \\
\hline Apfelbaum 1996 & Volunteers not surgery \\
\hline Aqil 2009 & No awareness test \\
\hline Arndt 1995a & Not randomized \\
\hline Aubrun 2008 & No awareness test \\
\hline Ausems 1983 & No randomization of medications \\
\hline Ausems 1986 & No awareness test \\
\hline Bailey 1985 & Wake up test \\
\hline Balci 2006 & No awareness test \\
\hline Bannister 2001 & No awareness test \\
\hline Baraka 1990 & No randomization of medications \\
\hline Barclay 1980 & No randomization of medications \\
\hline Barr 1973 & No randomization of medications \\
\hline
\end{tabular}




\begin{tabular}{|c|c|}
\hline Study & Reason for exclusion \\
\hline Barr 1999 & Volunteers not surgery \\
\hline Barr 2001 & Volunteers not surgery \\
\hline Barvais 2003 & No randomization of medications \\
\hline Basar 2003 & No awareness test \\
\hline Becker-Blease 2006 & Volunteers not surgery \\
\hline Bejjani 2009 & No randomization of medications \\
\hline Bennett 1985 & No randomization of medications \\
\hline Bilotta 2007 & No awareness test-POCD \\
\hline Bischoff 1997 & Expert commentary about awareness: EEG review \\
\hline Block1991b & No awareness test-therapeutic suggestion results only \\
\hline Bogetz 1984 & No randomization of medications \\
\hline Bogod 1990 & No randomization of medications \\
\hline Bonhomme 2006 & No awareness test \\
\hline Bonke 1986 & No randomization of medications \\
\hline Bonke 1992 & No awareness test \\
\hline Bould 2007 & No randomization of medications \\
\hline Brice 1970 & No randomization of medications \\
\hline Brosius 2002 & No awareness test \\
\hline Bruhn 2000 & Expert commentary about awareness: case report \\
\hline Buffett-Jerrott 2003 & $\begin{array}{l}\text { No awareness test - complicated memory test but no evidence awareness of intraoperative } \\
\text { events assessed }\end{array}$ \\
\hline Bulach 2005 & No awareness test \\
\hline Burn 1963 & No randomization of medications \\
\hline Burrow 2001 & No awareness test \\
\hline Byers 1997 & No randomization of medications \\
\hline Capitanio 1997 & No awareness test; no randomization of medications \\
\hline Chiu 2007 & No awareness test \\
\hline Chortkoff 1995 & Volunteers not surgery \\
\hline
\end{tabular}




\begin{tabular}{|c|c|}
\hline Study & Reason for exclusion \\
\hline Cirillo 2012 & $\begin{array}{l}\text { Unable to find either the citation or full-text paper in PubMed (despite European Journal of Anaes- } \\
\text { thesiology } 2012 \text { search), Embase or Cochrane databases }\end{array}$ \\
\hline Clark 2009 & No awareness test \\
\hline Coetzee 1998 & No randomization of medications for anaesthesia but narcotic randomized at wound closure \\
\hline Coppens 2010 & No awareness test \\
\hline Cormack 1979 & No randomization of medications \\
\hline Crawford 1976 & No randomization of medications \\
\hline Dahaba 2009 & No awareness test \\
\hline Dahaba 2010 & No randomization of medications \\
\hline Davidson 2005 & No randomization of medications \\
\hline Davies 1996 & No randomization of medications \\
\hline De Cosmo 2008 & No awareness test \\
\hline De Kock 2005 & No awareness test \\
\hline Ding 1993 & No awareness test \\
\hline Ding 2007 & Not general anaesthesia - retrospective study of postoperative complications \\
\hline Diz 2010 & No awareness test \\
\hline Doufas 2009 & No randomization of medications during surgery; not performed after skin incision \\
\hline Downing 1976 & Expert commentary about awareness - retrospective review records for patient awareness reports \\
\hline Dressler 2007 & No randomization of medications \\
\hline Driscoll 2007 & No randomization of medications \\
\hline Eisele 1976 & No randomization of medications \\
\hline Ekman 2004a & No randomization of medications \\
\hline Ekman 2004b & No awareness test \\
\hline El-Kerdawy 2000 & No awareness test \\
\hline Eldar 1992 & Wake up test \\
\hline Erhan 2003 & No awareness test \\
\hline Erk 2007 & No awareness test \\
\hline Eroglu 2003 & No awareness test \\
\hline
\end{tabular}




\begin{tabular}{|c|c|}
\hline Study & Reason for exclusion \\
\hline Evans 1988 & No randomization of medications by anaesthetic but only word test \\
\hline Fahlenkamp 2010 & No awareness test \\
\hline Fairley 1956 & No randomization of medications \\
\hline Famewo 1976 & No randomization of medications \\
\hline Farag 2006 & No awareness test \\
\hline Filipov 2007 & $\begin{array}{l}\text { No awareness test in abstract - unable to get full paper through University of Utah Library (they } \\
\text { tried through all possible sources) }\end{array}$ \\
\hline Fisher 2006 & No randomization of medications \\
\hline Fitzgerald 2001 & Volunteers not surgery \\
\hline Flaishon 1997 & No randomization of medications \\
\hline Flaitz 1986 & No randomization of medications \\
\hline Flier 1986 & No randomization of medications \\
\hline Forrest 1990 & Not general anaesthesia \\
\hline Frank 2000 & No awareness test \\
\hline Fung 2008 & Wake up test performed \\
\hline Gajraj 1998 & Not general anaesthesia \\
\hline Gajraj 1999 & Not general anaesthesia \\
\hline Gan 1997 & No awareness test \\
\hline Gan 1999 & No awareness test \\
\hline Gazzanelli 2005 & No randomization of medications \\
\hline Ge 2003 & No randomization of medications \\
\hline Gelman 1984 & No awareness interview \\
\hline Ghabash 1996 & No awareness test \\
\hline Ghoneim 1988 & No awareness test \\
\hline Ghoneim 1998 & Volunteers not surgery \\
\hline Ghoneim 2007 & No randomization of medications \\
\hline Glass 1997 & Volunteers not surgery \\
\hline Gordon 1994 & No randomization of medications \\
\hline
\end{tabular}




\begin{tabular}{|c|c|}
\hline Study & Reason for exclusion \\
\hline Gregory 1969 & No randomization of medications \\
\hline Greif 2002 & Volunteers not surgery \\
\hline Gross 1988 & No awareness test \\
\hline Gu 2010 & No awareness test \\
\hline Guignard 2001 & No randomization of medications \\
\hline Gunawardane 2002 & No randomization of medications \\
\hline Guo 2012 & Not general anaesthesia \\
\hline Gupta 2006 & No awareness test \\
\hline Hadzidiakos 2006 & No randomization of medications - only word test \\
\hline Haessler 1993 & No awareness test \\
\hline Hall 1986 & No awareness test \\
\hline Hans 1998 & No awareness test \\
\hline Harris 1971 & No randomization of medications \\
\hline Hartridge 1963 & No randomization of medications \\
\hline Hartung 1986 & No awareness test \\
\hline Hashimoto 2012 & $\begin{array}{l}\text { Unable to find either the citation or full-text paper in PubMed, Embase or Cochrane databases; } \\
\text { peer reviewed study not published }\end{array}$ \\
\hline Hayashi 2007 & No awareness test \\
\hline Head-Rapson 1995 & No randomization of medications \\
\hline Heipertz 1986 & No awareness test \\
\hline Heisterkamp 1975 & Not general anaesthesia \\
\hline Heller 2005 & No randomization of medications \\
\hline Hellwagner 2003 & No awareness test \\
\hline Hetem 2000 & Volunteers not surgery \\
\hline Hirschi 2000 & No randomization of medications \\
\hline Honarmand 2008 & No awareness test \\
\hline Hong 2008 & No awareness test \\
\hline Horn 2009 & No awareness test; volunteers not surgery \\
\hline
\end{tabular}




\begin{tabular}{|c|c|}
\hline Study & Reason for exclusion \\
\hline Hoymork 2003 & No randomization of medications \\
\hline Hoymork 2005 & No randomization of medications \\
\hline Huang 1988 & No randomization of medications \\
\hline Huang 2005 & No randomization of medications - randomized by child positive awareness \\
\hline Hudetz 2007 & No awareness test \\
\hline Hughes 1994 & No randomization of medications \\
\hline Hughes 2009 & Expert commentary about awareness \\
\hline Hutchinson 1960 & No randomization of medications \\
\hline lannuzzi 2005 & Expert commentary about awareness \\
\hline Ibrahim 2001a & Not general anaesthesia \\
\hline Ibrahim 2001b & Not general anaesthesia \\
\hline Inagaki 1997 & No awareness test \\
\hline Ingelmo 2007 & No awareness test \\
\hline Inglis 1993 & No awareness test \\
\hline Iqbal 1985 & No randomization of medications \\
\hline Iselin-Chaves 1998 & Volunteers not surgery \\
\hline Iselin-Chaves 2000 & Volunteers not surgery \\
\hline Iselin-Chaves 2005 & No randomization of medications \\
\hline Ishiyama 2005 & Not general anaesthesia \\
\hline Isomura 2008 & $\begin{array}{l}\text { Not general anaesthesia - sedated for } 20 \text { hours on average in the ICU after maxillofacial surgery } \\
\text { (translated Jiro Kurata MD) }\end{array}$ \\
\hline Ittichaikulthol 2007 & $\begin{array}{l}\text { No awareness test in abstract - unable to get full paper through University of Utah Library (they } \\
\text { tried through all possible sources) }\end{array}$ \\
\hline Ivanov 1969 & No randomization of medications \\
\hline Jacoby 1981 & Volunteers not surgery \\
\hline Jaffrelot 2007 & No awareness test \\
\hline Jeleazcov 2007 & No awareness test \\
\hline Jelicic 1993a & No randomization of medications \\
\hline Jelicic 1993b & No randomization of medications \\
\hline
\end{tabular}




\begin{tabular}{|c|c|}
\hline Study & Reason for exclusion \\
\hline Jellish 2000 & No awareness test \\
\hline Jellish 2009 & No awareness test \\
\hline Jensen 1996 & No awareness test \\
\hline Jeon 2000 & No randomization of medications: IFT \\
\hline Jessop 1991 & Expert commentary about awareness: editorial \\
\hline Jones 1990 & No awareness test \\
\hline Jordan 2012 & $\begin{array}{l}\text { Unable to find citation and/or abstract or full paper after searching other databases; emailed au- } \\
\text { thor with no response }\end{array}$ \\
\hline Jospin 2007 & No awareness test \\
\hline Juckenhofel 1999 & No awareness test \\
\hline Katoh 1993 & No awareness test \\
\hline Katoh 1994 & No awareness test \\
\hline Kavey 1979 & No randomization of medications \\
\hline Kennedy 1985 & No awareness test \\
\hline Kenny 1999 & No randomization \\
\hline Kerssens 2002 & No randomization of medications \\
\hline Kerssens 2003 & No randomization and pre-incision (IFT) \\
\hline Kerssens 2005a & Volunteers not surgery \\
\hline Kertai 2011 & No awareness test \\
\hline Kestin 1990 & Not general anaesthesia \\
\hline Kevin 2002 & No randomization of medications \\
\hline Khandwala 2008 & Unrelated study \\
\hline Kiernan 1995 & Volunteers not surgery \\
\hline Kim 1978 & No randomization of medications \\
\hline Kim 2010 & No awareness test \\
\hline Kliempt 1999 & No randomization of medications \\
\hline Kocaman 2007 & No randomization of medications \\
\hline Kokki 2007 & No awareness test \\
\hline
\end{tabular}




\begin{tabular}{|c|c|}
\hline Study & Reason for exclusion \\
\hline Kotiniemi 1996 & No awareness test as performed in adults only behavioural changes \\
\hline Kreuer 2001 & No randomization of medications \\
\hline Lapidus 2007 & Unrelated study \\
\hline Latto 1977 & No randomization of medications \\
\hline Lefoll-Masson 2007 & No randomization of medications \\
\hline Lehmann 2000 & Paper retracted; survey response: email a@klilu.de \\
\hline Lehmann 2002 & Paper retracted; survey response: email a@klilu.de \\
\hline Lehmann 2003 & Paper retracted; survey response: 21 January 2011 a@klilu.de \\
\hline Lequeux 2003 & $\begin{array}{l}\text { No awareness test evaluation - memory tapes randomized; survey response: } 10 \text { February } \\
2011 \text { Lequeux pilequeu@ulb.ac.be }\end{array}$ \\
\hline Leslie 2007 & No randomization of medications \\
\hline Levine 1993 & No awareness test \\
\hline Liao 2010 & No awareness test \\
\hline Liou 1994 & No randomization of medications \\
\hline Liu 2005 & No awareness test \\
\hline Liu 2006 & No awareness assessment; ROB survey response m.fischler@hopital-foch.org \\
\hline Liu 2009 & No awareness test \\
\hline Lopez 2007 & No randomization of medications \\
\hline Low 2007 & Not general anaesthesia; no awareness test \\
\hline Luginbuhl 2007 & No awareness test \\
\hline Luginbuhl 2010 & No awareness test \\
\hline Lyons 1991 & No randomization of medications \\
\hline Magni 2009 & No awareness test \\
\hline Mahomedy 1976 & No randomization of medications \\
\hline Malek 2009 & No awareness test - abstract only available \\
\hline Malek 2010 & No randomization of medications \\
\hline Malviya 2009 & No randomization - children 5 to 15 - expert adjudication \\
\hline Martorano 2008 & No awareness test \\
\hline
\end{tabular}




\begin{tabular}{|c|c|}
\hline Study & Reason for exclusion \\
\hline Mathews 2008 & No awareness test \\
\hline Maybauer 2007 & No awareness test \\
\hline Mayer 2007 & No awareness test \\
\hline Mellema 2010 & No awareness test \\
\hline Messahel 2003 & No randomization of medications \\
\hline Messahel 2007 & No randomization of medications \\
\hline Mi 1998 & No awareness test \\
\hline Mi 1999 & No awareness test \\
\hline Mirakhur 1986 & No awareness test \\
\hline Moerman 1995 & No randomization of medications \\
\hline Motsch 1996 & No awareness test \\
\hline Mourisse 2007 & No awareness test \\
\hline Moustafa 2008 & No awareness test \\
\hline Nakagawa 2001 & No awareness test and not general anaesthesia \\
\hline Nelskyla 2001 & No awareness test \\
\hline Ng 1974 & No randomization of medications \\
\hline Nishijima 1999 & $\begin{array}{l}\text { No awareness test: "quality of awareness" by how fast the patients became aware and oriented } \\
\text { after discontinuation of general anaesthetics. Translator Jiro Kurata MD. }\end{array}$ \\
\hline O'Sullivan 1988 & No randomization \\
\hline Oikkonen 1994 & No awareness test \\
\hline Onaka 1998 & No awareness test; abstract only \\
\hline Oudenaarden 1979 & No awareness test no randomization \\
\hline Padmanabhan 2009 & Not general anaesthesia \\
\hline Panousis 2007 & No randomization of medications \\
\hline Philbin 1990 & No awareness test \\
\hline Philipp 2002 & No awareness test - CPB membrane associated with $50 \%$ reduction isoflurane level \\
\hline Piano 2007 & No randomization of medications \\
\hline Pomfrett 2009 & No awareness test \\
\hline
\end{tabular}




\begin{tabular}{|c|c|}
\hline Study & Reason for exclusion \\
\hline Pompeo 2007 & Unrelated study \\
\hline Porter 2008 & No randomization of medications \\
\hline Pryor 2010 & No awareness test and volunteers not surgery \\
\hline Qi 2014 & $\begin{array}{l}\text { Unable to find either the citation or full-text paper in PubMed, Embase or Cochrane databases; } \\
\text { unable to identify authors communication information }\end{array}$ \\
\hline Rabiee 2012 & $\begin{array}{l}\text { Unable to find either the citation or full-text paper in PubMed, Embase or Cochrane databases; } \\
\text { emailed author with no response }\end{array}$ \\
\hline Reinhart 1985 & Not general anaesthesia \\
\hline Russell 1997 & $\begin{array}{l}\text { No randomization of medications; ROB survey response i.f.russell@hull.ac.uk: randomized only } \\
\text { for audio message; only one anaesthetic used }\end{array}$ \\
\hline Russell 2001 & $\begin{array}{l}\text { No randomization of medications; ROB survey response i.f.russell@hull.ac.uk: randomized audio } \\
\text { message }\end{array}$ \\
\hline Samuelsson 2007 & No randomization of medications \\
\hline Schneider 2005 & Wake up test \\
\hline Schraag 1998 & No awareness test \\
\hline Schroeck 2010 & No randomization of medications \\
\hline Schulz 2007 & No awareness test \\
\hline Schwender 1994 & No awareness test \\
\hline Schwender 1991a & No randomization of medications \\
\hline Schwender 1991b & No randomization of medications \\
\hline Schwender 1993 & No awareness test \\
\hline Schwender 1997 & No randomization of medications \\
\hline Schwieger 1989 & No randomization of medications \\
\hline Schwieger 1991 & No randomization of medications \\
\hline See 2007 & No awareness test \\
\hline Shariffuddin 2007 & No awareness test \\
\hline Shiau 2007 & $\begin{array}{l}\text { No randomization of medications or ADMs - randomization at end of surgery (desflurane stopped } \\
\text { before closure) }\end{array}$ \\
\hline Shimohata 2007 & Unrelated study - sleep apnoea under anaesthesia and death \\
\hline Short 1991 & No awareness test \\
\hline
\end{tabular}




\begin{tabular}{|c|c|}
\hline Study & Reason for exclusion \\
\hline Sidiropoulou 2008 & No awareness test \\
\hline Sintavanuruk 2010 & No awareness test \\
\hline Skaja 2006 & No awareness test \\
\hline Sosner 2010 & No awareness test abstract only available \\
\hline Spaulding 1984 & Not general anaesthesia; volunteers \\
\hline Stonell 2006 & $\begin{array}{l}\text { No randomization only word test. Survey response: } 4 \text { February 2011, Kate Leslie } \\
\text { kate.leslie@mh.org.au }\end{array}$ \\
\hline Struys 2001 & No awareness test \\
\hline Suarez 1994 & No randomization \\
\hline Suliman 2007 & Not general anaesthesia; no randomization \\
\hline Terblanche 2008 & No awareness test \\
\hline Ting 2004 & Wake up test \\
\hline Toraman 2013 & Unable to find either the citation or full-text paper in PubMed, EMBASE or Cochrane databases \\
\hline Treggiari 2009 & ICU not surgery \\
\hline Trillo 2009 & No awareness test \\
\hline Tufano 2000 & $\begin{array}{l}\text { No awareness test: Quote: "There was no significant differences in the incidence of intraoperative } \\
\text { responses between groups." email address not available to send survey to clarify the author's def- } \\
\text { inition of "intraoperative responses" }\end{array}$ \\
\hline Tunstall 1981 & No awareness test \\
\hline Turan 2010 & No awareness test \\
\hline Turner 1969 & No randomization of medications \\
\hline Ueyama 1986 & No randomization of medications \\
\hline Valtonen 1988 & Not general anaesthesia - sedation for cardioversion \\
\hline Vanacker 2002 & No randomization of medications \\
\hline Vanacker 2007 & No awareness test \\
\hline Vann 2007 & Not general anaesthesia \\
\hline Velly 2007 & No awareness test \\
\hline Wanatabe 1984 & No randomization of medications \\
\hline Wang 2005 & No randomization of medications \\
\hline
\end{tabular}




\begin{tabular}{|c|c|}
\hline Study & Reason for exclusion \\
\hline Wang 2007 & Volunteers not surgery \\
\hline Watanabe 1998 & Volunteers not surgery \\
\hline Weber 2005 & No aware test - indirect signs only in paediatrics \\
\hline Weber 2009 & No awareness test \\
\hline Wellisch 2012 & Unable to find either the citation or full-text paper in PubMed, Embase or Cochrane databases \\
\hline Wihelm 2000 & No awareness test \\
\hline Wilson 1970 & Expert commentary about awareness: letter to editor \\
\hline Wu 2005 & No randomization of medications \\
\hline Xu 2009 & No randomization of medications \\
\hline Yan 2005 & $\begin{array}{l}\text { No awareness test: Zancong translator quote: "Awareness was checked based on OAAS criteria } \\
\text { post surgery. The paper does not mention follow up with pts on any memory during the surgery" }\end{array}$ \\
\hline Yan 2014 & $\begin{array}{l}\text { No awareness test - translation issue: no assessment patient reports of awareness rather "aware- } \\
\text { ness" was translated instead of "consciousness or awake, etc.": "The recovery time of awareness } \\
\text { and extubation time in the treatment group" }\end{array}$ \\
\hline Yang 1994 & No awareness test; no randomization \\
\hline Yeh 2009 & No awareness test; post-surgery randomization \\
\hline Yi 2008 & No awareness test \\
\hline Yildiz 2007 & No awareness test \\
\hline Zhang 2009 & No awareness test \\
\hline Zohar 2007 & No awareness test \\
\hline
\end{tabular}

Acronyms and abbreviations

$\mathrm{ADM}=$ anaesthesia depth monitor; $\mathrm{CPB}=$ cardiopulmonary bypass; $\mathrm{EEG}=$ electroencephalogram; ICU = intensive care unit; IFT = isolated forearm technique; OAAS = Observer's Assessment of Alertness/Sedation; $P O C D=$ postoperative cognitive dysfunction; ROB = risk of bias

Characteristics of studies awaiting assessment [ordered by study ID]

Aceto 2015

Methods Study design: randomized parallel groups

Study dates: not stated

Participants

Country: pending full-text review

Sex: female and male

Age: pending full-text review

Procedure: elective thyroidectomy 


\section{Interventions Randomized portion of anaesthetic: TIVA vs volatile}

Maintenance: auditory recording was presented to patients during anaesthesia maintenance Intervention 1: BIS-guided group in which sevoflurane MAC was adjusted on the basis of BIS values Intervention 2: haemodynamic parameters (HP)-guided group in which MAC was adjusted based on HP

\section{Outcomes}

Primary outcomes: "...whether Bispectral Index (BIS)-guided anaesthesia might decrease sevoflurane minimum alveolar concentration (MAC) when compared with haemodynamically-guided anaesthesia, and to search for a MAC threshold useful for preventing arousal, dream recall and implicit memory"

Secondary outcome: awareness/wakefulness as defined using an awareness classification system (see Table 1): class pending full text review cotics/hypnotics bolus/NMBsinduction no/maintenance no

Anaesthesia was induced with propofol $2 \mathrm{mg} \mathrm{kg}(-1)$, fentanyl $3 \mu \mathrm{g} \mathrm{kg}(-1)$ and cis-atracurium 0.15 $\mathrm{mg} / \mathrm{kg}(-1)$

Dream recall and explicit/implicit memory were investigated upon awakening and approximately after $24 \mathrm{~h}$

RESULTS: mean sevoflurane MAC during auditory presentation was similar in the 2 groups $(0.85$ \pm 0.16 and $0.87 \pm 0.17(P=0.53)$ in BIS-guided and HP-guided groups, respectively). Frequency of dream recall was similar in the 2 groups: $27 \%(N=17)$ in BIS-guided group, $18 \%(N=12)$ in HP-guided group, $\mathrm{P}=0.37$

In both groups, dream recall was less probable in patients anaesthetized with MAC values $>1=0.9$ (area under ROC curve $=0.83$, sensitivity $=90 \%$, and specificity $=49 \%$ )

Conclusion: BIS-guided anaesthesia was not able to generate different MAC values compared to HP-guided anaesthesia

Independent of the guide used for anaesthesia, a sevoflurane MAC over 0.9 was required to prevent postoperative dream recall

Methods Study design: randomized parallel groups

Study dates: not stated

Sex: female and male

Age: pending full-text review

ASA: pending full-text review

Procedure:craniotomy for aneurysm clipping or tumour dissection were randomly

Study. size: 42 


\section{Intervention 1: propofol, $\mathrm{N}=21$}

Intervention 2: sevoflurane, $\mathrm{N}=21$

esmolol group received $500 \mu \mathrm{g} / \mathrm{kg}$ of esmolol bolus $10 \mathrm{~min}$ before induction of anaesthesia, followed by additional $200 \mu \mathrm{g} / \mathrm{kg} / \mathrm{min}$ of esmolol

inspired concentration of sevoflurane and the infusion rate of propofol were adjusted in order to maintain a BIS value between $40-50$

Bispectral Index-BIS and cardiac output

\section{Outcomes}

Primary outcomes: effect of esmolol on the consumption of propofol and sevoflurane in patients undergoing craniotomy

Secondary outcome: Awareness/wakefulness as defined using an awareness classification system (see Table 1) class pending full-text review

\section{Notes}

\section{Non-Randomized portion of anaesthetic: parts of IV vs parts of volatile agent $N 20: U /$ nar- cotics/hypnotics Bolus/NMBsinduction Y/maintenance U/ADM: Y: Bispectral Index-BIS}

Anaesthesia was induced with propofol, fentanyl and a single dose of cis-atracurium, followed by continuous infusion of remifentanil and either propofol or sevoflurane Esmolol group: doses of propofol and sevoflurane were $18-50 \mu \mathrm{g} / \mathrm{kg} / \mathrm{min}$ and 0.2-0.5 MAC

Control group: $100-150 \mu \mathrm{g} / \mathrm{kg} /$ and $0.9-2.0 \mathrm{MAC}(\mathrm{P}=0.000$ for both groups)

All procedures were anaesthesiologically uneventful with no episodes of intraoperative emerge

Conclusions: Esmolol is effective not only in attenuating intraoperative haemodynamic changes related to sympathetic overdrive but also in minimizing significant propofol and sevoflurane requirements without compromising the haemodynamic status

ClinicalTrials.gov Identifier: NCT02455440 . Registered 26 May 2015

\section{Elbadawy 2015}

Methods Study design: randomized parallel groups

Study dates: not stated

Participants

Country: pending full-text review

Sex: female and male

Age: pending full-text review

ASA: I and II

Procedure: orthopaedic procedures

Study size: 40

$\begin{array}{ll}\text { Interventions } & \text { Randomized portion of anaesthetic: } \\ & \text { Intervention 1: TIVA, } \mathrm{N}=20 \\ & \text { Intervention 2: volatile anaesthesia, } \mathrm{N}=20 \\ & \text { BIS-guided ( } 40 \text { to } 60)\end{array}$


Elbadawy 2015 (Continued)

Outcomes
Primary outcomes: no implicit memory of previously introduced auditory material

Secondary outcome: no awareness/wakefulness as defined using an awareness classification system (see Table 1) class pending full-text review

Notes

\section{Non-randomized portion of anaesthetic: parts of IV vs parts of volatile agent $\mathrm{N}_{2} \mathrm{O}$ unclear/nar- cotics/hypnotics bolus/NMBs induction yes/maintenance yes/ADM: yes: BIS-guided (40 to 60)}

Anaesthesia was induced with propofol and maintained with propofol, fentanyl, and cis-atracurium. In Group II anaesthesia was induced with propofol and maintained with sevoflurane, fentanyl, and cis-atracurium

Explicit memory was evaluated by asking 4 standard questions regarding intraoperative awareness. Free recall and recognition tests for implicit memory testing were carried out 30 min and 120 min after recovery.

BIS-controlled anaesthesia appears to abolish implicit memory

No PubMed citation

\section{Hoymork 2007}

$\begin{array}{ll}\text { Methods } & \text { Study design: randomized parallel groups } \\ \text { Study dates: not stated }\end{array}$

Participants Country: Norway and Denmark

Sex: female and male

Age: NA

ASA: I and II

Procedure: laparoscopy or breast/surface surgery

Study size: 55

Interventions

\section{Outcomes}

Quote: "The patients were randomly allocated to whether BIS or CSM was placed on the upper part of the forehead or closer to the eyebrows, where an eventual EMG influence could be more pronounced"

Quote: "None of our patients reported any recall from the operation, and clinical awakening was never observed during surgery, despite one episode of movement"
Quote: "In conclusion, the cerebral state monitor was a satisfactory alternative to BIS for monitoring hypnotic effect in $87 \%$ of our patients. In $13 \%$ of the patients, CSI displayed values indicating an awake state despite clinical sleep, all correctly identified with the BIS. Our study was done with the very first version of the CSM, while the BIS monitor has undergone several revisions. Clinical studies in other patient populations, undergoing different anaesthetic regimens, are warranted" 
Jiang 2016 (Continued)

Participants
Country: pending full-text review

Sex: female and male

Age: pending full-text review

ASA: pending full-text review

Procedure: laparoscopic radical gastrectomy

Study size: 100

Interventions

Randomized portion of anaesthetic: total intravenous anaesthesia (TIVA) and combined intravenous and inhaled anaesthesia (CIIA)

Intervention 1: TIVA, propofol and remifentanil: target controlled infusion (TCI), N = 50

Intervention 2: CIIA, sevoflurane and continuous infusion of remifentanil after anaesthesia induction, $\mathrm{N}=50$

State entropy (SE) maintained in the range of 45 to 60

Outcomes

Primary outcomes: concentrations: epinephrine, norepinephrine and dopamine; durations of surgical operation, breathing recovery, extubation, awakening, and postoperative orientation recovery recorded; and $48 \mathrm{H}$ postoperative adverse reactions: time patient becomes calm for $5 \mathrm{~min}$ after entering the operating theatre (T0); upon completion of pneumoperitoneum (PPT) (T1); 15 min after PPT (T2); intraoperative detection (T3), immediately after extubation (T4); and 15 min after extubation (T5)

Secondary outcome: no awareness/wakefulness as defined using an awareness classification system (see Table 1): class pending full-text review

Notes

Non-randomized portion of anaesthetic: parts of IV vs parts of volatile agent $\mathrm{N}_{2} \mathrm{O}$ unclear/narcotics/hypnotics bolus/NMBs induction no/maintenance no/ADM: yes: entropy indices

Conclusion: at the same anaesthetic depth, the CIIA method outperforms the TIVA method in suppressing the stress response and obtaining smooth awakening after laparoscopic radical gastrectomy for patients with gastric cancer; therefore, the CIIA method has a better anaesthetic effect

Methods Study design: randomized parallel groups

Study dates: not stated

Participants

Country: pending full-text review

Sex: female and male

Age: pending full-text review

ASA: pending full-text review

Procedure: caesarean section

Study size: 90

Interventions

\section{Randomized portion of anaesthetic:}

Intervention 1: inhalation (isoflurane) maintenance: isoflurane 1 MAC 
Khanjani 2014 (Continued)

Intervention 2: intravenous protocol (propofol) propofol $100 \mu \mathrm{g} / \mathrm{kg} /$ minute

Bispectral Index (BIS) between 45 and 60
Notes $\begin{aligned} & \text { Non-randomized portion of anaesthetic: parts of IV vs parts of volatile agent } \mathrm{N}_{2} \mathrm{O} \text { yes/nar- } \\ & \text { cotics/hypnotics bolus/NMBs induction no/maintenance no }\end{aligned}$

Induction: propofol and succinylcholine

\section{Methods}

Study design: randomized parallel groups

Study dates: not stated

Country: pending full-text review
Sex: female and male
Age: pending full-text review
ASA: pending full-text review
Procedure: pending full-text review
Study size: 120

Interventions

\section{Randomized portion of anaesthetic:}

Intervention 1: high-dose: remifentanil effect-site concentration (in $\mathrm{ng} / \mathrm{mL}$ ) was always double that of propofol (in mug/mL)

Intervention 2: low-dose: half of above

Patients in these 2 groups were played a list of 20 words via headphones during surgery

Intervention 3: control for memory tests: not played any words during anaesthesia

Outcomes Primary outcomes: no implicit learning of intraoperative auditory stimuli

Secondary outcome: no awareness/wakefulness as defined using an awareness classification system (see Table 1): class pending full-text review

Notes

\section{Non-randomized portion of anaesthetic: parts of IV vs parts of volatile agent $\mathrm{N}_{2} \mathrm{O}$ yes/nar- cotics/hypnotics bolus/NMBs induction no/maintenance no}

All patients were anaesthetized with a target-controlled infusion of propofol and remifentanil, targeting a bispectral index (BIS) value of 50

Conclusions: could not demonstrate the presence of implicit or explicit memorization under propofol-remifentanil anaesthesia either with a low- or a high-dose opioid anaesthetic regimen 
Mehmandoost 2013

Methods Study design: randomized parallel groups

Study dates: not stated

\begin{tabular}{ll}
\hline Participants & Country: Iran \\
Sex: female & Age: 18 to 35 years \\
ASA: ASA I-II & Procedure: caesarean section \\
& Study size: 90 \\
\hline Interventions & Intervention 1 : propofol (100 $\mu \mathrm{gg} / \mathrm{kg} /$ min) \\
& Intervention 2: isoflurane $1 \mathrm{MAC}$ (minimum alveolar concentration) \\
& Both groups titrated to BIS 45 to 60 \\
\hline Outcomes & Quote: "There was not a significant difference between two groups in incidence of awareness" \\
\hline Notes & Awaiting Persian translation \\
\hline
\end{tabular}

Rajan 2015

Methods Study design: randomized parallel groups

Study dates: not stated

Participants

Country: pending full-text review

Sex: female and male

Age: pending full-text review

ASA: pending full-text review

Procedure: caesarean section

Study size: 40

Interventions

\section{Randomized portion of anaesthetic: pre-induction: hypnotic vs placebo}

Just before induction of anaesthesia

Intervention $1: 0.25 \mathrm{mg} / \mathrm{kg}$ ketamine, $\mathrm{N}=20$

Intervention 2: $5 \mathrm{ml}$ normal saline intravenously (IV), $\mathrm{N}=20$

\section{Outcomes}

Primary outcomes: efficacy and safety of low-dose ketamine, used as an adjunct analgesic and amnesic

Secondary outcome: awareness/wakefulness as defined using an awareness classification system (see Table 1): class pending full-text review 
Rajan 2015 (Continued)

Quote: "Higher number of the patients in Group $\mathrm{C}$ had intraoperative lacrimation as compared to Group K ( $50 \%$ vs. $0 \%, \mathrm{P}<0.001)$. Ten percent of the patients in Group C had hallucinations/recall of intraoperative events while none of the patients in Group K experienced the same, but the difference was statistically insignificant $(P=0.487) "$ bolus/NMBs induction yes/maintenance unclear

After intubation, patients were ventilated with $\mathrm{O}_{2}$ and $\mathrm{N}_{2} \mathrm{O}$ (40\%:60\%) with $0.7 \%$ end-tidal isoflurane. Fentanyl and midazolam were given following delivery of the baby

Results: Pre-induction haemodynamic parameters and those recorded at $1 \mathrm{~min}$ after induction were comparable in both groups. However, heart rate and systolic blood pressure recorded after intubation (at 3, 5, 7, 9, 12, 15, 20, 30 and 45 min after induction) showed significantly high values in Group C $(\mathrm{P}<0.05)$. Mean arterial pressure also showed a similar pattern

Umbilical vein $\mathrm{pO}_{2}, \mathrm{pCO}_{2}$ and $\mathrm{pH}$ were comparable in both groups. In Group C, intraoperative lacrimation (50\% vs $0 \%$ ) and hallucinations/recall of intraoperative events ( $10 \%$ vs $0 \%$ ) were high

Conclusion: IV ketamine $0.25 \mathrm{mg} / \mathrm{kg}$ can be safely used as an adjunct analgesic and amnesic to attenuate haemodynamic responses during caesarean section under GA without affecting the foetal outcome

Methods Study design: randomized parallel groups

Study dates: December 2013 to May 2014

\section{Participants}

Country: pending full-text review

Sex: female and male

Age: pending full-text review

ASA: pending full-text review

Procedure: elective surgery

Study size: 150

\section{Randomized portion of anaesthetic: TIVA vs volatile: implicit memory tests}

Intervention 1: induced and maintained with sevoflurane, $N=50$

Intervention 2: induced and maintained with propofol, $\mathrm{N}=50$

Intervention 1 and 2: given a list of test materials to remember and listen before the anaesthesia

Intervention 3: given the same test materials, and received test with the PDP in 12 to 36 hours before surgery, $\mathrm{N}=50$

\begin{tabular}{ll}
\hline Outcomes & Primary outcomes: effects of sevoflurane and propofol on preoperative implicit memories \\
& $\begin{array}{l}\text { Secondary outcome: awareness/wakefulness as defined using an awareness classification syste } \\
\text { (see Table 1): class pending full-text review }\end{array}$ \\
\hline Notes & $\begin{array}{l}\text { Non-randomized portion of anaesthetic: parts of IV vs parts of volatile agent } \mathbf{N}_{\mathbf{2}} \mathrm{O} \text { yes/nar- } \\
\text { cotics/hypnotics bolus/NMBs induction unclear/maintenance unclear }\end{array}$
\end{tabular}


Xie 2015 (Continued)

Conclusion: propofol and sevoflurane can decrease the score of explicit memory after anaesthesia within 12 to 36 hours, and there are no significant differences in explicit memory between the 2 drugs. Both propofol and sevoflurane can decrease the score of implicit memory, but the influence of sevoflurane on the implicit memory is less than propofol within 12 to 36 hours

No PubMed citation

Acronyms and abbreviations

$\mathrm{ADM}=$ anaesthesia depth monitor; $\mathrm{ASA}=$ American Society of Anesthesiology; $\mathrm{BIS}=$ Bispectral Index; cis = cisatracurium is one of the 10 isomers of the parent molecule, atracurium; $\mathrm{CIIA}=$ combined intravenous and inhaled anaesthesia; $\mathrm{GA}=$ general anaesthesia; $\mathrm{H}=$ hours; $\mathrm{HP}=$ haemodynamic parameters; $\mathrm{IV}=$ intravenous; $\mathrm{kg}=$ kilogram; $\mathrm{MAC}=$ minimal alveolar concentration; $\mu \mathrm{g}=\operatorname{micrograms} ;$ min = minute; $\mathrm{mL}=$ millilitres; $\mathrm{N}$ = sample size; $\mathrm{ng}=$ nanograms; $\mathrm{NMB}=$ neuromuscular blocking agents; $\mathrm{PDP}=$ parallel distributed processing; $\mathrm{PPT}=$ pneumoperitoneum; $\mathrm{ROC}=$ receiver operating characteristic; $\mathrm{SE}=$ state entropy; $\mathrm{T}=$ time; $\mathrm{TCl}=$ target-controlled infusions; TIVA = total intravenous anaesthesia; vs = versus

\section{DATA AND ANALYSES}

\section{Comparison 1. Anaesthesia depth monitors (BIS and M-entropy) versus standard clinical and electronic monitoring}

\begin{tabular}{|c|c|c|c|c|}
\hline Outcome or subgroup title & No. of studies & $\begin{array}{l}\text { No. of partici- } \\
\text { pants }\end{array}$ & Statistical method & Effect size \\
\hline 1 Definite and possible awareness (Grade 4) & & & Other data & No numeric data \\
\hline
\end{tabular}

\section{Analysis 1.1. Comparison 1 Anaesthesia depth monitors (BIS and M-entropy) versus standard clinical and electronic monitoring, Outcome 1 Definite and possible awareness (Grade 4).}

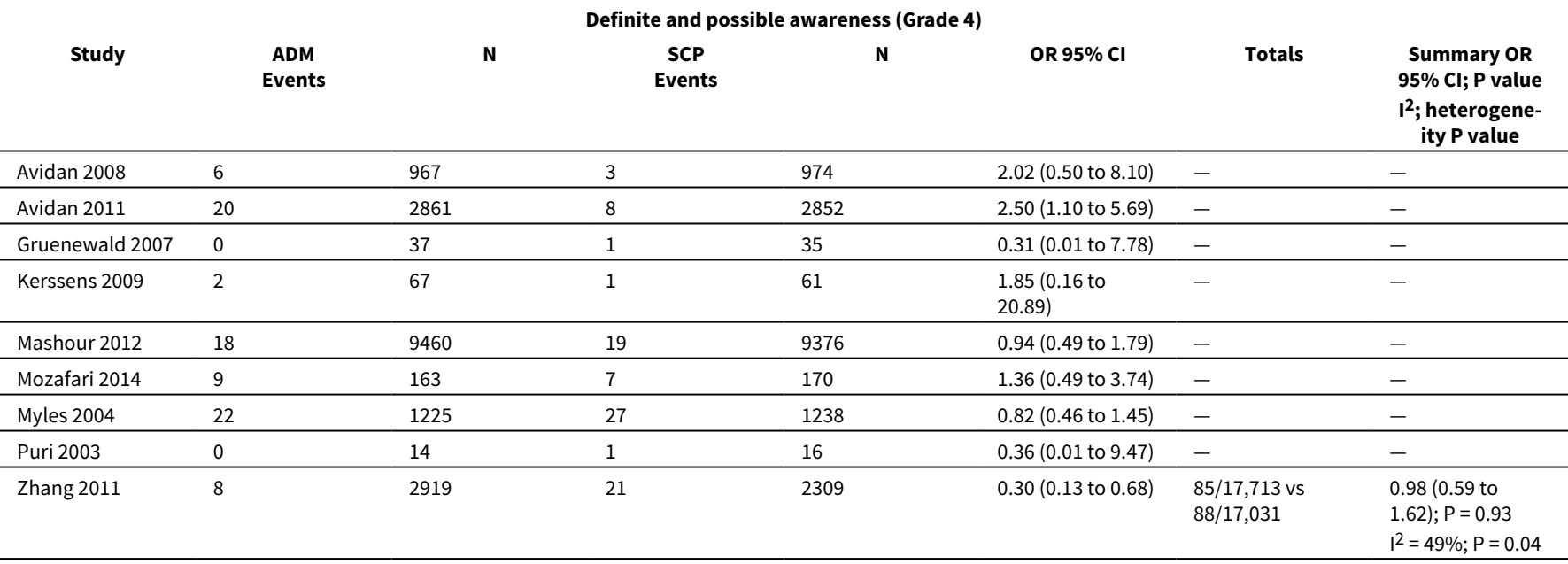

\section{Comparison 2. Anaesthesia depth monitors (BIS) versus standard clinical and electronic monitoring}

\begin{tabular}{|c|c|c|c|c|}
\hline Outcome or subgroup title & No. of studies & $\begin{array}{l}\text { No. of partici- } \\
\text { pants }\end{array}$ & $\begin{array}{l}\text { Statistical } \\
\text { method }\end{array}$ & Effect size \\
\hline 1 Definite and possible awareness (Grade 4) & & & Other data & No numeric data \\
\hline
\end{tabular}




\begin{tabular}{lllll}
\hline Outcome or subgroup title & No. of studies & $\begin{array}{l}\text { No. of partici- } \\
\text { pants }\end{array}$ & $\begin{array}{l}\text { Statistical } \\
\text { method }\end{array}$ & Effect size \\
\hline 2 Definite awareness (Grade 4) & Other data & No numeric data \\
\hline
\end{tabular}

\section{Analysis 2.1. Comparison 2 Anaesthesia depth monitors (BIS) versus standard clinical and electronic monitoring, Outcome 1 Definite and possible awareness (Grade 4).}

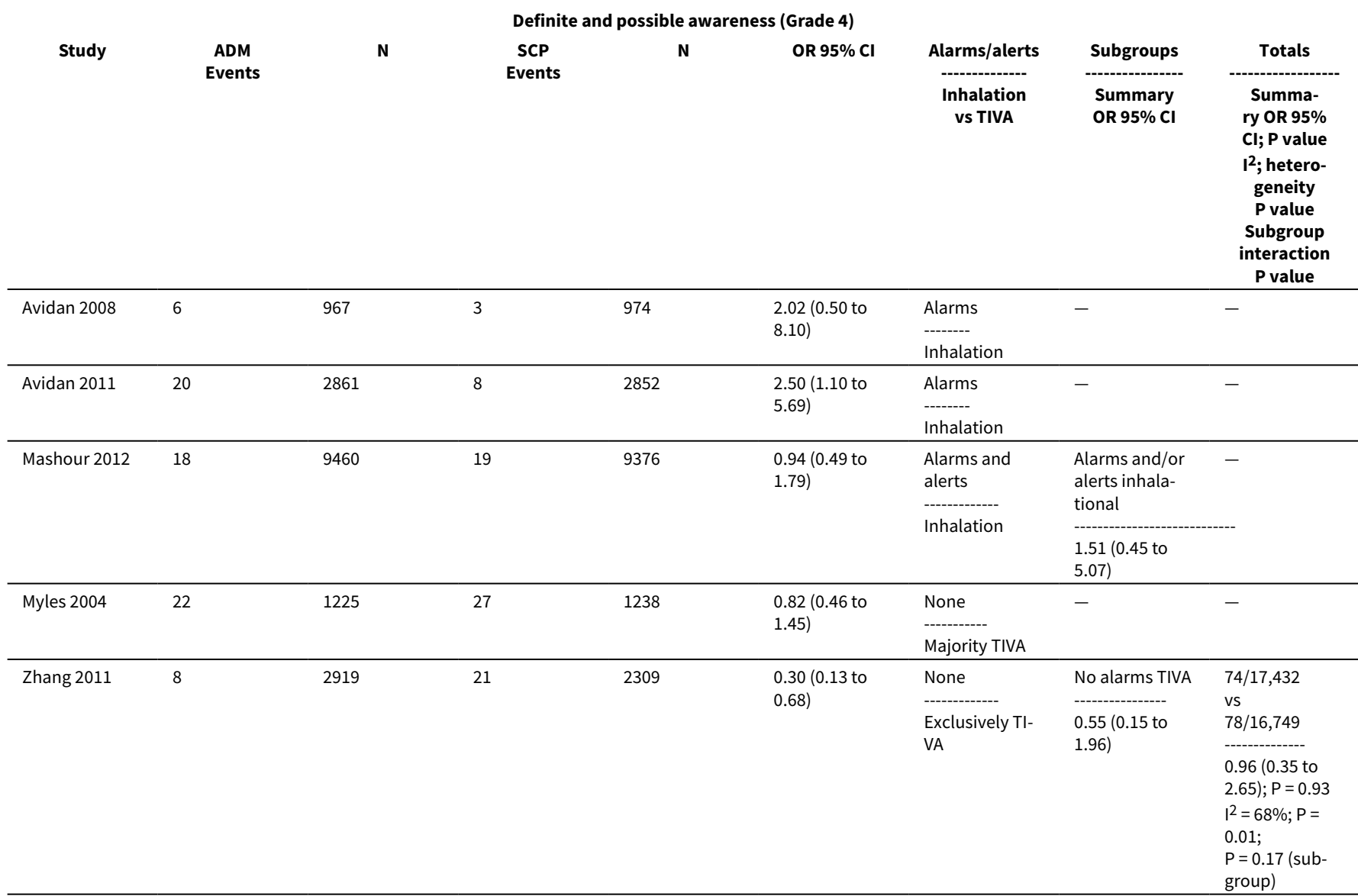

Analysis 2.2. Comparison 2 Anaesthesia depth monitors (BIS) versus standard clinical and electronic monitoring, Outcome 2 Definite awareness (Grade 4).

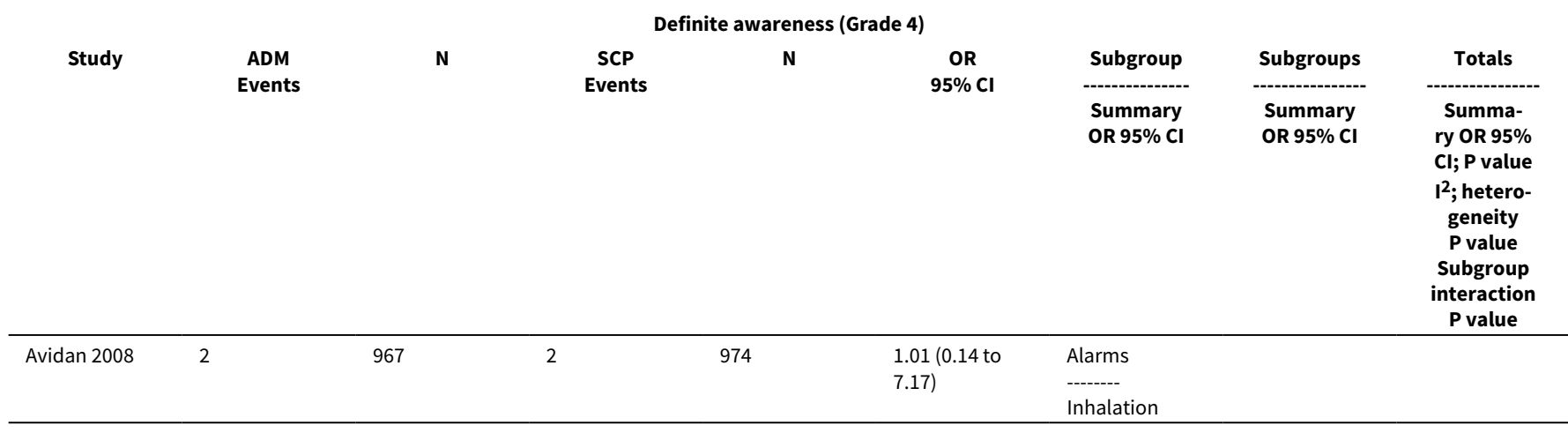




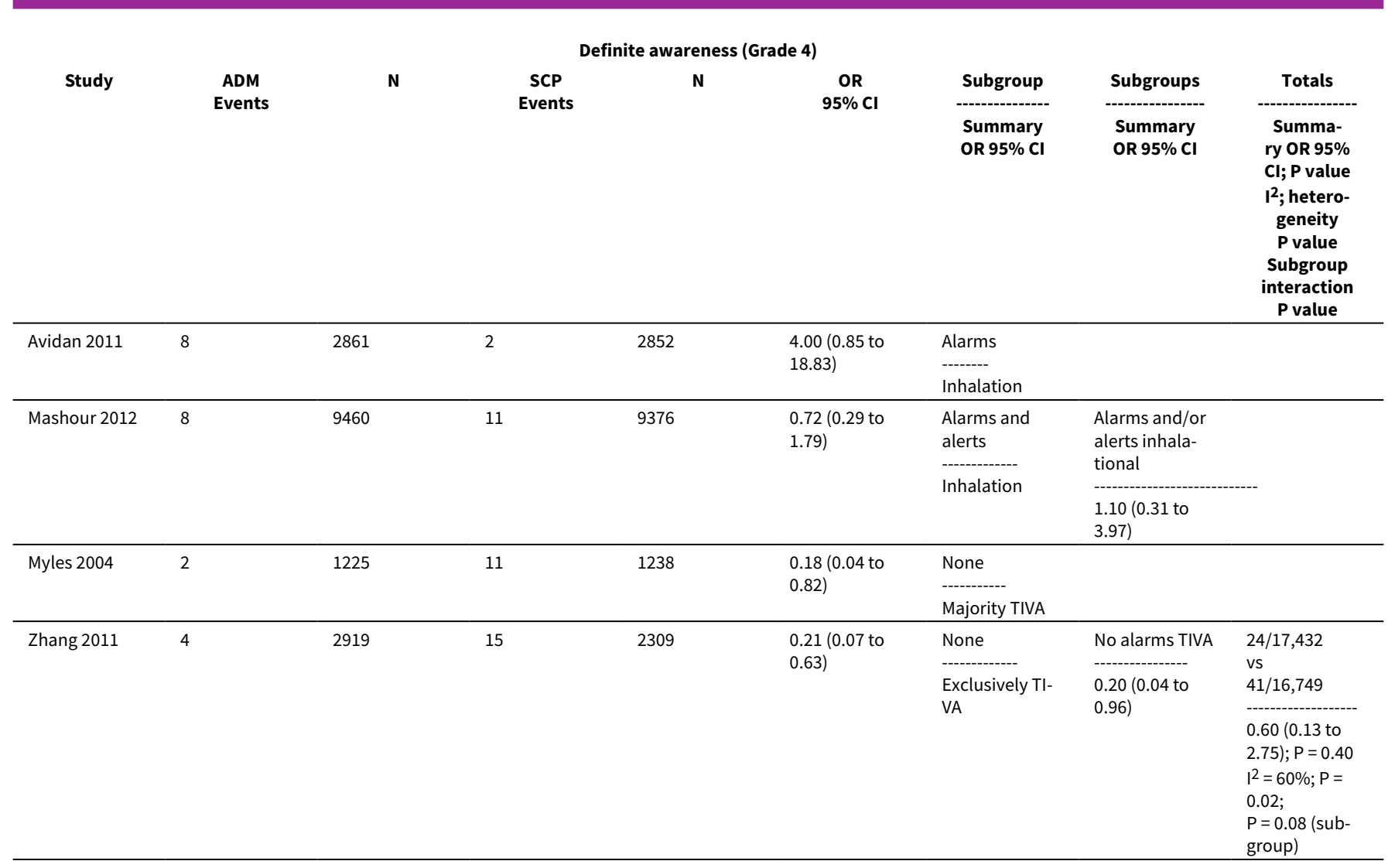

Comparison 3. Thiopentone with and without added hypnotic drugs (ketamine, etomidate)

\begin{tabular}{|c|c|c|c|c|}
\hline Outcome or subgroup title & No. of studies & $\begin{array}{l}\text { No. of partici- } \\
\text { pants }\end{array}$ & Statistical method & Effect size \\
\hline 1 Wakefulness (IFT studies) (Grades 4, 5) & & & Other data & No numeric data \\
\hline
\end{tabular}

Analysis 3.1. Comparison 3 Thiopentone with and without added hypnotic drugs (ketamine, etomidate), Outcome 1 Wakefulness (IFT studies) (Grades 4, 5).

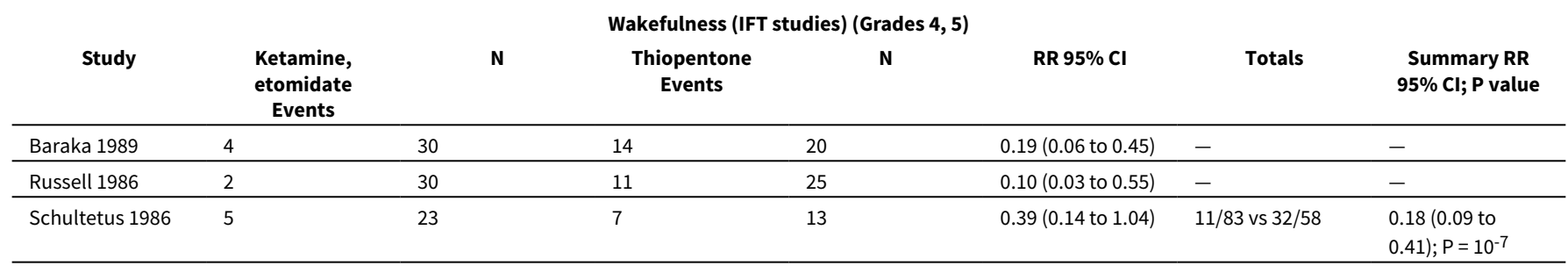


Comparison 4. Thiopentone and ketamine vs benzodiazepine anaesthetic techniques

\begin{tabular}{|c|c|c|c|c|}
\hline Outcome or subgroup title & No. of studies & $\begin{array}{l}\text { No. of partici- } \\
\text { pants }\end{array}$ & Statistical method & Effect size \\
\hline 1 Awareness (Grade 4) & & & Other data & No numeric data \\
\hline
\end{tabular}

Analysis 4.1. Comparison 4 Thiopentone and ketamine vs benzodiazepine anaesthetic techniques, Outcome 1 Awareness (Grade 4).

\begin{tabular}{|c|c|c|c|c|c|c|c|c|}
\hline \multicolumn{9}{|c|}{ Awareness (Grade 4) } \\
\hline Study & $\begin{array}{c}\text { Benzodiazepines } \\
\text { Events }\end{array}$ & & $\mathbf{N}$ & $\begin{array}{c}\text { Ketamine, } \\
\text { thiopentone } \\
\text { Events }\end{array}$ & $\mathbf{N}$ & RR $95 \% \mathrm{Cl}$ & Totals & $\begin{array}{c}\text { Summary RR } \\
\text { 95\% Cl; } \mathrm{P} \text { value }\end{array}$ \\
\hline Haram 1981 & 0 & 39 & & 5 & 40 & 0.00 (0.00 to 0.83$)$ & - & - \\
\hline McNulty 1995 & 0 & 71 & & 3 & 25 & $0.00(0.00$ to 0.56$)$ & - & - \\
\hline Miller 1996 & 2 & 69 & & 4 & 21 & 0.12 (0.02 to 0.83$)$ & $2 / 192$ vs $16 / 99$ & $\begin{array}{l}0.17(0.02 \text { to } \\
0.25) ; \mathrm{P}<10^{-7}\end{array}$ \\
\hline
\end{tabular}

Comparison 5. Caesarean section low- and high-dose inhaled agents

\begin{tabular}{|c|c|c|c|c|}
\hline Outcome or subgroup title & No. of studies & $\begin{array}{l}\text { No. of partici- } \\
\text { pants }\end{array}$ & Statistical method & Effect size \\
\hline 1 Awareness (Grade 4) & & & Other data & No numeric data \\
\hline
\end{tabular}

Analysis 5.1. Comparison 5 Caesarean section low- and high-dose inhaled agents, Outcome 1 Awareness (Grade 4).

\begin{tabular}{|c|c|c|c|c|c|c|c|}
\hline \multicolumn{8}{|c|}{ Awareness (Grade 4) } \\
\hline Study & $\begin{array}{l}\text { High dose } \\
\text { Events }\end{array}$ & $\mathbf{N}$ & $\begin{array}{c}\text { Low dose } \\
\text { Events }\end{array}$ & $\mathbf{N}$ & RR 95\% Cl & Totals & $\begin{array}{c}\text { Summary RR } \\
\text { 95\% Cl; P value }\end{array}$ \\
\hline Abboud 1985 & 0 & 65 & 2 & 16 & $0.00(0.00$ to 0.80$)$ & - & - \\
\hline Crawford 1985 & 3 & 384 & 19 & 393 & $0.13(0.04$ to 0.51$)$ & $3 / 449$ vs $21 / 409$ & $\begin{array}{l}0.13(0.04 \text { to } \\
0.43) ; P=0.0001\end{array}$ \\
\hline
\end{tabular}

\section{ADDITIONAL TABLES}

Table 1. Classification of intraoperative cognitive states

\begin{tabular}{|c|c|c|c|c|c|c|}
\hline Grade & $\begin{array}{l}\text { Intraoper- } \\
\text { ative state }\end{array}$ & $\begin{array}{l}\text { Intraoperative } \\
\text { state }\end{array}$ & $\begin{array}{l}\text { Immediate } \\
\text { postoperative } \\
\text { state }\end{array}$ & $\begin{array}{l}\text { Late postoperative } \\
\text { state (> month ) }\end{array}$ & Descriptor & $\begin{array}{l}\text { Exemplar } \\
\text { study or } \\
\text { review }\end{array}$ \\
\hline 0 & $\begin{array}{l}\text { Uncon- } \\
\text { scious }\end{array}$ & $\begin{array}{l}\text { No signs light } \\
\text { anaesthesia, no } \\
\text { response to com- } \\
\text { mand }\end{array}$ & No recall & No recall & Adequate anaesthesia & $\begin{array}{l}\text { Russell } \\
1997\end{array}$ \\
\hline
\end{tabular}


Table 1. Classification of intraoperative cognitive states (Continued)

\begin{tabular}{|c|c|c|c|c|c|c|}
\hline 1 & Conscious & $\begin{array}{l}\text { Signs light } \\
\text { anaesthesia/re- } \\
\text { sponse to com- } \\
\text { mand }\end{array}$ & No recall & $\begin{array}{l}\text { No recall or emotion- } \\
\text { al sequelae }\end{array}$ & $\begin{array}{l}\text { Intraoperative wake- } \\
\text { fulness with obliterat- } \\
\text { ed explicit and implicit } \\
\text { memory }\end{array}$ & $\begin{array}{l}\text { Andrade } \\
2008\end{array}$ \\
\hline 2 & $\begin{array}{l}\text { Conscious; } \\
\text { word stim- } \\
\text { uli present- } \\
\text { ed }\end{array}$ & $\begin{array}{l}\text { Signs/response } \\
\text { to command }\end{array}$ & $\begin{array}{l}\text { No explicit re- } \\
\text { call, implicit } \\
\text { memory for } \\
\text { word stimuli }\end{array}$ & $\begin{array}{l}\text { No explicit recall, } \\
\text { implicit memory for } \\
\text { word stimuli but no } \\
\text { emotional sequelae }\end{array}$ & $\begin{array}{l}\text { Intraoperative wakeful- } \\
\text { ness with subsequent } \\
\text { implicit memory }\end{array}$ & $\begin{array}{l}\text { Merikle } \\
1996\end{array}$ \\
\hline 3 & Conscious & $\begin{array}{l}\text { Signs/response } \\
\text { to command }\end{array}$ & No recall & $\begin{array}{l}\text { PTSD/nightmares but } \\
\text { no explicit recall }\end{array}$ & $\begin{array}{l}\text { Intraoperative wakeful- } \\
\text { ness with implicit emo- } \\
\text { tional memory }\end{array}$ & Wang 2000 \\
\hline 4 & Conscious & $\begin{array}{l}\text { Signs/response } \\
\text { to command }\end{array}$ & $\begin{array}{l}\text { Explicit recall } \\
\text { with or without } \\
\text { pain }\end{array}$ & $\begin{array}{l}\text { Explicit recall but no } \\
\text { emotional sequelae }\end{array}$ & $\begin{array}{l}\text { Awareness but resilient- } \\
\text { patient }\end{array}$ & $\begin{array}{l}\text { Sandin } \\
2000\end{array}$ \\
\hline 5 & Conscious & $\begin{array}{l}\text { Signs/response } \\
\text { to command }\end{array}$ & $\begin{array}{l}\text { Explicit recall } \\
\text { with distress } \\
\text { and/or pain }\end{array}$ & $\begin{array}{l}\text { PTSD/nightmares } \\
\text { with explicit recall }\end{array}$ & $\begin{array}{l}\text { Awareness with emo- } \\
\text { tional sequelae }\end{array}$ & $\begin{array}{l}\text { Osterman } \\
2001\end{array}$ \\
\hline
\end{tabular}

First presented at the 7th International Symposium on Memory and Awareness in Anaesthesia, Munich, Germany, March 2008. Revised in publication Wang 2012. Permission granted by John Wiley \& Sons Inc. on 17 June 2014.

PTSD = post-traumatic stress disorder

\section{APPENDICES}

\section{Appendix 1. Dryad website link}

Data available from the Dryad Digital Repository: http://dx.doi.org/10.5061/dryad.2vn65

\section{Appendix 1: Associated Dryad word document title within each section of review}

\section{Background section}

\section{Description of the condition}

Psychological sequelae\&Light anaesthesia.docx

Cardiovascular Function \& Pathologies

PTSD Diagnostic Criteria.docx

Wakefulness endnote 2014 annotate.docx

\section{Why it is important to do this review section}

Psychological sequelae\&Light anaesthesia.docx

\section{Methods}

\section{Types of outcomes}

Refinement of Sebel classification system.docx

\section{Results}

\section{Description of studies}

\section{Included studies}

Sample size $\mathrm{N}=160 . \mathrm{xls} \mathrm{x}$ 
Language.xlsx

surgical risk.xlsx

primary.secondary.outcome.xlsx

Nomenclature.docx

ROB.results.xlsx

\section{Excluded studies}

Excluded RCTs.315.xlsx

Trial location

Continents.countries.xlsx

\section{Anaesthetic interventions}

Frequencies of anaesthetics techniques

Anesthesia Techniques.xlsx

MR.use.xlsx

\section{ADM interventions}

ADM all types.xlsx

Classification of outcomes

Classification.Wang.Messina.Ward.grade

Response to complex command.xlsx

\section{Effect of interventions}

Primary outcomes

Awareness

patient awareness reports.xlsx

\section{Wakefulness}

wakeful v wakeful.aware v wakeful.xlsx

\section{Discussion}

Summary of main results

Classification.Wang.Messina.Ward.grade.xlsx

Thiopental studies.docx

\section{Overall completeness and applicability of evidence}

RCTs not used in comparisons.xlsx

\section{Quality of the evidence}

Quality of the evidence.docx

ACE130 reviewer\#1.defense RCT merge criteria.summary.docx ACE 130 reviewer\#1.defense RCT merge criteria.details.docx ACE 130 Peer reviewer.\#2.docx

ACE 130 reviewer \#2.MWa response.classification table.docx

ACE 130 reviewer \#3 peer review.docx

ACE 130 consumer TL.am.docx 
Potential biases in the review process

Potential biases in the review process.docx

\section{Appendix 2. Search strategy for CENTRAL}

\#1 MeSH descriptor: [General Surgery] explode all trees

\#2 MeSH descriptor: [Surgical Procedures, Operative] this term only

\#3 MeSH descriptor: [Anesthesia] this term only

\#4 MeSH descriptor: [Autonomic Agents] this term only

\#5 MeSH descriptor: [Anesthetics] this term only

\#6 MeSH descriptor: [Muscle Relaxants, Central] explode all trees

\#7 MeSH descriptor: [Neuromuscular Blocking Agents] explode all trees

\#8 surgical stimulation ${ }^{\star}$ or an?esth*:ti,ab or ((neuromuscular or nondepolarizing) near blocking) or muscle relaxant*:ti,ab

\#9 \#1 or \#2 or \#3 or \#4 or \#5 or \#6 or \#7 or \#8

\#10 MeSH descriptor: [Wakefulness] explode all trees

\#11 MeSH descriptor: [Memory] explode all trees

\#12 MeSH descriptor: [Awareness] explode all trees

\#13 MeSH descriptor: [Attention] explode all trees

\#14 (memor* or wakefulness or awareness or attention or awakeness or wake up threshold):ti,ab

$\# 15$ \#10 or \#11 or \#12 or \#13 or \#14

\#16 MeSH descriptor: [Immobilization] explode all trees

\#17 MeSH descriptor: [Stress Disorders, Post-Traumatic] explode all trees

\#18 MeSH descriptor: [Paralysis] explode all trees

\#19 MeSH descriptor: [Unconsciousness] explode all trees

\#20 MeSH descriptor: [Consciousness] explode all trees

\#21 MeSH descriptor: [Dreams] explode all trees

\#22 MeSH descriptor: [Panic] this term only

\#23 MeSH descriptor: [Amnesia] this term only

\#24 paraliz ${ }^{*}$ or dream*:ti,ab or post?traumatic*:ti,ab or (an?esthetic near depth) or (((evok ${ }^{\star}$ near potential $\left.{ }^{\star}\right)$ or eeg or electroencephalogra*) and processed)

$\# 25 \# 16$ or \#17 or \#18 or \#19 or \#20 or \#21 or \#22 or \#23 or \#24

$\# 26 \# 9$ and (\#15 or \#25)

\section{Appendix 3. Search strategy for MEDLINE (Ovid SP)}

1. General Surgery/ or anaesthesia/ or Surgical Procedures, Operative/ or Autonomic Agents/ or Anesthetics/ or Muscle Relaxants, Central/ or Neuromuscular Blocking Agents/ or surgical stimulation*.mp. or an?esth ${ }^{\star} . t i, a b$. or ((neuromuscular or nondepolarizing) adj6 blocking).mp. or muscle relaxant*.ti,ab.

2. Wakefulness/ or Memory/ or Awareness/ or Attention/ or (memor ${ }^{\star}$ or wakefulness or awareness or attention or awakeness or wake up threshold).mp.

3. Immobilization/ or Stress Disorders, Post-Traumatic/ or (((evok ${ }^{\star}$ adj3 potential $\left.{ }^{\star}\right)$ or eeg or electroencephalogra $\left.{ }^{\star}\right)$ and processed).mp. or Paralysis/ or Unconsciousness/ or Consciousness/ or Dreams/ or Panic/ or Amnesia/ or paraliz ${ }^{\star} . \mathrm{mp}$ or $\mathrm{dream}^{\star} . \mathrm{ti}, \mathrm{ab} . \mathrm{or}^{\mathrm{n}}$ post? traumatic ${ }^{\star} . \mathrm{ti}, \mathrm{ab}$. or (an?esthetic adj6 depth).mp.

4. 1 and $(2$ or 3$)$

5. ((randomized controlled trial or controlled clinical trial).pt. or clinical trials as topic.sh. or (random* or double-blind ${ }^{\star}$ or placebo).ti,ab.) not (animals not (humans and animals)).sh.

6.4 and 5

The definitions of the following abbreviations are: [tw] is the PubMed tag for text word, [pt] is the PubMed tag for publication type, and $[\mathrm{mh}]$ is the PubMed tag for the MeSH term.

\section{Appendix 4. Search strategy for EMBASE (Ovid SP)}

1. surgery/ or surgical-patient/ or anaesthesia/ or "agents interacting with transmitter, hormone or drug receptors"/ or anestheticagent/ or muscle-relaxant-agent/ or neuromuscular-blocking-agent/ or surgical stimulation*.ti,ab. or an?esth*.ti,ab. or ((neuromuscular or nondepolarizing) adj3 blocking).ti,ab. or muscle relaxant*.ti,ab.

2. wakefulness/ or memory/ or awareness/ or attention/ or (memor* or wakefulness or awareness or attention or awakeness or wake up threshold).ti,ab.

3. immobilization/ or posttraumatic-stress-disorder/ or posttraumatic-stress-disorder/ or (((evok* adj3 potential $\left.{ }^{\star}\right)$ or eeg or electroencephalogra*) adj3 processed).ti,ab. or paralysis/ or unconsciousness/ or consciousness/ or dream/ or panic/ or amnesia/ or paraliz ${ }^{\star} . t i, a b$. or dream ${ }^{\star} . t i, a b$. or post?traumatic ${ }^{\star} . t i, a b$. or (an?esthetic adj3 depth).ti,ab.

4. 1 and (2 or 3 ) 
5. ((randomized controlled trial or controlled clinical trial).pt. or randomized.ab. or placebo.ab. or randomly.ab. or trial.ti.) not (animals not (humans and animals)).sh.

6. 4 and 5

\section{Appendix 5. Selection criteria and checklists}

Selection criteria

Study design randomized (if no, exclude)

Drug randomized

\section{Brain monitor randomized}

Learning test randomized (if yes, exclude)

Study assessed for awareness (if no/unclear, exclude)

Study done after skin incision but before end of surgery (if no, exclude)

ICU study (if yes, exclude)

Blinding (patient, physician, postoperative interviewer)

See 'Risk of bias' table

Abbreviations for checklist table

PMID PubMed identification number for each study


Checklist: Data extraction $1 \mathrm{~A}$

\begin{tabular}{|c|c|c|c|c|c|c|c|c|c|}
\hline PMID & Author & Title & Date-yr & $\begin{array}{l}\text { Drug or brain } \\
\text { monitor random- } \\
\text { ized }\end{array}$ & $\begin{array}{l}\text { Random- } \\
\text { ized quote } \\
\text { in data- } \\
\text { base }\end{array}$ & Aware test & $\begin{array}{l}\text { Aware } \\
\text { quote in } \\
\text { database }\end{array}$ & $\begin{array}{l}\text { After skin } \\
\text { inc }\end{array}$ & $\begin{array}{l}\text { Category } \\
\text { rev1 }\end{array}$ \\
\hline \multicolumn{10}{|c|}{ Checklist: Data extraction 2} \\
\hline Author & Year & $\begin{array}{l}\text { IV vs IV } 1,0 \\
\text { yes no }\end{array}$ & $\begin{array}{l}\text { IV vs Inhal } \\
\text { (balanced) } 1,0\end{array}$ & Regional + GA 1,0 & $\begin{array}{l}\text { Regional } \\
+ \text { GA de- } \\
\text { scription }\end{array}$ & $\begin{array}{l}\text { Inhal vs Inhal } \\
\text { (balanced) } 1,0\end{array}$ & $\begin{array}{l}\text { Multiple } \\
\text { anaesthe- } \\
\text { sia tech- } \\
\text { niques }\end{array}$ & Surgery & $\begin{array}{l}\text { Induc ran- } \\
\text { dom } 1,0\end{array}$ \\
\hline \multicolumn{10}{|c|}{ Checklist: Data extraction 3} \\
\hline IFT 1.0 & $\begin{array}{l}\text { Wang chart } \\
\text { classification }\end{array}$ & Country & $\begin{array}{l}\text { Sample size, } \\
\mathrm{N}\end{array}$ & $\begin{array}{l}\text { Explicit memory } \\
\text { events \# }\end{array}$ & $\begin{array}{l}\% \text { Aware- } \\
\text { ness }\end{array}$ & $\begin{array}{l}\text { Implicit IFT } \\
\text { Wakefulness \# }\end{array}$ & $\begin{array}{l}\% \text { Wake- } \\
\text { fulness }\end{array}$ & $\begin{array}{l}\text { Intraop- } \\
\text { erative } \\
\text { dream } \\
\text { events \# }\end{array}$ & $\begin{array}{l}\text { \% Intra- } \\
\text { operative } \\
\text { dreams }\end{array}$ \\
\hline
\end{tabular}

Checklist: Data extraction

1B

\begin{tabular}{|c|c|c|c|c|c|c|c|c|}
\hline Reviewer 1 & Category rev 2 & Reviewer 2 & $\begin{array}{l}\text { Category rev } \\
\text { am }\end{array}$ & Reviewer am & $\begin{array}{l}\text { CATEGORY } \\
\text { FINAL }\end{array}$ & $\begin{array}{l}\text { Characteris- } \\
\text { tics table }\end{array}$ & Bias table & Data chart \\
\hline
\end{tabular}

$\stackrel{\omega}{\omega}$ 


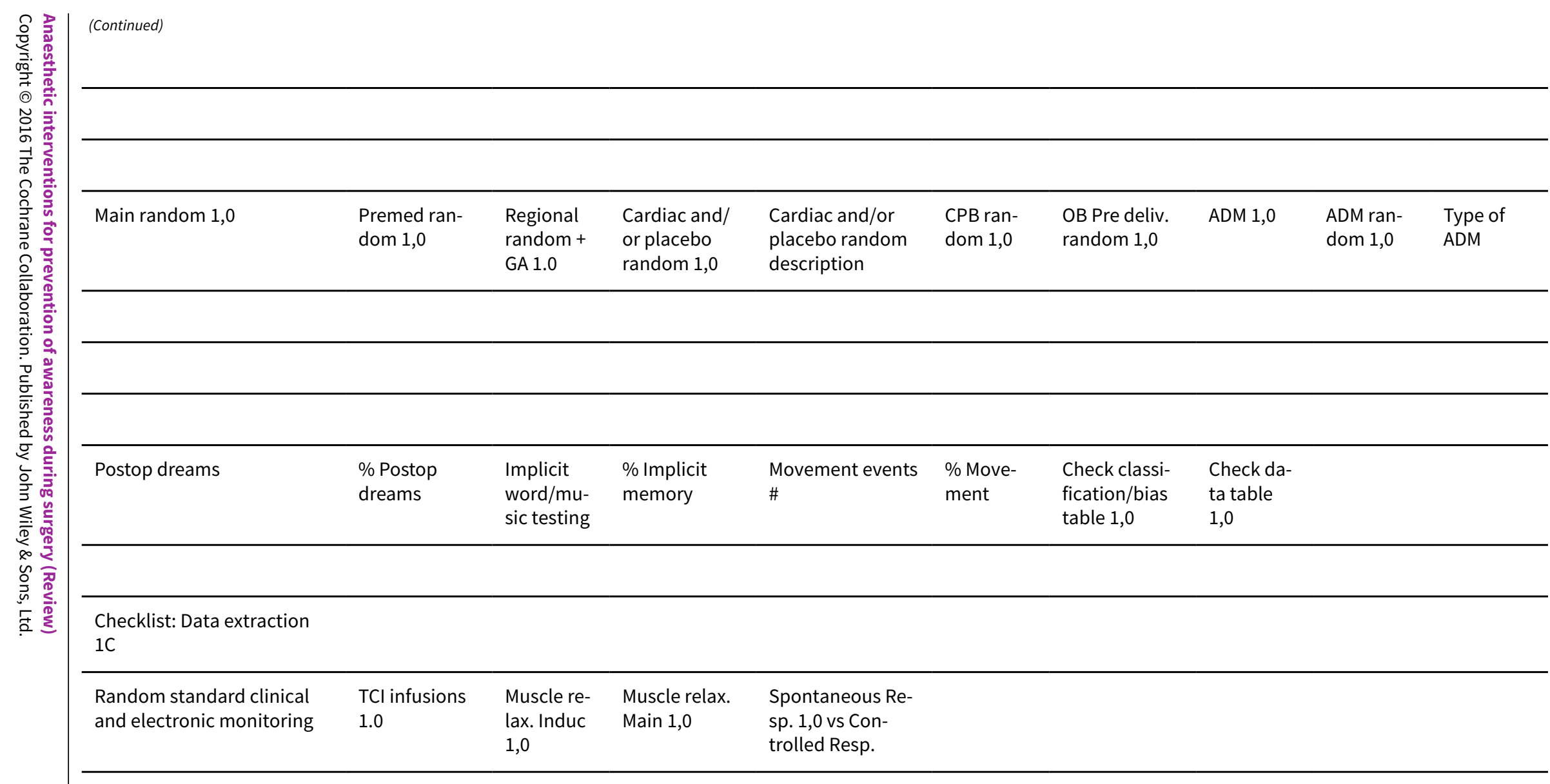




\section{Appendix 6. Author survey}

A survey was sent to the authors of all of the papers included in this review in order to obtain information not stated in the papers and, if possible, to obtain more detailed information regarding the methodology of the included studies. The survey questions were as follows:

1. Can you define the dates during which patients were enrolled and studied?

2. What method of randomization did you use?

3. How could participants and investigators enrolling participants not foresee assignment? Or How did you conceal to what groups patients were randomized to the anaesthetists?

4. Indicate whether or not blinding occurred for patient, anaesthetist, Awareness outcome assessor (interviewer), other, or if no blinding occurred?

5. Describe the completeness of outcome data for each main outcome, including attrition and exclusions from the analysis. State whether attrition and exclusions were reported, the numbers in each intervention group (compared with total randomized participants), reasons for attrition/exclusions where reported, and any re-inclusions in analyses performed by the review authors.

6. The study protocol is available and all of the study's pre-specified (primary and secondary) outcomes that are of interest in the review have been reported in the pre-specified way. The study protocol is not available but it is clear that the published reports include all expected outcomes, including those that were pre-specified (convincing text of this nature may be uncommon).

7. Did you not report any non-significant results from your study?

8. There is at least one important risk of bias? For example, the study had a potential source of bias related to the specific study design used; or stopped early due to some data-dependent process (including a formal-stopping rule); or had extreme baseline imbalance; or has been claimed to have been fraudulent; or had some other problem.

9. In the postoperative period, did investigators interview patients about awareness during surgery with either a standard questionnaire or an informal interview? Did any patients spontaneously report awareness during surgery?

10.After skin incision, was the study performed during all or part of the surgery? If only part, when?

Cochrane ROB policies:

Cochrane Handbook 2008, Table 8.5.C "Either participants or some key study personnel were not blinded, but outcome assessment was blinded and the non-blinding of others unlikely to introduce bias."

\section{Risk of bias survey}

\section{0}

$=160 * 7$

\begin{tabular}{lllll}
\hline & High & Low & Unclear & Total \\
\hline Survey responders $\mathrm{N}=54$ & 53 & 281 & 44 & 378 \\
\hline Survey responders $\mathrm{N}=54$ & 378 & 378 & 378 & \\
\hline Survey responders $\mathrm{N}=54$ & $14.0 \%$ & $74.3 \%$ & $11.6 \%$ & $100.0 \%$ \\
\hline
\end{tabular}

\begin{tabular}{lllll}
\hline Survey non-responders N = 106 & 31 & 286 & 425 & 742 \\
\hline Survey non-responders N = 106 & 742 & 742 & 742 & \\
\hline Survey non-responders N = 106 & $4.2 \%$ & $38.5 \%$ & $57.3 \%$ & $100.0 \%$ \\
\hline
\end{tabular}


(Continued)

\begin{tabular}{lccc} 
All patients (yes + no survey responders) N = 160 & 86 & 564 & 1120 \\
\hline All patients (yes + no survey responders) N = 160 & 1120 & 1120 & 1120 \\
\hline All patients (yes + no survey responders) N = 160 & $7.7 \%$ & $50.4 \%$ & $42.0 \%$ \\
\hline
\end{tabular}

Meta-analysis $\mathrm{N}=18$

\section{6 domains}

$=18^{\star} 7$

\begin{tabular}{lllll}
\hline Meta-analysis $N=6$ responders & High & Low & Unclear \\
\hline Meta-analysis $N=6$ responders & 9 & 31 & 2 & 42 \\
\hline Meta-analysis $N=6$ responders & 42 & 42 & 42 & \\
\hline Meta-analysis $N=6$ responders & $21.4 \%$ & $73.8 \%$ & $4.8 \%$ & $100 \%$ \\
\hline
\end{tabular}

\begin{tabular}{lllll}
\hline Meta-analysis N = 12 non-responders & High & Low & Unclear & 84 \\
\hline Meta-analysis N = 12 non-responders & 3 & 37 & 44 & 84 \\
\hline Meta-analysis N = 12 non-responders & 84 & 84 & $52.4 \%$ & $100 \%$ \\
\hline Meta-analysis N = 12 non-responders & $3.6 \%$ & $44.0 \%$ & \\
\hline
\end{tabular}

\begin{tabular}{lllll}
\hline $\begin{array}{l}\text { All merged patients (yes + no survey responders) N } \\
=18\end{array}$ & 30 & 62 & 34 & 126 \\
\hline $\begin{array}{l}\text { All merged patients (yes + no survey responders) N } \\
=18\end{array}$ & 126 & 126 & 126 \\
\hline $\begin{array}{l}\text { All merged patients (yes + no survey responders) N } \\
=18\end{array}$ & $24 \%$ & $49 \%$ & $27 \%$ \\
\hline
\end{tabular}




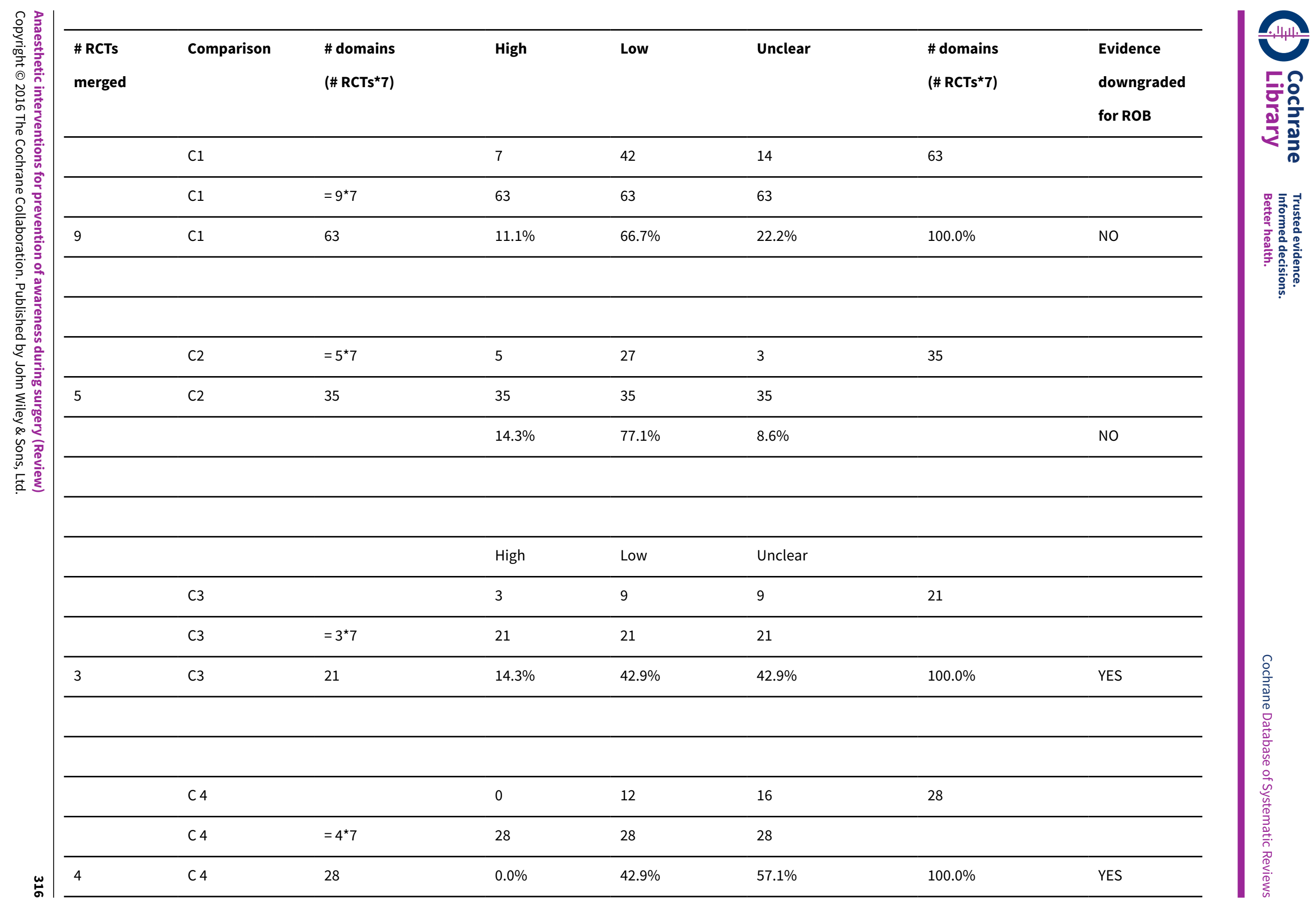




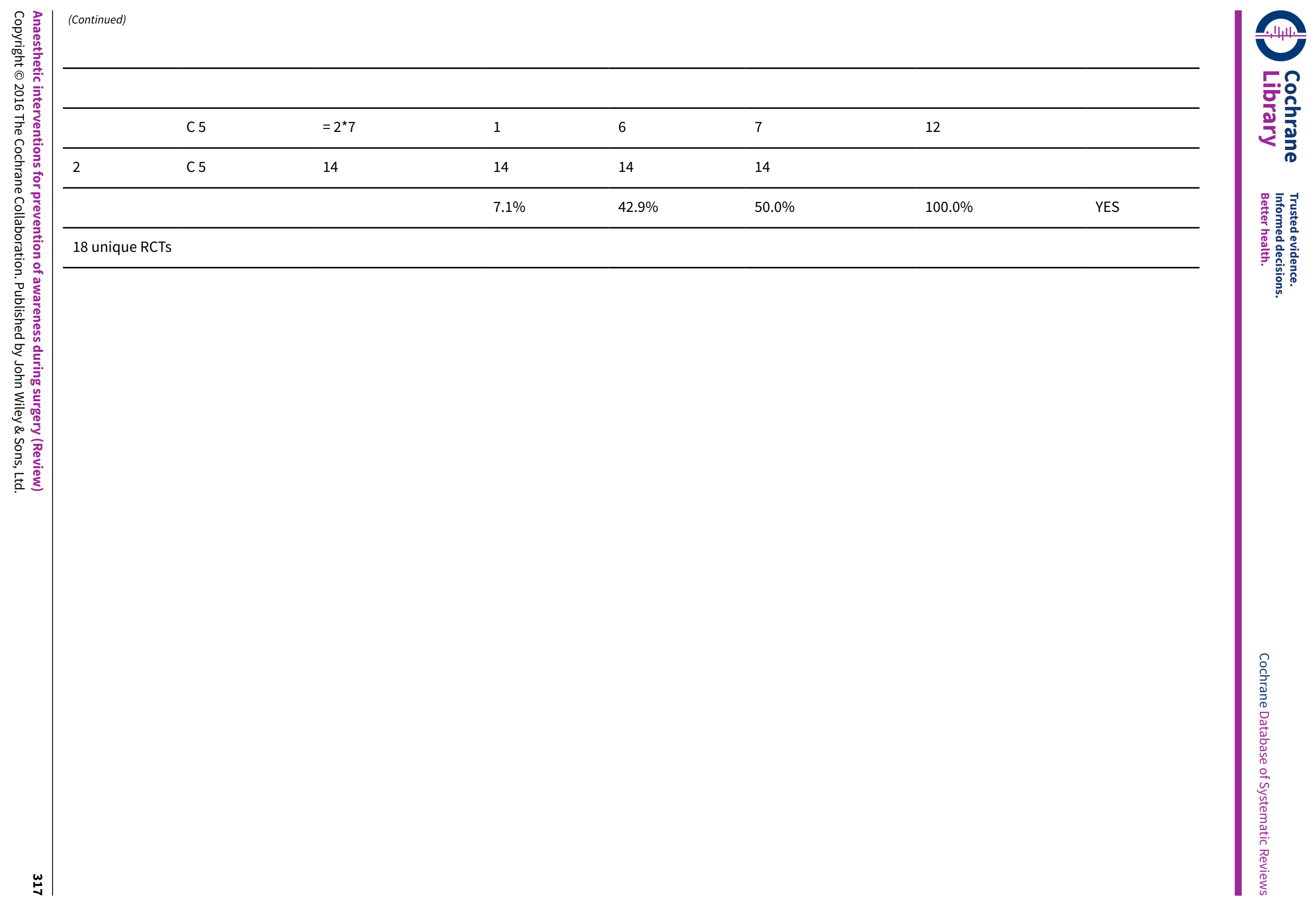




\section{Appendix 7. R Data, Code, Output}

The effectiveness of anaesthetic interventions for prevention of wakefulness and awareness during and after surgery

NLP

R Project started October 21, 2014

This analysis run on Fri Jun 17 14:36:23 2016.

\section{checkpoint}

setup

snapshot

\section{Analysis 1.1}

df.1.1

\#\# studynames exp.y exp.n ctl.y ctl.n Year risk \#\# 1 Avidan 2008696739742008 High \#\# 2 Avidan 2011202861828522011 High \#\# 3 Gruenewald 20070371352007 Not High \#\# 4 Kerssens 20092671612009 Not High \#\# 5 Mashour 20121894601993762012 Not High \#\# 6 Mozafari 2014916371702014 Not High \#\# 7 Myles 20042212252712382004 High \#\# 8 Puri 20030141162003 High \#\# 9 Zhang 2011829192123092011 Not High

summary(df.1.1)

\#\# studynames exp.y exp.n ctl.y

\#\# Length:9 Min. : 0.000 Min. : 14 Min. : 1.000

\#\# Class :character 1st Qu.: 2.000 1st Qu.: 67 1st Qu.: 1.000

\#\# Mode :character Median : 8.000 Median : 967 Median : 7.000

\#\# Mean : 9.444 Mean :1968 Mean : 9.778

\#\# 3rd Qu.:18.000 3rd Qu.:2861 3rd Qu.:19.000

\#\# Max. :22.000 Max. :9460 Max. :27.000

\#\# ctl.n Year risk

\#\# Min. : 16 Min. :2003 High :4

\#\# 1st Qu.: 61 1st Qu.:2007 Not High:5

\#\# Median : 974 Median :2009

\#\# Mean :1892 Mean :2009

\#\# 3rd Qu.:2309 3rd Qu.:2011

\#\# Max. :9376 Max. :2014

df.1.1.rma <- rma.uni(ai = exp.y, $c i=c t l . y, n 1 i=\exp . n, n 2 i=c t l . n$, measure = "OR", data $=$ df.1.1, slab $=$ studynames, method $=$ "ML") summary(df.1.1.rma)

\#\#

\#\# Random-Effects Model ( $k=9$; tau^2 estimator: $M L)$

\#\#

\#\# logLik deviance AIC BIC AICC

\#\#-10.9729 13.1464 25.9458 26.3403 27.9458

\#\#

\#\# $\operatorname{tau}^{\wedge} 2$ (estimated amount of total heterogeneity): $0.2416(S E=0.2379)$

\#\# tau (square root of estimated tau^2 value): 0.4916

\#\# I^2 (total heterogeneity / total variability): $49.04 \%$

\#\# H^2 (total variability / sampling variability): 1.96

\#\#

\#\# Test for Heterogeneity:

$\# \# \mathrm{Q}(\mathrm{df}=8)=16.0004, \mathrm{p}-\mathrm{val}=0.0424$ 
\#\#

\#\# Model Results:

\#\#

\#\# estimate se zval pval ci.lb ci.ub

\#\# -0.0220 0.2559-0.0860 0.9314 -0.52350.4795

\#\#

\#\# ---

\#\# Signif. codes: $0^{1 \star \star \star \prime} 0.001^{1 \star \star \prime} 0.01^{1 * \prime} 0.055^{\prime .} 0.1^{\prime \prime} 1$

predict(df.1.1.rma, transf $=\exp$, digits $=2)$

\#\# pred ci.lb ci.ub cr.lb cr.ub

\#\# 0.980 .591 .620 .332 .90

anova.rma(df.1.1.rma)

\#\#

\#\# Test of Moderators (coefficient(s) 1):

\#\# QM $(\mathrm{df}=1)=0.0074, \mathrm{p}-\mathrm{val}=0.9314$

\# Figure 4 forest(df.1.1.rma, atransf $=\exp$, refline $=0$, addcred $=T$ )

\section{Analysis 1.1 subgroups Risk}

df.1.1.risk.rma <- rma.uni(ai = exp.y, ci = ctl.y, n1i = exp.n, n2i = ctl.n, measure = "OR", data $=$ df.1.1, slab = studynames, method = "ML", mods = risk, knha $=\mathrm{T}$ )

summary(df.1.1.risk.rma)

\#\#

\#\# Mixed-Effects Model ( $k=9$; tau^2 estimator: $M L)$

\#\#

\#\# logLik deviance AIC BIC AICC

\#\# -10.1621 11.5248 26.3242 26.9159 31.1242

\#\#

\#\# tau^2 (estimated amount of residual heterogeneity): 0.1551 (SE = 0.1844)

\#\# tau (square root of estimated tau^ 2 value): 0.3938

\#\# |^2 (residual heterogeneity / unaccounted variability): $34.75 \%$

\#\# $\mathrm{H}^{\wedge} 2$ (unaccounted variability / sampling variability): 1.53

\#\# R^2 (amount of heterogeneity accounted for): $35.81 \%$

\#\#

\#\# Test for Residual Heterogeneity:

\#\# QE $(\mathrm{df}=7)=13.3148, \mathrm{p}-\mathrm{val}=0.0648$

\#\#

\#\# Test of Moderators (coefficient(s) 2):

\#\# F(df1 = 1, df2 = 7) = 1.7001, p-val = 0.2335

\#\#

\#\# Model Results:

\#\#

\#\# estimate se tval pval ci.lb ci.ub

\#\# intrcpt $0.29420 .34120 .86210 .4172-0.51271 .1010$

\#\# riskNot High -0.6121 0.4695 -1.3039 0.2335 -1.7222 0.4980

\#\#

\#\# ---

\#\# Signif. codes: $0^{1 * \star * \prime} 0.001^{1 * * 1} 0.01^{1 * \prime} 0.055^{\prime \prime} 0.1^{\prime \prime} 1$

anova.rma(df.1.1.rma, df.1.1.risk.rma)

\#\# df AIC BIC AICc logLik LRT pval QE tau^2

\#\# Full 326.324226 .915931 .1242 -10.1621 13.3148 0.1551

\#\# Reduced 225.945826 .340327 .9458 -10.9729 1.6216 0.2029 16.0004 0.2416

\#\# R^2

\#\# Full

\#\# Reduced 35.81\% 
predict(df.1.1.risk.rma, transf $=\exp$, digits $=2$, newmods $=0: 1$ )

\#\# pred ci.lb ci.ub cr.lb cr.ub

\#\# 11.340 .603 .010 .394 .60

\#\# 20.730 .341 .560 .222 .42

\section{Analysis 2.1}

df.2.1

\#\# studynames exp.y exp.n ctl.y ctl.n Year type risk \#\# 1 Avidan 2008696739742008 Alarms High \#\# 2 Avidan 2011202861828522011 Alarms High \#\# 3 Mashour 20121894601993762012 Alarms Not High \#\# 4 Myles 20042212252712382004 TIVA High \#\# 5 Zhang 2011829192123092011 TIVA Not High

summary(df.2.1)

\#\# studynames exp.y exp.n ctl.y

\#\# Length:5 Min. : 6.0 Min. : 967 Min. : 3.0

\#\# Class :character 1st Qu.: 8.0 1st Qu.:1225 1st Qu.: 8.0

\#\# Mode :character Median :18.0 Median :2861 Median :19.0

\#\# Mean :14.8 Mean :3486 Mean :15.6

\#\# 3rd Qu.:20.0 3rd Qu.:2919 3rd Qu.:21.0

\#\# Max. :22.0 Max. :9460 Max. :27.0

\#\# ctl.n Year type risk

\#\# Min. : 974 Min. :2004 Alarms:3 High :3

\#\# 1st Qu.:1238 1st Qu.:2008 TIVA :2 Not High:2

\#\# Median :2309 Median :2011

\#\# Mean :3350 Mean :2009

\#\# 3rd Qu.:2852 3rd Qu.:2011

\#\# Max. :9376 Max. :2012

df.2.1.rma <- rma.uni (ai = exp.y, ci = ctl.y, n1i = exp.n, n2i = ctl.n, measure = "OR", data $=$ df.2.1, slab = studynames, method = "ML", knha = T) summary(df.2.1.rma)

\#\# \#\# Random-Effects Model ( $\mathrm{k}=5$; tau^2 estimator: $\mathrm{ML})$

\#\#

\#\# logLik deviance AIC BIC AICC

\#\#-5.5848 10.8575 15.1697 14.3885 21.1697

\#\#

\#\# tau^2 (estimated amount of total heterogeneity): 0.3323 (SE = 0.3151)

\#\# tau (square root of estimated tau^ 2 value): 0.5764

$\left.\# \#\right|^{\wedge} 2$ (total heterogeneity / total variability): $68.35 \%$

$\# \# \mathrm{H}^{\wedge} 2$ (total variability / sampling variability): 3.16

\#\#

\#\# Test for Heterogeneity:

$\# \# \mathrm{Q}(\mathrm{df}=4)=14.3557, \mathrm{p}-\mathrm{val}=0.0062$

\#\#

\#\# Model Results:

\#\#

\#\# estimate se tval pval ci.lb ci.ub

\#\#-0.0361 0.3645 -0.0992 0.9258-1.0481 0.9758

\#\#

\#\#---

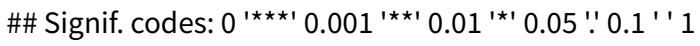

predict(df.2.1.rma, transf $=$ exp, digits $=2)$

\#\# pred ci.lb ci.ub cr.lb cr.ub

\#\# 0.960 .352 .650 .156 .41 
anova.rma(df.2.1.rma)

\#\#

\#\# Test of Moderators (coefficient(s) 1 ):

$\# \#$ F $(\mathrm{df} 1=1, \mathrm{df} 2=4)=0.0098, \mathrm{p}-\mathrm{val}=0.9258$

\# Figure 5 forest(df.2.1.rma, atransf $=\exp$, refline $=0$, addcred $=T$ )

\section{Analysis 2.1 subgroups TIVA}

df.2.1.type.rma <- rma.uni (ai = exp.y, ci = ctl.y, $n 1 i=$ exp.n, n2i = ctl.n, measure = "OR", data = df.2.1, slab = studynames, method = "ML", mods = type, knha $=\mathrm{T}$ )

summary(df.2.1.type.rma)

\#\#

\#\# Mixed-Effects Model ( $k=5$; tau^2 estimator: $M L)$

\#\#

\#\# logLik deviance AIC BIC AICC

\#\#-3.6018 6.8915 13.2037 12.0320 37.2037

\#\#

\#\# tau^2 (estimated amount of residual heterogeneity): 0.0919 ( $S E=0.1506$ )

\#\# tau (square root of estimated tau^ 2 value): 0.3032

$\# \# I^{\wedge} 2$ (residual heterogeneity / unaccounted variability): $34.90 \%$

\#\# $\mathrm{H}^{\wedge} 2$ (unaccounted variability / sampling variability): 1.54

\#\# R^2 (amount of heterogeneity accounted for): $72.33 \%$

\#\#

\#\# Test for Residual Heterogeneity:

\#\# $\mathrm{QE}(\mathrm{df}=3)=7.5974, \mathrm{p}-\mathrm{val}=0.0551$

\#\#

\#\# Test of Moderators (coefficient(s) 2):

$\# \# F(d f 1=1, d f 2=3)=3.3692, p-v a l=0.1638$

\#\#

\#\# Model Results:

\#\#

\#\# estimate se tval pval ci.lb ci.ub

\#\# intrcpt $0.41270 .38061 .08430 .3576-0.79851 .6240$

\#\# typeTIVA -1.0129 0.5518 -1.8355 $0.1638-2.76900 .7432$

\#\#

\#\# ---

\#\# Signif. codes: $0^{1 * \star \star \prime} 0.001^{1 * \star \prime} 0.01^{1 * *} 0.05$ '.' $0.1^{\prime \prime}$ ' 1

anova.rma(df.2.1.rma, df.2.1.type.rma)

\#\# df AIC BIC AICc logLik LRT pval QE tau^2

\#\# Full $313.203712 .032037 .2037-3.60187 .59740 .0919$

\#\# Reduced 215.169714 .388521 .1697 -5.5848 3.9660 0.0464 14.35570 .3323

$\# \# \mathrm{R}^{\wedge} 2$

\#\# Full

\#\# Reduced $72.33 \%$

predict(df.2.1.type. rma, transf $=$ exp, digits $=2$, newmods $=0: 1)$

\#\# pred ci.lb ci.ub cr.lb cr.ub

\#\# 11.510 .455 .070 .327 .11

\#\# 20.550 .151 .960 .112 .71

\section{Analysis 2.1 subgroups Risk}

df.2.1.risk.rma <- rma.uni(ai = exp.y, ci = ctl.y, n1i = exp.n, n2i = ctl.n, measure $=$ "OR", data $=$ df.2.1, slab $=$ studynames, method $=$ "ML", mods = risk, knha $=\mathrm{T})$

summary(df.2.1.risk.rma)

\#\# 
\#\# Mixed-Effects Model ( $k=5$; tau^2 estimator: $M L)$

\#\#

\#\# logLik deviance AIC BIC AICC

\#\# -4.2051 8.0980 14.4101 13.238538.4101

\#\#

\#\# tau^2 (estimated amount of residual heterogeneity): 0.1613 (SE =0.1993)

\#\# tau (square root of estimated tau^ 2 value): 0.4016

\#\# I^2 (residual heterogeneity / unaccounted variability): $48.60 \%$

\#\# $\mathrm{H}^{\wedge} 2$ (unaccounted variability / sampling variability): 1.95

\#\# $\mathrm{R}^{\wedge} 2$ (amount of heterogeneity accounted for): $51.46 \%$

\#\#

\#\# Test for Residual Heterogeneity:

$\# \# \mathrm{QE}(\mathrm{df}=3)=9.9456, \mathrm{p}-\mathrm{val}=0.0190$

\#\#

\#\# Test of Moderators (coefczvficient(s) 2):

$\# \# \mathrm{~F}(\mathrm{df} 1=1, \mathrm{df} 2=3)=2.1102, \mathrm{p}-\mathrm{val}=0.2423$

\#\#

\#\# Model Results:

\#\#

\#\# estimate se tval pval ci.lb ci.ub

\#\# intrcpt $0.34800 .42020 .82820 .4683-0.98931 .6853$

\#\# riskNot High -0.9211 0.6340 -1.4527 0.2423 -2.9389 1.0968

\#\#

\#\# ---

\#\# Signif. codes: $0^{1 * \star * \prime} 0.001^{1 * * \prime} 0.01^{\prime * \prime} 0.05$ '.' $0.1^{\prime \prime}$ ' 1

anova.rma(df.2.1.rma, df.2.1.risk.rma)

\#\# df AIC BIC AICc logLik LRT pval QE tau^2

\#\# Full 314.410113 .238538 .4101 -4.2051 9.94560 .1613

\#\# Reduced 215.169714 .388521 .1697 -5.5848 2.7595 0.0967 14.3557 0.3323

$\# \# \mathrm{R}^{\wedge} 2$

\#\# Full

\#\# Reduced $51.46 \%$

predict(df.2.1.risk.rma, transf $=\exp$, digits $=2$, newmods $=0: 1$ )

\#\# pred ci.lb ci.ub cr.lb cr.ub

\#\# 11.420 .375 .390 .229 .01

\#\# 20.560 .122 .550 .084 .08

\section{Analysis 2.2}

df.2.2

\#\# studynames exp.y exp.n ctl.y ctl.n Year type risk

\#\# 1 Avidan 2008296729742008 Alarms High

\#\# 2 Avidan 201182861228522011 Alarms High

\#\# 3 Mashour 2012894601193762012 Alarms Not High

\#\# 4 Myles 2004212251112382004 TIVA High

\#\# 5 Zhang 2011429191523092011 TIVA Not High

summary(df.2.2)

\#\# studynames exp.y exp.n ctl.y

\#\# Length:5 Min. :2.0 Min. : 967 Min. : 2.0

\#\# Class :character 1st Qu.:2.0 1st Qu.:1225 1st Qu.: 2.0

\#\# Mode :character Median :4.0 Median :2861 Median :11.0

\#\# Mean :4.8 Mean :3486 Mean : 8.2

\#\# 3rd Qu.:8.0 3rd Qu.:2919 3rd Qu.:11.0

\#\# Max. :8.0 Max. :9460 Max. :15.0

\#\# ctl.n Year type risk

\#\# Min. : 974 Min. :2004 Alarms:3 High :3

\#\# 1st Qu.:1238 1st Qu.:2008 TIVA :2 Not High:2 
\#\# Median :2309 Median :2011

\#\# Mean :3350 Mean :2009

\#\# 3rd Qu.:2852 3rd Qu.:2011

\#\# Max. :9376 Max. :2012

df.2.2.rma <- rma.uni(ai = exp.y, ci = ctl.y, n1i = exp.n, n2i = ctl.n, measure = "OR",

data $=$ df.2.2, slab = studynames, method $=$ "ML", knha $=\mathrm{T}$ )

summary(df.2.2.rma)

\#\#

\#\# Random-Effects Model ( $\mathrm{k}=5$; tau^2 estimator: $\mathrm{ML})$

\#\#

\#\# logLik deviance AIC BIC AICC

\#\#-7.6377 9.7555 19.2753 18.4942 25.2753

\#\#

\#\# tau^2 (estimated amount of total heterogeneity): $0.6684(\mathrm{SE}=0.7169)$

\#\# tau (square root of estimated tau^ 2 value): 0.8176

\#\# I^2 (total heterogeneity / total variability): $59.88 \%$

\#\# $\mathrm{H}^{\wedge} 2$ (total variability / sampling variability): 2.49

\#\#

\#\# Test for Heterogeneity:

\#\# Q $(\mathrm{df}=4)=11.9667, \mathrm{p}-\mathrm{val}=0.0176$

\#\#

\#\# Model Results:

\#\#

\#\# estimate se tval pval ci.lb ci.ub

\#\# -0.5172 0.5503 -0.9399 0.4005-2.0451 1.0107

\#\#

\#\#---

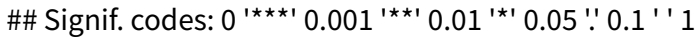

predict(df.2.2.rma, transf $=$ exp, digits $=2)$

\#\# pred ci.lb ci.ub cr.lb cr.ub

\#\# 0.600 .132 .750 .049 .20

anova.rma(df.2.2.rma)

\#\#

\#\# Test of Moderators (coefficient(s) 1 ):

$\# \# \mathrm{~F}(\mathrm{df} 1=1, \mathrm{df} 2=4)=0.8833, \mathrm{p}-\mathrm{val}=0.4005$

\# Figure 6 forest(df.2.2.rma, atransf $=\exp$, refline $=0$, addcred $=T$ )

\section{Analysis 2.2 subgroups TIVA}

df.2.2.type.rma <- rma.uni(ai = exp.y, ci = ctl.y, n1i = exp.n, n2i = ctl.n, measure = "OR", data $=$ df.2.2, slab $=$ studynames, method $=$ "ML", mods = type, knha $=\mathrm{T}$ )

summary(df.2.2.type.rma)

\#\#

\#\# Mixed-Effects Model ( $k=5$; tau^2 estimator: $M L)$

\#\#

\#\# logLik deviance AIC BIC AICC

\#\# -4.5182 3.516515 .036413 .864739 .0364

\#\#

\#\# tau^2 (estimated amount of residual heterogeneity): $0(\mathrm{SE}=0.2302)$

\#\# tau (square root of estimated tau^2 value): 0

\#\# I^2 (residual heterogeneity / unaccounted variability): 0.00\%

$\# \# \mathrm{H}^{\wedge} 2$ (unaccounted variability / sampling variability): 1.00

$\# \# \mathrm{R}^{\wedge} 2$ (amount of heterogeneity accounted for): $100.00 \%$

\#\#

\#\# Test for Residual Heterogeneity: 
$\# \# \mathrm{QE}(\mathrm{df}=3)=3.5165, \mathrm{p}-\mathrm{val}=0.3186$

\#\#

\#\# Test of Moderators (coefficient(s) 2):

$\# \# \mathrm{~F}(\mathrm{df} 1=1, \mathrm{df} 2=3)=7.2090, \mathrm{p}-\mathrm{val}=0.0747$

\#\#

\#\# Model Results:

\#\#

\#\# estimate se tval pval ci.lb ci.ub

\#\# intrcpt $0.09760 .40280 .24220 .8242-1.18441 .3796$

\#\# typeTIVA -1.7078 0.6361 -2.6850 0.0747 -3.7320 0.3164.

\#\#

\#\# ---

\#\# Signif. codes: $0^{1 * \star * \prime} 0.001^{1 * * 1} 0.01^{1 * \prime} 0.05$ '.' $0.1^{\prime \prime} 1$

anova.rma(df.2.2.rma, df.2.2.type.rma)

\#\# df AIC BIC AICc logLik LRT pval QE tau^2

\#\# Full $315.036413 .864739 .0364-4.51823 .51650 .0000$

\#\# Reduced 219.275318 .494225 .2753 -7.6377 6.23890 .012511 .96670 .6684

$\# \# \mathrm{R}^{\wedge} 2$

\#\# Full

\#\# Reduced 100\%

predict(df.2.2.type.rma, transf $=\exp$, digits $=2$, newmods $=0: 1$ )

\#\# pred ci.lb ci.ub cr.lb cr.ub

\#\# 11.100 .313 .970 .313 .97

\#\# 20.200 .040 .960 .040 .96

\section{Analysis 2.2 subgroupsRisk}

df.2.2.risk.rma <- rma.uni(ai = exp.y, ci = ctl.y, $n 1 i=$ exp. $n, n 2 i=c t l . n$, measure = "OR", data $=$ df.2.2, slab $=$ studynames, method $=$ "ML", mods = risk, knha $=\mathrm{T}$ )

summary(df.2.2.risk.rma)

\#\#

\#\# Mixed-Effects Model ( $k=5$; tau^2 estimator: $M L)$

\#\#

\#\# logLik deviance AIC BIC AICC

\#\#-7.2858 9.0517 20.5716 19.3999 44.5716

\#\#

\#\# tau^2 (estimated amount of residual heterogeneity): $0.5201(\mathrm{SE}=0.6159)$

\#\# tau (square root of estimated tau^2 value): 0.7212

\#\# I^2 (residual heterogeneity / unaccounted variability): 53.13\%

\#\# $\mathrm{H}^{\wedge} 2$ (unaccounted variability / sampling variability): 2.13

$\# \# \mathrm{R}^{\wedge} 2$ (amount of heterogeneity accounted for): $22.19 \%$

\#\#

\#\# Test for Residual Heterogeneity:

\#\# QE $(\mathrm{df}=3)=10.7061, \mathrm{p}-\mathrm{val}=0.0134$

\#\#

\#\# Test of Moderators (coefficient(s) 2):

$\# \# F(d f 1=1, d f 2=3)=0.4309, p-v a l=0.5584$

\#\#

\#\# Model Results:

\#\#

\#\# estimate se tval pval ci.lb ci.ub

\#\# intrcpt $-0.12990 .8451-0.15370 .8876-2.81932 .5594$

\#\# riskNot High $-0.77491 .1805-0.65640 .5584-4.53182 .9821$

\#\#

\#\# ---

\#\# Signif. codes: $0^{1 * \star * 1} 0.001^{1 * * 1} 0.01^{1 * 1} 0.05$ '.' $0.1^{\prime \prime} 1$

anova.rma(df.2.2.rma, df.2.2.risk.rma) 
\#\# df AIC BIC AICc logLik LRT pval QE tau^2

\#\# Full 320.571619 .399944 .5716 -7.2858 10.70610 .5201

\#\# Reduced 219.275318 .494225 .2753 -7.6377 0.7038 0.4015 11.9667 0.6684

\#\# R^2

\#\# Full

\#\# Reduced 22.19\%

predict(df.2.2.risk.rma, transf $=\exp$, digits $=2$, newmods $=0: 1$ )

\#\# pred ci.lb ci.ub cr.lb cr.ub

\#\# 10.880 .0612 .930 .0330 .13

\#\# 20.400 .035 .580 .0113 .21

\section{Analysis 3.1}

\#\# studlab exp.y exp.n ctl.y ctl.n

\#\# 1 Baraka 19894301420

\#\# 2 Russell 19862301125

\#\# 3 Schultetus 1986523713

\#\# studlab exp.y exp.n ctl.y

\#\# Length:3 Min. :2.000 Min. :23.00 Min. : 7.00

\#\# Class :character 1st Qu.:3.000 1st Qu.:26.50 1st Qu.: 9.00

\#\# Mode :character Median :4.000 Median :30.00 Median :11.00

\#\# Mean :3.667 Mean :27.67 Mean :10.67

\#\# 3rd Qu.:4.500 3rd Qu.:30.00 3rd Qu.:12.50

\#\# Max. :5.000 Max. :30.00 Max. :14.00

\#\# ctl.n

\#\# Min. : 13.00

\#\# 1st Qu.:16.50

\#\# Median :20.00

\#\# Mean :19.33

\#\# 3rd Qu.:22.50

\#\# Max. :25.00

\#\# study= 1

\#\# study $=2$

\#\# study= 3

\#\# \$ci.fixed

\#\# constant inverse-variance fisher asymptotical-MH range

\#\# est $0.191866870 .179060590 .150660712 .286242 \mathrm{e}-01 \mathrm{NA}$

\#\# lower Cl $0.087902250 .087902250 .087902251 .265683 \mathrm{e}-01$ 1e-03

\#\# upper $\mathrm{Cl} 0.407380280 .410204100 .430526614 .129708 \mathrm{e}-011 \mathrm{e}+03$

\#\# p 0.000000000 .000000000 .000000001 .001218 e-06 NA

\#\#

\#\# \$study.ci

\#\# est lower $\mathrm{Cl}$ upper $\mathrm{Cl}$ p limit

\#\# study 10.193757130 .062462190 .44739410 .0010883071

\#\# study 20.098045540 .027441200 .54526200 .0042488561

\#\# study 30.390615040 .139703281 .04431600 .0670759781

\#\#

\#\# \$precision

\#\# [1] "+/- 0.00690430312741843"

\section{Analysis 3.1 meta regression}

explicit.df

\#\# studlab cognitiveState events count logitEstimator logitVariance \#\# 1 Baraka 1989 wakefulness $1850-0.57536 \ldots . .0 .08680556$

\#\# 2 Baraka 1989 awareness 250 -3.17805.... 0.52083333

\#\# 3 Russell 1986 wakefulness $1355-1.17272$.... 0.10073260

\#\# 4 Russell 1986 awareness 155 -3.98898.... 1.01851852 
\#\# 5 Schultetus 1986 wakefulness $1236-0.69314 \ldots . .0 .12500000$

\#\# 6 Schultetus 1986 awareness $336-2.39789 . . .0 .36363636$

\#\# 7 Tunstall 1989 wakefulness $47113-0.33950 \ldots . . .0 .03642811$

\#\# 8 Tunstall 1989 awareness $0113-5.42495 \ldots . .2 .00881057$

summary(explicit.df)

\#\# studlab cognitiveState events count

\#\# Length:8 wakefulness:4 Min. : 0.00 Min. : 36.0

\#\# Class :character awareness :4 1st Qu.: 1.75 1st Qu.: 46.5

\#\# Mode :character Median : 7.50 Median : 52.5

\#\# Mean :12.00 Mean : 63.5

\#\# 3rd Qu.:14.25 3rd Qu.: 69.5

\#\# Max. :47.00 Max. :113.0

\#\# logitEstimator logitVariance

\#\# Min. :-5.4249 Min. :0.03643

\#\# 1st Qu.:-3.3808 1st Qu.:0.09725

\#\# Median :-1.7853 Median :0.24432

\#\# Mean :-2.2213 Mean :0.53260

\#\# 3rd Qu.:-0.6637 3rd Qu.:0.64525

\#\# Max. :-0.3395 Max. :2.00881

\#\#

\#\# Multivariate Meta-Analysis Model ( $k=8$; method: REML)

\#\#

\#\# Variance Components:

\#\#

\#\# outer factor: studlab (nlvls $=4$ )

\#\# inner factor: cognitiveState (nlvls $=2$ )

\#\#

\#\# estim sqrt fixed

\#\# tau^2 0.06120 .2473 no

\#\# rho -0.9566 no

\#\#

\#\# Test for Residual Heterogeneity:

$\# \# \mathrm{QE}(\mathrm{df}=6)=10.0016, \mathrm{p}$-val $=0.1246$

\#\#

\#\# Test of Moderators (coefficient(s) 2):

$\# \# F(d f 1=1, d f 2=6)=26.4014, p-v a l=0.0021$

\#\#

\#\# Model Results:

\#\#

\#\# estimate se tval pval ci.lb

\#\# intrcpt $-0.65360 .1870-3.49460 .0129-1.1112$

\#\# cognitiveStateawareness -2.5263 0.4917 -5.1382 0.0021 -3.7294

\#\# ci.ub

\#\# intrcpt -0.1959 *

\#\# cognitiveStateawareness -1.3232 **

\#\#

\#\# ---

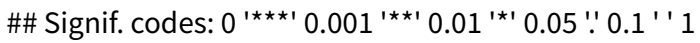

\#\# pred ci.lb ci.ub cr.lb cr.ub

\#\# 10.34220 .24760 .45120 .19590 .5263

\#\# 20.03990 .01450 .10530 .01230 .1217

\section{Analysis 4.1}

df.4.1

\#\# studlab exp.y exp.n ctl.y ctl.n

\#\# 1 Ellingson 1977013413

\#\# 2 Haram 1981039540 
\#\# 3 McNulty 1985071325

\#\# 4 Miller 1996269421

$\operatorname{summary}(d f .4 .1)$

\#\# studlab exp.y exp.n ctl.y

\#\# Length:4 Min. :0.0 Min. :13.0 Min. :3.00

\#\# Class :character 1st Qu.:0.0 1st Qu.:32.5 1st Qu.:3.75

\#\# Mode :character Median :0.0 Median :54.0 Median :4.00

\#\# Mean :0.5 Mean :48.0 Mean :4.00

\#\# 3rd Qu.:0.5 3rd Qu.:69.5 3rd Qu.:4.25

\#\# Max. :2.0 Max. :71.0 Max. :5.00

\#\# ctl.n

\#\# Min. : 13.00

\#\# 1st Qu.:19.00

\#\# Median :23.00

\#\# Mean :24.75

\#\# 3rd Qu.:28.75

\#\# Max. : 40.00

exact.4.1 <- meta.exact(data = mat.4.1, type = 'risk ratio')

\#\# study $=1$

$\#$ \# study $=2$

\#\# study $=3$

\#\# study= 4

exact.4.1

\#\# \$ci.fixed

\#\# constant inverse-variance fisher asymptotical-MH range \#\# est 0.207014130 .169433780 .122461620 .1043379866 NA

\#\# lower Cl 0.023988330 .023988330 .023988330 .0314276549 1e-03

\#\# upper Cl $0.265460560 .247742210 .224905460 .34639604861 \mathrm{e}+03$

\#\# p $0.000000000 .000000000 .000000000 .0002228273 \mathrm{NA}$

\#\#

\#\# \$study.ci

\#\# est lower $\mathrm{Cl}$ upper $\mathrm{Cl}$ p limit

\#\# study 10.00000000 .00000001 .11625130 .038245971

\#\# study 20.00000000 .00000000 .82689400 .038511011

\#\# study 30.00000000 .00000000 .56362350 .029420111

\#\# study 40.12265590 .02393840 .83320030 .029740911

\#\#

\#\# \$precision

\#\# [1] "+/- 0.00690430312741843"

\section{Analysis 5.1}

df.5.1

\#\# studlab exp.y exp.n ctl.y ctl.n

\#\# 1 Abboud 1985065216

\#\# 2 Crawford JS 1985338419393

summary(df.5.1)

\#\# studlab exp.y exp.n ctl.y

\#\# Length:2 Min. :0.00 Min. : 65.0 Min. : 2.00

\#\# Class :character 1st Qu.:0.75 1st Qu.:144.8 1st Qu.: 6.25

\#\# Mode :character Median :1.50 Median :224.5 Median :10.50

\#\# Mean :1.50 Mean :224.5 Mean :10.50

\#\# 3rd Qu.:2.25 3rd Qu.:304.2 3rd Qu.:14.75

\#\# Max. :3.00 Max. :384.0 Max. :19.00

\#\# ctl.n 
\#\# Min. : 16.0

\#\# 1st Qu.:110.2

\#\# Median :204.5

\#\# Mean :204.5

\#\# 3rd Qu.:298.8

\#\# Max. :393.0

exact.5.1 <- meta.exact (data = mat.5.1, type = "risk ratio")

\#\# study= 1

\#\# study= 2

exact.5.1

\#\# \$ci.fixed

\#\# constant inverse-variance fisher asymptotical-MH range \#\# est 0.131219990 .131219990 .131219990 .1431659640 NA

\#\# lower Cl 0.03999447 0.03999447 0.03999447 0.0453311444 1e-03

\#\# upper Cl $0.430526610 .427562890 .421696500 .45215035991 \mathrm{e}+03$

\#\# p $0.000100000 .000100000 .000100000 .0009238782 \mathrm{NA}$

\#\#

\#\# \$study.ci

\#\# est lower $\mathrm{Cl}$ upper $\mathrm{Cl} \mathrm{p}$ limit

\#\# study 10.00000000 .000000000 .80200270 .0366726831

\#\# study 20.13141580 .039816110 .51396950 .0018511411

\#\#

\#\# \$precision

\#\# [1] "+/- $0.00690430312741843 "$

save.image("Data/implicit.RData")

Appendix 8. Adjudication of awareness events

\begin{tabular}{llllll}
\hline \multirow{2}{*}{ Study } & Study size & Number of events & Judged & Judged & Judged \\
\cline { 3 - 6 } & & To be adjudicated & No awareness & Possible awareness & Definite awareness \\
\hline Avidan 2008 & 1941 & $16(0.82 \%)$ & $7(0.36 \%)$ & $5(0.26 \%)$ & $4(0.21 \%)$ \\
\hline Avidan 2011 & 5713 & $50(0.88 \%)$ & $22(0.38 \%)$ & $18(0.32 \%)$ & $10(0.18 \%)$ \\
\hline Mashour 2012 & 18,836 & $76(0.40 \%)$ & $39(0.21 \%)$ & $18(0.10 \%)$ & $19(0.10 \%)$ \\
\hline Myles 2004 & 2463 & $61(2.48 \%)$ & $12(0.49 \%)$ & $36(1.46 \%)$ & $13(0.53 \%)$ \\
\hline Zhang 2011 & 5228 & $300(5.73 \%)$ & $271(5.18 \%)$ & $10(0.19 \%)$ & $19(0.36 \%)$ \\
\hline Totals & 34,181 & $503(1.47 \%)$ & $351(1.03 \%)$ & $87(0.23 \%)$ & $65(0.19 \%)$ \\
\hline
\end{tabular}

\begin{tabular}{lllll}
\hline Study & $\begin{array}{l}\text { Number of } \\
\text { events }\end{array}$ & Judged & Judged & Judged \\
\cline { 2 - 4 } & $\begin{array}{l}\text { To be adjudicat- } \\
\text { ed }\end{array}$ & No awareness & Possible awareness & Definite awareness \\
\hline
\end{tabular}




\begin{tabular}{|c|c|c|c|c|}
\hline Avidan 2008 & 16 & $7(43.8 \%)$ & $5(31.3 \%)$ & $4(25.0 \%)$ \\
\hline Avidan 2011 & 50 & $22(44.0 \%)$ & $18(36.0 \%)$ & $10(20.0 \%)$ \\
\hline Mashour 2012 & 76 & 39 (51.3\%) & $18(23.7)$ & $19(25.0 \%)$ \\
\hline Myles 2004 & 61 & $12(19.7 \%)$ & $36(59.0 \%)$ & $13(21.3 \%)$ \\
\hline Zhang 2011 & 300 & $271(90.3 \%)$ & $10(3.3 \%)$ & $19(6.3 \%)$ \\
\hline Totals & 503 & $351(69.9 \%)$ & $87(15.3 \%)$ & 65 (12.9\%) \\
\hline
\end{tabular}

Details of the adjudication process were tallied from the published study or were sought by communication with the authors.

In the two-stage process, structured interviews of patients were conducted one or more times. Potential awareness episodes were recorded in a narrative report.

An independent committee of three anaesthetists, blinded to treatment group, coded the report as no awareness, possible awareness, and awareness.

- As a percentage of study size, events flagged for adjudication ranged from $0.40 \%$ to $5.73 \%$.

- As a percentage of study size, no awareness ranged from $0.21 \%$ to $5.18 \%$; possible awareness ranged from $0.10 \%$ to $1.46 \%$; definite awareness ranged from $0.10 \%$ to $0.53 \%$.

A random-effects meta-analysis of the logit transformed proportions of 'no awareness' events of all adjudicated events was performed in metafor (Viechtbauer 2010).

Similar models were also estimated for the proportion of potential awareness episodes and definite awareness events.

Average proportions, $95 \% \mathrm{Cls}$ and $95 \%$ prediction intervals (PI) were obtained in the meta-analysis.

- Average proportion of events flagged for adjudication $0.013(95 \% \mathrm{Cl} 0.005$ to $0.034 ; 95 \% \mathrm{PI} 0.001$ to 0.119$)$.

- Average proportion of adjudicated events judged no awareness $0.53(95 \% \mathrm{Cl} 0.25$ to $0.79 ; 95 \% \mathrm{PI} 0.06$ to 0.95 ).

- Average proportion of adjudicated events judged awareness $0.17(95 \% \mathrm{Cl} 0.10$ to $0.28 ; 95 \% \mathrm{PI} 0.05$ to 0.46 ).

- Between-study statistical heterogeneity was very high ( $12=99 \%, 96 \%, 80 \%)$ for events flagged, events adjudicated 'no awareness' and events adjudicated definite awareness.

The Zhang 2011 study had a greater proportion of events adjudicated and events not judged awareness. A sensitivity meta-analysis excluding Zhang 2011 was also estimated.

Averages, 95\% Cls and 95\% prediction intervals (PI) were obtained in the meta-analysis.

- Average proportion of events flagged for adjudication 0.009 (95\% $\mathrm{Cl} 0.004$ to $0.019 ; 95 \% \mathrm{PI} 0.002$ to 0.047 ).

- Average proportion of adjudicated events judged no awareness: $0.39(95 \% \mathrm{Cl} 0.25$ to 0.55 ; $95 \% \mathrm{PI} 0.14$ to 0.71 ).

- Average proportion of adjudicated events judged awareness $0.22(95 \% \mathrm{Cl} 0.17$ to $0.29 ; 95 \% \mathrm{PI} 0.17$ to 0.29 ).

- Between-study statistical heterogeneity remained very high ( $12=96 \%, 78 \%)$ for events flagged and events adjudicated 'no awareness'.

- Between-study statistical heterogeneity was eliminated $\left(I^{2}=0 \%\right)$ for events adjudicated definite awareness.

Explicit recall is a subjective experience. Corroboration by operating theatre staff that matches specifics of recall with intraoperative events has been reported.

It is very difficult to be certain of the veracity of explicit recall without this corroboration.

Lacking external corroboration, suggestions have been made for improving and revising the adjudication process (Myles 2015 (personal communication)).

- Membership of adjudication panels should be taken from diverse clinical/research disciplines.

- Prerequisites for adjudication panel membership should be established, e.g. years of clinical experience, avoidance of conflicts of interest. 
- Establishment of consensus guidelines of the diagnostic criteria including external corroboration if available.

- Workflow standards for the panel should be established, e.g. blinding, clear majority voting, independent ascertainment/categorization.

- Evaluating agreement (e.g. kappa statistic) amongst the review panel members would be worthwhile.

\section{Adjudicate Analysis}

NLP

RStudio Project started December 12, 2014

This analysis was run Fri Jun 17 17:10:49 2016.

\section{checkpoint}

snapshot

\section{prepareData}

List data

\#\# slab studySize adjudicated notAwareness definiteAwareness

\#\# 1 Avidan 200819411674

\#\# 2 Avidan 20115713502210

\#\# 3 Mashour 201218836763919

\#\# 4 Myles 20042463611213

\#\# 5 Zhang 2011522830027119

\section{prepareMeta}

List effect sizes

\#\# slab studySize adjudicated notAwareness definiteAwareness

\#\# 1 Avidan 200819411674

\#\# 2 Avidan 20115713502210

\#\# 3 Mashour 201218836763919

\#\# 4 Myles 20042463611213

\#\# 5 Zhang 2011522830027119

\#\# adjudicated.yi adjudicated.vi notAwareness.yi notAwareness.vi

\#\# 1 -4.7901 $0.0630-0.25130 .2540$

\#\# $2-4.72970 .0202-0.24120 .0812$

\#\# $3-5.50870 .01320 .05260 .0527$

\#\# 4 -3.6732 $0.0168-1.40690 .1037$

\#\# 5 -2.7989 0.00352 .23480 .0382

\#\# definiteAwareness.yi definiteAwareness.vi

\#\# 1 - 1.09860 .3333

\#\# 2 - 1.38630 .1250

\#\# 3 - 1.09860 .0702

\#\# $4-1.30630 .0978$

\#\# 5 -2.6939 0.0562

\section{meta1}

Display meta analysis models. Zhang 2011 data excluded.

\#\# [1] "Adjudicated Events Meta Analysis"

\#\#

\#\# Random-Effects Model ( $k=4$; tau^2 estimator: REML)

\#\#

\#\# $\operatorname{tau}^{\wedge} 2$ (estimated amount of total heterogeneity): $0.5679(\mathrm{SE}=0.4863)$

\#\# tau (square root of estimated tau^2 value): 0.7536

\#\# I^2 (total heterogeneity / total variability): $96.39 \%$

\#\# $\mathrm{H}^{\wedge} 2$ (total variability / sampling variability): 27.68

\#\#

\#\# Test for Heterogeneity:

$\# \# \mathrm{Q}(\mathrm{df}=3)=112.3584, \mathrm{p}-\mathrm{val}<.0001$

\#\# 
\#\# Model Results:

\#\#

\#\# estimate se zval pval ci.lb ci.ub

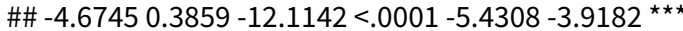

\#\#

\#\# ---

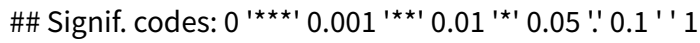

\#\# [1] "Not Awareness Event Meta Analysis"

\#\#

\#\# Random-Effects Model ( $k=4$; tau^2 estimator: REML)

\#\#

\#\# $\operatorname{tau}^{\wedge} 2$ (estimated amount of total heterogeneity): $0.3433(\mathrm{SE}=0.3711)$

\#\# tau (square root of estimated tau^2 value): 0.5859

\#\# I^2 (total heterogeneity / total variability): $78.04 \%$

$\# \# \mathrm{H}^{\wedge} 2$ (total variability / sampling variability): 4.55

\#\#

\#\# Test for Heterogeneity:

$\# \# \mathrm{Q}(\mathrm{df}=3)=14.0155, \mathrm{p}-\mathrm{val}=0.0029$

\#\#

\#\# Model Results:

\#\#

\#\# estimate se zval pval ci.lb ci.ub

\#\# -0.4553 0.3372 -1.3500 $0.1770-1.11630 .2057$

\#\#

\#\# ---

\#\# Signif. codes: $00^{1 * * * 1} 0.001^{1 * * 1} 0.01^{1 * \prime} 0.05$ '.' $0.1^{\prime \prime} 1$

\#\# [1] "Definite Awareness Event Meta Analysis"

\#\#

\#\# Random-Effects Model ( $\mathrm{k}=4$; tau^2 estimator: REML)

\#\#

\#\# tau^2 (estimated amount of total heterogeneity): $0(\mathrm{SE}=0.0909)$

$\# \#$ tau (square root of estimated tau^2 value): 0

$\left.\# \#\right|^{\wedge} 2$ (total heterogeneity / total variability): $0.00 \%$

$\# \# \mathrm{H}^{\wedge} 2$ (total variability / sampling variability): 1.00

\#\#

\#\# Test for Heterogeneity:

$\# \# \mathrm{Q}(\mathrm{df}=3)=0.5511, \mathrm{p}-\mathrm{val}=0.9075$

\#\#

\#\# Model Results:

\#\#

\#\# estimate se zval pval ci.lb ci.ub

\#\#-1.2233 $0.1679-7.2868<.0001-1.5524-0.8943$ ***

\#\#

\#\# ---

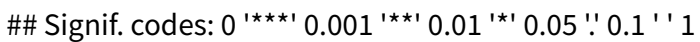

\section{predict1}

List prediction intervals. Zhang 2011 data excluded.

\#\# [1] "Adjudicated \%"

\#\# pred ci.lb ci.ub cr.lb cr.ub

\#\# 0.00920 .00440 .01950 .00180 .0467

\#\# [1] "Not Awareness Event \%"

\#\# pred ci.lb ci.ub cr.lb cr.ub

\#\# 0.38810 .24670 .55120 .14430 .7047

\#\# [1] "Definite Awareness Event \%"

Anaesthetic interventions for prevention of awareness during surgery (Review) 
\#\# pred ci.lb ci.ub cr.lb cr.ub

\#\# 0.22730 .17470 .29020 .17470 .2902

\section{meta2}

Display meta analysis models. Zhang 2011 data included.

\#\# [1] "Adjudicated Events Meta Analysis"

\#\#

\#\# Random-Effects Model ( $k=5$; tau^2 estimator: REML)

\#\#

\#\# tau^2 (estimated amount of total heterogeneity): 1.1330 (SE = 0.8174)

\#\# tau (square root of estimated tau^2 value): 1.0644

$\# \# I^{\wedge} 2$ (total heterogeneity / total variability): $98.81 \%$

\#\# $\mathrm{H}^{\wedge} 2$ (total variability / sampling variability): 84.05

\#\#

\#\# Test for Heterogeneity:

$\# \# \mathrm{Q}(\mathrm{df}=4)=543.2804, \mathrm{p}-\mathrm{val}<.0001$

\#\#

\#\# Model Results:

\#\#

\#\# estimate se zval pval ci.lb ci.ub

\#\# -4.2933 $0.4808-8.9290<.0001-5.2357-3.3509$ ***

\#\#

\#\# ---

\#\# Signif. codes: $0{ }^{1 * \star * \prime} 0.001^{1 * \star \prime} 0.01^{1 * \prime} 0.05$ '.' $0.1^{\prime \prime} 1$

\#\# [1] "Not Awareness Event Meta Analysis"

\#\#

\#\# Random-Effects Model ( $k=5$; tau^2 estimator: REML)

\#\#

\#\# tau^2 (estimated amount of total heterogeneity): 1.7454 (SE = 1.3066)

\#\# tau (square root of estimated $\operatorname{tau}^{\wedge} 2$ value): 1.3211

\#\# I^2 (total heterogeneity / total variability): $95.83 \%$

\#\# $\mathrm{H}^{\wedge} 2$ (total variability / sampling variability): 23.99

\#\#

\#\# Test for Heterogeneity:

$\# \# \mathrm{Q}(\mathrm{df}=4)=126.0925, \mathrm{p}-\mathrm{val}<.0001$

\#\#

\#\# Model Results:

\#\#

\#\# estimate se zval pval ci.lb ci.ub

\#\# $0.09750 .60800 .16030 .8726-1.09421 .2891$

\#\#

\#\# ---

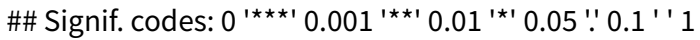

\#\# [1] "Definite Awareness Event Meta Analysis"

\#\#

\#\# Random-Effects Model ( $k=5$; tau^2 estimator: REML)

\#\#

\#\# tau^2 (estimated amount of total heterogeneity): $0.4153(\mathrm{SE}=0.3781)$

\#\# tau (square root of estimated tau^2 value): 0.6444

\#\# I^2 (total heterogeneity / total variability): $80.67 \%$

\#\# $\mathrm{H}^{\wedge} 2$ (total variability / sampling variability): 5.17

\#\#

\#\# Test for Heterogeneity:

$\# \# \mathrm{Q}(\mathrm{df}=4)=26.1814, \mathrm{p}-\mathrm{val}<.0001$

\#\#

\#\# Model Results:

\#\# 
\#\# estimate se zval pval ci.lb ci.ub

\#\# -1.5624 $0.3276-4.7688<.0001-2.2045-0.9202$ ***

\#\#

\#\# ---

\#\# Signif. codes: 0 '***' $0.001^{1 * \star \prime} 0.01^{1 * \prime} 0.05$ '.' $0.1^{\prime \prime} 1$

\section{predict2}

List prediction intervals. Zhang 2011 data included.

\#\# [1] "Adjudicated \%"

\#\# pred ci.lb ci.ub cr.lb cr.ub

\#\# 0.01350 .00530 .03390 .00140 .1188

\#\# [1] "Not Awareness Event \%"

\#\# pred ci.lb ci.ub cr.lb cr.ub

\#\# 0.52440 .25080 .78400 .05990 .9502

\#\# [1] "Definite Awareness Event \%"

\#\# pred ci.lb ci.ub cr.lb cr.ub

\#\# 0.17330 .09930 .28490 .04840 .4637

\section{CONTRIBUTIONS OF AUTHORS}

Anthony G Messina (AGM), Michael Wang (MaW), Marshall J Ward (MJW), Chase C Wilker (CCW), Brett B Smith (BS), Daniel P Vezina (DV), Nathan Leon Pace (NLP)

Conceiving the review: AGM

Co-ordinating the review: $A G M$

Undertaking manual searches: AGM, NLP, MaW, CCW, BS

Screening search results: AGM, NLP, PMaW, CCW, BS

Organizing retrieval of papers: AGM, NLP, MaW, CCW, BS

Screening retrieved papers against inclusion criteria: AGM, NLP, MaW, CCW, BS

Appraising quality of papers: AGM, NLP, MaW, BS, CCW

Abstracting data from papers: AGM, NLP, MaW, BS, CCW

Writing to authors of papers for additional information: AGM, NLP, MaW, CCW, BS

Providing additional data about papers: AGM, NLP, MaW, MJW, DV

Obtaining and screening data on unpublished studies: AGM, NLP, CCW

Data management for the review: AGM, NLP, MaW, CCW

Entering data into Review Manager (RevMan): NLP, AGM, MaW, CCW

RevMan statistical data: NLP, AGM, CCW, DV

Other statistical analysis not using RevMan: NLP, AGM, CCW, DV

Double entry of data: AGM, NLP, MaW, CCW

Interpretation of data: NLP, AGM, MaW, CCW, MJW, DV

Statistical inferences: NLP, AGM, NP, CCW, MJW, DV

Writing the review: AGM, NLP, MaW, MJW, CCW, NP, DV

Securing funding for the review: not applicable

Performing previous work that was the foundation of the present study: AGM, NLP

Guarantor for the review (one author): AGM

Person responsible for reading and checking review before submission: AGM

\section{DECLARATIONS OF INTEREST}

Anthony G Messina: none known.

Michael Wang was involved in the design, conduct, or publication of potentially eligible studies for this Cochrane review (Russell 1997; Russell 2001). Prof Wang has received funding from Abbvie for invited lectures and meeting attendance, including accidental anaesthetic awareness events. He has in the past been loaned two Bispectral Index monitors for research purposes by Aspect Medical/Covidian.

Marshall J Ward: none known.

Chase C Wilker: none known. 
Brett B Smith: none known.

Daniel P Vezina: board member and executive position since January 2012 with a Big Data analytics private company (MedAnalytics), and a congestive heart failure clinical solution private company since June 2008 (Guardsman Scientific).

Nathan Leon Pace: none known.

\section{SOURCES OF SUPPORT}

\section{Internal sources}

- None, Other.

- University of Utah, USA.

Institutional salary

- University of Leicester, UK. Institutional salary

- Veterans Administration, USA. Institutional salary

\section{External sources}

- No sources of support supplied

\section{DIFFERENCES BETWEEN PROTOCOLANDREVIEW}

\section{Background:}

This has been updated since the protocol (Messina 2008), with new sections in RevMan. We have added new paragraphs in the Dryad appendix about the psychological sequelae of cases of anaesthetic awareness, complications from muscle relaxant use, intraoperative dreams, onset of explicit memory in the infant, lack of intraoperative wakefulness, post-traumatic stress disorder, and delayed memory amongst other topics that were not in the protocol (Appendix 1).

\section{Methods section:}

More authors were added to the review. We updated many of the methods sections. Assessment of heterogeneity was interpreted in the context of recently published criteria for the assessment of inconsistency (Guyatt 2011). Statistical meta-analyses were done in the R language using the exactmeta and metafor packages (Tian 2008; Viechtbauer 2010).

The web app Rayyan was used to assist in citation review (Elmagarmid 2014).

\section{Outcomes:}

We have changed the sensitivity analysis mentioned in the protocol from risk of bias domains to subgroup analyses based on clinical characteristics.

We added an analysis of the adjudication process for patient awareness reports by expert panels in Analysis 1.1, Analysis 2.1, and Analysis 2.2 .

We have changed the secondary outcomes in the review:

Secondary outcomes

- Signs or adverse effects of intraoperative wakefulness and/or postoperative awareness are intraoperative patient movement, haemodynamic changes, portions of intraoperative dreams and postoperative dreams and/or nightmares, delayed memory, full (PTSD) or partial (PTS) forms of post-traumatic stress syndrome, myocardial infarction, cardiac arrest, death, and suicide.

\section{Search methods for identification of studies:}

The search strategies have been revised and expanded. 


\section{N D EX TERMS}

\section{Medical Subject Headings (MeSH)}

*Anesthesia; *Anesthetics; Benzodiazepines [administration \& dosage]; Consciousness Monitors; Electroencephalography [methods]; Etomidate; Intraoperative Awareness [* prevention \& control]; Ketamine; Mental Recall; Monitoring, Intraoperative [instrumentation] [ ${ }^{\star}$ methods]; Randomized Controlled Trials as Topic; Thiopental [administration \& dosage]; Wakefulness

\section{MeSH check words}

Humans 